\title{
ANTARCTIC MICROALGAE: \\ PHYSIOLOGICAL ACCLIMATION TO ENVIRONMENTAL CHANGE
}

BY

MEGHANA AMARNATH RAJANAHALLY

\begin{abstract}
A thesis
submitted to the Victoria University of Wellington

in fulfilment of the requirements for the degree of

Master of Science
\end{abstract}

Victoria University of Wellington 


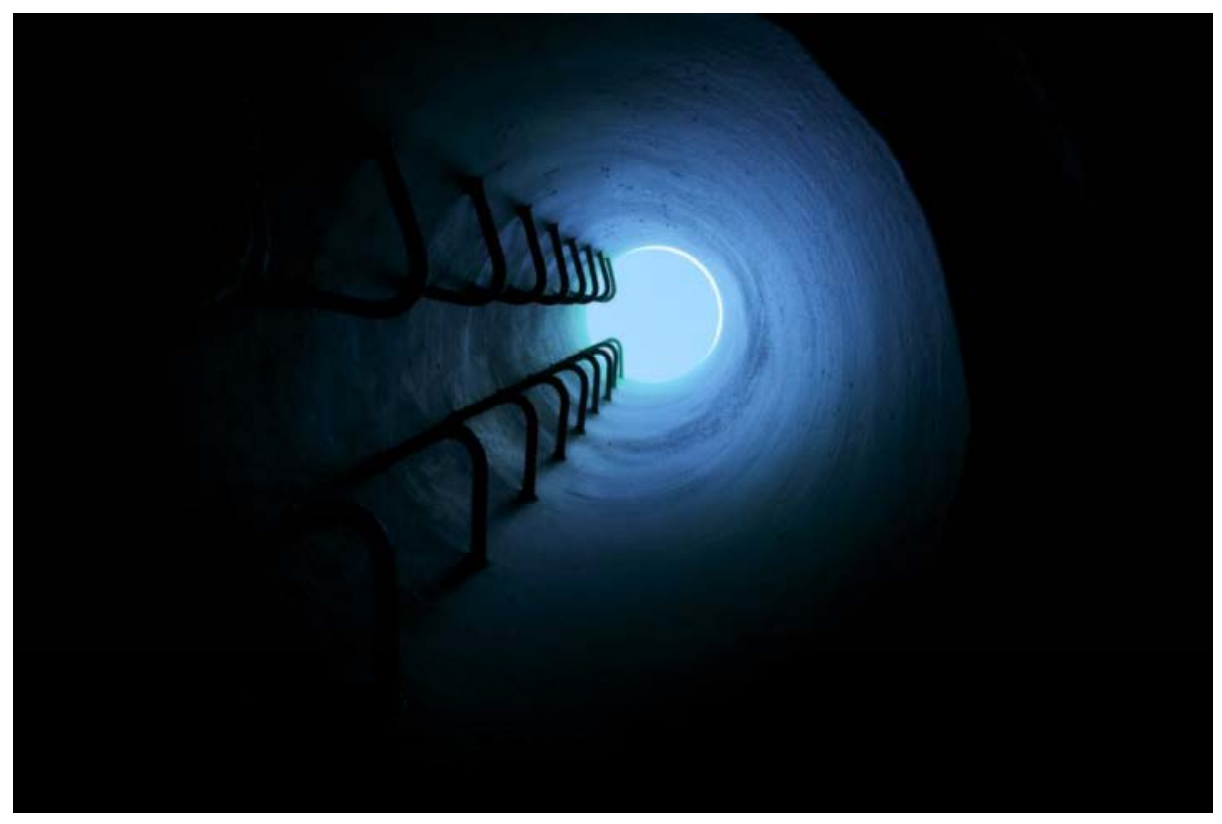

It is not the strongest of the species that survives, nor the most intelligent that survives. It is the one that is most adaptable to change.

Charles Darwin 


\section{ABSTRACT}

Sea ice algal communities play a very significant role in primary production in the Southern Ocean, being the only source of fixed carbon for all other life in this habitat and contributing up to $22 \%$ of Antarctic primary production in ice-covered regions. Therefore it is important to understand how these organisms adapt to this highly variable and harsh environment. Previous studies have described their acclimation to changes in environmental conditions but we still do not understand the physiological basis of these responses. This study examines the effects of varying levels of photosynthetically active radiation (PAR), ultraviolet-B (UV-B) radiation and temperature on bottom ice algal communities and individual algal species using pulseamplitude modulation (PAM) fluorometry, the production of mycosporine-like amino acids (MAAs) and superoxide dismutase (SOD) activity.

The experiments conducted in this thesis show that bottom ice algae are capable of acclimating to the higher levels of PAR and temperature that would likely be experienced during sea ice melt. As temperature was increased past a threshold temperature of thylakoid integrity, it became the major stressor, causing decreases in photosynthetic yield at around $14^{\circ} \mathrm{C}$, even at ambient PAR exposure. Similarly, a thylakoid integrity experiment independently suggested that the critical temperature for the onset of thylakoid damage was $14^{\circ} \mathrm{C}$, which correlated well to the $14^{\circ} \mathrm{C}$ incubation observations, although this is a temperature that sea ice algae are unlikely to encounter in the polar regions.

It is likely that sea ice algae produce additional MAAs, known to be cellular sunscreens, in response to increasing levels of UV-B, allowing tolerance of this stressor. This is the first study in the marine environment to demonstrate that algae can produce MAAs in response to increasing PAR and temperature, even in the absence of UV-B, indicating that MAAs may be more than just sunscreen compounds. The levels of UV-B used in this study were representative of those likely to be faced by the algae during sea ice melt. With increasing temperature, the algae maintained photosynthetic yield and decreased MAA production, implying that the rise in temperature aids the algae with another 
element of photoprotection such as enzymatic repair. As these results contrasted with previous studies of bottom ice algae that showed no additional MAA production in response to higher levels of PAR and UV-B, it was hypothesized that this difference was attributed to variations in species composition that could modify the productivity of the community.

The short-term effects of increasing PAR and UV-B on three unialgal cultures of Thalassiosira sp., Fragilariopsis sp. (from the Ross Sea), and Chaetoceros sp. (from the Antarctic Peninsula) were therefore examined. In unialgal culture studies, these three algal species showed higher tolerance to PAR and UV-B compared to that of the mixed culture of bottom ice algae, although there remained species-specific variation. Both Ross Sea species showed increasing photosynthetic yield with increasing PAR and UV-B exposure, but there was a difference in the tolerance shown by the two species. Thalassiosira sp. tolerated higher PAR and lower UV-B and Fragilariopsis tolerated lower PAR and higher UV-B. Both species produced MAAs in response to these stressors, indicating that these compounds allowed the algae to decrease levels of photoinhibition. In comparison to the Ross Sea, the Antarctic Peninsula is an area of higher environmental variability and change, meaning that the species in both regions could have varying acclimatory capabilities. Although data from three species alone cannot conclusively demonstrate that algae from different regions have different acclimatory capabilities, they do illustrate considerable variation between species. Chaetoceros sp. from the Antarctic Peninsula region showed a higher tolerance to PAR and UV-B compared to the Ross Sea species. The former species showed an increase in photosynthetic yield in response to increasing PAR and this was accompanied by a lack of MAA production in response to the experimental levels of PAR, which indicates that the two Ross Sea species have a higher tolerance to PAR compared to the Antarctic Peninsula species. Chaetoceros sp. from the Antarctic Peninsula showed an increase in photosynthetic yield in response to high UV-B exposures, accompanied by MAA production and had no signs of photoinhibition.

A further experiment was conducted to address the weaknesses in the initial methodologies, particularly related to control conditions in the short-term experiments. Common species from the Ross Sea, Antarctic Peninsula and the Arctic were exposed to a combination of increased PAR and UV-B over a period of seven days to compare 
acclimatory abilities using PAM and SOD activity. Thalassiosira antarctica from the Ross Sea, Chaetoceros socialis from the Antarctic Peninsula and C. socialis from the Arctic showed no significant change in quantum yield over the incubation period. This further highlights the importance of running experiments with compounding factors, as an increase in one factor could alleviate the negative effect of the other. There was an unexpected lack of change in SOD activity for all species under all treatments applied, which could indicate that the levels of PAR and UV-B used were not high enough to cause stress in these species. This work also points to the need to assay for various antioxidants, as algae are known to rely on a network of antioxidants in their defence against environmental stresses.

The data from this thesis clarify the influence of PAR, UV-B and temperature on sea ice algae, and could help better evaluate the fate of these communities under various climate change scenarios. This study has made important steps towards understanding the acclimatory abilities of sea ice algae. Increasing knowledge of sea ice algal physiology, particularly of photosynthetic health in response to environmental change, will help improve predictions of productivity in the most productive ocean on this planet. Algal tolerance to increasing PAR, UV-B and temperature is remarkable, and this ability could be crucial in the context of future climate change. The productivity of these autotrophic microorganisms strongly influences secondary production that ties their fate to that of all other life in the Southern Ocean. 


\section{I would like to dedicate this PhD to the two most important men in my life:}

My father, Amarnath, without his inspiration, I would not have had this dream

$$
\text { and }
$$

My grandfather, Govindaiah, without him, I would not have realized this dream. 


\title{
ACKNOWLEDGEMENTS
}

\begin{abstract}
While PhDs are thought to measure your intelligence, I have learnt that it really is a test of endurance. One that I would have failed without all the support I received.
\end{abstract}

I am extremely grateful to my mentor, supervisor and friend, Dr. Peter Convey for taking me under his wings and showing faith in my abilities. Thank you for teaching me how to be a scientist and never loosing faith. I would not have made it without you.

Thank you to my supervisor, Prof. Phil Lester for guiding me through this process and for all the advice and motivation. You took me under your wings when I thought all was lost.

Dr. Claire Hughes and Associate Professor Else Hegeth for providing me with unialgal cultures. Dr. Dalice Sim for endless hours of support and rescuing me from Statistics! David Flynn for endless hours of help and company at the Electron Microscopy unit. Dr St John Wakefield from Wellington Hospital for countless hours at the transmission electron microscope. Thomas Krueger for helping me navigate the jungles of antioxidant assays. Thank you Dr Mike Sparrow for the encouragement and proof reading my thesis.

All my fellow field researchers, thank you for all the help and company on the ice. Thank you Antarctic NZ, expecially Shulamit Gordon and Paul Woodgate for all the logistic support in the field.

The SBS community without whom I would have gone insane. Craig Doney, Shaun Graham, Derek Heath, Neville Higgison, Alan Hoverd, Cameron Jack, Sushila Pillai and Chris Thorn for helping me in the lab. Paul Marsden, Mary Murray, Mark Stephen and Lesley Thompson for assisting me always. Sandra Taylor, for always rescuing me from anything that came my way! At VUW, Shone de Sain, Maria Goncalves Rorke, and Patricia Stein. Liz Medford and Kent Smith for their unshakeable support and encouragement.

For funding, I would like to thank FRST grant VICX07 06, Victoria University, the Trans Antarctic Association, the Antarctic Research Center (VUW) Endowed Development Fund, Education NZ, the Kathleen Stewart postgraduate award, Vice Chancellor Professor Pat Walsh and Deputy Vice Chancellor (Research) Neil Quigley.

Assistant Vice Chancellor (Research) Charles Daugherty for helping me past the line. My boss, Jon Winnall and Universities New Zealand for being incredibly supportive through the hardest period of my life!

My school teachers, Dr. Sudha Premnath and Mrs. Mallika Sen, you inspired and nurtured me through all my formative years.

I would like to thank my friends for tolerating and supporting me always. You know who you are.

A special thank you to the Bhagavans, Milosevics and the Atreshes, you were my 'family' away from home and I'll never forget the number of times you have fed me! Wilbert, for providing me refuge when I needed it most. I will never be able to thank you enough!

I would like to thank my family - thata, avva, amma and varsha for standing by me, not only during my PhD, but also throughout my life. You believed in me even when I didn't believe in myself. For supporting me across the oceans, you guys are wonderful and I couldn't do it without you! 


\section{TABLE OF CONTENTS}

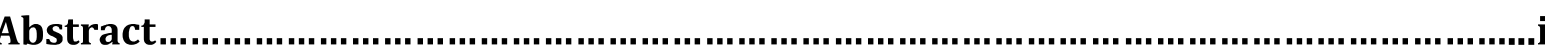

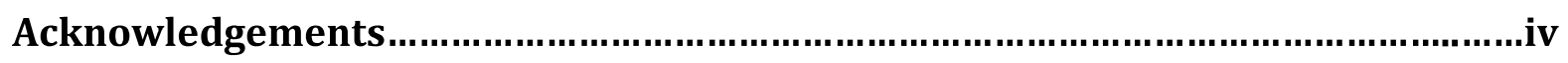

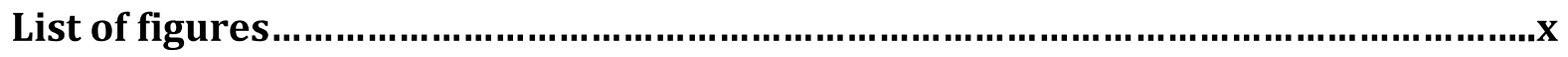

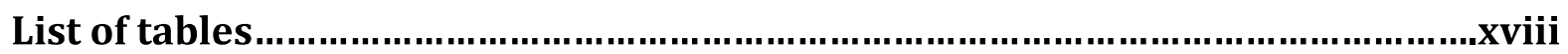

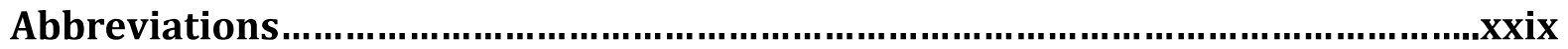

\section{CHAPTER 1: Antarctic sea ice algae}

1.1. Sea ice in Antarctica.................................................................................................

1.2. 1.2 Effect of climate change on sea ice............................................................................

1.3. Microbial diversity in sea ice and its role in the ecosystem........................................

1.4. Microalgae in sea ice......................................................................................................13

1.5. The influence of PAR on sea ice algae...............................................................

1.6. The effects of ultraviolet radiation (UVR) on sea ice................................................16

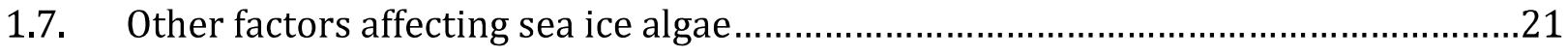

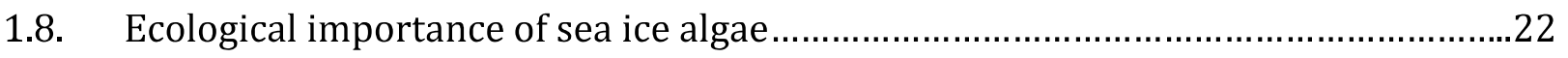

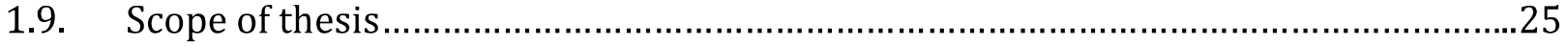

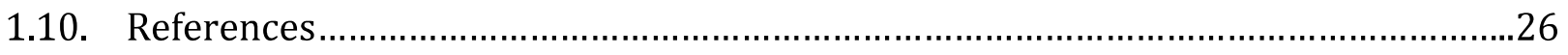

CHAPTER 2: Can bottom ice algae tolerate changes in PAR and temperature during the melting of sea ice?

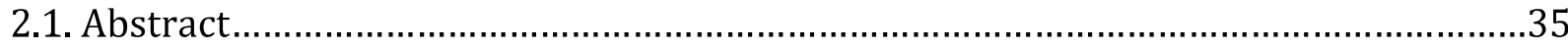

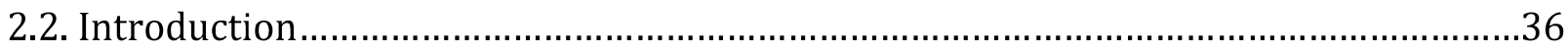

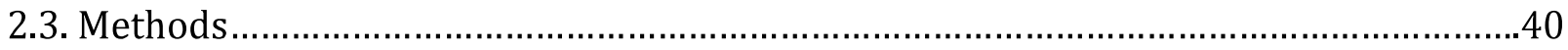

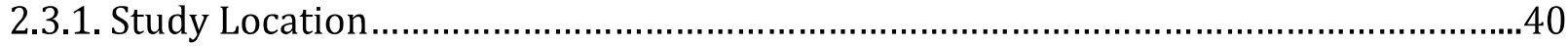

2.3.2. Field parameters and algal community taxonomic composition.....................................40

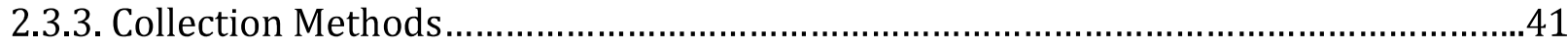

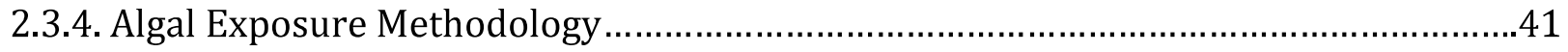

2.3.5. PAM fluorometry in bottom ice algae ......................................................................4 


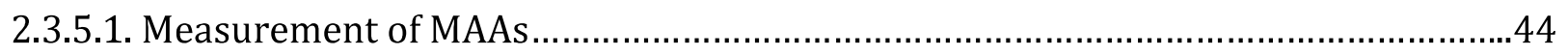

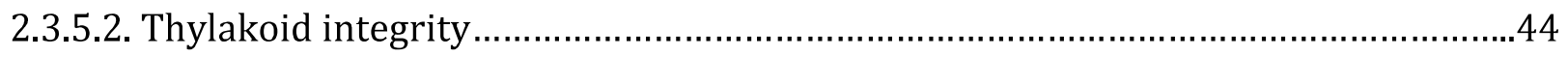

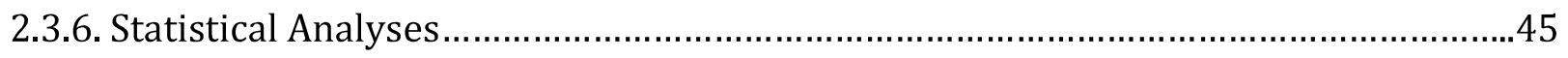

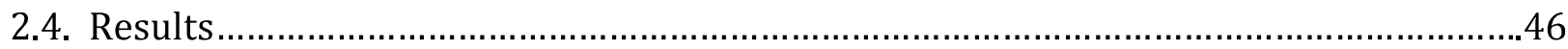

2.4.1. Field parameters and taxonomic composition ..........................................................46

2.4.2. Response of algae to temperature and light changes during melting of sea ice...........47

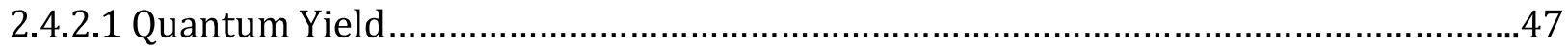

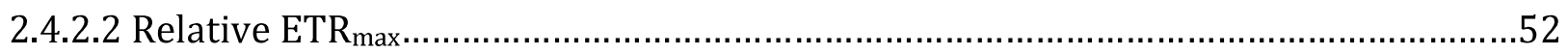

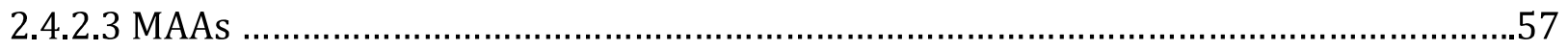

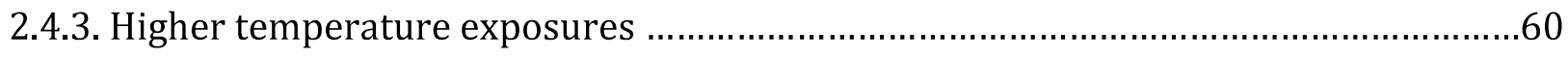

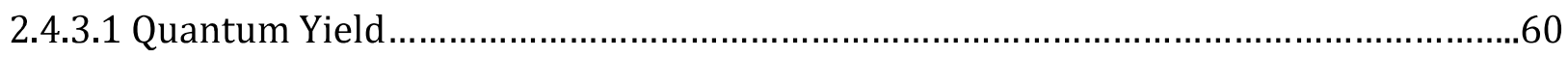

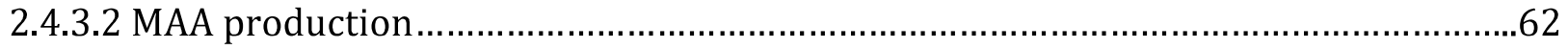

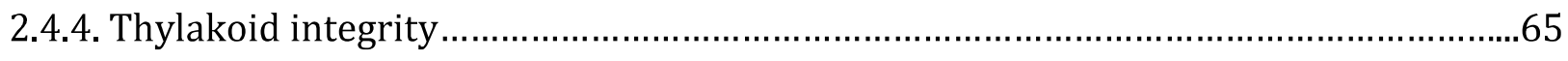

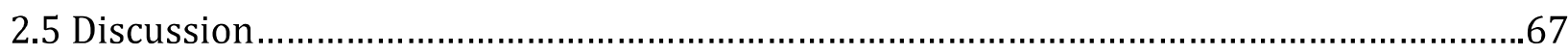

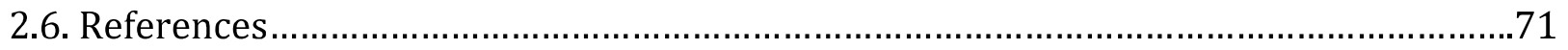

\section{CHAPTER 3: Effects of increasing UV-B and temperature on bottom ice algae in the}

\section{Ross Sea}

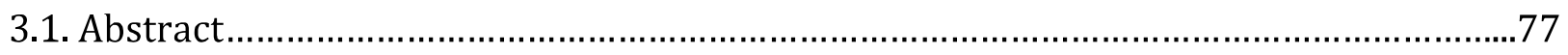

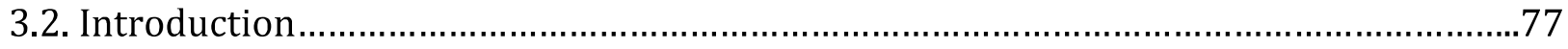

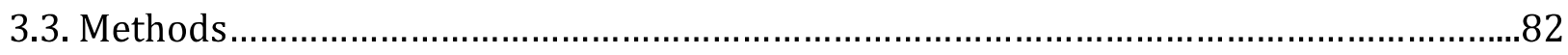

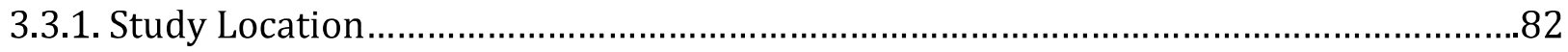

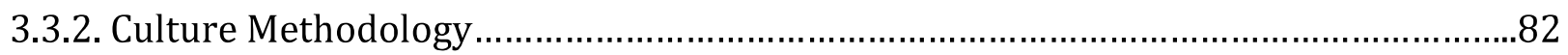

3.3.3. Sub-sampling, PAM fluorometry and statistical analysis...........................................83

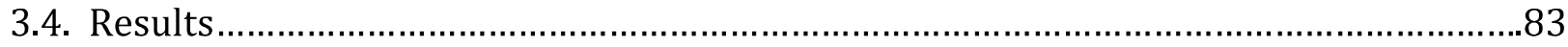

3.4.1. Field parameters and taxonomic composition.......................................................... 83

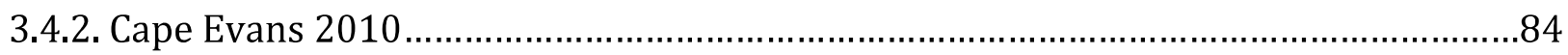

3.4.2.1. Exposure to UV-B level of $5 \mathrm{~mW} \mathrm{~m}^{-2}$ at three temperatures ...................................84

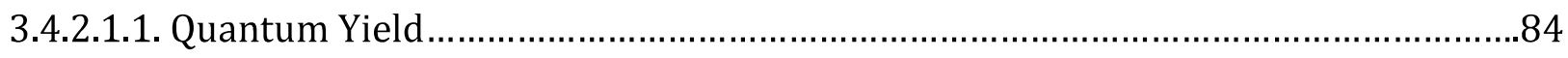

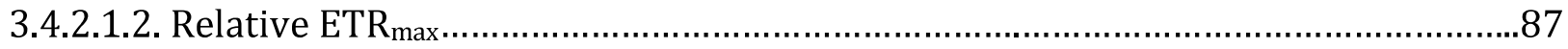

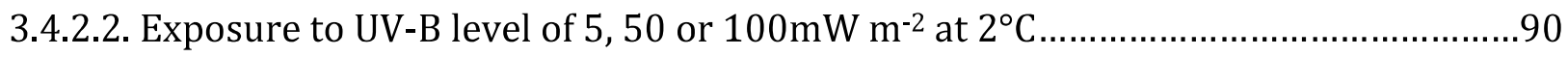

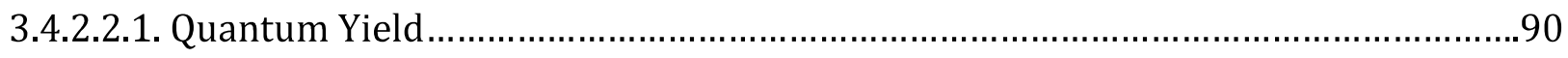

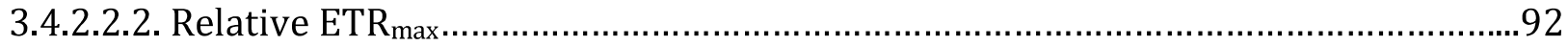




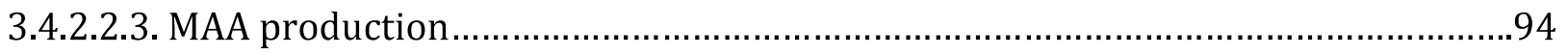

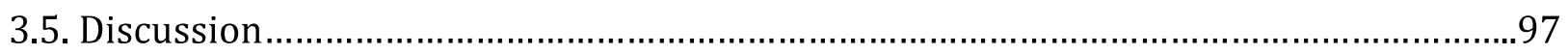

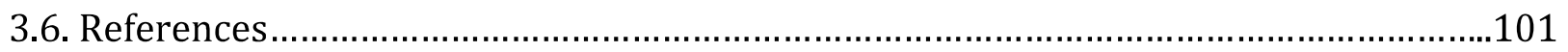

CHAPTER 4: The effects of PAR and UV-B on sea ice algal cultures from contrasting areas of the Antarctic and Arctic

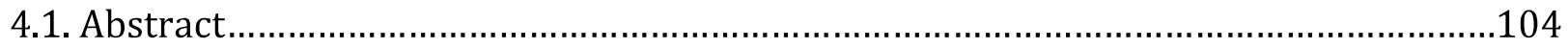

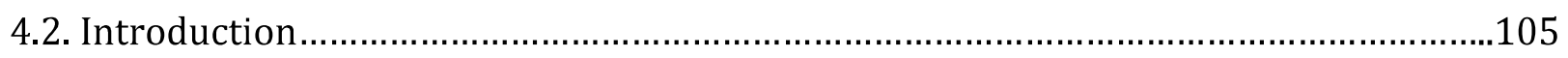

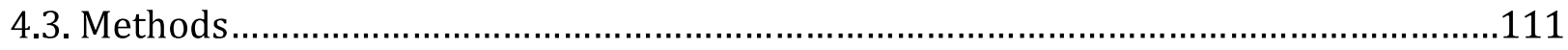

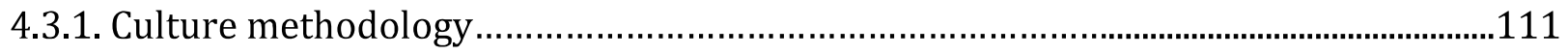

4.3.2. Sub-sampling, PAM fluorometry and statistical analyses.......................................112

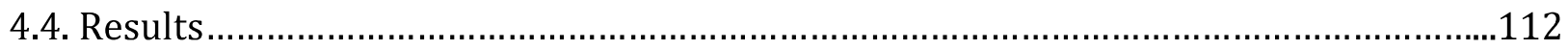

4.4.1. Effect of different PAR levels on Thalassiosira sp. and Fragilariopsis sp...................112

4.4.2. Effect of PAR on photosynthetic performance of Thalassiosira sp. and

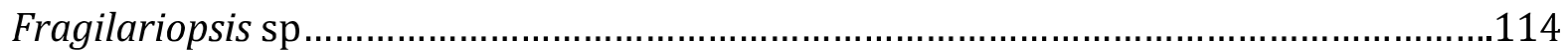

4.4.3. Effect of UV-B on photosynthetic performance of Thalassiosira sp. and

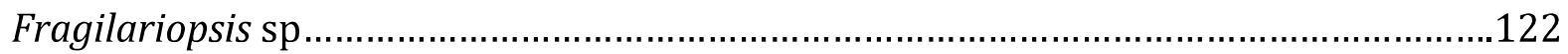

4.4.4 Effect of PAR on photosynthetic parameters of Chaetoceros sp.................................129

4.4.5 Effect of UV-B on photosynthetic parameters on Chaetoceros sp..............................132

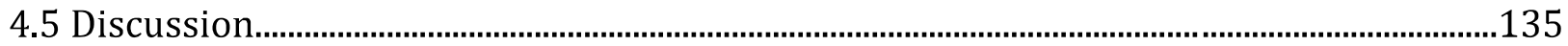

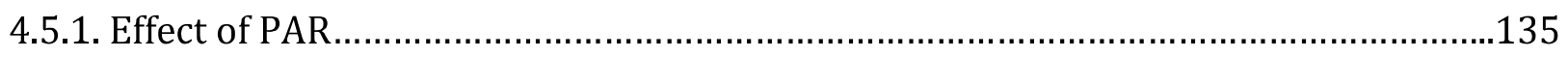

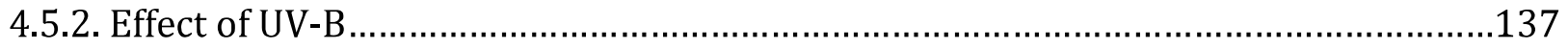

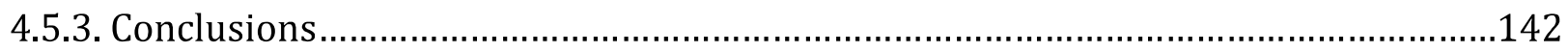

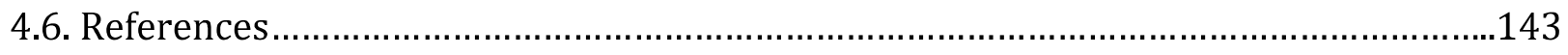

\section{CHAPTER 5: Title: Photo-protective responses in polar unialgal cultures}

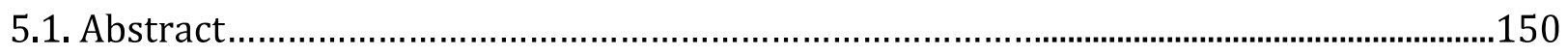

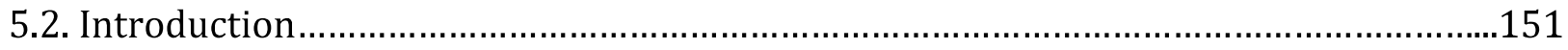

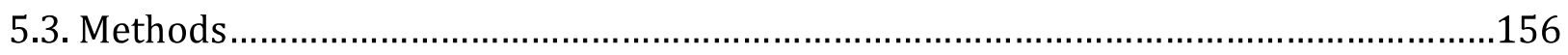

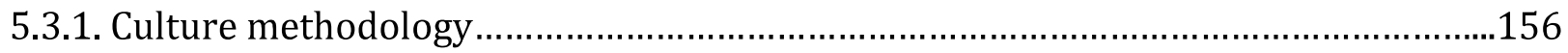

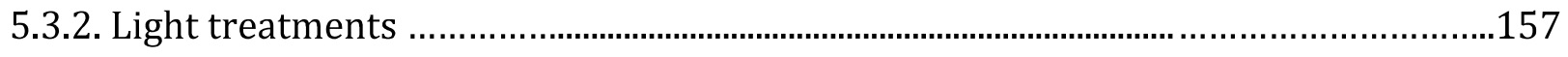

5.3.3. Chlorophyll a content …........................................................................................157

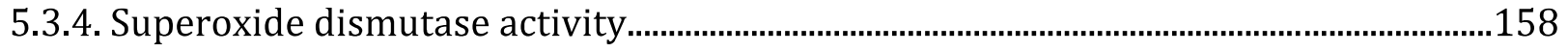




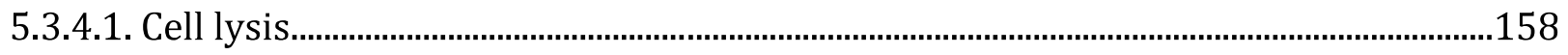

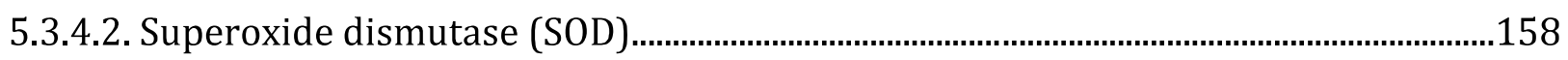

5.3.5 Sub-sampling, PAM fluorometry, MAA analysis and statistical analyses........................159

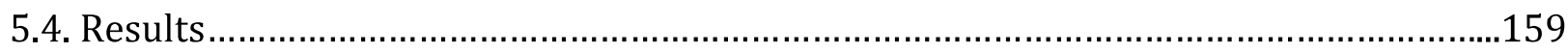

5.4.1. Effect of different light levels on the photosynthetic performance of Thalassiosira antarctica (Ross Sea), Chaetoceros socialis (Antarctic Peninsula) and C. socialis

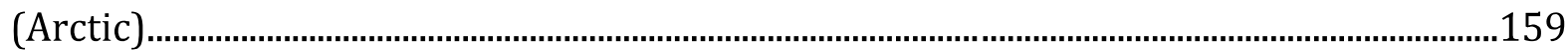

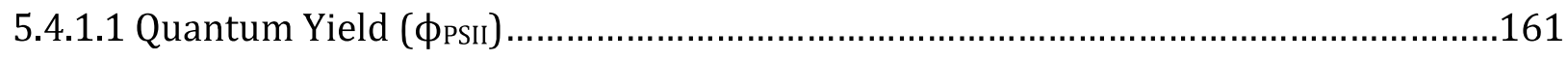

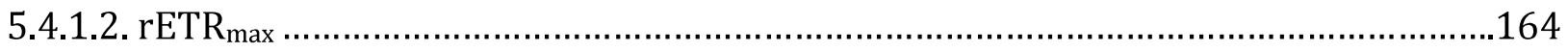

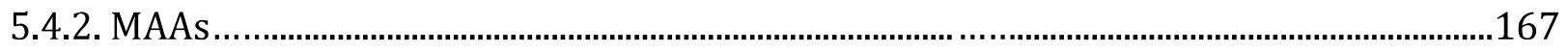

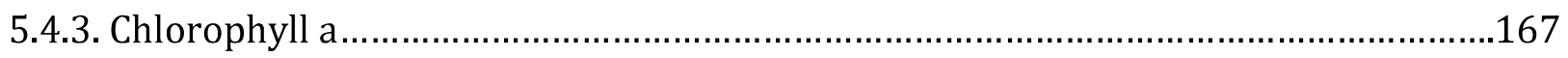

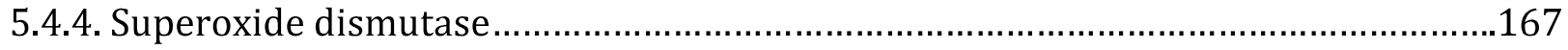

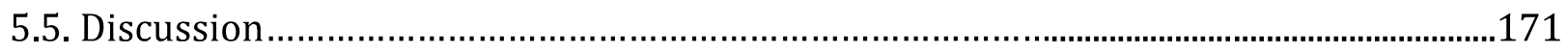

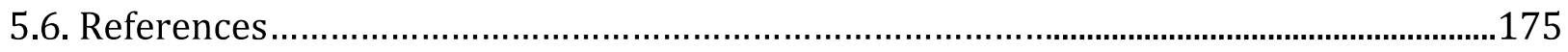

CHAPTER 6: Title:Antarctic microalgae: physiological acclimation to environmental change

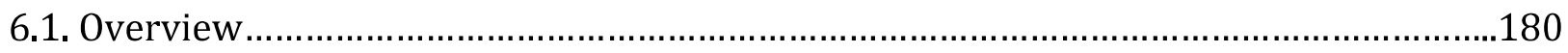

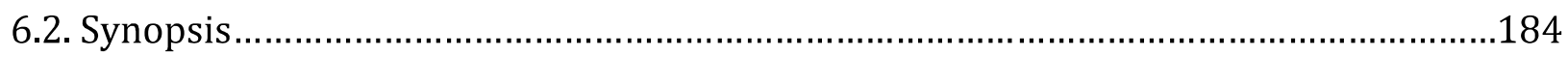

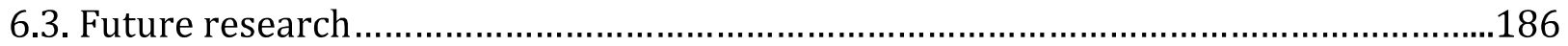

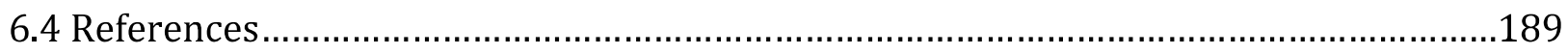

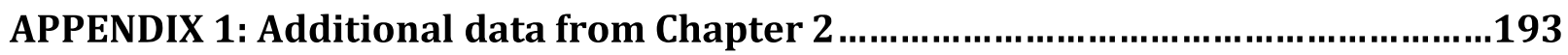

APPENDIX 2: Additional data from Chapter 3 .........................................................203

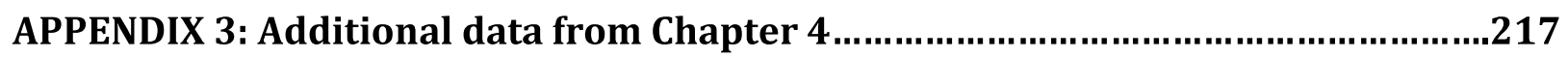

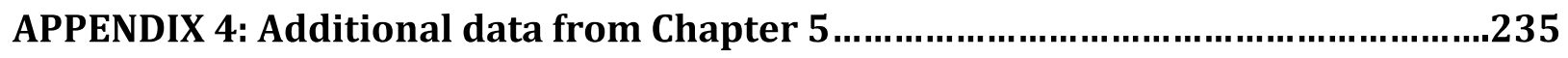




\section{LIST OF FIGURES}

\section{CHAPTER 1}

1.1: Pack ice and land-fast ice showing the major physical features and locations of microbial habitats (Arrigo \& Thomas, 2004).

1.2: Gradients of temperature, salinity and brine volume across an ice floe. The diagram also shows the effect of snow cover on attenuation of PAR (Thomas \& Dieckmann, 2002).

1.3: Simplified diagram of the ocean food web showing the dominant roles of the microbial loop. The major fluxes of carbon and energy are represented by continuous lines and fluxes of lesser magnitude are represented by broken lines. Mucus-net feeders such as salp are separated from other mesozooplankton because of differences in feeding modes. Other than the mucus-net feeders, mesozooplankton and fishes, represented by the blue boxes, the remaining boxes represent organisms that make up the microbial loop, green boxes representing photosynthetic and yellow representing heterotrophic organisms (from Pomeroy et al., 2007).

1.4: Components of the biological pump responsible for transforming DIC into organic biomass and pumping it in particulate or dissolved form into the deep ocean (from Ducklow et al., 2007).

1.5: Hypothesised relationships between krill recruitment success and environmental (sea ice) and biological factors (salp abundance, spawning and timing) (after Siegel et al., 2000).

1.6: Standard solar radiation energy spectrum at the Earth's surface in the visible and ultraviolet ranges. The UV spectrum in this standard contributes $\sim 17 \%$ of the energy between $250 \mathrm{~nm}$ and $700 \mathrm{~nm}$. UV-A accounts for most of this energy, UV-B for $0.3 \%$ and 
UV-C a non-detectable component. As wavelength decreases, biologically relevant action spectra for damage increase exponentially. The action spectra for different biological processes vary. UV-C causes considerably more DNA damage than UV-A and UV-B, whereas UV-A and UV-B cause inhibition of photosynthesis (from (Gao \& Garcia-Pichel, 2011)). No units are shown in the diagram but are assumed to be representative of irradiance levels.

\section{CHAPTER 2}

2.1: (a) Map of the Ross Sea region and (b) Close up of Ross Sea indicating the three sea ice collection locations of Terra Nova Bay, Granite Harbour and Cape Evans (Maps prepared by P.Fretwell, BAS).

2.2: Quantum Yield ( $\phi_{\text {PSII }}$ ) of bottom ice algae measured at $0,2,4,6,12,24$ and $48 \mathrm{~h}$. Cultures were maintained at four PAR levels of $0,1,45$ or $100 \mu \mathrm{mol} \mathrm{m}^{-2} \mathrm{~s}^{-1}$ and at (a) $-1^{\circ} \mathrm{C}$, (b) $2^{\circ} \mathrm{C}$ and (c) $5^{\circ} \mathrm{C}$. Error bars indicate standard error.

2.3: Relative ETR $R_{\max }$ of bottom ice algae at $0,2,4,6,12,24$ and $48 \mathrm{~h}$. Cultures were maintained at four PAR levels of $0,1,45$ or $100 \mu \mathrm{mol} \mathrm{m}{ }^{-2} \mathrm{~s}^{-1}$ and at (a) $-1^{\circ} \mathrm{C}$, (b) $2^{\circ} \mathrm{C}$ and (c) $5^{\circ} \mathrm{C}$. Error bars indicate standard error.

2.4: MAA production of bottom ice algae determined at 0 and $48 \mathrm{~h}$. Cultures were maintained at four PAR levels of 0, 1, 45 or $100 \mu \mathrm{mol} \mathrm{m}{ }^{-2} \mathrm{~s}^{-1}$ and at (a) $-1^{\circ} \mathrm{C}$, (b) $2^{\circ} \mathrm{C}$ and (c) $5^{\circ} \mathrm{C}$. Error bars indicate standard error.

2.5: Quantum yield ( $\phi$ PsII) of bottom ice algae determined at $0,2,4,6,12,24$ and $48 \mathrm{~h}$. The incubation at $4^{\circ} \mathrm{C}$ ran for $72 \mathrm{~h}$. Cultures were maintained at three PAR levels of 1,45 or 100 $\mu \mathrm{mol} \mathrm{m}{ }^{-2} \mathrm{~s}^{-1}$ and at (a) $4^{\circ} \mathrm{C}$, (b) $14^{\circ} \mathrm{C}$ and (c) $24^{\circ} \mathrm{C}$. Error bars indicate standard error. 
2.6: MAA production of bottom ice algae determined at 0 and $48 \mathrm{~h}$. The incubation at $4^{\circ} \mathrm{C}$ ran for $72 \mathrm{~h}$. Cultures were maintained at three PAR levels of 1, 45, $100 \mu \mathrm{mol} \mathrm{m}^{-2} \mathrm{~s}^{-1}$ and at (a) $4^{\circ} \mathrm{C}$, (b) $14^{\circ} \mathrm{C}$ and (c) $24^{\circ} \mathrm{C}$. Error bars indicate standard error.

2.7: Changes in photosynthetic parameters with increase in temperature. (a) Change in quantum yield. (b) Change in initial fluorescence. $T_{c}$ is the critical temperature where permanent damage is initiated and there is irreversible reduction in maximum quantum yield, and $\mathrm{T}_{\mathrm{p}}$ is the temperature at which there is complete loss of photosynthesis and maximum quantum yield becomes zero.

\section{CHAPTER 3}

3.1: Quantum Yield ( $\phi$ PSII) of bottom ice algae at 0, 2, 4, 6, 12, 24 and $48 \mathrm{~h}$. Cultures were maintained at $5 \mathrm{~mW} \mathrm{~m}^{-2} \mathrm{UV}-\mathrm{B}$ and either $1 \mu \mathrm{mol} \mathrm{m}^{-2} \mathrm{~s}^{-1}$ or at $0 \mu \mathrm{mol} \mathrm{m}^{-2} \mathrm{~s}^{-1}$ at (a) $-1^{\circ} \mathrm{C}$, (b) $2^{\circ} \mathrm{C}$ and (c) $5^{\circ} \mathrm{C}$. Error bars indicate standard error.

3.2: Relative ETR $\max _{\max }$ of bottom ice algae at $0,2,4,6,12,24$ and $48 \mathrm{~h}$. Cultures were maintained at $5 \mathrm{~mW} \mathrm{~m}^{-2} \mathrm{UV}-\mathrm{B}$ and $1 \mu \mathrm{mol} \mathrm{m}{ }^{-2} \mathrm{~s}^{-1}$ or at $0 \mu \mathrm{mol} \mathrm{m}^{-2} \mathrm{~s}^{-1}$ at $(\mathrm{a}) 1^{\circ} \mathrm{C}$, (b) $2^{\circ} \mathrm{C}$ and (c) $5^{\circ} \mathrm{C}$. Error bars indicate standard error.

3.3: Quantum yield of bottom ice algae at $0,2,4,6,12,24$ and $48 \mathrm{~h}$. Cultures were maintained at (a) $50 \mathrm{~mW} \mathrm{~m}^{-2} \mathrm{UV}$-B and a PAR level of $1 \mu \mathrm{mol} \mathrm{m}^{-2} \mathrm{~s}^{-1}$ or at $0 \mu \mathrm{mol} \mathrm{m}^{-2} \mathrm{~s}^{-1}$ and (b) $100 \mathrm{~mW} \mathrm{~m}^{-2} \mathrm{UV}-\mathrm{B}$ and a PAR level of $1 \mu \mathrm{mol} \mathrm{m}^{-2} \mathrm{~s}^{-1}$ or at $0 \mu \mathrm{mol} \mathrm{m}^{-2} \mathrm{~s}^{-1}$. Error bars indicate standard error.

3.4: $\mathrm{rETR}_{\max }$ of bottom ice algae at $0,2,4,6,12,24$ and $48 \mathrm{~h}$. Cultures were maintained at (a) $50 \mathrm{~mW} \mathrm{~m}^{-2} \mathrm{UV}-\mathrm{B}$ and a PAR level of $1 \mu \mathrm{mol} \mathrm{m}^{-2} \mathrm{~s}^{-1}$ or at $0 \mu \mathrm{mol} \mathrm{m}^{-2} \mathrm{~s}^{-1}$ and (b) $100 \mathrm{~mW}$ $\mathrm{m}^{-2} \mathrm{UV}$-B and a PAR level of $1 \mu \mathrm{mol} \mathrm{m} \mathrm{m}^{-2} \mathrm{~s}^{-1}$ or at $0 \mu \mathrm{mol} \mathrm{m}^{-2} \mathrm{~s}^{-1}$. Error bars indicate standard error. 
3.5: MAA production in bottom ice algae at 0 and $48 \mathrm{~h}$. Cultures were maintained at (a) 5 $\mathrm{mW} \mathrm{m}{ }^{-2} \mathrm{UV}-\mathrm{B}$ and a PAR level of $1 \mu \mathrm{mol} \mathrm{m}^{-2} \mathrm{~s}^{-1}$ or at $0 \mu \mathrm{mol} \mathrm{m}^{-2} \mathrm{~s}^{-1}$ and (b) $50 \mathrm{~mW} \mathrm{~m}^{-2} \mathrm{UV}-\mathrm{B}$ and a PAR level of $1 \mu \mathrm{mol} \mathrm{m}^{-2} \mathrm{~s}^{-1}$ or at $0 \mu \mathrm{mol} \mathrm{m}^{-2} \mathrm{~s}^{-1}$ (c) $100 \mathrm{~mW} \mathrm{~m}^{-2} \mathrm{UV}-\mathrm{B}$ and a PAR level of $1 \mu \mathrm{mol} \mathrm{m}-2 \mathrm{~s}^{-1}$ or at $0 \mu \mathrm{mol} \mathrm{m} \mathrm{s}^{-2} \mathrm{~s}^{-1}$. Error bars indicate standard error.

\section{CHAPTER 4}

4.1: Quantum Yield (申PSII) at 0, 2, 4, 6, 12, 24 and $48 \mathrm{~h}$. Cultures were maintained at PAR levels of 0, 1, 45 or $100 \mu \mathrm{mol} \mathrm{m}^{-2} \mathrm{~s}^{-1}$, for (a) Thalassiosira sp. and (b) Fragilariopsis sp. Error bars indicate standard error.

4.2: Relative ETR $\max _{\max }$ determined at $0,2,4,6,12,24$ and $48 \mathrm{~h}$. Cultures were maintained at PAR levels of 0, 1, 45 or $100 \mu \mathrm{mol} \mathrm{m}^{-2} \mathrm{~s}^{-1}$, for (a) Thalassiosira sp. and (b) Fragilariopsis sp. Error bars indicate standard error.

4.3: MAA production determined at 0 and $48 \mathrm{~h}$. Cultures were maintained at PAR levels of 0, 1, 45 or $100 \mu \mathrm{mol} \mathrm{m}^{-2} \mathrm{~s}^{-1}$ for (a) Thalassiosira sp. and (b) Fragilariopsis sp. Error bars indicate standard error.

4.4: Quantum Yield ( $\phi_{\text {PSII }}$ ) at 0, 2, 4, 6, 12, 24 and $48 \mathrm{~h}$. Cultures were maintained in the dark and at $0,50 \mathrm{~mW} \mathrm{~m}^{-2}$ or $150 \mathrm{~mW} \mathrm{~m}^{-2} \mathrm{UV}-\mathrm{B}$ and a PAR level of $1 \mu \mathrm{mol} \mathrm{m}^{-2} \mathrm{~s}^{-1}$ for the 2 UV-B treatments, for (a) Thalassiosira sp. and (b) Fragilariopsis sp. Error bars indicate standard error.

4.5: Relative ETR max $_{\text {ax }}$ at $0,2,4,6,12,24$ and $48 \mathrm{~h}$. Cultures were maintained at $0,50 \mathrm{~mW} \mathrm{~m}^{-2}$, $150 \mathrm{~mW} \mathrm{~m}^{-2} \mathrm{UV}-\mathrm{B}$ and a PAR level of $1 \mu \mathrm{mol} \mathrm{m}^{-2} \mathrm{~s}^{-1}$ for the $2 \mathrm{UV}-\mathrm{B}$ treatments, for (a) Thalassiosira sp. and (b) Fragilariopsis sp. Error bars indicate standard error 
4.6: MAA production determined at 0 and $48 \mathrm{~h}$. Cultures were maintained at $0,50 \mathrm{~mW} \mathrm{~m}^{-2}$, $150 \mathrm{~mW} \mathrm{~m}^{-2}$ and a PAR level of $1 \mu \mathrm{mol} \mathrm{m}^{-2} \mathrm{~s}^{-1}$ for the $2 \mathrm{UV}$-B treatments, for (a) for Thalassiosira sp. and (b) Fragilariopsis sp. Error bars indicate standard error.

4.7: Photosynthetic parameters of Chaetoceros sp. at 0, 2, 6, 12, 24 and $48 \mathrm{~h}$. Cultures were maintained at PAR levels of $0,1,45$ or $100 \mu \mathrm{mol} \mathrm{m}^{-2} \mathrm{~s}^{-1}$ and the graphs indicate (a) ФPSII, (b)

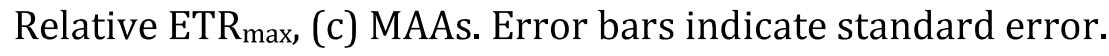

4.8: Photosynthetic parameters of Chaetoceros sp. at 0, 2, 4, 6, 12, 24 and $48 \mathrm{~h}$. Cultures were maintained in the dark and at $50 \mathrm{~mW} \mathrm{~m}^{-2}$ and $150 \mathrm{~mW} \mathrm{~m}^{-2} \mathrm{UV}-\mathrm{B}$ and a PAR level of 1

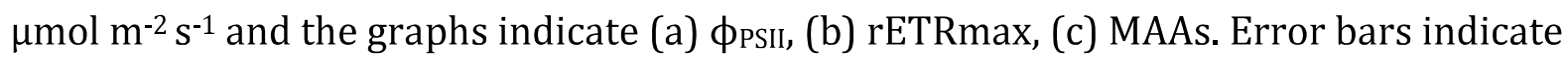
standard error.

\section{CHAPTER 5}

5.1: Quantum Yield (申PSII) at 0, 2, 4, 6, 12, 24, 48, 72, 96, 120, 144 and $168 \mathrm{~h}$. Cultures were maintained at different combinations of PAR and UV-B levels $\left(0 \mu \mathrm{mol} \mathrm{m} \mathrm{m}^{-2} \mathrm{~s}^{-1} ; 1 \mu \mathrm{mol} \mathrm{m}^{-2} \mathrm{~s}^{-1}\right.$; $45 \mu \mathrm{mol} \mathrm{m}^{-2} \mathrm{~s}^{-1}$ and $50 \mathrm{mWm}^{-2} ; 100 \mu \mathrm{mol} \mathrm{m}^{-2} \mathrm{~s}^{-1}$ and $100 \mathrm{mWm}^{-2}$ ), for (a) Thalassiosira antarctica (Ross Sea), (b) Chaetoceros socialis (Antarctic Peninsula) and (c) C. socialis (Arctic Ocean). Error bars indicate standard error.

5.2: $\mathrm{rETR}_{\max }$ at $0,2,4,6,12,24,48,72,96,120,144$ and $168 \mathrm{~h}$. Cultures were maintained at light levels $\left(0 \mu \mathrm{mol} \mathrm{m}^{-2} \mathrm{~s}^{-1} ; 1 \mu \mathrm{mol} \mathrm{m}{ }^{-2} \mathrm{~s}^{-1} ; 45 \mu \mathrm{mol} \mathrm{m}^{-2} \mathrm{~s}^{-1}\right.$ and $50 \mathrm{mWm}^{-2} ; 100 \mu \mathrm{mol} \mathrm{m}^{-2} \mathrm{~s}^{-1}$ and $100 \mathrm{mWm}^{-2}$ ), for (a) Thalassiosira antarctica (Ross Sea), (b) Chaetoceros socialis (Antarctic Peninsula) and (c) C. socialis (Arctic Ocean). Error bars indicate standard error.

5.3: SOD activity per cell at 0,48 , and $168 \mathrm{~h}$. Cultures were maintained at different combinations of PAR and UV-B levels $\left(0 \mu \mathrm{mol} \mathrm{m} \mathrm{m}^{-2} \mathrm{~s}^{-1} ; 1 \mu \mathrm{mol} \mathrm{m}^{-2} \mathrm{~s}^{-1} ; 45 \mu \mathrm{mol} \mathrm{m}{ }^{-2} \mathrm{~s}^{-1}\right.$ and 50 $\mathrm{mWm}^{-2} ; 100 \mu \mathrm{mol} \mathrm{m}^{-2} \mathrm{~s}^{-1}$ and $100 \mathrm{mWm}^{-2}$ ), for (a) Thalassiosira antarctica (Ross Sea), (b) 
Chaetoceros socialis (Antarctic Peninsula) and (c) C. socialis (Arctic Ocean). Error bars indicate standard error.

\section{APPENDIX 1}

A1.1: Photosynthetic efficiency ( $\alpha$ ) of bottom ice algae at $0,2,4,6,12,24$ and $48 \mathrm{~h}$. Cultures were maintained at four PAR levels of $0,1,45$ or $100 \mu \mathrm{mol} \mathrm{m}^{-2} \mathrm{~s}^{-1}$ and at (a) $-1^{\circ} \mathrm{C}$, (b) $2^{\circ} \mathrm{C}$ and (c) $5^{\circ} \mathrm{C}$. Error bars indicate standard error.

A1.2: Photoacclimation Index ( $\left.E_{\mathrm{k}}\right)$ of bottom ice algae at $0,2,4,6,12,24$ and $48 \mathrm{~h}$. Cultures were maintained at four PAR levels of $0,1,45$ or $100 \mu \mathrm{mol} \mathrm{m}^{-2} \mathrm{~s}^{-1}$ and at (a) $-1^{\circ} \mathrm{C}$, (b) $2^{\circ} \mathrm{C}$ and (c) $5^{\circ} \mathrm{C}$. Error bars indicate standard error.

A2: Algal cell sections as viewed under the transmission electron microscope, showing (a) An entire algal cell with a chloroplast at the left margin and (b) Details of thylakoids in the chloroplast.

\section{APPENDIX 2}

A2.1: Photosynthetic efficiency ( $\alpha$ ) of bottom ice algae at $0,2,4,6,12,24$ and $48 \mathrm{~h}$. Cultures were maintained at $5 \mathrm{~mW} \mathrm{~m}{ }^{-2}$ and $1 \mu \mathrm{mol} \mathrm{m}^{-2} \mathrm{~s}^{-1}$ or at $0 \mu \mathrm{mol} \mathrm{m}^{-2} \mathrm{~s}^{-1}$ (a) $-1^{\circ} \mathrm{C}$, (b) $2^{\circ} \mathrm{C}$ and (c) $5^{\circ} \mathrm{C}$. Error bars indicate standard error.

A2.2: Saturation irradiance $\left(E_{\mathrm{k}}\right)$ of bottom ice algae at $0,2,4,6,12,24$ and $48 \mathrm{~h}$. Cultures were maintained at $5 \mathrm{~mW} \mathrm{~m}{ }^{-2}$ and $1 \mu \mathrm{mol} \mathrm{m}^{-2} \mathrm{~s}^{-1}$ or at $0 \mu \mathrm{mol} \mathrm{m}^{-2} \mathrm{~s}^{-1}$ (a) $-1^{\circ} \mathrm{C}$, (b) $2^{\circ} \mathrm{C}$ and (c) $5^{\circ} \mathrm{C}$. Error bars indicate standard error.

A2.3: MAA production of bottom ice algae determined at 0 and $48 \mathrm{~h}$. Cultures were maintained at $5 \mathrm{~mW} \mathrm{~m} \mathrm{~m}^{-2} \mathrm{UV}-\mathrm{B}$ and a PAR level of $1 \mu \mathrm{E} \mathrm{m}^{-2} \mathrm{~s}^{-1}$ at (a) $-1^{\circ} \mathrm{C}$, (b) $2^{\circ} \mathrm{C}$ and (c) $5^{\circ} \mathrm{C}$. Error bars indicate standard error. 
A2.4: Photosynthetic efficiency ( $\alpha$ ) of bottom ice algae at $0,2,4,6,12,24$ and $48 \mathrm{~h}$. Cultures were maintained at (a) $50 \mathrm{~mW} \mathrm{~m}^{-2} \mathrm{UV}-\mathrm{B}$ and a PAR level of $1 \mu \mathrm{mol} \mathrm{m} \mathrm{m}^{-2} \mathrm{~s}^{-1}$ or at $0 \mu \mathrm{mol} \mathrm{m}^{-2} \mathrm{~s}^{-}$ 1 and (b) $100 \mathrm{~mW} \mathrm{~m}^{-2} \mathrm{UV}-\mathrm{B}$ and a PAR level of $1 \mu \mathrm{mol} \mathrm{m}^{-2} \mathrm{~s}^{-1}$ or at $0 \mu \mathrm{mol} \mathrm{m}^{-2} \mathrm{~s}^{-1}$. Error bars indicate standard error.

A2.5: Saturation irradiance $\left(E_{\mathrm{k}}\right)$ of bottom ice algae at $0,2,4,6,12,24$ and $48 \mathrm{~h}$. Cultures were maintained at (a) $50 \mathrm{~mW} \mathrm{~m} \mathrm{~m}^{-2} \mathrm{UV}-\mathrm{B}$ and a PAR level of $1 \mu \mathrm{mol} \mathrm{m} \mathrm{m}^{-2} \mathrm{~s}^{-1}$ or at $0 \mu \mathrm{mol} \mathrm{m}^{-2} \mathrm{~s}^{-}$ 1 and (b) $100 \mathrm{~mW} \mathrm{~m}^{-2} \mathrm{UV}-\mathrm{B}$ and a PAR level of $1 \mu \mathrm{mol} \mathrm{m}^{-2} \mathrm{~s}^{-1}$ or at $0 \mu \mathrm{mol} \mathrm{m}^{-2} \mathrm{~s}^{-1}$. Error bars indicate standard error.

\section{APPENDIX 3}

A3.1: Photosynthetic efficiency $(\alpha)$ determined at $0,2,4,6,12,24$ and $48 \mathrm{~h}$. Cultures were maintained at PAR levels of 0, 1, 45 or $100 \mu \mathrm{E} \mathrm{m}^{-2} \mathrm{~s}^{-1}$ for (a) Thalassiosira sp. and (b) Fragilariopsis sp. Error bars indicate standard error.

A3.2: Saturation irradiance $\left(E_{\mathrm{k}}\right)$ determined at $0,2,4,6,12,24$ and $48 \mathrm{~h}$. Cultures were maintained at PAR levels of 0, 1, 45 or $100 \mu \mathrm{E} \mathrm{m}^{-2} \mathrm{~s}^{-1}$ for (a) Thalassiosira sp. and (b) Fragilariopsis sp. Error bars indicate standard error.

A3.3: Photosynthetic efficiency at $0,2,4,6,12,24$ and $48 \mathrm{~h}$. Cultures were maintained at 0 , $50 \mathrm{~mW} \mathrm{~m}^{-2}, 150 \mathrm{~mW} \mathrm{~m}^{-2} \mathrm{UV}$-B and a PAR level of $1 \mu \mathrm{E} \mathrm{m}^{-2} \mathrm{~s}^{-1}$ for (a) Thalassiosira sp. and (b) Fragilariopsis sp. Error bars indicate standard error.

A3.4: Photacclimation Index $\left(E_{\mathrm{k}}\right)$ at $0,2,4,6,12,24$ and $48 \mathrm{~h}$. Cultures were maintained at $0,50 \mathrm{~mW} \mathrm{~m}^{-2}, 150 \mathrm{~mW} \mathrm{~m}^{-2} \mathrm{UV}-\mathrm{B}$ and a PAR level of $1 \mu \mathrm{E} \mathrm{m}^{-2} \mathrm{~s}^{-1}$ for (a) Thalassiosira sp. and (b) Fragilariopsis sp. Error bars indicate standard error. 
A3.5: (a) Photosynthetic Efficiency $(\alpha)$ and (b) Saturation irradiance $\left(E_{\mathrm{k}}\right)$ determined at 0, $2,4,6,12,24$ and $48 \mathrm{~h}$. Cultures were maintained at PAR levels of $0,1,45$ or $100 \mu \mathrm{E} \mathrm{m}^{-2} \mathrm{~s}^{-1}$ for Chaetoceros sp. Error bars indicate standard error.

A3.6: (a) Saturation irradiance $(\alpha)$ and (b) Photacclimation Index $\left(E_{\mathrm{k}}\right)$ at $0,2,4,6,12,24$ and $48 \mathrm{~h}$. Cultures were maintained at $0,50 \mathrm{~mW} \mathrm{~m}^{-2}, 150 \mathrm{~mW} \mathrm{~m}^{-2} \mathrm{UV}-\mathrm{B}$ and a PAR level of 1 $\mu \mathrm{E} \mathrm{m}^{-2} \mathrm{~s}^{-1}$ for Chaetoceros sp. Error bars indicate standard error.

\section{APPENDIX 4}

Fig A4.1. Alpha( $\alpha$ ) at $0,2,4,6,12,24,48,72,96,120,144$ and $168 \mathrm{~h}$. Cultures were maintained at light levels $\left(0 \mu \mathrm{mol} \mathrm{m}^{-2} \mathrm{~s}^{-1} ; 1 \mu \mathrm{mol} \mathrm{m}^{-2} \mathrm{~s}^{-1} ; 45 \mu \mathrm{mol} \mathrm{m}^{-2} \mathrm{~s}^{-1}\right.$ and $50 \mathrm{mWm}^{-2}$; $100 \mu \mathrm{mol} \mathrm{m}^{-2} \mathrm{~s}^{-1}$ and $100 \mathrm{mWm}^{-2}$ ), for (a) Thalassiosira antarctica (Ross Sea), (b) Chaetoceros socialis (Antarctic Peninsula) and (c) C. socialis (Arctic Ocean). Error bars indicate standard error.

Fig A4.2. $E_{\mathrm{k}}$ at $0,2,4,6,12,24,48,72,96,120,144$ and $168 \mathrm{~h}$. Cultures were maintained at light levels $\left(0 \mu \mathrm{mol} \mathrm{m}^{-2} \mathrm{~s}^{-1} ; 1 \mu \mathrm{mol} \mathrm{m}^{-2} \mathrm{~s}^{-1} ; 45 \mu \mathrm{mol} \mathrm{m}^{-2} \mathrm{~s}^{-1}\right.$ and $50 \mathrm{mWm}^{-2} ; 100 \mu \mathrm{mol} \mathrm{m}^{-2} \mathrm{~s}^{-1}$ and $100 \mathrm{mWm}^{-2}$ ), for (a) Thalassiosira antarctica (Ross Sea), (b) Chaetoceros socialis (Antarctic Peninsula) and (c) C. socialis (Arctic Ocean). Error bars indicate standard error. 


\section{LIST OF TABLES}

\section{CHAPTER 2}

\section{1: Field parameters and dominant taxa present}

2.2: Changes in quantum yield of photosystem II over $48 \mathrm{~h}$ experimental treatments at different PAR levels $\left(0,1,45\right.$ and $\left.100 \mu \mathrm{mol} \mathrm{m}-2 \mathrm{~s}^{-1}\right)$ at $-1{ }^{\circ} \mathrm{C}, 2^{\circ} \mathrm{C}$ and $5^{\circ} \mathrm{C}$, analysed using repeated measures ANOVA. Significant changes identified by post hoc pairwise analyses are also listed.

(a) Effect of changing PAR at a specific incubation temperature.

(b). Effect of changing temperature at a specific PAR level.

2.3: Changes in relative ETR max $_{\text {over }} 48 \mathrm{~h}$ experimental treatments at different PAR levels $\left(0,1,45\right.$ and $\left.100 \mu \mathrm{mol} \mathrm{m} \mathrm{m}^{-2} \mathrm{~s}^{-1}\right)$ at $-1^{\circ} \mathrm{C}, 2^{\circ} \mathrm{C}$ and $5^{\circ} \mathrm{C}$, analysed using repeated measures ANOVA. Significant changes identified by post hoc pairwise analyses are also listed.

(a)Effect of changing rETR $_{\max }$ at a specific incubation temperature.

(b)Effect of changing temperature at a specific PAR level.

2.4: Changes in MAA production over $48 \mathrm{~h}$ experimental treatments at different PAR levels $\left(0,1,45\right.$ and $\left.100 \mu \mathrm{mol} \mathrm{m}^{-2} \mathrm{~s}^{-1}\right)$ at $-1^{\circ} \mathrm{C}, 2^{\circ} \mathrm{C}$ and $5^{\circ} \mathrm{C}$, analysed using repeated measures ANOVA. Significant changes identified by post hoc pairwise analyses are also listed.

2.5: Changes in MAA production over $48 \mathrm{~h}$ experimental treatments at different PAR levels $\left(1,45\right.$ and $\left.100 \mu \mathrm{mol} \mathrm{m}^{-2} \mathrm{~s}^{-1}\right)$ at $4^{\circ} \mathrm{C}, 14^{\circ} \mathrm{C}$ and $24^{\circ} \mathrm{C}$, analysed using repeated measures ANOVA. Significant changes identified by post hoc pairwise analyses are also listed. Only algae at $4^{\circ} \mathrm{C}$ were incubated over $72 \mathrm{~h}$. 


\section{CHAPTER 3}

3.1: Treatments used in experiments at Cape Evans, November 2010

3.2: Field parameters and dominant algal taxa present.

3.3: Changes in quantum yield of photosystem II over $48 \mathrm{~h}$ experimental treatments at one UV-B level of $5 \mathrm{~mW} \mathrm{~m}^{-2}$ and $1 \mu \mathrm{mol} \mathrm{m}^{-2} \mathrm{~s}^{-1}$ or at $0 \mu \mathrm{mol} \mathrm{m} \mathrm{m}^{-2} \mathrm{~s}^{-1}$ at $-1^{\circ} \mathrm{C}, 2^{\circ} \mathrm{C}$ and $5^{\circ} \mathrm{C}$, analysed using repeated measures ANOVA. Significant changes identified by post hoc pairwise analyses are also listed.

(a) Effect of UV-B on $\phi_{P S I I}$ at different temperatures.

(b) Effect of different temperatures on $\phi$ PSII at different UV-B treatments:

3.4: Changes in EETR $_{\max }$ of photosystem II over $48 \mathrm{~h}$ experimental treatments at one UV-B level of $5 \mathrm{~mW} \mathrm{~m}^{-2}$ and $1 \mu \mathrm{mol} \mathrm{m} \mathrm{m}^{-2} \mathrm{~s}^{-1}$ or at $0 \mu \mathrm{mol} \mathrm{m}^{-2} \mathrm{~s}^{-1}$ at $-1^{\circ} \mathrm{C}, 2^{\circ} \mathrm{C}$ and $5^{\circ} \mathrm{C}$, analysed using repeated measures ANOVA. Significant changes identified by post hoc pairwise analyses are also listed.

(a) Effect of UV-B on $\phi_{P S I I}$ at different temperatures:

(b) Effect of different temperatures on $\phi_{P S I I}$ at different UV-B treatments.

3.5: Changes in quantum yield of photosystem II over $48 \mathrm{~h}$ experimental treatments at (a) UV-B level of $50 \mathrm{~mW} \mathrm{~m}{ }^{-2}$ and $1 \mu \mathrm{mol} \mathrm{m}^{-2} \mathrm{~s}^{-1}$ or at $0 \mu \mathrm{mol} \mathrm{m}^{-2} \mathrm{~s}^{-1}$ and (b) UV-B level of 100 $\mathrm{mW} \mathrm{m}{ }^{-2}$ and $1 \mu \mathrm{mol} \mathrm{m} \mathrm{m}^{-2} \mathrm{~s}^{-1}$ or at $0 \mu \mathrm{mol} \mathrm{m}^{-2} \mathrm{~s}^{-1}$ at $2^{\circ} \mathrm{C}$ and analysed using repeated measures ANOVA. Significant changes identified by post hoc pairwise analyses are also listed.

3.6: Changes in $\mathrm{rETR}_{\max }$ of photosystem II over $48 \mathrm{~h}$ experimental treatments at (a) UV-B level of $50 \mathrm{~mW} \mathrm{~m}^{-2}$ and $1 \mu \mathrm{mol} \mathrm{m}^{-2} \mathrm{~s}^{-1}$ or at $0 \mu \mathrm{mol} \mathrm{m}^{-2} \mathrm{~s}^{-1}$ and (b) UV-B level of $50 \mathrm{~mW} \mathrm{~m}^{-2}$ and $1 \mu \mathrm{mol} \mathrm{m}{ }^{-2} \mathrm{~s}^{-1}$ or at $0 \mu \mathrm{mol} \mathrm{m}{ }^{-2} \mathrm{~s}^{-1}$ at $2^{\circ} \mathrm{C}$ and analysed using repeated measures ANOVA. Significant changes identified by post hoc pairwise analyses are also listed. 
3.7: Changes in MAA production over $48 \mathrm{~h}$ experimental treatments at (a) UV-B level of 5 $\mathrm{mW} \mathrm{m} \mathrm{m}^{-2}$ and $1 \mu \mathrm{mol} \mathrm{m} \mathrm{m}^{-2} \mathrm{~s}^{-1}$ or at $0 \mu \mathrm{mol} \mathrm{m}^{-2} \mathrm{~s}^{-1}$, (b) UV-B level of $50 \mathrm{~mW} \mathrm{~m}^{-2}$ and $1 \mu \mathrm{mol} \mathrm{m}^{-2}$ $\mathrm{s}^{-1}$ or at $0 \mu \mathrm{mol} \mathrm{m}{ }^{-2} \mathrm{~s}^{-1}$ and (c) UV-B level of $50 \mathrm{~mW} \mathrm{~m}^{-2}$ and $1 \mu \mathrm{mol} \mathrm{m}^{-2} \mathrm{~s}^{-1}$ or at $0 \mu \mathrm{mol} \mathrm{m}^{-2}$ $\mathrm{s}^{-1}$ at $2^{\circ} \mathrm{C}$ and analysed using repeated measures ANOVA. Significant changes identified by post hoc pairwise analyses are also listed.

\section{CHAPTER 4}

4.1: Probability values for changes in quantum yield of photosystem II, rETR max $_{\text {ax }}$ and MAA production for Thalassiosira sp. and Fragilaropsis sp. over $48 \mathrm{~h}$ experimental treatments at (a) different PAR levels $\left(0,1,45\right.$ and $\left.100 \mu \mathrm{mol} \mathrm{m}^{-2} \mathrm{~s}^{-1}\right)$ at $4^{\circ} \mathrm{C}$ and (b) different UV-B levels $\left(0,50\right.$ and $\left.150 \mathrm{mWm}^{-2}\right)$ and a PAR level of $1 \mu \mathrm{mol} \mathrm{m}^{-2} \mathrm{~s}^{-1}$ for the two UV-B treatments at $4^{\circ} \mathrm{C}$, analysed using repeated measures ANOVA.

4.2: Changes in quantum yield of photosystem II over $48 \mathrm{~h}$ experimental treatments at different PAR levels $\left(0,1,45\right.$ and $\left.100 \mu \mathrm{mol} \mathrm{m}^{-2} \mathrm{~s}^{-1}\right)$ at $4^{\circ} \mathrm{C}$, analysed using repeated measures ANOVA. Significant changes identified by post hoc pairwise analyses are also listed.

4.3: Changes in EETR $_{\max }$ of photosystem II over $48 \mathrm{~h}$ experimental treatments at different PAR levels $\left(0,1,45\right.$ and $\left.100 \mu \mathrm{mol} \mathrm{m}^{-2} \mathrm{~s}^{-1}\right)$ at $4^{\circ} \mathrm{C}$, analysed using repeated measures ANOVA. Significant changes identified by post hoc pairwise analyses are also listed.

4.4: Changes in MAA production over $48 \mathrm{~h}$ experimental treatments at different PAR levels $\left(0,1,45\right.$ and $\left.100 \mu \mathrm{mol} \mathrm{m}^{-2} \mathrm{~s}^{-1}\right)$ at $4^{\circ} \mathrm{C}$, analysed using repeated measures ANOVA. Significant changes identified 
UV-B treatments at $4^{\circ} \mathrm{C}$, analysed using repeated measures ANOVA. Significant changes identified by post hoc pairwise analyses are also listed.

4.6: Changes in $\mathrm{rETR}_{\max }$ of photosystem II over $48 \mathrm{~h}$ experimental treatments at different UV-B levels $\left(0,50\right.$ and $\left.150 \mathrm{mWm}^{-2}\right)$ and a PAR level of $1 \mu \mathrm{mol} \mathrm{m}^{-2} \mathrm{~s}^{-1}$ for the two UV-B treatments at $4{ }^{\circ} \mathrm{C}$, analysed using repeated measures ANOVA. Significant changes identified by post hoc pairwise analyses are also listed.

4.7: Changes in MAA production over $48 \mathrm{~h}$ experimental treatments at different UV-B levels $\left(0,50\right.$ and $\left.150 \mathrm{mWm}^{-2}\right)$ and a PAR level of $1 \mu \mathrm{mol} \mathrm{m}^{-2} \mathrm{~s}^{-1}$ for the two UV-B treatments at $4^{\circ} \mathrm{C}$, analysed using repeated measures ANOVA. Significant changes identified by post hoc pairwise analyses are also listed.

4.8: Changes in photosynthetic parameters for Chaetoceros sp. over $48 \mathrm{~h}$ experimental treatments at PAR levels $\left(0,1,45\right.$ and $\left.100 \mu \mathrm{mol} \mathrm{m}^{-2} \mathrm{~s}^{-1}\right)$ at $4^{\circ} \mathrm{C}$, analysed using repeated measures ANOVA. Significant changes identified by post hoc pairwise analyses are also listed.

4.9: Changes in photosynthetic parameters for Chaetoceros sp. over $48 \mathrm{~h}$ experimental treatments at different UV-B levels $\left(0,50\right.$ and $\left.150 \mathrm{mWm}^{-2}\right)$ and a PAR level of $1 \mu \mathrm{mol} \mathrm{m}^{-2} \mathrm{~s}^{-1}$ at $4^{\circ} \mathrm{C}$, analysed using repeated measures ANOVA. Significant changes identified by post hoc pairwise analyses are also listed.

\section{CHAPTER 5}

5.1: Significance values for changes in quantum yield of photosystem II, $\mathrm{rETR}_{\max }, \operatorname{Alpha}(\alpha)$ and $E_{\mathrm{k}}$ for Thalassiosira antarctica (Ross Sea), Chaetoceros socialis (Antarctic Peninsula) and C. socialis (Arctic) over $168 \mathrm{~h}$ experimental treatments at different combinations of PAR and UV-B levels ( $\mathrm{L} 0=0 \mu \mathrm{mol} \mathrm{m}^{-2} \mathrm{~s}^{-1} ; \mathrm{L} 1=1 \mu \mathrm{mol} \mathrm{m}^{-2} \mathrm{~s}^{-1} ; \mathrm{L} 2=45 \mu \mathrm{mol} \mathrm{m}^{-2} \mathrm{~s}^{-1}$ and 50 
$\mathrm{mWm}^{-2} ; \mathrm{L} 3=100 \mu \mathrm{mol} \mathrm{m}^{-2} \mathrm{~s}^{-1}$ and $100 \mathrm{mWm}^{-2}$ ) at $4^{\circ} \mathrm{C}$, analysed using repeated measures ANOVA.

5.2: Changes in quantum yield of photosystem II over $168 \mathrm{~h}$ experimental treatments at different combinations of PAR and UV-B levels ( $\mathrm{L} 0=0 \mu \mathrm{mol} \mathrm{m} \mathrm{m}^{-2} \mathrm{~s}^{-1} ; \mathrm{L} 1=1 \mu \mathrm{mol} \mathrm{m}{ }^{-2} \mathrm{~s}^{-1}$; $\mathrm{L} 2=45 \mu \mathrm{mol} \mathrm{m}^{-2} \mathrm{~s}^{-1}$ and $50 \mathrm{mWm}^{-2} ; \mathrm{L} 3=100 \mu \mathrm{mol} \mathrm{m}^{-2} \mathrm{~s}^{-1}$ and $100 \mathrm{mWm}^{-2}$ ) at $4^{\circ} \mathrm{C}$, analysed using repeated measures ANOVA. Significant changes identified by post hoc pairwise analyses are also listed.

5.3: Changes in rETR $_{\max }$ of photosystem II over $168 \mathrm{~h}$ experimental treatments at different combinations of PAR and UV-B levels (L0 $=0 \mu \mathrm{mol} \mathrm{m}^{-2} \mathrm{~s}^{-1} ; \mathrm{L} 1=1 \mu \mathrm{mol} \mathrm{m}^{-2} \mathrm{~s}^{-1} ; \mathrm{L} 2=45 \mu \mathrm{mol} \mathrm{m}^{-}$ ${ }^{2} \mathrm{~s}^{-1}$ and $50 \mathrm{mWm}^{-2}$; L3=100 $\mathrm{mmol} \mathrm{m}^{-2} \mathrm{~s}^{-1}$ and $100 \mathrm{mWm}^{-2}$ ) at $4^{\circ} \mathrm{C}$, analysed using repeated measures ANOVA. Significant changes identified by post hoc pairwise analyses are also listed.

5.4: Changes in SOD activity over $168 \mathrm{~h}$ experimental treatments at different combinations of PAR and UV-B levels (L0 $=0 \mu \mathrm{mol} \mathrm{m}{ }^{-2} \mathrm{~s}^{-1} ; \mathrm{L} 1=1 \mu \mathrm{mol} \mathrm{m}{ }^{-2} \mathrm{~s}^{-1} ; \mathrm{L} 2=45 \mu \mathrm{mol} \mathrm{m}^{-2} \mathrm{~s}^{-1}$ and 50 $\mathrm{mWm}^{-2}$; L3=100 $\mu \mathrm{mol} \mathrm{m}^{-2} \mathrm{~s}^{-1}$ and $100 \mathrm{mWm}^{-2}$ ) at $4^{\circ} \mathrm{C}$, analysed using repeated measures ANOVA. Significant changes identified by post hoc pairwise analyses are also listed.

\section{APPENDIX 1}

A1.1: Changes in quantum yield of photosystem II over $48 \mathrm{~h}$ experimental treatments at different PAR levels $\left(0,1,45\right.$ and $\left.100 \mu \mathrm{mol} \mathrm{m}-2 \mathrm{~s}^{-1}\right)$ at $-1^{\circ} \mathrm{C}, 2^{\circ} \mathrm{C}$ and $5^{\circ} \mathrm{C}$, analysed using a 2 factor repeated measures ANOVA. Significant changes identified by post hoc pairwise analyses are also listed. 
A1.2: Changes in rETRmax over $48 \mathrm{~h}$ experimental treatments at different PAR levels $(0,1$, 45 and $100 \mu \mathrm{mol} \mathrm{m}^{-2} \mathrm{~s}^{-1}$ at $-1^{\circ} \mathrm{C}, 2^{\circ} \mathrm{C}$ and $5^{\circ} \mathrm{C}$, analysed using a 2 factor repeated measures ANOVA. Significant changes identified by post hoc pairwise analyses are also listed.

A1.3: Changes in MAA production over $48 \mathrm{~h}$ experimental treatments at different PAR levels $\left(0,1,45\right.$ and $\left.100 \mu \mathrm{mol} \mathrm{m}^{-2} \mathrm{~s}^{-1}\right)$ at $-1^{\circ} \mathrm{C}, 2^{\circ} \mathrm{C}$ and $5^{\circ} \mathrm{C}$, analysed using a 2 factor repeated measures ANOVA. Significant changes identified by post hoc pairwise analyses are also listed.

A1.4: Changes in photosynthetic efficiency $(\alpha)$ over $48 \mathrm{~h}$ experimental treatments at different PAR levels $\left(0,1,45\right.$ and $\left.100 \mu \mathrm{mol} \mathrm{m}^{-2} \mathrm{~s}^{-1}\right)$ at $-1^{\circ} \mathrm{C}, 2^{\circ} \mathrm{C}$ and $5^{\circ} \mathrm{C}$, analysed using a 2 factor repeated measures ANOVA. Significant changes identified by post hoc pairwise analyses are also listed.

A1.5: Changes in saturation irradiance $\left(E_{\mathrm{k}}\right)$ over $48 \mathrm{~h}$ experimental treatments at different PAR levels $\left(0,1,45\right.$ and $\left.100 \mu \mathrm{mol} \mathrm{m}{ }^{-2} \mathrm{~s}^{-1}\right)$ at $-1^{\circ} \mathrm{C}, 2^{\circ} \mathrm{C}$ and $5^{\circ} \mathrm{C}$, analysed using a 2 factor repeated measures ANOVA. Significant changes identified by post hoc pairwise analyses are also listed.

A1.6: Changes in MAA production over $48 \mathrm{~h}$ experimental treatments at different PAR levels $\left(1,45\right.$ and $\left.100 \mu \mathrm{mol} \mathrm{m}^{-2} \mathrm{~s}^{-1}\right)$ at $4^{\circ} \mathrm{C}, 14^{\circ} \mathrm{C}$ and $24^{\circ} \mathrm{C}$, analysed using a 2 factor repeated measures ANOVA. Significant changes identified by post hoc pairwise analyses are also listed.

\section{APPENDIX 2}

A2.1: Changes in quantum yield of photosystem II over $48 \mathrm{~h}$ experimental treatments at one UV-B level of $5 \mathrm{mWm}^{-2}$ and $1 \mu \mathrm{mol} \mathrm{m}^{-2} \mathrm{~s}^{-1}$; and $0 \mu \mathrm{mol} \mathrm{m}^{-2} \mathrm{~s}^{-1}$ at $-1^{\circ} \mathrm{C}, 2^{\circ} \mathrm{C}$ and $5^{\circ} \mathrm{C}$, analysed using a 2 factor repeated measures ANOVA. Significant changes identified by post hoc pairwise analyses are also listed. 
A2.2: Changes in rETRmax over $48 \mathrm{~h}$ experimental treatments at one UV-B level of $5 \mathrm{mWm}^{-}$ 2 and $1 \mu \mathrm{mol} \mathrm{m}-2 \mathrm{~s}^{-1}$; and $0 \mu \mathrm{mol} \mathrm{m}{ }^{-2} \mathrm{~s}^{-1}$ at $-1^{\circ} \mathrm{C}, 2^{\circ} \mathrm{C}$ and $5^{\circ} \mathrm{C}$, analysed using a 2 factor repeated measures ANOVA. Significant changes identified by post hoc pairwise analyses are also listed.

A2.3: Changes in photosynthetic efficiency over $48 \mathrm{~h}$ experimental treatments at one UV-B level of $5 \mathrm{mWm}^{-2}$ and $1 \mu \mathrm{mol} \mathrm{m} \mathrm{m}^{-2} \mathrm{~s}^{-1}$; and $0 \mu \mathrm{mol} \mathrm{m}^{-2} \mathrm{~s}^{-1}$ at $-1^{\circ} \mathrm{C}, 2^{\circ} \mathrm{C}$ and $5^{\circ} \mathrm{C}$, analysed using a 2 factor repeated measures ANOVA. Significant changes identified by post hoc pairwise analyses are also listed.

A2.4: Changes in saturation irradiance over $48 \mathrm{~h}$ experimental treatments at one UV-B level of $5 \mathrm{mWm}^{-2}$ and $1 \mu \mathrm{mol} \mathrm{m}^{-2} \mathrm{~s}^{-1}$; and $0 \mu \mathrm{mol} \mathrm{m}^{-2} \mathrm{~s}^{-1}$ at $-1^{\circ} \mathrm{C}, 2^{\circ} \mathrm{C}$ and $5^{\circ} \mathrm{C}$, analysed using a 2 factor repeated measures ANOVA. Significant changes identified by post hoc pairwise analyses are also listed.

A2.5: Changes in MAA production over $48 \mathrm{~h}$ experimental treatments at one UV-B level of 5 $\mathrm{mWm}^{-2}$ and $1 \mu \mathrm{mol} \mathrm{m}^{-2} \mathrm{~s}^{-1}$; and $0 \mu \mathrm{mol} \mathrm{m}^{-2} \mathrm{~s}^{-1}$ at $-1^{\circ} \mathrm{C}, 2^{\circ} \mathrm{C}$ and $5^{\circ} \mathrm{C}$, analysed using a 2 factor repeated measures ANOVA. Significant changes identified by post hoc pairwise analyses are also listed.

A2.6: Changes in quantum yield over $48 \mathrm{~h}$ experimental treatments at (a) UV-B level of 50 $\mathrm{mWm}^{-2}$ and $1 \mu \mathrm{mol} \mathrm{m}^{-2} \mathrm{~s}^{-1}$; and $0 \mu \mathrm{mol} \mathrm{m}^{-2} \mathrm{~s}^{-1}$ and (b) UV-B level of $50 \mathrm{mWm}^{-2}$ and $1 \mu \mathrm{mol}$ $\mathrm{m}^{-2} \mathrm{~s}^{-1}$; and $0 \mu \mathrm{mol} \mathrm{m}{ }^{-2} \mathrm{~s}^{-1}$ at $2^{\circ} \mathrm{C}$, analysed using a repeated measures ANOVA. Significant changes identified by post hoc pairwise analyses are also listed.

A2.7: Changes in rETR max $_{\text {ax }}$ over $48 \mathrm{~h}$ experimental treatments at (a) UV-B level of $50 \mathrm{mWm}^{-2}$ and $1 \mu \mathrm{mol} \mathrm{m} \mathrm{m}^{-2} \mathrm{~s}^{-1}$; and $0 \mu \mathrm{mol} \mathrm{m}^{-2} \mathrm{~s}^{-1}$ and (b) UV-B level of $50 \mathrm{mWm}^{-2}$ and $1 \mu \mathrm{mol} \mathrm{m}^{-2} \mathrm{~s}^{-1}$; and $0 \mu \mathrm{mol} \mathrm{m} \mathrm{m}^{-2} \mathrm{~s}^{-1}$ at $2^{\circ} \mathrm{C}$, analysed using a repeated measures ANOVA. Significant changes identified by post hoc pairwise analyses are also listed. 
A2.8: Changes in MAA production over $48 \mathrm{~h}$ experimental treatments at (a) UV-B level of 50 $\mathrm{mWm}^{-2}$ and $1 \mu \mathrm{mol} \mathrm{m}^{-2} \mathrm{~s}^{-1}$; and $0 \mu \mathrm{mol} \mathrm{m}^{-2} \mathrm{~s}^{-1}$ and (b) UV-B level of $50 \mathrm{mWm}^{-2}$ and $1 \mu \mathrm{mol}$ $\mathrm{m}^{-2} \mathrm{~s}^{-1}$; and $0 \mu \mathrm{mol} \mathrm{m}{ }^{-2} \mathrm{~s}^{-1}$ at $2^{\circ} \mathrm{C}$, analysed using a repeated measures ANOVA. Significant changes identified by post hoc pairwise analyses are also listed.

A2.9: Changes in photosynthetic efficiency over $48 \mathrm{~h}$ experimental treatments at (a) UV-B level of $50 \mathrm{mWm}^{-2}$ and $1 \mu \mathrm{mol} \mathrm{m}^{-2} \mathrm{~s}^{-1}$; and $0 \mu \mathrm{mol} \mathrm{m}^{-2} \mathrm{~s}^{-1}$ and (b) UV-B level of $50 \mathrm{mWm}^{-2}$ and $1 \mu \mathrm{mol} \mathrm{m}{ }^{-2} \mathrm{~s}^{-1}$; and $0 \mu \mathrm{mol} \mathrm{m}{ }^{-2} \mathrm{~s}^{-1}$ at $2^{\circ} \mathrm{C}$, analysed using a repeated measures ANOVA. Significant changes identified by post hoc pairwise analyses are also listed.

A2.10: Changes in saturation irradiance over $48 \mathrm{~h}$ experimental treatments at (a) UV-B level of $50 \mathrm{mWm}^{-2}$ and $1 \mu \mathrm{mol} \mathrm{m}^{-2} \mathrm{~s}^{-1}$; and $0 \mu \mathrm{mol} \mathrm{m}^{-2} \mathrm{~s}^{-1}$ and (b) UV-B level of $50 \mathrm{mWm}^{-2}$ and $1 \mu \mathrm{mol} \mathrm{m}{ }^{-2} \mathrm{~s}^{-1}$; and $0 \mu \mathrm{mol} \mathrm{m}{ }^{-2} \mathrm{~s}^{-1}$ at $2^{\circ} \mathrm{C}$, analysed using a repeated measures ANOVA. Significant changes identified by post hoc pairwise analyses are also listed.

\section{APPENDIX 3}

A3.1: Changes in quantum yield of Photosystem II over $48 \mathrm{~h}$ experimental treatments at different PAR levels $\left(0,1,45\right.$ and $\left.100 \mu \mathrm{mol} \mathrm{m}^{-2} \mathrm{~s}^{-1}\right)$ at $4^{\circ} \mathrm{C}$, analysed using a 2 factor repeated measures ANOVA. Significant changes identified by post hoc pairwise analyses are also listed.

A3.2: Changes in EETR $_{\max }$ of Photosystem II over $48 \mathrm{~h}$ experimental treatments at different PAR levels $\left(0,1,45\right.$ and $\left.100 \mu \mathrm{mol} \mathrm{m}^{-2} \mathrm{~s}^{-1}\right)$ at $4^{\circ} \mathrm{C}$, analysed using a 2 factor repeated measures ANOVA. Significant changes identified by post hoc pairwise analyses are also listed.

A3.3: Changes in MAA production over $48 \mathrm{~h}$ experimental treatments at different PAR levels $\left(0,1,45\right.$ and $\left.100 \mu \mathrm{mol} \mathrm{m}^{-2} \mathrm{~s}^{-1}\right)$ at $4^{\circ} \mathrm{C}$, analysed using a 2 factor repeated measures ANOVA. Significant changes identified by post hoc pairwise analyses are also listed. 
A3.4: Changes in $\alpha$ of Photosystem II over $48 \mathrm{~h}$ experimental treatments at different PAR levels $\left(0,1,45\right.$ and $\left.100 \mu \mathrm{mol} \mathrm{m}^{-2} \mathrm{~s}^{-1}\right)$ at $4^{\circ} \mathrm{C}$, analysed using a 2 factor repeated measures ANOVA. Significant changes identified by post hoc pairwise analyses are also listed.

A3.5: Changes in $E_{\mathrm{k}}$ of Photosystem II over $48 \mathrm{~h}$ experimental treatments at different PAR levels $\left(0,1,45\right.$ and $\left.100 \mu \mathrm{mol} \mathrm{m}^{-2} \mathrm{~s}^{-1}\right)$ at $4^{\circ} \mathrm{C}$, analysed using a 2 factor repeated measures ANOVA. Significant changes identified by post hoc pairwise analyses are also listed.

A3.6: Changes in Quantum Yield of Photosystem II over $48 \mathrm{~h}$ experimental treatments at different UV-B levels $\left(0,50\right.$ and $\left.150 \mathrm{mWm}^{-2}\right)$ and a PAR level of $1 \mu \mathrm{mol} \mathrm{m}^{-2} \mathrm{~s}^{-1}$ at $4^{\circ} \mathrm{C}$, analysed using a 2 factor repeated measures ANOVA. Significant changes identified by post hoc pairwise analyses are also listed.

A3.7: Changes in rETR $_{\max }$ of Photosystem II over $48 \mathrm{~h}$ experimental treatments at different UV-B levels (0, 50 and $\left.150 \mathrm{mWm}^{-2}\right)$ and a PAR level of $1 \mu \mathrm{mol} \mathrm{m}^{-2} \mathrm{~s}^{-1}$ at $4^{\circ} \mathrm{C}$, analysed using a 2 factor repeated measures ANOVA. Significant changes identified by post hoc pairwise analyses are also listed.

A3.8: Changes in MAA production over $48 \mathrm{~h}$ experimental treatments at different UV-B levels $\left(0,50\right.$ and $\left.150 \mathrm{mWm}^{-2}\right)$ and a PAR level of $1 \mu \mathrm{mol} \mathrm{m}^{-2} \mathrm{~s}^{-1}$ at $4^{\circ} \mathrm{C}$, analysed using a 2 factor repeated measures ANOVA. Significant changes identified by post hoc pairwise analyses are also listed.

A3.9: Changes in Photosynthetic Efficiency of Photosystem II over $48 \mathrm{~h}$ experimental treatments at different UV-B levels $\left(0,50\right.$ and $\left.150 \mathrm{mWm}^{-2}\right)$ and a PAR level of $1 \mu \mathrm{mol} \mathrm{m}^{-2} \mathrm{~s}^{-1}$ at $4^{\circ} \mathrm{C}$, analysed using a 2 factor repeated measures ANOVA. Significant changes identified by post hoc pairwise analyses are also listed.

A3.10: Changes in Saturation Irradiance of Photosystem II over $48 \mathrm{~h}$ experimental treatments at different UV-B levels $\left(0,50\right.$ and $\left.150 \mathrm{mWm}^{-2}\right)$ and a PAR level of $1 \mu \mathrm{mol} \mathrm{m}^{-2} \mathrm{~s}^{-1}$ 
at $4^{\circ} \mathrm{C}$, analysed using a 2 factor repeated measures ANOVA. Significant changes identified by post hoc pairwise analyses are also listed.

A3.11: Changes in photosynthetic parameters for Chaetoceros sp. over $48 \mathrm{~h}$ experimental treatments at PAR levels $\left(0,1,45\right.$ and $\left.100 \mu \mathrm{mol} \mathrm{m} \mathrm{m}^{-2} \mathrm{~s}^{-1}\right)$ at $4^{\circ} \mathrm{C}$, analysed using repeated measures ANOVA. Significant changes identified by post hoc pairwise analyses are also listed.

A3.12: Changes in photosynthetic parameters for Chaetoceros sp. over $48 \mathrm{~h}$ experimental treatments at different UV-B levels $\left(0,50\right.$ and $\left.150 \mathrm{mWm}^{-2}\right)$ and a PAR level of $1 \mu \mathrm{mol} \mathrm{m}^{-2} \mathrm{~s}^{-1}$ at $4^{\circ} \mathrm{C}$, analysed using repeated measures ANOVA. Significant changes identified by post hoc pairwise analyses are also listed.

\section{APPENDIX 4}

Table A4.1 Changes in quantum yield of Photosystem II over $168 \mathrm{~h}$ experimental treatments at different light levels (L0 $=0 \mu \mathrm{mol} \mathrm{m}{ }^{-2} \mathrm{~s}^{-1} ; \mathrm{L} 1=1 \mu \mathrm{mol} \mathrm{m}^{-2} \mathrm{~s}^{-1} ; \mathrm{L} 2=45 \mu \mathrm{mol} \mathrm{m}^{-2} \mathrm{~s}^{-}$ 1 and $50 \mathrm{mWm}^{-2} ; \mathrm{L} 4=100 \mu \mathrm{mol} \mathrm{m}^{-2} \mathrm{~s}^{-1}$ and $100 \mathrm{mWm}^{-2}$ ) at $4^{\circ} \mathrm{C}$, analysed using a 2 factor repeated measures ANOVA. Significant changes identified by post hoc pairwise analyses are also listed.

Table A4.2 Changes in rETR $_{\max }$ of Photosystem II over $168 \mathrm{~h}$ experimental treatments at different light levels (L0 $=0 \mu \mathrm{mol} \mathrm{m}^{-2} \mathrm{~s}^{-1} ; \mathrm{L} 1=1 \mu \mathrm{mol} \mathrm{m}{ }^{-2} \mathrm{~s}^{-1} ; \mathrm{L} 2=45 \mu \mathrm{mol} \mathrm{m}^{-2} \mathrm{~s}^{-1}$ and 50 $\mathrm{mWm}^{-2} ; \mathrm{L} 4=100 \mu \mathrm{mol} \mathrm{m}^{-2} \mathrm{~s}^{-1}$ and $100 \mathrm{mWm}^{-2}$ ) at $4^{\circ} \mathrm{C}$, analysed using a 2 factor repeated measures ANOVA. Significant changes identified by post hoc pairwise analyses are also listed.

Table A4.3 Changes in SOD activity per cell over $168 \mathrm{~h}$ experimental treatments at different light levels ( $\mathrm{L} 0=0 \mu \mathrm{mol} \mathrm{m}{ }^{-2} \mathrm{~s}^{-1} ; \mathrm{L} 1=1 \mu \mathrm{mol} \mathrm{m}{ }^{-2} \mathrm{~s}^{-1} ; \mathrm{L} 2=45 \mu \mathrm{mol} \mathrm{m}^{-2} \mathrm{~s}^{-1}$ and $50 \mathrm{mWm}^{-2}$; 
$\mathrm{L} 4=100 \mu \mathrm{mol} \mathrm{m}^{-2} \mathrm{~s}^{-1}$ and $100 \mathrm{mWm}^{-2}$ ) at $4^{\circ} \mathrm{C}$, analysed using a 2 factor repeated measures ANOVA. Significant changes identified by post hoc pairwise analyses are also listed.

Table A4.4. Changes in alpha( $\alpha)$ of photosystem II over $168 \mathrm{~h}$ experimental treatments at different light levels ( $\mathrm{L} 0=0 \mu \mathrm{mol} \mathrm{m}{ }^{-2} \mathrm{~s}^{-1} ; \mathrm{L} 1=1 \mu \mathrm{mol} \mathrm{m}^{-2} \mathrm{~s}^{-1} ; \mathrm{L} 2=45 \mu \mathrm{mol} \mathrm{m}^{-2} \mathrm{~s}^{-1}$ and 50 $\mathrm{mWm}^{-2} ; \mathrm{L} 4=100 \mu \mathrm{mol} \mathrm{m}^{-2} \mathrm{~s}^{-1}$ and $100 \mathrm{mWm}^{-2}$ ) at $4^{\circ} \mathrm{C}$, analysed using repeated measures ANOVA. Significant changes identified by post hoc pairwise analyses are also listed.

Table A4.5. Changes in Saturation Irradiance $\left(E_{\mathrm{k}}\right)$ of photosystem II over $168 \mathrm{~h}$ experimental treatments at different light levels $\left(\mathrm{L} 0=0 \mu \mathrm{mol} \mathrm{m}^{-2} \mathrm{~s}^{-1} ; \mathrm{L} 1=1 \mu \mathrm{mol} \mathrm{m}^{-2} \mathrm{~s}^{-1}\right.$; $\mathrm{L} 2=45 \mu \mathrm{mol} \mathrm{m}^{-2} \mathrm{~s}^{-1}$ and $50 \mathrm{mWm}^{-2} ; \mathrm{L} 4=100 \mu \mathrm{mol} \mathrm{m}^{-2} \mathrm{~s}^{-1}$ and $100 \mathrm{mWm}^{-2}$ ) at $4^{\circ} \mathrm{C}$, analysed using repeated measures ANOVA. Significant changes identified by post hoc pairwise analyses are also listed. 


\section{ABBREVIATIONS}

\begin{tabular}{|c|c|}
\hline$\alpha$ & photosynthetic efficiency \\
\hline ANOVA & analysis of variance \\
\hline BWF & biological weighting function \\
\hline $\mathrm{C}$ & Celsius \\
\hline $\mathrm{cm}$ & centimetre \\
\hline Chl a & Chlorophyll a \\
\hline Chl c & Chlorophyll c \\
\hline DMSP & dimethylsulfonioproprionate \\
\hline DIC & dissolved inorganic carbon \\
\hline DD & diadinoxanthin \\
\hline DT & diatoxanthin \\
\hline DMSP & dimethylsulfonioproprionate \\
\hline DOM & dissolved organic matter \\
\hline DPPH & diphenyl-picrylhydrazyl \\
\hline$E_{\mathrm{k}}$ & saturation irradiance \\
\hline ETR & electron transport rate \\
\hline ETC & electron transport chain \\
\hline EPS & extracellular polymeric substances \\
\hline $\mathrm{F}$ & F statistic for ANOVA \\
\hline $\mathrm{F}^{\prime}$ & fluorescence yield \\
\hline$F^{\prime} / F_{o}$ & initial fluorescence \\
\hline $\mathrm{F}_{\mathrm{m}}^{\prime} / \mathrm{F}_{\mathrm{p}}$ & maximum fluorescence \\
\hline $\mathrm{F}_{\mathrm{v}} / \mathrm{F}_{\mathrm{m}}$ & maximum quantum yield of PS II \\
\hline $\mathrm{HO}^{\bullet}$ & hydroxyl radical \\
\hline HPLC & high performance liquid chromatography \\
\hline IPCC & Intergovernmental Panel on Climate Change \\
\hline MAA & mycosporine-like amino acids \\
\hline
\end{tabular}




\begin{tabular}{|c|c|}
\hline $\mathrm{m}$ & metre \\
\hline $\min$ & minutes \\
\hline $\mathrm{mL}$ & millilitre \\
\hline NPQ & non-photochemical quenching \\
\hline$\phi$ PSII & effective quantum yield \\
\hline $\mathrm{p}$ & significance value \\
\hline PAM & pulse amplitude modulation fluorometry \\
\hline PAR & photosynthetically active radiation $(400-700 \mathrm{~nm})$ \\
\hline PS I & photosystem I \\
\hline PS II & photosystem II \\
\hline PUFA & polyunsaturated fatty acid \\
\hline $\mathrm{rETR}_{\max }$ & maximum relative electron transport rate \\
\hline RLC & rapid light curve \\
\hline RF/NBT & Riboflavin/NitroBlue Tetrozolium \\
\hline ROS & reactive oxygen species \\
\hline SAM & Southern Hemisphere Annular Mode \\
\hline SIMCO & sea ice microbial communities \\
\hline SOD & superoxide dismutase \\
\hline $\mathrm{O}_{2} \cdot$ & superoxide anion - \\
\hline $\mathrm{T}_{\mathrm{c}}$ & critical temperature where permanent damage occurs \\
\hline $\mathrm{T}_{\mathrm{p}}$ & temperature of maximum fluorescence \\
\hline TEM & transmission electron microscope \\
\hline$\mu \mathrm{mol}$ & micromoles \\
\hline UV-A & ultraviolet-A (315-400 nm) \\
\hline UV-B & ultraviolet-B $(280-315 \mathrm{~nm})$ \\
\hline UV-C & ultraviolet-C (200-280 nm) \\
\hline UVR & ultraviolet radiation $(<400 \mathrm{~nm})$ \\
\hline wAP & western Antarctic Peninsula \\
\hline
\end{tabular}




\section{CHAPTER 1}

\section{Antarctic sea ice algae}

\subsection{Sea ice in Antarctica}

Antarctica was formed about 120 million years ago during the fragmentation of the Gondwana supercontinent, and finally separated from South America about 33 million years ago (Barrett, 1996, Whitehead et al., 2006). It is not only the fifth largest continent on the planet but $99.7 \%$ of its area is currently covered by ice (Convey et al., 2009b). It is a habitat of extremes, the coldest, driest, windiest region on the planet, and enveloped in continuous daylight or darkness for months (McGonigal \& Woodworth, 2002). Seasonal formation of sea ice effectively doubles the area of the continent each winter, covering an area of up to 7\% of the Earth's surface, and is a critical component not only of the cryosphere but also of the global climate system (Turner et al., 2009). The formation and disintegration of this habitat has a profound effect on many processes in the world's oceans. The annual advance and retreat of sea ice may be the largest seasonal process on Earth (Fritsen et al., 2008), and influences the life cycles of marine organisms. It covers up to $20 \times 10^{6} \mathrm{~km}^{2}$ of the ocean's surface during winter and receding to less than $4 \times 10^{6} \mathrm{~km}^{2}$ in summer in the Antarctic (Cavalieri \& Parkinson, 2008) and $15 \times 10^{6} \mathrm{~km}^{2}$ in the winter to $5 \times 10^{6} \mathrm{~km}^{2}$ in the summer in the Arctic (Arrigo, 2014).

Sea ice forms a large stable habitat for microorganisms as it floats on the surface of the ocean. It begins to form in autumn when there are still some microbial populations remaining in surface waters from the spring bloom. Fast ice is the term used for ice which is attached to the land, and forms large continuous sheets that can cover many square kilometers (Fig. 1.1) (Arrigo \& Thomas, 2004). Platelet ice is often found beneath fast ice where the seawater can become super-cooled. It can range from a few centimetres to a few metres in thickness and is the most porous sea ice type, with the greatest surface area for algae to attach to. This layer can hold the highest biomass of sea ice algae (Arrigo et al., 1993). Pack ice, which is not connected to the land, is much more dynamic, changes with the wind and generally has more snow cover, so is variable in thickness. 
In the marine environment, as temperatures drop, thin layers of ice crystals called frazil ice form on the water surface and eventually coalescence into thicker pancake ice. Pancake ice becomes consolidated before further ice growth takes place vertically as the heat is extracted from the surface by the cold air, leading to the formation of columnar ice crystals that extend from the bottom of the ice into the water column (Fig. 1.1). The bottom layer of the columnar ice is termed the skeletal layer, and is at just below the freezing temperature of seawater and is highly porous (Arrigo \& Thomas, 2004).
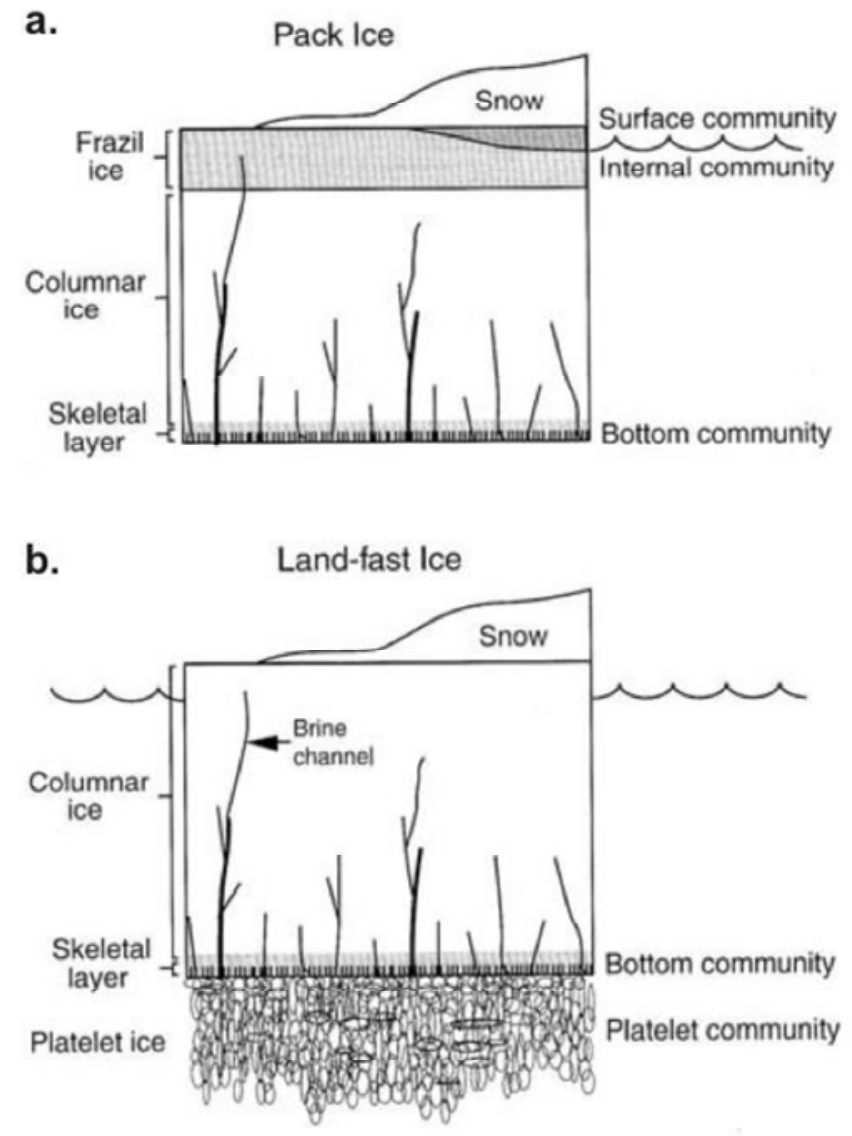

Figure 1.1. Pack ice and land-fast ice showing the major physical features and locations of microbial habitats (Arrigo \& Thomas, 2004).

Ice formation generates crystals of pure water, while salt accumulates in the surrounding brine. This drains into the ocean and, being denser than the surrounding water, descends through the water column, eventually leading to the formation of Antarctic Deep Water in some areas (Thomas \& Dieckmann, 2003, van Wijk \& Rintoul, 2014). Some of the higher salinity brine remains trapped in pockets between the ice 
crystals. As the temperature drops', further freezing occurs, leaving more concentrated brine in the brine channels. Sea ice thus has a complex structure composed of crystals of essentially pure water surrounded by brine of variable salinity. Close to the surface where the temperatures are coldest, the brine will have the highest salt content. Over time, as the ice warms from winter to summer, the dense brine drains out and is replaced by normal strength seawater and the overall salinity of the sea ice decreases (Arrigo \& Thomas, 2004).

Brine algal communities face the combined stresses of high salinity and low temperatures (Ralph et al., 2005). Temperatures in the ice typically range between $1.9^{\circ} \mathrm{C}$ to $-6.7^{\circ} \mathrm{C}$ and salinity can be approximately $110 \%$ (Ralph et al., 2005). The coldest part of the ice for brine algae is the uppermost part of the profile where irradiance is highest (Thomas \& Dieckmann, 2002). With increasing depth in the profile, irradiance is reduced and temperature stabilises to $-1.8^{\circ} \mathrm{C}$ at the ice-seawater interface.

The composition of sea ice brine in the summer is influenced by biological activity, predominately that of algae, as this can lead to variation in nutrient salts such as nitrate and ammonia (Gleitz et al., 1995). In contrast, in winter, brine composition is determined by abiotic factors such as temperature. Primary production in summer sea ice is sustained until nutrients become depleted and this results in a brine composition quite different to that of the surrounding seawater (Gleitz et al., 1995).

Most microbial biomass in the different strata of fast ice is found in the bottom $20 \mathrm{~cm}$, as this provides the most stable and favourable habitat where environmental conditions are generally constant (Arrigo \& Thomas, 2004). Algal productivity in the freeboard (sea level) layer of first year ice is limited by nutrients due to the rapid spring bloom leading to nutrient depletion, but PAR is the main limiting factor at all other times (Arrigo et al., 1997, Fritsen et al., 2008).

In pack ice, due to thicker layers of snow cover, there can also be considerable production higher in the ice profile, as the layer between the ice and the snow can become flooded with water encouraging algal growth. Snow cover may modify algal biomass (Juhl \& Krembs, 2010). The thicker the snow layer, the lower the irradiance transmitted to the ice below and the higher the average ice temperature. Juhl \& Krembs (2010) reported that ice algal biomass reduced after removal of a thick layer of snow 
$(\geq 9 \mathrm{~cm})$, but increased after the removal of a thin layer $(4-5 \mathrm{~cm})$. Even though removing a layer of snow caused ice ablation at the bottom of the ice, it did not always result in a net loss of algae as the increase in irradiance promoted growth sufficiently to compensate for the loss from bottom ablation. Snow cover can also have a positive effect on sea ice primary production as it depresses the ice below sea level and causes flooding of the surface, delivering algae and nutrients (interstitial ice algae) (Lizotte, 2001). In some conditions, algae can also be found in internal layers of the ice, remaining where they were trapped during frazil ice formation. These internal communities face steep gradients in environmental conditions such as salinity, temperature and irradiance (Arrigo \& Thomas, 2004, Stoecker et al., 1998).

The sea ice layer regulates photosynthetically active radiation (PAR) in the underlying water column, determining productivity in that habitat (Eicken, 1992). It also provides shade-adapted organisms at the bottom of the ice profile with steady levels of PAR that would not be possible in the upper layer of the open ocean due to mixing. The structure of the sea ice also determines temperature and salinity levels for the microorganisms found there (Fig. 1.2). While the air temperature determines the temperature at the top of the sea ice, the temperature at the bottom of the sea ice is at a constant $-1.8 \mathrm{C}$, the freezing point of seawater (Eicken, 1992). This difference in temperature through the sea ice profile, in turn, determines brine volume. PAR and temperature of sea ice structure the community within it. Considering the extent and role of sea ice as a stable and productive habitat, it clearly forms an important component of the planet which cannot be ignored when predicting future climatic conditions (Eicken, 1992).

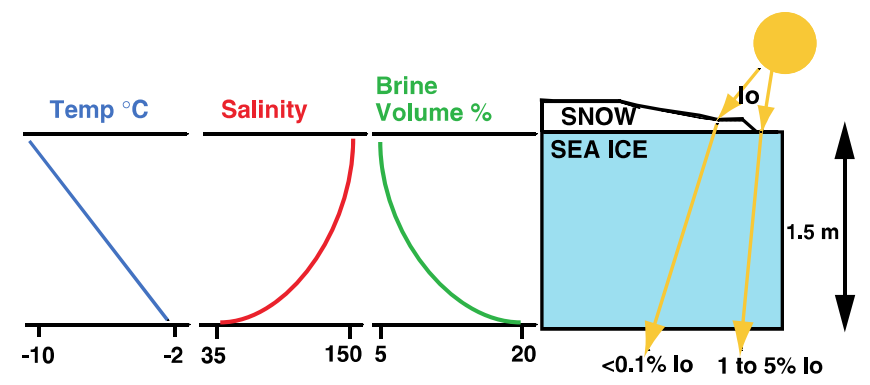

Figure 1.2. Gradients of temperature, salinity and brine volume across an ice floe. The diagram also shows the effect of snow cover on attenuation of PAR (Thomas \& Dieckmann, 2002). 


\subsection{Effect of climate change on sea ice}

Unprecedented global climate change trends have become apparent over the past century. In Antarctica, there are also strong regional trends that may not be related to the global process, and region-specific effects such as the consequences of the annual formation of the stratospheric Antarctic ozone hole (Convey et al., 2009a, Dixon et al., 2012, Turner et al., 2009, 2012). The IPCC Fourth Assessment forecasted a continuing increase in positive polarity of the Southern Hemisphere Annular Mode, leading to increasing westerly winds over the Southern Ocean (Bracegirdle et al., 2008, Comiso et al., 2011, Convey et al., 2009a). Recent data from the IPCC Fifth Assessment show a positive trend in the annual mean ice extent in the Antarctic of 1.2 to $1.8 \%$ per decade (Turner et al., 2013)(http://www.ipcc.ch/report/ar5/wg1/\#.UuhKY2SBoYI). However, sea ice extent and duration have also significantly reduced in the Bellinghausen Sector, and maximum annual ice loss is expected in the central Weddell Sea and the Bellingshausen-Amundsen Seas (Lefebvre \& Goosse, 2008), while concomitantly increasing by about $4.5 \%$ in the Ross Sea (Turner et al., 2009). In the north-east and west Antarctic Peninsula and southern Bellinghausen Sea region, later ice advance and earlier retreat have caused a shorter duration of sea ice over the period between 1979/1980 and 2010/2011, while opposite trends have been observed in the western Ross Sea (Stammerjohn et al., 2012). The long term rate of change in the Arctic is much greater than in the Antarctic, with summer ice extent reducing by $45 \%$ in only the past three decades (Maksym et al., 2012, Stammerjohn et al., 2012). A reduction in sea ice extent and duration can have significant impacts on the phytoplankton community, with changes in species composition and abundance (Montes-Hugo et al., 2009, Schloss et al., 2012) and consequential impacts on species further up the food chain (Forcada et al., 2006). These changes have been linked with reductions in krill stocks and their replacement by salps, effects that in turn impact the entire Southern Ocean food web (Atkinson et al., 2004, Trivelpiece et al., 2011).

At high latitudes such as those found in the polar regions, sunlight is strongly seasonal and ice-free days in the summer leads to orders of magnitude more light than in winter (Clark et al., 2013). Early sea ice breakout will cause an exponential increase in the amount of sunlight reaching these ice-covered ecosystems. This likely to drive ecological tipping points where primary producers thrive and out-compete dark- 
adapted communities. Tipping points are events where small changes in environmental conditions breach critical thresholds and cause rapid and extensive changes in an ecosystem (Scheffer et al., 2001). Tipping points can lead to loss in biodiversity and ecological changes that are irreversible. Earlier sea ice break-out is likely to lead to a tipping point in the shallow polar seabed ecosystem that leads to a change from predominately heterotrophic to autotrophic communities, as has been observed in the Arctic Svalbard (Kortsch et al., 2012) and the western Antarctic Peninsula (Quartino et al., 2013) where macroalgae have invaded rocky reef habitats during a period of sea-ice reduction. This light-driven tipping point can cause widespread shifts from invertebrate to algal-dominated states, reduce coastal biodiversity and alter ecosystem functioning (Worm et al., 2006). With pack ice expected to reduce by $24-40 \%$ around the Antarctic by 2100 (Mayewski et al., 2009) and increased wind speed and storm frequency (Bracegirdle et al., 2008) that should result in earlier fast ice break-up (Massom \& Stammerjohn, 2010), future ice loss is likely to lead to autotroph-dominated polar ecosystems, with higher productivity and carbon-sequestration but lower regional biodiversity (Clark et al., 2013).

If global warming trends are considered beyond scenarios of the next 100 years, the Southern Ocean could undergo greater warming than is predicted in the recent IPCC Assessments (Plattner et al., 2008). Even the current assessments are increasingly appearing conservative. For instance, the inclusion of previously neglected carbon cycle feedbacks into models may result in warming of global air temperatures of $5.5^{\circ} \mathrm{C}$, rather than the current prediction of $4^{\circ} \mathrm{C}$ over the same time period (Friedlingstein et al., 2006). The AR4 climate models indicated that the annual average sea ice area around the Antarctic will decrease by 33\%, this being most apparent in winter and spring, decreasing the amplitude of seasonal sea ice cycles. The IPCC AR5 models predict that there will be a nearly ice-free state in February within this century (http://www.ipcc.ch/report/ar5/wg1/\#.UuhKY2SBoYI).

Spring levels of ozone in the stratosphere declined rapidly in the late 1970s due to the anthropogenic release of chlorofluorocarbons, leading to formation of the ozone hole over the continent each spring (Farman et al., 1985). This decrease has now stabilised even though convincing signals of the predicted recovery have yet to be seen (Bodeker et al., 2005, Convey et al., 2009a, Turner et al., 2013). Springtime depletion of ozone 
over Antarctica has led to an increase in the shorter wavelength high energy and biologically damaging UV-B part of the ultraviolet radiation (UVR) spectrum reaching the sea surface. This increase in UV-B has resulted in a reduction in primary productivity and increased DNA damage in both pelagic and sea ice algae (Arrigo et al., 2003, Arrigo \& Thomas, 2004, Hessen et al., 2012, Nahon et al., 2010, Peinado et al., 2004).

Along the Antarctic Peninsula, the recent loss of ice shelves and retreat of coastal glaciers have resulted in phytoplankton blooms and increasing carbon sinks in the newly exposed area and water column (Peck et al., 2010). In contrast, an unexpected consequence of reducing sea ice cover in some areas on the western side of the Antarctic Peninsula has been a decrease in phytoplankton concentrations (MontesHugo et al., 2009). As noted above, changes in phytoplankton biomass have been linked with subsequent decreases in krill populations and increases in salp numbers in the Atlantic sector of the Southern Ocean (Atkinson et al., 2004, Hays et al., 2005, Trivelpiece et al., 2011). A shift in the contribution of phytoplankton to ecosystem processes, ultimately influenced by current trends in temperature, therefore appears to

be leading to an ecologically significant negative impact on the entire oceanic food web, as salps are not as nutritious or palatable as krill (Ducklow et al., 2007, Moline et al., 2004). Furthermore, during periods of decreased sea ice extent, chinstrap and Adélie penguin breeding failures due to a reduction in Antarctic krill biomass have been documented (Forcada et al., 2006). Changes in sea ice extent are also expected to alter the balance between different penguin populations, as chinstrap and gentoo penguins are better adapted to ice-free conditions than Adélie penguins (Forcada et al., 2006).

\subsection{Microbial diversity in sea ice and its role in the ecosystem}

Various microorganisms occupy unique niches in this habitat making them an essential part of the trophic web of the ice-covered Southern Ocean (Brown \& Bowman, 2001, Thomas et al., 2008). Sea ice is dominated by microorganisms due to the small spaces and varied physico-chemical conditions in the ice structure (Krembs et al., 2000). Sea ice biota include algae, bacteria, archaea, protists, copepods, krill larvae and viruses, collectively termed the SIMCO (sea ice microbial communities) (Fig. 1.3). A welldeveloped SIMCO supports a microbial loop and a host of protozoans, zooplankton and 
small metazoans (Brown \& Bowman, 2001, Martin et al., 2011). In the microbial loop, there is a close proximity between algae, cyanobacteria and autotrophic bacteria, which make up the primary producers of the habitat. The production of extracellular polymeric substances (EPS) by ice algae may physically affect both the structure of the sea ice and community structure, probably contributing to their survival in these extreme environments (Arrigo \& Thomas, 2004, Thomas \& Dieckmann, 2002).

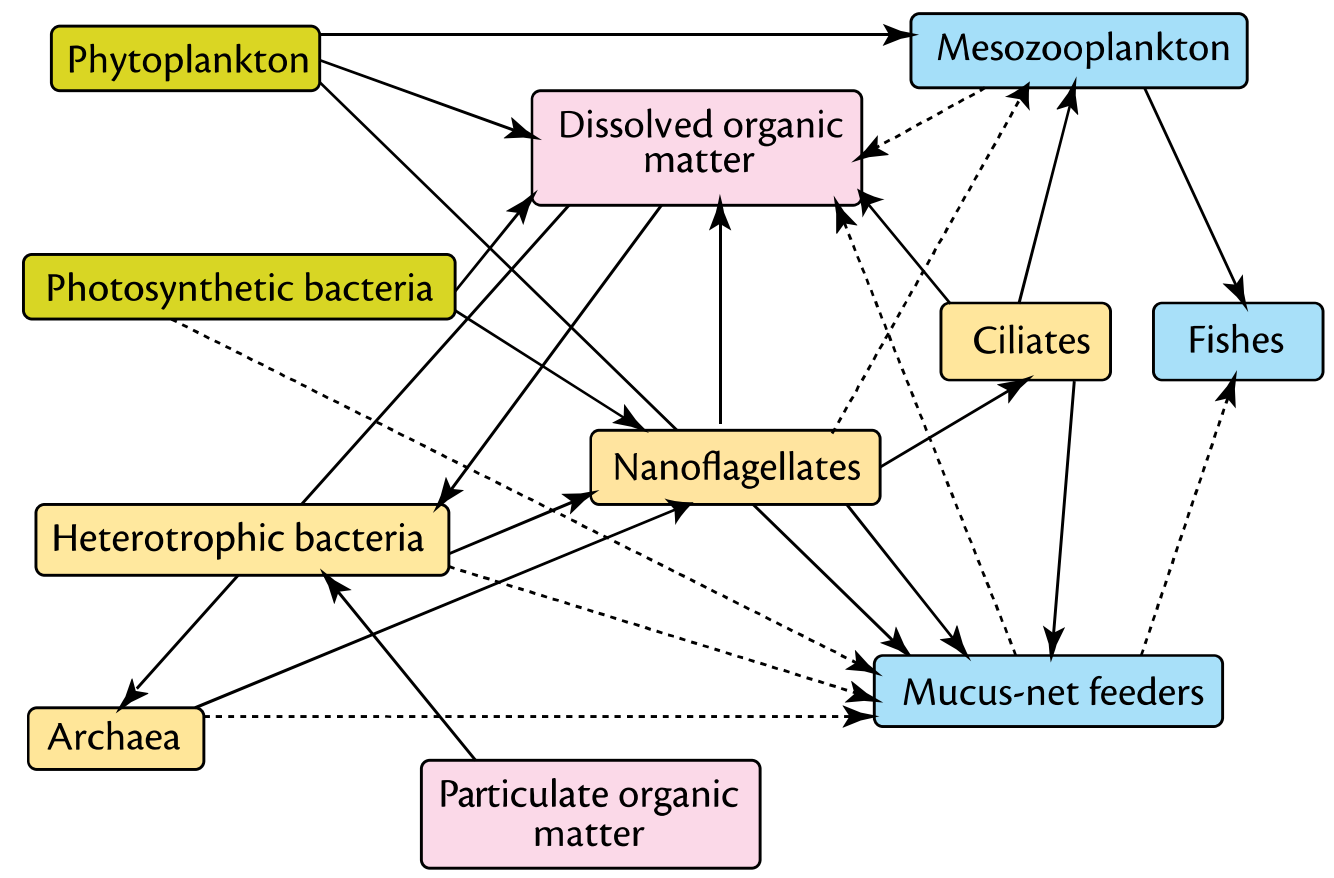

Figure 1.3. Simplified diagram of the ocean food web showing the dominant roles of the microbial loop. The major fluxes of carbon and energy are represented by continuous lines and fluxes of lesser magnitude are represented by broken lines. Mucus-net feeders such as salp are separated from other mesozooplankton because of differences in feeding modes. Other than the mucus-net feeders, mesozooplankton and fishes, represented by the blue boxes, the remaining boxes represent organisms that make up the microbial loop, green boxes representing photosynthetic and yellow representing heterotrophic organisms (from Pomeroy et al., 2007).

Photosynthesis fixes carbon into organic matter in the ocean (Pomeroy et al., 2007). Volk \& Hoffert (1985) identified three $\mathrm{CO}_{2}$ pumps in the oceans. One is physical and associated with ocean circulation, where cooling of surface water drives $\mathrm{CO}_{2}$ from the 
atmosphere into the ocean. One of the biological pumps is the carbonate pump and the other is the biological $\mathrm{CO}_{2}$ pump, the latter, related to sea ice biological production. The processes involving fixing of inorganic carbon during photosynthesis, its transformation by food web processes, physical mixing, transport and gravitational settling are referred to collectively as the "biological pump" (Fig. 1.4) (Ducklow et al., 2001). Inorganic nutrients and $\mathrm{CO}_{2}$ are fixed by photosynthesis in phytoplankton, which release dissolved organic matter (DOM), and both are consumed by zooplankton. DOM is partially consumed by bacteria and respired, while the remaining DOM is advected and mixed into the deep ocean. DOM and aggregates of larger zooplankton such as copepods are exported into deep water, consumed and respired which results in the organic carbon being returned into the deep ocean reservoir of dissolved inorganic carbon (DIC), where it can remain for millions of years. The net effect of these processes is to remove organic carbon from the surface. Diatoms are known to be a major contributor to the biological pump as they dominate the phytoplankton that are involved in autotrophic fixation of carbon on the surface of the world's oceans (Frost, 1984).

As sea ice ages, there are distinct changes from a more diverse community to a predominance of psychrophilic species (Arrigo \& Thomas, 2004). Algal communities are know to follow successional patterns with time, with communities becoming more diatom-dominated (Lizotte \& Arrigo, 1998) and bacteria/archaea diversity decreasing due to their more limited tolerance to salinity and changes in substrates available (Lawrence \& William, 2001). The microorganisms present in the ice community also modify sea ice structure, both physically and chemically (Thomas \& Dieckmann, 2002). The production of polymeric compounds such as dissolved organic material can lead to concentrations a magnitude higher than in the surrounding sea water (Thomas \& Dieckmann, 2002). 


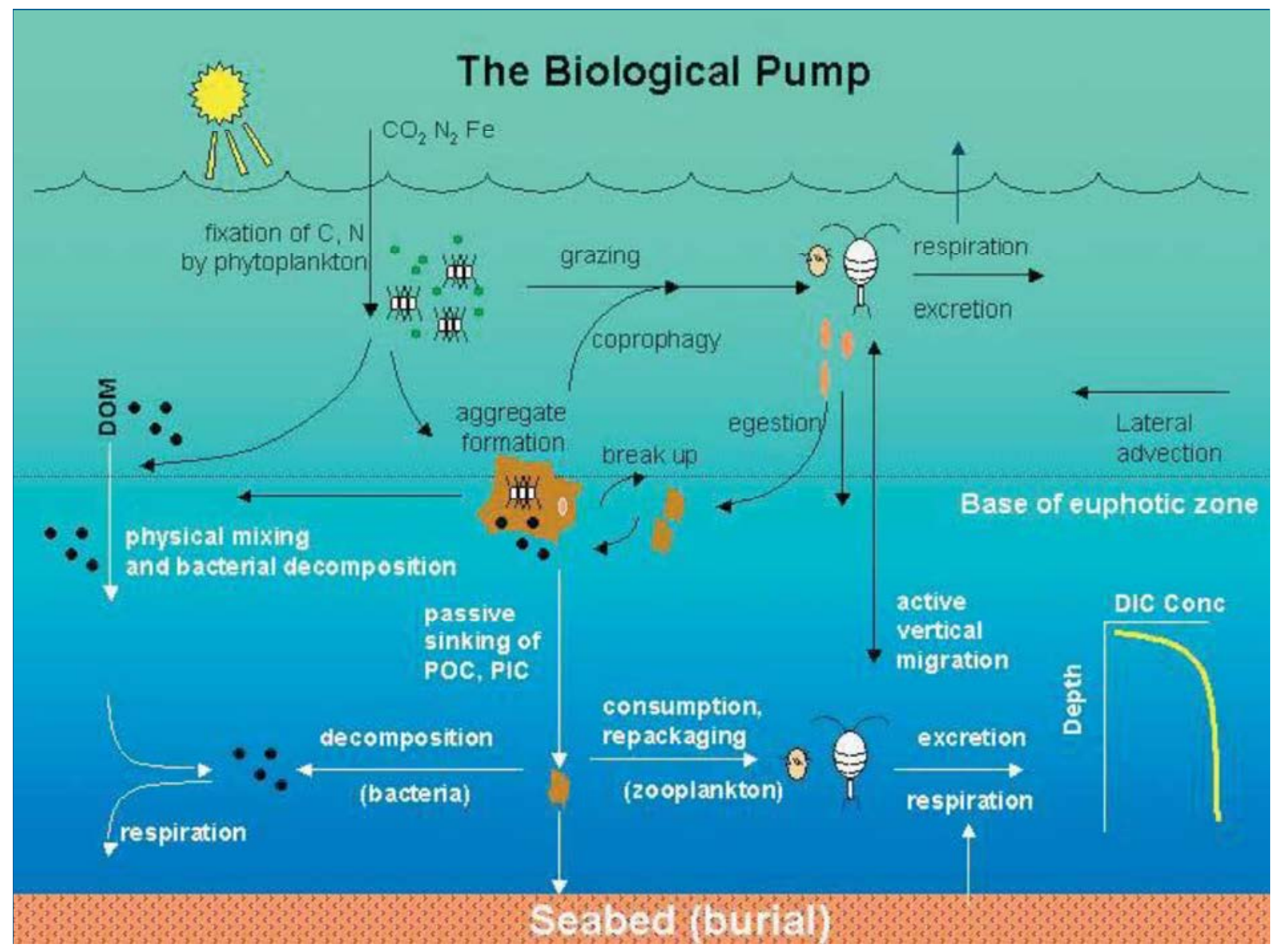

Figure 1.4. Components of the biological pump responsible for transforming DIC into organic biomass and pumping it in particulate or dissolved form into the deep ocean (from Ducklow et al., 2007).

The most common pioneer species in newly formed ice are pennate diatoms (Thomas \& Dieckmann, 2002). Bacterial species that are associated with these diatoms also become important members of this newly formed community. Species incorporated later in the successional process are likely to be less adept at dispersal and colonization, show slower growth rates and have more specific requirements for particular microenvironmental parameters. Multi-year sea ice has been observed to have a more heterotrophic community (Thomas \& Dieckmann, 2002).

One ecological role of sea ice lies in providing an important environmental refuge to cells and propagules over the winter and for seeding phytoplankton blooms in marginal ice zones (Lizotte, 2001). The large magnitudes of algal production in sea ice during summer and spring provide a key source of food for zooplankton during their life cycle. This algal mass is critical to larval krill largely due to the dearth of food found in the water column in winter (Atkinson et al 2004). 
Moline et al. (2004) showed that there was a consistent change from diatoms to cryptophytes every summer along the Antarctic Peninsula between 1991 and 1996, as cryptophytes preferred the lower salinity meltwater. This led to a significant decrease in the size of phytoplankton, affecting grazing efficiency by various zooplankton, and could further contribute to the decline in krill populations in this area as salps can more efficiently graze on smaller food particles than adult krill (Harbison \& McAlister, 1979, Madin \& Kremer, 1995). Adult krill are known to select for diatoms (Haberman et al., 2003) and higher growth rates of young krill have been observed when phytoplankton communities were dominated by diatoms (Ross et al., 2000).

In contrast to high levels of diversity in the surrounding water column, the number of ice-inhabiting metazoans is low, suggesting these organisms are highly specialized (Thomas \& Dieckmann, 2002). Krill larvae shift their habitat to the sea ice from the water column in order to feed on ice algae in winter and spring (Fig. 1.5) (Quetin \& Ross, 1991, Siegel, 2000). This is vital to their survival as krill larvae do not store enough lipids during the summer to survive the winter (Quetin et al., 1996). Krill populations are also tightly coupled with seasonal sea ice dynamics (Fig.1.4), as the ice provides nurseries for krill larvae, making it a critical habitat especially during the austral spring when spawning occurs (Ducklow et al., 2007). Predicting the effects of climate change on krill populations is complex and decreases in sea ice extent, through their impacts on populations of primary producer micro-organisms, could have an ecologically significant negative impact on the coastal food web.

Marine birds and mammals may utilise sea ice for specialized access to food or, alternatively, it may act as a barrier to them reaching open areas such as polynyas for feeding (Thomas \& Dieckmann, 2003). Polynyas are areas of ocean surface that are maintained free of ice formation due to, for instance, strong winds or warm water currents. In some areas of the polar regions, there are recurring polynyas that can be found at the same location every year (Thomas \& Dieckmann, 2003). In the Antarctic, the importance of winter polynyas is poorly understood, as they are too far south to receive any sunlight to support primary producers. However, if they persist until spring, they are known to affect the dynamics of Adélie penguin colonies (Ainley, 2002). 


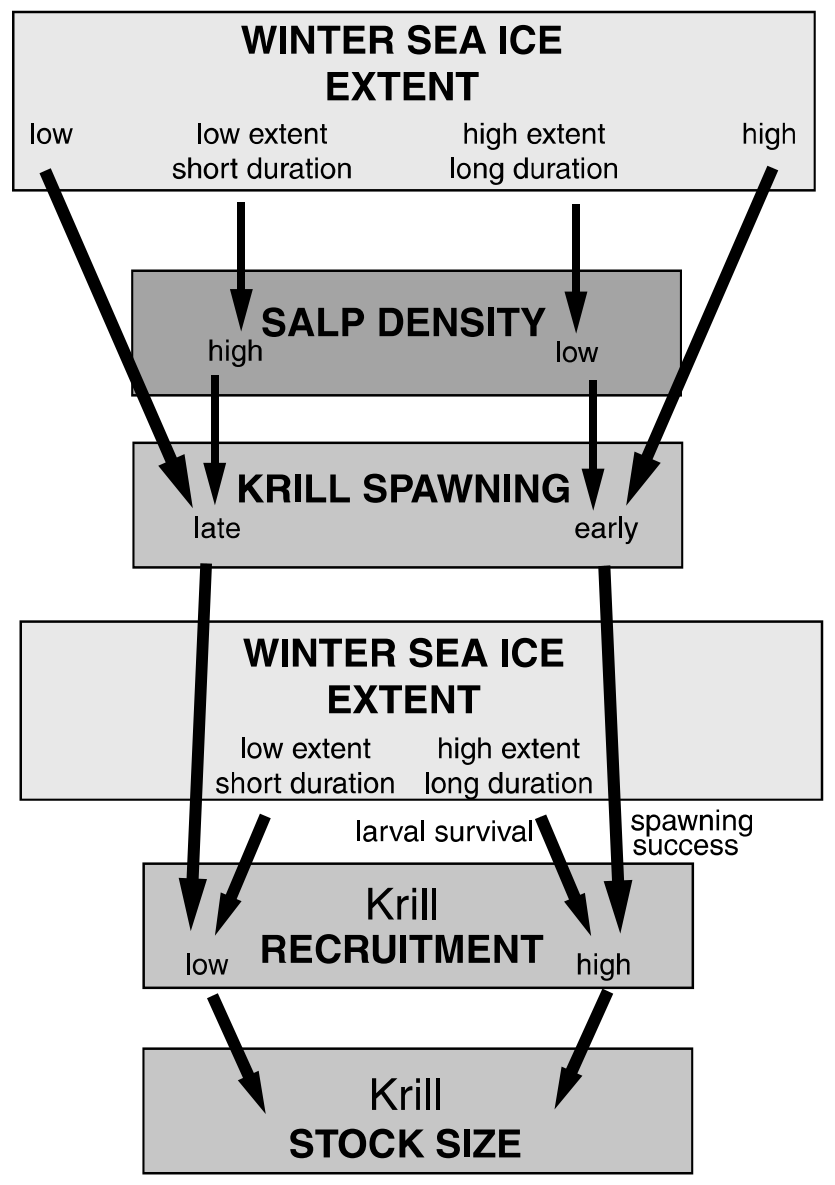

Figure 1.5. Hypothesised relationships between krill recruitment success and environmental (sea ice) and biological factors (salp abundance, spawning and timing) (after Siegel et al., 2000).

In the Antarctic, a number of marine mammal and bird species use sea ice as a platform for reproduction (Thomas \& Dieckmann, 2003). Crabeater, leopard, Ross and Weddell seals and emperor penguins use pack and fast ice for breeding. Sea ice also provides these organisms with a rich under-ice source of prey as a range of fish and invertebrates are present in the ecosystems beneath it (Ainley et al., 1991). In the Arctic, the same dependence on sea ice for breeding and feeding is seen in marine birds such as Ross's and ivory gulls, ringed seals and walrus (Thomas \& Dieckmann, 2003). Polar bears are confined to ice-covered areas of the Arctic as they search for their primary prey of seals. At both the poles, changes in sea ice thickness, extent and duration can affect the migratory patterns of whales that utilise these areas as feeding grounds in the summer (Thomas \& Dieckmann, 2003). 


\subsection{Microalgae in sea ice}

Microalgae are found in a range of different aquatic habitats in Antarctica where they are exposed to extreme environmental conditions such as increased levels of UVR, PAR and salinity and decreased levels of temperature and nutrients (Vincent, 1988). These habitats include seawater, sea ice, pack ice and lakes. They can reach standing crops of greater than $400 \mathrm{mg} \mathrm{m}^{-2}$ of chlorophyll a and have rates of primary production of more than $1 \mathrm{~g} \mathrm{C} \mathrm{m}^{-2}$ day $^{-1}$ depending on habitats and seasons (Arrigo et al., 1997). Sea ice algae contribute $10-28 \%$ of total primary production in the Southern Ocean, with the higher end of the range referring to the Ross Sea region (Arrigo \& Thomas, 2004, Eicken, 1992). Average productivity in ice free areas of the Southern Ocean is generally low ( 0.4 to $0.8 \mathrm{~g} \mathrm{C} \mathrm{m}^{-2} \mathrm{~d}^{-1}$ ), while areas covered by annual fast ice may reach up to 1.62 $\mathrm{g} \mathrm{C} \mathrm{m}^{-2} \mathrm{~d}^{-1}$ (Arrigo et al., 1998).

Algae, especially diatoms, are the most abundant primary producers in the sea ice ecosystem being found throughout the ice profile but predominantly in bottom ice and brine channels (Arrigo et al., 1997, Vincent, 1988). The sea ice microbial community is dominated by small pennate diatom species such as Fragilariopsis curta and F. cylindrus (Lizotte, 2001). Bottom ice communities also commonly include diatoms such as Nitzschia stellata, N. lecointei, Entomoneis kjellmanii and Cylindrotheca closterium (Ryan et al., 2006b).

Mangoni et al. (2009) observed a shift in diatom community composition following the transition to planktonic conditions when platelet ice melted. Chaetoceros spp. and $F$. cylindrus performed better when the sea ice had melted and they were released into the water column, as they could be limited by low irradiance under the ice. In contrast, Amphiprora kufferathii (a benthic species) and N. stellata could not grow in the planktonic condition, as they preferred the low PAR regime under the bottom ice. However, such characteristics may not be absolute, as $N$. stellata has been observed in the water column at Cape Hallett (Ryan et al., 2006a)

In the western Antarctic Peninsula region, primary production is governed by day length. Pelagic phytoplankton growth commences after sea ice break-up in early October and continues until early autumn (Ducklow et al., 2007). Summer sea ice biological production in this area is very low in absolute terms due simply to the lack of 
sea ice, being replaced by a large pelagic phytoplankton bloom which itself provides a major contribution to the marine food web (Clarke et al., 2007).

Recent studies have found that shallow sea temperature can vary as much as $1^{\circ} \mathrm{C}$ annually even in McMurdo Sound (Barnes et al., 2006, Hunt et al., 2003). Such rapid changes in temperature would lead to thinner sea ice and earlier sea ice melt, causing ice algae to face higher PAR and UV-B levels (Arrigo, 2014). There is also more intense resource limitation in the sea ice ecosystem at higher latitudes that is associated with strong seasonality. Algal growth is usually restricted to 2-4 months as they face winters with no light, low temperatures and low nutrient levels, due to depletion after algal blooms in summer (Peck et al., 2006).

\subsection{The influence of PAR on sea ice algae}

Antarctic ice algae are amongst the most shade-adapted species known (Thomas \& Dieckmann, 2002), with low $E_{\mathrm{k}}$ values (intensity of PAR required for maximum photosynthesis), and are also able to adjust their photosynthetic rates to suit changing diurnal irradiance levels (Arrigo et al., 1997). Photosynthesis in these algae has been recorded at PAR of less than $1 \mu \mathrm{mol} \mathrm{m} \mathrm{m}^{-2} \mathrm{~s}^{-1}$ and their $E_{\mathrm{k}}$ values are often less than 15 $\mu \mathrm{mol} \mathrm{m} \mathrm{m}^{-2} \mathrm{~s}^{-1}$ (McMinn et al., 2003). The combination of low PAR conditions, low photosynthetic parameters, high pigment concentrations and the abundance of chloroplasts in algal cells are strong indications of the shade-adapted abilities of bottom ice microalgal communities (Lazzara et al., 2007).

Although inconclusive, there is evidence that, especially in winter under low PAR conditions, sea ice algae may be able to switch from autotrophic to heterotrophic uptake of organic matter (mixotrophy) (Thomas \& Dieckmann, 2002). This has important implications for the krill larvae that rely on microalgae as (the only) source of biomass over winter. Mixotrophy has been commonly observed in phytoplankton found in Antarctic lakes that are dominated by phytoflagellates (Laybourn-Parry et al., 2005, Perriss \& Laybourn-Parry, 1997).

Ice algae generally have Chl-c in large concentrations as an adaptive response to the predominance of blue-green light under ice (Strickland, 1960). When the quality of this light changes as it does during the seasonal cycle, other pigments such as $\mathrm{Chl}-\mathrm{a}$ and 
carotenoids increase in concentration, presumably in order to increase the photosynthetic efficiency (Zonneveld, 1998). The carbon:Chl-a ratio per cell is considered to be a key quantity in phytoplankton growth which increases linearly with increased light level at constant temperature and decreases exponentially with increased temperature at constant light level (Geider, 1987). Sea ice algae may adapt to changing irradiances by adjusting their intracellular carbon:Chl- $a$ ratio from 25 to 100 to cope with a ten fold increase in irradiance from 100 to $1000 \mu \mathrm{mol} \mathrm{m}^{-2} \mathrm{~s}^{-1}$ (McMinn et al., 1999). This change is largely due to changes in Chl-a, as carbon concentrations remain more or less constant. Sea ice microalgae adapt to changes in irradiance by shifting Chl- $a$ content and modifying the number of photosystem reaction centers (Ralph et al., 2005). In under-ice microalgae, a rapid decline in Chl-a content could be associated with an interruption of energy flow through photosynthetic units, which is reversible, or be due to degradation of photosynthetic systems (Ralph et al., 2005). Surface ice algae, on the other hand, increase light-harvesting capacity and carbon fixation capacity to increase photosynthetic rate under low irradiances. Rates of photoadaptation in sea ice algae are comparable to those in phytoplankton, suggesting that sea ice algae would be equally capable of adapting to PAR conditions observed in a vertically mixed water column (McMinn et al., 1999). However, these rates of photoadaptation can vary widely between species, as observed by the severe stress caused by high PAR in large bottom ice diatoms in contrast to unaffected small pennate diatoms (Lizotte, 2001). The ability of some species of sea ice algae to photo-adapt to ever-changing irradiances may permit them to seed phytoplankton blooms in the marginal ice zones during melting (Lizotte \& Sullivan, 1991).

Bottom ice algae are exposed to large increases in PAR during melting in spring. Sea ice algae that stay at the surface use state-II transitions along with other physiological adaptations to overcome low irradiances (Ralph et al., 2005). Illumination that leads to excess excitement of PS II compared to PS I leads to a transition to state-II where more absorbed energy is diverted to PS I (Mullineaux \& Emlyn-Jones, 2005). The transition acts as a mechanism to balance the excitation energy between the two photosystems when light exposures to algae are in flux. 
The xanthophyll cycle involves the enzymatic removal of epoxy groups from carotenoid pigments (xanthophylls) to give de-epoxidised xanthophylls (Goss \& Jakob, 2010). Xanthophyll cycling dissipates absorbed energy from the pigment bed of PS II as a protective mechanism against high irradiances, avoiding photoinhibitory damage (Lohr \& Wilhelm, 1999, Robinson et al., 1997). The second major xanthophyll cycle, the diadinoxanthin (DD)/diatoxanthin (DT) cycle operates in diatoms providing protection against high irradiances (Griffith et al., 2009, Robinson et al., 1997). There is a known relationship between this activity and the onset of non-photochemical quenching (NPQ), providing the algae with an effective method of photoprotection against excess PAR (Demers et al., 1991, Lavaud et al., 2002). One of the main defense systems of ice algae to the liberation of free radicals and reactive oxygen species (ROS) produced due to high irradiances is through the production of antioxidants such as superoxide dismutase (SOD) (Martínez, 2007). Antioxidants prevent oxidative stress, cell protein damage and also damage to nucleic acids and membranes.

Increasing PAR plays an important role in affecting the nutritional quality of sea ice algae by decreasing polyunsaturated fatty acid (PUFA) content because of a decrease in C:N ratios (Leu et al., 2010). This could have major implications elsewhere in the food chain as it can affect the nutritional quality of krill available to macrofauna. PUFA have been proven to be important for successful egg production, hatching and larval development of zooplankton (Jónasdóttir et al., 2009). A decrease in Arctic sea ice leads to a decrease in PUFAs due to increased irradiance exposure (Leu et al., 2010). This leads to the krill grazing on lower quality algae, affecting maturation, egg production, hatching and nauplii development negatively.

\subsection{The effects of ultraviolet radiation (UVR) on sea ice algae}

Springtime anthropogenic ozone depletion occurs in the stratosphere over the Antarctic and leads to an increase of approximately $15 \%$ in the transmittance of UV-B to the Earth's surface (Arrigo et al., 2003). This has led to a decrease in primary productivity in phytoplankton (Moreau et al., 2010, Neale et al., 1998). However, due to the rapid attenuation through the water column, UV-B has a $10 \%$ penetration depth at $305 \mathrm{~nm}$ of $<10 \mathrm{~m}$ (Arrigo et al., 2003). Therefore, photoinhibition due to UV-B is limited to depths within $\sim 20 \mathrm{~m}$ of the surface of the ocean. Although bottom ice algae are not 
exposed to high levels of UV-B whilst in the sea ice (Ryan et al., 2012), they may face substantial photoinhibition during sea ice melting, due to the higher levels of UV-B experienced at shallow depths near the ocean surface (Arrigo \& Thomas, 2004, Ryan et al., 2011).

Under normal ozone conditions, 1 to $5 \%$ of incident UVR penetrates the sea ice to affect the bottom ice algal community (Karentz \& Bosch, 2001). UVR consists of UV-A, UV-B and UV-C, each having their own effects on biological organisms (Fig. 1.6) (Gao \& Garcia-Pichel, 2011). With ozone depletion, there is an increase in UV-B wavelengths and transmission of UV-B through ice may increase by up to 10\% (Karentz \& Bosch, 2001). Under such high exposures, ice algal productivity may decrease by up to $5 \%$ (Ryan et al., 2002). The increase in UV-B causes changes in species successional patterns that are also dependent on amount of snow cover and initial species composition of the algal community (Karentz \& Bosch, 2001). Ozone depletion does not significantly affect UV-A, which also has a lower attenuation through water (Franklin \& Forster, 1997, Karentz \& Bosch, 2001) and, thus, UV-A is not usually a factor that is considered in studying the effects of climate change on algae in the Antarctic. UV-C is largely absorbed by the atmosphere and, hence, although very damaging to cells and organisms under direct experimental exposure, is not of relevance in field situations (Holzinger \& Lütz, 2006).

UV-B radiation (280-320 $\mathrm{nm}$ ) readily damages many organic molecules of living organisms and, in the Antarctic, many ecosystems including those of the sea ice and the ocean surface may be vulnerable to ozone-induced increase in UV-B (Larkum \& Wood, 1993, Ryan, 1992, Ryan \& Hunt, 2005, Solheim et al., 2006). To protect themselves from UV-B, many organisms produce mycosporine-like amino acids (MAAs). MAAs are small water-soluble compounds that consist of an aminocyclohexenone or an aminocycloheximine ring that is substituted with amino acid residues (Oren \& GundeCimerman, 2007). They are found widely among marine and terrestrial organisms such as fungi, algae, cyanobacteria, corals and urchins and absorb in the range of 310-360 nm (Schick \& Dunlap, 2002). They are transparent to visible light and are, therefore, technically not pigments. HPLC analysis of sea ice samples from the Ross Sea region have shown the presence of MAAs such as porphyra-334, shinorine, mycosporineglycine and palythine (Arrigo \& Thomas, 2004, Ryan et al., 2002). 


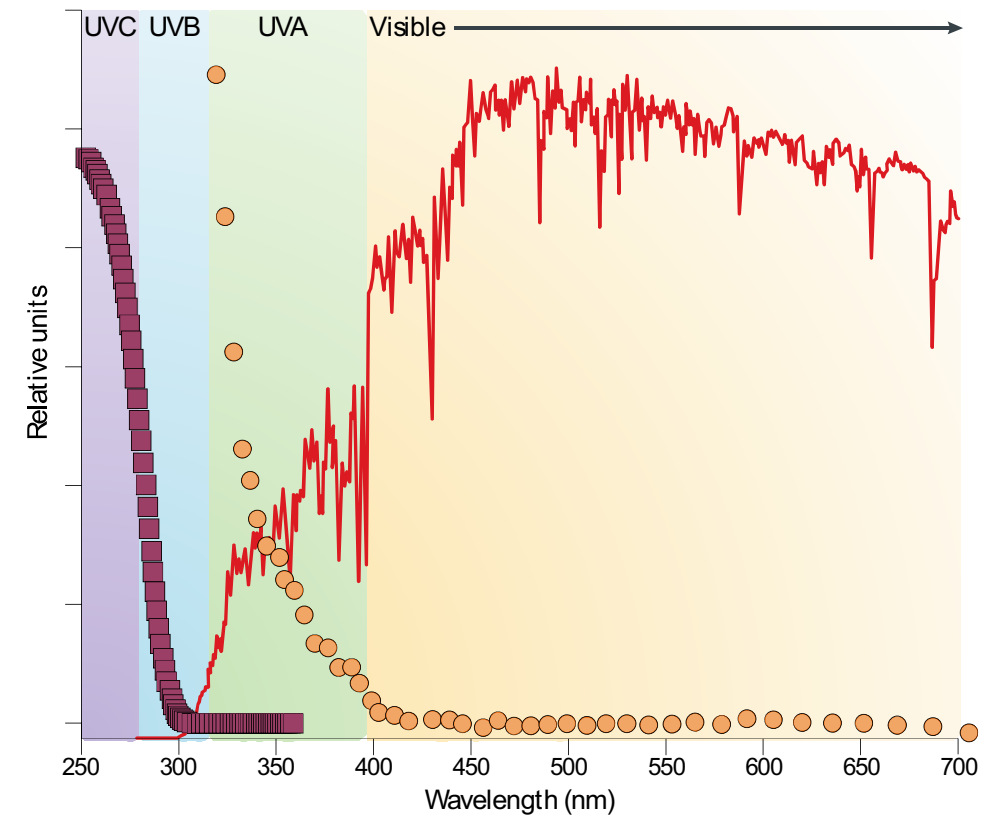

\footnotetext{
- Standard solar spectrum at the Earth's surface

Action spectrum for DNA damage

Efficiency (action) spectrum for inhibition of photosynthesis
}

Figure. 1.6. Standard solar radiation energy spectrum at the Earth's surface in the visible and ultraviolet ranges. The UV spectrum in this standard contributes $\sim 17 \%$ of the energy between $250 \mathrm{~nm}$ and $700 \mathrm{~nm}$. UV-A accounts for most of this energy, UV-B for $0.3 \%$ and UV-C a non-detectable component. As wavelength decreases, biologically relevant action spectra for damage increase exponentially. The action spectra for different biological processes vary. UV-C causes considerably more DNA damage than UV-A and UV-B, whereas UV-A and UV-B cause inhibition of photosynthesis (from (Gao $\&$ Garcia-Pichel, 2011)). No units are shown in the diagram but are assumed to be representative of irradiance levels.

Although polar regions are exposed to higher than normal levels of UV-B during spring, sea ice is a barrier to the transmission of this radiation and damage is restricted to those organisms living in the higher layers of the ice (Thomas \& Dieckmann, 2002). UV$B$ induced damage has been seen in sea ice diatoms in the form of damage to RNA transcription, DNA replication and specific inhibition of carbon assimilation in cells (Prézelin et al., 1998). There may also be changes in community composition due to differences in the ability of species to adapt to higher levels of UVR (Thomas \& Dieckmann, 2002). 
Ryan et al. (2002) reported that sea ice diatoms have more than an order of magnitude lower concentrations of MAAs than do phytoplankton in the water column. Despite this, the sea ice algae grew well and the lack of MAAs caused no discernable reduction in viability. It is also possible that UV-B protection in sea ice algae acts at a community level rather than at a cellular level, with the algae closest to the upper surface of ice bearing the highest burden of UV protection for the entire community in the ice profile (Ryan et al., 2002). In that study, even though initial concentration of MAAs per cell was relatively high, as the community grew the net concentration reduced. However, the overall concentration of MAAs per unit area did not alter during the period o 
pigment level by increasing cellular concentration of photosynthetic pigments such as chlorophyll $a$, fucoxanthin, diadinoxanthin and diatoxanthin (Van de Poll \& Buma, 2009) (see also Section 1.5, with reference to PAR).

There have been few studies on the effect of elevated temperatures on UV responses in sea ice algae (Halac et al., 2010, Sobrino \& Neale, 2007). In a study conducted using Thalassiosira pseudonona, photoinhibition under higher UV radiation increased at colder temperatures after short-term temperature change (Sobrino \& Neale, 2007). Algae subjected to long-term acclimation at lower temperatures showed decreased photoinhibition at low temperatures but less tolerance to higher temperatures compared to algae that had not undergone acclimation. It is likely that photoenzymatic repair induced by temperature acclimation was insufficient to counteract damage caused by the UV radiation. Repair in these algae is temperature dependent due to higher enzymatic activity at higher temperatures, making temperature a very important factor influencing photosynthetic productivity (Sobrino \& Neale, 2007). UV-B has varying detrimental effects on marine phytoplankton. It is less damaging to diatoms than to other groups of phytoplankton (Häder et al., 2003, Hannach \& Sigleo, 1998). There is also a difference in tolerance to UV-A or UV-B in some groups (Hernando et al., 2006). The latter authors showed that, when different PAR treatments were used in a mixed community experiment, photosynthesis was inhibited by UV-B at the beginning of the experiment but the community had acclimated by the end of the experiment. This was accompanied by a change in species composition from a phytoflagellate-dominated community to one with a relatively high abundance of diatoms (Hernando et al., 2006).

Karentz et al. (1991) reported a wide range of variability in species responses when Antarctic diatoms were exposed to different levels of PAR and UV-B. For example, Thalassiosira australis was capable of low induction of products of photosynthesis as a result of their morphology. When in chains, the algae had their girdle areas exposed, which consisted of only $20 \%$ of the total cell surface, minimizing UV-B exposure. Chaetoceros sp. showed more than an order of magnitude greater photoinhibition. Variations in cell size are considered to determine cellular protection, as increased cell volume protected sensitive sites, such as centrally located DNA, by an increase in path length of light travelling through a cell (Garcia-Pichel, 1994). 
The studies discussed above demonstrate the important influence of UV-B on sea ice algae. The research available is however limited in predicting community responses, which needs further investigation. This could be achieved by studying the effect of different levels of UV-B on single species. The effect of temperature on responses to UVB exposure also requires study, as this could be related to events at the ice edge during and after sea ice melt. Community composition could vary between regions in Antarctica and the tolerance of the same species could also vary between these regions. Any variation in tolerance could determine the fate of an algal species during sea ice melt, which in turn could influence the productivity of that area during the summer pelagic bloom.

\subsection{Other factors affecting sea ice algae}

Low temperatures are a constraint that Antarctic ice algae must face constantly. A drop in temperature occurs during early winter, often leading to reduced membrane fluidity, reduction in salt solubility and an increase in gas solubility within the cells (Mock \& Valentin, 2004). It can also lead to a decrease in $\mathrm{pH}$ that can adversely affect protein solubility and lower enzyme activity (Somero, 1981). Antarctic ice algae have adapted to this stress by many mechanisms including producing 'cold-adapted' enzymes and antifreeze proteins during sea ice formation (Feller \& Gerday, 2003, Georlette et al., 2004, Mock \& Valentin, 2004). There is an interrelationship between membrane lipid composition and photosynthetic function when acclimating to low temperature in circumstances either of nitrogen limitation or low irradiance (Morgan-Kiss et al., 2006). Ice algae have large chloroplasts, which enable them to adapt to low irradiances, producing cells whose cellular membranes were dominated by those in the thylakoid.

The other primary factors that control the growth of algae in sea ice are elevated salinity and access to nutrients (Arrigo \& Thomas, 2004). Bottom ice communities form in the skeletal layer and extend up to about $0.2 \mathrm{~m}$ above the bottom of the ice. This upward distribution is limited by low nutrient concentrations and high brine salinities in the interior of the ice where temperatures can also be very low. Algae can experience salinities that are up to 3 times or more that of seawater when they are incorporated into the sea ice lattice in winter (Ryan et al., 2004). Alternatively, during melting of ice, they can be exposed to hyposaline conditions in low salinity meltwater, causing salinity 
shock (Ryan et al., 2004). The lowest salinities seem to cause the greatest stress in these algae. Under high salinity stress, lipid structure and composition of fatty acids are regulated and enzymes tolerant to salinity stress are found.

An important osmolyte found in sea ice algae is dimethylsulfonioproprionate (DMSP) (Thomas \& Dieckmann, 2002). The functions of DMSP in algal cells are multiple, being a compatible solute that protects the cells against high salinity and freezing, a defence precursor for production of acrylic acid, a coupling mechanism between assimilatory sulphate and nitrate reduction and an antioxidant (Trevena \& Jones, 2006). Following exposure to hypersaline conditions, DMSP accumulates within the cell rapidly allowing the cell to reach equilibrium with its surroundings and function, enabling them to tolerate hypersalinity (Dickson \& Kirst, 1986).

As shown by Ralph et al. (2007), salinity stress is dependent on irradiance, as there was a clear decrease in photochemical efficiency when sea ice algae were exposed to irradiances of $150 \mu \mathrm{mol} \mathrm{m}^{-2} \mathrm{~s}^{-1}$ at elevated or reduced salinities. Hyposaline conditions create a greater challenge than hypersaline conditions. Even though the algae showed acclimation to hyposalinity over $7 \mathrm{~h}$, they underwent photoinhibitory stress when exposed to high PAR levels. When sea ice algae melt out into the surrounding seawater, they experience considerable stress due to hyposaline conditions and high ambient PAR levels, which would lead to photoinhibition. As some species are more adaptable to changes in salinity than others, there are likely to be changes in meltwater bloom community compositions as compared to those in the sea ice (Ralph et al., 2007). The effect of hypersalinity on the same algal populations is less as they show evidence of lower photosynthetic stress when freezing in, being exposed only to moderate PAR conditions at this time. This is probably due to the ability to use state-II transitions with other physiological adaptations to overcome low irradiances (Ralph et al., 2007).

\subsection{Ecological importance of sea ice algae}

Sea ice algae released from melting sea ice during summer and spring seed the subsequent blooms seen in the melt-water stabilized water column of the marginal ice zone (Arrigo \& Thomas, 2004). Iron is derived from atmospheric dust particles that accumulate in snowfall during the winter season, which then becomes incorporated 
into the sea ice (Sedwick \& DiTullio, 1997). As iron accumulates and is then released during ice melt, it can increase surface water iron concentrations by almost an order of magnitude (Sedwick et al., 2000). This release of iron could be an important factor in stimulation of the phytoplankton bloom at the sea ice edge during melting. Any decrease in the sea ice zone could result in fewer algae being present in the marginal ice zone, as the seed population has decreased and there are fewer nutrients in the water column from iron release or due to the disintegration of sea ice algae (Arrigo \& Thomas, 2004).

If climate change trends continue and the sea ice continues to break up and melt earlier as seen in recent decades in the western Antarctic Peninsula region (Montes-Hugo et al., 2009), diatom diversity could be severely reduced, with consequences for the entire ecosystem (Arrigo \& Thomas, 2004). In parts of this region, summer time surface $\mathrm{Chl}$ a has decreased by $12 \%$ over the past 30 years (Montes-Hugo et al., 2009). However, the area of the permanently open ocean zone would increase and primary production would increase here assuming sufficient nutrient availability (Arrigo et al., 1999). It has been predicted that an increase in the permanently open ocean zone could result in an increase in the growth of non-diatom species such as Phaeocystis antarctica (Arrigo et al., 1999). An increase in P. antarctica could result in increased primary production, as this is a species that can fix twice as much carbon as most diatoms (Arrigo et al., 1999). Increased primary production does not occur now due to changes in upper mixed layer stratification caused by melting of sea ice. During the early stages of the phytoplankton bloom at Terra Nova Bay, diatoms and P. antarctica equally dominated the phytoplankton community (Arrigo et al., 1999). However, later in the season, after the sea ice had melted, the water column developed mixed layers that were much shallower and more strongly stratified making the environmental conditions more suitable to diatoms (Arrigo et al., 1999). Increases in temperature could also lead to increased surface stratification (Sarmiento et al., 1998), and therefore to higher PAR exposure for algae in surface waters and decreased nutrient mixing from the deep. These conditions favour diatom growth, which would reduce primary production in waters that are nutrient limited (Arrigo et al., 1999). 
Localized disturbances can have a profound impact on the properties of sea ice in an entire ecosystem. This was observed in ice cores sampled in McMurdo Sound in the Ross Sea between 1999 and 2003 (Remy et al., 2008) associated with the stranding of the B-15 iceberg at the entrance to the Sound. This obstruction led to accumulation of multi-year ice and prevented ice breakout as normally occurs each summer, disrupting breeding and feeding behavior in penguins and seals and negatively affecting the entire ecosystem. The increased sea ice thickness also reduced autotrophic productivity as it limited PAR available to the under-ice algae, and there was also a decrease in brine volume, which affected the sea ice microbial community.

A study on various microbial ecosystems in the Arctic emphasizes their vulnerability to ongoing climate change (Vincent et al., 2009). The habitats studied, most of which have equivalents in the Antarctic, included glacial lakes on ice shelves and meromictic lakes. Record daily maximum air temperatures of $20^{\circ} \mathrm{C}$ were noted in some areas. Ward Hunt Lake lost $25 \%$ of its ice cover for the first time on record, which would expose photosynthetic organisms in this ecosystem to increased temperatures, PAR and UVR. Arctic summer sea ice extent also reached historic lows in the 2007 and 2008 seasons (Comiso, 2006, Comiso et al., 2008, Stroeve et al., 2008), which would have damaging implications for ice algae and phytoplankton in the water column and for the wider food web due to loss of habitat.

As discussed above, sea ice communities show significant physiological responses to a wide range of environmental conditions including light, PAR, UVR, temperature and salinity. In today's paradigm of changing environmental conditions, the adaptability and physiology of Antarctic sea ice organisms becomes highly significant due to their importance in the food web (Arrigo \& Thomas, 2004, Karentz \& Bosch, 2001). As sea ice algal communities play a very significant role in primary production in the Southern Ocean and are the only source of fixed carbon for all other life in this habitat (Arrigo et $a l ., 1997)$ increased understanding of how these organisms adapt to the highly variable and seasonal environment of Antarctica is an urgent research requirement. 


\subsection{Scope of thesis}

My thesis sets out to address the effects of increasing light, temperature and UV-B on bottom ice algal communities. It also addresses the lack of knowledge on speciesspecific responses to these parameters and includes studies that look at the effect of PAR and UV-B on species from the Ross Sea, Antarctic Peninsula and the Arctic. It is structured in four chapters that examine the functioning of the bottom ice algae in increasing detail. The thesis was written with the intention to submit each chapter for publication and, thus, there is inevitably some repetition of introductory material in the chapters.

The central questions addressed in this thesis are:

How do PAR, UV-B and temperature affect the photosynthetic activity of sea ice algal communities and unialgal cultures?

Does this have further implications with respect to changes in environmental parameters due to ice melt and/or reduction in sea ice thickness?

In Chapters 2 and 3, I examine the consequences of increased PAR, temperature and UV-B on freshly collected bottom ice algal communities in the field. These studies focus on photosynthetic responses measured using chlorophyll fluorescence techniques and MAA production of freshly collected mixed species communities from the Ross Sea. The algae were exposed to a narrow range of experimentally imposed temperatures soon after collection, mimicking the scale of temperature and irradiance changes experienced during and after sea ice melt in the Southern Ocean. Further, responses of these communities to a wider range of temperatures were also studied to observe the capability of the algae to retain their functioning if transported, for instance, to latitudes north of the Polar Front. Chapter 2 also documents an initial study of critical temperatures that affect thylakoid integrity using chlorophyll fluorescence techniques. In Chapter 4, I examine in more detail in the laboratory the effect of PAR and UV-B on unialgal cultures of Thalassiosira sp. and Fragilariopsis sp. derived from the Ross Sea, and Chaetoceros sp. from the naturally more variable Antarctic Peninsula in order to differentiate the influences identified in the previous chapters. This study attempts to improve assessment of species' viability during the melting process. 
In Chapter 5, I examine the photosynthetic, antioxidative and other responses of unialgal cultures from the Ross Sea, Antarctic Peninsula and Arctic in ecologically relevant PAR and UV-B levels to further analyse the differences in acclimatory capabilities of common species from three regions with varying patterns of environmental conditions. This work also addresses weaknesses in methodologies, particularly relating to control conditions, identified in the analyses of Chapters 3 and 4 , and permits increasing confidence in the interpretations drawn in those chapters. Understanding individual species responses could help us improve predictions of possible future community responses.

\subsection{REFERENCES}

Ainley, D. G., Fraser, W. R., Smith, W. O., Hopkins, T. L., \& Torres, J. J. (1991). The structure of upper level pelagic food webs in the Antarctic: effect of phytoplankton distribution. Journal of Marine Systems, 2, 111-121.

Ainley, D. G. (2002). The Adélie Penguin: Bellwether of Climate Change. New York: Columbia University Press.

Arrigo, K. R., Robinson, D. H., \& Sullivan, C. W. (1993). A high resolution study of the platelet ice ecosystem in McMurdo Sound, Antarctica: Photosynthetic and biooptical characteristics of a dense microalgal bloom. Marine Ecology Progress Series, 98, 173-185.

Arrigo, K. R., Worthen, D. L., Lizotte, M. P., Dixon, P., \& Dieckmann, G. (1997). Primary Production in Antarctic Sea Ice. Science, 276, 394-397.

Arrigo, K. R., Worthen, D., Schnell, A., \& Lizotte, M. P. (1998). Primary production in Southern Ocean waters. Journal of Geophysical Research, 103, 15587-15600.

Arrigo, K. R., Robinson, D. H., Worthen, D. L., Dunbar, R. B., DiTullio, G. R., VanWoert, M., et al. (1999). Phytoplankton community structure and the drawdown of nutrients and $\mathrm{CO} 2$ in the Southern Ocean. Science, 283, 365-367.

Arrigo, K. R., Lubin, D., van Dijken, G. L., Holm-Hansen, O., \& Morrow, E. (2003). Impact of a deep ozone hole on Southern Ocean primary production. Journal of Geophysical Research, 108, 3154.

Arrigo, K. R., \& Thomas, D. N. (2004). Large scale importance of sea ice biology in the Southern Ocean. Antarctic Science, 16, 471-486.

Arrigo, K. R. (2014). Sea Ice Ecosystems. Annual Review of Marine Science, 6, 439-467.

Atkinson, A., Siegel, V., Pakhomov, E., \& Rothery, P. (2004). Long-term decline in krill stock and increase in salps within the Southern Ocean. Nature, 432, 100-103.

Barnes, D. K. A., Fuentes, V., Clarke, A., Schloss, I. R., \& Wallace, M. I. (2006). Spatial and temporal variation in shallow seawater temperatures around Antarctica. Deep Sea Research Part II, 53, 853-865.

Barrett, P. J. (1996). Antarctic paleoenvironments through Cenozoic time - a review. Terra Antarctica, 3, 103-119.

Bodeker, G. E., Shiona, H., \& Eskes, H. (2005). Indicators of Antarctic ozone depletion. Atmospheric Chemistry and Physics, 5, 2603-2615. 
Bracegirdle, T. J., Connolley, W. M., \& Turner, J. (2008). Antarctic climate change over the twenty first century. Journal of Geophysical Research, 113, D03103.

Brown, M. V., \& Bowman, J. P. (2001). A molecular phylogenetic survey of sea-ice microbial communities (SIMCO). FEMS Microbiology Ecology, 35, 267-275.

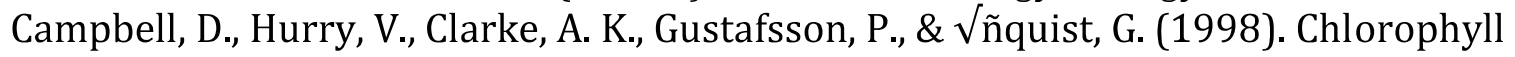
Fluorescence Analysis of Cyanobacterial Photosynthesis and Acclimation. Microbiology and Molecular Biology Reviews, 62, 667-683.

Cavalieri, D. J., \& Parkinson, C. L. (2008). Antarctic sea ice variability and trends, 19792006. Journal of Geophysical Research, 113, C07004.

Clark, G. F., Stark, J. S., Johnston, E. L., Runcie, J. W., Goldsworthy, P. M., Raymond, B., et al. (2013). Light-driven tipping points in polar ecosystems. Global Change Biology, 19, 3749-3761.

Clarke, A., Murphy, E. J., Meredith, M. P., King, J. C., Peck, L. S., Barnes, D. K. A., et al. (2007). Climate change and the marine ecosystem of the western Antarctic Peninsula. Philosophical Transactions of the Royal Society B: Biological Sciences, 362, 149-166.

Comiso, J. C. (2006). Abrupt decline in the Arctic winter sea ice cover. Geophysical Research Letters, 33, L18504.

Comiso, J. C., Parkinson, C. L., Gersten, R., \& Stock, L. (2008). Accelerated decline in the Arctic sea ice cover. Geophysical Research Letters, 35.

Comiso, J. C., Kwok, R., Martin, S., \& Gordon, A. L. (2011). Variability and trends in sea ice extent and ice production in the Ross Sea. Journal of Geophysical Research C: Oceans, 116.

Convey, P., Bindschadler, R., di Prisco, G., Fahrbach, E., Gutt, J., Hodgson, D. A., et al. (2009a). Antarctic climate change and the environment. Antarctic Science, 21, 541-563.

Convey, P., Stevens, M. I., Hodgson, D. A., Smellie, J. L., Hillenbrand, C.-D., Barnes, D. K. A., et al. (2009b). Exploring biological constraints on the glacial history of Antarctica. Quaternary Science Reviews, 28, 3035-3048.

Cullen, J., \& Neale, P. (1994). Ultraviolet radiation, ozone depletion, and marine photosynthesis. Photosynthesis Research, 39, 303-320.

Demers, S., Roy, S., Gagnon, R., \& Vignault, C. (1991). Rapid light-induced changes in cell fluorescence and in xanthophyll pigments of Alexandrium excavatum (Dinophyceae) and Thalassiosira pseudonana (Bacillariophyceae): a photoprotection mechanism. Marine Ecology Progress Series, 76, 185-193.

Dickson, D. M. J., \& Kirst, G. O. (1986). The role of $\beta$-dimethylsulphoniopropionate, glycine betaine and homarine in the osmoacclimation of Platymonas subcordiformis. Planta, 167, 536-543.

Dixon, D. A., Mayewski, P. A., Goodwin, I. D., Marshall, G. J., Freeman, R., Maasch, K. A., et al. (2012). An ice-core proxy for northerly air mass incursions into West Antarctica. International Journal of Climatology, 32, 1455-1465.

Ducklow, H. W., Steinberg, D. K., \& Buesseler, K. O. (2001). Upper ocean crbon export and the biological pump. Oceanography-Washington DC-Oceanographic Society, $14,50-58$.

Ducklow, H. W., Baker, K., Martinson, D. G., Quetin, L. B., Ross, R. M., Smith, R. C., et al. (2007). Marine pelagic ecosystems: the West Antarctic Peninsula. Philosophical Transactions of the Royal Society B: Biological Sciences, 362, 67-94.

Eicken, H. (1992). The role of sea ice in structuring Antarctic ecosystems. Polar Biology, $12,3-13$. 
Farman, J. C., Gardiner, B. G., \& Shanklin, J. D. (1985). Large losses of total ozone in Antarctica reveal seasonal ClOx/NOx interaction. Nature, 315, 207-210.

Feller, G., \& Gerday, C. (2003). Psychrophilic enzymes: hot topics in cold adaptation. Nature reviews. Microbiology, 1, 200-208.

Forcada, J., Trathan, P. N., Reid, K., Murphy, E. J., \& Croxall, J. P. (2006). Contrasting population changes in sympatric penguin species in association with climate warming. Global Change Biology, 12, 411-423.

Franklin, L., \& Forster, R. (1997). The changing irradiance environment: consequences for marine macrophyte physiology, productivity and ecology. European Journal of Phycology, 32, 207-232.

Friedlingstein, P., Cox, P., Betts, R., Bopp, L., von Bloh, W., Brovkin, V., et al. (2006). Climate-Carbon Cycle Feedback Analysis: Results from the C4MIP Model Intercomparison. Journal of Climate, 19, 3337-3353.

Fritsen, C. H., Memmott, J., \& Stewart, F. J. (2008). Inter-annual sea-ice dynamics and micro-algal biomass in winter pack ice of Marguerite Bay, Antarctica. Deep Sea Research Part II: Topical Studies in Oceanography, 55, 2059-2067.

Frost, B. W. (1984). Utilization of phytoplankton production in the surface layer. Paper presented at the Global Ocean Flux Study, National Academy Press, Washington D.C.

Gao, Q., \& Garcia-Pichel, F. (2011). Microbial ultraviolet sunscreens. Nature Reviews Microbiology, 9, 791-802.

Garcia-Pichel, F. (1994). A model for internal self-shading in planktonic organisms and its implications for the usefulness of ultraviolet sunscreens. Limnology and Oceanography, 39, 1704-1717.

Geider, R. J. (1987). Light and temperature dependence of the carbon to chlorophyll $a$ ration in microlagae and cyanobacteria: Implications for physiology and growth of phytoplankton. New Phytologist, 106, 1-34.

Georlette, D., Blaise, V., Collins, T., D'Amico, S., Gratia, E., Hoyoux, A., et al. (2004). Some like it cold: biocatalysis at low temperatures. FEMS Microbiology Reviews, 28, 2542.

Gleitz, M., v.d. Loeff, M. R., Thomas, D. N., Dieckmann, G. S., \& Millero, F. J. (1995). Comparison of summer and winter inorganic carbon, oxygen and nutrient concentrations in Antarctic sea ice brine. Marine Chemistry, 51, 81-91.

Goss, R., \& Jakob, t. (2010). Regulation and function of xanthophyll cycle-dependent photoprotection in algae. Photosynthesis Research, 106, 103-122.

Griffith, G. P., Vennell, R., \& Lamare, M. D. (2009). Diadinoxanthin cycle of the bottom ice algal community during spring in McMurdo Sound, Antarctica. Polar Biology, 32, 623-636.

Haberman, K. L., Ross, R. M., \& Quetin, L. B. (2003). Diet of the Antarctic krill (Euphausia superba Dana): II. Selective grazing in mixed phytoplankton assemblages. Journal of Experimental Marine Biology and Ecology, 283, 97-113.

Häder, D.-P., Kumar, H. D., Smith, R. C., \& Worrest, R. C. (2003). Aquatic ecosystems: effects of solar ultraviolet radiation and interactions with other climatic change factors. Photochemical \& Photobiological Sciences, 2, 39-50.

Halac, S. R., Villafañe, V. E., \& Helbling, E. W. (2010). Temperature benefits the photosynthetic performance of the diatoms Chaetoceros gracilis and Thalassiosira weissflogii when exposed to UVR. Journal of Photochemistry and Photobiology B: Biology, 101, 196-205. 
Hannach, G., \& Sigleo, A. C. (1998). Photoinduction of UV-absorbing compounds in six species of marine phytoplankton. Marine Ecology Progress Series, 174, 207-222.

Harbison, G. R., \& McAlister, V. L. (1979). The filter-feeding rates and particle retention efficiencies of three species of Cyclosalpha (Tunicata, Thalliacca). Limnology and Oceanography, 24.

Hays, G. C., Richardson, A. J., \& Robinson, C. (2005). Climate change and marine plankton. Trends in Ecology and Evolution, 20, 337-344.

Helbling, E. W., Buma, A. G. J., Boelen, P., van der Strate, H. J., Giordanino, M. V. F., \& Villafañe, V. E. (2011). Increase in Rubisco activity and gene expression due to elevated temperature partially counteracts ultraviolet radiation-induced photoinhibition in the marine diatom Thalassiosira weissflogii. Limnology and Oceanography, 56, 1330-1342.

Hernando, M., Schloss, I., Roy, S., \& Ferreyra, G. (2006). Photoacclimation to long-term Ultraviolet radiation exposure of natural Sub-Antarctic phytoplankton communities: fixed surface incubations versus mixed mesocosms. Photochemistry and Photobiology, 82, 923-935.

Hessen, D. O., Frigstad, H., Færøvig, P. J., Wojewodzic, M. W., \& Leu, E. (2012). UV radiation and its effects on P-uptake in arctic diatoms. Journal of Experimental Marine Biology and Ecology, 411, 45-51.

Holzinger, A., \& Lütz, C. (2006). Algae and UV irradiation: Effects on ultrastructure and related metabolic functions. Micron, 37, 190-207.

Hunt, B. N., Hoefling, K., \& Cheng, C.-H., C. (2003). Annual warming episodes in seawater temperatures in McMurdo Sound in relationship to endogenous ice in notothenioid fish. Antarctic Science, 15, 333-338.

Jónasdóttir, S. H., Visser, A. W., \& Jespersen, C. (2009). Assessing the role of food quality in the production and hatching of Temora longicornis eggs. Marine Ecology Progress Series, 382, 139-150.

Juhl, A., \& Krembs, C. (2010). Effects of snow removal and algal photoacclimation on growth and export of ice algae. Polar Biology, 33, 1057-1065.

Karentz, D., Cleaver, J. E., \& Mitchell, D. L. (1991). Cell survival characteristics and molecular responses of Antarctic phytoplankton to ultraviolet-B radiation. Journal of Phycology, 27, 326-341.

Karentz, D., \& Bosch, I. (2001). Influence of ozone-related increases in ultraviolet radiation on Antarctic marine organisms. American Zoologia, 41, 3-16.

Kortsch, S., Primicerio, R., Beuchel, F., Renaud, P. E., Rodrigues, J., Jørgen, L. O., et al. (2012). Climate-driven regime shifts in Arctic marine benthos. Proceedings of the National Academy of Sciences, 109, 14052-14057.

Krembs, C., Gradinger, R., \& Spindler, M. (2000). Implications of brine channel geometry and surface area for the interaction of sympagic organisms in Arctic sea ice. Journal of Experimental Marine Biology and Ecology, 243, 55-80.

Larkum, A. W. D., \& Wood, W. F. (1993). The effect of UV-B radiation on photosynthesis and respiration of phytoplankton, benthic macroalgae and seagrasses. Photosynthesis Research, 36, 17-23.

Lavaud, J., Rousseau, B., van Gorkom, H., \& Etienne, A.-L. (2002). Influence of the diadinoxanthin pool size on photoprotection in the marine planktonic diatom Phaeodactylum tricornutum. Plant Physiology, 129, 1398-1406.

Lawrence, R. P., \& William, J. W. (2001). Temperature and substrates as interactive limiting factors for marine heterotrophic bacteria. Aquatic Microbial Ecology, 23, 187-204. 
Laybourn-Parry, J., Marshall, W. A., \& Marchant, H. J. (2005). Flagellate nutritional versatility as a key to survival in two contrasting Antarctic saline lakes. Freshwater Biology, 50, 830-838.

Lazzara, L., Nardello, I., Ermanni, C., Mangoni, O., \& Saggiomo, V. (2007). Light environment and seasonal dynamics of microalgae in the annual sea ice at Terra Nova Bay, Ross Sea, Antarctica. Antarctic Science, 19, 83-92.

Lefebvre, W., \& Goosse, H. (2008). Analysis of the projected regional sea-ice changes in the Southern Ocean during the twenty-first century. Climate Dynamics, 30, 59-76.

Leu, E., Wiktor, J., Søreide, J. E., Berge, J., \& Falk-Petersen, S. (2010). Increased irradiance reduces food quality of sea ice algae. Marine Ecology Progress Series, 411, 49-60.

Lizotte, M. P., \& Sullivan, C. W. (1991). Rates of photoadaptation in sea ice diatoms from McMurdo Sound, Antarctica. Journal of Phycology, 27, 367-373.

Lizotte, M. P., \& Arrigo, K. R. (1998). Antarctic Sea Ice: Biological Processes, Interactions and Variability (Vol. 73). Washington, D.C.: American Geophysical Union.

Lizotte, M. P. (2001). The contributions of sea ice algae to Antarctic marine primary production. American Zoologist, 41, 57-73.

Lohr, M., \& Wilhelm, C. (1999). Algae displaying the diadinoxanthin cycle also possess the violaxanthin cycle. Proceedings of the National Academy of Sciences, 96, 87848789.

Madin, L. P., \& Kremer, P. (1995). Determination of the filter-feeding rates of salps (Tunicata, Thaliacea) ICES. Journal of Marine Science, 52.

Maksym, T., Stammerjohn, S. E., Ackley, S., \& Massom, R. (2012). Antarctic sea ice- A polar opposite? Oceanography, 25, 140-151.

Mangoni, O., Saggiomo, M., Modigh, M., Catalano, G., Zingone, A., \& Saggiomo, V. (2009). The role of platelet ice microalgae in seeding phytoplankton blooms in Terra Nova Bay (Ross Sea, Antarctica): a mesocosm experiment. Polar Biology, 32, 311323.

Marcoval, M. A., Villafañe, V. E., \& Helbling, E. W. (2007). Interactive effects of ultraviolet radiation and nutrient addition on growth and photosynthesis performance of four species of marine phytoplankton. Journal of Photochemistry and Photobiology B: Biology, 89, 78-87.

Martin, A., Anderson, M. J., Thorn, C., Davy, S. K., \& Ryan, K. G. (2011). Response of seaice microbial communities to environmental disturbance: an in situ transplant experiment in the Antarctic. Marine Ecology Progress Series, 424, 25-37.

Martínez, R. (2007). Effects of ultraviolet radiation on protein content, respiratory electron transport system (ETS) activity and superoxide dismutase (SOD) activity of Antarctic plankton. Polar Biology, 30, 1159-1172.

Massom, R. A., \& Stammerjohn, S. E. (2010). Antarctic sea ice change and variability physical and ecological complications. Polar Science, 4, 149-186.

Mayewski, P. A., Meredith, M. P., Summerhayes, C. P., Turner, J., Worby, A., Barrett, P. J., et al. (2009). State of the Antarctic and Southern Ocean climate system. Reviews of Geophysics, 47, RG1003.

McGonigal, D., \& Woodworth, L. (2002). Antarctica: The Blue Continent. New Zealand: Random House.

McMinn, A. (1998). Species succession in fast ice algal communities; a response to UV-B radiation? Korean Journal of Polar Research, 8, 47-52.

McMinn, A., Ashworth, C., \& Ryan, K. (1999). Growth and productivity of Antarctic sea ice algae under PAR and UV irradianes. Botanica Marina, 42, 401-407. 
McMinn, A., Ryan, K., \& Gademann, R. (2003). Diurnal changes in photosynthesis of Antarctic fast ice algal communities determined by pulse amplitude modulation fluorometry. Marine Biology, 143, 359-367.

Mock, T., \& Valentin, K. (2004). Photosynthesis and cold acclimation: molecular evidence from a polar diatom. Journal of Phycology, 40, 732-741.

Moline, M. A., Claustre, H., Frazer, T. K., Schofield, O., \& Vernet, M. (2004). Alteration of the food web along the Antarctic Peninsula in response to a regional warming trend. Global Change Biology, 10, 1973-1980.

Montes-Hugo, M., Doney, S. C., Ducklow, H. W., Fraser, W., Martinson, D., Stammerjohn, S. E., et al. (2009). Recent changes in phytoplankton communities associated with rapid regional climate change along the Western Antarctic Peninsula. Science, $323,1470-1473$.

Moreau, S., Ferreyra, G., Mercier, B., Lemarchand, K., Lionard, M., Roy, S., et al. (2010). Variability of the microbial community in the western Antarctic Peninsula from late fall to spring during a low ice cover year. Polar Biology, 33, 1599-1614.

Morgan-Kiss, R. M., Priscu, J. C., Pocock, T., Gudynaite-Savitch, L., \& Huner, N. P. A. (2006). Adaptation and acclimation of photosynthetic microorganisms to permanently cold environments. Microbiology and Molecular Biology Reviews, 70, 222-252.

Mullineaux, C. W., \& Emlyn-Jones, D. (2005). State transitions: an example of acclimation to low-light stress. Journal of Experimental Botany, 56, 389-393.

Nahon, S., Charles, F., Lantoine, F., Vetion, G., Escoubeyrou, K., Desmalades, M., et al. (2010). Ultraviolet radiation negatively affects growth and food quality of the pelagic diatom Skeletonema costatum. Journal of Experimental Marine Biology and Ecology, 383, 164-170.

Neale, P. J., Cullen, J. J., \& Davis, R. F. (1998). Inhibition of marine photosynthesis by ultraviolet radiation: Variable sensitivity of phytoplankton in the Weddell-Scotia Confluence during the austral spring. Limnology and Oceanography, 43, 433-448.

Oren, A., \& Gunde-Cimerman, N. (2007). Mycosporines and mycosporine-like amino acids: UV protectants or multipurpose secondary metabolites? FEMS Microbiology Letters, 269, 1-10.

Peck, L. S., Convey, P., \& Barnes, D. K. A. (2006). Environmental constraints on life histories in Antarctic ecosystems: tempos, timings and predictability. Biological Reviews, 81, 75-109.

Peck, L. S., Barnes, D. K. A., Cook, A. J., Fleming, A. H., \& Clarke, A. (2010). Negative feedback in the cold: ice retreat produces new carbon sinks in Antarctica. Global Change Biology, 16, 2614-2623.

Peinado, N. K., Abdala Díaz, R. T., Figueroa, F. L., \& Helbling, E. W. (2004). Ammonium and UV radiation stimulate the accumulation of mycosporine-like amino acids in Porphyra columbina (Rhodophyta) from Patagonia, Argentina. Journal of Phycology, 40, 248-259.

Perriss, S. J., \& Laybourn-Parry, J. (1997). Microbial communities in saline lakes of the Vestfold Hills (eastern Antarctica). Polar Biology, 18, 135-144.

Plattner, G. K., Knutti, R., Joos, F., Stocker, T. F., von Bloh, W., Brovkin, V., et al. (2008). Long-Term Climate Commitments Projected with Climate-Carbon Cycle Models. Journal of Climate, 21, 2721-2751.

Pomeroy, L. R., Williams, P. J., Azam, F., \& Hobbie, J. E. (2007). The Microbial Loop. Oceanography, 20. 
Prézelin, B. B., Moline, M. A., \& Matlick, H. A. (1998). Icecolors '93: Spectral UV radiation effects on Antarctic frazil ice algae. Antarctic Research Series, 73, 45-83.

Quartino, M. L., Deregibus, D., Campana, G. L., Latorre, G. E. J., \& Momo, F. R. (2013). Evidence of macroalgal colonization on newly ice-free areas following glacial retreat in potter cove (South Shetland Islands), Antarctica. PLoS ONE, 8, e58223.

Quetin, L. B., \& Ross, R. M. (1991). Behavioural and physiological characteristics of the Antarctic krill, Euphausia superba. American Zoologist, 31, 49-63.

Quetin, L. B., Ross, R. M., Frazer, T. K., \& Haberman, K. L. (1996). Factors affecting distribution and abundance of zooplankton, with an emphasis on Antarctic krill, Euphasia superba. Antarctic Research Series, 70, 357-371.

Ralph, P. J., McMinn, A., Ryan, K. G., \& Ashworth, C. (2005). Short-term effect of temperature on the photokinetics of microalgae from the surface layers of Antarctic pack ice. Journal of Phycology, 41, 763-769.

Ralph, P. J., Ryan, K. G., Martin, A., \& Fenton, G. (2007). Melting out of sea ice causes greater photosynthetic stress in algae than freezing in. Journal of Phycology, 43, 948-956.

Remy, J.-P., Becquevort, S., Haskell, T. G., \& Tison, J. L. (2008). Impact of the B-15 iceberg "stranding event" on the physical and biological properties of sea ice in McMurdo Sound, Ross Sea, Antarctica. Antarctic Science, 20, 593-604.

Robinson, D. H., Kolber, Z., \& Sullivan, C. W. (1997). Photophysiology and photoacclimation in surface sea ice algae from McMurdo Sound, Antarctica. Marine Ecology Progress Series, 147, 243-256.

Ross, R. M., Langdon, B. Q., Baker, K. S., Vernet, M., \& Smith, R. C. (2000). Growth limitation in young Euphausia superba under field conditions. Limnology and Oceanography, 45, 31-43.

Ryan, K. G. (1992). UV radiation and photosynthetic production in Antarctic sea ice microalgae. Journal of Photochemistry and Photobiology B: Biology, 13, 235-240.

Ryan, K. G., McMinn, A., Mitchell, K. A., \& Trenerry, L. (2002). Mycosporine-like amino acids in Antarctic sea ice algae, and their response to UVB radiation. Zeitschrift fur Naturforschung, 57, 471-477.

Ryan, K. G., Ralph, P., \& McMinn, A. (2004). Acclimation of Antarctic bottom-ice algal communities to lowered salinities during melting. Polar Biology, 27, 679-686.

Ryan, K. G., \& Hunt, J. E. (2005). The effectd of UVB radiation on temperate southern hemisphere forests. Environmental Pollution, 137, 415-427.

Ryan, K. G., Hegseth, E. N., Martin, A., Davy, S. K., O'Toole, R., Ralph, P. J., et al. (2006a). Comparison of the microalgal community within fast ice at two sites along the Ross Sea coast, Antarctica. Antarctic Science, 18, 583-594.

Ryan, K. G., Hegseth, E. N., Martin, A., Davy, S. K., O'Toole, R., Ralph, P. J., et al. (2006b). Comparison of the microalgal community within fast ice at two sites along the Ross Sea coast, Antarctica. Antarctic Science, 18, 583-594.

Ryan, K. G., Tay, M. L., Martin, A., McMinn, A., \& Davy, S. K. (2011). Chlorophyll fluorescence imaging analysis of the responses of Antarctic bottom-ice algae to light and salinity during melting. Journal of Experimental Marine Biology and Ecology, 399, 156-161.

Ryan, K. G., McMinn, A., Hegseth, E. N., \& Davy, S. K. (2012). The Effects of Ultraviolet-B Radiation on Antarctic Sea-Ice Algae. Journal of Phycology, 48, 74-84.

Sarmiento, J. L., Hughes, T. M. C., Stouffer, R. J., \& Manabe, S. (1998). Simulated response of the ocean carbon cycle to anthropogenic climate warming. Nature, 393, 245249. 
Scheffer, M., Carpenter, S., Foloey, J. A., Folke, C., \& Walker, B. (2001). Catastrophic shifts in ecosystems. Nature, 413, 591-596.

Schick, J. M., \& Dunlap, W. C. (2002). Mycosporine-like amino acids and related gadusols: Biosynthesis, accumulation and UV-protective functions in aquatic organisms. Annual Review of Physiology, 64, 223-262.

Schloss, I. R., Abele, D., Moreau, S., Demers, S., Bers, A. V., Gonzalez, O., et al. (2012). Response of phytoplankton dynamics to 19-year (1991-2009) climate trends in Potter Cove (Antarctica). Journal of Marine Systems, 92, 53-66.

Sedwick, P. N., \& DiTullio, G. R. (1997). Regulation of algal blooms in Antarctic Shelf Waters by the release of iron from melting sea ice. Geophysical Research Letters, 24, 2515-2518.

Sedwick, P. N., DiTullio, G. R., \& Mackey, D. J. (2000). Iron and manganese in the Ross Sea, Antarctica: seasonal iron limitation in Antarctic shelf waters. Journal of Geophysical Research, 105, 11321-11336.

Siegel, V. (2000). Krill (Euphausiacea) life history and aspects of population dynamics. Canadian Journal of Fisheries and Aquatic Sciences, 57, 130-150.

Sobrino, C., \& Neale, P. J. (2007). Short-term and long-term effects of temperature on photosynthesis in the diatom Thalassiosira pseudonana under UVR exposures. Journal of Phycology, 43, 426-436.

Solheim, B., Zielke, M., Bjerke, J. W., \& Rozema, J. (2006). Effects of enhanced UV-B radiation on nitrogen fixation in arctic ecosystems. Plant Ecology, 182, 109-118.

Somero, G. N. (1981). pH- temperature interactions on proteins: principles of optimal pH and buffer system design. Marine Biology Letters, 2, 163-178.

Stammerjohn, S., Massom, R., Rind, D., \& Martinson, D. (2012). Regions of rapid sea ice change: An inter-hemispheric seasonal comparison. Geophysical Research Letters, 39.

Stoecker, D. K., Gustafson, D. E., Black, M. M. D., \& Baier, C. T. (1998). Population dynamics of microalgae in the upper land-fast sea ice at a snow-free location. Journal of Phycology, 34, 60-69.

Strickland, J. D. H. (1960). Measuring the production of marine phyoplankton. Bull Fish Res Board Can, 122, 1-172.

Stroeve, J., Serreze, M., Gearhead, S., Holland, M., Maslanik, J., Meier, W., et al. (2008). Arctic sea ice extent plummets in 2007. Eos, Transactions American Geophysical Union, 89, 13-14.

Thomas, D. N., \& Dieckmann, G. S. (2002). Antarctic Sea Ice--a Habitat for Extremophiles. Science, 295, 641.

Thomas, D. N., \& Dieckmann, G. S. (2003). Sea Ice: An Introduction to its Physics, Chemistry, Biology and Geology: Wiley-Blackwell.

Thomas, D. N., Fogg, G. E., Convey, P., Fritsen, C. H., Gili, J.-M., Gradinger, R., et al. (2008). The Biology of Polar Regions. Oxford: Oxford University Press.

Trevena, A. J., \& Jones, G. B. (2006). Dimethylsulphide and dimethylsulphoniopropionate in Antarctic sea ice and their release during sea ice melting. Marine Chemistry, 98, 210-222.

Trivelpiece, W. Z., Hinke, J. T., Miller, A. K., Reiss, C. S., Trivelpiece, S. G., \& Watters, G. M. (2011). Variability in krill biomass links harvesting and climate warming to penguin population changes in Antarctica. Proceedings of the National Academy of Sciences, 108, 7625-7628.

Turner, J., Comiso, J. C., Marshall, G. J., Lachlan-Cope, T. A., Bracegirdle, T., Maksym, T., et al. (2009). Non-annular atmospheric circulation change induced by stratospheric 
ozone depletion and its role in the recent increase of Antarctic sea ice extent. Geophysical Research Letters, 36, L08502.

Turner, J., Bracegirdle, T. J., Phillips, T., Marshall, G. J., \& Hosking, J. S. (2012). An Initial Assessment of Antarctic Sea Ice Extent in the CMIP5 Models. Journal of Climate, 26, 1473-1484.

Turner, J., Barrand, N. E., Bracegirdle, T. J., Convey, P., Hodgson, D. A., Jarvis, M., et al. (2013). Antarctic climate change and the environment: an update. Polar Record, FirstView, 1-23.

Van de Poll, W. H., \& Buma, A. G. J. (2009). Does ultraviolet radiation affect the xanthophyll cycle in marine phytoplankton? Photochemical and Photobiological Sciences, 8, 1295-1301.

van Wijk, E. M., \& Rintoul, S. R. (2014). Freshening drives contraction of Antarctic Bottom Water in the Australian Antarctic Basin. Geophysical Research Letters, 41, 2013GL058921.

Vincent, W. F. (1988). Microbial ecosystems of Antarctica. Cambridge: Cambridge University Press.

Vincent, W. F., Whyte, L. G., Lovejoy, C., Greer, C. W., Laurion, I., Suttle, C. A., et al. (2009). Arctic microbial ecosystems and impacts of extreme warming during the International Polar Year. Polar Science, 3, 171-180.

Volk, T., \& Hoffert, M. I. (1985). Ocean carbon pumps: analysis of relative strengths and efficiencies in ocean-driven atmospheric $\mathrm{CO}_{2}$ changes. In E. T. Sundquist \& W. S. Broecker (Eds.), The carbon cycle and atmospheric $\mathrm{CO}_{2}$ : natural variations archean to present. (Vol. 32, pp. 99-110): American Geophysical Union.

Whitehead, J. M., Quilty, P. G., McKelvey, B. C., \& O'Brien, P. E. (2006). A review of the Cenozoic stratigraphy and glacial history of the Lambert Graben - Prydz Bay region, East Antarctica. Antarctic Science, 18, 83-99.

Worm, B., Barbier, E. B., \& Beaumont, N. (2006). Impacts of biodiversity loss on ocean ecosystem services. Science, 314, 787-790.

Zonneveld, C. (1998). A cell-based model for the chlorophyll a to carbon ration in phytoplankton. Ecological Modelling, 113, 55-70. 


\section{CHAPTER 2}

\section{Can bottom ice algae tolerate changes in PAR and temperature during the melting of sea ice?}

\subsection{ABSTRACT}

Sea ice algae are exposed to various environmental stresses in the Antarctic and are the primary producers of the ice-covered environment. For most of the year, sea ice provides algae with a stable habitat, but they are challenged by varying levels of PAR, UV-B, temperature and salinity during the melt in summer. To study how they tolerate increasing temperature and PAR during sea ice melt, a series of incubations using fieldfresh algal communities were carried out to examine their tolerance to these factors as expressed by photosynthetic response and production of MAAs. The algae were also subjected to a manipulation involving a broader range of temperatures, to evaluate their potential to function in warmer seas in the event for instance of anthropogenic transfer to areas north of the Polar Front.

When subjected to an increase in PAR ( 0 to $\left.100 \mu \mathrm{mol} \mathrm{m}^{-2} \mathrm{~s}^{-1}\right)$ at temperatures the algae are realistically likely to face within the ice $\left(-1^{\circ} \mathrm{C}\right)$, during sea ice melt $\left(2^{\circ} \mathrm{C}\right)$ and in the water column $\left(5^{\circ} \mathrm{C}\right)$, the algae acclimated rapidly, indicated by a lack of decline in the quantum efficiency of PSII. The data show that bottom ice algae are capable of tolerating increasing temperature and PAR during sea ice melt, and also indicate that they would survive regional changes in these parameters envisaged in current climate change scenarios. MAA production showed an increase with increasing PAR which was further enhanced by increasing temperatures. At ambient PAR levels, increased temperatures resulted in lower $\phi_{\text {PSII. }}$ However, as PAR levels were increased, higher temperature reduced the level of stress as indicated by higher $\phi_{P S I I}$ values. This result suggests, for the first time in sea ice algal studies, that higher temperatures can ameliorate the negative effects of increased PAR. Exposure to much higher temperatures provided evidence of the photosystems becoming stressed beyond $5^{\circ} \mathrm{C}$. When temperature was gradually increase past a threshold temperature of $14^{\circ} \mathrm{C}$, the photosystems started to become inactivated. This suggests that the algae could retain photosynthetic function at water temperatures above those currently experienced in the Antarctic habitat, and hence could impact community structure in lower latitude areas if carried in ballast 
water from the Antarctic and subsequently discharged. With increased ship traffic between the Southern Ocean and lower latitudes, there is a likelihood of crosscontamination occurring between regions.

\subsection{INTRODUCTION}

The seasonal formation and melting of sea ice is one of the most striking features of the Antarctic marine environment (Convey et al., 2014). As sea ice algae play an important role in primary production in the Southern Ocean and are the only source of fixed carbon for all other life in ice-covered habitats of this region (Arrigo et al., 1997), it is important to understand their responses to environmental change. The marine environment of the Southern Ocean including the bottom of the sea ice is generally thermally stable, but during ice melt this stability is disturbed and algae are exposed to higher temperatures and levels of UV-B and PAR than they experience in the ice matrix (Arrigo \& Sullivan, 1992, Ralph et al., 2007, Ryan et al., 2011). The thermal stability of the Southern Ocean marine environment has also led to the evolution of strong stenothermy in some marine organisms, which show particular sensitivity to what might otherwise be regarded as small temperature changes (Peck et al., 2006). Antarctic bottom ice algal communities are thought to be extremely shade-adapted, with low $E_{\mathrm{k}}$ values (a measure of the intensity of PAR required to permit maximum photosynthesis), and are able to adjust photosynthetic rates to suit changing diurnal irradiance levels (Arrigo et al., 1997, Ryan et al., 2009). Algae in the sea ice and the water column are also influenced by seasonality in nutrients, with their productivity mainly restricted to a three to four month period in summer (Arrigo, 2014, Peck et al., 2006, Smetacek \& Nicol, 2005). This is critical for all marine organisms that feed on these algae as, unlike their terrestrial counterparts, marine organisms do not undergo dormancy in the frozen environment and must maintain their physiological activity even in winter.

Low PAR conditions are typical of the under-ice environment, while a snow cover of as little as $10 \mathrm{~cm}$ can further halve light transmission (Lizotte, 2001). Measurements of daily average PAR under $2.5 \mathrm{~m}$ thick spring pack ice in the Ross Sea region have shown a range of 5.6 to $10.6 \mu \mathrm{mol} \mathrm{m}^{-2} \mathrm{~s}^{-1}$ in the under-ice habitat (Lazzara et al., 2007). Under 1.8 $\mathrm{m}$ thick fast ice in McMurdo Sound, PAR levels can be even lower, with as little as $1 \mu \mathrm{mol}$ $\mathrm{m}^{-2} \mathrm{~s}^{-1}$ measured at noon on a clear sunny day in spring (Ryan et al., 2011). Low 
photosynthetic capacity, high photosynthetic pigment concentrations and the abundance of chloroplasts in algal cells are strong indications of the shade-adapted features of these microalgal communities (Lazzara et al., 2007). Unicellular algae are known to acclimate to changes in irradiance by changing their intracellular photosynthetic pigment content. For example, Skeletonema costatum (a diatom) and Dunaliella tertiolecta (a chlorophyte) both showed an increase in their chlorophyll content when PAR was decreased (Falkowski \& Owens, 1980). Photosynthetic response of algae to temperature is dependent on the level of PAR (Davison, 1991), as the response to sub-saturating is different to that to saturating light. Although the photochemical reactions of photosynthesis are light dependent, carbon fixation is an enzyme-driven process and highly temperature dependent (Öquist, 1983). In Arctic sea ice diatoms, photosynthetic efficiency decreases with increasing temperature (Palmisano et al., 1987). Claquin et al. (2008) showed that several temperate marine algae were able to survive a large temperature range, with all the species studied being viable at least between 7 and $24^{\circ} \mathrm{C}$. In contrast, polar diatoms can have a much lower temperature tolerance range, sometimes limited to a maximum of $7^{\circ} \mathrm{C}$ (Suzuki et al., 1995).

To protect themselves from environmental stresses, many microorganisms produce mycosporine-like amino acids (MAAs) (Vincent, 1988). Other than their production being a response to exposure to UV-B radiation (Klisch \& Hader, 2008), MAAs may also perform osmo-protective functions as they are found in high abundance in cyanobacteria from hypersaline environments (Arrigo \& Thomas, 2004, Oren, 1997). A further function of MAAs may lie in antioxidative protection, as proposed for mycosporine-glycine in corals (Dunlap \& Yamamoto, 1995, Oren \& Gunde-Cimerman, 2007). Experiments using light and dark cycles indicate that, in cyanobacteria and algae, MAAs are synthesized during the light period and their synthesis is closely linked to photosynthesis but can also be stimulated by osmotic stress (Oren \& Gunde-Cimerman, 2007).

Unprecedented global climate change trends have become apparent over the past century. In Antarctica, there are also strong regional trends that may not be related to the global process, and region-specific effects such as the consequences of the annual formation of the anthropogenic Antarctic ozone hole (Convey et al., 2009, Dixon et al., 2012, Turner et al., 2009, 2012). The IPCC Fourth Assessment forecasted a further 
increase in positive polarity of the Southern Hemisphere Annular Mode, leading to increasing winds over the Southern Ocean (Bracegirdle et al., 2008, Comiso et al., 2011, Convey et al., 2009). Recent data from the IPCC Fifth Assessment show a positive trend in the annual mean ice extent in the Antarctic of 1.2 to $1.8 \%$ per decade (Turner et al., 2013)(http://www.ipcc.ch/report/ar5/wg1/\#.UuhKY2SBoYI). However, sea ice extent and duration have also significantly reduced in the Bellinghausen Sector, and maximum ice loss is expected in the central Weddell Sea and the Bellingshausen-Amundsen Seas (Lefebvre \& Goosse, 2008), while increasing by about $4.5 \%$ in the Ross Sea (Turner et al., 2009). In the north-east and west Antarctic Peninsula and southern Bellinghausen Sea region, later ice advance and earlier retreat have caused a shorter duration of sea ice over the period between 1979/1980 and 2010/2011, while opposite trends have been observed in the western Ross Sea (Stammerjohn et al., 2012). Reduction in sea ice extent and duration can have significant impacts on the phytoplankton community, with changes in species composition and abundance (Montes-Hugo et al., 2009, Schloss et al., 2012) and consequential impacts on species further up the food chain (Forcada et al., 2006). These changes have been linked with reductions in krill stocks and their replacement by salps, effects that in turn impact the entire Southern Ocean food web (Atkinson et al., 2004, Trivelpiece et al., 2011).

If global warming trends are considered beyond current 100-year scenarios, the Southern Ocean could undergo greater warming than is predicted in the recent IPCC Assessments (Plattner et al., 2008). Even the current assessments are increasingly appearing conservative: for instance, the inclusion of previously neglected carbon cycle feedbacks into models may result in warming of global air temperatures of $5.5^{\circ} \mathrm{C}$, rather than the current prediction of $4^{\circ} \mathrm{C}$ over the same time period (Friedlingstein et al., 2006). The AR4 climate models indicated that the annual average sea ice area around the Antarctic will decrease by 33\%, most of which will occur in winter and spring, decreasing the amplitude of seasonal sea ice cycles. The AR5 models indicate that there will be a nearly ice-free state in February within this century (http://www.ipcc.ch/report/ar5/wg1/\#.UuhKY2SBoYI). Antarctic ice algae may therefore be challenged by these temperature changes and by the likelihood of significantly decreased ice cover in the summer earlier than previously thought. Separately, there is also a risk of contamination of Antarctic marine algae into lower latitude waters such as those around Australia, New Zealand and southern South 
America (Lewis et al., 2003). These waters are separated from each other by the oceanic Polar Front that forms a barrier to movement of species from Antarctic waters and vice versa (Barnes et al., 2006). Antarctica itself is to some extent protected from this source of non-native species, as ships generally do not take on sufficient cargo at Antarctic research stations to require discharge of externally derived ballast water. However, there is a largely unappreciated risk of ballast water, if taken on during cargo offloading in Antarctica, being discharged north of the Polar Front (including near the subAntarctic islands), and even near to southern cool temperate ports. The presence of Antarctic continental shelf species of microalgae in ballast water, and their subsequent survival in culture, provides evidence that this algal transport is possible (Lewis et al., 2003).

This field-based study focused on photosynthetic responses (measured using chlorophyll fluorescence techniques) and MAA production of fresh-collected mixed species ice algal communities. First the algae were exposed to a relatively narrow range of experimentally-imposed temperatures shortly after collection, mimicking the scale of temperature changes that might influence the timing of sea ice melt or be experienced after the melt is completed and in parts of the Southern Ocean. Second, their response to exposure to a wider range of temperatures, to examine whether algae are capable of functioning at temperatures more typical of lower latitudes north of the Polar Front, was also studied. The responses of sea ice algae to temperature and PAR were monitored using chlorophyll fluorescence techniques (McMinn et al., 2010, Ralph \& Gademann, 2005, Ralph et al., 2007, Ryan et al., 2009) and MAA production. Finally, an initial study was made of the critical temperatures affecting thylakoid integrity, which determine irreversible changes in photosynthetic function. Such damage has been observed in coral algal symbionts (Buxton et al., 2012, Fitt et al., 2001, Tchernov et al., 2004) and can also be measured using chlorophyll fluorescence techniques (Hill et al., 2009). Determining critical temperatures could help in identifying tipping points where small changes in the environment cause rapid and extensive changes in an ecosystem (Clark et al., 2013, Scheffer et al., 2001). 


\subsection{METHODS}

\subsubsection{Study Location}

Fresh bottom ice algae were collected from sea ice, ranging from 1.8 to $3.2 \mathrm{~m}$ thickness,

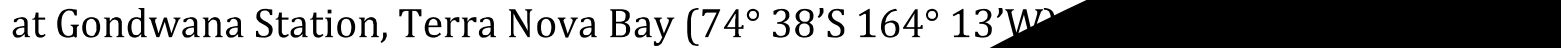
at Cape Evans ( $77^{\circ} 38^{\prime} \mathrm{S} 166^{\circ} 24^{\prime} \mathrm{E}$ ) during November 2010 (Fig. 1). Experiments were also conducted with algae collected and transported to Wellington, New Zealand, from Granite Harbour ( $77^{\circ} 0^{\prime} \mathrm{S} 162^{\circ} 54^{\prime} \mathrm{E}$ ) during the $2009 / 10$ season. The latter commenced within $5 \mathrm{~d}$ of collection in the field.

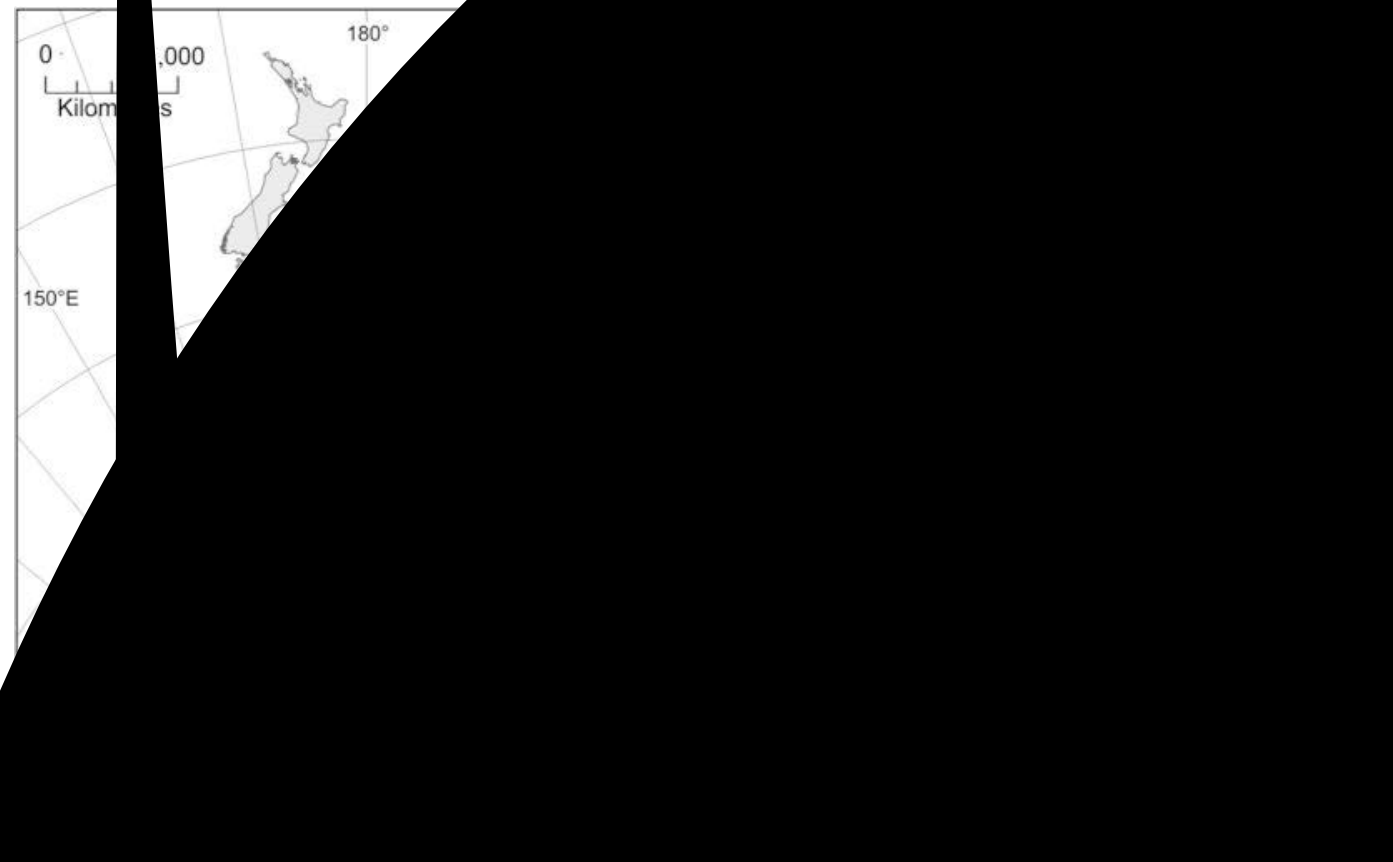

Figure 2.1. (a) Map of the Ross Sea region and (b) Close up of Ross Sea indicating the three sea ice collection locations of Terra Nova Bay, Granite Harbour and Cape Evans (Maps prepared by P. Fretwell, BAS).

\subsubsection{Field parameters and algal community taxonomic composition}

PAR and UV-B levels were recorded at solar noon on a cloudless day in each season at Grani 
years, diatoms including Nitzschia stellata, Entomoneis kjellmannii, Berkelya adeliensis, Navicula sp. and Fragillariopsis curta have dominated the community at this location (Ryan et al., 2011).

\subsubsection{Collection methods}

Core samples were obtained from the bottom $20 \mathrm{~cm}$ of the sea ice using a Kovaks (Lebanon, NH, USA) $13 \mathrm{~cm}$ diameter coring drill. Three to five replicate cores were collected at each location. During collection, the cores were protected from PAR exposure by performing all operations underneath a black sheet and immediately transferring the cores into opaque black plastic bags and then into insulated boxes (Ryan et al., 2004, 2006, 2009, 2012). The bottom of each core was then cut into a standard size (width $\mathrm{x}$ height $\mathrm{x}$ length of $4 \times 4 \times 10 \mathrm{~cm}$ ) in a dimly lit room $(1-10 \mu \mathrm{mol}$ $\left.\mathrm{m}^{-2} \mathrm{~s}^{-1}\right)$, and melted into three times the quantity of filtered seawater $(35 \%, 0.22 \mu \mathrm{m}$, $1.8^{\circ} \mathrm{C}$ ) in the dark over a period of $12 \mathrm{~h}$ (Martin et al., 2012, McMinn et al., 2010, Mundy et al., 2011, Ryan et al., 2006). If slowly melted in the dark in this way, sea ice algae do not undergo cell lysis due to osmotic shock (Mikkelsen \& Witkowski, 2010). Once melted, the suspensions obtained were homogenized using a small plastic paddle on a battery drill (Ryobi, Australia) and filtered through a $20 \mu \mathrm{m}$ plankton mesh to remove large chains of cells. These homogenized samples were then used in the experiments described below, normally within 1-2 $\mathrm{h}$ of preparation.

Aliquots were taken from the melted ice core samples and used to count algal cell numbers and to assess taxonomic composition. Cell counts were performed on samples from all cores using custom-made counting slides under an inverted microscope. Cells in a volume of $0.5 \mathrm{~mL}$ were allowed to settle for $2-4 \mathrm{~h}$ before counts were made. Identification to at least genus level was made for at least 300 cells per sample, following Scott \& Marchant (2005).

\subsubsection{Algal Exposure Methodology}

At Cape Evans, $50 \mathrm{~mL}$ sub-samples of melted bottom ice samples ( $\mathrm{n}=5$ cores) were incubated under each of three PAR levels using 5W LED lights (Greenlights, Taiwan) (0 $\mu \mathrm{mol} \mathrm{m} \mathrm{m}^{-2} \mathrm{~s}^{-1}, 1 \mu \mathrm{mol} \mathrm{m}{ }^{-2} \mathrm{~s}^{-1}, 45 \mu \mathrm{mol} \mathrm{m}^{-2} \mathrm{~s}^{-1}, 100 \mu \mathrm{mol} \mathrm{m}^{-2} \mathrm{~s}^{-1}$ ) at either $-1^{\circ} \mathrm{C}, 2^{\circ} \mathrm{C}$ or $5^{\circ} \mathrm{C}$ for $48 \mathrm{~h}$ in a temperature controlled water bath (Haake, Cleveland, OH, USA) filled with a 15\% ethylene glycol mixture in water. The different experimental light levels were 
chosen as they represent those typical in the sea ice profile from the bottom to the middle, where these algal communities are found (Ryan, pers. comm.). The $50 \mathrm{~mL}$ samples were incubated in $70 \mathrm{~mL}$ opaque specimen containers, each covered with appropriate neutral density filters to allow exposure to specific PAR levels.

Samples obtained from Granite Harbour were used to examine response to the scenario of conditions that might be experienced following transfer to waters beyond the Southern Ocean. Here, bottom ice samples ( $n=3$ cores) were again melted into filtered seawater after collection and then transported refrigerated at $4^{\circ} \mathrm{C}$ to Wellington (New

Zealand) within a period of $5 \mathrm{~d}$, where they were used in experiments within $24 \mathrm{~h}$. Fifty $\mathrm{mL}$ sub-samples were again incubated under each of three PAR levels $\left(100 \mu \mathrm{mol} \mathrm{m}^{-2} \mathrm{~s}^{-1}\right.$, $45 \mu \mathrm{mol} \mathrm{m}{ }^{-2} \mathrm{~s}^{-1}, 1 \mu \mathrm{mol} \mathrm{m} \mathrm{m}^{-2} \mathrm{~s}^{-1}$ at $4^{\circ} \mathrm{C}, 14^{\circ} \mathrm{C}$ or $24^{\circ} \mathrm{C}$ for $48 \mathrm{~h}$ as described above. The incubation at $4^{\circ} \mathrm{C}$ was carried out for $72 \mathrm{~h}$ to observe responses over a longer period of time.

Samples of $1 \mathrm{~mL}$ for cell counts were taken at the start and end of each incubation in all treatments, preserved using $1 \%$ glutaraldehyde in seawater and stored at $4{ }^{\circ} \mathrm{C}$. The remaining $48 \mathrm{~mL}$ of suspension was used for measurement of MAA content. This was filtered onto GF/F (Whatman, UK) filters which were then placed in containers with 10 $\mathrm{mL} 100 \%$ HPLC grade methanol and extracted at $4^{\circ} \mathrm{C}$ for $24 \mathrm{~h}$. The methanol extract was then stored at $-20^{\circ} \mathrm{C}$, and analysed using High Performance Liquid Chromatography (HPLC) at Victoria University of Wellington following Ryan et al. (2002).

\subsubsection{PAM fluorometry in bottom ice algae}

Unicellular algae can acclimate to changes in irradiance by changing their intracellular photosynthetic pigment content (Falkowski \& Owens, 1980). This response has been used to study the strategy of light-shade adaptation in algae but requires large volumes of cultures and incubation protocols that are difficult to achieve in the field. Therefore, to study the photosynthetic responses of sea ice algae to (a) a range of temperatures mimicking sea ice melt and (b) a wider range of temperatures to determine their limits of photosynthetic activity, Pulse Amplitude Modulation (PAM) fluorometry was used. PAM provides a rapid, non-invasive assessment of the photosynthetic apparatus of algal cells (Bilger \& Schreiber, 1990) making it a useful tool for non-invasive study and for smaller volumes of cultures. 
Fluorometry has been used widely in studies of the photosynthetic activity of sea ice algae (eg:Hawes et al., 2012, Kühl et al., 2001, McMinn et al., 2003, Mou et al., 2013, Ralph \& Gademann, 2005, Ralph et al., 2005, Runcie \& Riddle, 2006, Ryan et al., 2006). It is a useful tool for examining the ability of a photosynthetic organism to tolerate environmental stressors and the extent of damage caused by these stresses (Maxwell \& Johnson, 2000).

The measurement of fluorescence is initiated by switching on a measuring light that gives the initial fluorescence $\left(F_{0}\right)$ (Maxwell \& Johnson, 2000). A saturated flash of light is then applied to measure maximum fluorescence level $\left(\mathrm{Fo}_{\mathrm{m}}\right)$. This dark-adapted measure is known as maximum quantum yield of PS II $\left(\mathrm{F}_{\mathrm{v}} / \mathrm{F}_{\mathrm{m}}\right)$. An actinic light is then turned on to stimulate photosynthesis. The fluorescence level just before this saturating pulse is applied is termed Ft. After a period of time, another saturating pulse is applied that allows for the measurement of maximum fluorescence in the light $\left(\mathrm{F}^{\prime}{ }_{\mathrm{m}}\right)$. The fluorescence emitted by the algal cells is a measurement of quantum yield of PS II ( $\left.\phi_{\mathrm{PSII}}\right)$ :

$$
\phi_{\text {PSII }}=\frac{\mathrm{F}_{m}^{\prime}-F_{t}}{F_{m}^{\prime}}
$$
where, the ratio of variable fluorescence $\left(\mathrm{F}_{\mathrm{m}}^{\prime}-\mathrm{F}_{\mathrm{t}}\right)$ and maximum fluorescence $\left(\mathrm{F}_{\mathrm{m}}^{\prime}\right)$ is used to assess effective quantum yield of PS II (Genty et al., 1989, Hill et al., 2004, Parkhill et al., 2001).

Immediately after collection and thawing of ice core samples as described above, photosynthetic properties of the algal community at Cape Evans were examined using a Water PAM (Walz, Effeltrich, Germany) fluorometer to measure effective quantum yield for photosystem II ( $\left.\phi_{\text {PSII }}\right)$. Before commencing observations, the cells were dark acclimated. Thereafter, all PAM measurements were made on light adapted cells. The Water PAM fluorometer was also used to generate rapid light curves (RLC) at Cape Evans. An RLC describes the effective quantum yield as a function of irradiance (Ralph \& Gademann, 2005). Each sample was treated with a series of eight increasing actinic light treatments, after which a strong saturating pulse was applied and $\phi_{\text {PSII }}$ was recorded. The RLC takes $90 \mathrm{~s}$ to generate. The electron transport rate (ETR) values were calculated by multiplying the $\phi_{P S I I}$ value by the irradiance just applied. As the $\phi_{\text {PSII value }}$ is a ratio and ETR is derived from this parameter, it is termed relative ETR (rETR). An RLC permits derivation of different parameters that can be used to describe the photosynthetic properties of an algal sample, including rETRmax (the maximum value 
for rETR), photosynthetic efficiency $(\alpha)$ and saturation irradiance $\left(E_{\mathrm{k}}\right)$ (Ryan et al., 2009). To determine these parameters, the rETR data were imported into Microsoft Excel v 10.0 (Microsoft, USA) and the curve was fitted with a "waiting-in-line" function (Ritchie, 2008). An RLC was generated for each sample at time 0, 2, 4, 6, 12, 24 and $48 \mathrm{~h}$.

\subsubsection{Measurement of MAAs}

A $10 \mathrm{~mL}$ aliquot from each sub-sample was evaporated at $30^{\circ} \mathrm{C}$ on a heating block and resuspended in a mixture of $40 \mu \mathrm{L} \mathrm{HPLC} \mathrm{grade} \mathrm{methanol} \mathrm{and} 160 \mu \mathrm{L} 0.13 \%$ acetic acid. The resultant solutions were analysed by reverse-phase HPLC (Dunlap \& Chalker, 1986). Chromatography was carried out on a Phenomenex C18 column (Gemini 5 micron; 110 Å; 250 x 4.6 mm) using a Phenomenex RP.8 security guard cartridge (4 x 2 mm ID), an Agilent 1100 HPLC system (Agilent, Loveland, CO, USA) and Chemstation software (Agilent, Loveland, CO, USA). Injection volumes were $5 \mu \mathrm{L}$ and elution was performed using a flow rate of $0.6 \mathrm{~mL} \mathrm{~min}^{-1}$ at $30^{\circ} \mathrm{C}$. An isocratic mobile phase consisting of $0.1 \%$ acetic acid and $20 \%$ methanol in water was used. Spectral data were accumulated in a fixed range and chromatograms plotted at 310, 330 and $360 \mathrm{~nm}$. MAA peaks were identified using comparison with publicly available online absorption spectra and retention times. Relative concentrations were estimated based on the area under the peaks at $360 \mathrm{~nm}$, which was standardized per cell using the cell count data.

\subsubsection{Thylakoid integrity}

As temperature increases, a threshold temperature will be reached where irreversible damage occurs in the thylakoid membranes. The occurrence of this damage can be demonstrated through measurement of fluorescence yield $\left(\mathrm{F}^{\prime}\right)$ as temperatures are increased (Hill et al., 2009). At the critical temperature (Tc) permanent damage starts to occur and there is irreversible reduction in maximum quantum yield. At the temperature of maximum fluorescence (Tp) there is complete loss of photosynthesis and maximum quantum yield becomes zero (Hill et al., 2009).

At Terra Nova Bay in 2007, a small incubation chamber system was set up in the Imaging PAM (Walz, Germany) to allow measurement and assessment of photosynthetic yield ( $\phi_{\text {PSIII) }}$. The sample chamber consisted of a $600 \mathrm{~mL}$ tub containing nine short opaque tubes fixed in place with silicon sealant. The tub was connected to a water bath and coolant was continuously circulated through the chamber using a $65 \mathrm{~W}$ aquarium 
pump to maintain a constant temperature. This system allowed temperatures inside the sample tubes to be controlled.

Five $\mathrm{mL}$ of sea ice algal cell suspension was poured into six of the nine tubes (two replicates from each of the three ice core samples). The other three tubes contained filtered seawater to monitor background readings and temperature. The experiment was run following Hill et al. (2009). The start reading of $\phi_{\text {PSII }}$ was dark-adapted and the samples remained in the dark for the duration of the experiment other than the measuring light. The samples were stabilized at $-1.8^{\circ} \mathrm{C}$ over a period of $5 \mathrm{~min}$ and then subjected to a temperature increase of $2^{\circ} \mathrm{C}$ every $5 \mathrm{~min}$. After every increase, the samples were held at that temperature for $5 \mathrm{~min}$ and then a saturating pulse was applied and $\phi_{\text {PSII }}$ was recorded. In a second set of experiments, $F^{\prime}$ readings only were recorded after each temperature increase. The experimental temperature increases were continued until F' or $\phi_{\text {PSII }}$ reached zero.

\subsubsection{Statistical Analyses}

First, a repeated measures ANOVA was applied to test specifically for changes over time within each treatment. The assumptions of normality and equal variance were satisfied. When analyzing differences across time points, the data from successive time points are likely not to be independent, and hence to be correlated. The covariance matrix is the matrix of all covariances between time points. If that matrix is spherical (as confirmed by Mauchly's test of sphericity), then a standard repeated measures ANOVA calculation is carried out, generating the F statistic and associated degrees of freedom (which are integer values). If, however, the sphericity assumption does not hold, then a correction such as the Greenhouse Geisser adjustment has to be applied (Greenhouse \& Geisser, 1959). The adjustment affects the degrees of freedom rather than the F statistic, with these becoming non-integer values as a consequence. In most of the datasets obtained in this study, the sphericity assumption did not hold and, hence, the Greenhouse Geisser correction was used.

Repeated measures ANOVA as specified here was used to analyse effective quantum yield, $\mathrm{rETR}_{\max }, \alpha$ and $E_{\mathrm{k}}$ data, with 'treatment' being the irradiance treatments and time points of $0,2,4,6,12,24$ and $48 \mathrm{~h}$. The significance of differences between pairs of time points was adjusted using Bonferroni's correction. Three separate experiments were 
conducted at three temperatures $\left(-1^{\circ} \mathrm{C},+2^{\circ} \mathrm{C},+5^{\circ} \mathrm{C}\right.$ ) (see Section 2.3.4). Since they were completed at different times, these were analysed separately.

Finally, one-way ANOVA was used to compare the different treatment groups at specific time points. Post hoc tests using Bonferroni's correction were used for subsequent pairwise comparisons, e.g. between different pairs of treatment groups at a time point, or between different time points within a treatment group. All significant differences referred to below are significant at $\mathrm{p}<0.05$ and all error bars presented indicate standard errors.

\subsection{RESULTS}

\subsubsection{Field parameters and taxonomic composition}

Environmental parameters at the time of collection and community taxonomic composition are summarised in Table 2.1. The sea ice thickness at Granite Harbour was greater than at Terra Nova Bay and Cape Evans, which can be attributed to local conditions in each year. Due to this difference, the light level at the bottom of the sea ice at Granite Harbour was half of that at the other two sites 


\subsubsection{Response of algae to temperature and light changes during melting of sea ice}

\subsubsection{Quantum Yield}

Initially a repeated measures ANOVA was conducted with time as the 'within' factor and temperature and treatment as 'between' factors. This showed significant effects of time $(p<0.001)$, time by temperature $(p<0.001)$ and time by treatment $(p=0.046)$, but the three-way interaction between time, temperature and treatment was not significant ( $p=0.487$ ) (see Table A1.1, Appendix 1). Consequently repeated measures analyses were carried out for each exposure temperature separately to test for the effect of all treatments and time, and for each treatment separately to test for the effect of temperature and time.

Quantum yield for algae used in these experiments was relatively low, possibly due to strands of Berkeleya sp. present in the samples. The general response of algae to the treatments at all PAR levels at $-1^{\circ} \mathrm{C}$ and $2^{\circ} \mathrm{C}$ was an initial rapid change in $\phi$ PSII followed by settling over time to a more or less constant value by $48 \mathrm{~h}$. Algae incubated at higher PAR levels showed rapid initial decreases before recovering to the same $\phi_{\text {PsII values as }}$ those incubated at lower PAR levels. At $5^{\circ} \mathrm{C}$, algae at all the three PAR levels showed an initial decrease followed by an increase in $\phi_{\text {PSII }}$ that continued until the end of the $48 \mathrm{~h}$ incubation period.

At $-1^{\circ} \mathrm{C}$ (Fig. 2.2a), there were varying significant contributions to differences in $\phi_{\text {PSII }}$ by time (Bonferroni, $p=0.015$ ), the time by treatment (Bonferroni, $p=0.001$ ) interaction for algae incubated at different PAR treatments, and between treatments (Bonferroni, $\mathrm{p}=0.002$ ) (Table 2.2(a)). For algae incubated at $100 \mu \mathrm{mol} \mathrm{m}^{-2} \mathrm{~s}^{-1}$, there was a decrease in $\phi$ PsI after $2 \mathrm{~h}$, followed by recovery by $6 \mathrm{~h}$ to reach levels lower than but not significantly different to those achieved by algae incubated at $1 \mu \mathrm{mol} \mathrm{m}{ }^{-2} \mathrm{~s}^{-1}$ and $45 \mu \mathrm{mol}$ $\mathrm{m}^{-2} \mathrm{~s}^{-1}$. All these treatments then showed no further change. Algae incubated at $0 \mu \mathrm{mol}$ $\mathrm{m}^{-2} \mathrm{~s}^{-1}$ showed a significant increase (Bonferroni, $\mathrm{p}=0.020$ ) in $\phi_{\mathrm{PSII}}$ over $48 \mathrm{~h}$, relative to the start of the incubation, but final values were not significantly different from those of the other treatments.

At $2^{\circ} \mathrm{C}$ (Fig. 2.2b), both 45 and $100 \mu \mathrm{mol} \mathrm{m}^{-2} \mathrm{~s}^{-1}$ incubations showed an initial decrease before recovery. There were significant differences in $\phi$ PSII by time (Bonferroni, $\mathrm{p}<0.001$ ) and between treatments (Bonferroni, $\mathrm{p}=0.026$ ) averaged over time for algae incubated at different PAR treatments (Table 2.2(a)). For algae incubated at $0 \mu \mathrm{mol} \mathrm{m}{ }^{-2}$ $\mathrm{s}^{-1}$, there was a significant increase (Bonferroni, $\mathrm{p}=0.017$ ) over $48 \mathrm{~h}$ relative to the start 
of the incubation. However, despite a similar magnitude of change being observed, with the relatively large variability in the data obtained, no significant changes were identified for algae incubated at other exposures.

At $5^{\circ} \mathrm{C}$ (Fig. 2.2c), the higher light intensity incubations again showed an initial decrease and then recovery. However, the only significant differences identified in $\phi_{P S I}$ over time (Bonferroni, $\mathrm{p}=0.001$ ) were for algae incubated under different PAR treatments (Table 2.2(a)). Algae incubated at 0 (Bonferroni, $\mathrm{p}=0.005$ ) and $1 \mu \mathrm{mol} \mathrm{m}^{-2} \mathrm{~s}^{-1}$ (Bonferroni, $\mathrm{p}=0.014$ ) showed a significant increase in $\phi_{\text {PSII }}$ over $48 \mathrm{~h}$, relative to the start of the incubation but did not differ from each other. No significant changes in $\phi$ PsII were identified for algae incubated at 45 or $100 \mu \mathrm{mol} \mathrm{m}^{-2} \mathrm{~s}^{-1}$. 
Table 2.2. Changes in quantum yield of photosystem II over $48 \mathrm{~h}$ experimental treatments at different PAR levels $\left(0,1,45\right.$ and $\left.100 \mu \mathrm{mol} \mathrm{m}{ }^{-2} \mathrm{~s}^{-1}\right)$ at $-1^{\circ} \mathrm{C}, 2^{\circ} \mathrm{C}$ and $5^{\circ} \mathrm{C}$, analysed using repeated measures ANOVA. Significant changes identified by post hoc pairwise analyses are also listed. (a) Effect of changing PAR at a specific incubation temperature:

\begin{tabular}{|c|c|c|c|c|c|}
\hline Source of variation & $\mathrm{df}$ & MS & $F$ & $\mathrm{p}$ & post hoc comparisons \\
\hline \multirow{2}{*}{\multicolumn{6}{|c|}{$\begin{array}{l}\text { At }-1^{\circ} \mathrm{C} \\
\text { Within subjects }\end{array}$}} \\
\hline & & & & & \\
\hline Time & 3.273 & 0.015 & 3.667 & 0.015 & \multirow{3}{*}{$\begin{array}{l}\text { Increase over } 48 \mathrm{~h} \\
\text { (see text for details) }\end{array}$} \\
\hline Time $\mathrm{x}$ Treatments & 9.819 & 0.014 & 3.547 & 0.001 & \\
\hline Error & 52.368 & 0.004 & & & \\
\hline \multicolumn{6}{|l|}{ Between subjects } \\
\hline Treatments & 3 & 0.115 & 8.206 & 0.002 & \multirow[t]{2}{*}{$100 \mu \mathrm{mol} \mathrm{m}{ }^{-2} \mathrm{~s}^{-1}<0=1 \mu \mathrm{mol} \mathrm{m}^{-2} \mathrm{~s}^{-1}$} \\
\hline Error & 16 & 0.014 & & & \\
\hline \multicolumn{6}{|l|}{ At $2^{\circ} \mathrm{C}$} \\
\hline \multicolumn{6}{|l|}{ Within subjects } \\
\hline Time & 3.323 & 0.099 & 15.751 & $<0.001$ & \multirow{3}{*}{$\begin{array}{l}\text { Increase over } 48 \mathrm{~h} \\
\text { (see text for details) }\end{array}$} \\
\hline Time $\mathrm{x}$ Treatments & 9.97 & 0.01 & 1.559 & 0.145 & \\
\hline Error & 53.171 & 0.006 & & & \\
\hline \multicolumn{6}{|l|}{ Between subjects } \\
\hline Treatments & 3 & 0.076 & 4.01 & 0.026 & \multirow[t]{4}{*}{$100 \mu \mathrm{mol} \mathrm{m}^{-2} \mathrm{~s}^{-1}<0 \mu \mathrm{mol} \mathrm{m} \mathrm{m}^{-2} \mathrm{~s}^{-1}$} \\
\hline Error & 16 & 0.019 & & & \\
\hline At $5^{\circ} \mathrm{C}$ & & & & & \\
\hline \multicolumn{5}{|l|}{ Within subjects } & \\
\hline Time & 1.731 & 0.285 & 9.88 & 0.001 & \multirow{3}{*}{$\begin{array}{l}\text { Increase over } 48 \mathrm{~h} \\
\text { (see text for details) }\end{array}$} \\
\hline Time $\mathrm{x}$ Treatments & 5.193 & 0.018 & 0.611 & 0.698 & \\
\hline Error & 27.694 & 0.029 & & & \\
\hline \multicolumn{6}{|l|}{ Between subjects } \\
\hline Treatments & 3 & 0.043 & 2.229 & 0.124 & \\
\hline Error & 16 & 0.019 & & & \\
\hline
\end{tabular}


a)

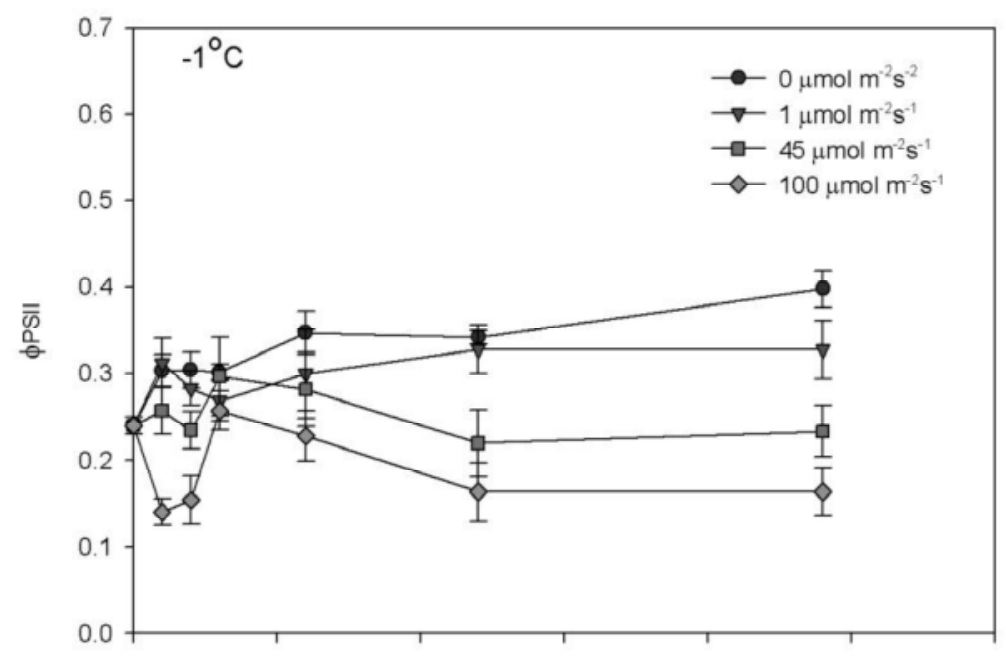

b)

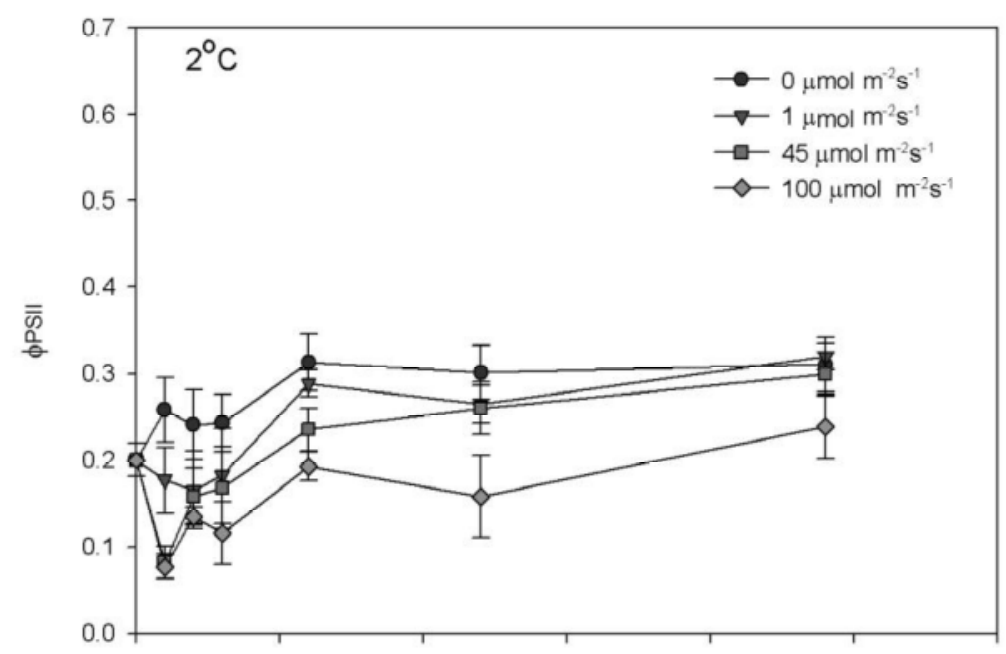

c)

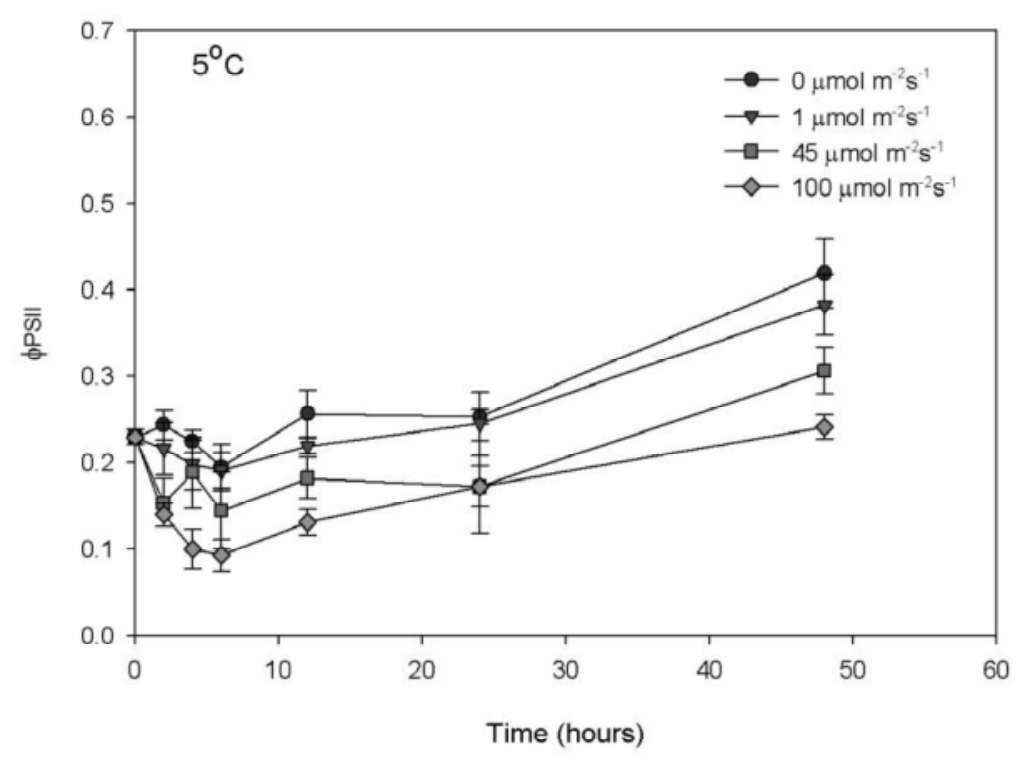

Fig 2.2. Quantum Yield ( $\phi_{\text {PSII }}$ ) of bottom ice algae measured at 0, 2, 4, 6, 12, 24 and $48 \mathrm{~h}$. Cultures were maintained at four PAR levels of $0,1,45$ or $100 \mu \mathrm{mol} \mathrm{m}^{-2} \mathrm{~s}^{-1}$ and at (a) $1^{\circ} \mathrm{C}$, (b) $2^{\circ} \mathrm{C}$ and (c) $5^{\circ} \mathrm{C}$. Error bars indicate standard error. 
Table 2.2 (b). Effect of changing temperature at a specific PAR level.

\begin{tabular}{|c|c|c|c|c|c|}
\hline Source of variation & $\mathrm{df}$ & MS & $F$ & $\mathrm{p}$ & post hoc comparisons \\
\hline \multicolumn{6}{|l|}{$\begin{array}{l}\text { In } 0 \mu \mathrm{mol} \mathrm{m}^{-2} \mathrm{~s}^{-1} \\
\text { Within subjects }\end{array}$} \\
\hline Time & 6 & 0.041 & 28.421 & $<0.001$ & Increase over $48 \mathrm{~h}$ \\
\hline Time $\mathrm{x}$ Temperature & 12 & 0.005 & 3.267 & 0.001 & (see text for details) \\
\hline Error & 72 & 0.001 & & & \\
\hline \multicolumn{6}{|l|}{ Between subjects } \\
\hline Temperature & 2 & 0.041 & 2.532 & 0.121 & No difference \\
\hline Error & 12 & 0.016 & & & between temperatures \\
\hline \multicolumn{6}{|l|}{ In $1 \mu \mathrm{mol} \mathrm{m}^{-2} \mathrm{~s}^{-1}$} \\
\hline \multicolumn{6}{|l|}{ Within subjects } \\
\hline Time & 6 & 0.031 & 8.391 & $<0.001$ & Increase over $48 \mathrm{~h}$ \\
\hline Time x Temperature & 12 & 0.007 & 1.775 & 0.069 & (see text for details) \\
\hline Error & 72 & 0.004 & & & \\
\hline \multicolumn{6}{|l|}{ Between subjects } \\
\hline Temperature & 2 & 0.042 & 2.974 & 0.089 & No difference \\
\hline Error & 12 & 0.014 & & & between temperatures \\
\hline \multicolumn{6}{|l|}{ In $45 \mu \mathrm{mol} \mathrm{m}^{-2} \mathrm{~s}^{-1}$} \\
\hline Time & 6 & 0.022 & 6.605 & $<0.001$ & Initial increase but return to baseline \\
\hline Time $\mathrm{x}$ Temperature & 12 & 0.015 & 4.677 & $<0.001$ & (see text for details) \\
\hline Error & 72 & 0.003 & & & \\
\hline \multicolumn{6}{|l|}{ Between subjects } \\
\hline Temperature & 2 & 0.033 & 1.500 & 0.262 & No difference \\
\hline Error & 12 & 0.022 & & & between temperatures \\
\hline \multicolumn{6}{|l|}{$\begin{array}{l}\text { In } 100 \mu \mathrm{mol} \mathrm{m}{ }^{-2} \mathrm{~s}^{-1} \\
\text { Within subjects }\end{array}$} \\
\hline Time & 1.561 & 0.120 & 3.047 & 0.082 & Initial increase but return to baseline \\
\hline Time x Temperature & 3.123 & 0.042 & 1.076 & 0.385 & (see text for details) \\
\hline Error & 18.737 & 0.039 & & & \\
\hline \multicolumn{6}{|l|}{ Between subjects } \\
\hline Temperature & 2 & 0.009 & 1.500 & 0.489 & No difference \\
\hline Error & 12 & 0.018 & & & Between temperatures \\
\hline
\end{tabular}


At $0 \mu \mathrm{mol} \mathrm{m}{ }^{-2} \mathrm{~s}^{-1}$, there was a significant increase (Bonferroni, $\mathrm{p}<0.001$ ) in $\phi_{\text {PSII }}$ over 48 $\mathrm{h}$ but no difference between the three incubation temperatures (Table 2.2(b)). There

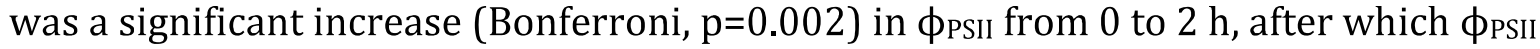
did not vary until after $6 \mathrm{~h}$. There was a significant increase in $\phi_{\text {PSII }}$ between 6 and $12 \mathrm{~h}$ (Bonferroni, $\mathrm{p}=0.001$ ), after which $\phi$ PsiI did not vary until after $24 \mathrm{~h}$. The algae then showed a significant increase (Bonferroni, $\mathrm{p}=0.014$ ) in $\phi_{\text {PSII }}$ in the last $24 \mathrm{~h}$. At $1 \mu \mathrm{mol} \mathrm{m}^{-}$ ${ }^{2} \mathrm{~s}^{-1}$, there was a significant increase (Bonferroni, $\mathrm{p}<0.001$ ) in $\phi_{\mathrm{PSII}}$ over $48 \mathrm{~h}$ but no difference between the three incubation temperatures. However, there was no change in $\phi_{\mathrm{PSII}}$ for the first $24 \mathrm{~h}$ after which $\phi_{\mathrm{PSII}}$ significantly increased (Bonferroni, $\mathrm{p}=0.008$ ) until $48 \mathrm{~h}$. At $45 \mu \mathrm{mol} \mathrm{m}^{-2} \mathrm{~s}^{-1}$, there was no difference between the three incubation temperatures (Table 2.2(b)). There was a significant increase (Bonferroni, $p=0.010$ ) in $\phi$ PsII in the last $24 \mathrm{~h}$ but no overall increase over $48 \mathrm{~h}$. At $100 \mu \mathrm{mol} \mathrm{m}^{-2} \mathrm{~s}^{-1}$, there was no difference between the three incubation temperatures (Table 2.2(b)). There was a significant decrease (Bonferroni, $\mathrm{p}<0.001$ ) in $\phi_{\text {PSII }}$ in the first $2 \mathrm{~h}$ after which it recovered to show no overall increase over $48 \mathrm{~h}$.

\subsubsection{Relative ETR max $_{\text {max }}$}

Initially a repeated measures ANOVA was conducted with time as the 'within' factor and both temperature and treatment as 'between' factors. This showed significant effects of time $(\mathrm{p}<0.001)$, time by temperature $(\mathrm{p}<0.001)$, time by treatment $(\mathrm{p}<0.001)$, and the interaction between time, temperature and treatment ( $\mathrm{p}<0.001)$ (Table A1.2, Appendix 1). There was a correlation between PAR and time that was dependent on temperature and a correlation between temperature and time that was dependent on PAR. Consequently repeated measures analyses were carried out for each temperature separately to test for the effect of all treatments and time, and for each treatment separately to test for the effect of temperature and time. 
Table 2.3. Changes in relative ETR $\mathrm{max}_{\max }$ over $48 \mathrm{~h}$ experimental treatments at different PAR levels $\left(0,1,45\right.$ and $\left.100 \mu \mathrm{mol} \mathrm{m}^{-2} \mathrm{~s}^{-1}\right)$ at $-1^{\circ} \mathrm{C}, 2^{\circ} \mathrm{C}$ and $5^{\circ} \mathrm{C}$, analysed using repeated measures ANOVA. Significant changes identified by post hoc pairwise analyses are also listed.

(a) Effect of changing $\mathrm{rETR}_{\max }$ at a specific incubation temperature.

\begin{tabular}{|c|c|c|c|c|c|}
\hline Source of & $\mathrm{df}$ & MS & $F$ & $\mathrm{p}$ & post hoc comparisons \\
\hline \multirow{2}{*}{\multicolumn{6}{|c|}{$\begin{array}{l}\text { At }-1^{\circ} \mathrm{C} \\
\text { Within subjects }\end{array}$}} \\
\hline & & & & & \\
\hline Time & 3.223 & 375.27 & 42.41 & $<0.00$ & \multirow{3}{*}{$\begin{array}{l}\text { Initial increase but return to baseline } \\
\text { (see text below) }\end{array}$} \\
\hline Time $\mathrm{x}$ & 9.670 & 90.076 & 10.18 & $<0.00$ & \\
\hline Error & 456.33 & 51.575 & 8.848 & & \\
\hline \multicolumn{6}{|c|}{ Between subjects } \\
\hline Treatments & 3 & 318.50 & 11.38 & $<0.00$ & \multirow{2}{*}{$\left(0=1 \mu \mathrm{mol} \mathrm{m}^{-2} \mathrm{~s}^{-1}\right)<\left(45=100 \mu \mathrm{mol} \mathrm{m}^{-2} \mathrm{~s}\right.$} \\
\hline Error & 16 & 27.984 & & & \\
\hline \multicolumn{6}{|c|}{ At $2^{\circ} \mathrm{C}$} \\
\hline Within subj & & & & & \\
\hline Time & 3.511 & 173.56 & 18.68 & $<0.00$ & \multirow{3}{*}{$45 \mu \mathrm{mol} \mathrm{m}^{-2} \mathrm{~s}^{-1} \uparrow$} \\
\hline Time $\mathrm{x}$ & 10.532 & 30.200 & 3.252 & 0.002 & \\
\hline Error & 56.168 & 9.288 & & & \\
\hline \multicolumn{6}{|c|}{ Between subjects } \\
\hline Treatments & 3 & 88.882 & 8.792 & 0.001 & \multirow{2}{*}{$\begin{array}{l}0=1 \& 100 \mu \mathrm{mol} \mathrm{m}^{-2} \mathrm{~s}^{-1} \\
1=100 \mu \mathrm{mol} \mathrm{m} \mathrm{m}^{-2} \mathrm{~s}^{-1} ; 45=100 \mu \mathrm{mol} \mathrm{m}{ }^{-2} \mathrm{~s}^{-1}\end{array}$} \\
\hline Error & 16 & 10.109 & & & \\
\hline \multicolumn{6}{|c|}{ At $5^{\circ} \mathrm{C}$} \\
\hline Within subj & & & & & \\
\hline Time & 2.614 & 131.97 & 18.51 & $<0.00$ & \multirow{3}{*}{$\begin{array}{l}\text { Initial increase but return to baseline } \\
\text { (see text below) }\end{array}$} \\
\hline Time $\mathrm{x}$ & 7.843 & 31.340 & 4.397 & 0.001 & \\
\hline Error & 41.829 & 7.127 & & & \\
\hline \multicolumn{6}{|c|}{ Between subjects } \\
\hline Treatments & 3 & 58.016 & 5.820 & 0.007 & $0=1=100 \mu \mathrm{mol} \mathrm{m}^{-2} \mathrm{~s}^{-1}$ \\
\hline Error & 16 & 9.968 & & & $45=100 \mu \mathrm{mol} \mathrm{m}^{-2} \mathrm{~s}^{-1}$ \\
\hline
\end{tabular}


Algae incubated at $-1^{\circ} \mathrm{C}$ and $2^{\circ} \mathrm{C}$ showed similar general responses in $\mathrm{rETR}_{\max }$. At both these temperatures, algae incubated at the higher PAR levels showed rapid increases before settling down to the same ETR $_{\max }$ as the other exposures by $48 \mathrm{~h}$. The only exception to this generalisation were the algae exposed to $45 \mu \mathrm{mol} \mathrm{m}^{-2} \mathrm{~s}^{-1}$, where the initial increase in $\mathrm{rETR}_{\max }$ was maintained until $48 \mathrm{~h}$. At $5^{\circ} \mathrm{C}$, there were intial changes in rETR $_{\max }$ that remained roughly constant until $24 \mathrm{~h}$, after which algae incubated at the higher PAR levels showed a continuing increase in $\mathrm{rETR}_{\text {max. }}$ At $-1^{\circ} \mathrm{C}$ (Fig. 2.3 a), there were significant increases in rETR $_{\max }$ over the time points (Bonferroni, $\mathrm{p}<0.001$ ) between 0 and $48 \mathrm{~h}$ for algae incubated at both higher PAR exposures (Table 2.3(a)). Algae incubated at $0 \mu \mathrm{mol} \mathrm{m}^{-2} \mathrm{~s}^{-1}$ showed a significant increase (Bonferroni, $\mathrm{p}=0.024$ ) in $\mathrm{rETR}_{\max }$ over the first $2 \mathrm{~h}$ after which it decreased, leading to no overall increase over $48 \mathrm{~h}$. Algae incubated at 1 and $100 \mu \mathrm{mol} \mathrm{m}^{-2} \mathrm{~s}^{-1}$ showed no significant changes over $48 \mathrm{~h}$. Those incubated at $45 \mu \mathrm{mol} \mathrm{m}-2 \mathrm{~s}^{-1}$ showed a significant increase (Bonferroni, $\mathrm{p}=0.040$ ) in $\mathrm{rETR}_{\max }$ over the first $2 \mathrm{~h}$. $\mathrm{rETR}_{\max }$ then stayed constant until $6 \mathrm{~h}$ after which it significantly increased (Bonferroni, $\mathrm{p}=0.033$ ) over the next $6 \mathrm{~h}$. rETR $\mathrm{max}_{\max }$ then remained constant for another $36 \mathrm{~h}$, showing no overall change over $48 \mathrm{~h}$.

At $2^{\circ} \mathrm{C}$ (Fig. $2.3 \mathrm{~b}$ ), there were significant increases in RETR $_{\max }$ over the time points (Bonferroni, $\mathrm{p}<0.001$ ) between 0 and $48 \mathrm{~h}$ for algae incubated at all PAR exposures (Table 2.3(a)). However, only algae incubated at $45 \mu \mathrm{mol} \mathrm{m}^{-2} \mathrm{~s}^{-1}$ showed a significant increase (Bonferroni, $\mathrm{p}=0.037$ ) in $\mathrm{rETR}_{\max }$ over $48 \mathrm{~h}$, relative to the start of the incubation.

At $5^{\circ} \mathrm{C}$ (Fig. $2.3 \mathrm{c}$ ), there were significant increases in $\mathrm{rETR}_{\max }$ over the time points (Bonferroni, $\mathrm{p}<0.001$ ) between 0 and $48 \mathrm{~h}$ for algae incubated at the high PAR exposures. Algae incubated at $45 \mu \mathrm{mol} \mathrm{m}^{-2} \mathrm{~s}^{-1}$ showed a significantly greater rETR $\mathrm{max}_{\max }$ compared with those incubated at 0 (Bonferroni, $\mathrm{p}=0.006$ ) and $1 \mu \mathrm{mol} \mathrm{m}{ }^{-2} \mathrm{~s}^{-1}$ (Bonferroni, $\mathrm{p}=0.010$ ) at $48 \mathrm{~h}$. 
a)

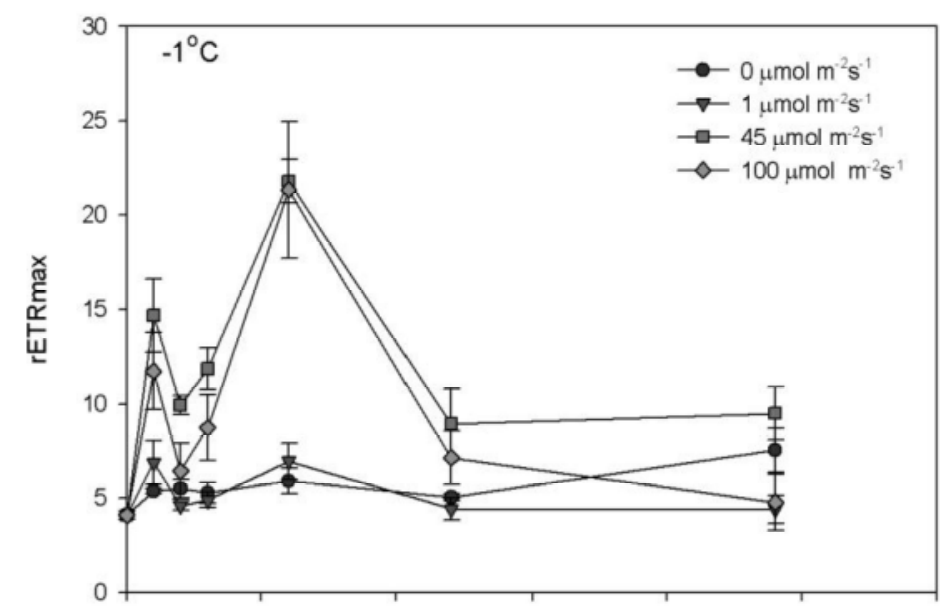

b)

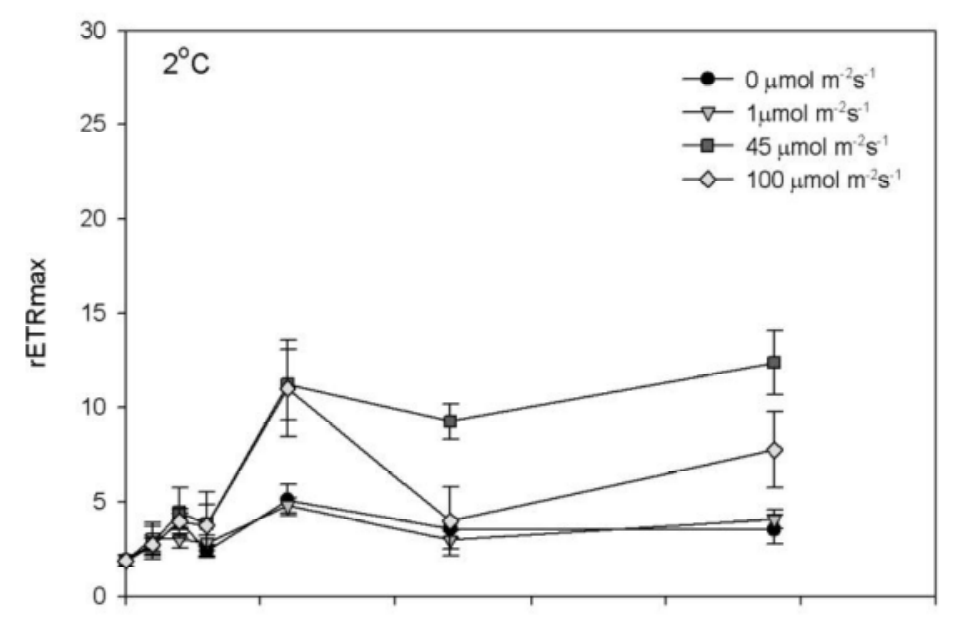

c)

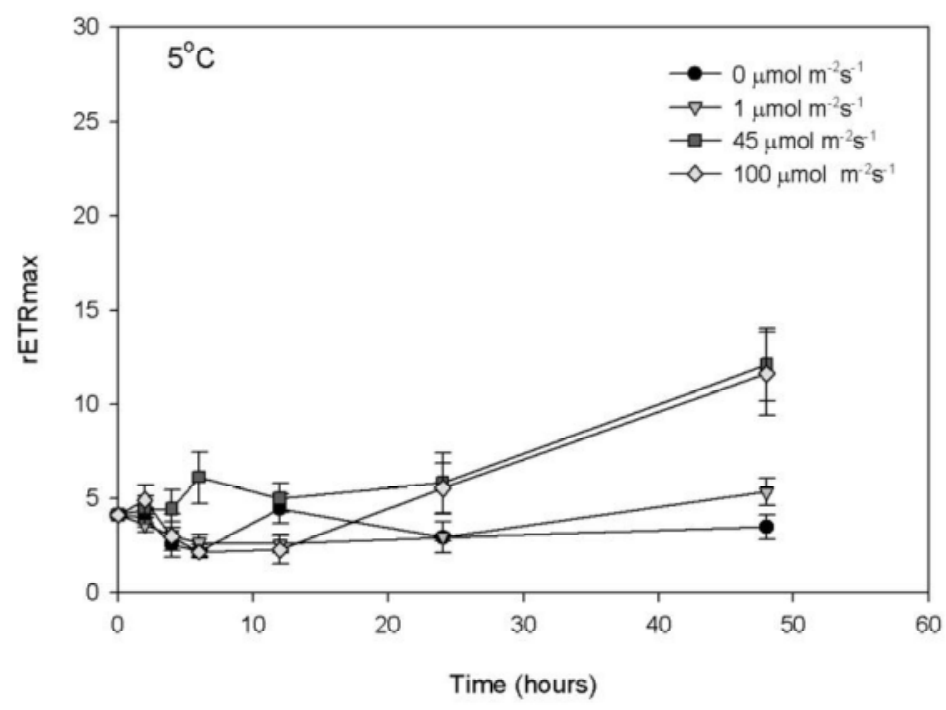

Fig 2.3. Relative ETR $\max _{\text {ax }}$ of bottom ice algae at $0,2,4,6,12,24$ and $48 \mathrm{~h}$. Cultures were maintained at four PAR levels of $0,1,45$ or $100 \mu \mathrm{mol} \mathrm{m}^{-2} \mathrm{~s}^{-1}$ and at (a) $-1^{\circ} \mathrm{C}$, (b) $2^{\circ} \mathrm{C}$ and (c) $5^{\circ} \mathrm{C}$. Error bars indicate standard error. 
Table 2.3(b). Effect of changing temperature at a specific PAR level.

\begin{tabular}{|c|c|c|c|c|c|}
\hline Source of variation & $\mathrm{df}$ & MS & $F$ & $\mathrm{p}$ & post hoc comparisons \\
\hline \multicolumn{6}{|l|}{$\begin{array}{l}\text { In } 0 \mu \mathrm{mol} \mathrm{m}^{-2} \mathrm{~s}^{-1} \\
\text { Within subjects }\end{array}$} \\
\hline Time & 2.786 & 18.070 & 6.734 & 0.001 & \multirow{3}{*}{$\begin{array}{l}\text { Initial increase \& return to baseline } \\
\text { (see text for details) }\end{array}$} \\
\hline Time $\mathrm{x}$ Temperature & 5.573 & 8.447 & 3.148 & 0.017 & \\
\hline Error & 33.435 & 2.683 & & & \\
\hline \multicolumn{6}{|l|}{ Between subjects } \\
\hline Temperature & 2 & 56.460 & 19.043 & $<0.001$ & $-1^{\circ} \mathrm{C}>\left(2^{\circ} \mathrm{C}=5^{\circ} \mathrm{C}\right)$ \\
\hline Error & 12 & 2.965 & & & \\
\hline \multicolumn{6}{|l|}{ In $1 \mu \mathrm{mol} \mathrm{m}^{-2} \mathrm{~s}^{-1}$} \\
\hline \multicolumn{6}{|l|}{ Within subjects } \\
\hline Time & 3.195 & 9.972 & 2.700 & 0.056 & \multirow{3}{*}{$\begin{array}{l}\text { No increase over } 48 \mathrm{~h} \\
\text { (see text for details) }\end{array}$} \\
\hline Time x Temperature & 6.391 & 9.060 & 2.454 & 0.039 & \\
\hline Error & 38.345 & 3.693 & & & \\
\hline \multicolumn{6}{|l|}{ Between subjects } \\
\hline Temperature & 2 & 40.251 & 12.074 & 0.010 & $-1^{\circ} \mathrm{C}>\left(2^{\circ} \mathrm{C}=5^{\circ} \mathrm{C}\right)$ \\
\hline Error & 12 & 3.334 & & & \\
\hline \multicolumn{6}{|l|}{$\begin{array}{l}\text { In } 45 \mu \mathrm{mol} \mathrm{m}^{-2} \mathrm{~s}^{-1} \\
\text { Within subjects }\end{array}$} \\
\hline Time & 6 & 142.398 & 24.706 & $<0.001$ & \multirow{3}{*}{$\begin{array}{l}\text { Initial increase but return to baseline } \\
\text { (see text for details) }\end{array}$} \\
\hline Time $\mathrm{x}$ Temperature & 12 & 70.479 & 12.228 & $<0.001$ & \\
\hline Error & 72 & 5.764 & & & \\
\hline \multicolumn{6}{|l|}{ Between subjects } \\
\hline Temperature & 2 & 308.840 & 12.034 & 0.001 & $-1^{\circ} \mathrm{C}>\left(2^{\circ} \mathrm{C}=5^{\circ} \mathrm{C}\right)$ \\
\hline Error & 12 & 25.664 & & & \\
\hline \multicolumn{6}{|l|}{$\begin{array}{l}\text { In } 100 \mu \mathrm{mol} \mathrm{m}^{-2} \mathrm{~s}^{-1} \\
\text { Within subjects }\end{array}$} \\
\hline Time & 2.467 & 285.498 & 13.419 & $<0.001$ & \multirow{3}{*}{$\begin{array}{l}\text { Initial increase but return to baseline } \\
\text { (see text for details) }\end{array}$} \\
\hline Time x Temperature & 4.934 & 204.142 & 9.595 & $<0.001$ & \\
\hline Error & 29.604 & 21.276 & & & \\
\hline \multicolumn{6}{|l|}{ Between subjects } \\
\hline Temperature & 2 & 221.559 & 6.898 & 0.010 & $-1^{\circ} \mathrm{C}>\left(2^{\circ} \mathrm{C}=5^{\circ} \mathrm{C}\right)$ \\
\hline Error & 12 & 32.119 & & & \\
\hline
\end{tabular}


At $0 \mu \mathrm{mol} \mathrm{m}{ }^{-2} \mathrm{~s}^{-1}$, there were significant increases in $\mathrm{rETR}_{\max }$ over $48 \mathrm{~h}$ (Bonferroni, $\mathrm{p}=0.001$ ) and a difference between the three incubation temperatures (Bonferroni, $\mathrm{p}<0.001$ ) (Table 2.3(b)). There was a slight increase in $\mathrm{rETR}_{\max }$ from 0 to $2 \mathrm{~h}$, after which it did not vary until $48 \mathrm{~h}$. $\mathrm{rETR}_{\max }$ for algae incubated at $-1^{\circ} \mathrm{C}$ was greater than that for those incubated at $2^{\circ} \mathrm{C}$ and $5^{\circ} \mathrm{C}$. At $1 \mu \mathrm{mol} \mathrm{m}^{-2} \mathrm{~s}^{-1}$, there was no significant increase in $\mathrm{rETR}_{\max }$ over $48 \mathrm{~h}$ but there was a difference between the three incubation temperatures (Bonferroni, $\mathrm{p}=0.010$ ) (Table 2.3(b)). At $45 \mu \mathrm{mol} \mathrm{m}^{-2} \mathrm{~s}^{-1}$ and $100 \mu \mathrm{mol} \mathrm{m}^{-2}$ $\mathrm{s}^{-1}$, there were significant increases in $\mathrm{rETR}_{\max }$ over $48 \mathrm{~h}$ (Bonferroni, $45 \mu \mathrm{mol} \mathrm{m}^{-2} \mathrm{~s}^{-1}$ : $\left.\mathrm{p}<0.001,100 \mu \mathrm{mol} \mathrm{m}^{-2} \mathrm{~s}-1: \mathrm{p}<0.001\right)$ and a difference between the three incubation temperatures (Bonferroni, $45 \mu \mathrm{mol} \mathrm{m}^{-2} \mathrm{~s}^{-1}: \mathrm{p}=0.001,100 \mu \mathrm{mol} \mathrm{m}^{-2} \mathrm{~s}-1: \mathrm{p}=0.010$ ) (Table 2.3(b)).

\subsubsection{MAAs}

Initially a repeated measures ANOVA was conducted with time as the 'within' factor and both temperature and treatment as 'between' factors. This showed significant effects of time $(\mathrm{p}<0.05)$, time by temperature $(\mathrm{p}<0.05)$, time by treatment $(\mathrm{p}<0.05)$, but the interaction between time, temperature and treatment was not significant $(p>0.05)$ (Table A1.3, Appendix 1). Consequently repeated measures analyses were carried out for each temperature separately to test for the effect of all treatments and time (Table 2.4).

The algae showed a general increase in MAA production at all temperatures when incubated at the higher PAR treatments. However, there was no significant increase (Table 2.4) in MAA production for algae incubated at -1 and $2^{\circ} \mathrm{C}$ (Figure 2.4 (a), (b)). At $5^{\circ} \mathrm{C}$, algae incubated at the higher PAR treatments (Figure 2.4 (c)) showed a significant increase (Bonferroni, $\mathrm{p}=0.002$ ) in MAA production over the $48 \mathrm{~h}$ with algae incubated at $100 \mu \mathrm{mol} \mathrm{m}^{-2} \mathrm{~s}^{-1}$ having a significantly higher (Bonferroni, $\mathrm{p}=0.020$ ) MAA production than those incubated at $45 \mu \mathrm{mol} \mathrm{m} \mathrm{m}^{-2} \mathrm{~s}^{-1}$. 
Table 2.4. Changes in MAA production over $48 \mathrm{~h}$ experimental treatments at different PAR levels $\left(0,1,45\right.$ and $\left.100 \mu \mathrm{mol} \mathrm{m} \mathrm{m}^{-2} \mathrm{~s}^{-1}\right)$ at $-1^{\circ} \mathrm{C}, 2^{\circ} \mathrm{C}$ and $5^{\circ} \mathrm{C}$, analysed using repeated measures ANOVA. Significant changes identified by post hoc pairwise analyses are also listed.

\begin{tabular}{|c|c|c|c|c|c|}
\hline Source of variation & $\mathrm{df}$ & MS & $F$ & $\mathrm{p}$ & post hoc comparisons \\
\hline \multicolumn{6}{|l|}{$\begin{array}{l}\text { At }-1^{\circ} \mathrm{C} \\
\text { Within subjects }\end{array}$} \\
\hline Time & 1 & $1.587 \mathrm{E}-006$ & 0.002 & 0.967 & No significance \\
\hline Time $\mathrm{x}$ Treatments & 3 & 0.001 & 0.764 & 0.531 & \\
\hline Error & 16 & 0.001 & & & \\
\hline \multicolumn{6}{|l|}{ Between subjects } \\
\hline Treatments & 3 & 0.002 & 0.893 & 0.466 & No significance \\
\hline Error & 16 & 0002 & & & \\
\hline \multicolumn{6}{|l|}{ At $2^{\circ} \mathrm{C}$} \\
\hline \multicolumn{6}{|l|}{ Within subjects } \\
\hline Time & 1 & 0.002 & 2.338 & 0.146 & No significance \\
\hline Time $\mathrm{x}$ Treatments & 3 & 0.000 & 0.342 & 0.795 & \\
\hline Error & 16 & 0.001 & & & \\
\hline \multicolumn{6}{|l|}{ Between subjects } \\
\hline Treatments & 3 & 0.003 & 2.283 & 0.146 & No significance \\
\hline Error & 16 & 0.001 & & & \\
\hline \multicolumn{6}{|l|}{ At $5^{\circ} \mathrm{C}$} \\
\hline \multicolumn{6}{|l|}{ Within subjects } \\
\hline Time & 1 & 0.032 & 13.118 & 0.002 & Increase over $48 \mathrm{~h}$ \\
\hline Time $\mathrm{x}$ Treatments & 3 & 0.008 & 3.152 & 0.054 & (see text below) \\
\hline Error & 16 & 0.002 & & & \\
\hline \multicolumn{6}{|l|}{ Between subjects } \\
\hline Treatments & 3 & 0.011 & 3.884 & 0.020 & $45<100 \mu \mathrm{mol} \mathrm{m}^{-2} \mathrm{~s}^{-1}$ \\
\hline Error & 16 & 0.003 & & & \\
\hline
\end{tabular}


a)

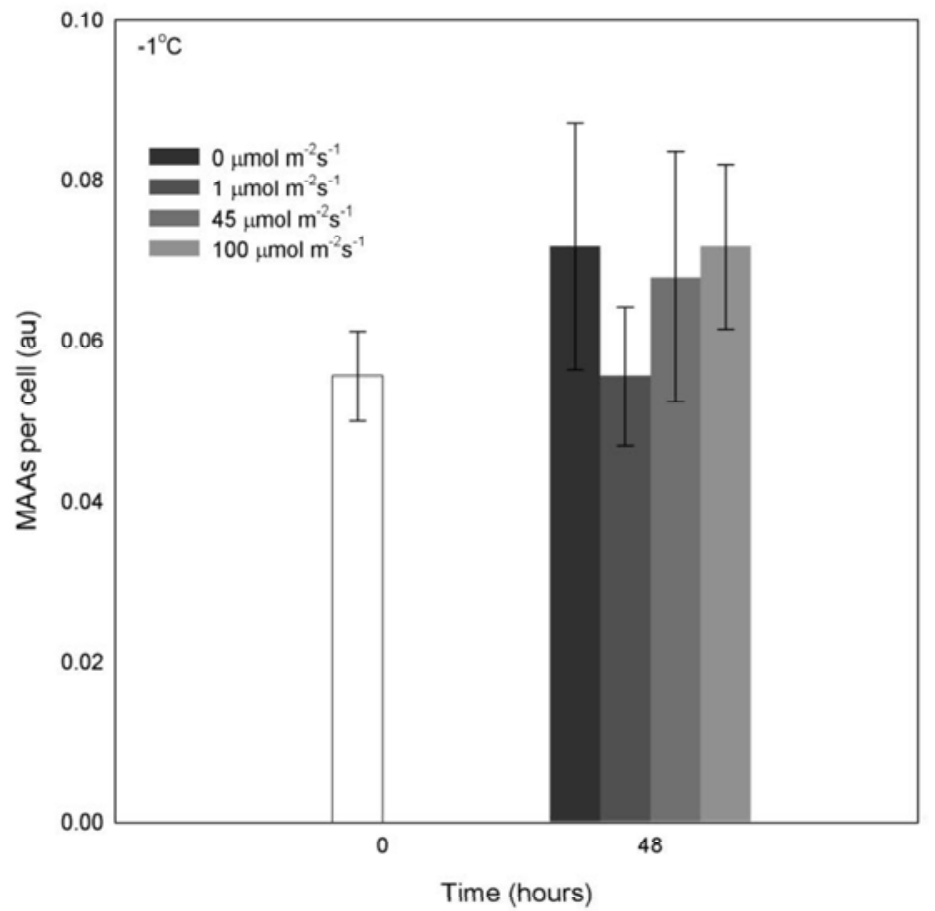

b)

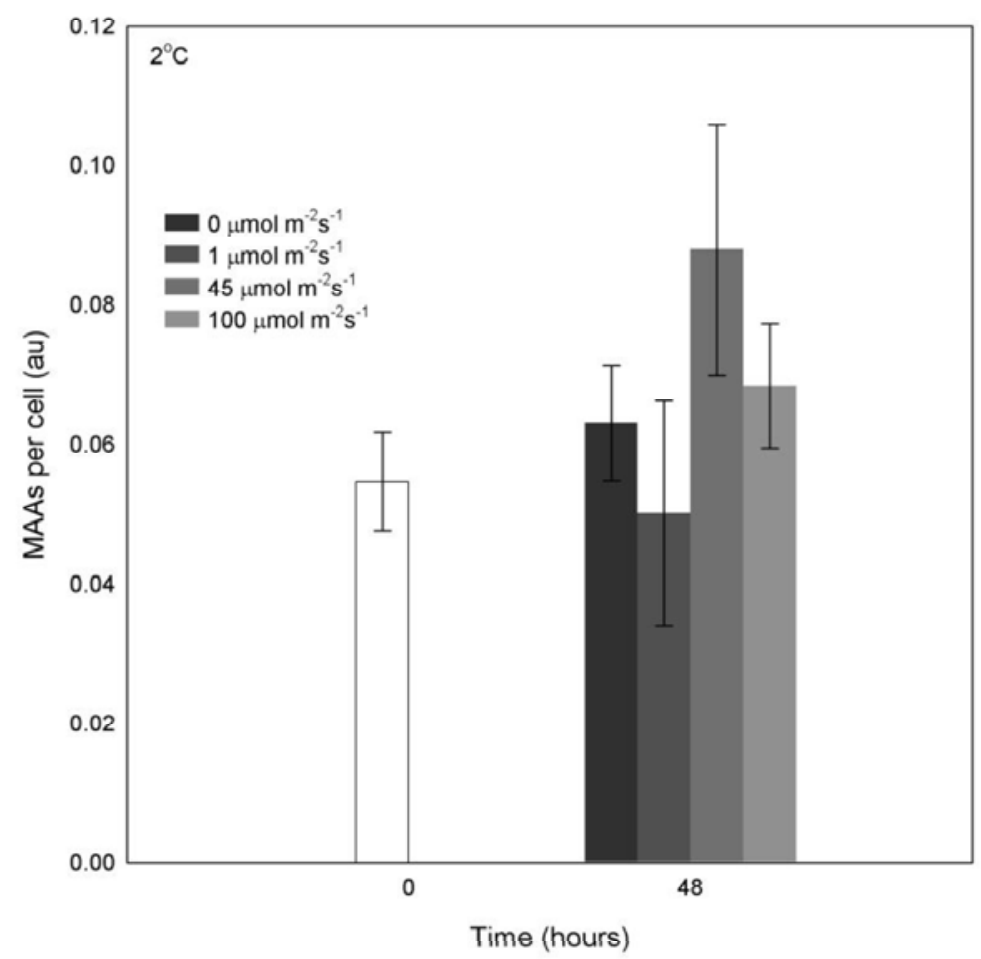


c)

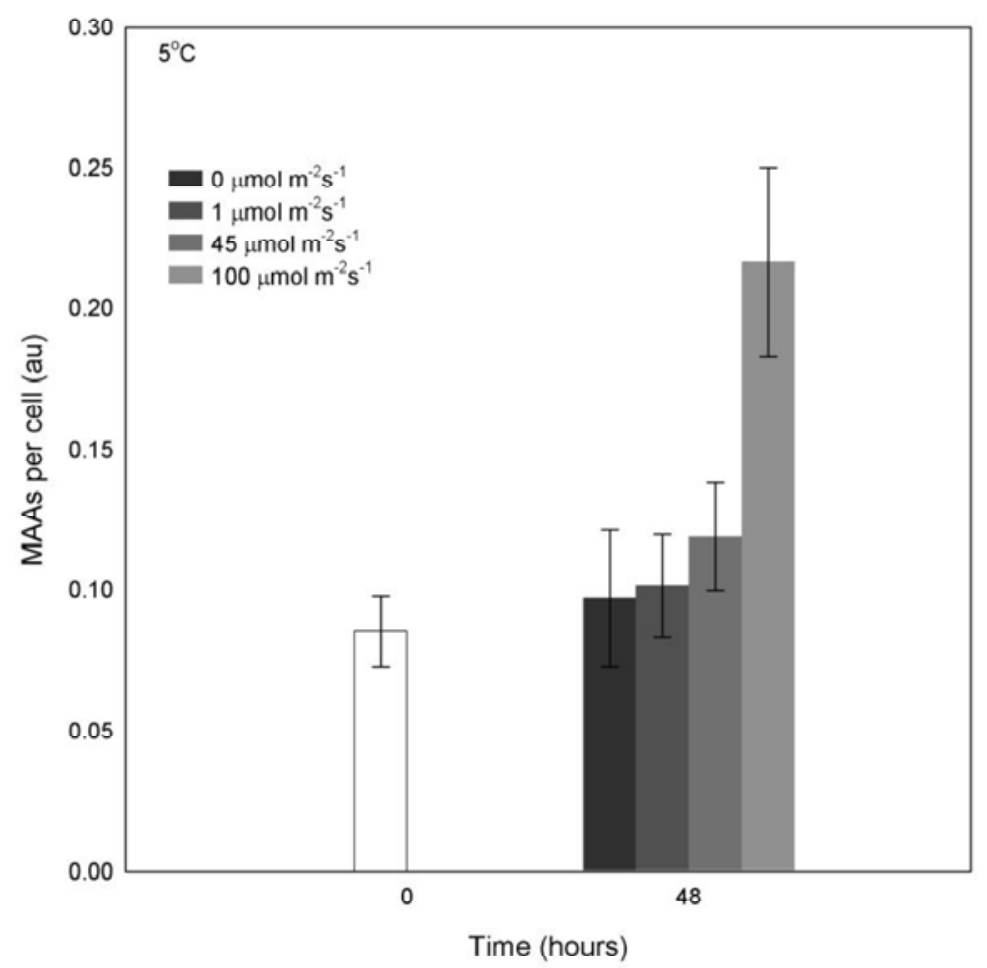

Fig 2.4. MAA production of bottom ice algae determined at 0 and $48 \mathrm{~h}$. Cultures were maintained at four PAR levels of $0,1,45$ or $100 \mu \mathrm{mol} \mathrm{m}^{-2} \mathrm{~s}^{-1}$ and at (a) $-1^{\circ} \mathrm{C}$, (b) $2^{\circ} \mathrm{C}$ and (c) $5^{\circ} \mathrm{C}$. Error bars indicate standard error.

\subsubsection{Higher temperature exposures}

\subsubsection{Quantum yield}

At $4^{\circ} \mathrm{C}$ (Fig. $2.4 \mathrm{a}$ ), $\phi$ PSII in algae incubated at $100 \mu \mathrm{mol} \mathrm{m}^{-2} \mathrm{~s}^{-1}$ reached zero after $24 \mathrm{~h}$. Given the form of the data obtained, and that all values for algae incubated at $100 \mu \mathrm{mol}$ $\mathrm{m}^{-2} \mathrm{~s}^{-1}$ were zero after $24 \mathrm{~h}$, it was not possible to analyse this response statistically. It was not possible to compute repeated measures ANOVA due to insufficient residual degrees of freedom. This limitation applies to all $\phi_{\text {PSII }}$ data obtained in these experiments. At $14^{\circ} \mathrm{C}$ (Fig. 2.4 b), $\phi_{\text {PSII }}$ in algae incubated at $1 \mu \mathrm{mol} \mathrm{m}^{-2} \mathrm{~s}^{-1}$ declined over $48 \mathrm{~h}$, whereas algae incubated at $45 \mu \mathrm{mol} \mathrm{m}^{-2} \mathrm{~s}^{-1}$ and $100 \mu \mathrm{mol} \mathrm{m}^{-2} \mathrm{~s}^{-1}$ reached zero after $4 \mathrm{~h}$. At $24^{\circ} \mathrm{C}$ (Fig. $2.4 \mathrm{c}$ ), $\phi$ PSII for algae at all PAR treatments reached zero after $6 \mathrm{~h}$. 
a)

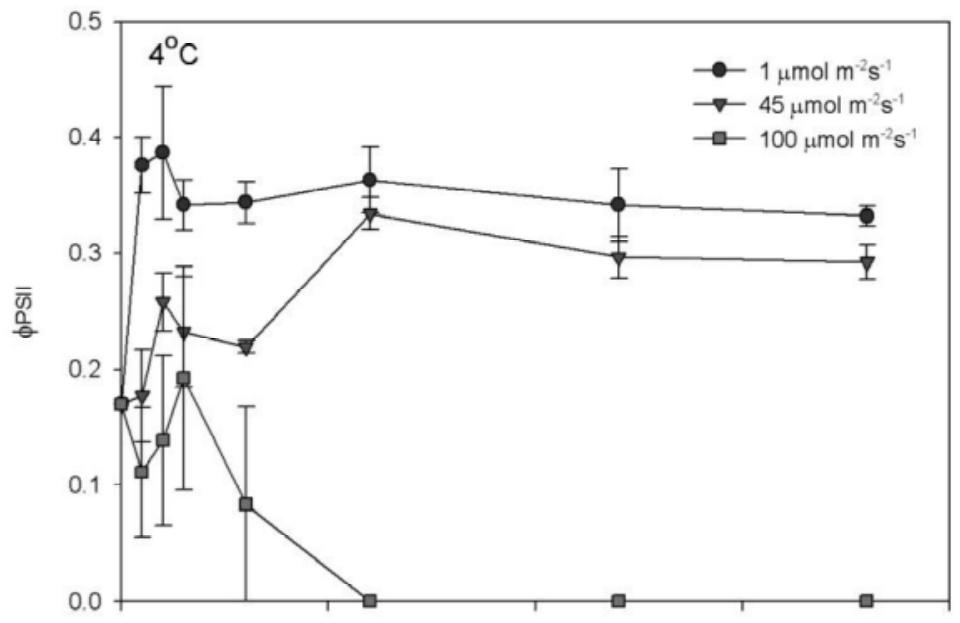

b)

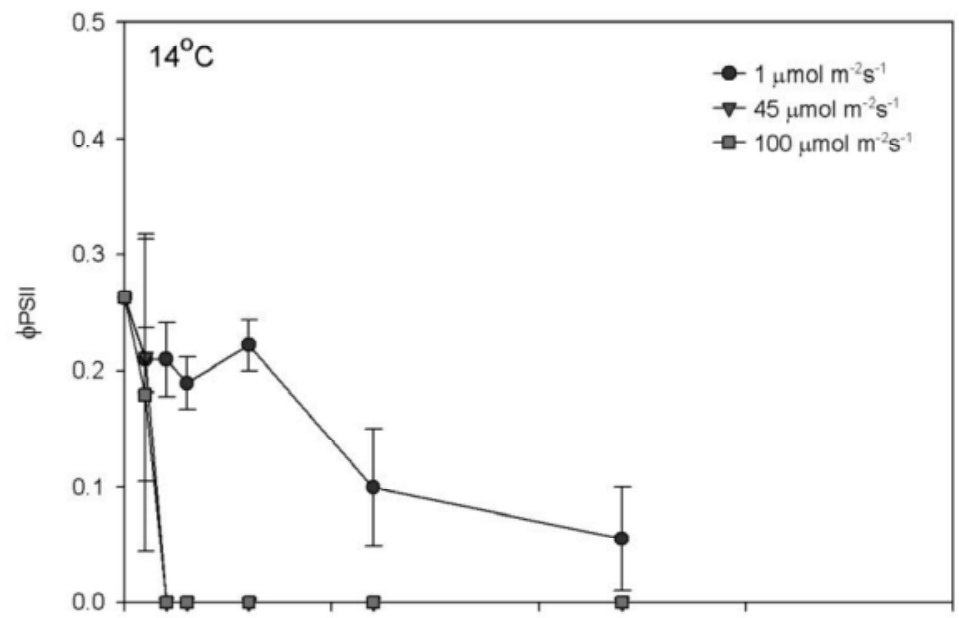

c)

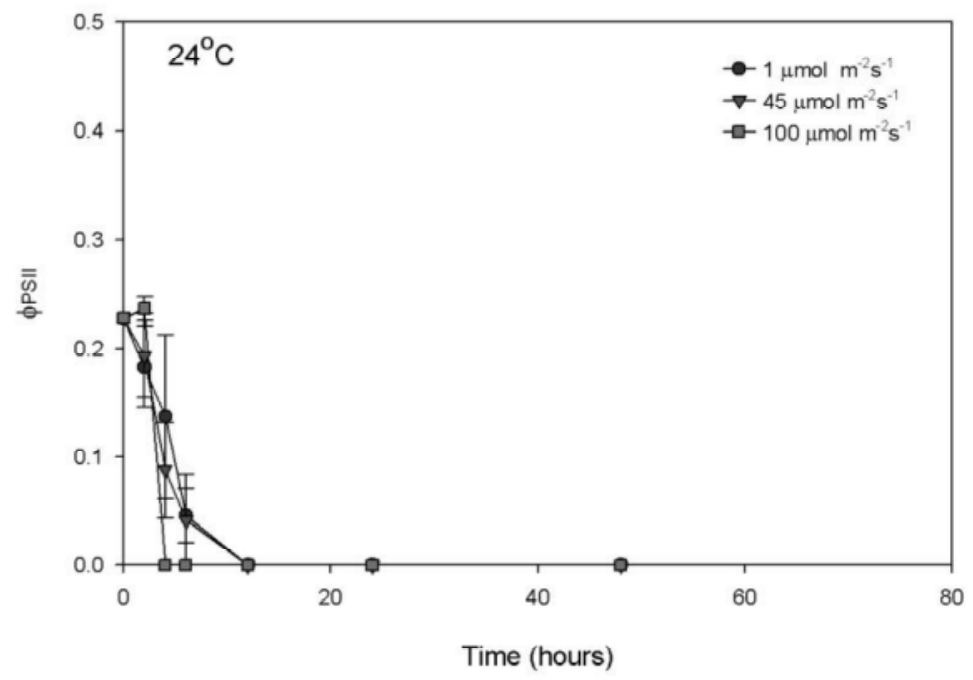

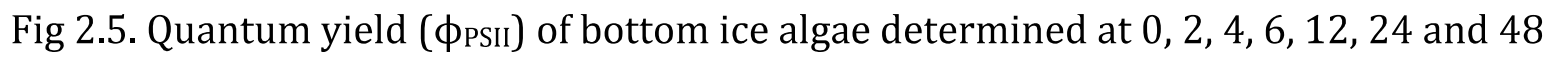
h. The incubation at $4^{\circ} \mathrm{C}$ ran for $72 \mathrm{~h}$. Cultures were maintained at three PAR levels of 1 , 45 or $100 \mu \mathrm{mol} \mathrm{m}^{-2} \mathrm{~s}^{-1}$ and at (a) $4^{\circ} \mathrm{C}$, (b) $14^{\circ} \mathrm{C}$ and (c) $24^{\circ} \mathrm{C}$. Error bars indicate standard error. 


\subsubsection{MAA production}

Initially a repeated measures ANOVA was conducted with time as the 'within' factor and both temperature and treatment as 'between' factors. This only showed significant effects of time $(\mathrm{p}<0.05)$ and temperature $(\mathrm{p}<0.05)$. All other interaction terms were not significant ( $p>0.05$ ) (Table A1.6, Appendix 1). Consequently repeated measures analyses were carried out for each temperature separately to test for the effect of all treatments and time (Table 2.5).

There were no significant changes in MAA production for algae incubated at 4 and $14^{\circ} \mathrm{C}$ (Fig. 2.5 (a), (b)). At $24^{\circ} \mathrm{C}$, algae incubated showed a slight increase in MAA production over 48 h. However, this increase was not statistically significant (Fig. 2.5 (c)). 
Table 2.5. Changes in MAA production over $48 \mathrm{~h}$ experimental treatments at different PAR levels $\left(1,45\right.$ and $\left.100 \mu \mathrm{mol} \mathrm{m}^{-2} \mathrm{~s}^{-1}\right)$ at $4^{\circ} \mathrm{C}, 14^{\circ} \mathrm{C}$ and $24^{\circ} \mathrm{C}$, analysed using repeated measures ANOVA. Significant changes identified by post hoc pairwise analyses are also listed. Only algae at $4^{\circ} \mathrm{C}$ were incubated over $72 \mathrm{~h}$.

\begin{tabular}{|llllll|}
\hline Source of variation & $\mathrm{df}$ & $\mathrm{MS}$ & $F$ & $\mathrm{p}$ & post hoc comparisons \\
\hline At $\mathbf{4}^{\circ} \mathrm{C}$ & & & & & \\
Within subjects & & & & & \\
Time & 2 & 0.015 & 3.646 & 0.058 & No significance \\
Time x Treatments & 4 & 0.001 & 0.132 & 0.967 & \\
Error & 12 & 0.004 & & & \\
Between subjects & & & & & \\
Treatments & 2 & 0.001 & 0.302 & 0.750 & No significance \\
Error & 6 & 0.004 & & & \\
& & & & & \\
At 14. ${ }^{\circ}$ C & & & & & \\
Within subjects & & & & & \\
Time & 1 & $1.857 \mathrm{E}-006$ & 0.002 & 0.964 & No significance \\
Time x Treatments & 2 & 0.001 & 0.646 & 0.557 & \\
Error & 6 & 0.001 & & & \\
Between subjects & & & & & \\
Treatments & 2 & 0.001 & 0.355 & 0.715 & No significance \\
Error & 6 & 0.002 & & & \\
At 24 ${ }^{\circ} \mathrm{C}$ & & & & & \\
Within subjects & & & & & \\
Time & 1 & 0.014 & 7.850 & 0.031 & Increase over 48 $\mathrm{h}$ \\
Time x Treatments & 2 & $9.500 \mathrm{E}-005$ & 0.053 & 0.949 & (see text below) \\
Error & 6 & 0.002 & & & \\
Between subjects & & & & & \\
Treatments & 2 & $9.500 \mathrm{E}-005$ & 0.047 & 0.954 & No significance \\
Error & 6 & 0.002 & & & \\
\hline
\end{tabular}


a)

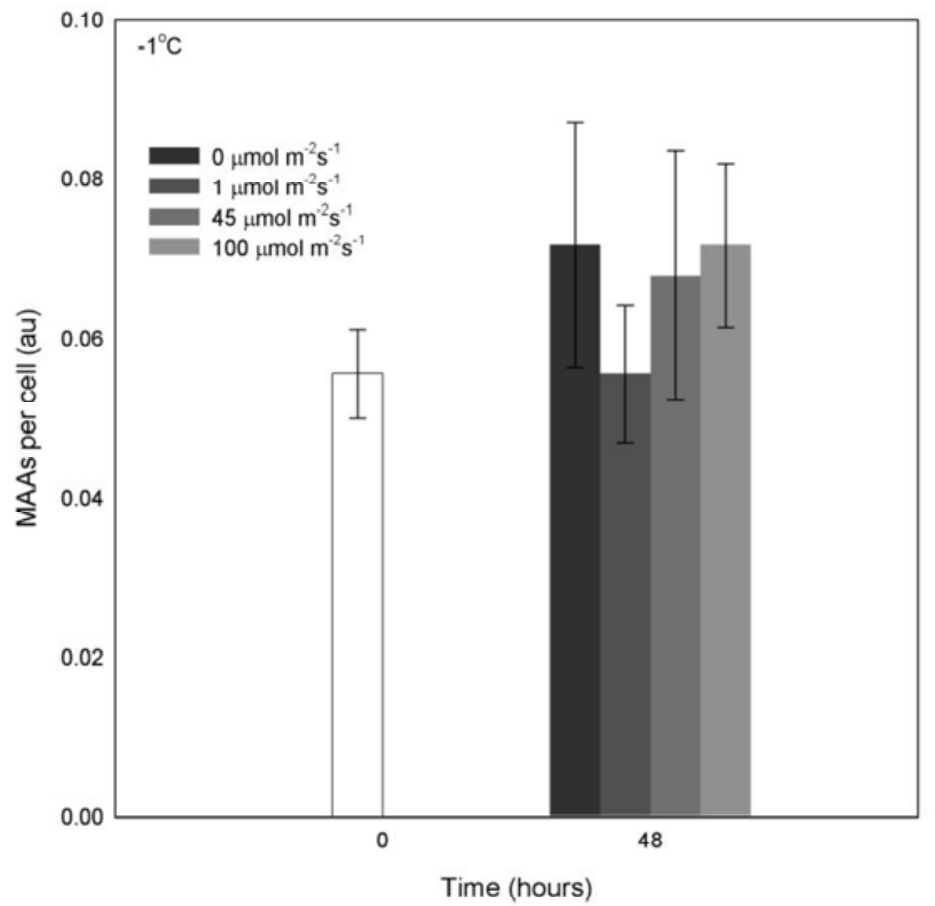

b)

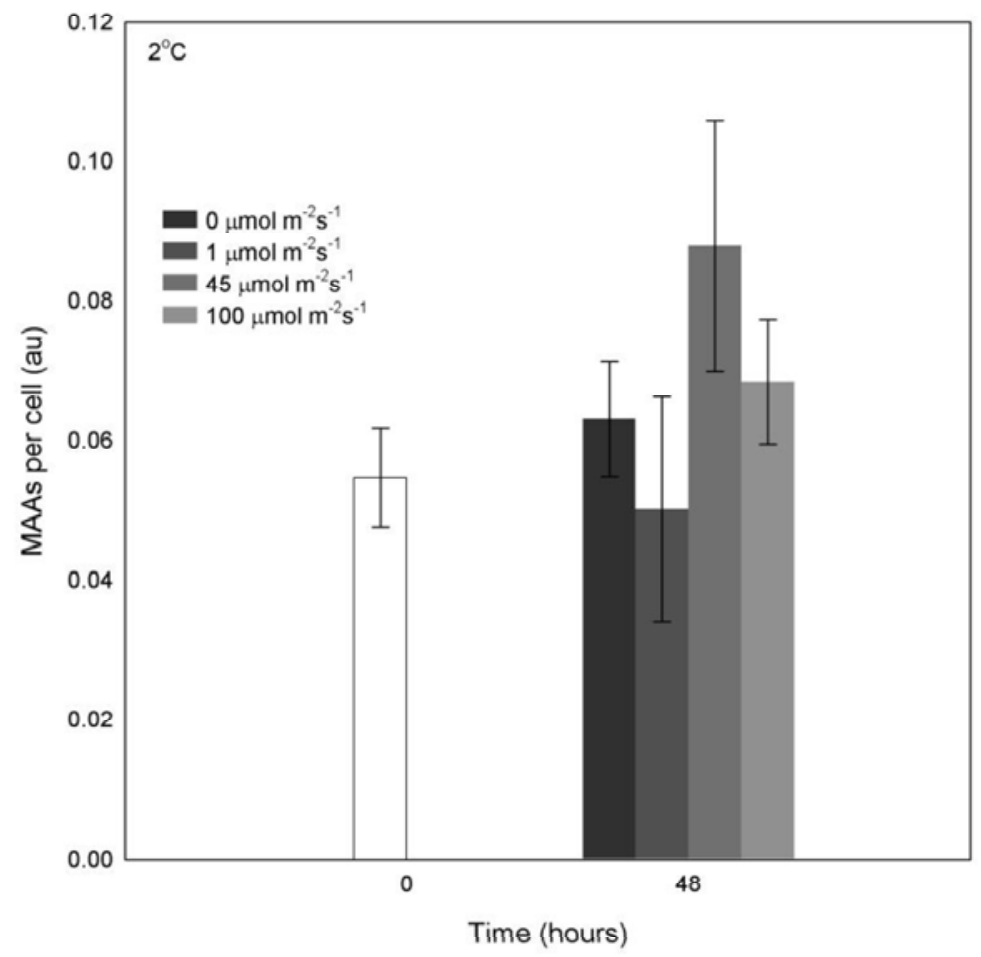


c)

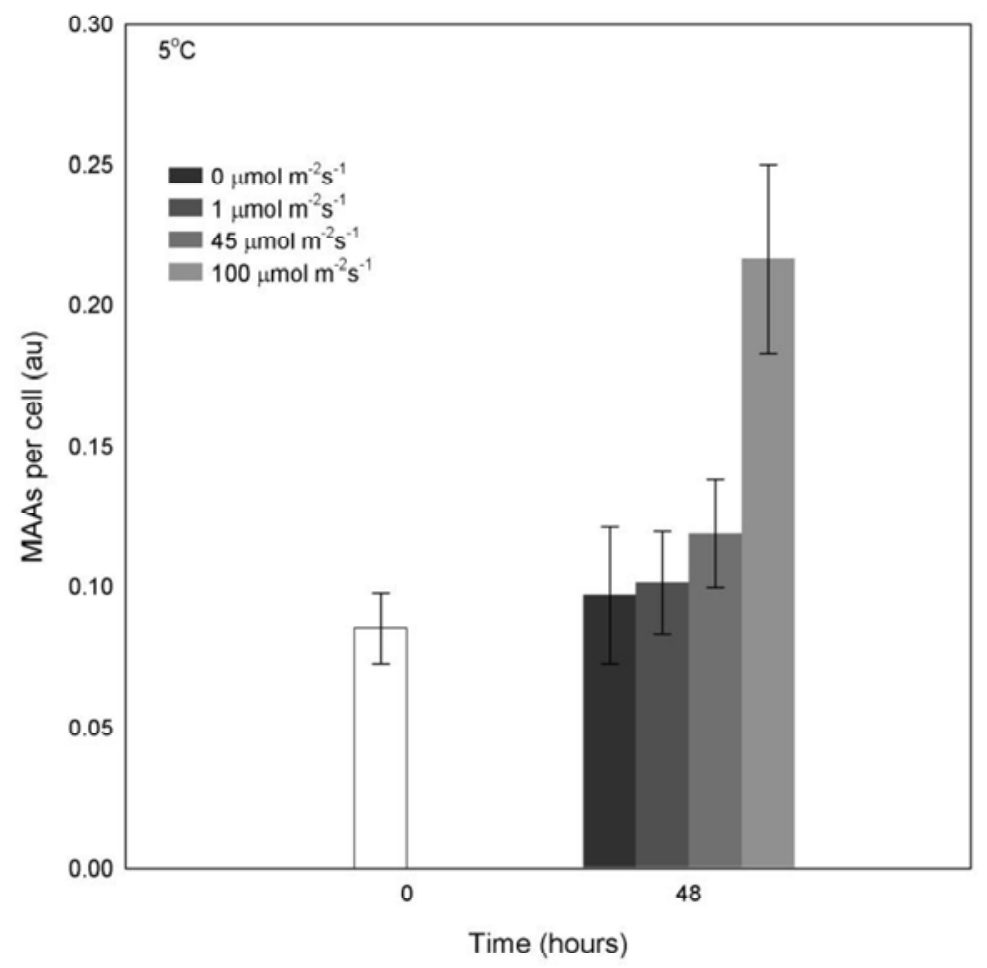

Fig 2.6. MAA production of bottom ice algae determined at 0 and $48 \mathrm{~h}$. The incubation at $4^{\circ} \mathrm{C}$ ran for $72 \mathrm{~h}$. Cultures were maintained at three PAR levels of $1,45,100 \mu \mathrm{mol} \mathrm{m}^{-2} \mathrm{~s}^{-1}$ and at (a) $4^{\circ} \mathrm{C}$, (b) $14^{\circ} \mathrm{C}$ and (c) $24^{\circ} \mathrm{C}$. Error bars indicate standard error.

\subsubsection{Thlyakoid integrity}

The response of $\mathrm{F}^{\prime}$ to increasing temperature (Fig. 2.7 (b)) was constant until $\sim 12^{\circ} \mathrm{C}$. This value then increased markedly at $\sim 14^{\circ} \mathrm{C}$, and reached a peak at $24^{\circ} \mathrm{C}$. Recording ceased at $48^{\circ} \mathrm{C}$ as there was no change in $\mathrm{F}^{\prime}$ for five consecutive readings. These data indicate that the temperature at which permanent damage to the thylakoid membrane is initiated (Tc) is $\sim 14^{\circ} \mathrm{C}$. As incubation temperature was slowly increased, $\phi_{\text {PSII }}$ declined with increasing temperature, with photosynthesis ceasing by $27^{\circ} \mathrm{C}$ (Fig. 2.7 (a)) (Tp). This temperature also corresponds to the maximum value of $F^{\prime}$ in Fig 2.7 (b). 
a)
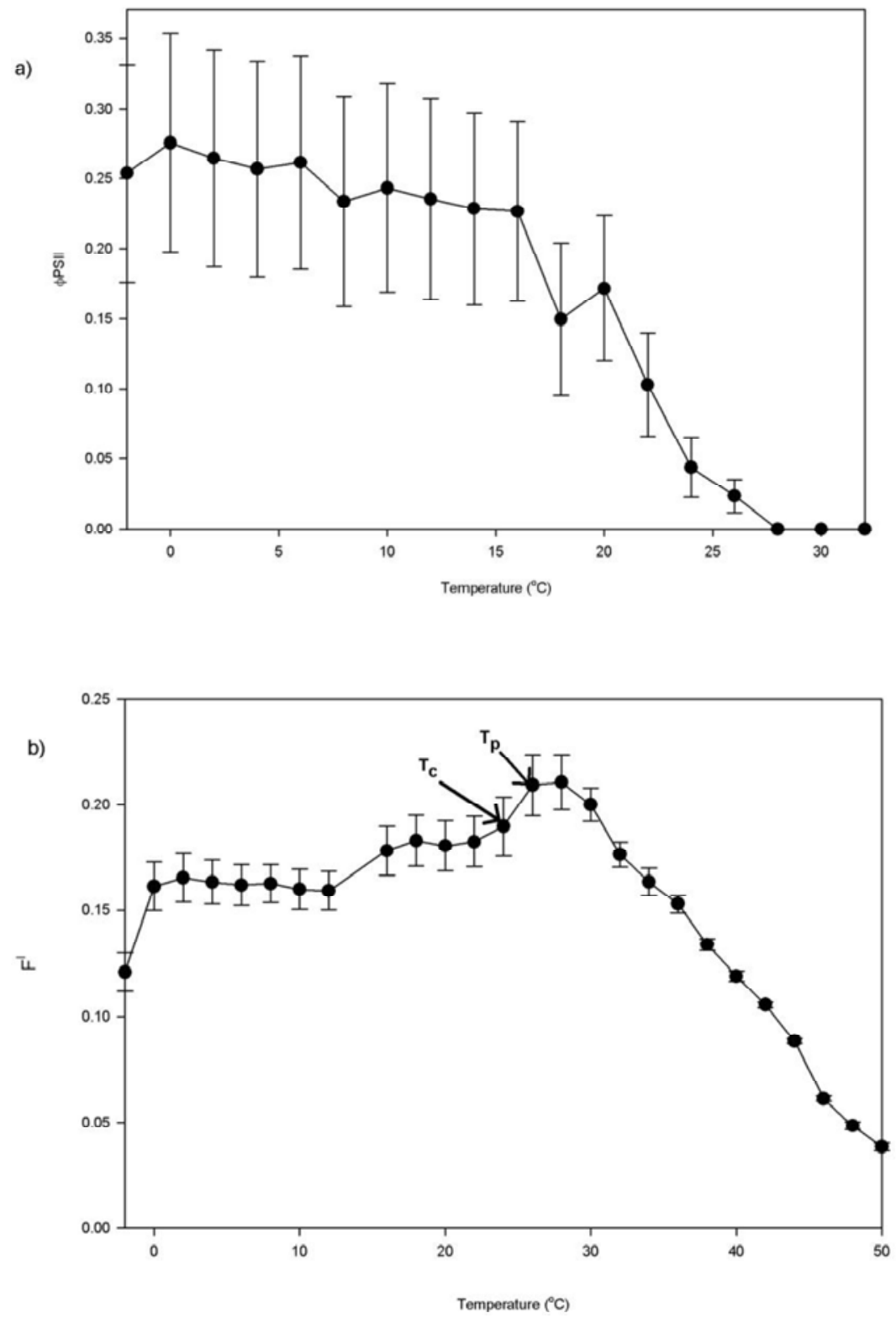

Fig. 2.7. Changes in photosynthetic parameters with increase in temperature. (a) Change in quantum yield. (b) Change in initial fluorescence. Tc is the critical temperature where permanent damage is initiated and there is irreversible reduction in maximum quantum yield, and $\mathrm{Tp}$ is the temperature at which there is complete loss of photosynthesis and maximum quantum yield becomes zero. 


\subsection{DISCUSSION}

Temperatures above zero and up to $5^{\circ} \mathrm{C}$ can be experienced by sea ice algae in shallow waters as well as in the open sea during summer in the Antarctic Peninsula region and northern zones of the Southern Ocean close to the Polar Front (Morley et al., 2010). The highest experimental PAR level of $100 \mu \mathrm{mol} \mathrm{m}^{-2} \mathrm{~s}^{-1}$ used here can be experienced during thinning and melting of sea ice, and therefore quantifying the ability of algae to withstand these conditions is ecologically relevant. Sea ice algae are generally photoinhibited by PAR of $20 \mu \mathrm{mol} \mathrm{m}^{-2} \mathrm{~s}^{-1}$, indicating potentially serious impacts on photosynthetic parameters over the short term during melting of sea ice (Ryan et al., 2011). At a PAR level of $1 \mu \mathrm{mol} \mathrm{m}{ }^{-2} \mathrm{~s}^{-1}$ (equivalent to ambient under-ice levels) in the present study (Figure 2.2(a)), the algae were able to maintain their $\phi_{\text {PsII }}$ throughout the duration of the incubation. Higher PAR did not cause a decrease in the $\phi_{\text {PSII, }}$ and suggests that these algae may survive the stresses of the melting of the sea ice and become part of the spring pelagic algal bloom (Ryan et al., 2011). These results extend the observations reported by Ryan et al. (2011), where quantum yield for bottom ice algae decreased over a $4 \mathrm{~h}$ incubation period during ice melt. Similarly here, quantum yield decreased over the first $4 \mathrm{~h}$ of the manipulation after which it recovered to reach levels similar to those at $0 \mathrm{~h}$. To test further the recovery potential identified in this study, measurements need to combine the process of melting of sea ice (cf. Ryan et al. 2011) and further extend observations over longer periods of time to investigate possible recovery.

At an ambient temperature of $-1^{\circ} \mathrm{C}$ (Figure $2.2(\mathrm{a})$ ), the algae used in this study showed no evidence of being stressed by exposure to PAR over a period of $48 \mathrm{~h}$, even at irradiances well above those experienced in their natural environment. At ambient PAR levels, increased temperatures resulted in lower фPSII (Figure 2.2 (b), (c)). However, as PAR levels were increased, higher temperature reduced the level of stress as indicated by $\phi$ PSII. This result suggests, for the first time in sea ice algal studies, that higher temperatures ameliorate the negative effects of increased PAR. Increasing PAR causes decreased quantum yield and increased photo-inhibition in sea ice algae in eastern Antarctica (Ralph et al., 2005). Compounding stressors such as higher PAR and temperature causing damage to PSII complexes could enhance photo-induced viability loss and reduce $\phi_{\text {PSII }}$ (Van de Poll et al., 2006). Similar compounding stressors are 
present in the current study, although temperature played a greater role in the decrease of $\phi_{\text {PSII }}$ than PAR.

Similar amelioration of the effects of increased UVR radiation by higher temperatures has also been observed in temperate diatoms (Halac et al., 2010a). It is likely that an increase in temperature could result in higher metabolic activity and hence a faster turnover in the D1 protein of the electron transport chain in PS II (Halac et al., (2010b), and this increased rate of recovery of PS II may suggest that any PAR stress associated with climate-change-induced earlier sea ice retreat could be of low impact.

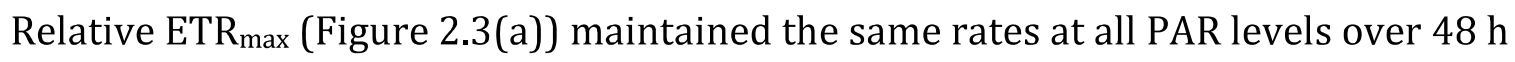
exposure at ambient temperatures, despite initial increases, meaning that the algae did not undergo significant photo-inactivation. As temperature was increased (Figure 2.3 (b), (c)), however, exposure to higher PAR levels resulted in higher rates of rETR max $_{\text {, }}$ which could again be due to faster turnover in the D1 protein. Even at the higher temperature of $5^{\circ} \mathrm{C}$ and high PAR of $100 \mu \mathrm{mol} \mathrm{m}^{-2} \mathrm{~s}^{-1}$ (Figure 2.2(c)), initial decreases in $\phi$ PSII were followed by recovery over a period of $48 \mathrm{~h}$. Previous studies of Antarctic bottom ice algal communities have also shown a high resilience to increased irradiance, as decreases in photosynthetic efficiency were rapidly reversed when the algae were returned to low PAR conditions (Petrou et al., 2011). The main mechanism involved in acclimation was hypothesized to be heat dissipation through activation of the xanthophyll cycle (Petrou et al., 2011). The data obtained here indicate that bottom ice algae may not be obligately shade-adapted as some studies have previously concluded (McMinn et al., 2003, 2007, Thomas \& Dieckmann, 2002), but have plasticity in tolerating changing irradiance.

Even with increasing temperatures (Figure 2.2(c)), the bottom ice algae acclimated to higher irradiances and showed recovery in $\phi_{\text {PSII }}$ after initial declines when exposed for a period of $48 \mathrm{~h}$. The current study indicates that bottom ice algae can acclimate to slower changes in irradiance such as would be experienced, for instance, during melting of sea ice. Previous studies have shown quantum yield declined in a dose-dependent manner in bottom ice algae when PAR was gradually increased (Ryan et al., 2009). Furthermore, when algae were suddenly exposed to the same high irradiances, $\phi_{\text {PSII }}$ dropped to the same values as seen in algae exposed to a gradual increase in irradiance, indicating that the previous exposure history did not influence the responses of bottom ice algae to high irradiances (Ryan et al., 2009). Photosynthetic efficiency and saturation irradiance 
did not show any significant responses (Table A1.4 and A1.5 in Appendix 1) when incubated at the range of temperatures and irradiances used to the test changes occurring during the melting of ice.

Manipulations involving a relatively small and ecologically realistic temperature range $\left(-1\right.$ to $5^{\circ} \mathrm{C}$, section 2.4 .2$)$ demonstrated significant changes in MAA production in algae incubated at $5^{\circ} \mathrm{C}$ under 45 and $100 \mu \mathrm{mol} \mathrm{m}^{-2} \mathrm{~s}^{-1}$ (Figure 2.4(c)). Concentration of MAAs per cell increased at higher PAR treatments, and were further enhanced at higher than ambient temperatures (Figure 2.4). These PAR and temperature levels are representative of conditions that algae could face around the Antarctic continent during and after melting of sea ice and in summer in parts of the Southern Ocean. This demonstrates for the first time in the marine environment that MAA production by algae can respond to PAR and temperature stress even in the absence of UV radiation. Previous studies (Aguilera et al., 2002, Helbling et al., 2011, Lesser \& Farrell, 2004) have examined the production of MAAs as a stress response to PAR exposure including UV radiation. MAAs are likely to be acting as photoprotective compounds, allowing the algae to maintain $\phi_{\text {PSII }}$, although this is yet to be formally confirmed. Some MAAs may also act as effective antioxidants and can scavenge reactive oxygen species created during UV-B exposure or when stressed by other factors (Gao \& Garcia-Pichel, 2011). As seen by the $\phi_{P S I I}$ response to larger-scale temperature manipulation (Fig. 2.5), temperature imposed a far greater level of stress than PAR. At lower temperatures, algae were capable of tolerating PAR of up to $45 \mu \mathrm{mol} \mathrm{m}{ }^{-2} \mathrm{~s}^{-1}$, but this tolerance rapidly decreased at higher temperatures. At $4^{\circ} \mathrm{C}$ (Fig. 2.5(a)), algae exposed to $100 \mu \mathrm{mol} \mathrm{m}^{-2} \mathrm{~s}^{-1}$ showed a rapid decline in quantum yield which contrasts with the response of algae from the incubation at $5^{\circ} \mathrm{C}$ at Terra Nova Bay (Section 2.4.3). This could again be due to a difference in the species composition of the algal communities present at both sites, and also to the thicker sea ice present at Granite Harbour. The thylakoid integrity data complement these findings, indicating that the photosynthetic apparatus of sea ice algae is able to tolerate increasing temperatures, at least over a relatively limited temperature range. The initial increase in F' (Figure 2.7a) observed with temperature is consistent with damage occurring at the reaction centre itself rather than within the electron transport chain (Ralph \& Gademann, 2005). At $27^{\circ} \mathrm{C}$, F' reached a maximum and other more damaging routes of energy dissipation may then come into play (Ralph et al., 2005). For instance, the production of free radicals may increase and non- 
photochemical quenching (NPQ) occur. At this point the reaction centre is no longer functioning (Ralph \& Gademann, 2005), and F' declines.

Data obtained in the current study showed that $\phi_{P S I I}$ decreased significantly with increasing PAR and temperature. At $14^{\circ} \mathrm{C}$ (Figure 2.5(b)), the algae performed poorly at high irradiances and showed a constant decline even at ambient irradiance. Exposure to $24^{\circ} \mathrm{C}$ (Figure 2.5(c)) was higher than the temperature that these algae were capable of tolerating, causing a stress response and a significant increase in MAA production. As temperature increased beyond currently realistic scenarios the susceptibility to higher PAR increased as indicated by decreasing $\phi_{P S I I}$. By the highest exposure temperature (Fig. 2.5(c)), when $\phi_{\text {PSII }}$ even at optimum PAR levels had deteriorated significantly, it was clear that temperature itself had become the main stressor.

The hypothesized change in the state of thylakoid membranes in the chloroplast, with irreparable damage occurring at $\sim 27^{\circ} \mathrm{C}$ (Fig. 2.7(a)), could be further verified using electron microscopy. These changes could indicate higher temperature tolerance of these algae than previously observed, as initial decreases in quantum yield could be reversed if there was no damage to the photosynthetic apparatus itself. The subsequent decline observed in photosynthetic ability most likely indicates the onset of other problems in maintaining organelle function, such as damage to the thylakoid membranes, which may in turn lead to an increase in antioxidant production to protect the algal cells from reactive oxygen species (Janknegt et al., 2008). To confirm this threshold temperature, attempts were made to analyse transmission electron microscopy sections for samples collected at temperatures where changes in fluorescence occurred (Appendix 1, Section A1.3). However, this work was not successful.

During sea ice melt, algae are exposed to increases in PAR and temperature. This study has demonstrated that the mixed algal community can tolerate higher PAR levels if temperature does not increase. Sea ice algae can acclimate to higher irradiances over periods of at least a week (Sobrino \& Neale, 2007). However, this has been seen in only a few individual species and cannot yet be generalized, while the community effect can vary greatly. In the current study, when the experimental temperature was increased, there was an increase in MAA production, which likely acts as a photoprotective compound (Helbling et al., 1996). Initial decreases in quantum yield at higher temperatures such as $5^{\circ} \mathrm{C}$ were followed by recovery, which supports the hypothesis 
that bottom ice algae are not shade-obligate species as previously thought (McMinn et al., 2003, 2007, Thomas \& Dieckmann, 2002) and are capable of acclimation (Petrou et al., 2011). Further work with longer incubations is required to clarify the time required for acclimation and to document recovery rates when the algae return to favourable conditions.

With increased ship traffic between the Southern Ocean and the temperate regions, there is a high likelihood for cross-contamination to occur (Baek et al., 2011, Lewis et al., 2003, Tin et al., 2009). This could lead to shifts in community structure in both areas, but more immediately in temperate areas due to discharged ballast water from the Antarctic. The algae studied here had decreased $\phi$ PSII even at ambient PAR at a temperature of $14^{\circ} \mathrm{C}$ and higher PAR levels at this temperature stressed them further. However, long-term acclimation is possible for some species (Sobrino \& Neale, 2007), which emphasises the need to study species-specific response to temperate conditions over long time periods. Based on these studies of fresh mixed-species natural communities, there is clearly a need to examine in more detail the species-specific responses to increasing PAR and temperature

\subsection{REFERENCES}

Aguilera, J., Bischof, K., Karsten, U., Hanelt, D., \& Wiencke, C. (2002). Seasonal variation in ecophysiological patterns in macroalgae from an Arctic fjord. II. Pigment accumulation and biochemical defence systems against high light stress. Marine Biology, 140, 1087-1095.

Arrigo, K. R., \& Sullivan, C. W. (1992). The influence of salinity and temperature covariation on the photophysiological characteristics of Antarctic sea ice microalgae. Journal of Phycology, 28, 746-756.

Arrigo, K. R., Worthen, D. L., Lizotte, M. P., Dixon, P., \& Dieckmann, G. (1997). Primary Production in Antarctic Sea Ice. Science, 276, 394-397.

Arrigo, K. R., \& Thomas, D. N. (2004). Large scale importance of sea ice biology in the Southern Ocean. Antarctic Science, 16, 471-486.

Arrigo, K. R. (2014). Sea Ice Ecosystems. Annual Review of Marine Science, 6, 439-467.

Atkinson, A., Siegel, V., Pakhomov, E., \& Rothery, P. (2004). Long-term decline in krill stock and increase in salps within the Southern Ocean. Nature, 432, 100-103.

Baek, S. H., Jung, S. W., \& Shin, K. (2011). Effects of temperature and salinity on growth of Thalassiosira pseudonana (Bacillariophyceae) isolated from ballast water. Journal of Freshwater Ecology, 26, 547-552.

Barnes, D. K. A., Hodgson, D. A., Convey, P., Allen, C. S., \& Clarke, A. (2006). Incursion and excursion of Antarctic biota: past, present and future. Global Ecology and Biogeography, 15, 121-142. 
Bilger, W., \& Schreiber, U. (1990). Chlorophyll luminescence as an indicator of stressinduced damage to the photosynthetic apparatus: Effects of heat-stress in isolated chloroplasts. Photosynthesis Research, 25, 161-171.

Bracegirdle, T. J., Connolley, W. M., \& Turner, J. (2008). Antarctic climate change over the twenty first century. Journal of Geophysical Research, 113, D03103.

Buxton, L., Takahashi, S., Hill, R., \& Ralph, P. (2012). Variability in the primary site of photosynthetic damage in Symbiodinium sp. (Dinophyceae) exposed to thermal stress. Journal of Phycology, 47, 117-126.

Claquin, P., Probert, I., Lefebvre, S., \& Veron, B. (2008). Effects of temperature on photosynthetic parameters and TEP production in eight species of marine microalgae. Aquatic Microbial Ecology, 51, 1-11.

Clark, G. F., Stark, J. S., Johnston, E. L., Runcie, J. W., Goldsworthy, P. M., Raymond, B., et al. (2013). Light-driven tipping points in polar ecosystems. Global Change Biology, 19, 3749-3761.

Comiso, J. C., Kwok, R., Martin, S., \& Gordon, A. L. (2011). Variability and trends in sea ice extent and ice production in the Ross Sea. Journal of Geophysical Research C: Oceans, 116.

Convey, P., Bindschadler, R., di Prisco, G., Fahrbach, E., Gutt, J., Hodgson, D. A., et al. (2009). Antarctic climate change and the environment. Antarctic Science, 21, 541-563.

Convey, P., Chown, S. L., Clarke, A., Barnes, D. K. A., Cummings, V., Ducklow, H., et al. (2014). The spatial structure of Antarctic Biodiversity. Ecological Monographs.

Davison, I. R. (1991). Environmental effects on algal photosynthesis: temperature. Journal of Phycology, 27, 2-8.

Dixon, D. A., Mayewski, P. A., Goodwin, I. D., Marshall, G. J., Freeman, R., Maasch, K. A., et al. (2012). An ice-core proxy for northerly air mass incursions into West Antarctica. International Journal of Climatology, 32, 1455-1465.

Dunlap, W. C., \& Chalker, B. E. (1986). Identification and quantitation of near-UV absorbing compounds (S-320) in a hermatypic scleractinian. Coral Reefs, 5, 155159.

Dunlap, W. C., \& Yamamoto, Y. (1995). Small-molecule antioxidants in marine organisms: antioxidant activity of mycosporine-glycine. Comparative Biochemistry and Physiology Part B: Biochemistry and Molecular Biology, 112, 105-114.

Falkowski, P. G., \& Owens, T. G. (1980). Light: shade Adaptation: two Strategies in marine phytoplankton. Plant Physiology, 66, 592-595.

Fitt, W. K., Brown, B. E., Warner, M. E., \& Dunne, R. P. (2001). Coral bleaching: interpretation of thermal tolerance limits and thermal thresholds in tropical corals. Coral Reefs, 20, 51-65.

Forcada, J., Trathan, P. N., Reid, K., Murphy, E. J., \& Croxall, J. P. (2006). Contrasting population changes in sympatric penguin species in association with climate warming. Global Change Biology, 12, 411-423.

Friedlingstein, P., Cox, P., Betts, R., Bopp, L., von Bloh, W., Brovkin, V., et al. (2006). Climate-Carbon Cycle Feedback Analysis: Results from the C4MIP Model Intercomparison. Journal of Climate, 19, 3337-3353.

Gao, Q., \& Garcia-Pichel, F. (2011). Microbial ultraviolet sunscreens. Nature Reviews Microbiology, 9, 791-802. 
Genty, B., Briantais, J.-M., \& Baker, N. R. (1989). The relationship between the quantum yield of photosynthetic electron transport and quenching of chlorophyll fluorescence. Biochimica et Biophysica Acta (BBA) - General Subjects, 990, 87-92.

Greenhouse, S. W., \& Geisser, S. (1959). On methods in the analysis of profile data. Psychometrika, 24, 95-112.

Halac, S. R., Villafañe, V. E., \& Helbling, E. W. (2010a). Temperature benefits the photosynthetic performance of the diatoms Chaetoceros gracilis and Thalassiosira weissflogii when exposed to UVR. Journal of Photochemistry and Photobiology B: Biology, 101, 196-205.

Halac, S. R., Villafañe, V. E., \& Helbling, E. W. (2010b). Temperature benefits the photosynthetic performance of the diatoms Chaetoceros gracilis and Thalassiosira weissflogii when exposed to UVR. Journal of Photochemistry and Photobiology B: Biology, 101, 196-205.

Hawes, I., Lund-Hansen, L. C., Sorrell, B. K., Nielsen, M. H., Borz $\sqrt{ }^{\circ}$ k, R., \& Buss, I. (2012). Photobiology of sea ice algae during initial spring growth in Kangerlussuaq, West Greenland: insights from imaging variable chlorophyll fluorescence of ice cores. Photosynthesis Research, 112, 103-115.

Helbling, E. W., Chalker, B. E., Dunlap, W. C., Holm-Hansen, O., \& Villafane, V. E. (1996). Photoacclimation of antarctic marine diatoms to solar ultraviolet radiation. Journal of Experimental Marine Biology and Ecology, 204, 85-101.

Helbling, E. W., Buma, A. G. J., Boelen, P., van der Strate, H. J., Valeria Fiorda Giordanino, M., \& Villafane, V. E. (2011). Increase in Rubisco activity and gene expression due to elevated temperature partially counteracts ultraviolet radiation-induced photoinhibition in the marine diatom Thalassiosira weissflogii. Limnology and Oceanography, 56, 1330-1342.

Hill, R., Schreiber, U., Gademann, R., Larkum, A. W. D., Kühl, M., \& Ralph, P. J. (2004). Spatial heterogeneity of photosynthesis and the effect of temperature-induced bleaching conditions in three species of corals. Marine Biology, 144, 633-640.

Hill, R., Ulstrup, K. E., \& Ralph, P. J. (2009). Temperature induced changes in thylakoid membrane thermostability of cultured, freshly isolated, and expelled zooxanthellae from Scleractinian corals. Bulletin of Marine Science, 85, 223-244.

Janknegt, P. J., van De Poll, W. H., Visser, R. J. W., Rijstenbil, J. W., \& Buma, A. G. J. (2008). Oxidative stress responses in the marine Antarctic diatom Chaetoceros brevis (Bacillariophyceae) during photoacclimation. Journal of Phycology, 44, 957-966.

Klisch, M., \& Hader, D.-P. (2008). Mycosporine-like amino acids and marine toxins- the common and the different. Marine Drugs, 6, 147-163.

Kühl, M., Glud, R. N., Borym, J., Roberts, R., \& Rysgaard, S. (2001). Photosynthetic performance of surface-associated algae below sea ice as measured with a pulseamplitude-modulated (PAM) fluorometer and 02 microsensors. Marine Ecology Progress Series, 223, 1-14.

Lazzara, L., Nardello, I., Ermanni, C., Mangoni, O., \& Saggiomo, V. (2007). Light environment and seasonal dynamics of microalgae in the annual sea ice at Terra Nova Bay, Ross Sea, Antarctica. Antarctic Science, 19, 83-92.

Lefebvre, W., \& Goosse, H. (2008). Analysis of the projected regional sea-ice changes in the Southern Ocean during the twenty-first century. Climate Dynamics, 30, 59-76.

Lesser, M. P., \& Farrell, J. H. (2004). Exposure to solar radiation increases damage to both host tissues and algal symbionts of corals during thermal stress. Coral Reefs, 23, 367-377. 
Lewis, P. N., Hewitt, C. L., Riddle, M., \& McMinn, A. (2003). Marine introductions in the Southern Ocean: an unrecognised hazard to biodiversity. Marine Pollution Bulletin, 46, 213-223.

Lizotte, M. P. (2001). The contributions of sea ice algae to Antarctic marine primary production. American Zoologist, 41, 57-73.

Martin, A., McMinn, A., Heath, M., Hegseth, E. N., \& Ryan, K. G. (2012). The physiological response to increased temperature in over-wintering sea ice algae and phytoplankton in McMurdo Sound, Antarctica and Tromso Sound, Norway. Journal of Experimental Marine Biology and Ecology, 428, 57-66.

Maxwell, K., \& Johnson, G. N. (2000). Chlorophyll fluorescence: A practical guide. Journal of Experimental Botany, 51, 659-668.

McMinn, A., Ryan, K., \& Gademann, R. (2003). Diurnal changes in photosynthesis of Antarctic fast ice algal communities determined by pulse amplitude modulation fluorometry. Marine Biology, 143, 359-367.

McMinn, A., Ryan, K. G., Ralph, P. J., \& Pankowski, A. (2007). Spring sea ice photosynthesis, primary productivity and biomass distribution in eastern Antarctica, 2002-2004. Marine Biology, 151, 985-995.

McMinn, A., Pankowskii, A., Ashworth, C., Bhagooli, R., Ralph, P., \& Ryan, K. (2010). In situ primary productivity and photosynthesis of Antarctic sea ice algal, phytoplankton and benthic algal communities. Marine Biology, 157, 1345-1356.

Mikkelsen, D. M., \& Witkowski, A. (2010). Melting sea ice for taxonomic analysis: a comparison of four melting procedures. Polar Research, 29, 451-454.

Montes-Hugo, M., Doney, S. C., Ducklow, H. W., Fraser, W., Martinson, D., Stammerjohn, S. E., et al. (2009). Recent changes in phytoplankton communities associated with rapid regional climate change along the Western Antarctic Peninsula. Science, 323, 1470-1473.

Morley, S. A., Griffiths, H. J., Barnes, D. K. A., \& Peck, L. S. (2010). South Georgia: a key location for linking physiological capacity to distributional changes in response to climate change. Antarctic Science, 22, 774-781.

Mou, S., Zhang, X., Ye, N., Miao, J., Cao, S., Xu, D., et al. (2013). Analysis of OEîpH and the xanthophyll cycle in NPQ of the Antarctic sea ice alga Chlamydomonas sp. ICE-L. Extremophiles, 17, 477-484.

Mundy, C., Gosselin, M., Ehn, J., Belzile, C., Poulin, M., Alou, E., et al. (2011). Characteristics of two distinct high-light acclimated algal communities during advanced stages of sea ice melt. Polar Biology, 34, 1869-1886.

Öquist, G. (1983). Effects of low temperature on photosynthesis. Plant, Cell \& Environment, 6, 281-300.

Oren, A. (1997). Mycosporine-like amino acids as osmotic solutes in a community of halophilic cyanobacteria. Geomicrobiology Journal, 14, 231-240.

Oren, A., \& Gunde-Cimerman, N. (2007). Mycosporines and mycosporine-like amino acids: UV protectants or multipurpose secondary metabolites? FEMS Microbiology Letters, 269, 1-10.

Palmisano, A. C., Beeler SooHoo, J., \& Sullivan, C. W. (1987). Effects of four environmental variables on photosynthesis-irradiance relationships in Antarctic sea-ice microalgae. Marine Biology, 94, 299-306.

Parkhill, J.-P., Maillet, G., \& Cullen, J. J. (2001). Fluorescence-based maximal quantum yield for PSII as a diagnostic of nutrient stress. Journal of Phycology, 37, 517-529. 
Peck, L. S., Convey, P., \& Barnes, D. K. A. (2006). Environmental constraints on life histories in Antarctic ecosystems: tempos, timings and predictability. Biological Reviews, 81, 75-109.

Petrou, K., Hill, R., Doblin, M. A., McMinn, A., Johnson, R., Wright, S. W., et al. (2011). Photoprotection of sea-ice microbial communities from the East Antarctic pack ice. Journal of Phycology, 47, 77-86.

Plattner, G. K., Knutti, R., Joos, F., Stocker, T. F., von Bloh, W., Brovkin, V., et al. (2008). Long-Term Climate Commitments Projected with Climate-Carbon Cycle Models. Journal of Climate, 21, 2721-2751.

Ralph, P. J., \& Gademann, R. (2005). Rapid light curves: A powerful tool to assess photosynthetic activity. Aquatic Botany, 82, 222-237.

Ralph, P. J., McMinn, A., Ryan, K. G., \& Ashworth, C. (2005). Short-term effect of temperature on the photokinetics of microalgae from the surface layers of Antarctic pack ice. Journal of Phycology, 41, 763-769.

Ralph, P. J., Ryan, K. G., Martin, A., \& Fenton, G. (2007). Melting out of sea ice causes greater photosynthetic stress in algae than freezing in. Journal of Phycology, 43, 948-956.

Ritchie, R. (2008). Fitting light saturation curves measured using modulated fluorometry. Photosynthesis Research, 96, 201-215.

Runcie, J. W., \& Riddle, M. J. (2006). Photosynthesis of marine macroalgae in ice-covered and ice-free environments in East Antarctica. European Journal of Phycology, 41, 223-233.

Ryan, K. G., McMinn, A., Mitchell, K. A., \& Trenerry, L. (2002). Mycosporine-like amino acids in Antarctic sea ice algae, and their response to UVB radiation. Zeitschrift fur Naturforschung, 57, 471-477.

Ryan, K. G., Ralph, P., \& McMinn, A. (2004). Acclimation of Antarctic bottom-ice algal communities to lowered salinities during melting. Polar Biology, 27, 679-686.

Ryan, K. G., Hegseth, E. N., Martin, A., Davy, S. K., O'Toole, R., Ralph, P. J., et al. (2006). Comparison of the microalgal community within fast ice at two sites along the Ross Sea coast, Antarctica. Antarctic Science, 18, 583-594.

Ryan, K. G., Cowie, R. O. M., Liggins, E., McNaughtan, D., Martin, A., \& Davy, S. K. (2009). The short-term effect of irradiance on the photosynthetic properties of antarctic fast-ice microalgal communities. Journal of Phycology, 45, 1290-1298.

Ryan, K. G., Tay, M. L., Martin, A., McMinn, A., \& Davy, S. K. (2011). Chlorophyll fluorescence imaging analysis of the responses of Antarctic bottom-ice algae to light and salinity during melting. Journal of Experimental Marine Biology and Ecology, 399, 156-161.

Ryan, K. G., McMinn, A., Hegseth, E. N., \& Davy, S. K. (2012). The Effects of Ultraviolet-B Radiation on Antarctic Sea-Ice Algae. Journal of Phycology, 48, 74-84.

Scheffer, M., Carpenter, S., Foloey, J. A., Folke, C., \& Walker, B. (2001). Catastrophic shifts in ecosystems. Nature, $413,591-596$.

Schloss, I. R., Abele, D., Moreau, S., Demers, S., Bers, A. V., Gonzalez, O., et al. (2012). Response of phytoplankton dynamics to 19-year (1991-2009) climate trends in Potter Cove (Antarctica). Journal of Marine Systems, 92, 53-66.

Scott, F. J., \& Marchant, H. J. (2005). Antarctic Marine Protists. Australia: CSIR0 Publishing.

Smetacek, V., \& Nicol, S. (2005). Polar ocean ecosystems in a changing world. Nature, 437, 362-368. 
Sobrino, C., \& Neale, P. J. (2007). Short-term and long-term effects of temperature on photosynthesis in the diatom Thalassiosira pseudonana under UVR exposures. Journal of Phycology, 43, 426-436.

Stammerjohn, S., Massom, R., Rind, D., \& Martinson, D. (2012). Regions of rapid sea ice change: An inter-hemispheric seasonal comparison. Geophysical Research Letters, 39.

Suzuki, K., Kudoh, S., \& Takahashi, M. (1995). Photosynthesis characteristics of ice algae with special emphasis on temperature and light conditions. Proceedings of the NIPR Symposium on Polar Biology, 8.

Tchernov, D., Gorbunov, M. Y., de Vargas, C., Narayan Yadav, S., Milligan, A. J., Häggblom, M., et al. (2004). Membrane lipids of symbiotic algae are diagnostic of sensitivity to thermal bleaching in corals. Proceedings of the National Academy of Sciences of the United States of America, 101, 13531.

Thomas, D. N., \& Dieckmann, G. S. (2002). Antarctic Sea Ice--a Habitat for Extremophiles. Science, 295, 641.

Tin, T., Fleming, Z. L., Hughes, K. A., Ainley, D. G., Convey, P., Moreno, C. A., et al. (2009). Impacts of local human activities on the Antarctic environment. Antarctic Science, 21, 3-33.

Trivelpiece, W. Z., Hinke, J. T., Miller, A. K., Reiss, C. S., Trivelpiece, S. G., \& Watters, G. M. (2011). Variability in krill biomass links harvesting and climate warming to penguin population changes in Antarctica. Proceedings of the National Academy of Sciences, 108, 7625-7628.

Turner, J., Comiso, J. C., Marshall, G. J., Lachlan-Cope, T. A., Bracegirdle, T., Maksym, T., et al. (2009). Non-annular atmospheric circulation change induced by stratospheric ozone depletion and its role in the recent increase of Antarctic sea ice extent. Geophysical Research Letters, 36, L08502.

Turner, J., Bracegirdle, T. J., Phillips, T., Marshall, G. J., \& Hosking, J. S. (2012). An Initial Assessment of Antarctic Sea Ice Extent in the CMIP5 Models. Journal of Climate, 26, 1473-1484.

Turner, J., Barrand, N. E., Bracegirdle, T. J., Convey, P., Hodgson, D. A., Jarvis, M., et al. (2013). Antarctic climate change and the environment: an update. Polar Record, FirstView, 1-23.

Van de Poll, W. H., Alderkamp, A. C., Janknegt, P. J., Roggeveld, J., \& Buma, A. G. J. (2006). Photoacclimation modulates excessive photosynthetically active and ultraviolet radiation effects in a temperate and an Antarctic marine diatom. Limnology and Oceanography, 51, 1239-1248.

Vincent, W. F. (1988). Microbial ecosystems of Antarctica. Cambridge: Cambridge University Press. 


\section{CHAPTER 3}

\section{Effects of increasing UV-B and temperature on bottom ice algae in the Ross sea}

\subsection{ABSTRACT}

Due to the formation of the springtime ozone hole over parts of Antarctica, there has been an increase over recent decades in the cumulative exposure of sea ice algae to UVB. This study assessed the impact of exposure to increasing temperature on a freshly collected bottom ice algal community incubated at ambient UV-B in order to test the hypothesis that more efficient or rapid repair due to increasing temperature negates the damage caused by UV-B. After an incubation of $48 \mathrm{~h}$, there was no decline on the photosynthetic yield of the algae at higher than ambient temperatures, which could be due to an increase in repair processes. I also examined the effect of increasing UV-B at $2{ }^{\circ} \mathrm{C}$ on algae in liquid suspension to observe the effect on photosynthetic yield. When UV-B was increased, there was no change in photosynthetic yield but, at this temperature, UV-B exposure triggered a significant increase in the production of photoprotective MAAs. These data contrast with previous studies, which have not shown MAA production in sea ice algae in response to UV-B. The evidence presented here indicates that higher temperatures can assist in alleviating the damaging effects of UV-B suggests that bottom ice communities could survive sea ice melt if they consist of species that produce MAAs in response to UV-B.

\subsection{INTRODUCTION}

Springtime depletion of stratospheric ozone over Antarctica has led to an increase in duration of damaging UV-B flux to the sea surface (Buckley \& Trodahl, 1987), resulting in a reduction in primary productivity and increased DNA damage to sea ice algae (Arrigo et al., 2003, Arrigo \& Thomas, 2004). Although the magnitude of this seasonal decrease in ozone has recently appeared to have stabilised, there are as yet no signs of the predicted recovery (Bodeker et al., 2005, Convey et al., 2009, Turner et al., 2013). Short wavelength, high energy, UV-B radiation inhibits photosynthesis in sea ice algae 
by decreasing the performance of the photosystems (Hernando et al., 2011, Schofield et al., 1995), through causing damage to many targets including the D1 protein complex within PSII (Franklin \& Forster, 1997). The inhibition happens to be largely due to the relative transparency of sea ice to UV-B at this time of the year and the inability of these organisms to avoid increased levels of incident radiation while in the ice (Ryan, 1992, Ryan \& Beaglehole, 1994, Ryan et al., 2002). Therefore, it is critical to study the protective mechanisms that could allow sea ice algae to survive increases in UV-B exposure.

When bottom ice algae are released into the water column during sea ice melt in the austral spring and summer, they can also experience photosynthetic stress through exposure to UV-B and higher and more variable temperatures (Ryan et al., 2012). These factors could be important in determining the productivity of the algal community, while different species may also vary in their response (Hannach \& Sigleo, 1998). Varying responses across species may also determine the proportion of sea ice algal biomass and the diversity that survives the melt to seed the pelagic algal bloom, and the proportion that subsequently seeds the following winter's ice community.

To protect themselves from UVR, sea ice algae produce mycosporine-like amino acids (MAAs) that act as sunscreen compounds (Mundy et al., 2011, Peinado et al., 2004, Ryan et al., 2002). HPLC analyses of sea ice samples from the Ross Sea region have shown the presence of MAAs such as porphyra-334, shinorine, mycosporine-glycine and palythine (Arrigo \& Thomas, 2004, Ryan et al., 2002). Very few studies have identified the production of MAAs by sea ice algae in response to other stressors such as irradiance (Hannach \& Sigleo, 1998, Helbling et al., 1996).

Under normal stratospheric ozone levels, 1 to $5 \%$ of incident UVR penetrates the sea ice to affect the bottom ice algal community (Karentz \& Bosch, 2001). During the spring period of ozone depletion, there is often a $>10 \%$ increase in exposure to UV-B wavelengths (290-320nm) (Karentz \& Bosch, 2001), but not higher wavelengths (Lubin et al., 1989), to levels comparable with those reaching the surface during mid-summer. UV-B levels of 4 to $300 \mathrm{mWm}^{-2}$ have been recorded in different habitats around the earth (Hannach \& Sigleo, 1998, Hessen et al., 2012, Wahl et al., 2004). If global climatic change trends continue and Antarctic sea ice starts to recede and melt earlier, ice algal productivity could therefore be severely reduced by this earlier exposure to UV-B, with 
negative implications for the entire ecosystem (Arrigo \& Thomas, 2004). In Arrigo and Thomas's 100 -year scenario, if sea ice cover was reduced by $50 \%$, the Southern Ocean is then assumed to be ice-free for 3 months of the year. The most recent IPCC AR5 climate models indicate that there will be a nearly ice-free state around Antarctica in February within the next century (http://www.ipcc.ch/report/ar5/wg1/\#.UuhKY2SBoYI). The strongest trends in sea ice change are currently seen in the Antarctic Peninsula region, where there is a later advance of sea ice in early winter resulting in a shorter period within which ice can thicken, contributing to thinner sea ice and earlier retreat in spring (Stammerjohn et al., 2008). As sea ice melts earlier, sea ice algae are also exposed to UVB for longer periods of time. Under such UV-B exposure, ice algal productivity decreases by $6-12 \%$ (Ryan \& Beaglehole, 1994). However, even though there is only a $6-12 \%$ drop in productivity, an approximately $40 \%$ decline in the standing crop has also observed (McMinn et al., 1999). There are also changes in species successional patterns that depend on amount of snow cover over the ice and initial community species composition (McMinn et al., 1999).

Exposure to UVR has various detrimental effects on marine phytoplankton, with different groups varying in their tolerance to UV-A and/or UV-B (Döhler et al., 1997, Helbling et al., 1996, Karentz, 1994, Martínez, 2007, Wahl et al., 2004). As some diatoms are more tolerant to UV-B, exposure to higher levels or cumulatively greater loads may lead to communities dominated by diatoms over other groups of phytoplankton (Häder et al., 2003). In a mixed algal community subjected to different photosynthetically active radiation (PAR) treatments, photosynthesis was initially inhibited by UV-B but the community then effectively acclimated by undergoing a shift in species composition to those that were tolerant to UV-B (Hernando et al., 2011). This involved a change from a phytoflagellate-dominated community to one with a relatively higher proportion of diatoms.

Ryan et al. (2002) found that sea ice diatoms contained concentrations of MAAs that were more than an order of magnitude lower than phytoplankton in the water column. The authors suggest that sea ice diatoms have a lower UV-B absorptive capacity, or could also imply that MAAs may play only a minor role in UV protection in these algae. However, despite this, the algae grew well under enhanced UV-B levels and showed no detectable reduction in their viability. It is possible that UV-B protection in sea ice algae 
acts at a community level rather than at a cellular level, with the algae closest to the upper surface of ice bearing the highest burden of UV protection for all the algae in the ice (Ryan et al., 2002). Ryan et al., (2002) further studied the development of the algal community over time and found that the net concentration of MAAs per cell were reduced even though the initial concentrations were relatively high. Even though the algal layer grew tenfold in thickness, the concentration of MAAs per unit area did not alter during the period of the study, supporting the hypothesis that the uppermost layers of cells were protecting the entire community (Ryan et al., 2002).

Ryan et al. (2012) studied the effect of varying levels of UVR on bottom ice algae under snow-free ice and concluded that increasing levels of UV-B radiation would have a minimal effect on the members of these communities while still in the ice matrix. There were no significant differences in Chl-a concentrations between algae exposed to ecologically relevant levels of UV-B and those that were exposed to ambient PAR or ambient PAR with UV-B, suggesting that the UV-B did not have a significant effect on undisturbed micro-algal assemblages. This result is in contrast to previous studies (Ryan et al., 2002) where natural snow cover was removed and the algae were exposed to PAR and UV-B levels three times the normal level; here the increased UV-B exposure led to a significant decrease in photosynthetic yield. Algae that were acclimated to a low UV-B environment under snow cover and then suddenly exposed to higher levels were unable to respond effectively.

There was however a highly significant effect of UV-B on bottom ice algae in liquid suspension, with quantum yield approaching zero after an exposure of $2 \mathrm{~h}$ to a UVR level $24 \%$ of that at the surface of the sea ice (Ryan et al., 2002). This could indicate that the thinning of sea ice will have a significant effect on the exposure and impact on bottom ice algae before sea ice is completely lost. If sea ice melts earlier in the summer, this therefore could result in exposure to higher UVR doses than algae are capable of withstanding, and lead to lower biomass remaining viable to seed the algal bloom. As sea ice melts and algae are released into the water column, they are then exposed to higher temperatures and PAR. Sudden changes in irradiance and temperature may occur if algal cells are trapped in a very shallow upper mixed layer (Halac et al., 2010). In Chapter 2, clear trends were identified with quantum yield decreasing with increasing temperature and PAR exposure. With increasing temperature, the tolerance 
of exposure to higher PAR levels also decreased. At an ambient temperature of $-1^{\circ} \mathrm{C}$, the algae were not stressed by exposure to PAR, even at levels well above those experienced in their natural environment. These PAR and temperature levels were representative of conditions that algae could face around the Antarctic continent during melting of sea ice and in summer in the Southern Ocean. In a further experiment to test their response over a broad range of temperatures, at the higher exposure temperatures of $14^{\circ} \mathrm{C}$ and $24^{\circ} \mathrm{C}$ algal photosynthetic yield deteriorated significantly even at ideal PAR levels, clearly indicating that temperature itself had become the main stressor. These higher temperatures were used to examine the possible impact of more extreme climate change scenarios and also to explore the implications of humanmediated introductions of Antarctic algae into temperate waters through shipping routes (see Chapter 2).

Sobrino and Neale (2007) studied the effect of elevated temperatures on short and long-term responses in sea ice algae under UVR exposure. They showed that short-term increases in temperature decrease photoinhibition caused by UVR exposure, demonstrating the importance of including recognition of temperature in studies of UVR effects. However, they did not study the effect of increasing UV-B levels at a higher than ambient temperature or examine if MAA production influenced photosynthetic yield. The effects of temperature and UV-B radiation in combination have been studied in zooplankton, where elevated temperatures increased UV-B tolerance in species that depended on photoenzymatic repair but decreased it in species that had lower capacity for repair (Williamson et al., 2002). Increasing temperatures might aid the algae in a similar manner, by accelerating repair and decreasing the detrimental effects of UVR, but this requires further investigation.

In this study, I examine the effect on bottom ice algae of exposure to a range of temperatures from $-1^{\circ} \mathrm{C}$ to $+5^{\circ} \mathrm{C}$ at ambient UV-B levels. These temperatures represent a range of possible long-term changes in temperature that sea ice algae could face under current scenarios, as discussed in Chapter 2. I also test the hypothesis that increasing temperatures could provide sea ice algae with increased opportunity for photoenzymatic repair and result in a lack of change in photosynthetic yield. I further examine the effect of exposure to higher but ecologically relevant UV-B levels (Ryan et 
al., 2012), from $5 \mathrm{mWm}^{-2}$ to $100 \mathrm{mWm}^{-2}$, on algae under temperatures that they face during sea ice melt.

\subsection{METHODS}

\subsubsection{Study Location}

A mixed bottom ice algal community was collected from sea ice (at Cape Evans, Antarctica ( $77^{\circ} 38^{\prime} \mathrm{S} 166^{\circ} 24^{\prime} \mathrm{E}$ ) during November 2010, as described in Section 2.3.3.

\subsubsection{Culture methodology}

Fifty ml sub-samples of melted bottom ice samples ( $n=5$ cores for each UV-B level) were incubated under $5 \mathrm{~mW} \mathrm{~m}^{-2} \mathrm{UV}-\mathrm{B}$ and $1 \mu \mathrm{mol} \mathrm{m} \mathrm{m}^{-2} \mathrm{~s}^{-1}$ PAR using a Philips Ultraviolet-B TL 12/40W tube and 5W LED lights (Greenlights, Taiwan), and at $0 \mu \mathrm{mol} \mathrm{m}^{-2} \mathrm{~s}^{-1}$. This incubation was repeated at $-1^{\circ} \mathrm{C},+2^{\circ} \mathrm{C}$ or $+5^{\circ} \mathrm{C}$ for $48 \mathrm{~h}$. Fifty $\mathrm{ml}$ sub-samples of melted bottom ice samples ( $n=5$ cores for each UV-B level) were also incubated at $+2^{\circ} \mathrm{C}$ for two higher levels of UV-B: $50 \mathrm{~mW} \mathrm{~m}^{-2}$ and $100 \mathrm{~mW} \mathrm{~m}^{-2}$. Both treatments were incubated separately with an ambient PAR of $1 \mu \mathrm{mol} \mathrm{m} \mathrm{m}^{-2} \mathrm{~s}^{-1}$ and a control kept at $0 \mu \mathrm{mol} \mathrm{m}^{-2} \mathrm{~s}^{-1}$. The number of treatments (Table 3.1) that could be applied was driven by logistic and time practicalities at the study location.

The experimental increases in UV-B level represent an additional 0.4 to $8 \%$ of the typical UV-B level experienced at the surface of the sea ice as measured in successive seasons (Ryan et al., 2012) and, hence, are ecologically plausible in the context of changes known to be associated with ozone hole exposure.

Table 3.1. Treatments used in experiments at Cape Evans, November 2010

\begin{tabular}{|l|l|}
\hline Temperature $\left.{ }^{\circ} \mathrm{C}\right)$ & UV-B treatments \\
\hline$-1^{\circ} \mathrm{C}$ & $5 \mathrm{~mW} \mathrm{~m}^{-2}$ and $1 \mu \mathrm{mol} \mathrm{m}^{-2} \mathrm{~s}^{-1}$ \\
\hline$+2^{\circ} \mathrm{C}$ & $5 \mathrm{~mW} \mathrm{~m}^{-2}, 50 \mathrm{~mW} \mathrm{~m}^{-2}, 100 \mathrm{~mW} \mathrm{~m}^{-2} ;$ each with $1 \mu \mathrm{mol} \mathrm{m}^{-2} \mathrm{~s}^{-1}$ \\
\hline$+5^{\circ} \mathrm{C}$ & $5 \mathrm{~mW} \mathrm{~m}^{-2}$ and $1 \mu \mathrm{mol} \mathrm{m} \mathrm{m}^{-2} \mathrm{~s}^{-1}$ \\
\hline
\end{tabular}


In all cultures in Section 2.4.2, there were no significant differences between any of the photosynthetic parameters of algae maintained at $0 \mu \mathrm{mol} \mathrm{m}^{-2} \mathrm{~s}^{-1}$ and at $1 \mu \mathrm{mol} \mathrm{m} \mathrm{m}^{-2} \mathrm{~s}^{-1}$. The control for the UV-B treatments used here was therefore the dark treatment (see also Chapter 5, Section 5.5). While the use of dark treatment as the control in this study has unfortunately limited the interpretation of the data obtained; it does still permit a comparison of low and high UV-B treatments.

PAR levels were measured using a SpectroSense 2 meter with a SKR 1850 radiometer (bandwith $400-1050 \mathrm{~nm}$ ) and a SKU 430 broad band UV-B radiometer (bandwidth 280 - $315 \mathrm{~nm}$ ) (Skye Instruments, UK). Values of $\sim 1300 \mathrm{~mW} \mathrm{~m}^{-2}$ at the surface and 1 $\mathrm{mW} \mathrm{m}{ }^{-2}$ at the bottom of the ice core were obtained at Cape Evans (Table 3.2). The water bath (Section 2.3.4) exposed to the UV-B lamp was separated into two sections with a black plastic sheet that allowed two different levels of UV-B to be applied to different cultures in parallel. The UV-B lamp (Philips Ultraviolet-B TL 12/40W tube) was covered with a polyvinyl chloride (PVC) sheet that acted as a UV-C filter. This lamp had a maximum emission at $270 \mathrm{~nm}$. The two halves of the fluorescent tube were covered with the appropriate shade cloth to achieve the required UV-B levels, which were verified with the SKU 430 radiometer.

\subsubsection{Sub-sampling, PAM fluorometry and statistical analyses}

Sub-sampling, PAM fluorometry and MAA analysis protocols are described in Section 2.3.5. Light curves were recorded using a water PAM (Walz, Effeltrich, Germany) at time $0,2,4,6,12,24$ and $48 \mathrm{~h}$. MAA samples were collected at 0 and $48 \mathrm{~h}$. Statistical analyses were performed as described in Section 2.3.6 and all differences referred to are statistically significant at $\mathrm{p}<0.05$.

\subsection{RESULTS}

\subsubsection{Field parameters and taxonomic composition}

There was negligible snow cover on the ice during the period of study and this was consistent with observations from previous seasons (Ryan, pers comm.). Environmental parameters and community taxonomic composition are summarised in Table 3.2. 
Table 3.2. Field parameters and dominant algal taxa present.

\begin{tabular}{|c|c|c|}
\hline \multicolumn{3}{|c|}{ Cape Evans Nov 2010} \\
\hline \multirow[t]{2}{*}{ Sea ice thickness } & \multicolumn{2}{|l|}{$1.9 \mathrm{~m}$} \\
\hline & UV-B level $\left(\mathrm{mW} \mathrm{m}^{-2}\right)$ & PAR level $\left(\mu E \mathrm{~m}^{-2} \mathbf{s}^{-1}\right)$ \\
\hline Bottom of sea ice & 1 & $1-10$ \\
\hline Surface of sea ice & 1300 & 1300 \\
\hline Dominant species & \multicolumn{2}{|c|}{$\begin{array}{l}\text { Nitzschia stellata; Navicula sp.; Fragilariopsis sp.; } \\
\text { Berkeleya sp. }\end{array}$} \\
\hline
\end{tabular}

\subsubsection{Cape Evans 2010}

\subsubsection{Exposure to UV-B level of $5 \mathrm{~mW} \mathrm{~m}^{-2}$ at three temperatures}

\subsection{Quantum Yield ( $\phi$ PSII)}

Initially a repeated measures ANOVA was conducted with time as a 'within' factor and temperature and treatment as 'between' factors. This showed significant effects of time $(p<0.001)$ and time by temperature $(p<0.001)$, but the interactions between time and treatment $(\mathrm{p}=0.533)$ and the three-way interaction between time, temperature and treatment ( $\mathrm{p}=0.845$ ) were not significant. (see Table A2.1, Appendix 2). To be consistent with other chapters, a 2-way repeated measures analyses was carried out for each exposure treatment separately to test for the effects of all treatments and time.

At $-1^{\circ} \mathrm{C}$ (Fig. $3.1 \mathrm{a}$ ), there was no change in $\phi$ Psil over the time points between 0 and $48 \mathrm{~h}$ in both exposure treatments. At $2^{\circ} \mathrm{C}$ (Fig. 3.1 b), there was a significant increase (Bonferroni, $\mathrm{p}=0.002$ ) in $\phi$ PSII for algae between 2 and $4 \mathrm{~h}$ resulting in an overall significant increase over $48 \mathrm{~h}$ (Bonferroni, $\mathrm{p}=0.045$ ). However there was no significant difference between the two treatments. At $5^{\circ} \mathrm{C}$ (Fig. $3.1 \mathrm{c}$ ), there was no change in $\phi_{\text {PSII }}$ between 0 and $48 \mathrm{~h}$ in both exposure treatments. 
Table 3.3. Changes in quantum yield of photosystem II over $48 \mathrm{~h}$ experimental treatments at one UV-B level of $5 \mathrm{~mW} \mathrm{~m}^{-2}$ and $1 \mu \mathrm{mol} \mathrm{m}{ }^{-2} \mathrm{~s}^{-1}$ or at $0 \mu \mathrm{mol} \mathrm{m}^{-2} \mathrm{~s}^{-1}$ at $-1^{\circ} \mathrm{C}$, $2^{\circ} \mathrm{C}$ and $5^{\circ} \mathrm{C}$, analysed using repeated measures ANOVA. Significant changes identified by post hoc pairwise analyses are also listed.

(a) Effect of UV-B on $\phi$ PSII at different temperatures:

\begin{tabular}{|c|c|c|c|c|c|}
\hline Source of variation & $\mathrm{df}$ & MS & $F$ & $\mathrm{p}$ & post hoc comparisons \\
\hline \multicolumn{6}{|l|}{$\begin{array}{l}\text { At }-1^{\circ} \mathrm{C} \\
\text { Within subjects }\end{array}$} \\
\hline Time & 6 & 0.009 & 3.982 & 0.003 & \multirow{3}{*}{$\begin{array}{l}\text { No change over } 48 \mathrm{~h} \\
\text { (see text below) }\end{array}$} \\
\hline Time $\mathrm{x}$ Treatments & 6 & 0.001 & 0.593 & 0.735 & \\
\hline Error & 48 & 0.002 & & & \\
\hline \multicolumn{6}{|l|}{ Between subjects } \\
\hline Treatments & 1 & 0.002 & 0.083 & 0.781 & \multirow[t]{2}{*}{ No significance } \\
\hline Error & 8 & 0.022 & & & \\
\hline \multicolumn{6}{|l|}{ At $2^{\circ} \mathrm{C}$} \\
\hline Within subjects & & & & & \multirow{4}{*}{$\begin{array}{l}\text { Increase over } 48 \mathrm{~h} \\
\text { (see text below) }\end{array}$} \\
\hline Time & 6 & 0.033 & 7.897 & $<0.001$ & \\
\hline Time $x$ Treatments & 6 & 0.002 & 0.455 & 0.838 & \\
\hline Error & 48 & 0.004 & & & \\
\hline \multicolumn{6}{|l|}{ Between subjects } \\
\hline Treatments & 1 & 0.042 & 1.410 & 0.269 & \multirow[t]{2}{*}{ No significance } \\
\hline Error & 8 & 0.030 & & & \\
\hline \multicolumn{6}{|l|}{ At $5^{\circ} \mathrm{C}$} \\
\hline Within subjects & & & & & \multirow{4}{*}{$\begin{array}{l}\text { No change over } 48 \mathrm{~h} \\
\text { (see text below) }\end{array}$} \\
\hline Time & 6 & 0.007 & 3.135 & 0.011 & \\
\hline Time $x$ Treatments & 6 & 0.003 & 1.152 & 0.347 & \\
\hline Error & 48 & 0.002 & & & \\
\hline \multicolumn{6}{|l|}{ Between subjects } \\
\hline Treatments & 1 & 0.121 & 4.172 & 0.075 & No significance \\
\hline Error & 8 & 0.029 & & & \\
\hline
\end{tabular}


a)

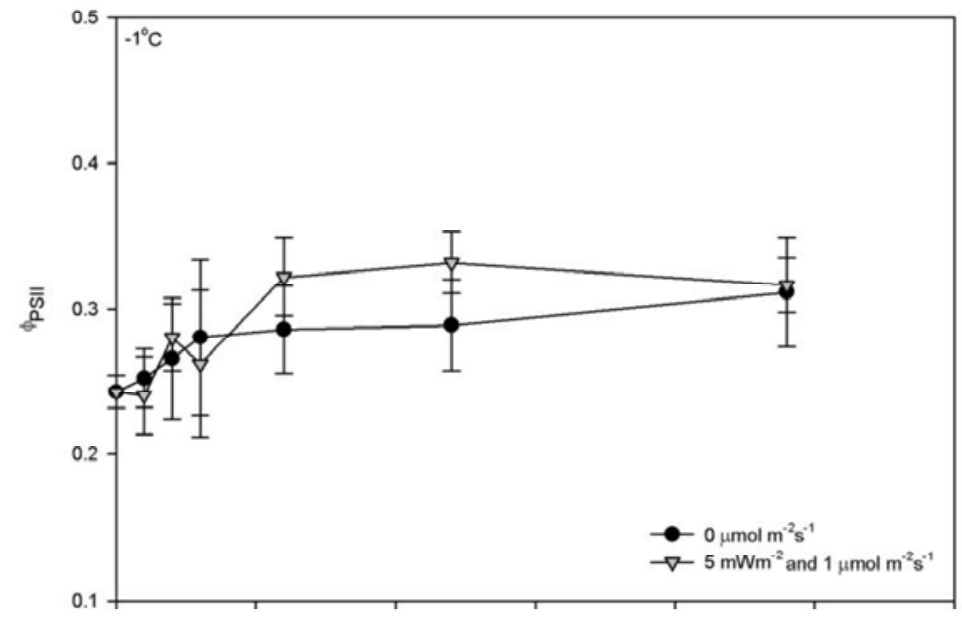

b)

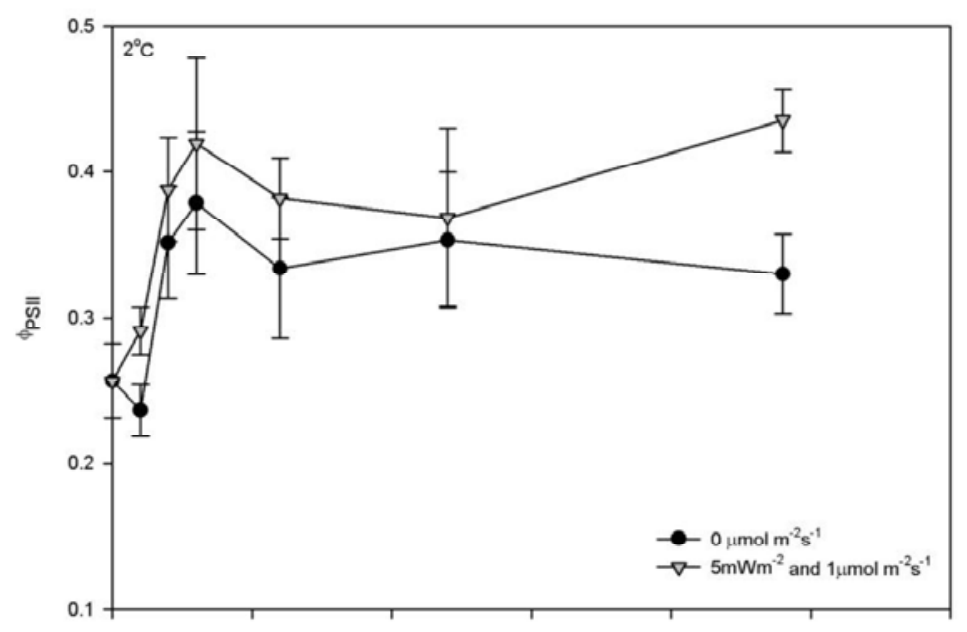

c)

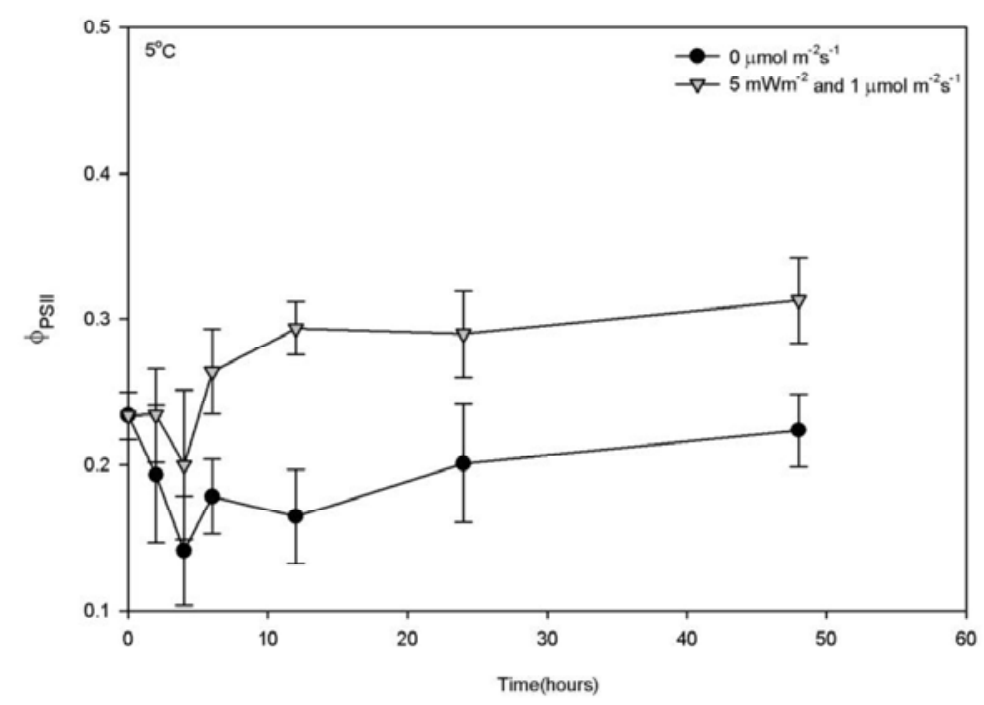

Fig 3.1. Quantum Yield ( were maintained at $5 \mathrm{~mW} \mathrm{~m}^{-2} \mathrm{UV}-\mathrm{B}$ and either $1 \mu \mathrm{mol} \mathrm{m}{ }^{-2} \mathrm{~s}^{-1}$ or at $0 \mu \mathrm{mol} \mathrm{m}^{-2} \mathrm{~s}^{-1}$ at (a) $1^{\circ} \mathrm{C}$, (b) $2^{\circ} \mathrm{C}$ and (c) $5^{\circ} \mathrm{C}$. Error bars indicate standard error. 
Table 3.3 (b) Effect of different temperatures on $\phi_{\text {PSII }}$ at different UV-B treatments:

\begin{tabular}{|c|c|c|c|c|c|}
\hline Source of variation & $\mathrm{df}$ & MS & $F$ & $\mathrm{p}$ & post hoc comparisons \\
\hline \multicolumn{6}{|l|}{ At $0 \mu \mathrm{mol} \mathrm{m} \mathrm{m}^{-2} \mathrm{~s}^{-1}$} \\
\hline \multicolumn{6}{|l|}{ Within subjects } \\
\hline Time & 6 & 0.009 & 2.858 & 0.015 & \multirow{3}{*}{$\begin{array}{l}\text { No change over } 48 \mathrm{~h} \\
\text { (see text below) }\end{array}$} \\
\hline Time $\mathrm{x}$ Treatments & 12 & 0.006 & 2.095 & 0.028 & \\
\hline Error & 72 & 0.003 & & & \\
\hline \multicolumn{6}{|l|}{ Between subjects } \\
\hline Treatments & 2 & 0.178 & 6.193 & 0.014 & $-1^{\circ} \mathrm{C}=2^{\circ} \mathrm{C} ;-1^{\circ} \mathrm{C}=5^{\circ} \mathrm{C}$ \\
\hline Error & 12 & 0.029 & & & $2^{\circ} \mathrm{C}>5^{\circ} \mathrm{C}$ \\
\hline \multicolumn{6}{|c|}{ At $5 \mathrm{~mW} \mathrm{~m}^{-2}$ and $1 \mu \mathrm{mol} \mathrm{m}^{-2} \mathrm{~s}^{-1}$} \\
\hline \multicolumn{6}{|c|}{ Within subjects } \\
\hline Time & 6 & 0.024 & 8.583 & $<0.001$ & \multirow{3}{*}{$\begin{array}{l}\text { Increase over } 48 \mathrm{~h} \\
\text { (see text below) }\end{array}$} \\
\hline Time $x$ Treatments & 12 & 0.005 & 1.767 & 0.070 & \\
\hline Error & 72 & 0.003 & & & \\
\hline \multicolumn{6}{|l|}{ Between subjects } \\
\hline Treatments & 2 & 0.106 & 4.192 & 0.042 & $-1^{\circ} \mathrm{C}=2^{\circ} \mathrm{C}=5^{\circ} \mathrm{C}$ \\
\hline Error & 12 & 0.025 & & & \\
\hline
\end{tabular}

Repeated measures ANOVA was conducted on data from separate experiments to check for the effect of temperature on UV-B exposures. A caveat for this analysis is that each incubation was carried out on a different day with different samples, which could sometimes result in varying levels of photosynthetic health.

At $0 \mu \mathrm{mol} \mathrm{m}{ }^{-2} \mathrm{~s}^{-1}$, repeated measures ANOVA showed no significant increase (Table 3.3 b) in $\phi_{\text {PSII. }}$ However, $\phi_{\text {PSII }}$ for algae at $2^{\circ} \mathrm{C}$ was significantly greater (Bonferroni, $\mathrm{p}=0.015$ ) than at $5^{\circ} \mathrm{C}$. At $5 \mathrm{~mW} \mathrm{~m}^{-2}$ (Table 3.3b), there was a significant increase (Bonferroni, $\mathrm{p}=0.001$ ) in $\phi_{\text {PSII }}$ for algae incubated all three temperatures but no difference between the temperatures.

\subsection{Relative ETR max}

Initially a repeated measures ANOVA was conducted with time as a 'within' factor and temperature and treatment as 'between' factors. This showed significant effects of time $(\mathrm{p}<0.001)$ and time by temperature $(\mathrm{p}<0.001)$, but the interactions between time and treatment $(\mathrm{p}=0.347)$ and the three-way interaction between time, temperature and treatment ( $\mathrm{p}=0.914$ ) were not significant. (see Table A2.2, Appendix 2). To be consistent 
with other chapters, a 2-way repeated measures analyses was carried out for each exposure treatment separately to test for the effects of all treatments and time.

In all three temperature treatments (Fig. 3.2), there was no change in rETR max $_{\text {over the }}$ time points between 0 and $48 \mathrm{~h}$ in both exposure treatments. However, at $48 \mathrm{~h}, \mathrm{rETR}_{\max }$ for algae at $5 \mathrm{~mW} \mathrm{~m}^{-2}$ at $5^{\circ} \mathrm{C}$ was significantly greater (Bonferroni, $\mathrm{p}=0.017$ ) than those at $0 \mu \mathrm{mol} \mathrm{m}{ }^{-2} \mathrm{~s}^{-1}$.

Table 3.4. Changes in rETR $_{\max }$ of photosystem II over $48 \mathrm{~h}$ experimental treatments at one UV-B level of $5 \mathrm{~mW} \mathrm{~m}^{-2}$ and $1 \mu \mathrm{mol} \mathrm{m}^{-2} \mathrm{~s}^{-1}$ or at $0 \mu \mathrm{mol} \mathrm{m}^{-2} \mathrm{~s}^{-1}$ at $-1^{\circ} \mathrm{C}, 2^{\circ} \mathrm{C}$ and $5^{\circ} \mathrm{C}$, analysed using repeated measures ANOVA. Significant changes identified by post hoc pairwise analyses are also listed.

(a) Effect of UV-B on $\phi_{P S I I}$ at different temperatures:

\begin{tabular}{|c|c|c|c|c|c|}
\hline Source of variation & $\mathrm{df}$ & MS & $F$ & $\mathrm{p}$ & post hoc comparisons \\
\hline \multicolumn{6}{|l|}{$\begin{array}{l}\text { At }-1^{\circ} \mathrm{C} \\
\text { Within subjects }\end{array}$} \\
\hline Time & 3.068 & 10.245 & 2.960 & 0.051 & \multirow{3}{*}{$\begin{array}{l}\text { No change over } 48 \mathrm{~h} \\
\text { (see text below) }\end{array}$} \\
\hline Time $\mathrm{x}$ Treatments & 3.068 & 4.013 & 1.159 & 0.346 & \\
\hline Error & 24.540 & 3.461 & & & \\
\hline \multicolumn{6}{|l|}{ Between subjects } \\
\hline Treatments & 1 & 9.355 & 3.043 & 0.119 & \multirow[t]{2}{*}{ No significance } \\
\hline Error & 8 & 3.074 & & & \\
\hline \multicolumn{6}{|l|}{ At $2^{\circ} \mathrm{C}$} \\
\hline Within subjects & & & & & \multirow{4}{*}{$\begin{array}{l}\text { No change over } 48 \mathrm{~h} \\
\text { (see text below) }\end{array}$} \\
\hline Time & 2.139 & 164.753 & 10.948 & 0.001 & \\
\hline Time $\mathrm{x}$ Treatments & 2.139 & 2.353 & 0.156 & 0.869 & \\
\hline Error & 17.110 & 15.049 & & & \\
\hline \multicolumn{6}{|l|}{ Between subjects } \\
\hline Treatments & 1 & 7.123 & 0.274 & 0.615 & \multirow[t]{2}{*}{ No significance } \\
\hline Error & 8 & 26.030 & & & \\
\hline \multicolumn{6}{|l|}{ At $5^{\circ} \mathrm{C}$} \\
\hline Within subjects & & & & & \multirow{4}{*}{$\begin{array}{l}\text { No change over } 48 \mathrm{~h} \\
\text { (see text below) }\end{array}$} \\
\hline Time & 6 & 2.150 & 3.575 & 0.005 & \\
\hline Time $x$ Treatments & 6 & 1.812 & 3.013 & 0.014 & \\
\hline Error & 48 & 0.601 & & & \\
\hline \multicolumn{6}{|l|}{ Between subjects } \\
\hline Treatments & 1 & 61.627 & 13.827 & 0.006 & $5 \mathrm{~mW} \mathrm{~m}^{-2}>0 \mu \mathrm{mol} \mathrm{m}^{-2} \mathrm{~s}^{-1}$ \\
\hline Error & 8 & 0.029 & & & \\
\hline
\end{tabular}


a)

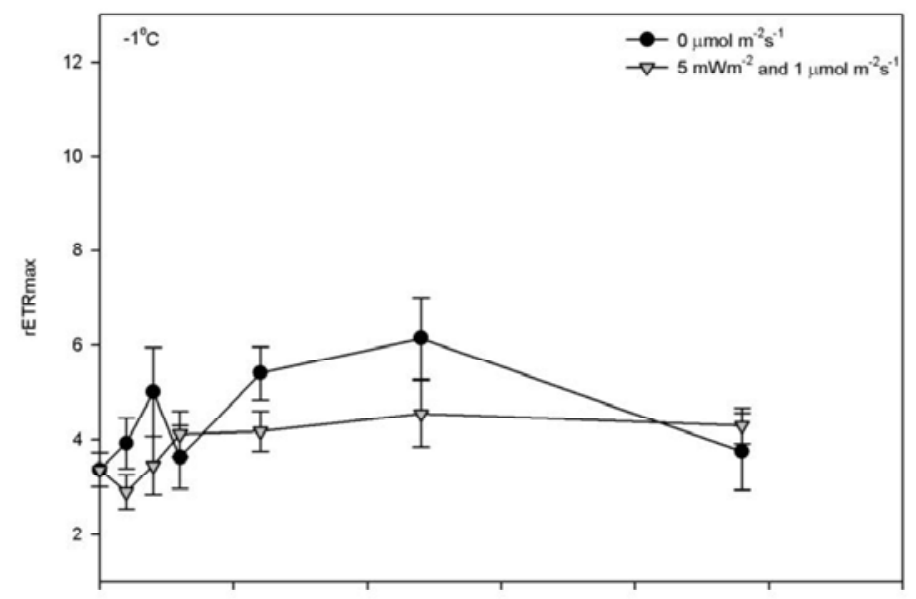

b)

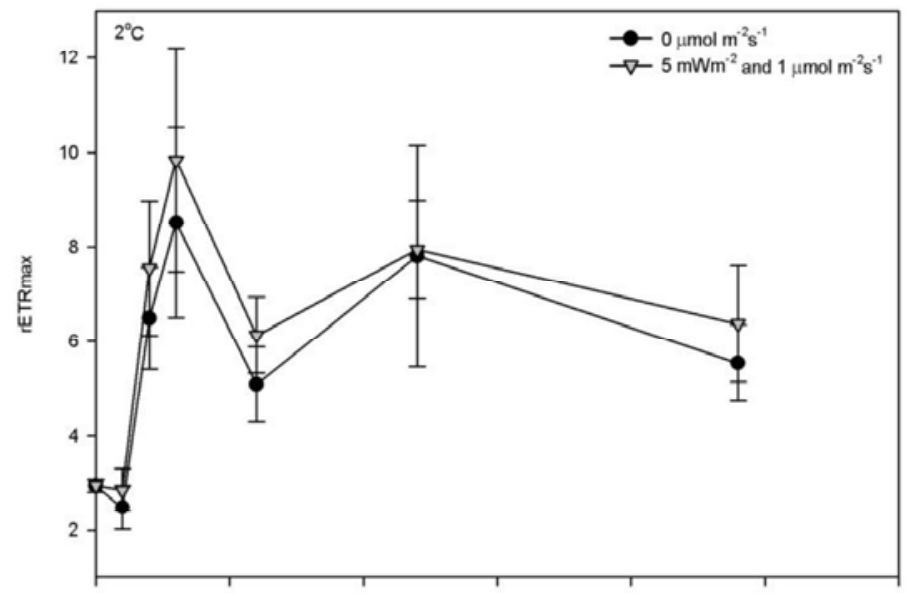

c)

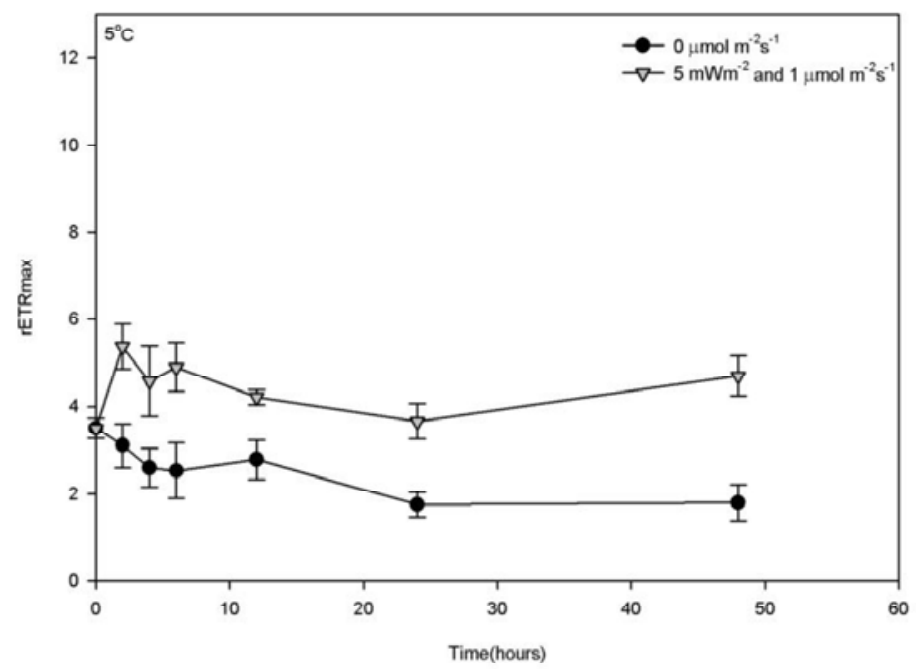

Fig 3.2. Relative ETR $\mathrm{Emax}_{\text {of }}$ of bottom ice algae at $0,2,4,6,12,24$ and $48 \mathrm{~h}$. Cultures were maintained at $5 \mathrm{~mW} \mathrm{~m}^{-2} \mathrm{UV}-\mathrm{B}$ and $1 \mu \mathrm{mol} \mathrm{m} \mathrm{m}^{-2} \mathrm{~s}^{-1}$ or at $0 \mu \mathrm{mol} \mathrm{m} \mathrm{m}^{-2} \mathrm{~s}^{-1}$ at (a) $1^{\circ} \mathrm{C}$, (b) $2^{\circ} \mathrm{C}$ and (c) $5^{\circ} \mathrm{C}$. Error bars indicate standard error. 
Table 3.4 (b) Effect of different temperatures on $\phi_{\text {PSII }}$ at different UV-B treatments:

\begin{tabular}{|c|c|c|c|c|c|}
\hline Source of variation & $\mathrm{df}$ & MS & $F$ & $\mathrm{p}$ & post hoc comparisons \\
\hline \multicolumn{6}{|l|}{ At $0 \mu \mathrm{mol} \mathrm{m} \mathrm{m}^{-2} \mathrm{~s}^{-1}$} \\
\hline \multicolumn{6}{|l|}{ Within subjects } \\
\hline Time & 2.636 & 21.728 & 3.008 & 0.051 & No change over $48 \mathrm{~h}$ \\
\hline Time $\mathrm{x}$ Treatments & 5.272 & 26.013 & 3.601 & 0.010 & (see text below) \\
\hline Error & 31.631 & 7.224 & & & \\
\hline \multicolumn{6}{|l|}{ Between subjects } \\
\hline Treatments & 2 & 81.692 & 8.014 & 0.006 & $-1^{\circ} \mathrm{C}=2^{\circ} \mathrm{C} ;-1^{\circ} \mathrm{C}=5^{\circ} \mathrm{C}$ \\
\hline Error & 12 & 10.194 & & & $2^{\circ} \mathrm{C}>5^{\circ} \mathrm{C}$ \\
\hline \multicolumn{6}{|c|}{ 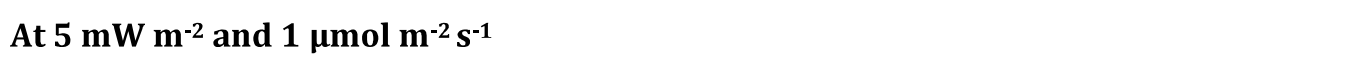 } \\
\hline \multicolumn{6}{|c|}{ Within subjects } \\
\hline Time & 2.369 & 43.025 & 8.566 & 0.001 & Increase over $48 \mathrm{~h}$ \\
\hline Time $\mathrm{x}$ Treatments & 4.739 & 27.130 & 5.402 & 0.001 & (see text below) \\
\hline Error & 28.432 & 5.023 & & & \\
\hline \multicolumn{6}{|l|}{ Between subjects } \\
\hline Treatments & 2 & 55.492 & 4.556 & 0.034 & $-1^{\circ} \mathrm{C}=2^{\circ} \mathrm{C}=5^{\circ} \mathrm{C}$ \\
\hline Error & 12 & 12.180 & & & \\
\hline
\end{tabular}

Repeated measures ANOVA was conducted on data from separate experiments to check for the effect of temperature on UV-B exposures. A caveat for this analysis is that each incubation was carried out on a different day with different samples, which could sometimes result in varying levels of photosynthetic health.

At $0 \mu \mathrm{mol} \mathrm{m}{ }^{-2} \mathrm{~s}^{-1}$, repeated measures ANOVA showed no significant increase (Table 3.4 b) in $\phi_{\text {PSII. }}$. However, $\phi_{\text {PSII }}$ for algae at $2^{\circ} \mathrm{C}$ was significantly greater (Bonferroni, $p=0.006$ ) than at $5^{\circ} \mathrm{C}$. At $5 \mathrm{~mW} \mathrm{~m}^{-2}$ (Table $3.4 \mathrm{~b}$ ), there was a significant increase (Bonferroni, $\mathrm{p}=0.012$ ) in $\phi_{\text {PSII }}$ for algae incubated all three temperatures but no difference between the temperatures.

\subsubsection{Exposure to UV-B levels of 5,50 or $100 \mathrm{~mW} \mathrm{~m}^{-2}$ at $2^{\circ} \mathrm{C}$}

\subsection{Quantum Yield ( $\phi$ PSII)}

Initially a repeated measures ANOVA was conducted with time as a 'within' factor and treatment as a 'between' factor. This showed significant effects of time $(p=0.030)$ and time by temperature ( $\mathrm{p}=0.003$ ) (Table A2.6, Appendix 2). Consequently repeated 
measures analyses were carried out for each exposure treatment separately to test for the effects of all treatments and time. The effect of the UV-B level of $5 \mathrm{~mW} \mathrm{~m}^{-2}$ has already been described in Section 3.4.2.1.

At $50 \mathrm{~mW} \mathrm{~m}{ }^{-2}$, there were significant differences in $\phi_{\text {PSII }}$ for the algae between 0 and 48 h (Fig. 3.3 a). However, post hoc tests identified no significant changes between the individual time points or between treatments. At $100 \mathrm{~mW} \mathrm{~m}^{-2}$, there was no significant change in $\phi_{\text {PSII }}$ for the algae between 0 and $48 \mathrm{~h}$ (Fig. $3.3 \mathrm{~b}$ ). However, at $48 \mathrm{~h}$, $\phi_{\text {PSII }}$ for algae incubated at $100 \mathrm{~mW} \mathrm{~m}^{-2}$ was significantly higher than those at $0 \mu \mathrm{mol} \mathrm{m}^{-2} \mathrm{~s}^{-1}$.

Table 3.5. Changes in quantum yield of photosystem II over $48 \mathrm{~h}$ experimental treatments at (a) UV-B level of $50 \mathrm{~mW} \mathrm{~m}^{-2}$ and $1 \mu \mathrm{mol} \mathrm{m}^{-2} \mathrm{~s}^{-1}$ or at $0 \mu \mathrm{mol} \mathrm{m}^{-2} \mathrm{~s}^{-1}$ and (b) UV-B level of $100 \mathrm{~mW} \mathrm{~m}^{-2}$ and $1 \mu \mathrm{mol} \mathrm{m}^{-2} \mathrm{~s}^{-1}$ or at $0 \mu$ 
a)

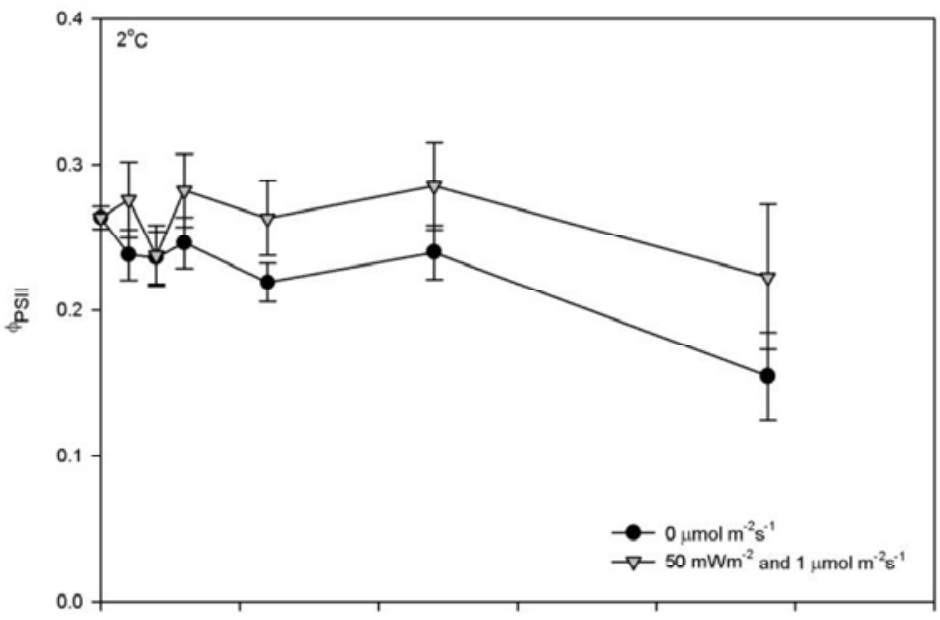

b)

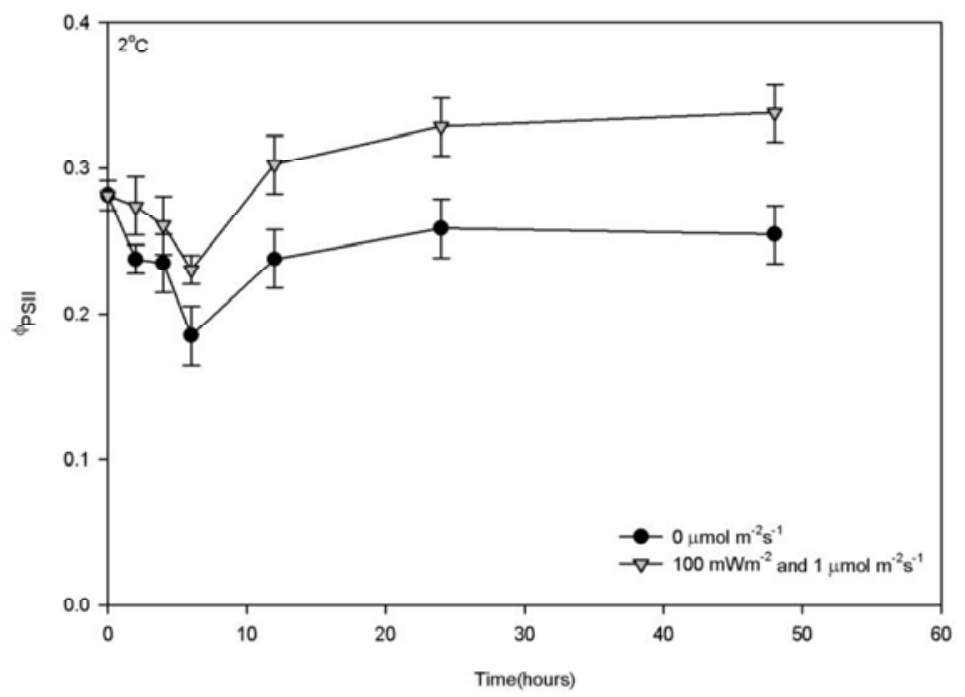

Figure 3.3. Quantum yield of bottom ice algae at $0,2,4,6,12,24$ and $48 \mathrm{~h}$. Cultures were maintained at (a) $50 \mathrm{~mW} \mathrm{~m}^{-2} \mathrm{UV}-\mathrm{B}$ and a PAR level of $1 \mu \mathrm{mol} \mathrm{m} \mathrm{m}^{-2} \mathrm{~s}^{-1}$ or at $0 \mu \mathrm{mol} \mathrm{m}^{-2} \mathrm{~s}^{-1}$ and (b) $100 \mathrm{~mW} \mathrm{~m}^{-2} \mathrm{UV}-\mathrm{B}$ and a PAR level of $1 \mu \mathrm{mol} \mathrm{m} \mathrm{m}^{-2} \mathrm{~s}^{-1}$ or at $0 \mu \mathrm{mol} \mathrm{m} \mathrm{m}^{-2} \mathrm{~s}^{-1}$. Error bars indicate standard error.

\subsection{Relative ETR $\max$}

Initially a repeated measures ANOVA was conducted with time as a 'within' factor and treatment as a 'between' factor. This showed significant effects of time $(p=0.002)$ and time by temperature $(\mathrm{p}=0.005)$ (Table A2.7, Appendix 2). Consequently repeated measures analyses were carried out for each exposure treatment separately to test for the effects of all treatments and time. The effect of the UV-B level of $5 \mathrm{~mW} \mathrm{~m}^{-2}$ has already been described in Section 3.4.2.1. 
Table 3.6. Changes in $\mathrm{rETR}_{\max }$ of photosystem II over $48 \mathrm{~h}$ experimental treatments at (a) UV-B level of $50 \mathrm{~mW} \mathrm{~m}^{-2}$ and $1 \mu \mathrm{mol} \mathrm{m}^{-2} \mathrm{~s}^{-1}$ or at $0 \mu \mathrm{mol} \mathrm{m}^{-2} \mathrm{~s}^{-1}$ and (b) UV-B level of $50 \mathrm{~mW} \mathrm{~m}^{-2}$ and $1 \mu \mathrm{mol} \mathrm{m} \mathrm{m}^{-2} \mathrm{~s}^{-1}$ or at $0 \mu \mathrm{mol} \mathrm{m}^{-2} \mathrm{~s}^{-1}$ at $2^{\circ} \mathrm{C}$ and analysed using repeated measures ANOVA. Significant changes identified by post hoc pairwise analyses are also listed.

\begin{tabular}{|c|c|c|c|c|c|}
\hline \multicolumn{6}{|r|}{ post hoc comparisons } \\
\hline \multicolumn{6}{|c|}{ 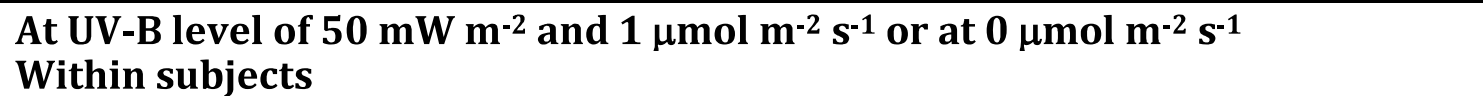 } \\
\hline Time & 2.057 & 13.183 & 5.643 & 0.013 & Decrease over $48 \mathrm{~h}$ \\
\hline Time $\mathrm{x}$ Treatments & 2.057 & 1.930 & 0.826 & 0.458 & (see text below) \\
\hline Error & 16.459 & 2.336 & & & \\
\hline \multicolumn{6}{|l|}{ Between subjects } \\
\hline Treatments & 1 & 10.353 & 4.180 & 0.075 & No significance \\
\hline Error & 8 & 2.477 & & & \\
\hline \multicolumn{6}{|c|}{$\begin{array}{l}\text { At UV-B level of } 100 \mathrm{~mW} \mathrm{~m}^{-2} \text { and } 1 \mu \mathrm{mol} \mathrm{m}^{-2} \mathrm{~s}^{-1} \text { or at } 0 \mu \mathrm{mol} \mathrm{m}^{-2} \mathrm{~s}^{-1} \\
\text { Within subjects }\end{array}$} \\
\hline Time & 2.163 & 6.730 & 5.921 & 0.010 & No change over $48 \mathrm{~h}$ \\
\hline Time $\mathrm{x}$ Treatments & 2.163 & 4.420 & 3.889 & 0.038 & (see text below) \\
\hline Error & 17.306 & 1.136 & & & \\
\hline \multicolumn{6}{|l|}{ Between subjects } \\
\hline Treatments & 1 & 21.885 & 7.426 & 0.026 & $100 \mathrm{mWm}^{-2}>0 \mu \mathrm{mol} \mathrm{m}^{-2} \mathrm{~s}^{-1}$ \\
\hline Error & 8 & 2.947 & & & \\
\hline
\end{tabular}

At $50 \mathrm{~mW} \mathrm{~m}^{-2}$, there was a significant increase (Bonferroni, $\mathrm{p}=0.034$ ) in $\mathrm{rETR}_{\max }$ (Fig. 3.4 a) for algae incubated at $0 \mu \mathrm{mol} \mathrm{m}{ }^{-2} \mathrm{~s}^{-1}$ over $48 \mathrm{~h}$ due to a significant decrease (Bonferroni, $\mathrm{p}=0.017$ ) in the last $24 \mathrm{~h}$. There was no significant change in $\mathrm{rETR}_{\max }$ for algae incubated at $50 \mathrm{~mW} \mathrm{~m}^{-2}$. At $100 \mathrm{~mW} \mathrm{~m}^{-2}$, there was no significant change in rETR $_{\max }$ (Fig. $3.4 \mathrm{~b}$ ) for the algae incubated at $0 \mu \mathrm{mol} \mathrm{m}^{-2} \mathrm{~s}^{-1}$ over $48 \mathrm{~h}$. rETR $\mathrm{max}_{\max }$ for algae incubated at $100 \mathrm{~mW} \mathrm{~m}^{-2}$ significantly increased (Bonferroni, $\mathrm{p}=0,017$ ). 
a)

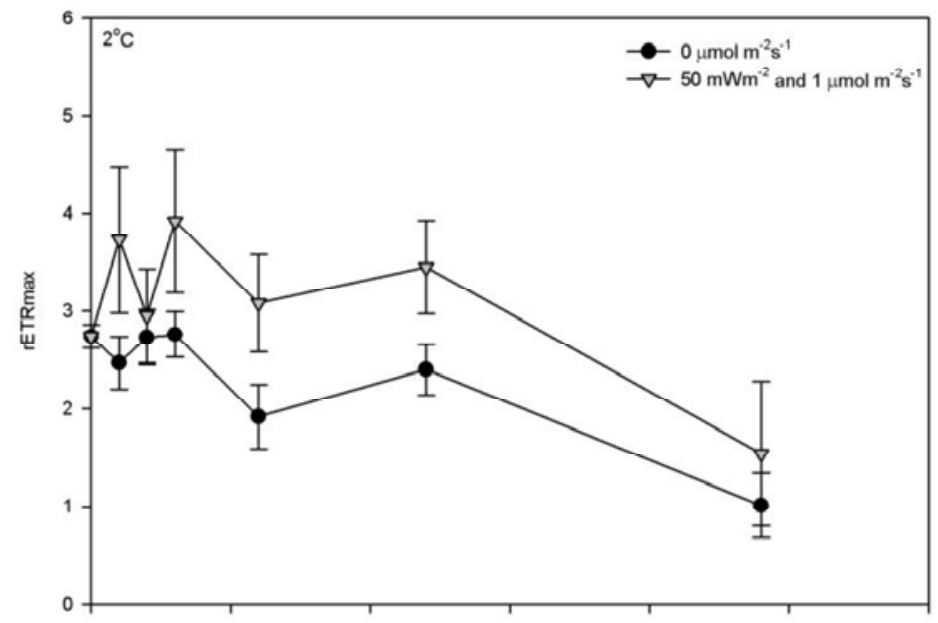

b)

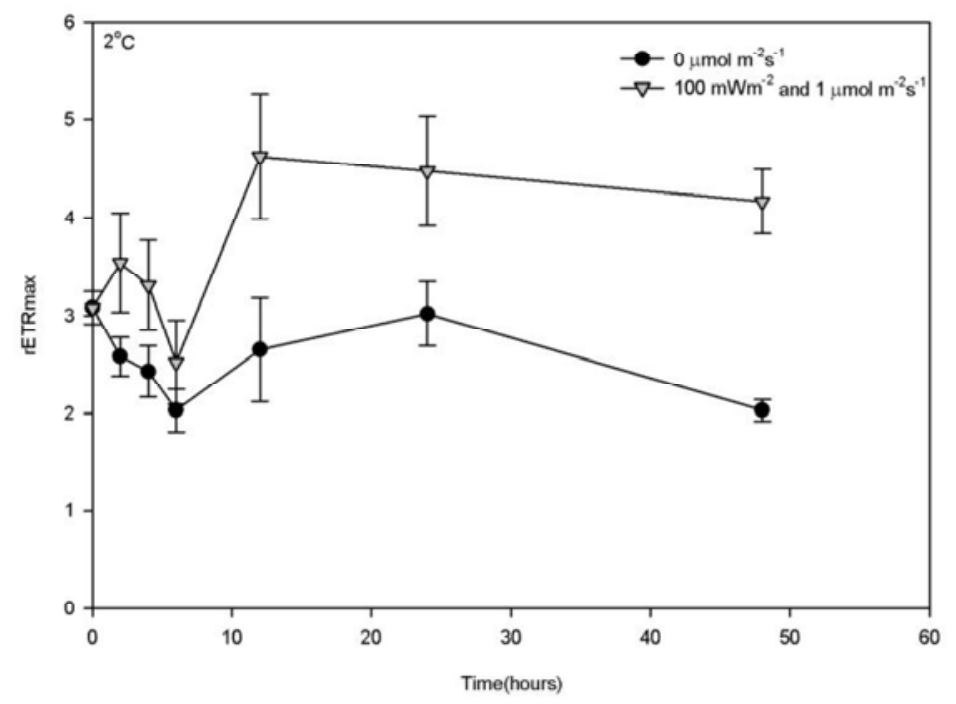

Figure 3.4. $\mathrm{rETR}_{\max }$ of bottom ice algae at $0,2,4,6,12,24$ and $48 \mathrm{~h}$. Cultures were maintained at (a) $50 \mathrm{~mW} \mathrm{~m}^{-2} \mathrm{UV}$-B and a PAR level of $1 \mu \mathrm{mol} \mathrm{m} \mathrm{m}^{-2} \mathrm{~s}^{-1}$ or at $0 \mu \mathrm{mol} \mathrm{m}^{-2} \mathrm{~s}^{-1}$ and (b) $100 \mathrm{~mW} \mathrm{~m}^{-2} \mathrm{UV}-\mathrm{B}$ and a PAR level of $1 \mu \mathrm{mol} \mathrm{m} \mathrm{m}^{-2} \mathrm{~s}^{-1}$ or at $0 \mu \mathrm{mol} \mathrm{m}^{-2} \mathrm{~s}^{-1}$. Error bars indicate standard error.

\subsection{MAA production}

Initially a repeated measures ANOVA was conducted with time as a 'within' factor and treatment as a 'between' factor. This showed significant effects of time $(p<0.001)$ but not for time by temperature $(\mathrm{p}=0.512)$ (Table A2.8, Appendix 2). Consequently repeated measures analyses were carried out for each exposure treatment separately to test for the effects of all treatments and time. 
At $5 \mathrm{~mW} \mathrm{~m}^{-2}$, there was no significant change in MAA production (Fig. 3.5 a) for algae at both exposure treatments. At $50 \mathrm{~mW} \mathrm{~m}^{-2}$, there was a significant increase (Bonferroni, p $<0.001$ ) in MAA production (Fig. 3.5b) for algae at both exposure treatments with MAA production significantly greater by more than two fold (Bonferroni, $p=0.001$ ) for those algae at $50 \mathrm{~mW} \mathrm{~m}^{-2}$. At $100 \mathrm{~mW} \mathrm{~m}^{-2}$, there was a significant increase (Bonferroni, p=0.028) in MAA production (Fig. $3.5 \mathrm{c}$ ) for algae at both exposure treatments with MAA production significantly greater by more than four fold (Bonferroni, $p=0.006$ ) for those algae at $100 \mathrm{~mW} \mathrm{~m}^{-2}$.

Table 3.7. Changes in MAA production over $48 \mathrm{~h}$ experimental treatments at (a) UV-B level of $5 \mathrm{~mW} \mathrm{~m}^{-2}$ and $1 \mu \mathrm{mol} \mathrm{m}^{-2} \mathrm{~s}^{-1}$ or at $0 \mu \mathrm{mol} \mathrm{m}^{-2} \mathrm{~s}^{-1}$, (b) UV-B level of $50 \mathrm{~mW} \mathrm{~m}^{-2}$ and $1 \mu \mathrm{mol} \mathrm{m} \mathrm{m}^{-2} \mathrm{~s}^{-1}$ or at $0 \mu \mathrm{mol} \mathrm{m}^{-2} \mathrm{~s}^{-1}$ and (c) UV-B level of $50 \mathrm{~mW} \mathrm{~m}^{-2}$ and $1 \mu \mathrm{mol} \mathrm{m}^{-2} \mathrm{~s}^{-}$ ${ }^{1}$ or at $0 \mu \mathrm{mol} \mathrm{m}^{-2} \mathrm{~s}^{-1}$ at $2^{\circ} \mathrm{C}$ and analysed using repeated measures ANOVA. Significant changes identified by post hoc pairwise analyses are also listed.

\begin{tabular}{|c|c|c|c|c|c|}
\hline Source of variation & $\mathrm{df}$ & MS & $\mathrm{p}$ & \multicolumn{2}{|c|}{ post hoc comparisons } \\
\hline \multicolumn{6}{|c|}{$\begin{array}{l}\text { At UV-B level of } 5 \mathrm{~mW} \mathrm{~m}^{-2} \text { and } 1 \mu \mathrm{mol} \mathrm{m}^{-2} \mathrm{~s}^{-1} \text { or at } 0 \mu \mathrm{mol} \mathrm{m}^{-2} \mathrm{~s}^{-1} \\
\text { Within subjects }\end{array}$} \\
\hline Time & 1 & 0.011 & 4.194 & 0.075 & No change over $48 \mathrm{~h}$ \\
\hline Time $\mathrm{x}$ Treatments & 1 & 0.000 & 0.067 & 0.803 & (see text below) \\
\hline Error & 8 & 0.003 & & & \\
\hline \multicolumn{6}{|l|}{ Between subjects } \\
\hline Treatments & 1 & 4.894E-006 & 0.003 & 0.957 & No significance \\
\hline Error & 8 & 0.022 & & & \\
\hline \multicolumn{6}{|c|}{$\begin{array}{l}\text { At UV-B level of } 50 \mathrm{~mW} \mathrm{~m} \mathrm{~m}^{-2} \text { and } 1 \mu \mathrm{mol} \mathrm{m}^{-2} \mathrm{~s}^{-1} \text { or at } 0 \mu \mathrm{mol} \mathrm{m}^{-2} \mathrm{~s}^{-1} \\
\text { Within subjects }\end{array}$} \\
\hline Time & 1 & 0.007 & 51.862 & $<0.001$ & Increase over $48 \mathrm{~h}$ \\
\hline Time $x$ Treatments & 1 & 0.002 & 14.179 & 0.006 & (see text below) \\
\hline Error & 8 & 0.000 & & & \\
\hline \multicolumn{6}{|l|}{ Between subjects } \\
\hline Treatments & 1 & 0.001 & 28.086 & 0.001 & $50 \mathrm{~mW} \mathrm{~m}^{-2}>0 \mu \mathrm{mol} \mathrm{m}^{-2} \mathrm{~s}^{-1}$ \\
\hline Error & 8 & $3.792 \mathrm{E}-005$ & & & \\
\hline \multicolumn{6}{|c|}{$\begin{array}{l}\text { At UV-B level of } 100 \mathrm{~mW} \mathrm{~m}^{-2} \text { and } 1 \mu \mathrm{mol} \mathrm{m}^{-2} \mathrm{~s}^{-1} \text { or at } 0 \mu \mathrm{mol} \mathrm{m}^{-2} \mathrm{~s}^{-1} \\
\text { Within subjects }\end{array}$} \\
\hline Time & 1 & 0.001 & 7.222 & 0.028 & Increase over $48 \mathrm{~h}$ \\
\hline Time $\mathrm{x}$ Treatments & 1 & 0.001 & 12.470 & 0.008 & (see text below) \\
\hline Error & 8 & 0.000 & & & \\
\hline \multicolumn{6}{|l|}{ Between subjects } \\
\hline Treatments & 1 & 0.001 & 13.413 & 0.006 & $100 \mathrm{~mW} \mathrm{~m}^{-2}>0 \mu \mathrm{mol} \mathrm{m}^{-2} \mathrm{~s}^{-1}$ \\
\hline Error & 8 & $4.499-005$ & & & \\
\hline
\end{tabular}


a)

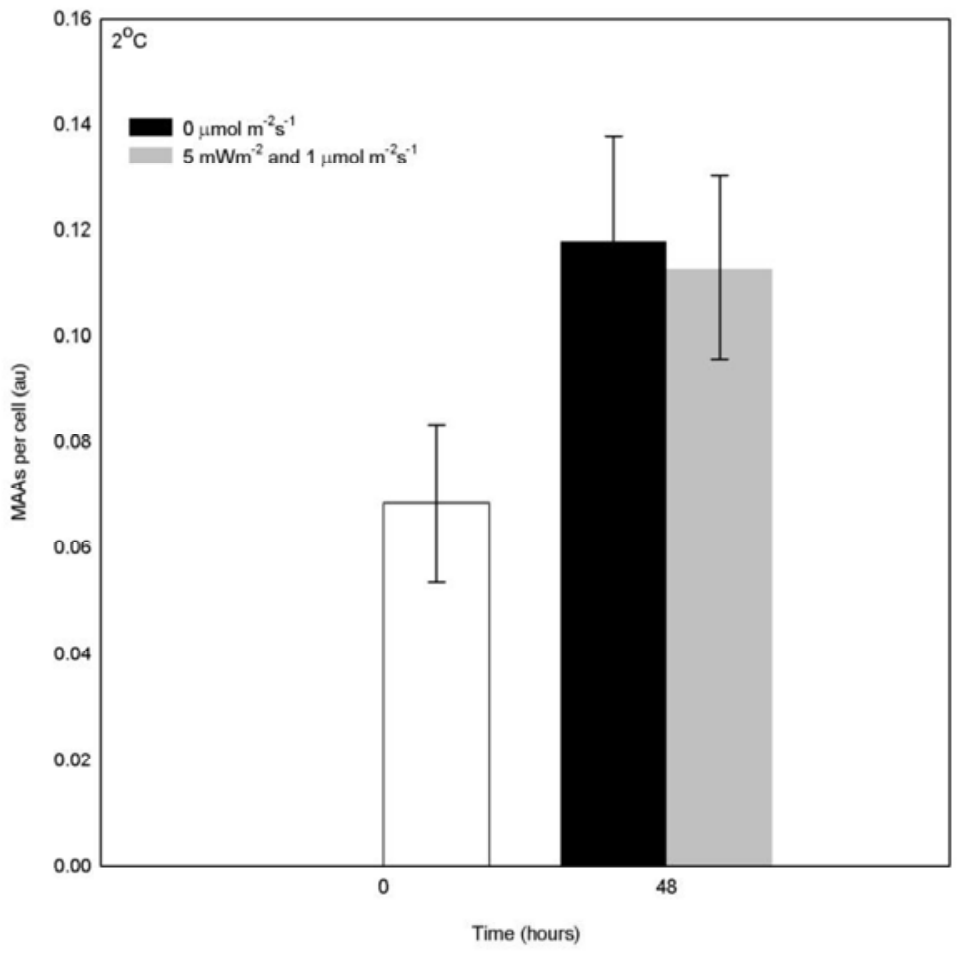

b)

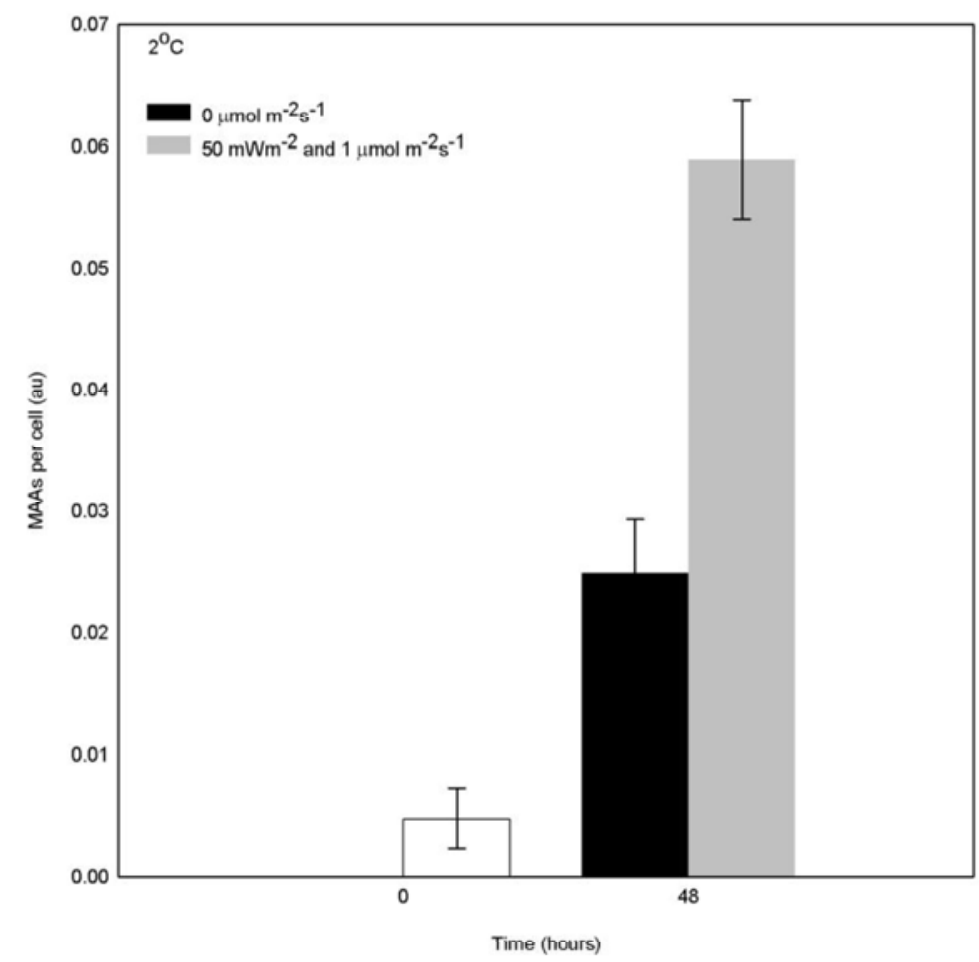




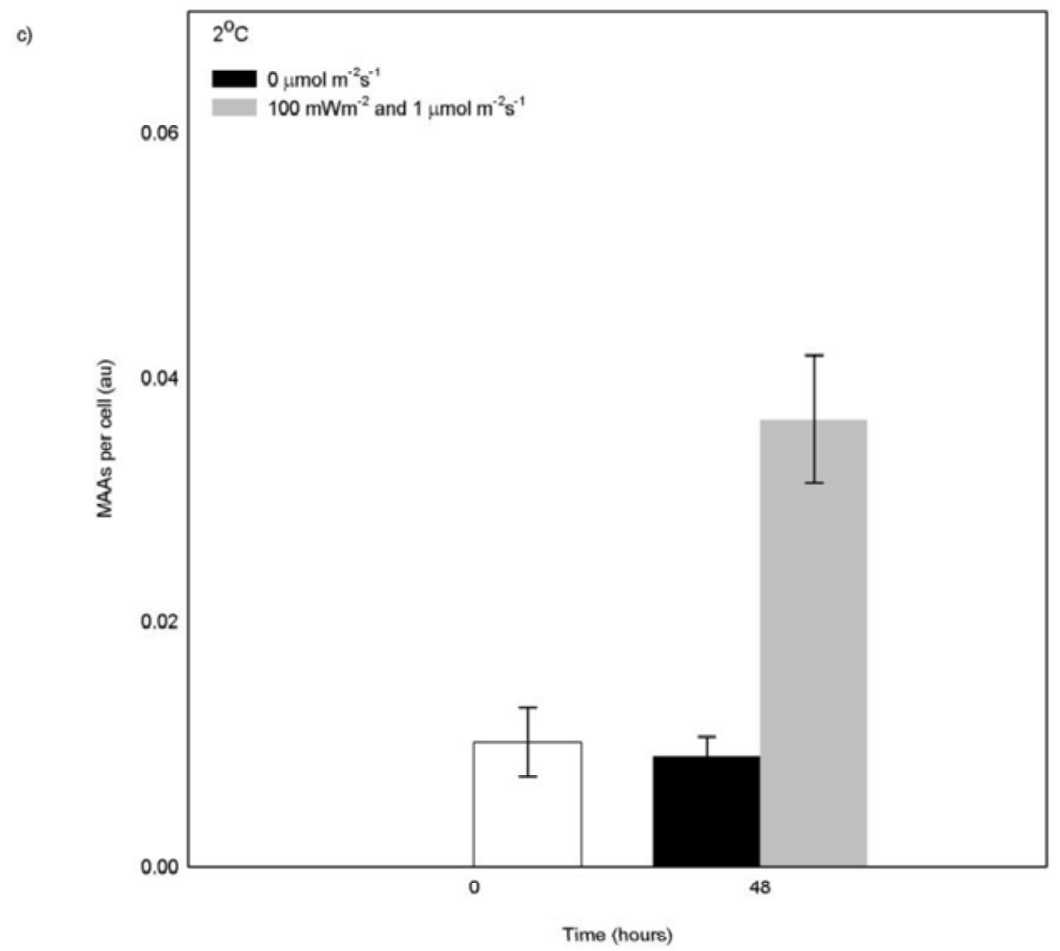

Figure 3.5. MAA production in bottom ice algae at 0 and $48 \mathrm{~h}$. Cultures were maintained at (a) $5 \mathrm{~mW} \mathrm{~m}^{-2} \mathrm{UV}$-B and a PAR level of $1 \mu \mathrm{mol} \mathrm{m}^{-2} \mathrm{~s}^{-1}$ or at $0 \mu \mathrm{mol} \mathrm{m} \mathrm{m}^{-2} \mathrm{~s}^{-1}$ and (b) 50 $\mathrm{mW} \mathrm{m} \mathrm{m}^{-2} \mathrm{UV}-\mathrm{B}$ and a PAR level of $1 \mu \mathrm{mol} \mathrm{m} \mathrm{m}^{-2} \mathrm{~s}^{-1}$ or at $0 \mu \mathrm{mol} \mathrm{m}^{-2} \mathrm{~s}^{-1}$ (c) $100 \mathrm{~mW} \mathrm{~m}^{-2} \mathrm{UV}-\mathrm{B}$ and a PAR level of $1 \mu \mathrm{mol} \mathrm{m}{ }^{-2} \mathrm{~s}^{-1}$ or at $0 \mu \mathrm{mol} \mathrm{m}^{-2} \mathrm{~s}^{-1}$. Error bars indicate standard error.

\subsection{DISCUSSION}

Experimental exposures to low and high doses of UV-B demonstrated that the sea ice algae used in this study have the potential to generate MAAs under appropriate UV-B conditions. In the ice, the three dimensional structure of the community means that some cells are exposed to higher UV-B and their increased production of MAAs may protect the rest of the community (Ryan et al., 2009). Ryan (2002) hypothesized that the algal cells at the top of the bottom ice layer produced more MAAs when exposed to the highest levels of UV-B. In this study, the bottom ice algae were no longer in the ice matrix, but were suspended in seawater ensuring all cells were exposed to the same level of UV-B, and allowing for observations at the cellular level. Typical under ice UV-B 
and PAR irradiances were $1 \mathrm{~mW} \mathrm{~m}^{-2}$ and $1 \mu \mathrm{mol} \mathrm{m}^{-2} \mathrm{~s}^{-1}$ at the two study locations. At low doses of UV-B (equivalent to the lower parts of the bottom ice community), no additional MAAs were produced, which could indicate that the cells already had sufficient MAAs to absorb this low dose of UV-B. At higher does of UV-B (equivalent to those experienced by the upper part of the bottom ice community), there was significantly higher MAA production, consistent with algae in the sea ice being able to produce more MAAs at higher UV-B exposure and provide protection at the community level. There was also, however, an increase in MAA production by algae incubated in the dark at $2^{\circ} \mathrm{C}$, which was unexpected, though interesting result. In this case the MAAs may perform a different function to that of photoprotection, and their production is responding directly to the increase in temperature. Some MAAs are known to have alternative physiological roles such as protection from osmotic shock, or involvement in morphogenetic changes (Gao \& Garcia-Pichel, 2011).

While algae clearly will not experience temperatures of $5^{\circ} \mathrm{C}$ or even $2^{\circ} \mathrm{C}$ within the sea ice matrix, this could easily be the case after the surrounding ice has melted. In addition, once melted they may also be exposed to higher UV-B levels than the $5 \mathrm{~mW} \mathrm{~m}^{-2}$ applied in the first part of this study. Many of the species that constitute the bottom ice community studied here are also found in areas of the Southern Ocean such as around South Georgia (Atkinson, 1994) where sea temperatures reach $5^{\circ} \mathrm{C}$ regularly, indicating that some sea ice algae have the ability to be pelagic species (Morley et al., 2010, Whitehouse et al., 1996).

Under the two higher levels of UV-B exposure used here, the algae responded with significant increases in MAA production compared to the control treatment. Compared to the dark control, MAA production increased by approximately $240 \%$ at $50 \mathrm{mWm}^{-2}$ and $410 \%$ at $100 \mathrm{mWm}^{-2}$. This increased MAA production could protect the photosynthetic machinery of the algal cells, explaining the lack of photosynthetic damage as indicated by quantum yield, electron transport rate, photosynthetic efficiency and saturation irradiance in this study (Hannach \& Sigleo, 1998, Hernando et al., 2011, Salleh \& McMinn, 2011). As is evident in Fig. 3.6(a) and 3.7(a), there was no change in photosynthetic yield after exposure to ecologically relevant levels of UV-B, while an increase in MAA production was seen (Fig. 3.6(e), 3.7(e)), again consistent with increased photoprotection due to an increase in MAA production. 


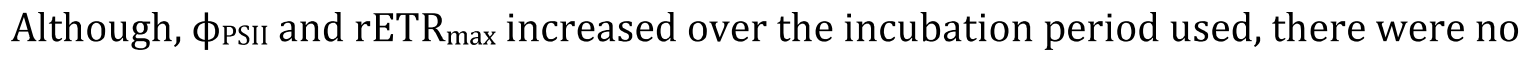
differences in these parameters between the algae exposed to UV-B and those held in the dark, which indicates that these levels of UV-B did not cause photo-inhibition in the algae in this community. When subjected to a temperature of $2^{\circ} \mathrm{C}$ and UV-B dose of $5 \mathrm{~mW} \mathrm{~m}{ }^{-2}$, conditions that sea ice algae are plausibly likely to experience during sea ice melt, there was no change in MAA production. The data obtained indicate an increase in photosynthetic yield and an increase in the saturation irradiance, which suggests acclimation to changing conditions and therefore that these algae could survive in the open ocean at warmer temperatures and moderate levels of UV-B exposure. Some algal species have been found both in sea ice and the water column (McMinn et al., 2010). At $5^{\circ} \mathrm{C}$ under low UV-B exposure level, the algae showed increasing photosynthetic yield but a decrease in MAA production. This is likely to be due to an improvement in protease-mediated photoenzymatic repair, particularly of the D1 protein of PSII, which is known to occur at higher temperatures (Halac et al., 2010), reducing the algal cell's need for the energy intensive production of MAAs (Hernando et al., 2011). Two temperate diatom species, Thalassiosira weissflogii and Chaetoceros gracilis showed lower photo-inhibition at higher experimental temperatures (Halac et al., 2010). Marine temperature increases such as those that have been observed in the Antarctic Peninsula region (Clarke et al., 2007) could, therefore, benefit algal species exposed to increased UVR levels.

The bottom ice communities studied at Cape Evans during the 2010 season showed tolerance to levels of UV-B that could be experienced during the melting of sea ice. The increase in MAA production documented here contrasts with results reported by Davidson et al. (1994), who recorded no MAA production in ice algal cells in response to UV-B exposure, However, community composition is likely to have differed between the two studies. Helbling et al. (1996) reported that centric diatoms were more capable of producing MAAs than pennate diatoms, which was reflected in the levels of photoinhibition shown by the two types of diatoms when exposed to PAR + UVR or PAR alone. After exposure to various treatments involving both PAR alone and PAR and UVR together, centric diatoms did not show any significant differences in photosynthetic rates whereas photoinhibition was observed in pennate diatoms. Therefore, the community species composition could significantly alter photosynthetic responses to stresses. The dominant sea ice algal species at Cape Evans in November 1999 were 
Nitzschia lecontei, N. stellata and Berkeleya adeliensis (Ryan et al., 2006). In November 2001, the dominant species were Entomoneis kjellmanii, N. stellata and Navicula glacei (Ryan et al., 2006). During the study at Cape Evans in 2010, the dominant species were N. stellata, Navicula sp. and Fragilariopsis sp. Clearly there can be considerable variation in community composition at the same site from one year to another, which could result in differences in photosynthetic parameters of the bottom ice community.

The use of a dark treatment as a control in this study unfortunately decreased the scope of interpretation of the data obtained. Although not ideal, other experiments with dark and low ambient light treatments described in this thesis demonstrated no significant difference in the quantum yield of algae from mixed communities (Chapter 2) or in unialgal cultures (Chapter 5) at these two temperatures. The temperature incubations for the low UV-B treatments were also run on different days and using different samples, which limits the comparison possible of the effect of temperature on UV-B exposures. Future experiments would be better designed if dark and low ambient levels of light were included and incubations for different temperatures were carried out simultaneously from samples collected together. Experiments described in Chapter 5 included both dark and low ambient light controls to improve the robustness of data. One of the major difficulties in evaluating the possible effect of UV-B on algal communities is that UV-B sensitivity is species-specific (Cullen \& Neale, 1994, Hernando et al., 2011). There is also a large variation in rates of photoacclimation (Hannach \& Sigleo, 1998). The current study demonstrates that, at the community level, the sea ice algae are capable of withstanding UV-B levels of up to $100 \mathrm{mWm}^{-2}$. They are also capable of withstanding temperatures of up to $5^{\circ} \mathrm{C}$ under ambient levels of UV-B, contrasting with similar studies (Davidson et al., 1994, Helbling et al., 1996) possibly due to differences in community composition. When exposed to increased levels of UV$\mathrm{B}$ at a temperature the algae are likely to face during sea ice melt, the algae maintained their photosynthetic health, likely facilitated by an increase in MAA production. Clearly there is a need for more detailed studies with individual species under carefully controlled laboratory conditions. The responses of individual species to PAR and UV-B are therefore explored further in Chapters 4 and 5 of this thesis. 


\subsection{REFERENCES}

Arrigo, K. R., Lubin, D., van Dijken, G. L., Holm-Hansen, O., \& Morrow, E. (2003). Impact of a deep ozone hole on Southern Ocean primary production. Journal of Geophysical Research, 108, 3154.

Arrigo, K. R., \& Thomas, D. N. (2004). Large scale importance of sea ice biology in the Southern Ocean. Antarctic Science, 16, 471-486.

Atkinson, A. (1994). Diets and feeding selectivity among the epipelagic copepod community near South Georgia in summer. Polar Biology, 14, 551-560.

Bodeker, G. E., Shiona, H., \& Eskes, H. (2005). Indicators of Antarctic ozone depletion. Atmospheric Chemistry and Physics, 5, 2603-2615.

Buckley, R. G., \& Trodahl, H. J. (1987). Scattering and absorption of visible light by sea ice. Nature, 326, 867-869.

Clarke, A., Murphy, E. J., Meredith, M. P., King, J. C., Peck, L. S., Barnes, D. K. A., et al. (2007). Climate change and the marine ecosystem of the western Antarctic Peninsula. Philosophical Transactions of the Royal Society B: Biological Sciences, 362, 149-166.

Convey, P., Bindschadler, R., di Prisco, G., Fahrbach, E., Gutt, J., Hodgson, D. A., et al. (2009). Antarctic climate change and the environment. Antarctic Science, 21, 541-563.

Cullen, J., \& Neale, P. (1994). Ultraviolet radiation, ozone depletion, and marine photosynthesis. Photosynthesis Research, 39, 303-320.

Davidson, A. T., Bramich, D., Marchant, H. J., \& McMinn, A. (1994). Effects of UV-B irradiation on growth and survival of Antarctic marine diatoms. Marine Biology, 119, 507-515.

Döhler, G., Drebes, G., \& Lohmann, M. (1997). Effect of UV-A and UV-B radiation on pigments, free amino acids and adenylate content of Dunaliella tertiolecta Butcher (Chlorophyta). Journal of Photobiology \& Photobiology, B: Biology, 40, 126-131.

Franklin, L., \& Forster, R. (1997). The changing irradiance environment: consequences for marine macrophyte physiology, productivity and ecology. European Journal of Phycology, 32, 207-232.

Gao, Q., \& Garcia-Pichel, F. (2011). Microbial ultraviolet sunscreens. Nature Reviews Microbiology, 9, 791-802.

Häder, D.-P., Kumar, H. D., Smith, R. C., \& Worrest, R. C. (2003). Aquatic ecosystems: effects of solar ultraviolet radiation and interactions with other climatic change factors. Photochemical \& Photobiological Sciences, 2, 39-50.

Halac, S. R., Villafañe, V. E., \& Helbling, E. W. (2010). Temperature benefits the photosynthetic performance of the diatoms Chaetoceros gracilis and Thalassiosira weissflogii when exposed to UVR. Journal of Photochemistry and Photobiology B: Biology, 101, 196-205.

Hannach, G., \& Sigleo, A. C. (1998). Photoinduction of UV-absorbing compounds in six species of marine phytoplankton. Marine Ecology Progress Series, 174, 207-222.

Helbling, E. W., Chalker, B. E., Dunlap, W. C., Holm-Hansen, O., \& Villafane, V. E. (1996). Photoacclimation of antarctic marine diatoms to solar ultraviolet radiation. Journal of Experimental Marine Biology and Ecology, 204, 85-101.

Hernando, M., Malanga, G., Puntarulo, S., \& Ferreyra, G. (2011). Non-enzymatic antioxidant photoprotection against potential UVBR-induced damage in an 
Antarctic diatom (Thalassiosira sp.). Latin American Journal of Aquatic Research, $39,397-408$.

Hessen, D. O., Frigstad, H., Færøvig, P. J., Wojewodzic, M. W., \& Leu, E. (2012). UV radiation and its effects on P-uptake in arctic diatoms. Journal of Experimental Marine Biology and Ecology, 411, 45-51.

Karentz, D. (1994). Ultraviolet tolerance mechanisms in Antarctic marine organisms. Antarctic Research Series, 62, 93-110.

Karentz, D., \& Bosch, I. (2001). Influence of ozone-related increases in ultraviolet radiation on Antarctic marine organisms. American Zoologia, 41, 3-16.

Lubin, D., Frederick, J. E., Booth, C. R., Lucas, T., \& Neuschuler, D. (1989). Measurements of enhanced springtime ultraviolet radiation at Palmer Station, Antarctica. Geophysical Research Letters, 16, 783-785.

Martínez, R. (2007). Effects of ultraviolet radiation on protein content, respiratory electron transport system (ETS) activity and superoxide dismutase (SOD) activity of Antarctic plankton. Polar Biology, 30, 1159-1172.

McMinn, A., Ashworth, C., \& Ryan, K. (1999). Growth and productivity of Antarctic sea ice algae under PAR and UV irradianes. Botanica Marina, 42, 401-407.

McMinn, A., Pankowskii, A., Ashworth, C., Bhagooli, R., Ralph, P., \& Ryan, K. (2010). In situ primary productivity and photosynthesis of Antarctic sea ice algal, phytoplankton and benthic algal communities. Marine Biology, 157, 1345-1356.

Morley, S. A., Griffiths, H. J., Barnes, D. K. A., \& Peck, L. S. (2010). South Georgia: a key location for linking physiological capacity to distributional changes in response to climate change. Antarctic Science, 22, 774-781.

Mundy, C., Gosselin, M., Ehn, J., Belzile, C., Poulin, M., Alou, E., et al. (2011). Characteristics of two distinct high-light acclimated algal communities during advanced stages of sea ice melt. Polar Biology, 34, 1869-1886.

Peinado, N. K., Abdala Díaz, R. T., Figueroa, F. L., \& Helbling, E. W. (2004). Ammonium and $\mathrm{UV}$ radiation stimulate the accumulation of mycosporine-like amino acids in Porphyra columbina (Rhodophyta) from Patagonia, Argentina. Journal of Phycology, 40, 248-259.

Ryan, K. G. (1992). UV radiation and photosynthetic production in Antarctic sea ice microalgae. Journal of Photochemistry and Photobiology B: Biology, 13, 235-240.

Ryan, K. G., \& Beaglehole, D. (1994). Ultraviolet radiation and bottom-ice algae: Laboratory and field studies from McMurdo Sound, Antarctica. Antarctic Research Series, 62, 229-242.

Ryan, K. G., McMinn, A., Mitchell, K. A., \& Trenerry, L. (2002). Mycosporine-like amino acids in Antarctic sea ice algae, and their response to UVB radiation. Zeitschrift fur Naturforschung, 57, 471-477.

Ryan, K. G., Hegseth, E. N., Martin, A., Davy, S. K., O'Toole, R., Ralph, P. J., et al. (2006). Comparison of the microalgal community within fast ice at two sites along the Ross Sea coast, Antarctica. Antarctic Science, 18, 583-594.

Ryan, K. G., Cowie, R. O. M., Liggins, E., McNaughtan, D., Martin, A., \& Davy, S. K. (2009). The short-term effect of irradiance on the photosynthetic properties of antarctic fast-ice microalgal communities. Journal of Phycology, 45, 1290-1298.

Ryan, K. G., McMinn, A., Hegseth, E. N., \& Davy, S. K. (2012). The Effects of Ultraviolet-B Radiation on Antarctic Sea-Ice Algae. Journal of Phycology, 48, 74-84.

Salleh, S., \& McMinn, A. (2011). Photosynthetic response and recovery of Antarctic marine benthic microalgae exposed to elevated irradiances and temperatures. Polar Biology, 34, 855-869. 
Schofield, O., Kroon, B. M. A., \& Prézelin, B. B. (1995). Impact of Ultraviolet-B radiation on photosystem activity and its relationship to the inhibition of carbon fixation rates for Antarctic ice algae communities. Journal of Phycology, 31, 703-715.

Sobrino, C., \& Neale, P. J. (2007). Short-term and long-term effects of temperature on photosynthesis in the diatom Thalassiosira pseudonana under UVR exposures. Journal of Phycology, 43, 426-436.

Stammerjohn, S. E., Martinson, D. G., Smith, R. C., \& Iannuzzi, R. A. (2008). Sea ice in the western Antarctic Peninsula region: Spatio-temporal variability from ecological and climate change perspectives. Deep Sea Research Part II: Topical Studies in Oceanography, 55, 2041-2058.

Turner, J., Barrand, N. E., Bracegirdle, T. J., Convey, P., Hodgson, D. A., Jarvis, M., et al. (2013). Antarctic climate change and the environment: an update. Polar Record, FirstView, 1-23.

Wahl, M., Molis, M., Davis, A., Dobretsov, S., Dürr, S. T., Johansson, J., et al. (2004). UV effects that come and go: a global comparison of marine benthic community level impacts. Global Change Biology, 10, 1962-1972.

Whitehouse, M. J., Priddle, J., \& Symon, C. (1996). Seasonal and annual change in seawater temperature, salinity, nutrient and chlorophyll a distributions around South Georgia, South Atlantic. Deep Sea Research Part I: Oceanographic Research Papers, 43, 425-443.

Williamson, C. E., Grad, G., De Lange, H. J., Gilroy, S., \& Karapelou, D. M. (2002). Temperature-dependent ultraviolet responses in zooplankton: implications of climate change. Limnology and Oceanography, 1844-1848. 


\section{CHAPTER 4}

\section{The effects of PAR and UV-B on sea ice algal cultures from contrasting areas of the Antarctic}

\subsection{ABSTRACT}

Algae in the bottom ice community typically experience low levels of ambient PAR and UV-B. However, during the melting of sea ice, they are exposed to higher levels of PAR, UV-B and temperature, among other factors. Their tolerance limits to these factors could determine their survival and contribution to the algal bloom in the Antarctic summer season. The Ross Sea and Antarctic Peninsula are two contrasting areas of the Antarctic today. The Ross Sea region has recently undergone a slight cooling and change in the wind regime, leading to an increase of sea ice extent of up to $4.5 \%$ per decade. In contrast, there has been a marked increase in temperature in the Antarctic Peninsula region since the 1950s. In this region there have been significant changes in sea ice cover, with delayed autumn ice formation and advance and earlier spring ice retreat resulting in a $10 \%$ decrease in sea ice extent. The thinner sea ice being formed over winter, and earlier melt, release sea ice algae into the water column earlier in spring than previously. As the Antarctic Peninsula region is naturally exposed to higher and more variable temperatures and light exposures than the Ross Sea, algae from here hypothetically should show greater acclimation ability compared to those from regions with lesser environmental variability.

To study PAR and UV-B tolerance and species-specific limits, liquid suspension cultures of the algae Thalassiosira sp. and Fragilariopsis sp. obtained from the Ross Sea, and of Chaetoceros sp. from the western Antarctic Peninsula region, were incubated in laboratory culture at three PAR levels and two UV-B levels over a period of $48 \mathrm{~h}$, and their photosynthetic health and production of MAAs were measured. The two Ross Sea taxa showed tolerance to PAR levels of up to $100 \mu \mathrm{mol} \mathrm{m}^{-2} \mathrm{~s}^{-1}$ and UV-B levels of up to $150 \mathrm{~mW} \mathrm{~m}^{-2}$, indicating their capacity to tolerate higher than ambient levels of PAR and UV-B. The photosynthetic yield of Chaetoceros sp. from the Antarctic Peninsula did not change with increasing stress, and an increase in MAA production was documented at 
the highest experimental UV-B exposure level. These characteristics might enable this species to survive changing conditions associated with sea ice melt, giving an insight into their acclimatory ability. This study has shown that both the Ross Sea species can tolerate higher PAR and UV-B levels than those faced at the bottom of the sea ice, and are less stressed by increasing PAR than by increasing UV-B. The Antarctic Peninsula species showed little evidence of being stressed by PAR or UV-B. Understanding variation in species-specific responses to changing PAR and UV-B conditions help improve predictions of possible future community responses to issues such as climate change.

\subsection{INTRODUCTION}

Sea ice algae contribute $10-28 \%$ of total primary production in the Southern Ocean, with the higher end of the range referring to the Ross Sea region (Arrigo \& Thomas, 2004, Eicken, 1992). However, average productivity in ice free areas of the Southern Ocean is generally low ( 0.4 to $0.8 \mathrm{~g} \mathrm{C} \mathrm{m}^{-2} \mathrm{~d}^{-1}$ ), while areas covered by annual fast ice may reach up to $1.62 \mathrm{~g} \mathrm{C} \mathrm{m}^{-2} \mathrm{~d}^{-1}$ (Arrigo et al., 1998). The structure of sea ice determines the levels of environmental parameters (see Figure 1.1), such as photosynthetically active radiation (PAR), UVR and salinity, experienced by algae within and below the ice (Eicken, 1992, Thomas \& Dieckmann, 2002).

The sea ice itself provides a stable light environment for algae that varies through its vertical profile (Arrigo \& Thomas, 2004, Eicken, 1992). The bottom of the ice is in thermal equilibrium with the underlying seawater at $-1.8^{\circ} \mathrm{C}$, creating a stable temperature habitat that typically results in the highest concentration of algae developing here (Arrigo \& Thomas, 2004). Colder temperatures, higher salinities and PAR intensity nearer the surface select for specialised algal species (Eicken, 1992) leading to niches in the sea ice profile that support several different species. The species composition of the sea ice community can thereby vary through the ice profile (Ryan et al., 2006a, Stoecker et al., 1998, 2000).

Photosynthetic stress caused by higher PAR levels, exposure to UV-B and higher/more variable temperature is experienced by bottom ice algae during sea ice melt in the austral summer, when ice thickness decreases and algae are released into the water 
column (Ryan et al., 2011). As different species respond differently to these environmental stressors, the magnitude of the stresses could provide important influences on the community productivity. Differential tolerance to these stresses may also determine the proportion of biomass and diversity that survives the melt to seed the pelagic algal bloom, and the subsequent winter ice community (Arrigo \& Thomas, 2004, Arrigo, 2014, Lizotte, 2001).

Unprecedented global climate trends have become apparent over the past century (https://www.ipcc.ch/report/ar5/wg1/). Rates of increase in air temperature have been particularly marked in the Antarctic Peninsula and to a lesser extent in West Antarctica generally (Convey et al., 2009, Steig et al., 2009, Turner et al., 2009, 2013b). There is also evidence for oceanic warming off the western Antarctic Peninsula (Martinson et al., 2008, Schofield et al., 2010), which has led to decreases in biological productivity and shifts in species abundance in ecosystems (Clarke et al., 2007, Ducklow et al., 2007, Morley et al., 2010). Since the 1950s, the largest trends in warming have been observed in the western and northern parts of the Antarctic Peninsula (Clarke et al., 2007, Convey et al., 2009), where a warming of $+0.53^{\circ} \mathrm{C}$ per decade (annual mean air temperature) has been observed at Faraday/Vernadsky Station ( $65^{\circ} 15^{\prime} \mathrm{S} 64^{\circ} 16^{\prime} \mathrm{W}$ ) (Turner et al., 2005). The largest increase in temperatures has also occurred here in winter, with an increase of $+1.03^{\circ} \mathrm{C}$ per decade between 1950 and 2006 (Turner et al., 2009). These changes in air temperature can be related to sea ice extent west of the Antarctic Peninsula, as there has been a marked decrease with sea ice duration reducing by more than 5 days a year (Vaughan et al., 2003). There has been a $40 \%$ reduction in annual sea ice duration in this region over a 26 year period, mainly due to reduction of winter sea ice extent (Stammerjohn et al., 2008).

There are currently contrasting responses to climatic change shown by sea ice extent in different parts of Antarctica, with a 4.5\% increase per decade in the Ross Sea and a significant reduction in the Bellinghausen Sea (Convey et al., 2009). The recent deepening of the Amundsen Sea Low (a consistent area of low pressure in the Amundsen Sea), linked with the decrease of stratospheric ozone, has been proposed to underlie the regional increase in sea ice extent in the Ross Sea (Turner et al., 2009). Over the same time period, there has also been a $10 \%$ decrease in sea ice extent in the Amundsen and Bellinghausen seas, mostly through a reduction in the duration of winter 
sea ice (Stammerjohn et al., 2008). The duration of sea ice cover has reduced by 1 to 2 days per year between 1979-1999 at higher southern latitudes (Parkinson, 2002, Vaughan et al., 2003). These changes are predicted to continue, enhancing present trends, and changing the annual dynamics of sea ice cover (Convey et al., 2009, Turner et al., 2009). Sea ice reductions allow greater levels of PAR to reach primary producers in the underlying water column. If these primary producers are able to utilise the increase in PAR, there might be an increase in primary production in these areas (Clarke et al., 2007). However, decreases in primary production have also been observed off some parts of the Antarctic Peninsula (Montes-Hugo et al., 2009), making interpretation more complex.

Spring levels of ozone in the stratosphere declined rapidly in the late 1970s due to the anthropogenic release of chlorofluorocarbons, leading to formation of the ozone hole over the continent each spring (Farman et al., 1985). This decrease has now stabilised even though no sign of the predicted recovery has yet been seen (Bodeker et al., 2005, Convey et al., 2009, Turner et al., 2013a). Springtime depletion of ozone over Antarctica has led to an increase in the shorter wavelength high energy and biologically damaging UV-B part of the ultraviolet radiation (UVR) spectrum reaching the sea surface. This increase in UV-B has resulted in a reduction in primary productivity and increased DNA damage in both pelagic and sea ice algae (Arrigo et al., 2003, Arrigo \& Thomas, 2004, Hessen et al., 2012, Nahon et al., 2010, Peinado et al., 2004). Ultraviolet radiation, specifically UV-B radiation, inhibits photosynthesis in sea ice algae by causing damage to the D1 reaction centre in photosystem II, decreasing electron transport (Peinado et al., 2004, Van de Poll \& Buma, 2009).

To protect themselves from UVR, one of the main mechanisms utilised by sea ice algae is the production of mycosporine-like amino acids (MAAs) (Helbling et al., 1996, Mundy et al., 2011, Peinado et al., 2004, Ryan et al., 2002, Schofield et al., 2010). When cellular MAA concentrations are low, photosynthesis is more inhibited than when they are high (Helbling et al., 1996). The greater capacity of Antarctic diatoms to produce MAAs also results in a shift in community species composition from flagellates to diatoms under greater UVR exposure (Helbling et al., 1996, Karentz et al., 1991, Karentz, 1994). Very few studies have identified the production of MAAs by sea ice algae in response to any 
other stressors, such as irradiance (Chapter 2, Section 2.4.2.3) (Hannach \& Sigleo, 1998, Helbling et al., 1996).

Along the Antarctic Peninsula, the recent loss of ice shelves and retreat of coastal glaciers have resulted in phytoplankton blooms and increasing carbon sinks in the newly exposed area and water column (Peck et al., 2010). In contrast, an unexpected consequence of reducing sea ice cover in some areas on the western side of the Antarctic Peninsula has been a decrease in phytoplankton concentrations (MontesHugo et al., 2009). Changes in phytoplankton biomass have been linked with subsequent decreases in krill populations and increases in salp numbers in the Atlantic sector of the Southern Ocean (Atkinson et al., 2004, Hays et al., 2005, Trivelpiece et al., 2011). A shift in the contribution of phytoplankton to ecosystem processes, ultimately influenced by current trends in temperature, therefore appears to be leading to an ecologically significant negative impact on the entire oceanic food web, as salps prefer the non-diatom species surviving these changes and are not as nutritious or palatable as krill (Ducklow et al., 2007, Moline et al., 2004). Furthermore, during periods of decreased sea ice extent, chinstrap and Adélie penguin breeding failures due to a reduction in Antarctic krill biomass have been documented (Forcada et al., 2006). Changes in sea ice extent are also expected to have a significant effect on the balance between different penguin populations as gentoo penguins are better adapted to icefree conditions than Adélie penguins (Forcada et al., 2006).

Many studies have examined the effects of particular environmental parameters on unialgal cultures isolated either directly from sea ice or from the phytoplankton (Antal et al., 2011, Lüder et al., 2002, Nahon et al., 2010, Petrou \& Ralph, 2011). However, very few of these have examined the synergistic effects of multiple stressors. In two chlorophyll fluorescence studies (Halac et al., $(2009,2010)$ on the effects of PAR, UVR and temperature on temperate and tropical diatom cultures, colder temperatures increased sensitivity to UVR. However, the opposite trends were seen in symbiotic dinoflagellates and cyanobacteria. Such studies suggest that different species do not react in the same manner to varying environmental parameters. Clarifying the effects of multiple stressors is crucial to our understanding of the effects of natural current and future environmental variability on algal productivity in sea ice and pelagic ecosystems. (Halac et al., 2010). 
The most common algae found in bottom-ice communities of fast ice are pennate diatoms, reaching high levels of biomass during the summer (Ryan et al., 2006b). Striking differences exist between the brine channel and bottom algal communities within the Ross Sea (Ryan et al., 2006b), as the environmental parameters of the brine channels allow the growth of species such as the dinoflagellate Polarella glacialis, which is usually found in upper sea ice where PAR levels are higher and temperatures are lower (Andreoli et al., 2000). Alternatively, locations such as Cape Hallett which are characterised by strong under-ice currents that prevent the formation of productive brine channels are not conducive to algal species with large cells such as Entomoneis kjellmanii and Berkeleya adeliensis (Ryan et al., 2006b). Such studies illustrate how the structure of the sea ice and the environmental parameters experienced within it can lead to the development of distinct sea ice algal communities.

Differences in algal species can also be seen in the communities of other ice-covered areas experiencing seasonal changes in environmental parameters. In McMurdo Sound, in the Ross Sea region, a dynamic successional change takes place, from cryo- and halotolerant chrysophytes and dinoflagellates in spring to an abundance of pennate diatoms in late summer, associated with increasing PAR, UVR and temperature and decreasing salinity (Stoecker et al., 1998, 2000).

The characteristics of phytoplankton assemblages have been extensively studied in the Ross Sea (Smith et al., 2014). Many studies have investigated the effect of changing environmental conditions on the physiology of sea ice algae in this region (Andreoli et al., 2000, Arrigo et al., 1993, McMinn et al., 1999, Ryan et al., 2012). However, although the distribution of marine algal biomass and productivity have been documented at several Antarctic Peninsula locations (Fritsen et al., 2008, 2011, Longhi et al., 2003, Moreau et al., 2010), very few studies have examined the effect of changing environmental conditions on the photosynthetic yield of sea ice algae or phytoplankton in this region (Alderkamp et al., 2011). Due to decreasing extent and duration of sea ice, the algae in this latter region of Antarctica are increasingly challenged to survive under conditions similar to those in the open ocean. Indeed, many species are found throughout the marine ecosystem (Petrou et al., 2011a) and, therefore, could show the ability to acclimatise to higher exposures of PAR and UVR. 
The effects of PAR and UV-B stresses on sea ice algae during melting have been studied using various techniques (Arrigo \& Thomas, 2004, Klisch \& Hader, 2008, Oren \& GundeCimerman, 2007), including Pulse Amplitude Modulation (PAM) fluorometry, an approach that permits measurement of photosynthetic yield in living algae (McMinn et al., 2003, Ryan et al., 2012, Salleh \& McMinn, 2011). Studies carried out in darkness or under low PAR conditions indicate that melting itself does not cause stress to the photosystems (Ryan et al., 2004, Ryan et al., 2011). However, when ice algae were subjected to melting under higher PAR conditions similar to those found in the middle to upper layers of the sea ice, the quantum yield dropped significantly followed by a gradual recovery (Ryan et al., 2011), indicating that high PAR stressed the algae but also that this damage may not be permanent. The ability to tolerate high levels of PAR stress during melting at the end of spring could be an important factor determining which algae become part of the algal bloom that occurs after ice melt. Alternatively, ice algae may simply become a source of nutrients for krill and other grazers should they not survive the stresses experienced during ice melt (Ryan et al., 2004).

Predictions of ice-associated algal community responses to decreasing sea ice cover are hard to test due to the complexity of the interactions between temperature, PAR and UV-B on the different components of this complex community (Clarke et al., 2007). Therefore, focusing studies on selected key species could help to clarify the effects of these parameters. This study examined the effect of exposure to three PAR levels and two UV-B levels on cultures of Thalassiosira sp. and Fragilariopsis sp. isolated from sea ice from the Ross Sea. Their ability to photo-acclimate, their limit of PAR saturation, and how efficiently they utilise PAR and can tolerate exposures to ecologically relevant levels of UV-B were measured. The data obtained are used to clarify the effects of PAR and UV-B stresses on unialgal cultures when they are exposed to conditions analogous to those they can experience during sea ice melt. The study sets out to improve our assessment of the species' vulnerability during the melting process and the effects of climate change, and in turn their possible influence on primary production during the summer algal bloom, and the seeding of future sea ice communities (Giesenhagen et al., 1999). This study also addresses the effects of varying PAR and UV-B levels on photosynthetic yield and MAA production in cultures of Chaetoceros sp., from the western Antarctic Peninsula. As environmental change here is occurring faster than elsewhere in the continent and much of the Southern Ocean, responses seen in this 
region could serve as a proxy for predicting changes in the future for the latter regions. As algae are naturally exposed in the Antarctic Peninsula region to higher and more variable temperatures and exposures to PAR and UV-B than are those associated with sea ice in the Ross Sea, it is hypothesized that they may show less evidence of stress under comparable experimental conditions. The response of each species to imposed variability in these parameters will give insight into their acclimatory capacity and thereby help improve predictions of possible future community responses.

\subsection{METHODS}

\subsubsection{Culture methodology}

Unialgal stock cultures were maintained in Victoria University of Wellington under illumination of $50 \mu \mathrm{mol} \mathrm{m}^{-2} \mathrm{~s}^{-1}$ at $4^{\circ} \mathrm{C}$ in $\mathrm{f} / 2$ medium (Ausaqua Pty Ltd., Australia) for 5 to 6 months prior to the studies described. Maintenance under these standard PAR and temperature conditions meant that these cultures were pre-acclimated to conditions different from those found naturally at the base of the sea ice.

The two Ross Sea taxa, Thalassiosira sp. and Fragilariopsis sp., were isolated from sea ice at Cape Evans in the summer of 2010/2011. Stock cultures of the Antarctic Peninsula species, Chaetoceros sp., were supplied by Dr. Claire Hughes (University of East Anglia) having been obtained as part of studies under the Rothera Time Series maintained by the British Antarctic Survey near its Rothera Research Station in Ryder

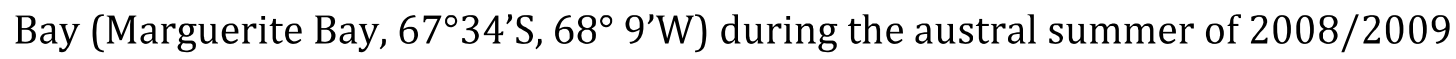
(http://www.antarctica.ac.uk//staff-profiles/webspace/mmm/RaTS/RaTS.html).

PAR treatments: $50 \mathrm{ml}$ sub-samples of unialgal cultures ( $\mathrm{n}=3$ at each PAR level) were incubated under one of four PAR levels $\left(100 \mu \mathrm{mol} \mathrm{m}^{-2} \mathrm{~s}^{-1}, 45 \mu \mathrm{mol} \mathrm{m}{ }^{-2} \mathrm{~s}^{-1}, 1 \mu \mathrm{mol} \mathrm{m}^{-2} \mathrm{~s}^{-1}\right.$, $0 \mu \mathrm{mol} \mathrm{m}^{-2} \mathrm{~s}^{-1}$ ) at $4^{\circ} \mathrm{C}$ for $48 \mathrm{~h}$ in a water bath as described in Section 2.3.4.

UV-B treatments: $50 \mathrm{ml}$ sub-samples of unialgal cultures ( $\mathrm{n}=4$ at each UV-B level) were incubated under one of two UV-B levels $\left(150 \mathrm{mWm}^{-2} \mathrm{~s}^{-1}, 50 \mathrm{mWm}^{-2} \mathrm{~s}^{-1}\right)$ or in the dark at $4^{\circ} \mathrm{C}$ for $48 \mathrm{~h}$. Both UV-B treatments also experienced an ambient PAR level of $1 \mu \mathrm{mol} \mathrm{m}{ }^{-2}$ $\mathrm{s}^{-1}$. 
In all cultures in the PAR exposure section (Section 4.4.1), there were no significant differences detected between any of the photosynthetic parameters of algae maintained in the dark and at $1 \mu \mathrm{mol} \mathrm{m} \mathrm{m}^{-2} \mathrm{~s}^{-1}$. The control for the UVB treatments used here was therefore the dark treatment. This does decrease the scope of interpretation of the data from these experiments. However difference in responses to varying levels of PAR and UV-B can still be discussed.

\subsubsection{Sub-sampling, PAM fluorometry and statistical analyses}

Sub-sampling, PAM fluorometry and MAA analysis protocols are described in Section 2.3.5. Statistical analyses were performed as described in Section 2.3.6 and all differences referred to are statistically significant at $p<0.05$.

Due to an artefact of the water PAM functioning, data obtained at the $4 \mathrm{~h}$ timepoint for all PAR treatments of Chaetoceros sp. were invalid, and were therefore removed before analysis of the results obtained.

\subsection{RESULTS}

\subsubsection{Effect of different PAR levels on Thalassiosira sp. and Fragilariopsis sp.}

This study addresses the effects of varying PAR and UV-B levels on photosynthetic yield and MAA production in cultures of two Ross Sea ice algal species, Thalassiosira sp. and Fragilariopsis sp.

Initially a two way repeated measures ANOVA was conducted for all parameters with time as the 'within' factor and treatment and species as 'between' factors (see Appendix 3, Table A3.1, A3.2, A3.3 for PAR, A3.6, A3.7, A3.8 for UV-B). These showed varying results, although all interaction terms were significant for the two photosynthetic parameters (Table 4.1). As the significant 3-way interactions make it impossible to separate the individual treatment effects, repeated measures analyses were carried out for each species separately to test for the effect of all treatments and time. 
Table 4.1. Probability values for changes in quantum yield of photosystem II, rETR max $_{\text {ax }}$ and MAA productior Fragilaropsis sp. over $48 \mathrm{~h}$ experimental treatments at (a) different PAR levels $\left(0,1,45\right.$ and $100 \mu \mathrm{mol} \mathrm{m}^{-2}$ $B$ levels $\left(0,50\right.$ and $\left.150 \mathrm{mWm}^{-2}\right)$ and a PAR level of $1 \mu \mathrm{mol} \mathrm{m}-2 \mathrm{~s}^{-1}$ for the two UV-B treatments at $4^{\circ} \mathrm{C}$, analy ANOVA.

\begin{tabular}{|c|c|c|c|c|}
\hline Source of variation & Time & Time $\mathrm{x}$ Treatments & Time $x$ Species & Time $\mathrm{x}^{\prime}$ \\
\hline \multicolumn{5}{|l|}{ (a) Effect of PAR: } \\
\hline фPSII & $<0.001$ & $<0.001$ & $<0.001$ & 0.002 \\
\hline rETR $_{\max }$ & $<0.001$ & $<0.001$ & $<0.001$ & $<0.001$ \\
\hline MAAs & $<0.001$ & 0.072 & 0.114 & 0.422 \\
\hline \multicolumn{5}{|l|}{ (b) Effect of UV-B } \\
\hline фPSII & $<0.001$ & $<0.001$ & $<0.001$ & $<0.001$ \\
\hline rETR $_{\max }$ & $<0.001$ & $<0.001$ & $<0.001$ & 0.415 \\
\hline MAAs & $<0.001$ & 0.163 & 0.003 & 0.128 \\
\hline
\end{tabular}




\subsubsection{Effect of different PAR levels on photosynthetic performance of \\ Thalassiosira sp. and Fragilariopsis sp.}

\section{Quantum Yield (申PSII)}

A repeated measures ANOVA was carried out for each species separately to test for effects of all treatments and time (Table 4.2).

Table 4.2. Changes in quantum yield of photosystem II over $48 \mathrm{~h}$ experimental treatments at different PAR levels $\left(0,1,45\right.$ and $\left.100 \mu \mathrm{mol} \mathrm{m}^{-2} \mathrm{~s}^{-1}\right)$ at $4^{\circ} \mathrm{C}$, analysed using repeated measures ANOVA. Significant changes identified by post hoc pairwise analyses are also listed.

\begin{tabular}{|c|c|c|c|c|c|}
\hline Source of variation & $\mathrm{df}$ & MS & $F$ & $\mathrm{p}$ & post hoc comparisons \\
\hline \multicolumn{6}{|l|}{$\begin{array}{l}\text { Thalassiosira sp. } \\
\text { Within subjects }\end{array}$} \\
\hline Time & 2.136 & 0.070 & 84.467 & $<0.001$ & Increase over $48 \mathrm{~h}$ \\
\hline Time $\mathrm{x}$ Treatments & 6.407 & 0.016 & 18.757 & $<0.001$ & (see text for details) \\
\hline Error & 17.085 & 0.004 & & & \\
\hline \multicolumn{6}{|l|}{ Between subjects } \\
\hline Treatments & 3 & 0.012 & 6.006 & 0.019 & $0=1=45 \mu \mathrm{mol} \mathrm{m}^{-2} \mathrm{~s}^{-1}$ \\
\hline Error & 8 & 0.014 & & & $\begin{array}{l}45=100 \mu \mathrm{mol} \mathrm{m}^{-2} \mathrm{~s}^{-1} \\
(0=1)>100 \mu \mathrm{mol} \mathrm{m}^{-2}\end{array}$ \\
\hline \multicolumn{6}{|l|}{$\begin{array}{l}\text { Fragilariopsis sp. } \\
\text { Within subjects }\end{array}$} \\
\hline Time & 1.629 & 0.082 & 73.687 & $<0.001$ & Increase over $48 \mathrm{~h}$ \\
\hline Time $\mathrm{x}$ Treatments & 4.886 & 0.013 & 11.847 & $<0.001$ & (see text for details) \\
\hline Error & 13.029 & 0.001 & & & \\
\hline \multicolumn{6}{|l|}{ Between subjects } \\
\hline Treatments & 3 & 0.131 & 38.206 & $<0.001$ & $(0=1)>45>100 \mu \mathrm{mol}$ \\
\hline Error & 8 & 0.003 & & & \\
\hline
\end{tabular}

\section{Thalassiosira sp.}

The general response of Thalassiosira sp. (Table 4.2; Figure 4.1(a)) at $0 \mu \mathrm{mol} \mathrm{m} \mathrm{m}^{-2} \mathrm{~s}^{-1}$ and $1 \mu \mathrm{mol} \mathrm{m} \mathrm{m}^{-2} \mathrm{~s}^{-1}$ was an initial increase followed by a stable response until $48 \mathrm{~h}$ resulting in an overall increase in PPSII. However, at the higher PAR levels of $45 \mu \mathrm{mol} \mathrm{m}^{-2} \mathrm{~s}^{-1}$ and $100 \mu \mathrm{mol} \mathrm{m} \mathrm{m}^{-2} \mathrm{~s}^{-1}$, the algae showed an initial decrease, followed by a recovery after $2 \mathrm{~h}$ to reach the same levels as algae at the lower PAR levels of $0 \mu \mathrm{mol} \mathrm{m} \mathrm{m}^{-2} \mathrm{~s}^{-1}$ and $1 \mu \mathrm{mol} \mathrm{m}^{-}$ ${ }^{2} \mathrm{~s}^{-1}$ by $12 \mathrm{~h}$. At this point, algae at $45 \mu \mathrm{mol} \mathrm{m} \mathrm{m}^{-2} \mathrm{~s}^{-1}$ showed a steady increase in $\phi_{\text {PSII }}$ until 
$48 \mathrm{~h}$. Those incubated at $100 \mu \mathrm{mol} \mathrm{m}{ }^{-2} \mathrm{~s}^{-1}$ remained stable until $24 \mathrm{~h}$, then showing a rapid increase in the last $24 \mathrm{~h}$ to reach the same $\phi_{\mathrm{PSII}}$ as those at $45 \mu \mathrm{mol} \mathrm{m}^{-2} \mathrm{~s}^{-1}$ by $48 \mathrm{~h}$. Repeated measures ANOVA identified no significant increase over the $48 \mathrm{~h}$ time interval in any treatment, although this may be a consequence of the relatively high variability in the data obtained at $\mathrm{t}=0 \mathrm{~h}$. At the $48 \mathrm{~h}$ time point, algae at the higher PAR treatments showed a significantly higher (Bonferroni, $\mathrm{p}<0.001$ ) $\phi_{P S I I}$ than those at the lower PAR treatments.

\section{Fragilariopsis sp.}

The general response of Fragilariopsis sp. (Table 4.2; Figure 4.1(b)) at $0 \mu \mathrm{mol} \mathrm{m}^{-2} \mathrm{~s}^{-1}$ and $1 \mu \mathrm{mol} \mathrm{m}{ }^{-2} \mathrm{~s}^{-1}$ was an initial increase in $\phi$ PsII in the first $2 \mathrm{~h}$ after which the response stayed constant. Algae at the higher PAR treatments showed an initial decrease in the first $2 \mathrm{~h}$, followed by a gradual recovery to reach the same $\phi_{\mathrm{PSII}}$ as algae at the lower PAR treatments by $12 \mathrm{~h}$. After $12 \mathrm{~h}$, algae at both high PAR treatments showed a slight decrease followed by a recovery in the last $24 \mathrm{~h}$. Repeated measures ANOVA identified only a significant increase (Bonferroni, $\mathrm{p}=0.027$ ) between time 6 and $12 \mathrm{~h}$ for algae at $45 \mu \mathrm{mol} \mathrm{m}{ }^{-2} \mathrm{~s}^{-1}$. However, at $48 \mathrm{~h}, \phi_{\text {PSII }}$ for algae at all PAR treatments were not significantly different from each other. 
a)

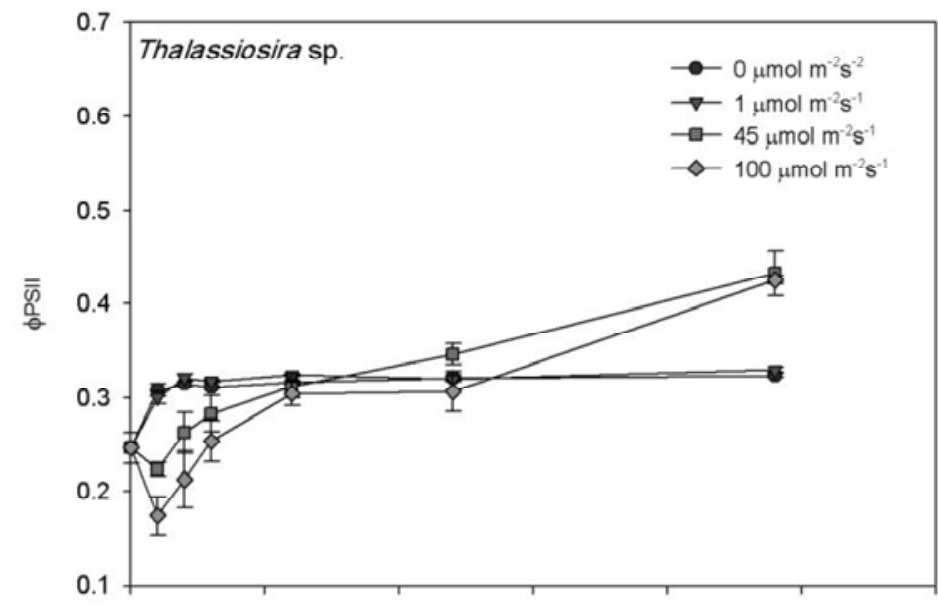

b)

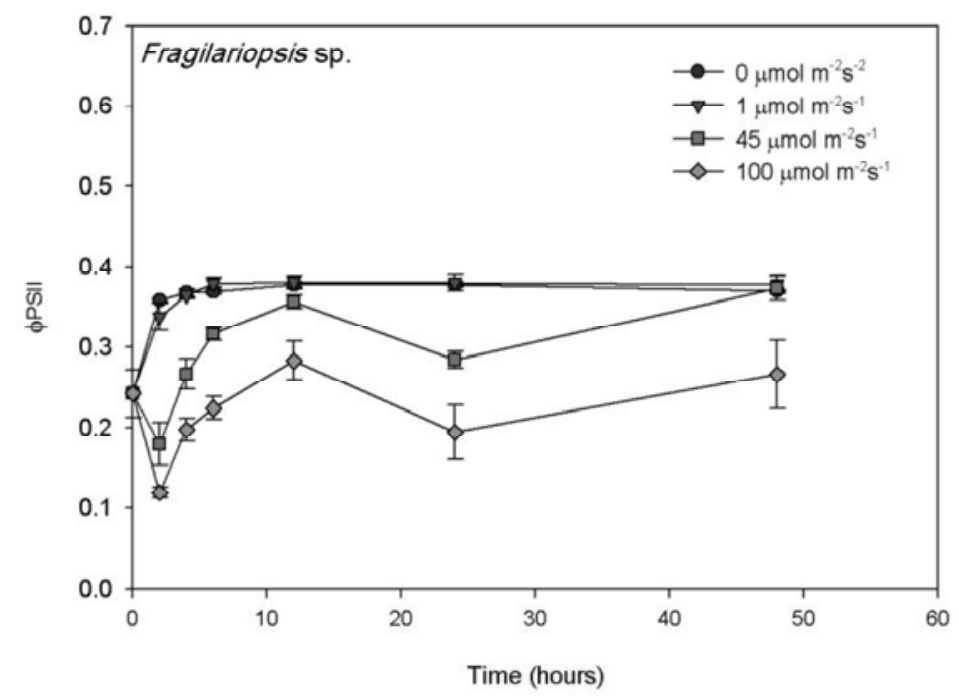

Fig 4.1. Quantum Yield ( $\phi_{\text {PSII }}$ ) at $0,2,4,6,12,24$ and $48 \mathrm{~h}$. Cultures were maintained at PAR levels of 0, 1, 45 or $100 \mu \mathrm{mol} \mathrm{m}^{-2} \mathrm{~s}^{-1}$, for (a) Thalassiosira sp. and (b) Fragilariopsis sp. Error bars indicate standard error.

\section{Relative ETR $\mathbf{R}_{\max }$}

A repeated measures ANOVA was carried out for each species separately to test for effects of all treatments and time (Table 4.3). 
Table 4.3: Changes in rETR max $_{\text {of }}$ photosystem II over $48 \mathrm{~h}$ experimental treatments at different PAR levels $\left(0,1,45\right.$ and $\left.100 \mu \mathrm{mol} \mathrm{m}^{-2} \mathrm{~s}^{-1}\right)$ at $4^{\circ} \mathrm{C}$, analysed using repeated measures ANOVA. Significant changes identified by post hoc pairwise analyses are also listed.

\begin{tabular}{|c|c|c|c|c|c|}
\hline Source of variation & $\mathrm{df}$ & MS & $F$ & $\mathrm{p}$ & post hoc comparisons \\
\hline \multicolumn{6}{|l|}{$\begin{array}{l}\text { Thalassiosira sp. } \\
\text { Within subjects }\end{array}$} \\
\hline Time & 1.420 & 198.588 & 67.166 & $<0.00$ & \multirow{3}{*}{$\begin{array}{l}\text { No significant change over } 48 \mathrm{~h} \\
\text { (see text for details) }\end{array}$} \\
\hline Time $\mathrm{x}$ Treatments & 4.260 & 108.049 & 36.544 & $<0.00$ & \\
\hline Error & 11.359 & 2.957 & & & \\
\hline \multicolumn{6}{|l|}{ Between subjects } \\
\hline Treatments & 3 & 56.268 & 14.691 & 0.001 & \multirow[t]{2}{*}{$(0=1)<(45=100) \mu \mathrm{mol} \mathrm{m}^{-2} \mathrm{~s}^{-1}$} \\
\hline Error & 8 & 3.830 & & & \\
\hline \multicolumn{6}{|l|}{$\begin{array}{l}\text { Fragilariopsis sp. } \\
\text { Within subjects }\end{array}$} \\
\hline Time & 6 & 4.803 & 7.254 & $<0.00$ & \multirow{3}{*}{$\begin{array}{l}\text { No change over } 48 \mathrm{~h} \\
\text { (see text for details) }\end{array}$} \\
\hline Time $\mathrm{x}$ Treatments & 18 & 2.633 & 3.976 & $<0.00$ & \\
\hline Error & 48 & 0.662 & & & \\
\hline \multicolumn{6}{|l|}{ Between subjects } \\
\hline Treatments & 3 & 1.041 & 0.379 & 0.771 & No significance \\
\hline Error & 8 & 2.749 & & & \\
\hline
\end{tabular}

\section{Thalassiosira sp.}

The general response of Thalassiosira sp. (Table 4.3; Figure 4.2(a)) was for rETR max $_{\text {ax }}$ to decrease for algae at all PAR treatments in the first $2 \mathrm{~h}$, after which it stayed constant until $12 \mathrm{~h}$. After this time point, values recorded at the lower PAR levels decreased until the end of the incubation, with algae at $1 \mu \mathrm{mol} \mathrm{m}^{-2} \mathrm{~s}^{-1}$ having a slightly lower $\mathrm{rETR}_{\max }$ than those in the dark. Algae at the higher PAR levels showed an increase in rETR max between $12 \mathrm{~h}$ and the end of the incubation, with algae at $45 \mu \mathrm{mol} \mathrm{m}^{-2} \mathrm{~s}^{-1}$ having a higher $\mathrm{rETR}_{\max }$ than those incubated at $100 \mu \mathrm{mol} \mathrm{m}^{-2} \mathrm{~s}^{-1}$. When each treatment was analysed with a repeated measures ANOVA, there was a significant decrease (Bonferroni, $\mathrm{p}=0.019$ ) in $\mathrm{rETR}_{\max }$ at $0 \mu \mathrm{mol} \mathrm{m}^{-2} \mathrm{~s}^{-1}$ over $48 \mathrm{~h}$. The only other significant change identified was the increase (Bonferroni, $\mathrm{p}=0.010$ ) seen in algae incubated at 45 $\mu \mathrm{mol} \mathrm{m}^{-2} \mathrm{~s}^{-1}$ between 24 and $48 \mathrm{~h}$. At $48 \mathrm{~h}, \mathrm{rETR}_{\max }$ for the algae at higher PAR levels was significantly greater (Bonferroni, $\mathrm{p}<0.001$ ) than those at the lower PAR levels. 


\section{Fragilariopsis sp.}

The general response of Fragilariopsis sp. (Table 4.3; Figure 4.2(b)) was for algae at the higher PAR levels to show increases in rETR $_{\max }$, giving higher values compared to the algae incubated at the lower PAR levels by the end of the incubation. Repeated measures ANOVA identified no significant changes over the $48 \mathrm{~h}$ period for any of the PAR treatments.

a)

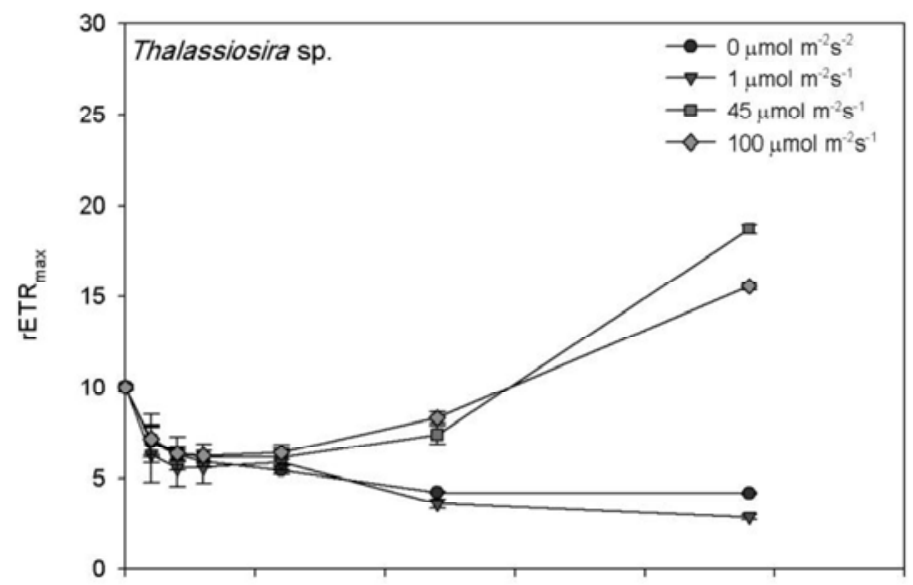

b)

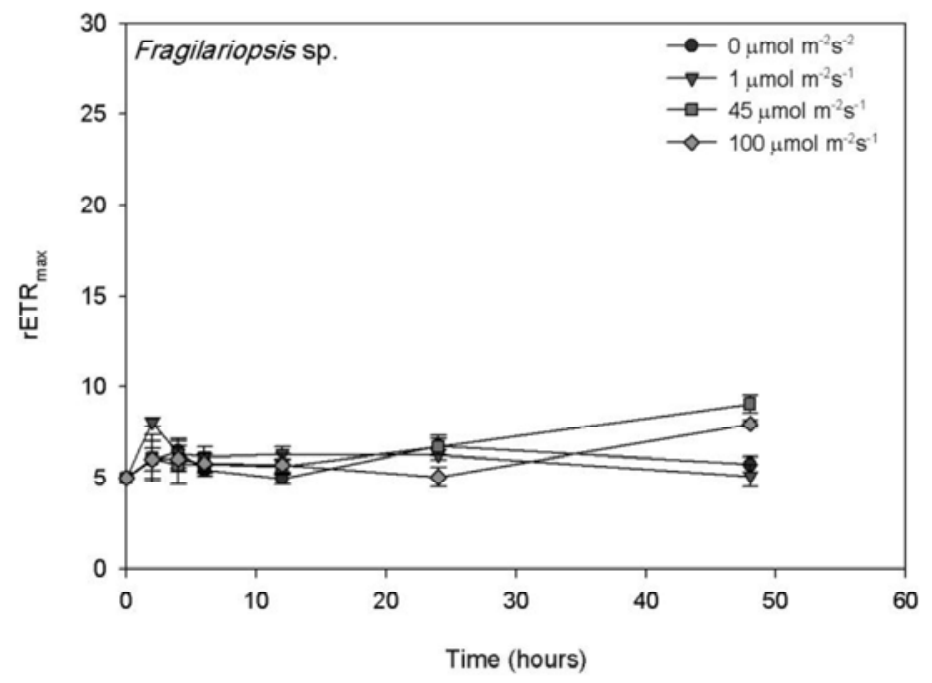

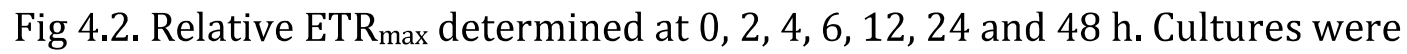
maintained at PAR levels of $0,1,45$ or $100 \mu \mathrm{mol} \mathrm{m}^{-2} \mathrm{~s}^{-1}$, for (a) Thalassiosira sp. and (b) Fragilariopsis sp. Error bars indicate standard error. 


\section{MAA production}

A repeated measures ANOVA was carried out for each species separately to test for effects of all treatments and time (Table 4.4).

Table 4.4. Changes in MAA production over $48 \mathrm{~h}$ experimental treatments at different PAR levels $\left(0,1,45\right.$ and $\left.100 \mu \mathrm{mol} \mathrm{m}^{-2} \mathrm{~s}^{-1}\right)$ at $4^{\circ} \mathrm{C}$, analysed using repeated measures ANOVA. Significant changes identified by post hoc pairwise analyses are also listed.

\begin{tabular}{|c|c|c|c|c|c|}
\hline Source of variation & $\mathrm{df}$ & MS & $F$ & $\mathrm{p}$ & post hoc comparisons \\
\hline \multicolumn{6}{|l|}{$\begin{array}{l}\text { Thalassiosira sp. } \\
\text { Within subjects }\end{array}$} \\
\hline Time & 1 & 1.549E-009 & 9.807 & 0.014 & Increase over $48 \mathrm{~h}$ \\
\hline Time $\mathrm{x}$ Treatments & 3 & 4.089E-011 & 0.259 & 0.853 & \\
\hline Error & 8 & $1.579 \mathrm{E}-010$ & & & \\
\hline \multicolumn{6}{|l|}{ Between subjects } \\
\hline Treatments & 3 & $4.089 \mathrm{E}-011$ & 0.280 & 0.838 & No significance \\
\hline Error & 8 & $1.458 \mathrm{E}-010$ & & & \\
\hline \multicolumn{6}{|l|}{$\begin{array}{l}\text { Fragilariopsis sp. } \\
\text { Within subjects }\end{array}$} \\
\hline Time & 1 & 5.352E-009 & 35.899 & $<0.05$ & Increase over $48 \mathrm{~h}$ \\
\hline Time $x$ Treatments & 3 & $4.646 \mathrm{E}-010$ & 3.116 & 0.088 & \\
\hline Error & 8 & $1.419 \mathrm{E}-010$ & & & \\
\hline \multicolumn{6}{|l|}{ Between subjects } \\
\hline Treatments & 3 & 7.374E-011 & 0.738 & 0.558 & No significance \\
\hline Error & 8 & $9.985 \mathrm{E}-011$ & & & \\
\hline
\end{tabular}

\section{Thalassiosira sp.}

Algae at the higher PAR treatments showed an increase in MAA production over $48 \mathrm{~h}$ (Table 4.4; Figure 4.3(a)). However, repeated measures ANOVA identified no significant increase over the $48 \mathrm{~h}$ time interval in any treatment, although this may be a consequence of the relatively high variability in the data obtained at $t=0 \mathrm{~h}$. At $48 \mathrm{~h}$, MAA production for algae at $100 \mu \mathrm{mol} \mathrm{m}^{-2} \mathrm{~s}^{-1}$ was significantly higher (Bonferroni, $\mathrm{p}=0.023$ ) than those incubated in the dark. 
Algae at all PAR treatments other than $1 \mu \mathrm{mol} \mathrm{m}^{-2} \mathrm{~s}^{-1}$ showed an increase in MAA production over $48 \mathrm{~h}$ (Table 4.4; Figure 4.3(b)). However, repeated measures ANOVA identified no significant increase over the $48 \mathrm{~h}$ time interval in any treatment, although this again may be a consequence of the relatively high variability in the data obtained at $\mathrm{t}=0 \mathrm{~h}$. 
a)

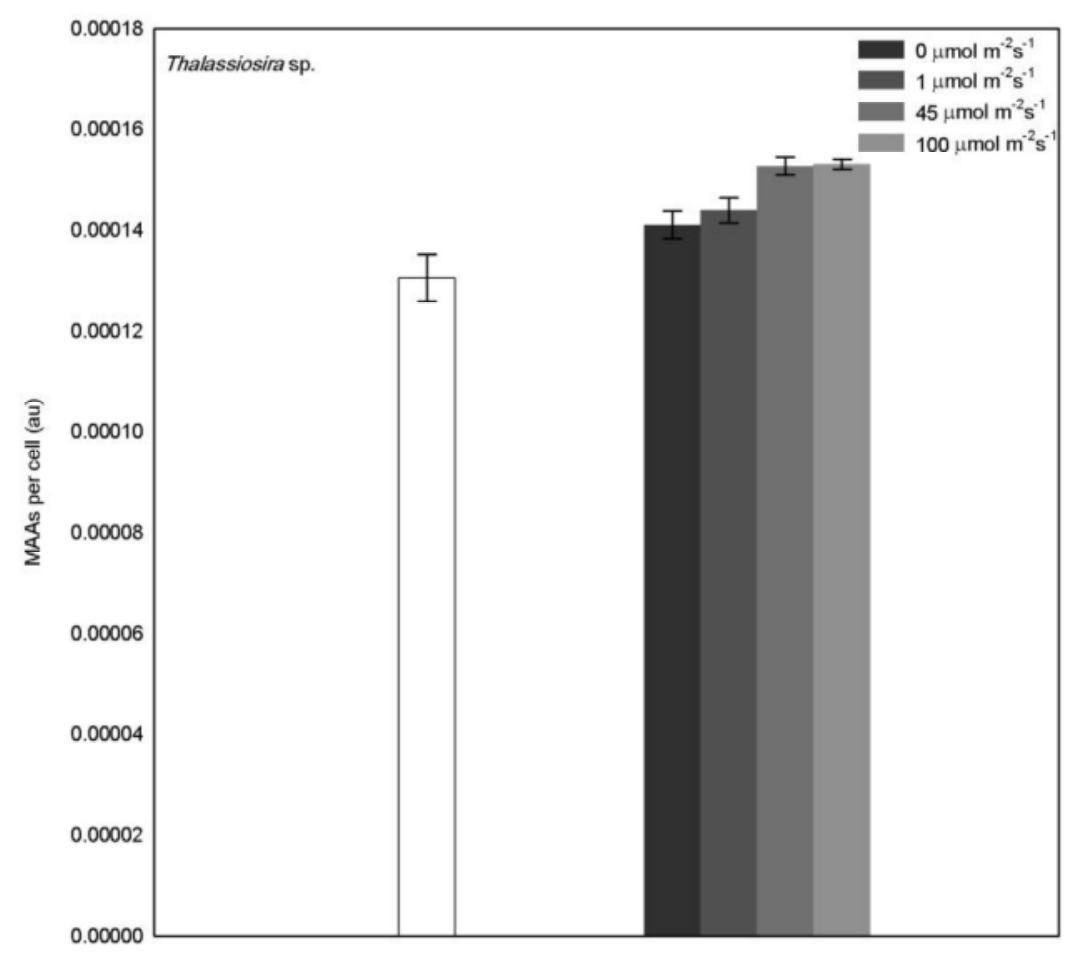

b)

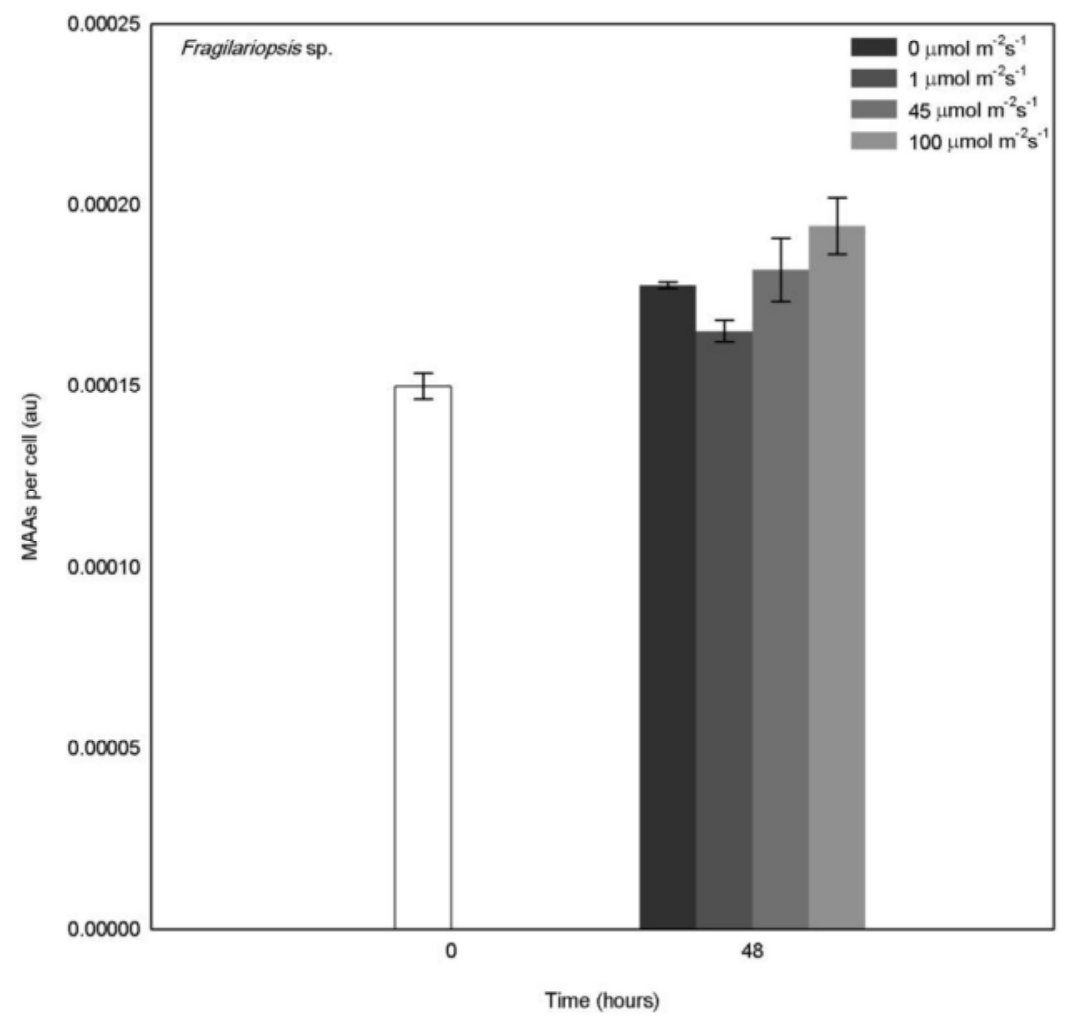

Fig 4.3. MAA production determined at 0 and $48 \mathrm{~h}$. Cultures were maintained at PAR levels of $0,1,45$ or $100 \mu \mathrm{mol} \mathrm{m}^{-2} \mathrm{~s}^{-1}$ for (a) Thalassiosira sp. and (b) Fragilariopsis sp. Error bars indicate standard error. 


\subsubsection{Effect of UV-B on photosynthetic parameters of Thalassiosira sp. and Fragilariopis sp.}

\section{Quantum Yield (}

A repeated measures ANOVA was carried out for each species separately to test for effects of all treatments and time (Table 4.5).

Table 4.5. Changes in quantum yield of photosystem II over $48 \mathrm{~h}$ experimental treatments at different UV-B levels $\left(0,50\right.$ and $\left.150 \mathrm{mWm}^{-2}\right)$ and a PAR level of $1 \mu \mathrm{mol} \mathrm{m}$ ${ }^{2} \mathrm{~s}^{-1}$ for the two UV-B treatments at $4^{\circ} \mathrm{C}$, analysed using repeated measures ANOVA.

Significant changes identified by post hoc pairwise analyses are also listed.

\begin{tabular}{|c|c|c|c|c|c|}
\hline Source of variation & $\mathrm{df}$ & MS & $F$ & $\mathrm{p}$ & post hoc comparisons \\
\hline \multicolumn{6}{|l|}{$\begin{array}{l}\text { Thalassiosira sp. } \\
\text { Within subjects }\end{array}$} \\
\hline Time & 2.993 & 0.002 & 28.998 & $<0.001$ & Increase over $48 \mathrm{~h}$ \\
\hline Time $\mathrm{x}$ Treatments & 5.986 & 0.001 & 17.973 & $<0.001$ & (see text for details) \\
\hline Error & 26.938 & $7.278 \mathrm{E}-005$ & & & \\
\hline \multicolumn{6}{|l|}{ Between subjects } \\
\hline Treatments & 2 & 0.002 & 5.064 & 0.034 & $0=50 \mathrm{mWm}^{-2}$ \\
\hline \multirow[t]{2}{*}{ Error } & 9 & 0.000 & & & $50=100 \mathrm{mWm}^{-2}$ \\
\hline & & & & & $0>150 \mathrm{mWm}^{-2}$ \\
\hline \multicolumn{6}{|l|}{$\begin{array}{l}\text { Fragilariopsis sp. } \\
\text { Within subjects }\end{array}$} \\
\hline Time & 2.090 & 0.029 & 353.96 & $<0.001$ & Increase over $48 \mathrm{~h}$ \\
\hline Time $\mathrm{x}$ Treatments & 4.181 & 0.007 & 86.345 & $<0.001$ & (see text for details) \\
\hline Error & 18.812 & $2.889 \mathrm{E}-005$ & & & \\
\hline \multicolumn{6}{|l|}{ Between subjects } \\
\hline Treatments & 2 & 0.010 & 44.537 & $<0.001$ & $(0=50)>150 \mathrm{mWm}^{-2}$ \\
\hline Error & 9 & 0.000 & & & \\
\hline
\end{tabular}

\section{Thalassiosira sp.}

The general response of Thalassiosira sp. (Table 4.5; Figure 4.4(a)) was for $\phi_{\text {PSII }}$ of algae at $0 \mathrm{mWm}^{-2}$ to decrease over the first $2 \mathrm{~h}$, after which algae at $0 \mathrm{mWm}^{-2}$ recovered and $\phi_{\text {PSII }}$ increased until the end of the incubation. For algae incubated at $50 \mathrm{mWm}^{-2}$ and 150 $\mathrm{mWm}^{-2}, \phi_{\text {PSII }}$ remained constant until $24 \mathrm{~h}$ after which that for algae incubated at 50

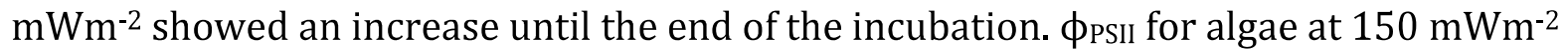
remained constant until the end of the incubation. Repeated measures ANOVA showed 
that only algae incubated at $0 \mathrm{mWm}^{-2}$ showed a significant increase (Bonferroni, $\mathrm{p}<0.001$ ) in $\phi$ PSII over $48 \mathrm{~h}$, with that increase (Bonferroni, $\mathrm{p}=0.033$ ) occurring in the last $24 \mathrm{~h}$.

\section{Fragilariopsis sp.}

The general response of Fragilariopsis sp. (Table 4.5; Figure 4.4(b)) was for $\phi_{P S I I}$ of algae at all PAR treatments to increase rapidly during the first $2 \mathrm{~h}$ after which it remained constant for another $2 \mathrm{~h}$. Between 4 and $6 \mathrm{~h}$, $\phi$ PSII for algae at $0 \mathrm{mWm}^{-2}$ and 50 $\mathrm{mWm}^{-2}$ then remained constant until $24 \mathrm{~h}$, after which algae incubated at $50 \mathrm{mWm}^{-2}$ showed a slight decrease. For algae incubated at $150 \mathrm{mWm}^{-2}, \phi_{\text {PSII }}$ decreased gradually between $4 \mathrm{~h}$ and the end of the $48 \mathrm{~h}$ incubation. Repeated measures ANOVA identified that algae at 0 and $50 \mathrm{mWm}^{-2}$ showed a significant increase (Bonferroni, $\mathrm{p}=0.001$, $\mathrm{p}<0.001$, respectively) in $\phi_{\text {PSII }}$ over $48 \mathrm{~h}$. Algae at $150 \mathrm{mWm}^{-2}$ showed a significant increase (Bonferroni, $\mathrm{p}=0.005$ ) in $\phi_{\text {PSII }}$ over the first $2 \mathrm{~h}$. However due to a subsequent significant decrease (Bonferroni, $\mathrm{p}=0.032$ ) between 12 and $24 \mathrm{~h}, \phi_{\text {PSII }}$ showed no significant change over the $48 \mathrm{~h}$ incubation. 
a)

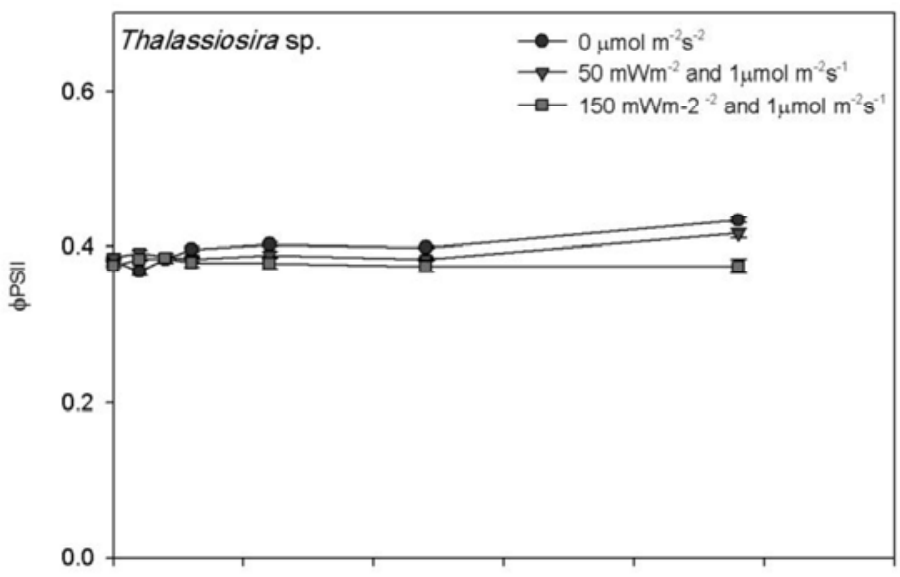

b)

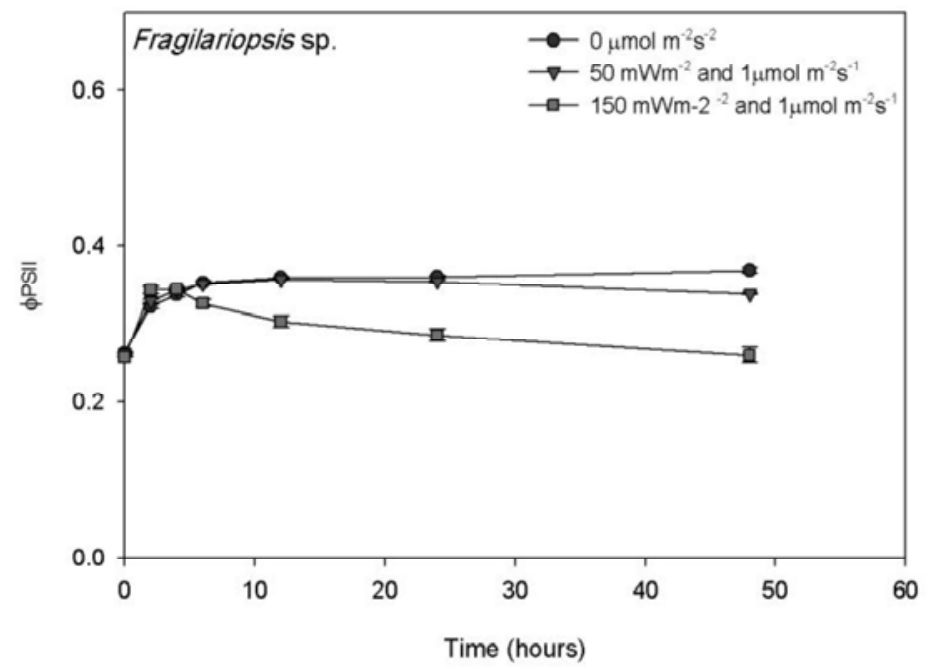

Fig 4.4. Quantum Yield ( $\phi_{\text {PSII }}$ ) at $0,2,4,6,12,24$ and 48 h. Cultures were maintained in the dark and at $0,50 \mathrm{~mW} \mathrm{~m}^{-2}$ or $150 \mathrm{~mW} \mathrm{~m}^{-2} \mathrm{UV}-\mathrm{B}$ and a PAR level of $1 \mu \mathrm{mol} \mathrm{m}^{-2} \mathrm{~s}^{-1}$ for the 2 UV-B treatments, for (a) Thalassiosira sp. and (b) Fragilariopsis sp. Error bars indicate standard error.

\section{Relative ETR $_{\max }$}

A repeated measures ANOVA was carried out for each species separately to test for effects of all treatments and time (Table 4.6). 
Table 4.6. Changes in $\mathrm{rETR}_{\max }$ of photosystem II over $48 \mathrm{~h}$ experimental treatments at different UV-B levels $\left(0,50\right.$ and $\left.150 \mathrm{mWm}^{-2}\right)$ and a PAR level of $1 \mu \mathrm{mol} \mathrm{m}^{-2} \mathrm{~s}^{-1}$ for the two UV-B treatments at $4^{\circ} \mathrm{C}$, analysed using repeated measures ANOVA. Significant changes identified by post hoc pairwise analyses are also listed.

\begin{tabular}{|c|c|c|c|c|c|}
\hline Source of variation & $\mathrm{df}$ & MS & $F$ & $\mathrm{p}$ & post hoc comparisons \\
\hline \multicolumn{6}{|l|}{$\begin{array}{l}\text { Thalassiosira sp. } \\
\text { Within subjects }\end{array}$} \\
\hline Time & 1.328 & 99.829 & 76.989 & $<0.001$ & Decrease over $48 \mathrm{~h}$ \\
\hline Time $\mathrm{x}$ Treatments & 2.656 & 3.441 & 2.653 & 0.101 & (see text for details) \\
\hline Error & 11.951 & 1.297 & & & \\
\hline \multicolumn{6}{|l|}{ Between subjects } \\
\hline Treatments & 2 & 6.697 & 32.325 & $<0.001$ & $(0=50)>150 \mathrm{mWm}^{-2}$ \\
\hline Error & 9 & 0.207 & & & \\
\hline \multicolumn{6}{|l|}{$\begin{array}{l}\text { Fragilariopsis sp. } \\
\text { Within subjects }\end{array}$} \\
\hline Time & 3.036 & 3.889 & 24.870 & $<0.001$ & Decrease over $48 \mathrm{~h}$ \\
\hline Time $\mathrm{x}$ Treatments & 6.072 & 1.682 & 10.757 & $<0.001$ & (see text for details) \\
\hline Error & 27.322 & 0.156 & & & \\
\hline \multicolumn{6}{|l|}{ Between subjects } \\
\hline Treatments & 2 & 1.074 & 4.577 & 0.043 & No significant differences \\
\hline Error & 9 & 0.235 & & & \\
\hline
\end{tabular}

\section{Thalassiosira sp.}

The general response of Thalassiosira sp. (Table 4.6; Figure 4.5(a)) was for rETR max $_{\text {ax }}$ at all UV-B treatments to decrease in the first $4 \mathrm{~h}$. Algae incubated at $0 \mathrm{mWm}^{-2}$ then remained constant until the end of the incubation. Those at $50 \mathrm{mWm}^{-2}$ then showed a gradual decrease in rETR $_{\max }$ until the end of the incubation, while those at $150 \mathrm{mWm}^{-2}$ showed a more rapid decrease until $24 \mathrm{~h}$, after which it remained constant for the rest of the incubation, reaching the same value as those incubated at $50 \mathrm{mWm}^{-2}$. Repeated measures ANOVA showed that the only significant change (Bonferroni, $p=0.029$ ) was a decrease in rETR $_{\max }$ for algae incubated at $150 \mathrm{mWm}^{-2}$ between 2 and $4 \mathrm{~h}$.

\section{Fragilariopsis sp.}

The general response of Fragilariopsis sp. (Table 4.6; Figure 4.5(b)) was for $\mathrm{rETR}_{\max }$ measured at $0 \mathrm{mWm}^{-2}$ to show an initial decrease over the first $2 \mathrm{~h}$, after which it 
recovered to a constant level maintained until end of the incubation. Algae at $50 \mathrm{mWm}^{-2}$ and $150 \mathrm{mWm}^{-2}$ showed an initial increase over the first $2 \mathrm{~h}$, after which $\mathrm{rETR}_{\max }$ remained constant until $6 \mathrm{~h}$. Over the next $6 \mathrm{~h}$, algae incubated at $50 \mathrm{mWm}^{-2}$ reached the same levels of rETR $_{\max }$ as those in the dark before showing a gradual decrease over the rest of the incubation. Under incubation at $150 \mathrm{mWm}^{-2}, \mathrm{rETR}_{\max }$ decreased between $6 \mathrm{~h}$ and the end of the incubation. Repeated measures ANOVA showed that algae incubated at $0 \mathrm{mWm}^{-2}$ showed no significant change over $48 \mathrm{~h}$. Algae incubated at 50 $\mathrm{mWm}^{-2}$ and $150 \mathrm{mWm}^{-2}$ showed a significant decrease (Bonferroni, $\mathrm{p}=0.002, \mathrm{p}=0.007$, respectively) in $\mathrm{rETR}_{\max }$ over the $48 \mathrm{~h}$ of the incubation.

a)

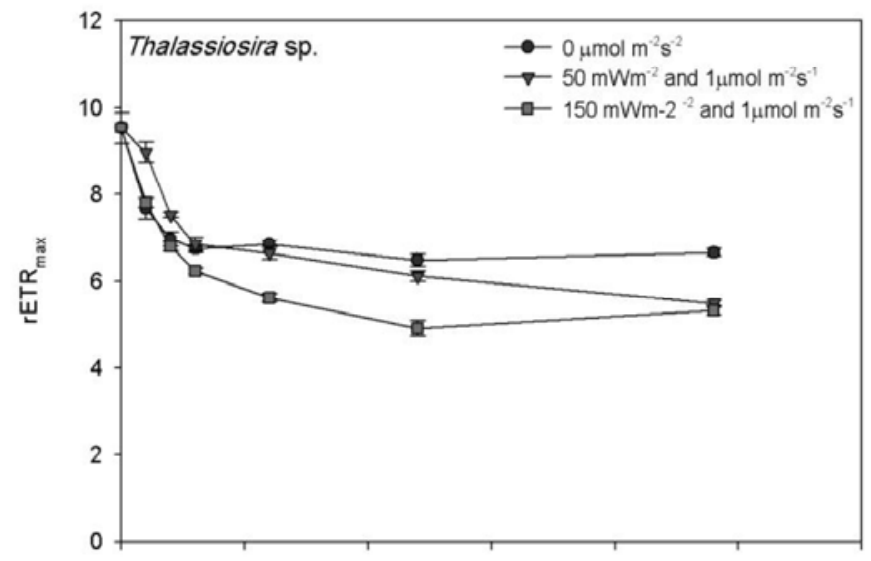

b)

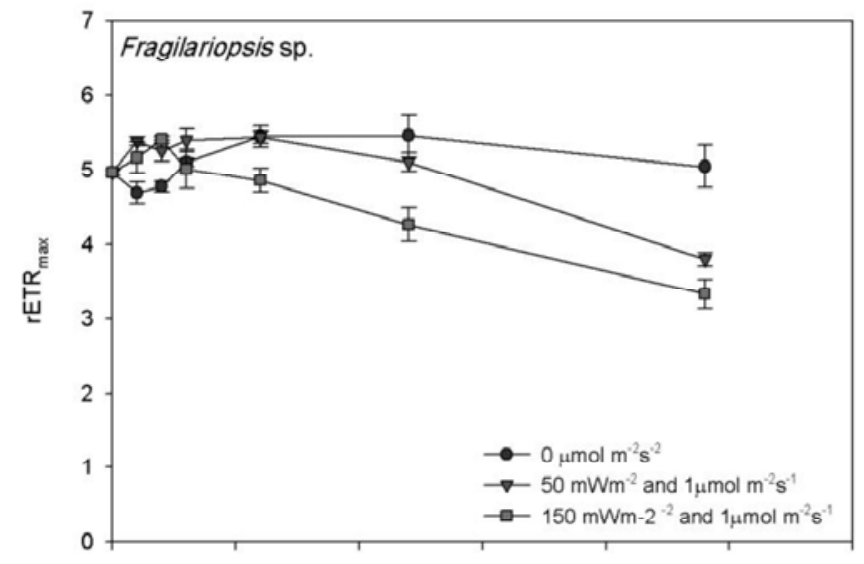

Fig 4.5. Relative ETR $\max _{\text {ax }}$ at $0,2,4,6,12,24$ and $48 \mathrm{~h}$. Cultures were maintained at 0,50 $\mathrm{mW} \mathrm{m}{ }^{-2}, 150 \mathrm{~mW} \mathrm{~m}^{-2} \mathrm{UV}-\mathrm{B}$ and a PAR level of $1 \mu \mathrm{mol} \mathrm{m}^{-2} \mathrm{~s}^{-1}$ for the 2 UV-B treatments, for (a) Thalassiosira sp. and (b) Fragilariopsis sp. Error bars indicate standard error. 


\section{MAA production}

A repeated measures ANOVA was carried out for each species separately to test for effects of all treatments and time (Table 4.7).

Table 4.7. Changes in MAA production over $48 \mathrm{~h}$ experimental treatments at different UV-B levels (0, 50 and $\left.150 \mathrm{mWm}^{-2}\right)$ and a PAR level of $1 \mu \mathrm{mol} \mathrm{m}^{-2} \mathrm{~s}^{-1}$ for the two UV-B treatments at $4^{\circ} \mathrm{C}$, analysed using repeated measures ANOVA. Significant changes identified by post hoc pairwise analyses are also listed.

\begin{tabular}{|llllll|}
\hline Source of variation & $\mathrm{df}$ & $\mathrm{MS}$ & $F$ & $\mathrm{p}$ & post hoc comparisons \\
\hline Thalassiosira sp. & & & & & \\
Within subjects & & & & & \\
Time & 1 & $1.649 \mathrm{E}-009$ & 41.628 & $<0.05$ & Increase over $48 \mathrm{~h}$ \\
Time x Treatments & 2 & $1.361 \mathrm{E}-010$ & 3.436 & 0.078 & \\
Error & 9 & $3.960 \mathrm{E}-011$ & & & \\
& & & & & \\
Between subjects & & & & & \\
Treatments & 2 & $2.514 \mathrm{E}-011$ & 1.278 & 0.325 & No significance \\
Error & 9 & $1.967 \mathrm{E}-011$ & & & \\
& & & & & \\
Fragilariopsis sp. & & & & & \\
Within subjects & & & & & \\
Time & 1 & $3.228 \mathrm{E}-009$ & 35.477 & $<0.05$ & Increase over $48 \mathrm{~h}$ \\
Time x Treatments & 2 & $5.403 \mathrm{E}-010$ & 5.830 & 0.024 & \\
Error & 9 & $9.268 \mathrm{E}-011$ & & & \\
& & & & & \\
Between subjects & & & & & \\
Treatments & 2 & $1.068 \mathrm{E}-010$ & 1.070 & 0.383 & No significance \\
Error & 9 & $9.986 \mathrm{E}-011$ & & & \\
& & & & & \\
\hline
\end{tabular}

Both species showed increases in MAA production under the two UV-B treatments (Table 4.7; Figure 4.6). The repeated measures ANOVA showed that, after 48h, Thalassiosira sp. at $150 \mathrm{~mW} \mathrm{~m}^{-2}$ showed a significantly higher (Bonferroni, $\mathrm{p}=0.045$ ) MAA production than those at $0 \mathrm{~mW} \mathrm{~m}^{-2}$. Fragilariopsis sp. (Figure yy) showed an increase in MAA production for all treatments, with the greatest increase seen in algae incubated under $150 \mathrm{~mW} \mathrm{~m}^{-2}$. Repeated measures ANOVA identified that, at $48 \mathrm{~h}$, algae incubated at $150 \mathrm{~mW} \mathrm{~m}^{-2}$ showed a significantly higher (Bonferroni, $\mathrm{p}=0.018$ ) MAA production than those at 0 and $50 \mathrm{~mW} \mathrm{~m}^{-2}$. 

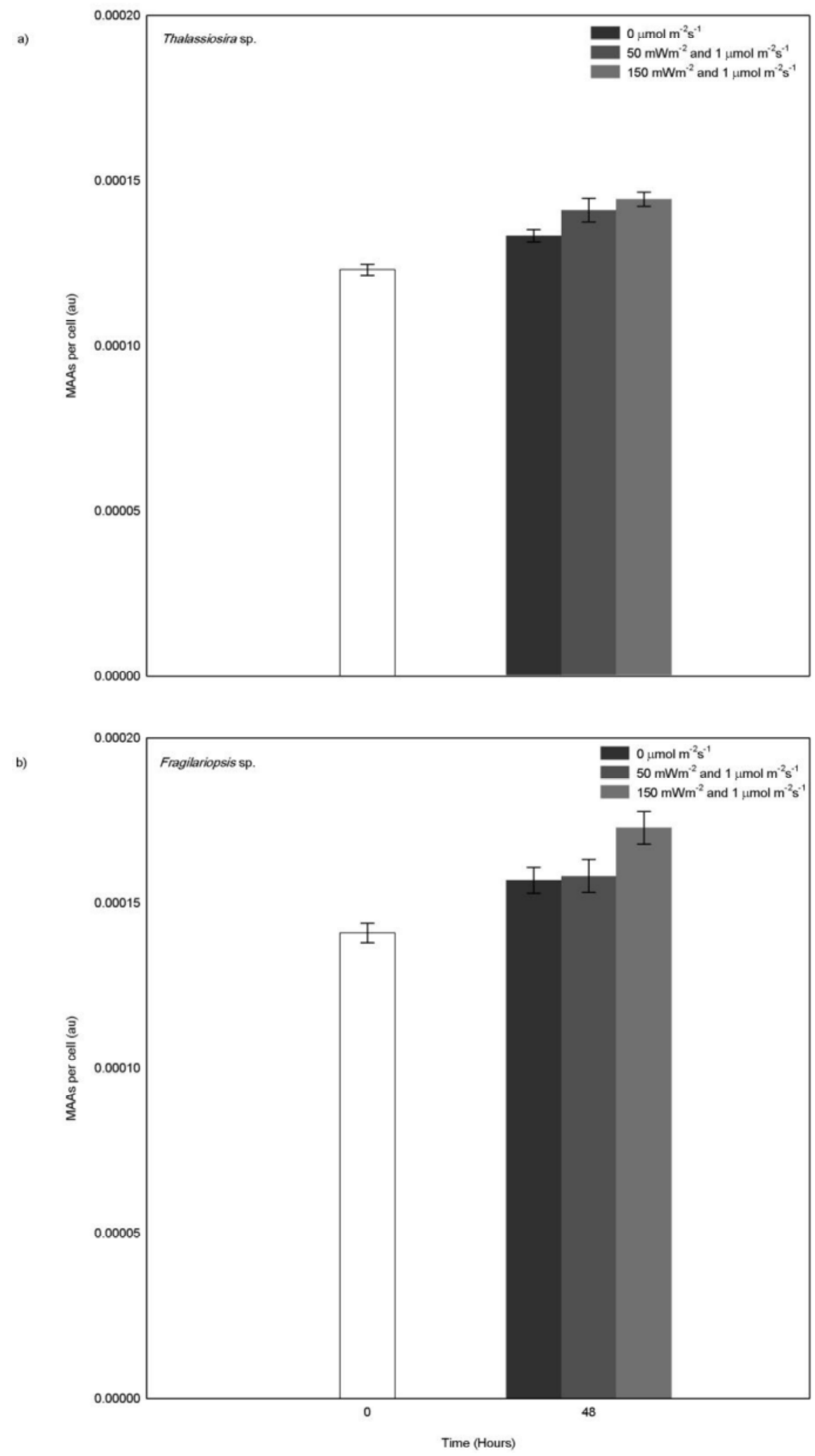

Fig 4.6. MAA production determined at 0 and $48 \mathrm{~h}$. Cultures were maintained at 0,50 $\mathrm{mW} \mathrm{m} \mathrm{m}^{-2}, 150 \mathrm{~mW} \mathrm{~m}^{-2}$ and a PAR level of $1 \mu \mathrm{mol} \mathrm{m}^{-2} \mathrm{~s}^{-1}$ for the 2 UV-B treatments, for (a) for Thalassiosira sp. and (b) Fragilariopsis sp. Error bars indicate standard error. 


\subsubsection{Effect of PAR on photosynthetic parameters of Chaetoceros sp.}

A repeated measures ANOVA was carried to test for effects of all treatments and time (Table 4.8).

Table 4.8. Changes in photosynthetic parameters for Chaetoceros sp. over $48 \mathrm{~h}$ experimental treatments at PAR levels $\left(0,1,45\right.$ and $\left.100 \mu \mathrm{mol} \mathrm{m}^{-2} \mathrm{~s}^{-1}\right)$ at $4^{\circ} \mathrm{C}$, analysed using repeated measures ANOVA. Significant changes identified by post hoc pairwise analyses are also listed.

\begin{tabular}{|c|c|c|c|c|c|}
\hline Source of variation & $\mathrm{df}$ & MS & $F$ & $\mathrm{p}$ & post hoc comparisons \\
\hline \multirow{2}{*}{\multicolumn{6}{|c|}{$\begin{array}{l}\text { PSII } \\
\text { Within subjects }\end{array}$}} \\
\hline & & & & & \\
\hline Time & 1.565 & 0.216 & 127.348 & $<0.001$ & \multirow{3}{*}{$\begin{array}{l}\text { Increase over } 48 \mathrm{~h} \\
\text { (see text for details) }\end{array}$} \\
\hline Time $\mathrm{x}$ Treatments & 4.694 & 0.003 & 1.753 & 0.196 & \\
\hline Error & 12.517 & 0.002 & & & \\
\hline \multicolumn{6}{|l|}{ Between subjects } \\
\hline Treatments & 3 & 0.014 & 5.560 & 0.023 & \multirow{2}{*}{$1>100 \mu \mathrm{mol} \mathrm{m}^{-2} \mathrm{~s}^{-1}$} \\
\hline Error & 8 & 0.003 & & & \\
\hline \multicolumn{6}{|l|}{ rETR $_{\max }$} \\
\hline \multicolumn{6}{|l|}{ Within subjects } \\
\hline Time & 1.654 & 1181.789 & 139.274 & $<0.001$ & \multirow{3}{*}{$\begin{array}{l}\text { Increase over } 48 \mathrm{~h} \\
\text { (see text for details) }\end{array}$} \\
\hline Time $\mathrm{x}$ Treatments & 4.963 & 41.729 & 4.918 & 0.009 & \\
\hline Error & 13.235 & 8.485 & & & \\
\hline \multicolumn{6}{|l|}{ Between subjects } \\
\hline Treatments & 3 & 150.643 & 44.390 & $<0.001$ & \multirow[t]{2}{*}{$(0=1)<(45=100) \mu \mathrm{mol} \mathrm{m}^{-2}$} \\
\hline Error & 8 & 3.394 & & & \\
\hline \multicolumn{6}{|l|}{ MAAs } \\
\hline \multicolumn{6}{|l|}{ Within subjects } \\
\hline Time & 1 & $1.144 \mathrm{E}-008$ & 0.142 & 0.716 & \multirow[t]{3}{*}{ No significance } \\
\hline Time $\mathrm{x}$ Treatments & 3 & $7.826 \mathrm{E}-008$ & 0.973 & 0.452 & \\
\hline Error & 8 & $8.040 \mathrm{E}-008$ & & & \\
\hline \multicolumn{6}{|l|}{ Between subjects } \\
\hline Treatments & 3 & $8.719 \mathrm{E}-009$ & 0.321 & 0.810 & No significance \\
\hline Error & 8 & $2.718 \mathrm{E}-008$ & & & \\
\hline
\end{tabular}

\section{Quantum Yield ( $\phi$ PSII)}

The general response of Chaetoceros sp. (Table 4.8; Figure 4.7(a)) was for $\phi$ PSII under all PAR treatments to decrease over the first $2 \mathrm{~h}$ and then show an increase until the end of 
the incubation, although algae incubated at $100 \mu \mathrm{mol} \mathrm{m} \mathrm{m}^{-2} \mathrm{~s}^{-1}$ reached a lower value compared to algae at all the other treatments. Repeated measures ANOVA showed that there was no significant change over time for the algae at the higher PAR treatments. Algae incubated at $0 \mu \mathrm{mol} \mathrm{m} \mathrm{m}^{-2} \mathrm{~s}^{-1}$ and $1 \mu \mathrm{mol} \mathrm{m} \mathrm{m}^{-2} \mathrm{~s}^{-1}$ however showed a significant increase (Bonferroni, $\mathrm{p}=0.009, \mathrm{p}=0.044$, respectively) over the last $24 \mathrm{~h}$.

\section{Relative ETR max $_{\max }$}

The general response (Table 4.8; Figure 4.7(b)) was an initial decrease in rETR max $_{\text {for }}$ algae incubated at all PAR treatments over the first $2 \mathrm{~h}$, followed by an increase until the end of the incubation, with algae at $45 \mu \mathrm{mol} \mathrm{m} \mathrm{m}^{-2} \mathrm{~s}^{-1}$ having the highest $\mathrm{rETR}_{\max }$. Repeated measures ANOVA showed that algae incubated at the lower PAR treatments showed a significant decrease (Bonferroni, both $\mathrm{p}<0.001$ ) in $r E T R_{\max }$ over the first $2 \mathrm{~h}$ after which they showed no significant change. Algae incubated at $45 \mu \mathrm{mol} \mathrm{m}^{-2} \mathrm{~s}^{-1}$ showed a significant increase (Bonferroni, $\mathrm{p}=0.040$ ) in $\mathrm{rETR}_{\max }$ in the last $24 \mathrm{~h}$ of the incubation whereas algae incubated at $100 \mu \mathrm{mol} \mathrm{m}{ }^{-2} \mathrm{~s}^{-1}$ showed no significant change over the $48 \mathrm{~h}$.

\section{MAA production}

There was no significant change in MAA production per cell over $48 \mathrm{~h}$. (Table 4.8; Figure $4.7(\mathrm{c}))$.

a)

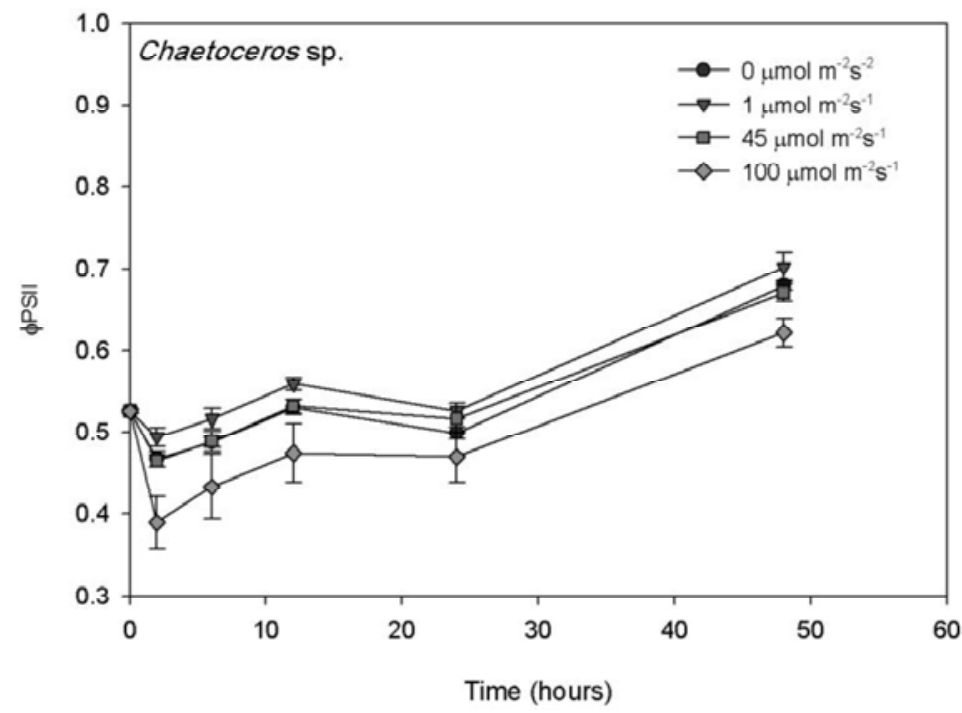


b)

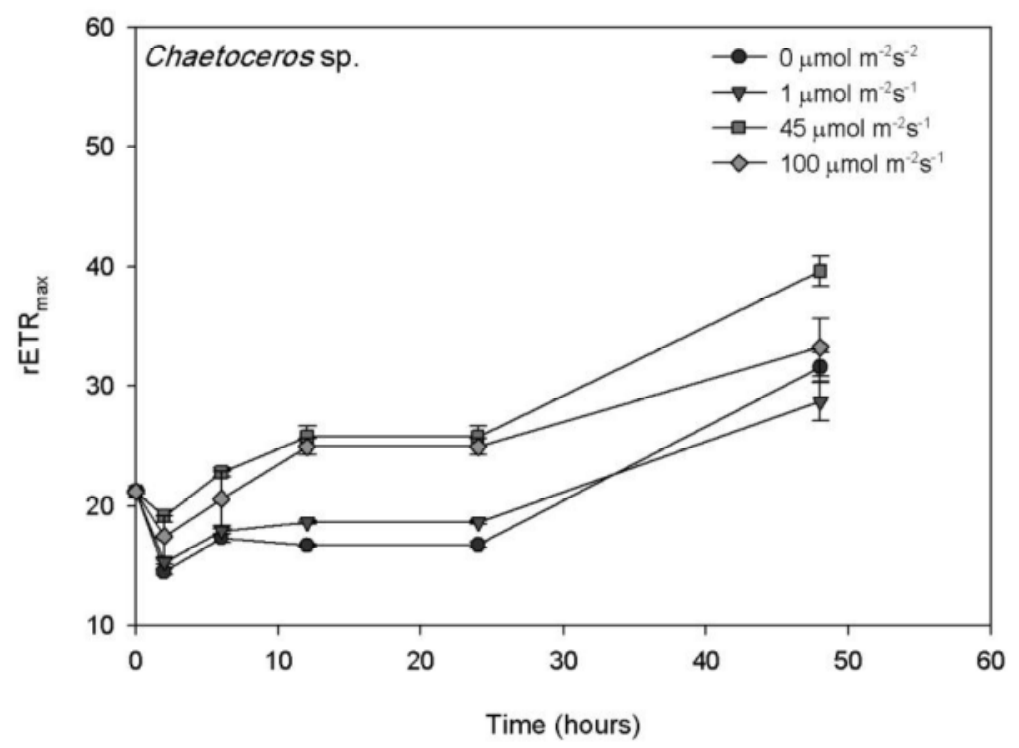

c)

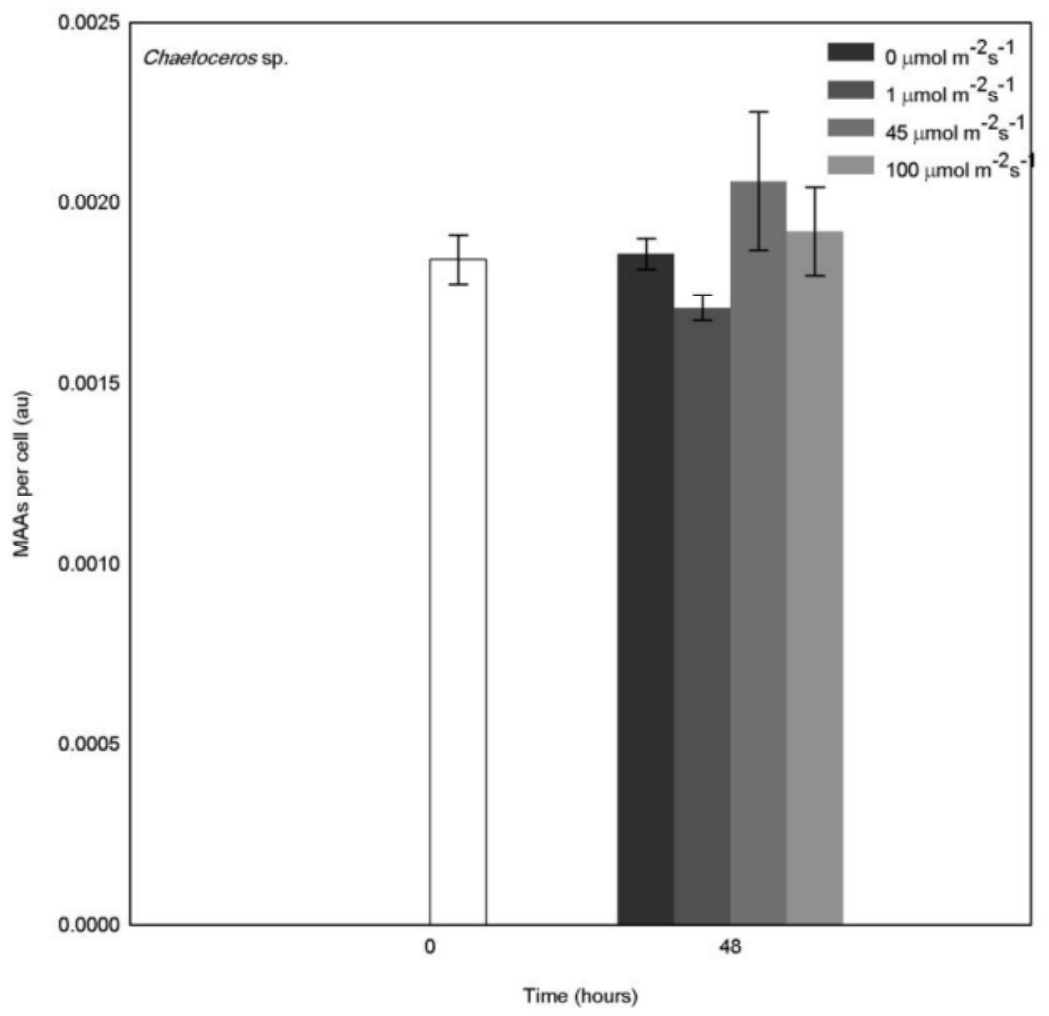

Fig 4.7. Photosynthetic parameters of Chaetoceros sp. at 0, 2, 6, 12, 24 and $48 \mathrm{~h}$. Cultures were maintained at PAR levels of $0,1,45$ or $100 \mu \mathrm{mol} \mathrm{m}^{-2} \mathrm{~s}^{-1}$ and the graphs indicate (a)

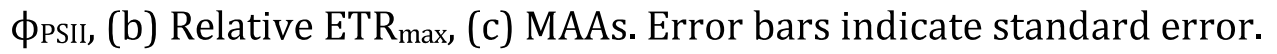




\subsubsection{Effect of UV-B on photosynthetic parameters on Chaetoceros sp.}

A repeated measures ANOVA was carried out to test for effects of all treatments and time (Table 4.9.).

Table 4.9. Changes in photosynthetic parameters for Chaetoceros sp. over $48 \mathrm{~h}$ experimental treatments at different UV-B levels $\left(0,50\right.$ and $\left.150 \mathrm{mWm}^{-2}\right)$ and a PAR level of $1 \mu \mathrm{mol} \mathrm{m}{ }^{-2} \mathrm{~s}^{-1}$ at $4^{\circ} \mathrm{C}$, analysed using repeated measures ANOVA. Significant changes identified by post hoc pairwise analyses are also listed.

\begin{tabular}{|c|c|c|c|c|c|}
\hline Source of variation & $\mathrm{df}$ & MS & $F$ & $\mathrm{p}$ & post hoc comparisons \\
\hline \multicolumn{6}{|l|}{$\phi_{\text {PSII }}$} \\
\hline \multicolumn{6}{|l|}{ Within subjects } \\
\hline Time & 6 & 0.013 & 70.778 & $<0.001$ & \multirow{3}{*}{$\begin{array}{l}\text { No increase/decrease } \\
\text { (see text for details) }\end{array}$} \\
\hline Time $x$ Treatments & 12 & 0.008 & 44.703 & $<0.001$ & \\
\hline Error & 54 & 0.000 & & & \\
\hline \multicolumn{6}{|l|}{ Between subjects } \\
\hline Treatments & 2 & 0.050 & 91.644 & $<0.001$ & $0<50<150 \mathrm{mWm}^{-2}$ \\
\hline Error & 9 & 0.001 & & & \\
\hline \multicolumn{6}{|l|}{ rETR $_{\max }$} \\
\hline \multicolumn{6}{|l|}{ Within subjects } \\
\hline Time & 6 & 104.302 & 87.065 & $<0.001$ & \multirow{3}{*}{$\begin{array}{l}\text { No increase/decrease } \\
\text { (see text for details) }\end{array}$} \\
\hline Time $x$ Treatments & 12 & 15.859 & 13.238 & $<0.001$ & \\
\hline Error & 54 & 1.198 & & & \\
\hline \multicolumn{6}{|l|}{ Between subjects } \\
\hline Treatments & 2 & 162.005 & 92.841 & $<0.001$ & $0<50<150 \mathrm{mWm}^{-2}$ \\
\hline Error & 9 & 1.745 & & & \\
\hline \multicolumn{6}{|l|}{ MAAs } \\
\hline \multicolumn{6}{|l|}{ Within subjects } \\
\hline Time & 1 & $1.941 \mathrm{E}-007$ & 11.016 & 0.009 & Increase over $48 \mathrm{~h}$ \\
\hline Time $x$ Treatments & 2 & $6.635 \mathrm{E}-008$ & 3.767 & 0.065 & \\
\hline Error & 9 & $1.762 \mathrm{E}-008$ & & & \\
\hline \multicolumn{6}{|l|}{ Between subjects } \\
\hline Treatments & 2 & 8.909E-008 & 3.489 & 0.076 & No significance \\
\hline Error & 9 & $2.576 \mathrm{E}-008$ & & & \\
\hline
\end{tabular}

\section{Quantum Yield (\$PSII)}

The general response (Table 4.9; Figure 4.8(a)) was an increase of $\phi_{P S I I}$ for algae incubated at $150 \mathrm{mWm}^{-2}$ over the first $4 \mathrm{~h}$, while that for algae at $0 \mathrm{mWm}^{-2}$ and 50 
$\mathrm{mWm}^{-2}$ stayed constant. Algae at $0 \mathrm{mWm}^{-2}$ then decreased until the end of the incubation whereas those at 50 and $150 \mathrm{mWm}^{-2}$ showed no overall change over $48 \mathrm{~h}$. Repeated measures ANOVA showed that there was a significant decrease (Bonferroni, $\mathrm{p}=0.018$ ) in $\phi_{\text {PSII }}$ for algae at $0 \mathrm{mWm}^{-2}$ between 4 and $6 \mathrm{~h}$ after which it showed another significant decrease (Bonferroni, $\mathrm{p}=0.035$ ) between 12 and $24 \mathrm{~h}$. For algae incubated at $50 \mathrm{mWm}^{-2}$, it showed a significant increase (Bonferroni, $\mathrm{p}=0.004$ ) in the last $24 \mathrm{~h}$, resulting in a significant increase (Bonferroni, $\mathrm{p}=0.045$ ) over the $48 \mathrm{~h}$ incubation. For algae at the highest UV-B treatment of $150 \mathrm{mWm}^{-2}$, $\phi_{\text {PSII }}$ significantly increased (Bonferroni, $\mathrm{p}=0.014$ ) between 6 and $12 \mathrm{~h}$ after which it significantly decreased (Bonferroni, $\mathrm{p}=0.026$ ) between 12 and $24 \mathrm{~h}$ resulting in no significant change over the $48 \mathrm{~h}$. At $48 \mathrm{~h}$, algae incubated at $0 \mathrm{mWm}^{-2}$ had a significantly lower (Bonferroni, $\mathrm{p}<0.001) \phi_{\text {PSII }}$ than those at $50 \mathrm{mWm}^{-2}$ and $150 \mathrm{mWm}^{-2}$.

\section{Relative ETR $\max$}

The general response (Table 4.9; Figure 4.8(b)) was an increase in $\mathrm{rETR}_{\max }$ for algae incubated at $150 \mathrm{mWm}^{-2}$ over the first $4 \mathrm{~h}$. Algae incubated at $0 \mathrm{mWm}^{-2}$ and $50 \mathrm{mWm}^{-2}$ remained constant in the same time period. Algae at $0 \mathrm{mWm}^{-2}$ then decreased until the end of the incubation whereas those at 50 and $150 \mathrm{mWm}^{-2}$ showed no overall change over $48 \mathrm{~h}$. Repeated measures ANOVA showed that there were no significant changes in $\mathrm{rETR}_{\max }$ for algae at $150 \mathrm{mWm}^{-2}$. Algae at $0 \mathrm{mWm}^{-2}$ showed a significant decrease (Bonferroni, $\mathrm{p}=0.003$ ) in $\mathrm{rETR}_{\max }$ between 4 and $6 \mathrm{~h}$ but no overall significant change. Algae at $50 \mathrm{mWm}^{-2}$ showed a significant increase (Bonferroni, $\mathrm{p}<0.001$ ) in $\mathrm{rETR}_{\max }$ between 6 and $12 \mathrm{~h}$ and then a significant decrease (Bonferroni, $\mathrm{p}=0.017$ ) between 12 and $24 \mathrm{~h}$, showing no overall change over $48 \mathrm{~h}$.

\section{MAA production}

MAA production remained constant for algae maintained in the dark and increased for those incubated under the UV-B treatments (Table 4.9; Figure 4.8(c)). Repeated measures ANOVA showed that there was a significant increase (Bonferroni, $p=0.029$ ) in MAAs for algae incubated at $150 \mathrm{~mW} \mathrm{~m}^{-2}$. 
a)

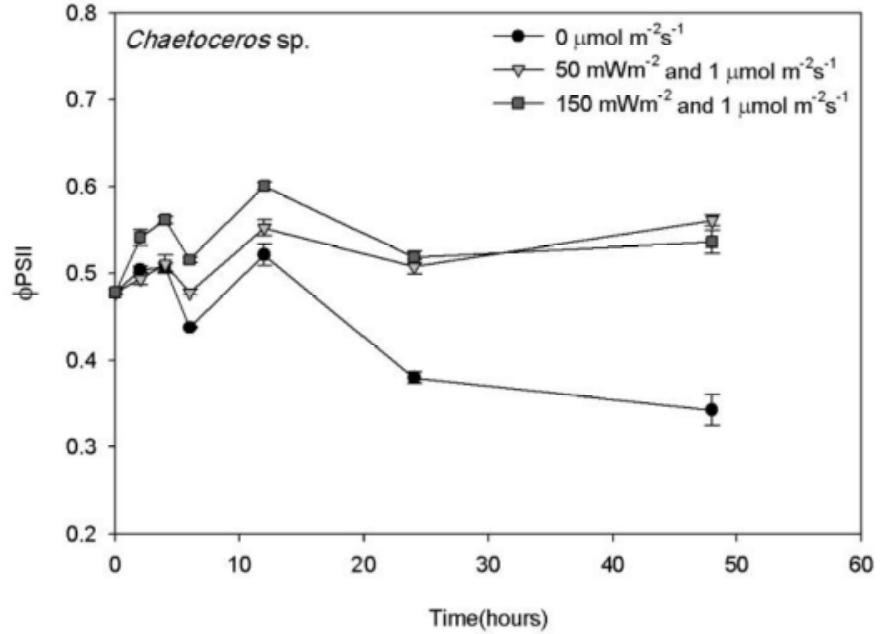

b)

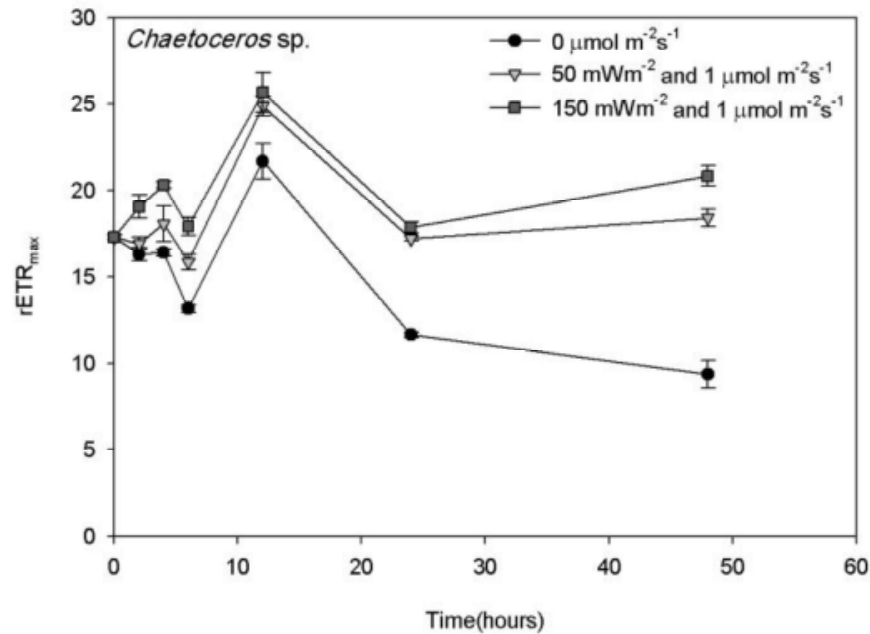




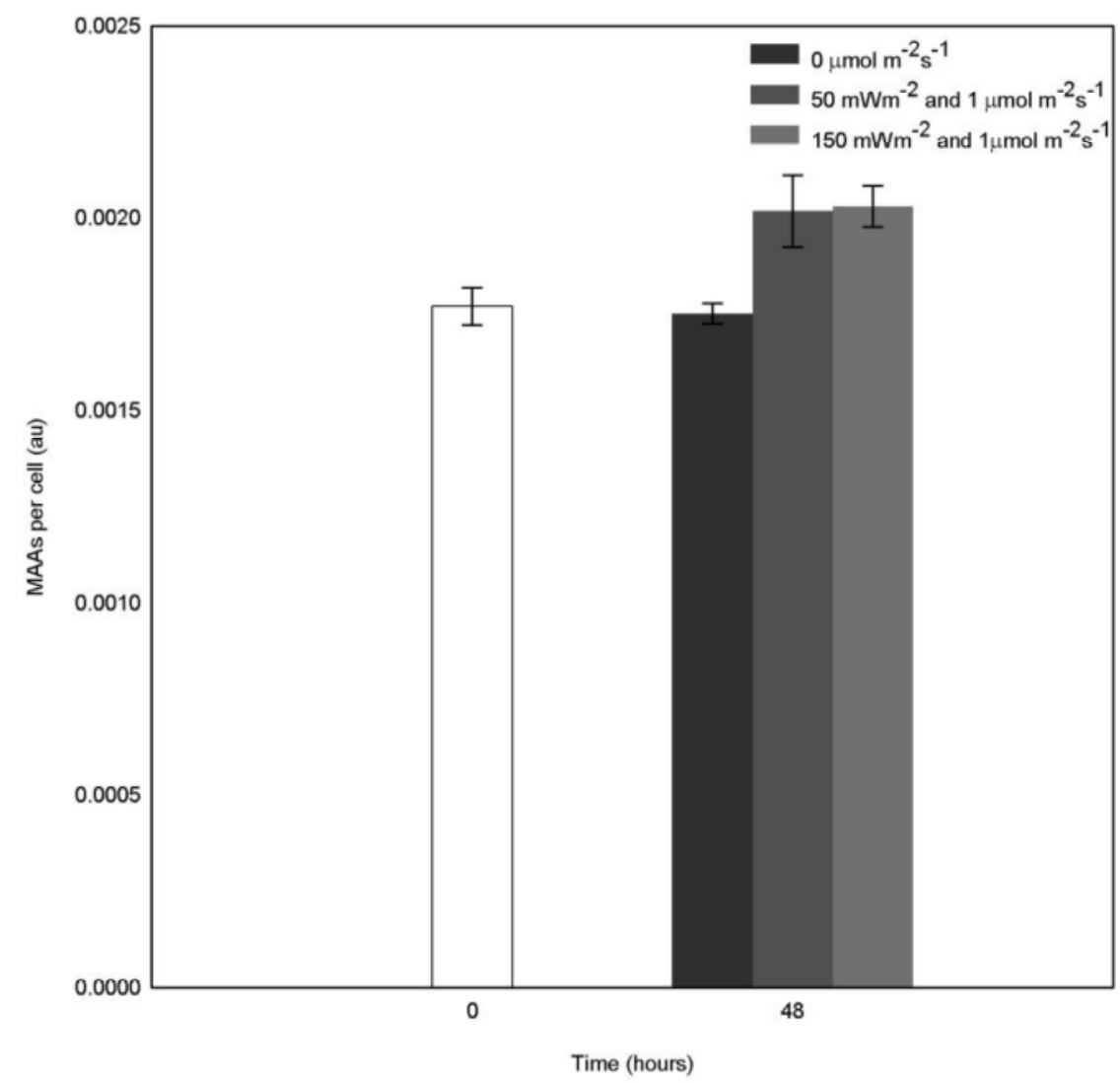

Figure 4.8. Photosynthetic parameters of Chaetoceros sp. at $0,2,4,6,12,24$ and $48 \mathrm{~h}$. Cultures were maintained in the dark and at $50 \mathrm{~mW} \mathrm{~m}^{-2}$ and $150 \mathrm{~mW} \mathrm{~m}^{-2} \mathrm{UV}-\mathrm{B}$ and a PAR level of $1 \mu \mathrm{mol} \mathrm{m} \mathrm{m}^{-2} \mathrm{~s}^{-1}$ and the graphs indicate (a) QPSII, (b) rETRmax, (c) MAAs. Error bars indicate standard error.

\subsection{DISCUSSION}

\subsubsection{Effect of PAR}

MAA production (Figure 4.3) increased significantly at higher PAR exposures for both Ross Sea ice algal species over the duration of the experimental treatments, which is consistent with a photo-protective response to increasing PAR. The production of MAAs induced by PAR alone has been seldom observed in sea ice algae (Helbling et al., 1996, Karsten et al., 1998). Helbling et al. (1996) reported MAA production related not only to exposure to UVR but also to irradiance. There was also a significant difference in production per cell between species, with Fragilariopsis sp. producing greater amounts than Thalassiosira sp. The difference in MAA production between the two species 
suggests that Fragilariopsis sp. will experience lower photoinhibition at higher PAR levels than will Thalassiosira sp., as increased MAA levels protect photosystems (Helbling et al., 1996). This could possibly indicate that the algae could be using PAR as a proxy for higher levels of UVR and increasing its production of MAAs.

In both Ross Sea ice algal species studied here (Figure 4.1), фPSII increased with PAR level, indicating that they could tolerate increases in PAR of the magnitude associated with sea ice melt. Neither species showed a significant change in $\phi_{\text {PsII }}$ after being maintained in the dark or at $1 \mu \mathrm{E} \mathrm{m}^{-2} \mathrm{~s}^{-1}$. This indicates that the algae were not highly shade acclimated. Across the range of PAR levels used in this study, Fragilariopsis sp. had a higher quantum yield at lower PAR levels but showed more evidence of stress at higher PAR levels. Thalassiosira sp. responded more effectively to higher PAR levels, suggesting that it is better able to adapt to levels that might be experienced under thinner ice, or higher in the ice profile. This further suggests that Thalassiosira sp. will be able to tolerate conditions better during sea ice melt and thus be more likely to become incorporated in the subsequent pelagic algal bloom than Fragilariopsis sp. Optimum PAR is known to be species-specific (Hannach \& Sigleo, 1998, Vernet et al., 2008) and this variation will influence productivity in a community when there are changing environmental conditions.

Sea ice algae could be exposed to higher PAR and UV-B levels than those used in the current study during sea ice melt (Eicken, 1992, Petrou \& Ralph, 2011), but in other studies have exhibited a high level of resilience to increases in PAR levels (Petrou et al., 2011a), to levels as high as $350 \mu \mathrm{E} \mathrm{m}^{-2} \mathrm{~s}^{-1}$ (Ralph \& Gademann, 2005). Significant reductions in quantum yield, indicating damage to the photosystems under high PAR levels were rapidly reversed by a return to reduced PAR levels (Petrou et al., 2011b). Relative ETRmax also varied between species (Figure 4.2). In Thalassiosira sp. (Figure 4.2(a)), rETRmax decreased at low PAR levels and increased at high PAR levels, indicating that the algae performed better at higher PAR. This acclimatory response would allow this species to survive sea ice melt and become part of the algal bloom as evidenced by their prevalence throughout the Antarctic marine ecosystem (Petrou et al., 2011a). In Fragilariopsis sp., there was no change in rETRmax (Figure 4.2(b)) or photosynthetic efficiency (Figure A3.1(a), Appendix 3) under the different PAR exposures. This result was unexpected and does not have a clear explanation. 
Under the culture conditions used in this experiment, $\phi_{\mathrm{PSII}}$ for Chaetoceros sp. (Figure 4.7(a)) showed an increase under lower PAR treatments and there was no evidence of photo-inactivation under the higher PAR treatments, indicating that this species can tolerate a wide range of irradiances. There were no differences in photosynthetic efficiency or the saturation irradiance (Figure A3.5 in Appendix 3) for Chaetoceros sp. under the different treatments. There was also no change in production of MAAs (Figure 4.7(c)) at any PAR level, indicating that additional MAAs were not produced in response to increasing PAR under the study conditions used. This suggests that this algal species is capable of acclimation to the high PAR level of $100 \mu \mathrm{E} \mathrm{m}^{-2} \mathrm{~s}^{-1}$, which could be consistent with them being exposed for a longer time to higher PAR levels than sea ice algae in other parts of the continent. This finding contrasts with the results observed in the Ross Sea ice species, where MAA production increased in response to increasing PAR alone.

Optimum PAR is species-specific and could finally determine total productivity (Vernet et al., 2008). The maintenance of a shallow mixed layer in open water zones of the Southern Ocean (Vernet et al., 2008) and seeding from ice algae (Giesenhagen et al., 1999) are required for the algal bloom at the edge of sea ice zones, which contributes up to $22 \%$ of the primary production in the Southern Ocean (Arrigo et al., 1998). Vernet et al. (2008) suggest that Antarctic diatoms will respond positively to an increase in exposure to PAR that results from the deepening of the shallow mixed layer. This can be related to the increase in rETR $_{\max }$ (Figure 4.2) observed in the current study, which indicates greater energy availability to the photosystem, possibly enabling the algae to be more productive (Ralph et al., 2005).

\subsubsection{Effect of UV-B}

In all cultures of the algae in the PAR exposure section (Section 4.4.2 and 4.4.4), there were no significant differences between any of the photosynthetic parameters of algae maintained in the dark and at $1 \mu \mathrm{E} \mathrm{m}^{-2} \mathrm{~s}^{-1}$. The control for the UV-B treatments used here was therefore the dark treatment. While the use of dark treatment as the control in this study has limited the interpretation of the data obtained, it does still permit a comparison of low and high UV-B treatments, and this aspect of the data will be emphasised below. 
Both Ross Sea ice algal species showed a significant increase in MAA production per cell (Figure 4.6) over $48 \mathrm{~h}$ at both levels of UV-B exposure, indicating a possible response to photoinactivation caused by UV-B. Subtle differences were apparent between the species. Fragilariopsis sp. (Figure 4.6(a)) showed a significantly higher production of MAAs per cell than Thalassiosira sp. Thalassiosira sp. (Figure 4.6(b)) showed the same increase at both UV-B exposure levels, and no change during the experimental period for those algae held in the dark. Fragilariopsis sp. showed a higher MAA production in response to both levels of UV-B, with algae incubated at the high UV-B level producing a higher quantity of MAAs compared to those at the low UV-B exposure. These data indicate that MAAs are produced as a direct response to the UV-B exposure, and that Fragilariopsis sp. could tolerate small increases in UV-B more effectively than Thalassiosira sp..

Both species showed significant increases in $\phi_{\text {PSII }}$ (Figure 4.4) over $48 \mathrm{~h}$ in the dark and Fragilariopsis sp. showed an increase at $50 \mathrm{mWm}^{-2}$. In both species, algae at $150 \mathrm{mWm}^{-2}$ had a significantly lower $\phi_{\text {PSII }}$ than that measured in the other treatments, however the value was still the same as at the start of the experiment, which was unexpected as exposure to UV-B generally has deleterious effects (Franklin \& Forster, 1997, Hernando et al., 2011). This could be an indication that the exposure to UV-B needs to be longer than $48 \mathrm{~h}$ to observe any effect of accumulated damage. Diatoms have the ability to photoacclimate not just by efficient utilisation of light, but also by modification of light harvesting complexes that control ratios and quantities of many photosynthetic pigments (Salleh \& McMinn, 2011). There are many mechanisms, such as involvement of the diadinoxanthin cycle and production of antioxidants, that may also play a role in photoprotection in sea ice algae (Griffith et al., 2009, Janknegt et al., 2008). The production of reactive oxygen species due to damage to the photosystem can be damaging to algal cells (Martínez, 2007), and antioxidants such as superoxide dismutase are known to protect algae from this damage (Janknegt et al., 2008, Van de Poll et al., 2009).

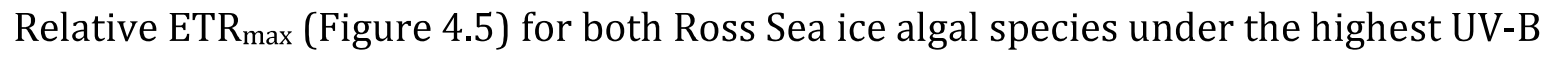
treatment showed a significant decrease over $48 \mathrm{~h}$, indicating photosystem damage as has been reported in temperate and pelagic diatoms (Franklin \& Forster, 1997, Gao \& Garcia-Pichel, 2011, Salleh \& McMinn, 2011, Singh et al., 2010). In these studies, the 
higher dose of UV-B caused a larger decline overall, with this also becoming apparent earlier than for the lower dose in the incubations carried out. Relative ETR max $_{\text {for both }}$ species showed no significant change in the dark, indicating that cells were unstressed in this situation. Thalassiosira sp. exposed to $150 \mathrm{mWm}^{-2}$ showed a significant decrease in rETR $_{\max }$, whereas Fragilariopsis sp. showed significant decreases in $\mathrm{rETR}_{\max }$ for both UV-B treatments, indicating more subtle differences in UV-B tolerance for the two species.

Both Ross Sea ice algal species showed an increase in photosynthetic efficiency (Figure A3.3, Appendix 3) after being held in the dark, indicating that they became more shade adapted after the treatment. However, additional UV-B exposure negated this change. A significantly higher MAA production at the higher UV-B level could decrease photoinactivation in this treatment, resulting in no change in photosynthetic efficency with UV-B exposure. The saturation irradiance (Figure A3.4(b), Appendix 3) for Fragilariopsis sp. decreased with UV-B exposure, indicating that the algae were becoming photoinhibited in response to increased UV-B stress, despite experiencing low PAR levels, as also seen in Petrou et al.'s (2011a) study.

Higher concentrations of MAAs prevent damage by UV-B, but, if used as a defence mechanism, require their rapid synthesis in response to exposure to the stress. Hernando et al. (2011) have shown that algae may synthesise MAAs in response to UV-B in a timescale of hours, and this has also been demonstrated in this study. The significant increase in MAA production by algae observed under high UV-B exposure most likely prevents photosystem damage (Gao \& Garcia-Pichel, 2011, Helbling et al., 1996). This proposal is further supported by the observation that photosynthetic efficiency and saturation irradiance (Figure A3.3, A3.4, Appendix 3) were not affected by UV-B exposure, suggesting that the algae were capable of maintaining function under the experimentally applied UV-B levels, at least over the duration of the study. For both Ross Sea ice algal species, increasing PAR levels led to an increase in photosynthetic activity. There was an increase in MAA production for Thalassiosira sp. (Figure 4.6(a)) and which could indicate less photoinactivation at higher PAR levels. Fragilariopsis sp. produced more MAAs per cell (Figure 4.6(b)), suggesting less photoinactivation being experienced in comparison with Thalassiosira sp.. Differences in cell (or organelle) size could also be important, as a larger cell has a smaller surface 
area to volume ratio, and so would not need as much sunscreen to protect the cell contents (Hannach \& Sigleo, 1998). The difference in photoinactivation is confirmed by the saturation irradiance (Figure A3.4, Appendix 3), where Fragilariopsis sp. had a higher $E_{\mathrm{k}}$ compared to Thalassiosira sp., which implies that photoinactivation is initiated at a higher PAR level for Fragilariopsis sp.

The quantum yield (Figure 4.8(a)) for Antarctic Peninsula Chaetoceros sp. held in the dark decreased significantly over $48 \mathrm{~h}$ whereas algae subjected to $50 \mathrm{mWm}^{-2}$ showed a significant increase over $48 \mathrm{~h}$, indicating that the algae were stressed by incubation in the dark due to the lack of energy from irradiance, but showed increased photosynthetic yield when exposed to increased UV-B at ambient PAR. This increase in quantum yield under the UV-B treatment could be due to the available PAR, rather than because of increased UV-B.

Chaetoceros sp. in this study showed no signs of photoinactivation at higher PAR and UV-B levels. The lack of MAA production (Figure 4.8(b)) in response to high levels of PAR could indicate that these algae were not stressed by higher PAR levels. The lack of photoinactivation contrasts with Alderkamp et al.'s (2011) study, where exposure to high levels of PAR caused photodamage in a mixed community of phytoplankton, leading to limited growth in regions with a deep upper mixed layer. The recovery of quantum yield in their study was faster in algae that were incubated under low PAR conditions, suggested to be because high PAR may have induced the accumulation of photodegradation products (Alderkamp et al., 2011). Consequently, the benefits of photoacclimation can be outweighed by the costs of photodamage. Integrating the results of such studies demonstrates why clarification of individual species responses is necessary to understand community responses. In the current study, Chaetoceros sp. exhibited a higher tolerance to increased PAR and UV-B compared to Thalassiosira sp. and Fragilariopsis sp. In a community, species will show varying tolerances to stressors, which implies that individual species responses must be integrated to predict outcomes for the overall algal community resulting from environmental change.

The period of exposure to a given stress can also influence both an organism's ability to acclimate to changing environmental parameters (Peck et al., 2006). Most photosynthetic parameters in the present study showed initial periods where there was no change or a decrease. Over $48 \mathrm{~h}$, the Ross Sea ice algae acclimated to show an 
increase in certain parameters. Algae exposed to UV-B showed further but more gradual reductions over time. The length of exposure to increasing UV-B levels, for instance through sea ice melting earlier, could determine the extent of damage to the photosystems. Sobrino and Neale (2007) assessed the effect of UVR and temperature on Thalassiosira pseudonana using biological weighting functions (BWFs). These functions quantify the damage caused by UVR in relation to wavelength. After short-term (1 h) manipulations in temperature that were either higher or lower than the ambient, increased sensitivity to UVR was apparent, indicated by a decrease in quantum yield. However, after acclimation over longer periods of time (days), while the responses were similar the magnitude of the differences seen was much smaller. Exposure to higher UVR led to lower $\phi_{\text {PSII }}$ due to photoinhibitory effects but, after a period of acclimation, there was then an increase and recovery in $\phi_{\mathrm{PSIII}}$.

An experiment that incorporated longer manipulation periods than those described in this chapter was conducted (Chapter 5) in order to examine the effect of length of incubation on acclimatory abilities. For all species exposed to similar exposure regimes, there were very few significant changes in photosynthetic parameters between 2 and 7 $d$, which strongly supports the shorter incubation periods used in these experiments.

Chaetoceros sp. used in this study produced additional MAAs only in response to UV-B radiation (Figure 4.8(c)). Even though they did not produce MAAs in response to PAR, their photosynthetic parameters did not decrease, indicating inherent tolerance to both high PAR and UV-B levels. The levels of PAR and UV-B experienced can vary widely depending on the biomass present in the water column (Mitchell \& Holm-Hansen, 1991). Boyd et al. (2000) found that 1\% of surface PAR could reach $84 \mathrm{~m}$ in the absence of a bloom, whereas this depth reduced to $45 \mathrm{~m}$ during the bloom. Helbling et al. (1996) reported that, in Thalassiosira sp., MAA production was related not only to exposure to UVR but also to irradiance, while in Fragilariopsis cylindrus, MAAs were produced mainly in response to UVR. Differences in the stimulus for MAA production will determine where in the upper mixed layer a species can survive, with species occurring lower in the water column being more likely to be those that can synthesize MAAs in response to irradiance only. This ability would be crucial to sea ice algae if they become part of the algal bloom where they will have to tolerate higher PAR and UV-B compared to the habitat at the bottom of the ice. 


\subsubsection{CONCLUSIONS}

This study has shown that both Ross Sea algal species examined can, to different extents, tolerate higher PAR and UV-B levels than they typically face at present at the bottom of the sea ice, and that they are less stressed by increasing PAR than by increasing UV-B. Increases in MAA production could decrease the effect of photoinactivation caused by the latter. In contrast, Chaetoceros sp. obtained from the Antarctic Peninsula showed showed little evidence of being stressed by either PAR or UV-B exposure. The increase in quantum yield observed in this species at all PAR levels, and also at high UV-B levels over a manipulation period of $48 \mathrm{~h}$, is an indication that decreasing sea ice cover could result in increased primary production. However, to further examine responses in all the study species, manipulations over longer time periods would be required, along with more precise descriptions of the time course of PAR and UVR exposure experienced by the under-ice community during the ice melt period. Furthermore, different populations in different areas could also respond differently, requiring experiments that compare the same species from different areas. Thalassiosira sp. and Fragilariopsis sp. produced MAAs in response to PAR and UV-B exposure in the current study (Figures $4.3,4.6$ ). This is in contrast to the study of Helbling et al. (1996), who showed that Fragilariopsis cylindrus increased MAA production in response to UV-B alone. In the present study, Thalassiosira sp. had higher MAA concentrations compared to Fragilariopsis sp. when exposed only to PAR, and had a higher photosynthetic yield at high PAR levels. However, Fragilariopsis sp. exhibited higher MAA production compared to Thalassiosira sp. when exposed to UV-B, and had a significantly higher quantum yield at all exposure levels. This is in contrast to members of the same genera studied in the Antarctic Peninsula region where Thalassiosira sp. produced MAAs in response to UVR and PAR, while Fragilariopsis cylindrus, produced very low concentrations of MAAs in response only to UVR (Helbling et al., 1996). The lack of MAA production in response to PAR in F. cylindrus is a possible indication that this species is resistant to higher PAR levels in the absence of MAAs. In some species, MAA synthesis could be dependent on photosynthetic activity, possibly via biosynthesis of precursors (Carreto et al., 1990). Some species cannot produce MAAs when they are exposed only to UV-B as they require PAR for the synthesis of its precursors, while others produce MAAs under increased UV-B only (Schick \& Dunlap, 2002). 
The strongest trend in sea ice in the western Antarctic Peninsula is the later advance of sea ice in early winter (Stammerjohn et al., 2008). A shorter sea ice season means less time for the ice to thicken, which could then contribute to higher irradiance exposure and an earlier sea ice retreat in spring. This not only reduces the amount of time sea ice algae are present in the ice matrix but also leads to an earlier release into the water column (Stammerjohn et al., 2008). Primary production in the western Antarctic Peninsula region is related to sea ice dynamics and its inter-annual variability (Vernet $e t$ al., 2008). Sea ice retreat resulted in a significant reduction in primary production in this area (Smith \& Nelson, 1985). Subsequent exposure of algae in the water column to higher PAR and UV-B levels for longer periods of time could lead to acclimatisation to these conditions. The lack of photosynthetic damage shown by Chaetoceros sp. in the current study even at high PAR and UV-B levels is an indication of this acclimatory ability.

Decreased sea ice extent has been widely reported in the Arctic (Arrigo et al., 2008, Comiso, 2006, Comiso et al., 2008) and in the Antarctic Peninsula region (Stammerjohn et al., 2008). Arctic phytoplankton productivity (Yun et al., 2012) in an area with decreasing sea ice cover (Melling, 1998) showed increased carbon fixation in the layer with maximum algal biomass under PAR enhancement. The authors (Yun et al., 2012) suggested that these algae were light-limited and their productivity could be increased under increased PAR. Similarly, in response to high levels of PAR, Chaetoceros sp. in this study showed a significant increase in their saturation irradiance (Figure A3.11(b), Appendix 3) within a period of two days, indicating capability of acclimating to higher PAR rapidly and demonstrating varying species-specific responses. There is a known variation in the time required for this response (Vernet et al., 2008), indicating that further research should be conducted that examines species-specific responses over longer periods of time.

\subsection{REFERENCES}

Alderkamp, A.-C., Garcon, V., de Baar, H. J. W., \& Arrigo, K. R. (2011). Short-term photoacclimation effects on photoinhibition of phytoplankton in the Drake Passage (Southern Ocean). Deep Sea Research Part I: Oceanographic Research Papers, 58, 943-955. 
Andreoli, C., Moro, I., LaRocca, N., Dalle Valle, L., Masiero, L., Rascio, N., et al. (2000). Ecological, physiological and biomolecular surveys on microalgae from Ross Sea (Antarctica). Italian Journal of Zoology, 67, 147-156.

Antal, T. K., Osipov, V., Matorin, D. N., \& Audrey, B. R. (2011). Membrane potential is involved in regulation of photosynthetic reactions in the marine diatom Thalassiosira weissflogii. Journal of Photochemistry and Photobiology B: Biology, 102, 169-173.

Arrigo, K. R., Robinson, D. H., \& Sullivan, C. W. (1993). A high resolution study of the platelet ice ecosystem in McMurdo Sound, Antarctica: Photosynthetic and biooptical characteristics of a dense microalgal bloom. Marine Ecology Progress Series, 98, 173-185.

Arrigo, K. R., Worthen, D., Schnell, A., \& Lizotte, M. P. (1998). Primary production in Southern Ocean waters. Journal of Geophysical Research, 103, 15587-15600.

Arrigo, K. R., Lubin, D., van Dijken, G. L., Holm-Hansen, O., \& Morrow, E. (2003). Impact of a deep ozone hole on Southern Ocean primary production. Journal of Geophysical Research, 108, 3154.

Arrigo, K. R., \& Thomas, D. N. (2004). Large scale importance of sea ice biology in the Southern Ocean. Antarctic Science, 16, 471-486.

Arrigo, K. R., van Dijken, G., \& Pabi, S. (2008). Impact of a shrinking Arctic ice cover on marine primary production. Geophyical Research Letters, 35, L19603.

Arrigo, K. R. (2014). Sea Ice Ecosystems. Annual Review of Marine Science, 6, 439-467.

Atkinson, A., Siegel, V., Pakhomov, E., \& Rothery, P. (2004). Long-term decline in krill stock and increase in salps within the Southern Ocean. Nature, 432, 100-103.

Bodeker, G. E., Shiona, H., \& Eskes, H. (2005). Indicators of Antarctic ozone depletion. Atmospheric Chemistry and Physics, 5, 2603-2615.

Boyd, P. W., Watson, A. J., Law, C. S., Abraham, E. R., Trull, T., Murdoch, R., et al. (2000). A mesoscale phytoplankton bloom in the polar Southern Ocean stimulated by iron fertilization. Nature, 407, 695-702.

Carreto, J. I., Carignan, M. O., Daleo, G., \& Marco, S. G. D. (1990). Occurrence of mycosporine-like amino acids in the red-tide dinoflagellate Alexandrium excavatum: UV-photoprotective compounds? Journal of Plankton Research, 12, 909-921.

Clarke, A., Murphy, E. J., Meredith, M. P., King, J. C., Peck, L. S., Barnes, D. K. A., et al. (2007). Climate change and the marine ecosystem of the western Antarctic Peninsula. Philosophical Transactions of the Royal Society B: Biological Sciences, 362, 149-166.

Comiso, J. C. (2006). Abrupt decline in the Arctic winter sea ice cover. Geophysical Research Letters, 33, L18504.

Comiso, J. C., Parkinson, C. L., Gersten, R., \& Stock, L. (2008). Accelerated decline in the Arctic sea ice cover. Geophysical Research Letters, 35.

Convey, P., Bindschadler, R., di Prisco, G., Fahrbach, E., Gutt, J., Hodgson, D. A., et al. (2009). Antarctic climate change and the environment. Antarctic Science, 21, 541-563.

Ducklow, H. W., Baker, K., Martinson, D. G., Quetin, L. B., Ross, R. M., Smith, R. C., et al. (2007). Marine pelagic ecosystems: the West Antarctic Peninsula. Philosophical Transactions of the Royal Society B: Biological Sciences, 362, 67-94.

Eicken, H. (1992). The role of sea ice in structuring Antarctic ecosystems. Polar Biology, 12, 3-13. 
Farman, J. C., Gardiner, B. G., \& Shanklin, J. D. (1985). Large losses of total ozone in Antarctica reveal seasonal ClOx/NOx interaction. Nature, 315, 207-210.

Forcada, J., Trathan, P. N., Reid, K., Murphy, E. J., \& Croxall, J. P. (2006). Contrasting population changes in sympatric penguin species in association with climate warming. Global Change Biology, 12, 411-423.

Franklin, L., \& Forster, R. (1997). The changing irradiance environment: consequences for marine macrophyte physiology, productivity and ecology. European Journal of Phycology, 32, 207-232.

Fritsen, C. H., Memmott, J., \& Stewart, F. J. (2008). Inter-annual sea-ice dynamics and micro-algal biomass in winter pack ice of Marguerite Bay, Antarctica. Deep Sea Research II, 55, 2059-2067.

Fritsen, C. H., Memmott, J., Ross, R. M., Quetin, L. B., Vernet, M., \& Wirthlin, E. (2011). The timing of sea ice formation and exposure to photosynthetically active radiation along the Western Antarctic Peninsula. Polar Biology, 34, 683-692.

Gao, Q., \& Garcia-Pichel, F. (2011). Microbial ultraviolet sunscreens. Nature Reviews Microbiology, 9, 79 
Karentz, D., Cleaver, J. E., \& Mitchell, D. L. (1991). Cell survival characteristics and molecular responses of Antarctic phytoplankton to ultraviolet-B radiation. Journal of Phycology, 27, 326-341.

Karentz, D. (1994). Ultraviolet tolerance mechanisms in Antarctic marine organisms. Antarctic Research Series, 62, 93-110.

Karsten, U., Franklin, L. A., Tüning, K., \& Wiencke, C. (1998). Natural ultraviolet radiation and photosynthetically active radiation induce formation of mycosporine-like amino acids in the marine macroalga Chondrus crispus (Rhodophyta). Planta, 205, 257-262.

Klisch, M., \& Hader, D.-P. (2008). Mycosporine-like amino acids and marine toxins- the common and the different. Marine Drugs, 6, 147-163.

Lizotte, M. P. (2001). The contributions of sea ice algae to Antarctic marine primary production. American Zoologist, 41, 57-73.

Longhi, M. L., Schloss, I. R., \& Wiencke, C. (2003). Effect of irradiance and temperature on photosynthesis and growth of two Antarctic benthic diatoms, Gyrosigma subsalinum and Odontella litigiosa. Botanica Marina, 46, 276-284.

Lüder, U. H., Wiencke, C., \& Knoetzel, J. (2002). Acclimation of photosynthesis and pigments during and after six months of darkness in Palmaria decipiens (Rhodophyta): A study to stimulate Antarctic winter sea ice cover. Journal of Phycology, 38, 904-913.

Martínez, R. (2007). Effects of ultraviolet radiation on protein content, respiratory electron transport system (ETS) activity and superoxide dismutase (SOD) activity of Antarctic plankton. Polar Biology, 30, 1159-1172.

Martinson, D. G., Stammerjohn, S. E., Iannuzzi, R. A., Smith, R. C., \& Vernet, M. (2008). Western Antarctic Peninsula physical oceanography and spatio-temporal variability. Deep Sea Research Part II: Topical Studies in Oceanography, 55, 19641987.

McMinn, A., Ashworth, C., \& Ryan, K. (1999). Growth and productivity of Antarctic sea ice algae under PAR and UV irradianes. Botanica Marina, 42, 401-407.

McMinn, A., Ryan, K., \& Gademann, R. (2003). Diurnal changes in photosynthesis of Antarctic fast ice algal communities determined by pulse amplitude modulation fluorometry. Marine Biology, 143, 359-367.

Melling, H. (1998). Hydrographic changes in the Canada Basin of the Arctic Ocean, 19791996. Journal of Geophysical Research, 103, 7637-7645.

Mitchell, B. G., \& Holm-Hansen, O. (1991). Bio-optical properties of Antarctic Peninsula waters: differentiation from temperate ocean models. Deep Sea Research, 38, 1009-1028.

Moline, M. A., Claustre, H., Frazer, T. K., Schofield, O., \& Vernet, M. (2004). Alteration of the food web along the Antarctic Peninsula in response to a regional warming trend. Global Change Biology, 10, 1973-1980.

Montes-Hugo, M., Doney, S. C., Ducklow, H. W., Fraser, W., Martinson, D., Stammerjohn, S. E., et al. (2009). Recent changes in phytoplankton communities associated with rapid regional climate change along the Western Antarctic Peninsula. Science, $323,1470-1473$.

Moreau, S., Ferreyra, G., Mercier, B., Lemarchand, K., Lionard, M., Roy, S., et al. (2010). Variability of the microbial community in the western Antarctic Peninsula from late fall to spring during a low ice cover year. Polar Biology, 33, 1599-1614. 
Morley, S. A., Griffiths, H. J., Barnes, D. K. A., \& Peck, L. S. (2010). South Georgia: a key location for linking physiological capacity to distributional changes in response to climate change. Antarctic Science, 22, 774-781.

Mundy, C., Gosselin, M., Ehn, J., Belzile, C., Poulin, M., Alou, E., et al. (2011). Characteristics of two distinct high-light acclimated algal communities during advanced stages of sea ice melt. Polar Biology, 34, 1869-1886.

Nahon, S., Charles, F., Lantoine, F., Vetion, G., Escoubeyrou, K., Desmalades, M., et al. (2010). Ultraviolet radiation negatively affects growth and food quality of the pelagic diatom Skeletonema costatum. Journal of Experimental Marine Biology and Ecology, 383, 164-170.

Oren, A., \& Gunde-Cimerman, N. (2007). Mycosporines and mycosporine-like amino acids: UV protectants or multipurpose secondary metabolites? FEMS Microbiology Letters, 269, 1-10.

Parkinson, C. L. (2002). Trends in the length of the Southern Ocean sea-ice season, 1979-99. Annals of Glaciology, 34, 435-440.

Peck, L. S., Convey, P., \& Barnes, D. K. A. (2006). Environmental constraints on life histories in Antarctic ecosystems: tempos, timings and predictability. Biological Reviews, 81, 75-109.

Peck, L. S., Barnes, D. K. A., Cook, A. J., Fleming, A. H., \& Clarke, A. (2010). Negative feedback in the cold: ice retreat produces new carbon sinks in Antarctica. Global Change Biology, 16, 2614-2623.

Peinado, N. K., Abdala Díaz, R. T., Figueroa, F. L., \& Helbling, E. W. (2004). Ammonium and UV radiation stimulate the accumulation of mycosporine-like amino acids in Porphyra columbina (Rhodophyta) from Patagonia, Argentina. Journal of Phycology, 40, 248-259.

Petrou, K., Doblin, M., \& Ralph, P. (2011a). Heterogeneity in the photoprotective capacity of three Antarctic diatoms during short-term changes in salinity and temperature. Marine Biology, 158, 1029-1041.

Petrou, K., Hill, R., Doblin, M. A., McMinn, A., Johnson, R., Wright, S. W., et al. (2011b). Photoprotection of sea-ice microbial communities from the East Antarctic pack ice. Journal of Phycology, 47, 77-86.

Petrou, K., \& Ralph, P. (2011). Photosynthesis and net primary productivity in three Antarctic diatoms: possible significance for their distribution in the Antarctic marine ecosystem. Marine Ecology Progress Series, 437, 27-40.

Ralph, P. J., \& Gademann, R. (2005). Rapid light curves: A powerful tool to assess photosynthetic activity. Aquatic Botany, 82, 222-237.

Ralph, P. J., McMinn, A., Ryan, K. G., \& Ashworth, C. (2005). Short-term effect of temperature on the photokinetics of microalgae from the surface layers of Antarctic pack ice. Journal of Phycology, 41, 763.

Ryan, K. G., McMinn, A., Mitchel, K. A., \& Trenerry, L. (2002). Mycosporine-like amino acids in Antarctic sea ice algae, and their response to UVB radiation. Zeitschrift fur Naturforschung - Section C Journal of Biosciences, 57, 471-477.

Ryan, K. G., Ralph, P., \& McMinn, A. (2004). Acclimation of Antarctic bottom-ice algal communities to lowered salinities during melting. Polar Biology, 27, 679-686.

Ryan, K. G., Hegseth, E. N., Martin, A., Davy, S. K., O'Toole, R., Ralph, P. J., et al. (2006a). Comparison of the microalgal community within fast ice at two sites along the Ross Sea coast, Antarctica. Antarctic Science, 18, 583-594. 
Ryan, K. G., Hegseth, E. N., Martin, A., Davy, S. K., O'Toole, R., Ralph, P. J., et al. (2006b). Comparison of the microalgal community within fast ice at two sites along the Ross Sea coast, Antarctica. Antarctic Science, 18, 583-594.

Ryan, K. G., Tay, M. L., Martin, A., McMinn, A., \& Davy, S. K. (2011). Chlorophyll fluorescence imaging analysis of the responses of Antarctic bottom-ice algae to light and salinity during melting. Journal of Experimental Marine Biology and Ecology, 399, 156-161.

Ryan, K. G., McMinn, A., Hegseth, E. N., \& Davy, S. K. (2012). The Effects of Ultraviolet-B Radiation on Antarctic Sea-Ice Algae. Journal of Phycology, 48, 74-84.

Salleh, S., \& McMinn, A. (2011). Photosynthetic response and recovery of Antarctic marine benthic microalgae exposed to elevated irradiances and temperatures. Polar Biology, 34, 855-869.

Schick, J. M., \& Dunlap, W. C. (2002). Mycosporine-like amino acids and related gadusols: Biosynthesis, accumulation and UV-protective functions in aquatic organisms. Annual Review of Physiology, 64, 223-262.

Schofield, O., Ducklow, H. W., Martinson, D. G., Meredith, M. P., Moline, M. A., \& Fraser, W. R. (2010). How do polar marine ecosystems respond to rapid climate change? Science, 328, 1520-1523.

Singh, S. P., Häder, D.-P., \& Sinha, R. P. (2010). Cyanobacteria and ultraviolet radiation (UVR) stress: Mitigation strategies. Ageing Research Reviews, 9, 79-90.

Smith, W. O., \& Nelson, D. M. (1985). Phytoplankton bloom produced by a receding ice edge in the Ross Sea: Spatial coherence with the density field. Science, 227, 163166.

Smith, W. O., Ainley, D. G., Arrigo, K. R., \& Dinniman, M. S. (2014). The Oceanography and Ecology of the Ross Sea. Annual Review of Marine Science, 6, 469-487.

Sobrino, C., \& Neale, P. J. (2007). Short-term and long-term effects of temperature on photosynthesis in the diatom Thalassiosira pseudonana under UVR exposures. Journal of Phycology, 43, 426-436.

Stammerjohn, S. E., Martinson, D. G., Smith, R. C., \& Iannuzzi, R. A. (2008). Sea ice in the western Antarctic Peninsula region: Spatio-temporal variability from ecological and climate change perspectives. Deep Sea Research Part II: Topical Studies in Oceanography, 55, 2041-2058.

Steig, E. J., Schneider, D. P., Rutherford, S. D., Mann, M. E., Comiso, J. C., \& Shindell, D. T. (2009). Warming of the Antarctic ice-sheet surface since the 1957 International Geophysical Year. Nature, 457, 459-462.

Stoecker, D. K., Gustafson, D. E., Black, M. M. D., \& Baier, C. T. (1998). Population dynamics of microalgae in the upper land-fast sea ice at a snow-free location. Journal of Phycology, 34, 60-69.

Stoecker, D. K., Gustafson, D. E., Baier, C. T., \& Black, M. M. D. (2000). Primary production in the upper sea ice. Aquatic Microbial Ecology, 21, 275-287.

Thomas, D. N., \& Dieckmann, G. S. (2002). Antarctic Sea Ice--a Habitat for Extremophiles. Science, 295, 641.

Trivelpiece, W. Z., Hinke, J. T., Miller, A. K., Reiss, C. S., Trivelpiece, S. G., \& Watters, G. M. (2011). Variability in krill biomass links harvesting and climate warming to penguin population changes in Antarctica. Proceedings of the National Academy of Sciences, 108, 7625-7628.

Turner, J., Colwell, S. R., Marshall, G. J., Lachlan-Cope, T. A., Carleton, A. M., Jones, P. D., et al. (2005). Antarctic climate change during the last 50 years. International Journal of Climatology, 25, 279-294. 
Turner, J., Comiso, J. C., Marshall, G. J., Lachlan-Cope, T. A., Bracegirdle, T., Maksym, T., et al. (2009). Non-annular atmospheric circulation change induced by stratospheric ozone depletion and its role in the recent increase of Antarctic sea ice extent. Geophysical Research Letters, 36, L08502.

Turner, J., Barrand, N. E., Bracegirdle, T. J., Convey, P., Hodgson, D. A., Jarvis, M., et al. (2013a). Antarctic climate change and the environment: an update. Polar Record, FirstView, 1-23.

Turner, J., Maksym, T., Phillips, T., Marshall, G. J., \& Meredith, M. P. (2013b). The impact of changes in sea ice advance on the large winter warming on the western Antarctic Peninsula. International Journal of Climatology, 33, 852-861.

Van de Poll, W. H., \& Buma, A. G. J. (2009). Does ultraviolet radiation affect the xanthophyll cycle in marine phytoplankton? Photochemical and Photobiological Sciences, 8, 1295-1301.

Van de Poll, W. H., Janknegt, P. J., van Leeuwe, M. A., Visser, R. J. W., \& Buma, A. G. J. (2009). Excessive irradiance and antioxidant responses of an Antarctic marine diatom exposed to iron limitation and to dynamic irradiance. Journal of Photochemistry and Photobiology B: Biology, 94, 32-37.

Vaughan, D. G., Marshall, G. J., Connolley, W. M., Parkinson, C., Mulvaney, R., Hodgson, D. A., et al. (2003). Recent rapid regional climate warming on the Antarctic Peninsula. Climatic Change, 60, 243-274.

Vernet, M., Martinson, D., Iannuzzi, R., Stammerjohn, S., Kozlowski, W., Sines, K., et al. (2008). Primary production within the sea-ice zone west of the Antarctic Peninsula: Sea ice, summer mixed layer, and irradiance. Deep Sea Research Part II: Topical Studies in Oceanography, 55, 2068-2085.

Yun, M., Chung, K., Zimmermann, S., Zhao, J., Joo, H., \& Lee, S. (2012). Phytoplankton productivity and its response to higher light levels in the Canada Basin. Polar Biology, 35, 257-268. 


\section{CHAPTER 5}

\section{Photo-protective responses in polar unialgal cultures}

\subsection{Abstract}

Sea ice algae are exposed to multiple environmental stresses in both the polar regions. They are the primary producers of the ice-covered oceans, which constitute one of the largest ecosystems on Earth. There are clear differences between the two polar regions and around the Antarctic continent. The loss of sea ice has been most pronounced in the Arctic Ocean and the seas west of the Antarctic Peninsula, whereas there is an increase in sea ice extent in the Ross Sea. Incubations using unialgal cultures of common species from these three regions were carried out at ecologically relevant PAR and UV-B levels to examine their tolerance to conditions faced during sea ice melt. Photosynthetic and antioxidative responses were measured using chlorophyll fluorescence techniques and through the activity of superoxide dismutase.

To study species-specific limits to PAR and UV-B, unialgal cultures of Thalassiosira antarctica from the Ross Sea, and the bipolar species Chaetoceros socialis from the Antarctic Peninsula and the Arctic were incubated at three irradiance levels over a period of seven days. All algal cultures showed no significant difference in quantum yield between those incubated in the dark and at ambient light levels. At the higher light levels, the Ross Sea and Arctic cultures showed no significant change in photosynthetic health over seven days, whereas there was an overall significant decrease for the culture from the Antarctic Peninsula. Both Antarctic taxa also showed no overall change in superoxide dismutase activity whereas the Arctic taxon showed a dynamic change over seven days, a significant increase over two days, which was followed by a significant decrease by the end of the seventh day. The lack of significant changes in several of the measured characteristics signals the needs for further parameters to be assessed during such experiments. The coupling of parameters led to a lack of differentiation in photosynthetic health in algae, even though they showed significant effects when subjected to PAR or UV-B alone in separate treatments. This could be indicative of a capacity for photo-protection being inherent in these algae. 


\subsection{Introduction}

Polar sea ice forms one of the largest ecosystems on Earth. In the Antarctic it covers an area of $19 \times 10^{6} \mathrm{~km}^{2}$ at its maximum extent in winter and diminishes to $3 \times 10^{6} \mathrm{~km}^{2}$ during the summer (Arrigo, 2014). The extent and variability of sea ice is somewhat less in the Arctic where it oscillates between $15 \times 10^{6} \mathrm{~km}^{2}$ and $5 \times 10^{6} \mathrm{~km}^{2}$. However the long term rate of change in the Arctic is much greater than in the Antarctic, with summer ice extent reducing by $45 \%$ in only the past three decades (Maksym et al., 2012, Stammerjohn et al., 2012). Antarctic ice extent has recorded a slight increase over the past three decades (Turner et al., 2013) (http://www.ipcc.ch/report/ar5/wg1/\#.UuhKY2SBoYI). The reasons for these contrasts are varied and were discussed further in Chapter 2, Section 2.1.

Due to the rapidly changing climatic conditions, there has been a drastic loss of sea ice in the Arctic (Stammerjohn et al., 2012). In areas of rapid sea ice decrease, the spring retreat now initiates two months earlier and autumn advance one month later as compared to $1979 / 1980$, resulting in the ice-free summer season lengthening by three months. Although winter sea ice extent in the Antarctic has slightly increased overall, the distribution has changed with increases in the Ross Sea region and decreases in the Weddell Sea that can be attributed to changing wind patterns and possibly other factors (Arrigo, 2014, Turner et al., 2013). In the Antarctic Peninsula and Bellinghausen Sea region, sea ice retreat is one month earlier and advance is two months later, again causing a three month longer ice-free period similar to that seen in the Arctic (Stammerjohn et al., 2012). In the Ross Sea region, sea ice retreat is one month later and advance is one month earlier, leading to a shortening of the summer ice-free season by almost two months.

The anomalies observed in both the polar regions can cause severe ecological disruptions (Arrigo, 2014). In the Arctic, earlier retreat of sea ice can cause a timing mismatch between the production of high-quality food in the form of algal blooms and the reproductive cycles of important grazers, that could lead to negative consequences for the whole ecosystem. In the Antarctic, decrease in sea ice extent and its associated algal communities is likely to cause a reduction in post-larval krill survival, affecting a critical food source for higher trophic level organisms such as fish, seals, penguins and whales (Nicol et al., 2008). 
Sea ice algal communities reach their peak standing biomass in spring, leading to a significant increase in pigment concentration in the ice (Arrigo, 2014). This reduces the amount of light available to the upper water column, affecting algal productivity in the water below the ice (Arrigo et al., 1991, SooHoo et al., 1987). Phytoplankton blooms in the water column are delayed until after the ice algal boom and hence the timing of ice algal blooms controls the timing of the subsequent phytoplankton bloom (Arrigo et al., 2012). When the sea ice melts, some of the algae released provide seed stock for blooms at the ice edge (Mangoni et al., 2009), which depends on the ability of the algal species to resist sinking (Riebesell et al., 1991) and to survive the melting transition and acclimate to the higher PAR and UV-B conditions they are then exposed to very rapidly (Mundy et al., 2011).

Sea ice can be annual ice, that forms and melts during one annual cycle, or multi-year ice that accrues layers formed over two or more seasons (Arrigo \& Thomas, 2004). In the Arctic, there has been a decrease in sea ice thickness along with the reduction in sea ice extent, which is mainly due to a decrease in multi-year ice in the central Arctic Ocean (Maslanik et al., 2011). In contrast, annual sea ice extent has increased in the Antarctic but multi-year ice has remained constant.

There is also a difference in patterns of changing snow cover on the sea ice in the two polar regions (Arrigo, 2014). In the Arctic, snow cover has significantly reduced, permitting increased PAR to penetrate the ice, with this being further compounded by the reduction in sea ice thickness. Decrease in snow cover and reduction in sea ice thickness leads to less ridged ice with more surface melt ponds, that reflects less solar radiation and has implications that reach beyond the sea ice ecosystem (Nicolaus et al., 2012). A decrease in solar radiation causes decreased surface albedo and increased energy absorption into the upper ocean which leads to a positive feedback in ocean warming. An emigration of diatoms from sea ice has been reported under these changed conditions that could lead to reductions in productivity from the ice algal bloom, thereby impacting overall productivity in the Arctic Ocean (Lund-Hansen et al., 2013). Analogous decreases in snow cover or ice thickness have not been reported in the Antarctic (Arrigo, 2014).

Microalgae are the primary producers found in the complex sea ice ecosystem, with diatoms (Bacillariophyceae) dominating the algal communities (Arrigo, 2014) and 
reaching large stocks due to the nutrient-rich waters of the Southern Ocean. The potential for nutrient limitation in the Antarctic is considered limited, but local depletion can occur if there are other growth-limiting factors (Harrison \& Cota, 1991) such as vertical stratification in the water column and depletion due to the sea ice algal bloom in spring. In Arctic waters, nutrient depletion can occur more commonly due to lower overall nutrient concentrations and water column stability. In both regions, factors other than nutrients, such as light and salinity, seem to be limiting, with nutrient concentrations playing a secondary role. Algal cell concentrations in sea ice can vary by up to six orders of magnitude, $<10^{4}$ to $>10^{9}$ cells per litre (Arrigo et al., 2010). This range covers typical global oceanic values to some of the highest recorded in any aquatic environment. Chlorophyll a ( $\mathrm{Chl} \mathrm{a)} \mathrm{biomass} \mathrm{in} \mathrm{sea} \mathrm{ice} \mathrm{varies} \mathrm{by} \mathrm{region,} \mathrm{ice} \mathrm{type}$ and over seasons. In the Arctic, volumetric Chl a concentrations range from 3 to $800 \mathrm{mg}$ $\mathrm{m}^{-3}$, and can be up to $10,100 \mathrm{mg} \mathrm{m}^{-3}$ in the Antarctic (Arrigo et al., 2010). This vast range can be explained by factors such as higher nutrient availability in the Antarctic and lower annual light availability at the highest latitudes in the Arctic.

The community of the sea ice ecosystem is largely microbial, and its composition is determined by various physical factors such as light, salinity, nutrients and temperature (Arrigo \& Thomas, 2004, Arrigo et al., 2010, Arrigo, 2014). Specific sea ice communities can consist of 30-170 diatom species. Commonly-encountered diatom genera in landfast ice include Nitzchia, Thalassiosira, Fragilariopsis and Navicula. They are found through the sea ice profile and often form strands that grow beneath the sea ice. Autotrophic flagellates, bacteria, archaea and protists are also found in this ecosystem. Microlagal biomass can vary through the sea ice profile, with the highest concentration found in the bottom $20 \mathrm{~cm}$ due to the stable light and temperature conditions present in this part of the sea ice (Arrigo \& Thomas, 2004). There is also a constant supply of nutrients to this bottom layer due to the interface with the underlying seawater (Arrigo, 2014). Microalgal blooms in the sea ice are short-lived and are limited by low light and low temperatures (Ratkova et al., 2004). The distribution of the algal biomass can also be patchy and show large variability (Rysgaard et al., 2001) due to local conditions such as snow cover and strong water currents (Lund-Hansen et al., 2013).

Many studies have examined the effects of particular environmental parameters on unialgal cultures (Davidson et al., 1994, Hannach \& Sigleo, 1998, Leu et al., 2010, Martin 
et al., 2012, Ryan et al., 2012). However, very few have examined the effect of multiple stressors (Halac et al., 2010, Hancke et al., 2008, Petrou et al., 2011, Salleh \& McMinn, 2011) or compared common algal species from different parts of the polar regions (Petrou \& Ralph, 2011).

Brief periods of exposure to high light levels may cause significant changes to the photosynthetic activity and composition (affecting its quality as a dietary item) of a common polar microalga, Thalassiosira antarctica var. borealis (Leu et al., 2006). Exposure to higher PAR and UVR caused a decline in the quantum yield of PSII and led to a significant reduction in C:P and N:P ratios. There was also a difference in the effects of PAR and UVR, with the algae affected strongly by increase in PAR but not UVR. However, as the alga was capable of increasing its content of photoprotective pigments such as diadinoxanthin, a capacity for photo-acclimation was observed which reduced the impacts of higher light exposure.

UVR has been observed to reduce photo-protective capacity in diatoms such as Phaedactylum tricornutum (Halac et al., 2009), affecting the xanthophyll cycle and causing a decrease in photosynthetic health when exposed to saturating PAR. In this species, PAR synergistically accelerated the damage caused by UVR to PSII activity. UVR decreased photoprotective capacity then increased the diatom's susceptibility to increased PAR. In contrast, another study (Halac et al., 2010) demonstrated how increased temperature could counteract the negative effects of UVR. This study showed that there was photoinhibition in the two diatom species studied, Thalassiosira weissflogii and Chaetoceros gracilis, due to PAR, which was further enhanced by UV-B. There was, however, a variation in photoinhibition due to length of exposure and size of cells, highlighting the importance of studying species-specific responses in diatoms. The antagonistic effect between temperature and UVR was observed clearly in Thalassiosira weissflogii whereas it was apparent in only some treatments for Chaetoceros gracilis.

PAM fluorometry is a widely used tool for studying the photosynthetic health of microalgae (Hancke et al., 2008, Katayama \& Taguchi, 2013, McMinn \& Hegseth, 2004, Parkhill et al., 2001, Ryan et al., 2009) as it provides a non-invasive method to study smaller cultures. Changes in chl a have also been used as way of examining algal photophysiology (Campbell et al., Hancke et al., 2008, Martin et al., 2012), but this approach is often limited by the volume of culture available for experimental use. A 
reduction in chl a content has been reported in microalgae under oxidative stress (Cirulis et al., 2013).

To protect themselves from environmental stresses, many microorganisms produce mycosporine-like amino acids (MAAs) (Vincent, 1988). Experiments using light and dark cycles indicate that, in cyanobacteria and algae, MAAs are synthesized during the light period and their synthesis is closely linked to photosynthesis but can also be stimulated by other factors such as osmotic stress (Oren \& Gunde-Cimerman, 2007). MAA production is a useful tool to assess photosynthetic stress in microalgae as their accumulation is correlated with UVR exposure in many marine organisms (Ha et al., 2014, Hernando et al., 2002, Janknegt et al., 2009a, Ryan et al., 2002).

Polar marine microalgae are known to experience high PAR and UVR stress that lead to detrimental photoreactions (Janknegt et al., 2007). UVR-driven photoreactions to biomolecules can interrupt important metabolic pathways and cause an over-reduction of the electron transport chain (ETC). When the production of reduced equivalents is faster than their consumption, electrons from the ETC combine with molecular $\mathrm{O}_{2}$ and lead to the formation of reactive oxygen species (ROS). ROS cause damage to photosystem II reaction center proteins leading to a decrease in the photosynthetic rate of the algae (Van De Poll et al., 2005). Microalgae have mechanisms that protect their organelles against ROS. However, when ROS production is too rapid, the ETCs become over-reduced and ROS accumulate quickly (Janknegt et al., 2007). In response to this damage, cells produce antioxidant enzymes that actively scavenge ROS intermediates. The first ROS produced is a superoxide anion $\left(\mathrm{O}_{2}{ }^{\circ}\right)$, which can be converted into a hydroxyl radical ( $\left.\mathrm{HO}^{\circ}\right)$ through a series of reductions. $\mathrm{HO}^{*}$ is one of the most reactive oxygen species in chemistry. To avoid the production of $\mathrm{HO}^{\circ}, \mathrm{O}_{2}{ }^{-}$is converted into hydrogen peroxide by the enzyme superoxide dismutase (SOD) (Gregory \& Fridovich, 1973). SOD is the first and only enzyme that can catalyse this reaction, making it key to the cell's antioxidant response (Janknegt et al., 2007). Studies that describe SOD responses in marine polar microalgae are rare due to difficulties such as obtaining sufficient biomass for reliable measurements (Janknegt et al., 2009b, Katayama \& Taguchi, 2013, Van de Poll et al., 2009). The Riboflavin/NitroBlue Tetrozolium (RF/NBT) assay is the most reliable assay for measuring SOD activity in marine microalgae within a large temperature range (Janknegt et al., 2007). 
The aim of this study was to examine the photosynthetic (measured using chlorophyll fluorescence techniques) and antioxidative (measured using the RF/NBT assay) response of sea ice algae in combined treatments of ecologically relevant PAR and UV-B exposures. The PAR and UV-B levels chosen were representative of those found from the middle to the bottom of the sea ice profile (Ryan et al., 2011) to study the capacity of common species to tolerate increased radiation levels such as might be experienced during ice melt and due to the thinning of sea ice. This study further attempted to compare acclimatory abilities across species using the photosynthetic and antioxidative responses of cultures of common algal species from each of three regions with different patterns of environmental variation, namely the Ross Sea, the Antarctic Peninsula and the Arctic Ocean. Assessing the capacity of these algae for photo-protection will provide a better foundation for predictions relating to their response in context of climate change.

\subsection{Methods}

\subsubsection{Culture methodology}

Unialgal stock cultures were maintained in Victoria University of Wellington at $50 \mu \mathrm{mol}$ $\mathrm{m}^{-2} \mathrm{~s}^{-1}$ and $4^{\circ} \mathrm{C}$ in $\mathrm{f} / 2$ medium (Ausaqua Pty Ltd., Australia) for 5 to 6 months prior to these experiments. The Ross Sea species, Thalassiosira antarctica used in the experiments described below were isolated from sea ice at Cape Evans in the summer of $2010 / 2011$.

A stock culture of Chaetoceros socialis from the Antarctic Peninsula was obtained from Dr. Claire Hughes (University of East Anglia) as part of studies under the Rothera Time Series maintained by the British Antarctic Survey near its Rothera Research Station in Ryder Bay (Marguerite Bay, 67³4'S, 68 9' $\mathrm{W}$ ) during the austral summer of 2008/2009 (http://www.antarctica.ac.uk//staff-profiles/webspace/mmm/RaTS/RaTS.html).

A stock culture of the same nominate species from the Arctic was obtained from Associate Professor Else Hegseth (University of Tromso) and was collected from Billefjorden, Svalbard in the summer of 2011. 


\subsubsection{Light treatments}

The light treatments were based on measurements taken in the field through the sea ice profile (pers. obs.). They are representative of the PAR and UV- B levels that sea ice algae would be exposed to from the middle to the bottom of the sea ice profile (Eicken, 1992, Petrou \& Ralph, 2011). Sub-samples ( $400 \mathrm{ml}$ ) of unialgal cultures ( $\mathrm{n}=3$ at each level) were incubated under each of four light levels ( $\mathrm{L} 0=0 \mu \mathrm{mol} \mathrm{m}^{-2} \mathrm{~s}^{-1}, \mathrm{~L} 1=1 \mu \mathrm{mol} \mathrm{m}{ }^{-2}$ $\mathrm{s}^{-1}$ of PAR, L2 $=45 \mu \mathrm{mol} \mathrm{m}^{-2} \mathrm{~s}^{-1}$ of PAR and $50 \mathrm{~mW} \mathrm{~m}^{-2}$ of UV-B, L3 $=100 \mu \mathrm{mol} \mathrm{m}^{-2} \mathrm{~s}^{-1}$ of PAR and $50 \mathrm{~mW} \mathrm{~m}^{-2}$ of UV-B) at $4^{\circ} \mathrm{C}$ for $168 \mathrm{~h}$ in a temperature controlled water bath (Haake, Cleveland, OH, USA). Samples were incubated at $4^{\circ} \mathrm{C}$ as this was the temperature at which these cultures had been maintained. The $400 \mathrm{ml}$ samples were incubated in $500 \mathrm{ml}$ opaque containers which were placed under $5 \mathrm{~W}$ LED lights (Greenlights, Taiwan) and a Philips Ultraviolet-B TL 12/40W UV-B tube. Different sections of the water bath were separated from each other with opaque black plastic sheets and the various levels of light and UV-B were obtained with appropriate shade cloth. The UV-B tube was also covered with a polyvinyl chloride (PVC) sheet to filter out harmful UV-C radiation. PAR levels were measured using a $2 \pi$ SKU 430 broad band UV$B$ radiometer (bandwidth $280-315 \mathrm{~nm}$ ) (Skye Instruments, UK) and the required UV-B levels were verified with an SKU 430 radiometer (Skye Instruments, UK).

Samples of $1 \mathrm{~mL}$ for cell counts were taken at 0,48 and $168 \mathrm{~h}$ from all replicates in each incubation, preserved using $2 \%$ Lugol's Iodine and stored at $4{ }^{\circ} \mathrm{C}$. Fifty $\mathrm{mL}$ of sample was used for the measurement of MAA content. This was filtered onto GF/F filters which were then placed in containers with $10 \mathrm{~mL} 100 \%$ HPLC methanol and extracted at $4 \mathrm{C}$ for $24 \mathrm{~h}$. The methanol extract was then stored at -20C and analysed using HPLC following Ryan et al. (2002).

\subsubsection{Chlorophyll a content}

Twenty-five $\mathrm{mL}$ of sample was used for the measurement of chlorophyll a content. This was filtered onto GF/F filters which were then placed in containers with $5 \mathrm{ml} 100 \%$ methanol and extracted in the dark at $4 \mathrm{C}$ for $24 \mathrm{~h}$. The extract was then measured on a digital fluorometer (Turner 10AU, Australia) following the acidification method of Evans et al. (1987). 


\subsubsection{Superoxide dismutase activity}

20 to $80 \mathrm{~mL}$ of the sample was stored in a container at $-20^{\circ} \mathrm{C}$ for measurement of superoxide dismutase (SOD) activity following Janknegt et al. (1997). The variation in volumes collected for determination of SOD activity was due to varying growth rates between species. As SOD activity had not been previously determined for these cultures, it was not possible to identify the minimum volume required $a$ priori. Therefore, a minimum of $30 \mathrm{ml}$ and, in some cases, a larger volume was collected, as a contingency to ensure the level of SOD activity was assayable. These samples were centrifuged $(2000 \mathrm{x}$ $\mathrm{g}, 5 \mathrm{~min}, 4^{\circ} \mathrm{C}$ ) in $1 \mathrm{~mL}$ eppendorf tubes and the pellets were stored at $-80^{\circ} \mathrm{C}$ to preserve enzyme activity.

\subsubsection{Cell lysis}

For enzyme measurements, cell pellets were thawed on ice, centrifuged $(2000 \mathrm{xg}, 5$ min, $4^{\circ} \mathrm{C}$ ) and resuspended in $1 \mathrm{~mL}$ cold lysis buffer mixture of $300 \mu \mathrm{L}$ potassium phosphate buffer (50 mM, pH 7.8) containing DTPA (0.2 mM), riboflavin (1.3 $\mu \mathrm{M})$, Lmethionine $(10 \mathrm{mM})$, NBT $(57 \mu \mathrm{M})$, and Triton X-100 (0.025\% (v/v)). The suspension was then centrifuged $\left(2000 \mathrm{xg}, 5 \mathrm{~min}, 4^{\circ} \mathrm{C}\right)$ again before the cells were resuspended in a final volume of $500 \mu \mathrm{L}$ of lysis buffer and sonicated (Ultrasonic liquid processor W-380, Heat Systems-Ultrasonics, Inc., New York) on ice for three $15 \mathrm{sec}$ pulses with a time interval of $10 \mathrm{sec}$ between each pulse. All lysates were centrifuged $(16000 \mathrm{xg}, 5 \mathrm{~min}$, $4^{\circ} \mathrm{C}$ ) and supernatants aliquoted and frozen at $-80^{\circ} \mathrm{C}$ until further analysis. Total aqueous soluble protein content was determined using the improved Bradford assay with BSA as standard (Zor \& Selinger, 1996).

\subsubsection{Superoxide dismutase (SOD)}

SOD assays were performed using the riboflavin/nitroblue tetrazolium (RF/NBT) assay in a microtiter plate format (Beauchamp \& Fridovich, 1971, Fryer et al., 1998). Samples of $20 \mu \mathrm{L}$ of lysate or SOD standard (0.5-500 $\left.\mathrm{U} \mathrm{mL}^{-1}\right)$ were added into a final reaction mixture of $300 \mu \mathrm{L}$ potassium phosphate buffer ( $50 \mathrm{mM}$, pH 7.8) containing EDTA (0.1 $\mathrm{mM})$, riboflavin $(1.3 \mu \mathrm{M})$, L-methionine $(10 \mathrm{mM})$, NBT $(57 \mu \mathrm{M})$, and Triton X-100 $(0.025 \%(\mathrm{v} / \mathrm{v}))$. Absorbance was read at $560 \mathrm{~nm}$ both immediately and after $10 \mathrm{~min}$ incubation under a homogenous light field $\left(130 \mu \mathrm{mol} \mathrm{m} \mathrm{m}^{-2} \mathrm{~s}^{-1}\right)$ at $25^{\circ} \mathrm{C}$. Standards and samples were measured using the same reaction mixture and a sigmoidal 5-parameter 
semi logarithmic standard curve (24 standard levels) used to determine SOD activity of samples. One unit of SOD activity was defined as the amount of enzyme that inhibited the NBT reduction by 50\% (Beyer \& Fridovich, 1987).

\subsubsection{Sub-sampling, PAM fluorometry, MAA analysis and statistical analyses}

Sub-sampling, PAM fluorometry and MAA analysis protocols are described in Section 2.3.5. An RLC was generated for each sample at time 0,2 , 4, 6, 12, 24, 48, 72, 96, 120 , 144 and $168 \mathrm{~h}$.

Statistical analyses were performed as described in Section 2.3.6 and all differences referred to are statistically significant at $\mathrm{p}<0.05$.

\subsection{Results}

\subsubsection{Effect of different light levels on the photosynthetic performance of Thalassiosira antarctica (Ross Sea), Chaetoceros socialis (Antarctic Peninsula) and C. socialis (Arctic)}

This study looked at the effects of varying light levels (PAR and UV-B) on the photosynthetic performance of three species that are commonly found in different parts of the polar regions under varying environmental conditions. The incubations were carried out for a duration of $7 \mathrm{~d}$ with PAM readings taken at $0,2,4,6,12,24,48,72,96$, 120,144 and $168 \mathrm{~h}$. Initially a two way repeated measures ANOVA was conducted for all parameters with time as the 'within' factor and treatment and species as 'between' factors (Tables A4.1, A4.2, A4.4, A4.5 in Appendix 4). These analyses showed varying results, summarised in Table 5.1. As the significant 3-way interactions make it impossible to interpret the treatment effects, repeated measures analyses were carried out for each species separately to test for the effect of all treatments and time. 
Table 5.1. Significance values for changes in quantum yield of photosystem II, rETR $\max _{\text {, }} \operatorname{Alpha}(\alpha)$ and $E_{\mathrm{k}}$ for Sea), Chaetoceros socialis (Antarctic Peninsula) and C. socialis (Arctic) over $168 \mathrm{~h}$ experimental treatments PAR and UV-B levels ( $\mathrm{L} 0=0 \mu \mathrm{mol} \mathrm{m}^{-2} \mathrm{~s}^{-1} ; \mathrm{L} 1=1 \mu \mathrm{mol} \mathrm{m}^{-2} \mathrm{~s}^{-1} ; \mathrm{L} 2=45 \mu \mathrm{mol} \mathrm{m}^{-2} \mathrm{~s}^{-1}$ and $50 \mathrm{mWm}^{-2} ; \mathrm{L} 3=100 \mu \mathrm{m}$ $4^{\circ} \mathrm{C}$, analysed using repeated measures ANOVA.

\begin{tabular}{|lllll}
\hline Source of variation & Time & Time x Treatments & Time x Species & Time x Treatn \\
\hline 申PSII & $<0.001$ & $<0.001$ & $<0.001$ & $<0.001$ \\
& & & & \\
rETR $_{\text {max }}$ & $<0.001$ & $<0.001$ & $<0.001$ & $<0.001$ \\
& & & & \\
Alpha( $(\alpha)$ & $<0.001$ & $<0.001$ & $<0.001$ & $<0.001$ \\
& & & & \\
$\boldsymbol{E}_{\mathbf{k}}$ & 0.002 & $<0.001$ & 0.001 & 0.064 \\
\hline
\end{tabular}




\subsubsection{Quantum Yield ( $\phi$ PSII)}

A repeated measures ANOVA was carried out for each species separately to test for effect of all treatments and time (Table 5.2).

Although the general response, except for Chaetoceros socialis (Antarctic Peninsula) at L2, appeared to show consistent patterns over time, the repeated measures ANOVA for algae incubated at all light treatments was not significant for $\phi_{\text {PSII }}$ over $168 \mathrm{~h}$.

The general response for Thalassiosira antarctica (Ross Sea) (Figure 5.1(a)) at L2 and L3 was an initial decrease followed by a recovery in $\phi_{\text {PSII, }}$ then maintaining a stable value over the rest of the incubation. Algae at L0 and L1 showed very little change over $168 \mathrm{~h}$. The general response for Chaetoceros socialis (Antarctic Peninsula)(Figure 5.1(b)) at L0 and L1 was a slight increase followed by a stable $\phi_{\text {PSII }}$ over $168 \mathrm{~h}$. For algae incubated at L2 and L3, there was a sharp decrease over the first two hours, followed by a recovery in $\phi_{\text {PSII }}$ between 2 and $4 \mathrm{~h}$. However, algae at the higher light treatments of L2 and L3 then showed a gradual decrease in $\phi$ PsII to reach levels similar to those at $2 \mathrm{~h}$. Although the repeated measures ANOVA showed no significant change in \$PSII over 168 $\mathrm{h}$ for this species at L0 , L1 and L3, those at L2 showed a significant decrease (Bonferroni, $\mathrm{p}=0.001$ ) over the full $168 \mathrm{~h}$ period.

C. socialis (Arctic Ocean) (Figure 5.1(c)) showed a gradual decrease in $\phi_{\text {PSII }}$ for algae incubated at L0 and a gradual increase for algae incubated at L1. Algae incubated at L2 showed an initial decrease in $\phi_{\text {PSII }}$ followed by a recovery to reach the same levels as the start of the incubation. Algae incubated at L3 showed a larger initial decrease than those at L2, followed by a recovery to reach a $\phi_{\text {PSII }}$ lower than that at time $0 \mathrm{~h}$. 
Table 5.2. Changes in quantum yield of photosystem II over $168 \mathrm{~h}$ experimental treatments at different combinations of PAR and UV-B levels $\left(\mathrm{L} 0=0 \mu \mathrm{mol} \mathrm{m}^{-2} \mathrm{~s}^{-1} ; \mathrm{L} 1=1\right.$ $\mu \mathrm{mol} \mathrm{m}^{-2} \mathrm{~s}^{-1}$; L2 $=45 \mu \mathrm{mol} \mathrm{m}^{-2} \mathrm{~s}^{-1}$ and $50 \mathrm{mWm}^{-2} ; \mathrm{L} 3=100 \mu \mathrm{mol} \mathrm{m}^{-2} \mathrm{~s}^{-1}$ and $100 \mathrm{mWm}^{-2}$ ) at $4^{\circ} \mathrm{C}$, analysed using repeated measures ANOVA. Significant changes identified by post hoc pairwise analyses are also listed.

\begin{tabular}{|c|c|c|c|c|c|}
\hline Source of variation & $\mathrm{df}$ & MS & $F$ & $\mathrm{p}$ & post hoc comparisons \\
\hline \multicolumn{6}{|c|}{ Thalassiosira antarctica (Ross Sea) } \\
\hline \multicolumn{6}{|l|}{ Within subjects } \\
\hline Time & 2.340 & 0.072 & 54.188 & $<0.001$ & \multirow{3}{*}{$\begin{array}{l}\text { No change over } 168 \mathrm{~h} \\
\text { (see text for details) }\end{array}$} \\
\hline Time $x$ Treatments & 7.021 & 0.027 & 20.116 & $<0.001$ & \\
\hline Error & 18.723 & 0.001 & & & \\
\hline \multicolumn{6}{|l|}{ Between subjects } \\
\hline Treatments & 3 & 0.479 & 91.685 & $<0.001$ & $(\mathrm{~L} 0=\mathrm{L} 1)>\mathrm{L} 3>\mathrm{L} 2$ \\
\hline Error & 8 & 0.005 & & & \\
\hline \multicolumn{6}{|c|}{ Chaetoceros socialis (Antarctic Peninsula) } \\
\hline \multicolumn{6}{|c|}{ Within subjects } \\
\hline Time & 4.325 & 0.034 & 41.242 & $<0.001$ & \multirow{3}{*}{$\begin{array}{l}\text { Decrease over } 168 \mathrm{~h} \\
\text { (see text for details) }\end{array}$} \\
\hline Time $\mathrm{x}$ Treatments & 12.974 & 0.029 & 34.796 & $<0.001$ & \\
\hline Error & 34.597 & 0.001 & & & \\
\hline \multicolumn{6}{|l|}{ Between subjects } \\
\hline Treatments & 3 & 0.687 & 143.726 & $<0.001$ & $(\mathrm{~L} 0=\mathrm{L} 1)>\mathrm{L} 3>\mathrm{L} 2$ \\
\hline Error & 8 & 0.003 & & & \\
\hline \multicolumn{6}{|c|}{ C. socialis (Arctic Ocean) } \\
\hline \multicolumn{6}{|c|}{ Within subjects } \\
\hline Time & 3.249 & 0.074 & 67.017 & $<0.001$ & No change over $168 \mathrm{~h}$ \\
\hline Time $x$ Treatments & 9.746 & 0.029 & 26.218 & $<0.001$ & (see text for details) \\
\hline Error & 25.991 & 0.001 & & & \\
\hline \multicolumn{6}{|l|}{ Between subjects } \\
\hline Treatments & 3 & 0.329 & 78.456 & $<0.001$ & $\mathrm{~L} 1>(\mathrm{L} 0=\mathrm{L} 3)>\mathrm{L} 2$ \\
\hline Error & 8 & 0.004 & & & \\
\hline
\end{tabular}


a)
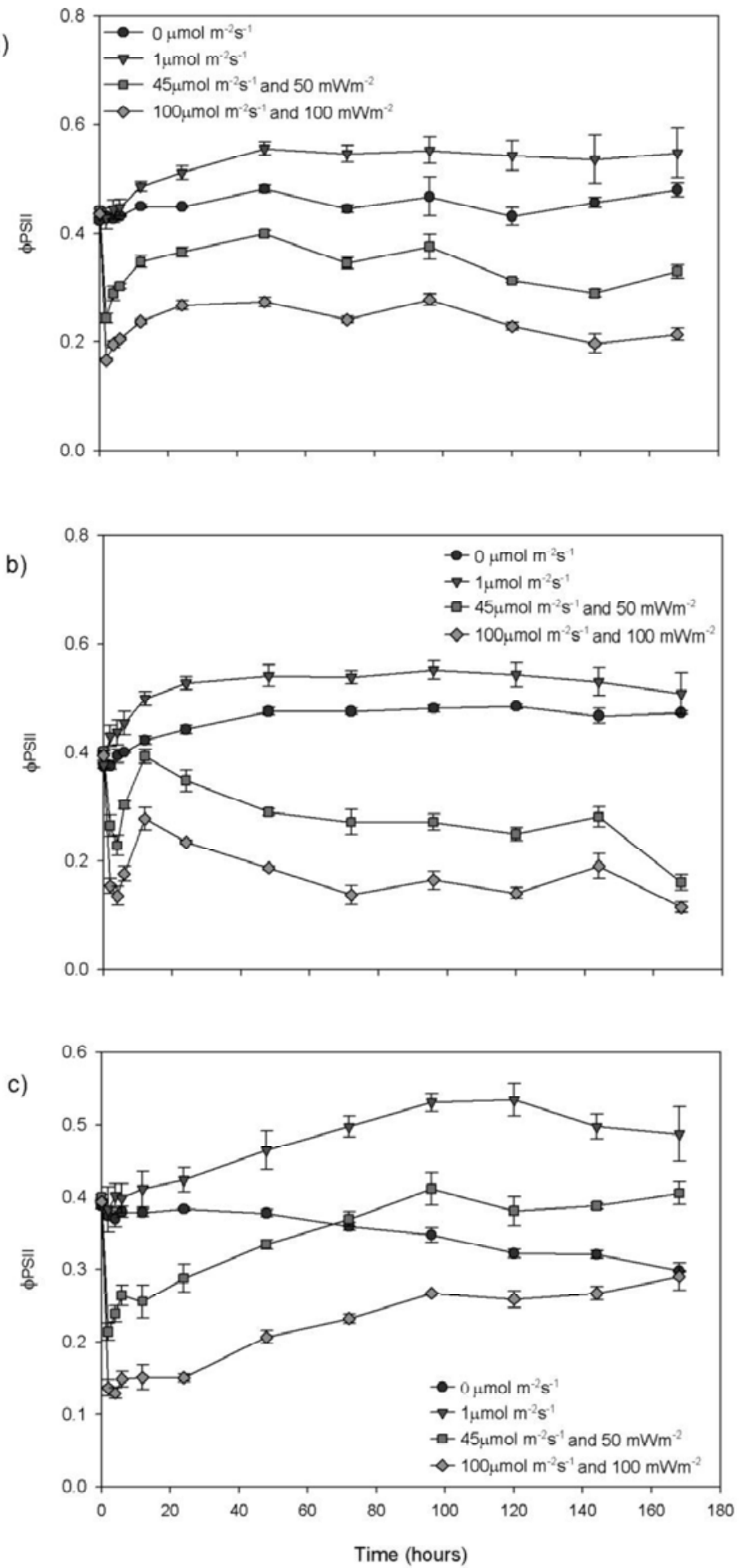

Fig 5.1. Quantum Yield ( were maintained at different combinations of PAR and UV-B levels $\left(0 \mu \mathrm{mol} \mathrm{m}^{-2} \mathrm{~s}^{-1} ; 1\right.$ $\mu \mathrm{mol} \mathrm{m}{ }^{-2} \mathrm{~s}^{-1} ; 45 \mu \mathrm{mol} \mathrm{m}^{-2} \mathrm{~s}^{-1}$ and $50 \mathrm{mWm}^{-2} ; 100 \mu \mathrm{mol} \mathrm{m}^{-2} \mathrm{~s}^{-1}$ and $100 \mathrm{mWm}^{-2}$ ), for (a) Thalassiosira antarctica (Ross Sea), (b) Chaetoceros socialis (Antarctic Peninsula) and (c) C. socialis (Arctic Ocean). Error bars indicate standard error. 


\subsubsection{2 rETR $_{\max }$}

A repeated measures ANOVA was carried out for each species separately to test for effect of all treatments and time (Table 5.3). Although the general response showed changes over time, the repeated measures ANOVA showed no significant change in rETR $_{\max }$ over $168 \mathrm{~h}$ for algae at all treatments, except for both Chaetoceros species at L2. The general response of Thalassiosira antarctica (Ross Sea) (Figure 5.2(a)) at L2 and L3 was an initial increase followed by rETR $_{\max }$ varying little throughout the incubation and not showing any change from time $0 \mathrm{~h}$. Algae at $\mathrm{L} 0$ showed a slight decrease in $\mathrm{rETR}_{\max }$ before it stabilized for the rest of the incubation. Algae incubated at L1 showed an increase in $\mathrm{rETR}_{\max }$ over the $168 \mathrm{~h}$. The general response of Chaetoceros socialis (Antarctic Peninsula) (Figure 5.2(b)) for all light treatments other than at L0 was a slight increase in $\mathrm{rETR}_{\max }$ followed by a decrease to reach a level higher than at time $0 \mathrm{~h}$. Algae at L0 did not show any change over time. Those incubated at L2 showed significant increase in $\mathrm{rETR}_{\max }$ (Bonferroni, $\mathrm{p}=0.018$ ) between 144 and $168 \mathrm{~h}$. However, there was no overall significant increase. The general response of $C$. socialis (Arctic Ocean) (Figure 5.2(c)) for all light treatments other than at L0 was a slight increase in rETR $\mathrm{max}_{\max }$ followed by a decrease to reach a level similar to that at time $0 \mathrm{~h}$. Algae at L0 did not show any change over time. Algae incubated at L2 showed an overall significant increase in $\mathrm{rETR}_{\max }$ (Bonferroni, $\mathrm{p}=0.040$ ). 
Table 5.3. Changes in $\mathrm{rETR}_{\max }$ of photosystem II over $168 \mathrm{~h}$ experimental treatments at different combinations of PAR and UV-B levels $\left(\mathrm{L} 0=0 \mu \mathrm{mol} \mathrm{m}^{-2} \mathrm{~s}^{-1}\right.$; $\mathrm{L} 1=1 \mu \mathrm{mol} \mathrm{m}^{-2} \mathrm{~s}^{-1}$; $\mathrm{L} 2=45 \mu \mathrm{mol} \mathrm{m}^{-2} \mathrm{~s}^{-1}$ and $50 \mathrm{mWm}^{-2} ; \mathrm{L} 3=100 \mu \mathrm{mol} \mathrm{m}^{-2} \mathrm{~s}^{-1}$ and $100 \mathrm{mWm}^{-2}$ ) at $4^{\circ} \mathrm{C}$, analysed using repeated measures ANOVA. Significant changes identified by post hoc pairwise analyses are also listed.

\begin{tabular}{|c|c|c|c|c|c|}
\hline Source of variation & $\mathrm{df}$ & MS & $F$ & $\mathrm{p}$ & post hoc comparisons \\
\hline \multicolumn{6}{|c|}{ Thalassiosira antarctica (Ross Sea) } \\
\hline \multicolumn{6}{|c|}{ Within subjects } \\
\hline Time & 1.755 & 707.828 & 43.814 & $<0.001$ & \multirow{3}{*}{$\begin{array}{l}\text { No change over } 168 \mathrm{~h} \\
\text { (see text for details) }\end{array}$} \\
\hline Time $\mathrm{x}$ Treatments & 5.266 & 229.137 & 14.184 & $<0.001$ & \\
\hline Error & 14.043 & 16.155 & & & \\
\hline \multicolumn{6}{|l|}{ Between subjects } \\
\hline Treatments & 3 & 703.075 & 149.478 & $<0.001$ & $\mathrm{~L} 1>\mathrm{L} 2>\mathrm{L} 3>\mathrm{L} 0$ \\
\hline Error & 8 & 4.704 & & & \\
\hline \multicolumn{6}{|c|}{ Chaetoceros socialis (Antarctic Peninsula) } \\
\hline \multicolumn{6}{|c|}{ Within subjects } \\
\hline Time & 2.824 & 157.000 & 38.798 & $<0.001$ & \multirow{3}{*}{$\begin{array}{l}\text { No change over } 168 \mathrm{~h} \\
\text { (see text for details) }\end{array}$} \\
\hline Time $\mathrm{x}$ Treatments & 8.471 & 82.856 & 20.475 & $<0.001$ & \\
\hline Error & 22.590 & 4.047 & & & \\
\hline \multicolumn{6}{|l|}{ Between subjects } \\
\hline Treatments & 3 & 489.269 & 119.725 & $<0.001$ & $\mathrm{~L} 1>\mathrm{L} 2>\mathrm{L} 3>\mathrm{L} 0$ \\
\hline Error & 8 & 4.087 & & & \\
\hline \multicolumn{6}{|c|}{ C. socialis (Arctic Ocean) } \\
\hline \multicolumn{6}{|c|}{ Within subjects } \\
\hline Time & 2.929 & 620.532 & 283.378 & $<0.001$ & Increase over $168 \mathrm{~h}$ \\
\hline Time $\mathrm{x}$ Treatments & 8.786 & 78.510 & 35.853 & $<0.001$ & (see text for details) \\
\hline Error & 23.429 & 2.190 & & & \\
\hline \multicolumn{6}{|l|}{ Between subjects } \\
\hline Treatments & 3 & 670.216 & 82.660 & $<0.001$ & $\mathrm{~L} 2>(\mathrm{L} 1=\mathrm{L} 3)>\mathrm{L} 0$ \\
\hline Error & 8 & 8.108 & & & \\
\hline
\end{tabular}



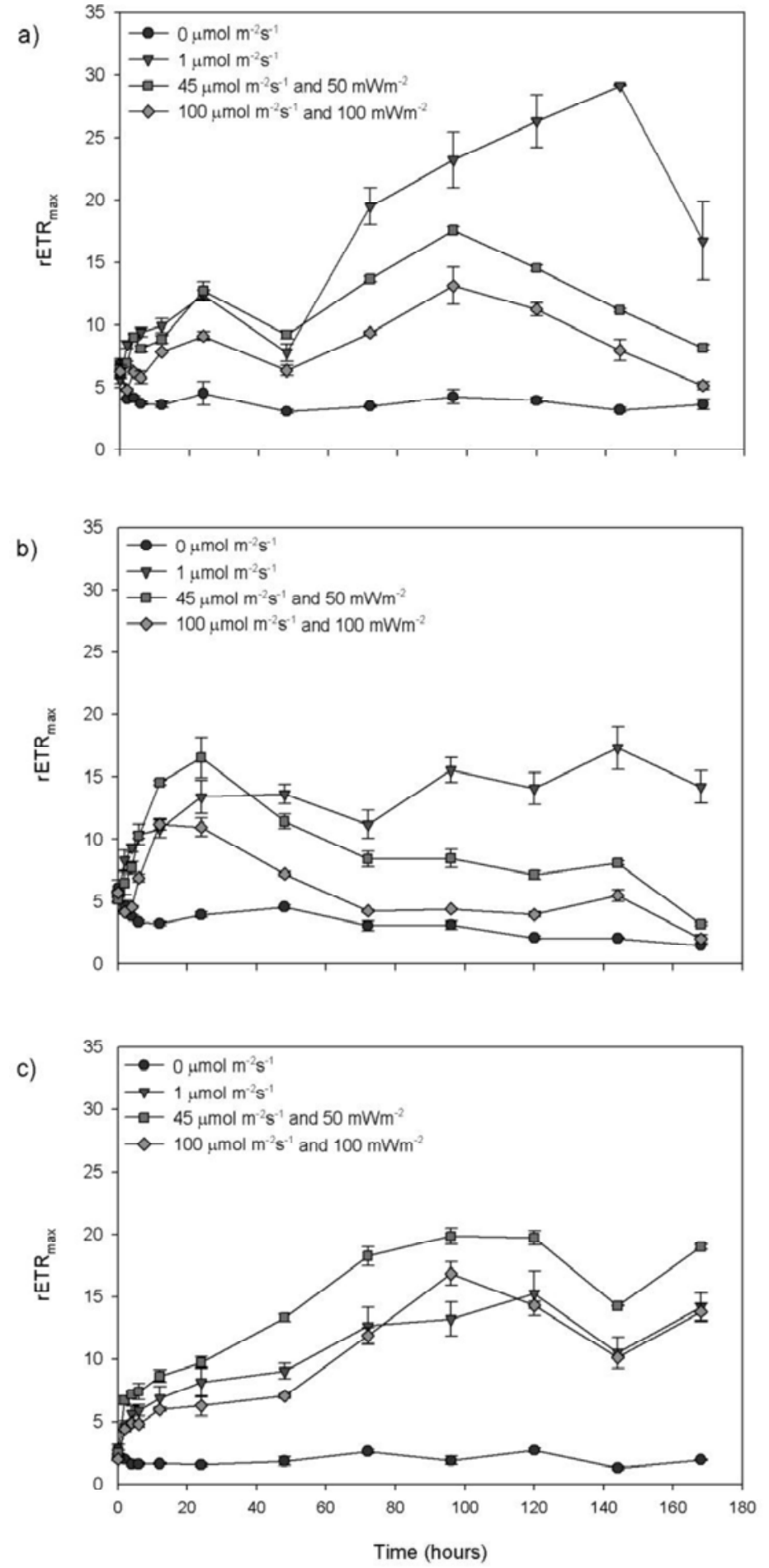

Fig 5.2. rETR $\max$ at $0,2,4,6,12,24,48,72,96,120,144$ and $168 \mathrm{~h}$. Cultures were maintained at light levels $\left(0 \mu \mathrm{mol} \mathrm{m} \mathrm{m}^{-2} \mathrm{~s}^{-1} ; 1 \mu \mathrm{mol} \mathrm{m}^{-2} \mathrm{~s}^{-1} ; 45 \mu \mathrm{mol} \mathrm{m} \mathrm{m}^{-2} \mathrm{~s}^{-1}\right.$ and $50 \mathrm{mWm}^{-2}$; $100 \mu \mathrm{mol} \mathrm{m}^{-2} \mathrm{~s}^{-1}$ and $100 \mathrm{mWm}^{-2}$ ), for (a) Thalassiosira antarctica (Ross Sea), (b) Chaetoceros socialis (Antarctic Peninsula) and (c) C. socialis (Arctic Ocean). Error bars indicate standard error. 


\subsubsection{MAAs}

The amounts of MAAs produced by these cultures were too low to be detected with the method as described in Ryan et al. (2002). Several attempts were made to increase the sensitivity of the procedure, which were unsuccessful. The samples were spectrophotometrically analysed to check for the presence of MAAs, giving negative results. Even if a combination of samples would have provided sufficient concentrations of MAAs to allow detection, this would not have provided data useful for the current study.

\subsubsection{Chlorophyll a}

A repeated measures ANOVA of this data set gave a significant effect of time $(\mathrm{p}<0.005)$ and interaction between time and species $(\mathrm{p}<0.005)$, but no significant interaction between time and light. However, Levene's test for equality of variances was significant at each time point, indicating that the data were highly variable. The chlorophyll data are. thus, too variable to permit conclusions to be drawn about the responses of the algae. This could be due to insufficient cell numbers or improper storage before measurements were recorded.

\subsubsection{Superoxide dismutase}

Initially a two way repeated measures ANOVA was conducted with time as the 'within' factor and treatment and species as 'between' factors (Table A4.3 in Appendix 4). As the significant 3-way interactions make it impossible interpret the treatment effects, repeated measures analyses were carried out for each species separately to test for the effect of all treatments and time. A repeated measures ANOVA was carried out for each species separately to test for effect of all treatments and time (Table 5.4). 
Table 5.4. Changes in SOD activity over $168 \mathrm{~h}$ experimental treatments at different combinations of PAR and UV-B levels ( $\mathrm{L} 0=0 \mu \mathrm{mol} \mathrm{m}^{-2} \mathrm{~s}^{-1} ; \mathrm{L} 1=1 \mu \mathrm{mol} \mathrm{m}^{-2} \mathrm{~s}^{-1} ; \mathrm{L} 2=45 \mu \mathrm{mol}$ $\mathrm{m}^{-2} \mathrm{~s}^{-1}$ and $50 \mathrm{mWm}^{-2} ; \mathrm{L} 3=100 \mu \mathrm{mol} \mathrm{m}^{-2} \mathrm{~s}^{-1}$ and $100 \mathrm{mWm}^{-2}$ ) at $4^{\circ} \mathrm{C}$, analysed using repeated measures ANOVA. Significant changes identified by post hoc pairwise analyses are also listed.

\begin{tabular}{|c|c|c|c|c|c|}
\hline Source of variation & $\mathrm{df}$ & MS & $F$ & $\mathrm{p}$ & post hoc comparisons \\
\hline \multicolumn{6}{|c|}{ Thalassiosira antarctica (Ross Sea) } \\
\hline \multicolumn{6}{|c|}{ Within subjects } \\
\hline Time & 2 & 55299.731 & 3.817 & 0.044 & \multirow{3}{*}{$\begin{array}{l}\text { No change over } 168 \mathrm{~h} \\
\text { (see text for details) }\end{array}$} \\
\hline Time $x$ Treatments & 6 & 23650.055 & 1.632 & 0.202 & \\
\hline Error & 16 & 14488.0404 & & & \\
\hline \multicolumn{6}{|l|}{ Between subjects } \\
\hline Treatments & 3 & 35853.695 & 2.271 & 0.157 & $\mathrm{~L} 0=\mathrm{L} 1=\mathrm{L} 2=\mathrm{L} 3$ \\
\hline Error & 8 & 15790.600 & & & \\
\hline \multicolumn{6}{|c|}{ Chaetoceros socialis (Antarctic Peninsula) } \\
\hline \multicolumn{6}{|c|}{ Within subjects } \\
\hline Time & 2 & 326604.643 & 23.878 & $<0.001$ & \multirow{3}{*}{$\begin{array}{l}\text { No change over } 168 \mathrm{~h} \\
\text { (see text for details) }\end{array}$} \\
\hline Time $\mathrm{x}$ Treatments & 6 & 18888.579 & 1.381 & 0.281 & \\
\hline Error & 16 & 13677.826 & & & \\
\hline \multicolumn{6}{|l|}{ Between subjects } \\
\hline Treatments & 3 & 11406.406 & 0.588 & 0.640 & $\mathrm{~L} 0=\mathrm{L} 1=\mathrm{L} 2=\mathrm{L} 3$ \\
\hline Error & 8 & 19382.839 & & & \\
\hline \multicolumn{6}{|c|}{ C. socialis (Arctic Ocean) } \\
\hline \multicolumn{6}{|c|}{ Within subjects } \\
\hline Time & 1.255 & 1307937.01 & 47.731 & $<0.001$ & Decrease over $168 \mathrm{~h}$ \\
\hline Time $x$ Treatments & 3.766 & 16582.805 & 0.605 & 0.659 & (see text for details) \\
\hline Error & 10.042 & 27402.151 & & & \\
\hline \multicolumn{6}{|l|}{ Between subjects } \\
\hline Treatments & 3 & 12677.400 & 0.910 & 0.478 & $\mathrm{~L} 0=\mathrm{L} 1=\mathrm{L} 2=\mathrm{L} 3$ \\
\hline Error & 8 & 13924.998 & & & \\
\hline
\end{tabular}


Although the general response appeared to show small and consistent patterns of change over time, the repeated measures ANOVA showed no significant change in SOD activity over $168 \mathrm{~h}$ for algae at all light treatments, except for Chaetoceros socialis (Antarctic Peninsula) which had a significant increase (Bonferroni, $\mathrm{p}=0.002$ ) in the first $48 \mathrm{~h}$ for all light treatments followed by a significant decrease (Bonferroni, $\mathrm{p}<0.001$ ) by $168 \mathrm{~h}$, resulting in no change over $168 \mathrm{~h}$.

The general response of Thalassiosira antarctica (Ross Sea) (Figure 5.3(a)) in the dark and at low light levels was an increase in SOD activity. At the two higher light levels, SOD activity increased over the first $48 \mathrm{~h}$, followed by a decrease by the end of the incubation at 168h. The general response of Chaetoceros socialis (Antarctic Peninsula) (Figure 5.3(b)) at all light levels was an increase in SOD activity over the first $48 \mathrm{~h}$, followed by a decrease to reach a similar level at $168 \mathrm{~h}$ compared to the start of the incubation. That of $C$. socialis (Arctic Ocean) (Figure 5.3(c)) for all light treatments was a large decrease in SOD activity over the first $48 \mathrm{~h}$, followed by a slight recovery by $168 \mathrm{~h}$.

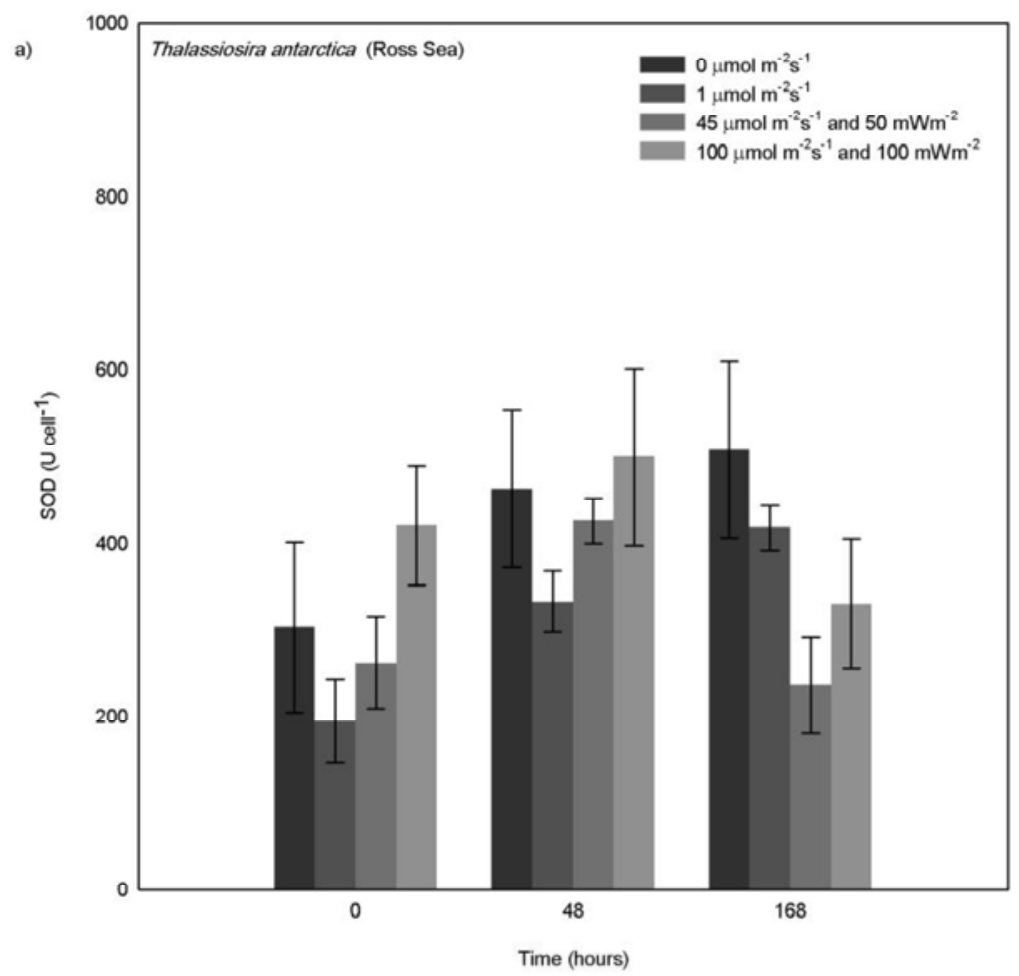



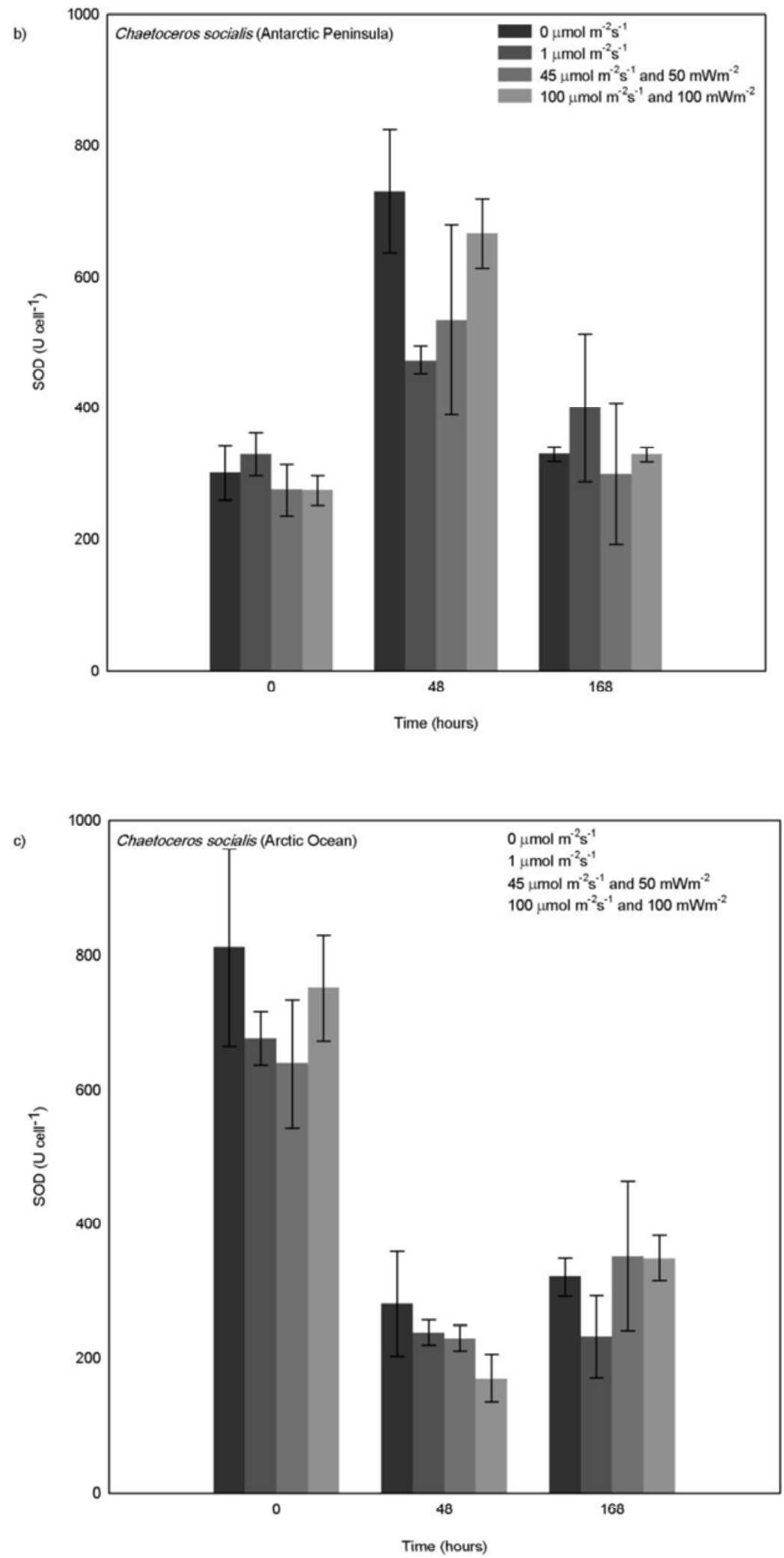

Fig 5.3. SOD activity per cell at 0,48 , and $168 \mathrm{~h}$. Cultures were maintained at different combinations of PAR and UV-B levels $\left(0 \mu \mathrm{mol} \mathrm{m} \mathrm{m}^{-2} \mathrm{~s}^{-1} ; 1 \mu \mathrm{mol} \mathrm{m}^{-2} \mathrm{~s}^{-1} ; 45 \mu \mathrm{mol} \mathrm{m}^{-2} \mathrm{~s}^{-1}\right.$ and $50 \mathrm{mWm}^{-2} ; 100 \mu \mathrm{mol} \mathrm{m}^{-2} \mathrm{~s}^{-1}$ and $100 \mathrm{mWm}^{-2}$ ), for (a) Thalassiosira antarctica (Ross 
Sea), (b) Chaetoceros socialis (Antarctic Peninsula) and (c) C. socialis (Arctic Ocean). Error bars indicate standard error.

\subsection{Discussion}

The aim of this study was to examine the photosynthetic, antioxidative and other stress responses of sea ice algae under ecologically relevant PAR and UV-B scenarios. Each of the species studied here is a common member of ice algal communities from each of three regions with different patterns of environmental variation, namely the Ross Sea, the Antarctic Peninsula and the Arctic Ocean.

Algal cultures were exposed to light levels representative of those found in the water column below the sea ice - L0 $\left(0 \mu \mathrm{mol} \mathrm{m}^{-2} \mathrm{~s}^{-1}\right)$, at the bottom of the sea ice - L1 $(1 \mu \mathrm{mol}$ $\left.\mathrm{m}^{-2} \mathrm{~s}^{-1}\right)$, a quarter of the way above the water-ice interface - L2 $\left(45 \mu \mathrm{mol} \mathrm{m}^{-2} \mathrm{~s}^{-1}\right.$ and 50 $\left.\mathrm{mW} \mathrm{m} \mathrm{m}^{-2}\right)$, or at the middle of the sea ice profile - $\mathrm{L} 3\left(100 \mu \mathrm{mol} \mathrm{m}^{-2} \mathrm{~s}^{-1}\right.$ and $\left.100 \mathrm{~mW} \mathrm{~m}^{-2}\right)$. These separate PAR and UV-B levels have been thus combined to reflect that the increase in PAR is synchronous with an increase in UV-B through the sea ice profile. The quantum yield of Thalassioria antarctica from the Ross Sea and Chaetoceros socialis from the Arctic did not show any significant change over $168 \mathrm{~h}$ under exposure to any of these regimes. The quantum yield of $C$. socialis from the Antarctic Peninsula, however, showed a significant decrease in quantum yield over the same time period under the L2 exposure but not the L3 exposure, which was unexpected. In the western Antarctic Peninsula (WAP) region, diatoms respond positively to increase in irradiance, with the effect being modulated by cell volume (Vernet et al., 2008). Although there has been a decrease in summer sea ice in this region leading to a decrease in phytoplankton blooms containing large, chain-forming diatoms (Garibotti et al., 2005), flagellate blooms are still able maintain daily productivity (Vernet et al., 2008). These speciesspecific tolerances emphasise the variability that could be observed in similar regions with varying community composition.

All the algal cultures showed no significant difference in quantum yield between those incubated in the dark (L0) or at ambient low light (L1) levels. For both the Antarctic species, quantum yield was lowest for algae incubated at L2 and highest for cultures incubated in the dark or at ambient light. For both species, quantum yield decreased 
significantly over the first two hours. However, quantum yield for Thalassiosira antarctica at L2 did not show a significant change over $168 \mathrm{~h}$ while Chaetoceros socialis showed an overall decrease in quantum yield. In the Arctic $C$. socialis, there was no overall change in quantum yield over $168 \mathrm{~h}$. However, at the end of the incubation, the quantum yield for the algae at ambient low light level was the highest and that of those in the dark and at the highest light exposure was the lowest. Differences between the same species from different regions could show specialization according to the niche they occupy. Species-specific sensitivities to environmental change have been observed that show there is a link between photosynthetic capacity and ecological niche occupancy (Petrou \& Ralph, 2011).

The combinations of PAR and UV-B exposures used, which mimic those that might reasonably be expected in the natural environment, mean that it is difficult to differentiate why a lack of change in quantum yield was observed at the higher light exposures. These exposures combine two parameters that are complementary to each other in the natural ecosystem, giving a better indication of how algae may tolerate increased radiation levels during summer and/or due to thinner sea ice conditions. The data obtained could more clearly be placed in context had the additional MAA and chlorophyll a assays proved successful. The limited data obtained do support a very low (undetectable) level of MAA production that does not appear to be a result of methodological error, perhaps indicating that MAAs are not amongst the mechanisms used by these algal taxa for photo-protection. This is different to studies elsewhere in this thesis observing MAA production in unialgal cultures (Section 4.5) where Thalassiosira sp. showed an increase in MAA production when exposed to a PAR level of $100 \mu \mathrm{mol} \mathrm{m}^{-2} \mathrm{~s}^{-1}$. Exposure to UV-B levels of $150 \mathrm{~mW} \mathrm{~m}^{-2}$ also led to an increase in MAA production for Thalassiosira sp. and Fragilariopsis sp. It is possible that one factor such as PAR could alleviate the stress caused by another factor such as UV-B, as observed with increasing PAR and temperature exposures in mixed algal samples in Chapter 2. When the three species were compared at each light level, there was no significant change in quantum yield for algae incubated in the dark or at ambient low light. Those cultures at the higher light exposures showed an overall significant decrease in quantum yield. In all treatments, Thalassiosira antarctica had the highest quantum yield at the start of the incubation. At both higher light levels, the Arctic culture of $C$. socialis 
had the highest quantum yield at $168 \mathrm{~h}$, perhaps indicating a better ability to tolerate higher light exposure. Longer incubations over $48 \mathrm{~h}$ (as used in earlier chapters) identified no significant change in photosynthetic parameters. This could be due to 
peroxide, in turn reducing the production of SOD. The variation in SOD activity was correlated to the cell size of the species, with those that had a higher surface area to volume ratio showing an increase in SOD activity whereas those with lower surface area to volume ratio showed a decrease in SOD activity. In the species examined in the current study, C. socialis cells are known to be smaller than those of T. antarctica. SOD activity in C. socialis from the Arctic (but not the Antarctic Peninsula) was higher than that of T. antarctica. This difference in SOD activity between cultures of $C$. socialis obtained from the Antarctic Peninsula and the Arctic could be related to the degree of change in the two regions. This cannot however be determined without measuring cell size of cells from cultures of the same species from various areas and re-running these experiments with various other parameters such as alternative antioxidants being tested.

This study incorporated longer manipulation periods than those described in earlier chapters, in order to examine the effect of length of incubation on acclimatory abilities. For all three species, there were very few significant changes in photosynthetic parameters between 2 and $7 \mathrm{~d}$, which strongly supports the shorter incubation periods used in experiments with similar exposure regimes being representative, as described in Chapters 2, 3 and 4. In the natural environment, the time taken for sea ice to melt can vary considerably and is influenced by various factors such as snow cover and initial thickness (Thomas \& Dieckmann, 2003). The levels of exposures to various parameters can also be much higher, meaning that the possibility cannot be ruled out that longer durations at higher exposures are required to fully understand species-specific differences in acclimation capabilities.

This study highlights the need to run algal experiments with multiple abiotic parameters such as PAR and UV-B, as the coupling of parameters led to a lack of differentiation in photosynthetic health in algae. This contrasts with the significant effects on photosynthetic parameters and MAA production that were observed in unialgal cultures when subjected to increases in PAR or UV-B separately (Section 4.5). There, Ross Sea algal species showed a capacity to tolerate higher than ambient levels of PAR and UV-B when exposed to both parameters separately, exhibiting a higher tolerance to higher PAR than UV-B which was accompanied by significant increases in MAA production that could provide photo-protection. The Antarctic Peninsula species 
used in the same study showed little evidence of being stressed by the higher levels of PAR or UV-B separately. In contrast, there was a lack of significant change to quantum yield of PS II in this study.

During and after sea ice melt, algae face increases in PAR, UV-B and temperature and decreases in salinity, making it essential for multivariate studies to be conducted that combine as many of these factors as possible in order to give insight into how algae tolerate the entirety of the processes of ice melt and release into the pelagic environment. Studies including evaluation of the photo-protective responses of these algae, will help assess their ability to survive current and predicted magnitudes of climate change and hence, maintain the productivity of the ice-covered regions of the polar regions.

\subsection{References}

Arrigo, K. R., Sullivan, C. W., \& Kremer, J. N. (1991). A bio-optical model of Antarctic sea ice. Journal of Geophysical Research: Oceans, 96, 10581-10592.

Arrigo, K. R., \& Thomas, D. N. (2004). Large scale importance of sea ice biology in the Southern Ocean. Antarctic Science, 16, 471-486.

Arrigo, K. R., Mock, T., \& Lizotte, M. P. (2010). Primary Producers and Sea Ice. In D. N. Thomas \& G. S. Dieckmann (Eds.), Sea Ice (Second edition ed., pp. 283-325): Blackwell Publishing Ltd.

Arrigo, K. R., Perovich, D. K., Pickart, R. S., Brown, Z. W., van Dijken, G. L., Lowry, K. E., et al. (2012). Massive Phytoplankton Blooms Under Arctic Sea Ice. Science, 336, $1408-1408$.

Arrigo, K. R. (2014). Sea Ice Ecosystems. Annual Review of Marine Science, 6, 439-467.

Beauchamp, C., \& Fridovich, I. (1971). Superoxide dismutase: Improved assays and an assay applicable to acrylamide gels. Analytical Biochemistry, 44, 276-287.

Beyer, W. F., \& Fridovich, I. (1987). Assaying for Superoxide Dismutase Activity: Some Large Consequences for Minor Changes in Conditions *,1. Analytical Biochemistry, 161.

Campbell, K., Mundy, C. J., Barber, D. G., \& Gosselin, M. Characterizing the sea ice algae chlorophyll a,Äìsnow depth relationship over Arctic spring melt using transmitted irradiance. Journal of Marine Systems.

Cirulis, J. T., Scott, J. A., \& Ross, G. M. (2013). Management of oxidative stress by microalgae. Canadian Journal of Physiology and Pharmacology, 91, 15-21.

Davidson, A. T., Bramich, D., Marchant, H. J., \& McMinn, A. (1994). Effects of UV-B irradiation on growth and survival of Antarctic marine diatoms. Marine Biology, 119, 507-515.

Eicken, H. (1992). The role of sea ice in structuring Antarctic ecosystems. Polar Biology, 12, 3-13.

Evans, C. A., O'Reilly, J. E., \& Thomas, J. P. (1987). A handbook for the measurement of chlorophyll $a$ and primary production. College Station: Texas A\&M University. 
Fryer, M. J., Andrews, J. R., Oxborough, K., Blowers, D. A., \& Baker, R. (1998).

Relationship between $\mathrm{CO} 2$ assimilation, photosynthetic electron transport, and active 02 metabolism in leaves of maize in the field during periods of low temperature. Plant Physiology, 116, 571-580.

Garibotti, I. A., Vernet, M., \& Ferrario, M. E. (2005). Annually recurrent phytoplanktonic assemblages during summer in the seasonal ice zone west of the Antarctic Peninsula (Southern Ocean). Deep Sea Research Part I: Oceanographic Research Papers, 52, 1823-1841.

Gregory, E. M., \& Fridovich, I. (1973). Induction of Superoxide Dismutase by Molecular Oxygen. Journal of Bacteriology, 114, 543-548.

Ha, S.-Y., La, H. S., Min, J.-O., Chung, K.-H., Kang, S.-H., \& Shin, K.-H. (2014).

Photoprotective function of mycosporine-like amino acids in a bipolar diatom

(Porosira glacialis): evidence from ultraviolet radiation and stable isotope probing. Diatom Research, 1-11.

Halac, S., Garcia-Mendoza, E., \& Banaszak, A. T. (2009). Ultraviolet radiation reduces the photoprotective capacity of the marine diatom Phaeodactylum tricornutum (Bacillariophyceae, Heterokontophyta). Photochemistry and Photobiology, 85, 807-815.

Halac, S. R., Villafañe, V. E., \& Helbling, E. W. (2010). Temperature benefits the photosynthetic performance of the diatoms Chaetoceros gracilis and Thalassiosira weissflogii when exposed to UVR. Journal of Photochemistry and Photobiology B: Biology, 101, 196-205.

Hancke, K., Hancke, T. B., Olsen, L. M., Johnsen, G., \& Glud, R. N. (2008). Temperature effects on microalgal photosynthesis-light responses measured by 02 production, pulse-amplitude-modulated fluorescence, and 14C assimilation. Journal of Phycology, 44, 501-514.

Hannach, G., \& Sigleo, A. C. (1998). Photoinduction of UV-absorbing compounds in six species of marine phytoplankton. Marine Ecology Progress Series, 174, 207-222.

Harrison, W. G., \& Cota, G. F. (1991). Primary production in polar waters: relation to nutrient availability. Polar Research, 10, 87-104.

Hernando, M. P., Carreto, J. C., Carignan, M. C., Ferreyra, G. F., \& Gross, C. (2002). Effects of solar radiation on growth and mycosporine-like amino acids content in Thalassiosira sp, an Antarctic diatom. Polar Biology, 25, 12-20.

Janknegt, P. J., Rijstenbil, J. W., van de Poll, W. H., Gechev, T. S., \& Buma, A. G. J. (2007). A comparison of quantitative and qualitative superoxide dismutase assays for application to low temperature microalgae. Journal of Photochemistry and Photobiology B: Biology, 87, 218-226.

Janknegt, P. J., De Graaff, C. M., Van De Poll, W. H., Visser, R. J. W., Helbling, E. W., \& Buma, A. G. J. (2009a). Antioxidative responses of two marine microalgae during acclimation to static and fluctuating natural uv radiation. Photochemistry and Photobiology, 85, 1336-1345.

Janknegt, P. J., Marco de Graaff, C., van de Poll, W. H., Visser, R. J. W., Rijstenbil, J. W., \& Buma, A. G. J. (2009b). Short-term antioxidative responses of 15 microalgae exposed to excessive irradiance including ultraviolet radiation. European Journal of Phycology, 44, 525-539.

Katayama, T., \& Taguchi, S. (2013). Photoprotective responses of an ice algal community in Saroma-Ko Lagoon, Hokkaido, Japan. Polar Biology, 36, 1431-1439.

Leu, E., Wängberg, S.-Å., Wulff, A., Falk-Petersen, S., Børre Ørbæk, J., \& Hessen, D. 0. (2006). Effects of changes in ambient PAR and UV radiation on the nutritional 
quality of an Arctic diatom (Thalassiosira antarctica var. borealis). Journal of Experimental Marine Biology and Ecology, 337, 65-81.

Leu, E., Wiktor, J., Søreide, J. E., Berge, J., \& Falk-Petersen, S. (2010). Increased irradiance reduces food quality of sea ice algae. Marine Ecology Progress Series, 411, 49-60.

Lund-Hansen, L. C., Hawes, I., Sorrell, B. K., \& Nielsen, M. H. (2013). Removal of snow cover inhibits spring growth of Arctic ice algae through physiological and behavioral effects. Polar Biology, 1-11.

Maksym, T., Stammerjohn, S. E., Ackley, S., \& Massom, R. (2012). Antarctic sea ice- A polar opposite? Oceanography, 25, 140-151.

Mangoni, O., Saggiomo, M., Modigh, M., Catalano, G., Zingone, A., \& Saggiomo, V. (2009). The role of platelet ice microalgae in seeding phytoplankton blooms in Terra Nova Bay (Ross Sea, Antarctica): a mesocosm experiment. Polar Biology, 32, 311323.

Martin, A., McMinn, A., Heath, M., Hegseth, E. N., \& Ryan, K. G. (2012). The physiological response to increased temperature in over-wintering sea ice algae and phytoplankton in McMurdo Sound, Antarctica and Tromso Sound, Norway. Journal of Experimental Marine Biology and Ecology, 428, 57-66.

Maslanik, J., Stroeve, J., Fowler, C., \& Emery, W. (2011). Distribution and trends in Arctic sea ice age through spring 2011. Geophysical Research Letters, 38.

McMinn, A., \& Hegseth, E. N. (2004). Quantum yield and photosynthetic parameters of marine microalgae from the southern Arctic Ocean, Svalbard. Journal of the Marine Biological Association of the United Kingdom, 84, 865-871.

Mundy, C., Gosselin, M., Ehn, J., Belzile, C., Poulin, M., Alou, E., et al. (2011). Characteristics of two distinct high-light acclimated algal communities during advanced stages of sea ice melt. Polar Biology, 34, 1869-1886.

Nicol, S., Clarke, J., Romaine, S. J., Kawaguchi, S., Williams, G., \& Hosie, G. W. (2008). Krill (Euphausia superba) abundance and $\mathrm{Ad} \sqrt{ } \mathrm{C}$ lie penguin (Pygoscelis adeliae) breeding performance in the waters off the $\mathrm{B} \sqrt{ }$ C Chervaise Island colony, East Antarctica in 2 years with contrasting ecological conditions. Deep Sea Research Part II: Topical Studies in Oceanography, 55, 540-557.

Nicolaus, M., Katlein, C., Maslanik, J., \& Hendricks, S. (2012). Changes in Arctic sea ice result in increasing light transmittance and absorption. Geophysical Research Letters, 39.

Oren, A., \& Gunde-Cimerman, N. (2007). Mycosporines and mycosporine-like amino acids: UV protectants or multipurpose secondary metabolites? FEMS Microbiology Letters, 269, 1-10.

Parkhill, J.-P., Maillet, G., \& Cullen, J. J. (2001). Fluorescence-based maximal quantum yield for PSII as a diagnostic of nutrient stress. Journal of Phycology, 37, 517-529.

Petrou, K., Kranz, S. A., Doblin, M. A., \& Ralph, P. J. (2011). Photophysiological responses of Fragilariopsis cylindrus (Bacillariophyceae) to nitrogn depletion at two temperatures. Journal of Phycology, Article in Press.

Petrou, K., \& Ralph, P. (2011). Photosynthesis and net primary productivity in three Antarctic diatoms: possible significance for their distribution in the Antarctic marine ecosystem. Marine Ecology Progress Series, 437, 27-40.

Ratkova, T. N., Sazhin, A. F., \& Kosobokova, K. N. (2004). Unicellular inhabitants of the White Sea underice pelagic zone during the early spring period. Oceanology, 44, 240-246. 
Riebesell, U., Schloss, I., \& Smetacek, V. (1991). Aggregation of algae released from melting sea ice: implications for seeding and sedimentation. Polar Biology, 11, 239-248.

Ryan, K. G., McMinn, A., Mitchell, K. A., \& Trenerry, L. (2002). Mycosporine-like amino acids in Antarctic sea ice algae, and their response to UVB radiation. Zeitschrift fur Naturforschung, 57, 471-477.

Ryan, K. G., Cowie, R. O. M., Liggins, E., McNaughtan, D., Martin, A., \& Davy, S. K. (2009). The short-term effect of irradiance on the photosynthetic properties of antarctic fast-ice microalgal communities. Journal of Phycology, 45, 1290-1298.

Ryan, K. G., Tay, M. L., Martin, A., McMinn, A., \& Davy, S. K. (2011). Chlorophyll fluorescence imaging analysis of the responses of Antarctic bottom-ice algae to light and salinity during melting. Journal of Experimental Marine Biology and Ecology, 399, 156-161.

Ryan, K. G., McMinn, A., Hegseth, E. N., \& Davy, S. K. (2012). The Effects of Ultraviolet-B Radiation on Antarctic Sea-Ice Algae. Journal of Phycology, 48, 74-84.

Rysgaard, S., Kuhl, M., Glud, R. N., \& Hansen, J. W. (2001). Biomass, production and horizontal patchiness of sea ice algae in a high-Arctic fjord (Young Sound, NE Greenland). Marine Ecology Progress Series, 223, 15-26.

Salleh, S., \& McMinn, A. (2011). Photosynthetic response and recovery of Antarctic marine benthic microalgae exposed to elevated irradiances and temperatures. Polar Biology, 34, 855-869.

SooHoo, J. B., Palmisano, A. C., Kottmeier, S. T., Lizotte, M. P., SooHoo, S. L., \& Sullivan, C. W. (1987). Spectral light absorption and quantum yield of photosynthesis in sea ice microalgae and a bloom of Phaeocystis pouchetii from McMurdo Sound, Antarctica. Marine Ecology Progress Series, 39, 175-189.

Stammerjohn, S., Massom, R., Rind, D., \& Martinson, D. (2012). Regions of rapid sea ice change: An inter-hemispheric seasonal comparison. Geophysical Research Letters, 39.

Thomas, D. N., \& Dieckmann, G. S. (2003). Sea Ice: An Introduction to its Physics, Chemistry, Biology and Geology: Wiley-Blackwell.

Turner, J., Barrand, N. E., Bracegirdle, T. J., Convey, P., Hodgson, D. A., Jarvis, M., et al. (2013). Antarctic climate change and the environment: an update. Polar Record, FirstView, 1-23.

Van De Poll, W. H., Van Leeuwe, M. A., Roggeveld, J., \& Buma, A. G. J. (2005). Nutrient limitation and high irradiance acclimation reduce PAR and UV-induced viability loss in the Antarctic diatom Chaetoceros Brevis (Bacillariophyceae). Journal of Phycology, 41, 840-850.

Van de Poll, W. H., \& Buma, A. G. J. (2009). Does ultraviolet radiation affect the xanthophyll cycle in marine phytoplankton? Photochemical and Photobiological Sciences, 8, 1295-1301.

Van de Poll, W. H., Janknegt, P. J., van Leeuwe, M. A., Visser, R. J. W., \& Buma, A. G. J. (2009). Excessive irradiance and antioxidant responses of an Antarctic marine diatom exposed to iron limitation and to dynamic irradiance. Journal of Photochemistry and Photobiology B: Biology, 94, 32-37.

Vernet, M., Martinson, D., Iannuzzi, R., Stammerjohn, S., Kozlowski, W., Sines, K., et al. (2008). Primary production within the sea-ice zone west of the Antarctic Peninsula: Sea ice, summer mixed layer, and irradiance. Deep Sea Research Part II: Topical Studies in Oceanography, 55, 2068-2085. 
Vincent, W. F. (1988). Microbial ecosystems of Antarctica. Cambridge: Cambridge University Press.

Zor, T., \& Selinger, Z. (1996). Linearization of the Bradford Protein Assay Increases Its Sensitivity: Theoretical and Experimental Studies. Analytical Biochemistry, 236, 302-308. 


\section{CHAPTER 6}

\section{Antarctic microalgae: physiological acclimation to environmental change}

\subsection{OVERVIEW}

Primary productivity in the ice-covered regions of Antarctica is dominated by sea ice algae (Arrigo \& Thomas, 2004). Although the sea ice provides a stable habitat through the winter, the algae are limited by the lack of PAR during this period. Productivity significantly increases through spring and summer but during this period the algae are exposed to multiple changes in stresses during sea ice melt. Although some pelagic areas of the Southern Ocean can be more productive than ice covered regions (Arrigo et al., 1999, Arrigo et al., 2003), those species that thrive in pelagic systems cannot necessarily do so under the conditions in sea ice or in the diluted upper mixed layer that forms following sea ice melt (Arrigo et al., 1999). The survival of sea ice algae is important for the entire ecosystem, as they are essentially the base of the food chain (Thomas et al., 2008). The main environmental factors that can stress the photosynthetic machinery of these algae include PAR, UV-B, temperature and salinity, nutrient levels, pH, grazing, and ice thickness (Arrigo \& Thomas, 2004, Clarke et al., 2007, Cullen \& Neale, 1994, Davidson et al., 1994, Davison, 1991, Hays et al., 2005, Lizotte, 2001, Thomas \& Dieckmann, 2002, Thomas et al., 2008, Vincent, 1988). In this thesis, I examined the effects of the first three factors on fresh-collected mixed communities in the field and unialgal cultures in the laboratory.

The experiments conducted in this thesis show that bottom ice algae are capable of acclimating to the higher levels of PAR and temperature that would likely be experienced during sea ice melt. As temperature was increased experimentally it became the major stressor, causing large declines in photosynthetic yield (Chapter 2). Sea ice algae produced MAAs in response to increasing PAR, UV-B and temperature, and it is likely that this helps them minimise photosynthetic damage. This is the first study in the marine environment that demonstrates production of MAAs in response to both PAR and temperature, even in the absence of UV-B, indicating that MAAs may function as more than sunscreen compounds. Previous studies (Aguilera et al., 2002, Helbling et 
al., 2011, Lesser \& Farrell, 2004) have examined the production of MAAs as a stress response to PAR exposure including UVR, but the present data demonstrate that there are now two further stimuli (beyond UV-B) that increase MAA production in sea ice algae: temperature and PAR. MAAs are known to play a role as effective antioxidants in zoanthids, ascidians, red algae and fish (Dunlap \& Yamamoto, 1995, Gao \& Garcia-Pichel, 2011) and may benefit those sea ice algae that face photoinhibition due to higher PAR. The role of MAAs is similar to that of flavonoids in higher plants (Ryan \& Hunt, 2005), which may also serve multiple functions including as antioxidants in photoprotection (Agati \& Tattini, 2010).

When subjected to different levels of PAR (dark to $100 \mu \mathrm{mol} \mathrm{m}^{-2} \mathrm{~s}^{-1}$ ) at temperatures the algae could experience within the ice $\left(-1^{\circ} \mathrm{C}\right)$, during sea ice melt $\left(2^{\circ} \mathrm{C}\right)$ and in the water column $\left(5^{\circ} \mathrm{C}\right.$ ), the algae acclimated rapidly (Chapter 2 ). At $5^{\circ} \mathrm{C}$, the algae produced less MAAs, indicating that other tolerance mechanisms such as increased photoenzymatic repair could be more effective (Halac et al., 2010). However, when exposed to higher temperatures, photosynthetic yield also decreased, indicating that they may not be able to tolerate sudden large increases (Chapter 2). It is possible that the algae in this study passed a threshold in temperature at approximately $14^{\circ} \mathrm{C}$ where acclimatisation could not occur due to irreversible damage to the photosystems. However, some algal species from the Southern Ocean survive passage northwards to temperate region ports in ballast water (Lewis et al., 2003), and grow well in incubations under temperate conditions (Baek et al., 2011). There is a large variation in this ability, which indicates that at least some species may be able to tolerate such drastic thermal changes, and further species-specific studies on tolerance must be explored.

Sea ice algae also tolerate increasing UV-B levels by increasing their production of MAAs (Chapters 3, 4) (Gao \& Garcia-Pichel, 2011, Ryan et al., 2002). The bottom ice algal community from the Ross Sea tolerated experimental levels of UV-B exposure comparable to those that they could face during sea ice melt. Even at high levels of UV-B, they did not show a decrease in photosynthetic yield, at least over the $48 \mathrm{~h}$ timescale of the experiments, which is consistent with the significant increases in MAA production and content per cell observed (Chapter 3). An increase in temperature from $-1{ }^{\circ} \mathrm{C}$ to $5^{\circ} \mathrm{C}$ did not modify the photosynthetic yield but resulted in a decrease in MAA production (Chapter 3), which has similarly been observed by Halac et al. (2010). MAA production 
is known to be an energy intensive process (Gao \& Garcia-Pichel, 2011). Under changing environmental conditions, the ability of these algae to acclimate to increasing UV-B will allow survival of longer exposure in the water column, which could occur due to the earlier receding of sea ice. The responses observed in this study contrast with previous studies (Davidson et al., 1994) that also examined the effect of UV-B on sea ice algae, where increased UV-B exposure did not result in increased MAA production. The contrasts between the studies could be underscored by differences in community species composition.

In fresh-collected mixed cultures of bottom ice algae, any UV-B-induced decrease in photosynthetic health was offset by production of MAAs. However, individual species responses varied as has been reported in other studies (Hannach \& Sigleo, 1998, Lionard et al., 2012, Rijstenbil, 2003). This is a significant factor to consider when predicting community responses to increased UV-B. Due to variations in winter conditions, thinner sea ice may form, leading to increased UV-B exposure. In this case, the algae in the upper regions of the bottom layer may determine the fate of the entire community. If they are species that are UV-B tolerant, the community will be UV-B tolerant, as the algae below this layer will not need to produce MAAs to protect themselves from UV-B. If there are more species in a community that can tolerate UV-B, then that community is likely to survive decreasing thickness of sea ice.

Algal species are capable of different levels of productivity (Arrigo et al., 1999). Therefore, the composition of a sea ice community will influence the productivity in a given area. In single species cultures, all three species examined (Chapter 4) tolerated higher PAR and UV-B levels than the mixed culture of bottom ice algae over a period of $48 \mathrm{~h}$. However, the degree of MAA production varied between the two Ross Sea species and the single Antarctic Peninsula species. Both the Ross Sea species showed increasing photosynthetic yield with increasing but still ecologically relevant PAR levels (Chapter 4). However, there was a difference in the tolerance of the two species, with Thalassiosira sp. performing better at higher PAR and lower UV-B, while Fragilariopsis sp. preferred lower PAR and higher UV-B. Both species produced MAAs in response to these stressors, suggesting that these compounds allowed the algae to decrease levels of photoinhibition. In response to high levels of UV-B, the two species showed no change in photosynthetic yield, accompanied by additional MAA production, again indicating 
the importance of MAAs in preventing photoinhibition. This result indicates that there are differences in each algal species' ability to acclimate to increasing PAR and UV-B. The western Antarctic Peninsula currently faces higher rates of environmental change than the Ross Sea (Convey et al., 2009). Sea ice cover is receding, releasing the contained algae into the water column earlier in spring (Stammerjohn et al., 2008). In Chaetoceros sp. from the Antarctic Peninsula region, there was an indication of higher tolerance to high PAR and UV-B levels (Chapter 4) than was the case with the two Ross Sea species. This species showed improved photosynthetic yield in response to an increase in PAR but, in contrast to the Ross Sea species, showed no production of MAAs. In response to higher levels of UV-B, both species showed an increase in photosynthetic yield, accompanied by an increase in MAA production, with no evidence of photoinhibition. Although based only on data from a single species, this finding is at least consistent with the scale of regional variation in environmental parameters having an impact on the ability of algal species to acclimate. There is a possibility of intraspecific variation across latitudes for tolerance and acclimation abilities, which would make unialgal exposure studies even more relevant.

During sea ice melt and/or due to the thinning of ice, sea ice algae are exposed to increasing levels of PAR and UV-B (Arrigo, 2014, Eicken, 1992). These parameters are often compounded by an increase in temperature and decrease in salinity, leading to a combination of stresses for ice algae to tolerate (Giesenhagen et al., 1999). Unialgal cultures of common species from three polar regions with different environmental variation, namely the Ross Sea, Antarctic Peninsula and Arctic, were incubated for seven days in combined treatments of ecologically relevant PAR and UV-B exposures (Chapter 5). Photosynthetic responses measured by chlorophyll fluorescence techniques and antioxidative responses measured by SOD activity, showed no significant change in the quantum yield of PS II when algae were subjected to high levels of PAR and UV-B. The only significant response was observed in quantum yield for Chaetoceros socialis from the Antarctic Peninsula, which unexpectedly decreased over medium exposure but not high exposure. Diatom species from the Antarctic Peninsula region have been observed to respond positively to increase in irradiance (Ducklow et al., 2013). In contrast, $C$. socialis from the Arctic showed no significant response. This could be an indication of the acclimatory abilities of these species to survive conditions during ice melt. 
Responses in quantum yield for these cultures were very different to those observed in Chapter 4, where an increase in PAR or UV-B over two days, led to a significant increase in quantum yield. This may point to the role of compounding stressors, where one alleviates the other, as suggested by the results of the mixed community experiments described in Chapter 2. The lack of significant change in photosynthetic parameters between two and seven days' incubation (Chapter 5) also validates the experimental periods used in previous chapters.

\subsection{SYNOPSIS}

This thesis indicates that bottom ice algae may not be obligate shade-adapted species as previously proposed (McMinn et al., 2003, McMinn et al., 2007, Thomas \& Dieckmann, 2002) but have a degree of plasticity in tolerating changing irradiance. This plasticity would allow these algae to endure the changes in PAR likely to be experienced during sea ice melt. They are also capable of tolerating these PAR levels in concert with an increase in temperature, which is a further indication of their acclimation ability. Small experimental increases in temperature led to decreasing MAA content without change in photosynthetic yield (Chapter 2) that could indicate that the algae were utilising an increase in other repair mechanisms such as enzymatic repair, contributing to their toleration of ecologically relevant temperature increases after release from the sea ice. When exposed to much higher temperatures, similar to those found in temperate regions, the algae showed significant decreases in photosynthetic yield consistent with there being a threshold point above which temperature ceases to benefit the algae through increased repair. This temperature $\left(\mathrm{T}_{\mathrm{c}}\right)$ was estimated at $14^{\circ} \mathrm{C}$ based on a series of experimental incubations in different cultures, and a temperature rise in the same culture (Chapter 2). At this temperature it is possible that there was irreversible damage to the photosystems (chronic photoinhibition (Fitt et al., 2001)), which could not be repaired even with a return to favourable conditions. The presence of a threshold temperature has been observed in symbionts in corals (Buxton et al., 2012, Fitt et al., 2001, Tchernov et al., 2004). However, algae could be undergoing dynamic photoinhibition, where the stress to the photosystems is reversible. A return to favourable temperatures would reveal whether the inhibition was indeed dynamic. The duration of exposure to critical temperature is also important as short periods of 
exposure could just lead to dynamic photoinhibition, which has been observed in symbionts in corals, where permanent damage was due to a longer than normal duration of unusual increases in temperature (Attwood et al., 1992, Fitt et al., 2001). Exposure to solar radiation is known to increase damage in algal symbionts of corals during temperature increases, causing damage to the photochemistry and carbon fixation (Lesser \& Farrell, 2004). These detailed interactions were not explored in my preliminary study. The interactions of $\mathrm{T}_{\mathrm{c}}$ with solar radiation and time period are therefore essential in the prediction of responses to future climate change scenarios. Subtle differences were observed in the short-term responses of individual species to increasing PAR and UV-B (Chapter 4) that illustrate the importance of species-specific responses. The presence of species that are tolerant to both increasing PAR and UV-B in a bottom ice community could determine its survival during sea ice melt, allowing these species to become part of the pelagic algal bloom. However, if a species could tolerate only one of the increasing parameters, it would have limited survival capabilities. The size of the annual ozone hole over Antarctica may have stabilised (Bodeker et al., 2005, Convey et al., 2009), however, as other factors such as temperature lead to an earlier sea ice melt (Martinson et al., 2008, Montes-Hugo et al., 2009), there can still be an increase in the accumulated dosage of UV-B due to the longer periods of time algae spend in the water column. Therefore, further research is required examining the tolerance of sea ice algae to longer periods of UV-B exposure. Even though an algal species such as Chaetoceros sp. could tolerate high levels of UV-B for 48 h (Chapter 4), products of photosynthetic damage could accumulate over longer periods, leading to a decline in algal photosynthetic yield (Janknegt et al., 2008, Sobrino \& Neale, 2007, Wu et al., 2009). Understanding this tolerance would indicate whether sea ice algae could survive longer periods in the water column. An algal species could survive the sea ice melt, but not be able to tolerate these conditions through the entire summer season. Incubations that include the return of an algal community or an algal species to ambient conditions would test for resilience to changing conditions, indicating an ability to survive future environmental change.

As described in Chapters 2 and 3, increased PAR and UV-B levels led to an increase in rETRmax, indicating that more energy was available to the sea ice algae. However, increases in temperature led to a decline in the photosynthetic yield, suggesting the 
formation of reactive oxygen species (ROS) (Martínez, 2007). Incubation of unialgal cultures with compounding increases in PAR and UV-B did not lead to a significant difference in SOD activity, which could indicate that other antioxidant pathways are in play.

Some studies predict increased primary productivity with earlier sea ice retreat (Arrigo et al., 1998, Arrigo et al., 2008) due to an increase in highly productive pelagic species such as Phaeocystis antarctica (Arrigo et al., 1999). However, when algal abundance was examined in the upper mixed layer following sea ice melt, diatoms were in greater abundance due to their tolerance to higher PAR and lowered salinity (Arrigo et al., 1998). Increases in more tolerant groups such as diatoms, which may include potentially less productive species in the community, will not lead to such clear increases in overall cellular productivity. This study has further clarified the need for species-specific incubations, future studies should focus on species-specific tolerances and photosynthetic characteristics in order to create a model that will predict the productivity of the sea ice covered regions of the Southern Ocean under current environmental change scenarios.

This thesis provides evidence of the acclimation abilities of bottom ice algae to increasing PAR, UV-B and temperature. The data clarify existing knowledge differentiating the influence of various environmental parameters. It further confirms that there is a large variability in the tolerance of sea ice algal species to changes in environmental parameters and examines the compounding effects of these factors, providing a better picture to evaluate the fate of algal communities during sea ice melts. The possible consequences of future climate change scenarios on sea ice algae are examined to provide information about inherent variability and acclimatory abilities in sea ice algae that will be valuable for future modelling of sea ice communities.

\subsection{FUTURE RESEARCH}

This thesis has examined various aspects of the photosystems of sea ice algae. Throughout the course of research, new questions have arisen that could extend the ideas presented in this thesis. Here I suggest areas for further research that would advance the field. 


\section{Is there a threshold temperature where damage to photosystems is irreversible?}

There may be a critical temperature (Hill et al., 2009) at which permanent damage occurs to the photosystem and a temperature at which there is a complete loss of photosynthetic function in sea ice algae, as has been observed in symbiotic coral algae (Buxton et al., 2012, Fitt et al., 2001, Tchernov et al., 2004). As an initial examination of the potential for this threshold, the thylakoid integrity experiment was conducted and samples were collected at temperatures where there were sudden changes in fluorescence yield in response to increasing temperature (Chapter 2). Observation of these algal cells under the TEM could provide more accurate estimates of the critical temperature for changes in thylakoid structure. However, due to difficulty in in obtaining adequate ultrastructural preservation of diatom samples fixed in the field, this work could not be concluded (Appendix 2). In addition, a return from the critical temperature to ambient temperatures could indicate how resilient these algae are to temperature fluctuations. The determination of this threshold temperature and any correlated ultrastructural changes through electron microscopy has never been attempted in sea ice algae.

\section{How important are the production of antioxidants in preventing damage to photosystems?}

One of the main defence systems of ice algae to the generation of free radicals and ROS produced due to high irradiances is through the production of antioxidants such as superoxide dismutase (SOD) (Martínez, 2007). The lack of significant change in SOD activity in the experiment in Chapter 5 points to a need to evaluate other antioxidant pathways. The levels of antioxidants such as peroxidase, ascorbate peroxidase and glutathione reductase can be evaluated using assays such as the 1,1-diphenylpicrylhydrazyl (DPPH) assay and other spectrophotometric methods (Bradford, 1976, Gechev et al., 2003, Rijstenbil, 2003). It is important to examine whether an array of antioxidants provide protection to the effects of increasing radiation by preventing cellular damage as antioxidant responses are known to be highly species-specific (Janknegt et al., 2009). 


\section{How important is the role of the diadinoxanthin cycle in sea ice algae?}

The data presented in Chapter 2 suggest that further photoprotective systems exist in sea ice algae enabling survival under high levels of PAR. One such system that has been examined in depth in diatoms is the diadinoxanthin cycle (Griffith et al., 2009). The diadinoxanthin cycle, the second major xanthophyll cycle, is an effective system of protecting photosynthetic machinery in algal cells that actively absorbs excess PAR energy that could otherwise be damaging, releasing it as non-radiative heat. Janknegt et al. (2009) suggested that photosensitivity decreases with increasing xanthophyll cycle activity but decreasing levels of SOD. Increases in irradiance stress in microalgae showed that this cycle could be more important than antioxidant responses (Janknegt et al., 2009). To further develop our understanding of the effect of irradiance on sea ice algae, it will be helpful to understand what proportion of excess light energy is dissipated through processes such as through the xanthophyll cycle.

\section{Is it possible to examine in combination the effect of all the physical parameters that change during sea ice melt?}

Some studies have examined the effect of changes in PAR, temperature and salinity on bottom ice algae that are experienced during sea ice melt (Ralph et al., 2005, Ralph et al., 2007, Ryan et al., 2004, Ryan et al., 2011). This thesis examines the effect of increasing PAR and temperature (Chapters 2, 4, 5) and increasing UV-B and temperature (Chapters $3,4,5$ ) on the photosynthetic machinery of sea ice algae. However, studies have yet to examine all the changes that occur in different physical parameters during sea ice melt, or to attempt this using a fully integrated and replicated multifactorial experimental approach. Ideally, examination of the most realistic effects of sea ice melt on the contained algae requires incubations under conditions of increasing temperature, PAR and UV-B levels and decreasing salinity. The development of an incubation chamber that mimics the freezing and melting of ice would result in more accurate determination of these effects on sea ice algae.

This study has made important steps towards understanding the acclimatory abilities of sea ice algae. Increasing our knowledge about sea ice algal physiology, particularly of 
their photosynthetic health in response to environmental change will improve our ability to predict productivity in the most productive ocean on this planet. Their tolerance to increasing PAR, UV-B and temperature is remarkable and this ability could be crucial in the context of future climate change. The productivity of these autotrophic microorganisms strongly influences secondary production that ties their fate to the fate of all other life in the Southern Ocean.

\subsection{REFERENCES}

Agati, G., \& Tattini, M. (2010). Multiple functional roles of flavonoids in photoprotection. New Phytologist, 186, 786-793.

Aguilera, J., Bischof, K., Karsten, U., Hanelt, D., \& Wiencke, C. (2002). Seasonal variation in ecophysiological patterns in macroalgae from an Arctic fjord. II. Pigment accumulation and biochemical defence systems against high light stress. Marine Biology, 140, 1087-1095.

Arrigo, K. R., Worthen, D., Schnell, A., \& Lizotte, M. P. (1998). Primary production in Southern Ocean waters. Journal of Geophysical Research, 103, 15587-15600.

Arrigo, K. R., Robinson, D. H., Worthen, D. L., Dunbar, R. B., DiTullio, G. R., VanWoert, M., et al. (1999). Phytoplankton community structure and the drawdown of nutrients and CO2 in the Southern Ocean. Science, 283, 365-367.

Arrigo, K. R., Lubin, D., van Dijken, G. L., Holm-Hansen, O., \& Morrow, E. (2003). Impact of a deep ozone hole on Southern Ocean primary production. Journal of Geophysical Research, 108, 3154.

Arrigo, K. R., \& Thomas, D. N. (2004). Large scale importance of sea ice biology in the Southern Ocean. Antarctic Science, 16, 471-486.

Arrigo, K. R., van Dijken, G., \& Pabi, S. (2008). Impact of a shrinking Arctic ice cover on marine primary production. Geophyical Research Letters, 35, L19603.

Arrigo, K. R. (2014). Sea Ice Ecosystems. Annual Review of Marine Science, 6, 439-467.

Attwood, D. K., Hendee, J. C., \& Mendez, A. (1992). An assessment of global warming stress on Caribbean coral reef ecosystems. Bull Marine Science, 51, 118-130.

Baek, S. H., Jung, S. W., \& Shin, K. (2011). Effects of temperature and salinity on growth of Thalassiosira pseudonana (Bacillariophyceae) isolated from ballast water. Journal of Freshwater Ecology, 26, 547-552.

Bodeker, G. E., Shiona, H., \& Eskes, H. (2005). Indicators of Antarctic ozone depletion. Atmospheric Chemistry and Physics, 5, 2603-2615.

Bradford, M. M. (1976). A rapid and sensitive method for the quantitation of microgram quantities of protein utilizing the principle of protein-dye binding. Analytical Biochemistry, 72, 248-254.

Buxton, L., Takahashi, S., Hill, R., \& Ralph, P. (2012). Variability in the primary site of photosynthetic damage in Symbiodinium sp. (Dinophyceae) exposed to thermal stress. Journal of Phycology, 47, 117-126.

Clarke, A., Murphy, E. J., Meredith, M. P., King, J. C., Peck, L. S., Barnes, D. K. A., et al. (2007). Climate change and the marine ecosystem of the western Antarctic Peninsula. Philosophical Transactions of the Royal Society B: Biological Sciences, 362, 149-166. 
Convey, P., Bindschadler, R., di Prisco, G., Fahrbach, E., Gutt, J., Hodgson, D. A., et al. (2009). Antarctic climate change and the environment. Antarctic Science, 21, 541-563.

Cullen, J., \& Neale, P. (1994). Ultraviolet radiation, ozone depletion, and marine photosynthesis. Photosynthesis Research, 39, 303-320.

Davidson, A. T., Bramich, D., Marchant, H. J., \& McMinn, A. (1994). Effects of UV-B irradiation on growth and survival of Antarctic marine diatoms. Marine Biology, $119,507-515$.

Davison, I. R. (1991). Environmental effects on algal photosynthesis: temperature. Journal of Phycology, 27, 2-8.

Ducklow, H. W., Fraser, W. R., Meredith, M. P., Stammerjohn, S. E., Doney, S. C., Martinson, D. G., et al. (2013). West Antarctic peninsula: An ice-dependent coastal marine ecosystem in transition. Oceanography, 26, 190-203.

Dunlap, W. C., \& Yamamoto, Y. (1995). Small-molecule antioxidants in marine organisms: antioxidant activity of mycosporine-glycine. Comparative Biochemistry and Physiology Part B: Biochemistry and Molecular Biology, 112, 105-114.

Eicken, H. (1992). The role of sea ice in structuring Antarctic ecosystems. Polar Biology, 12, 3-13.

Fitt, W. K., Brown, B. E., Warner, M. E., \& Dunne, R. P. (2001). Coral bleaching: interpretation of thermal tolerance limits and thermal thresholds in tropical corals. Coral Reefs, 20, 51-65.

Gao, Q., \& Garcia-Pichel, F. (2011). Microbial ultraviolet sunscreens. Nature Reviews Microbiology, 9, 791-802.

Gechev, T., Willekens, H., Van Montagu, M., Inzé, D., Van Camp, W., Toneva, V., et al. (2003). Different responses of tobacco antioxidant enzymes to light and chilling stress. Journal of Plant Physiology, 160, 509-515.

Giesenhagen, H. C., Detmer, A. E., de Wall, J., Weber, A., Gradinger, R. R., \& Jochem, F. J. (1999). How are Antarctic planktonic microbial food webs and algal blooms affected by melting of sea ice? Microcosm simulations. Aquatic Microbial Ecology, 20, 183-201.

Griffith, G. P., Vennell, R., \& Lamare, M. D. (2009). Diadinoxanthin cycle of the bottom ice algal community during spring in McMurdo Sound, Antarctica. Polar Biology, 32, 623-636.

Halac, S. R., Villafañe, V. E., \& Helbling, E. W. (2010). Temperature benefits the photosynthetic performance of the diatoms Chaetoceros gracilis and Thalassiosira weissflogii when exposed to UVR. Journal of Photochemistry and Photobiology B: Biology, 101, 196-205.

Hannach, G., \& Sigleo, A. C. (1998). Photoinduction of UV-absorbing compounds in six species of marine phytoplankton. Marine Ecology Progress Series, 174, 207-222.

Hays, G. C., Richardson, A. J., \& Robinson, C. (2005). Climate change and marine plankton. Trends in Ecology and Evolution, 20, 337-344.

Helbling, E. W., Buma, A. G. J., Boelen, P., van der Strate, H. J., Valeria Fiorda Giordanino, M., \& Villafane, V. E. (2011). Increase in Rubisco activity and gene expression due to elevated temperature partially counteracts ultraviolet radiation-induced photoinhibition in the marine diatom Thalassiosira weissflogii. Limnology and Oceanography, 56, 1330-1342. 
Hill, R., Ulstrup, K. E., \& Ralph, P. J. (2009). Temperature induced changes in thylakoid membrane thermostability of cultured, freshly isolated, and expelled zooxanthellae from Scleractinian corals. Bulletin of Marine Science, 85, 223-244.

Janknegt, P. J., van De Poll, W. H., Visser, R. J. W., Rijstenbil, J. W., \& Buma, A. G. J. (2008). Oxidative stress responses in the marine Antarctic diatom Chaetoceros brevis (Bacillariophyceae) during photoacclimation. Journal of Phycology, 44, 957-966. Janknegt, P. J., Marco de Graaff, C., van de Poll, W. H., Visser, R. J. W., Rijstenbil, J. W., \& Buma, A. G. J. (2009). Short-term antioxidative responses of 15 microalgae exposed to excessive irradiance including ultraviolet radiation. European Journal of Phycology, 44, 525-539.

Lesser, M. P., \& Farrell, J. H. (2004). Exposure to solar radiation increases damage to both host tissues and algal symbionts of corals during thermal stress. Coral Reefs, 23, 367-377.

Lewis, P. N., Hewitt, C. L., Riddle, M., \& McMinn, A. (2003). Marine introductions in the Southern Ocean: an unrecognised hazard to biodiversity. Marine Pollution Bulletin, 46, 213-223.

Lionard, M., Roy, S., Tremblay-Létourneau, M., \& Ferreyra, G. A. (2012). Combined effects of increased UV-B and temperature on the pigment-determined marine phytoplankton community of the St. Lawrence Estuary. Marine Ecology Progress Series, 445, 219-234.

Lizotte, M. P. (2001). The contributions of sea ice algae to Antarctic marine primary production. American Zoologist, 41, 57-73.

Martínez, R. (2007). Effects of ultraviolet radiation on protein content, respiratory electron transport system (ETS) activity and superoxide dismutase (SOD) activity of Antarctic plankton. Polar Biology, 30, 1159-1172.

Martinson, D. G., Stammerjohn, S. E., Iannuzzi, R. A., Smith, R. C., \& Vernet, M. (2008). Western Antarctic Peninsula physical oceanography and spatio-temporal variability. Deep Sea Research Part II: Topical Studies in Oceanography, 55, 19641987.

McMinn, A., Ryan, K., \& Gademann, R. (2003). Diurnal changes in photosynthesis of Antarctic fast ice algal communities determined by pulse amplitude modulation fluorometry. Marine Biology, 143, 359-367.

McMinn, A., Ryan, K. G., Ralph, P. J., \& Pankowski, A. (2007). Spring sea ice photosynthesis, primary productivity and biomass distribution in eastern Antarctica, 2002-2004. Marine Biology, 151, 985-995.

Montes-Hugo, M., Doney, S. C., Ducklow, H. W., Fraser, W., Martinson, D., Stammerjohn, S. E., et al. (2009). Recent changes in phytoplankton communities associated with rapid regional climate change along the Western Antarctic Peninsula. Science, 323, 1470-1473.

Ralph, P. J., McMinn, A., Ryan, K. G., \& Ashworth, C. (2005). Short-term effect of temperature on the photokinetics of microalgae from the surface layers of Antarctic pack ice. Journal of Phycology, 41, 763-769.

Ralph, P. J., Ryan, K. G., Martin, A., \& Fenton, G. (2007). Melting out of sea ice causes greater photosynthetic stress in algae than freezing in. Journal of Phycology, 43, 948-956.

Rijstenbil, J. W. (2003). Effects of UVB radiation and salt stress on growth, pigments and antioxidative defence of the marine diatom Cylindrotheca closterium. Marine Ecology Progress Series, 254, 37-48. 
Ryan, K. G., McMinn, A., Mitchell, K. A., \& Trenerry, L. (2002). Mycosporine-like amino acids in Antarctic sea ice algae, and their response to UVB radiation. Zeitschrift fur Naturforschung, 57, 471-477.

Ryan, K. G., Ralph, P., \& McMinn, A. (2004). Acclimation of Antarctic bottom-ice algal communities to lowered salinities during melting. Polar Biology, 27, 679-686.

Ryan, K. G., \& Hunt, J. E. (2005). The effectd of UVB radiation on temperate southern hemisphere forests. Environmental Pollution, 137, 415-427.

Ryan, K. G., Tay, M. L., Martin, A., McMinn, A., \& Davy, S. K. (2011). Chlorophyll fluorescence imaging analysis of the responses of Antarctic bottom-ice algae to light and salinity during melting. Journal of Experimental Marine Biology and Ecology, 399, 156-161.

Sobrino, C., \& Neale, P. J. (2007). Short-term and long-term effects of temperature on photosynthesis in the diatom Thalassiosira pseudonana under UVR exposures. Journal of Phycology, 43, 426-436.

Stammerjohn, S. E., Martinson, D. G., Smith, R. C., \& Iannuzzi, R. A. (2008). Sea ice in the western Antarctic Peninsula region: Spatio-temporal variability from ecological and climate change perspectives. Deep Sea Research Part II: Topical Studies in Oceanography, 55, 2041-2058.

Tchernov, D., Gorbunov, M. Y., de Vargas, C., Narayan Yadav, S., Milligan, A. J., Häggblom, M., et al. (2004). Membrane lipids of symbiotic algae are diagnostic of sensitivity to thermal bleaching in corals. Proceedings of the National Academy of Sciences of the United States of America, 101, 13531.

Thomas, D. N., \& Dieckmann, G. S. (2002). Antarctic Sea Ice--a Habitat for Extremophiles. Science, 295, 641.

Thomas, D. N., Fogg, G. E., Convey, P., Fritsen, C. H., Gili, J.-M., Gradinger, R., et al. (2008). The Biology of Polar Regions. Oxford: Oxford University Press.

Vincent, W. F. (1988). Microbial ecosystems of Antarctica. Cambridge: Cambridge University Press.

Wu, H., Gao, K., \& Wu, H. (2009). Responses of a marine red tide alga Skeletonema costatum (Bacillariophyceae) to long-term UV radiation exposures. Journal of Photochemistry and Photobiology B: Biology, 94, 82-86. 


\section{APPENDIX 1}

\section{Additional data from Chapter 2}

\section{A1.1 Response of algae to temperature and light changes during melting of sea ice}

\section{A1.1.1 Quantum Yield}

Initially a repeated measures ANOVA was conducted with time as the 'within' factor and temperature and treatment as 'between' factors. This showed significant effects of time $(p<0.001)$, time by temperature $(p<0.001)$ and time by treatment $(p=0.046)$, but the three-way interaction between time, temperature and treatment was not significant $(\mathrm{p}=0.487)$ (Table A1.1).

Table A1.1 Changes in quantum yield of photosystem II over $48 \mathrm{~h}$ experimental treatments at different PAR levels $\left(0,1,45\right.$ and $\left.100 \mu \mathrm{mol} \mathrm{m}^{-2} \mathrm{~s}^{-1}\right)$ at $-1^{\circ} \mathrm{C}, 2^{\circ} \mathrm{C}$ and $5^{\circ} \mathrm{C}$, analysed using a 2 factor repeated measures ANOVA. Significant changes identified by post hoc pairwise analyses are also listed.

\begin{tabular}{|llllll|}
\hline Source of variation & $\mathrm{df}$ & $\mathrm{MS}$ & $F$ & $\mathrm{p}$ & post hoc comparisons \\
\hline Within subjects & & & & & \\
Time & 3.135 & 0.186 & 20.878 & $<0.001$ & Increase over $48 \mathrm{~h}$ \\
Time x Temperature & 6.270 & 0.046 & 5.120 & $<0.001$ & \\
Time x Treatment & 9.406 & 0.017 & 1.951 & 0.046 & \\
Time x Temperature x Treatment & 18.811 & 0.009 & 0.981 & 0.487 & \\
Error & 150.491 & 0.009 & & & \\
Between subjects & & & & & \\
Temperature & 2 & 0.108 & 6.196 & 0.004 & $-1^{\circ} \mathrm{C}>\left(2{ }^{\circ} \mathrm{C}=5^{\circ} \mathrm{C}\right)$ \\
Treatments & 3 & 0.224 & 12.813 & $<0.001$ & $0=1 \mu \mathrm{mol} \mathrm{m}^{-2} \mathrm{~s}^{-1}$ \\
Temperature x Treatment & 6 & 0.005 & 0.305 & 0.931 & \\
Error & 48 & 0.017 & & & \\
\hline
\end{tabular}

\section{A1.1.2 rETR $_{\max }$}

Initially a repeated measures ANOVA was conducted with time as the 'within' factor and temperature and treatment as 'between' factors. This showed significant effects of time $(\mathrm{p}<0.001)$, time by temperature $(\mathrm{p}<0.001)$ and time by treatment $(\mathrm{p}<0.001)$. The threeway interaction between time, temperature and treatment was significant $(\mathrm{p}<0.001)$ (Table A1.2). 
Table A1.2 Changes in rETRmax over $48 \mathrm{~h}$ experimental treatments at different PAR levels $\left(0,1,45\right.$ and $\left.100 \mu \mathrm{mol} \mathrm{m}{ }^{-2} \mathrm{~s}^{-1}\right)$ at $-1^{\circ} \mathrm{C}, 2^{\circ} \mathrm{C}$ and $5^{\circ} \mathrm{C}$, analysed using a 2 factor repeated measures ANOVA. Significant changes identified by post hoc pairwise analyses are also listed.

\begin{tabular}{|llllll|}
\hline Source of variation & $\mathrm{df}$ & $\mathrm{MS}$ & $F$ & $\mathrm{p}$ & post hoc comparisons \\
\hline Within subjects & & & & & \\
Time & 3.830 & 284.716 & 41.020 & $<0.001$ & Increase over $48 \mathrm{~h}$ \\
Time x Temperature & 7.661 & 140.114 & 20.187 & $<0.001$ & \\
Time x Treatment & 11.491 & 47.893 & 6.900 & $<0.001$ & \\
Time x Temperature x Treatment & 22.982 & 38.489 & 5.545 & $<0.001$ & \\
Error & 1276.156 & 183.860 & 6.941 & & \\
& & & & & \\
Between subjects & & & & & \\
Temperature & 2 & 534.087 & 33.338 & $<0.001$ & $-1^{\circ} \mathrm{C}>\left(2^{\circ} \mathrm{C}=5^{\circ} \mathrm{C}\right)$ \\
Treatments & 3 & 403.386 & 25.180 & $<0.001$ & $0=1 \mu \mathrm{mol} \mathrm{m}^{-2} \mathrm{~s}^{-1}$ \\
Temperature x Treatment & 6 & 31.007 & 1.936 & 0.094 & \\
Error & 48 & 16.020 & & & \\
\hline
\end{tabular}

\section{A1.1.3 MAAs}

Initially a repeated measures ANOVA was conducted with time as the 'within' factor and temperature and treatment as 'between' factors. This showed significant effects of time $(\mathrm{p}=0.001)$, time by temperature $(\mathrm{p}=0.003)$ and time by treatment $(\mathrm{p}=0.025)$, but the three-way interaction between time, temperature and treatment was not significant $(\mathrm{p}=0.192)$ (Table A1.3). 
Table A1.3. Changes in MAA production over $48 \mathrm{~h}$ experimental treatments at different PAR levels $\left(0,1,45\right.$ and $\left.100 \mu \mathrm{mol} \mathrm{m}^{-2} \mathrm{~s}^{-1}\right)$ at $-1^{\circ} \mathrm{C}, 2^{\circ} \mathrm{C}$ and $5^{\circ} \mathrm{C}$, analysed using a 2 factor repeated measures ANOVA. Significant changes identified by post hoc pairwise analyses are also listed.

\begin{tabular}{|llllll|}
\hline Source of variation & df & MS & $F$ & p & post hoc comparisons \\
\hline Within subjects & & & & & \\
Time & 1 & 0.016 & 11.854 & 0.001 & \\
Time x Temperature & 2 & 0.009 & 6.674 & 0.003 & There was an increase \\
Time x Treatment & 3 & 0.005 & 3.403 & 0.025 & over $48 \mathrm{~h}$. \\
Time x Temperature x Treatment & 6 & 0.002 & 1.519 & 0.192 & \\
Error & 48 & 0.001 & & & \\
& & & & & \\
Between subjects & & & & & \\
Temperature & 2 & 0.023 & 11.923 & $<0.001$ & \\
Treatments & 3 & 0.003 & 1.689 & 0.182 & $5^{\circ} \mathrm{C}>\left(-1{ }^{\circ} \mathrm{C}=2^{\circ} \mathrm{C}\right)$ \\
Temperature x Treatment & 6 & 0.006 & 3.010 & 0.014 & \\
Error & 48 & 0.002 & & & \\
\hline
\end{tabular}

\section{A1.1.4 Photosynthetic Efficiency $(\alpha)$}

Initially a repeated measures ANOVA was conducted with time as the 'within' factor and temperature and treatment as 'between' factors. This showed no significant effects of time $(\mathrm{p}=0.544)$, time by temperature $(\mathrm{p}=0.369)$ and time by treatment $(\mathrm{p}=0.047)$ and the three-way interaction between time, temperature and treatment $(p=0.200)$ (Table A1.4). 
Table A1.4 Changes in photosynthetic efficiency ( $\alpha$ ) over $48 \mathrm{~h}$ experimental treatments at different PAR levels $\left(0,1,45\right.$ and $\left.100 \mu \mathrm{mol} \mathrm{m}^{-2} \mathrm{~s}^{-1}\right)$ at $-1^{\circ} \mathrm{C}, 2^{\circ} \mathrm{C}$ and $5^{\circ} \mathrm{C}$, analysed using a 2 factor repeated measures ANOVA. Significant changes identified by post hoc pairwise analyses are also listed.

\begin{tabular}{|llllll|}
\hline Source of variation & $\mathrm{df}$ & $\mathrm{MS}$ & $F$ & $\mathrm{p}$ & post hoc comparisons \\
\hline Within subjects & & & & & \\
Time & 3.966 & 1.929 & 0.771 & 0.544 & \\
Time x Temperature & 11.898 & 2.732 & 1.092 & 0.369 & No significance \\
Time x Treatment & 7.932 & 5.058 & 2.022 & 0.047 & \\
Time x Temperature x Treatment & 23.795 & 3.144 & 1.257 & 0.200 & \\
Error & 182.431 & 2.501 & & & \\
& & & & & \\
Between subjects & & & & & \\
Temperature & 3 & 0.536 & 0.253 & 0.859 & \\
Treatments & 2 & 3.440 & 1.623 & 0.208 & No significance \\
Temperature x Treatment & 6 & 2.712 & 1.280 & 0.285 & \\
Error & 46 & 2.119 & & & \\
\hline
\end{tabular}



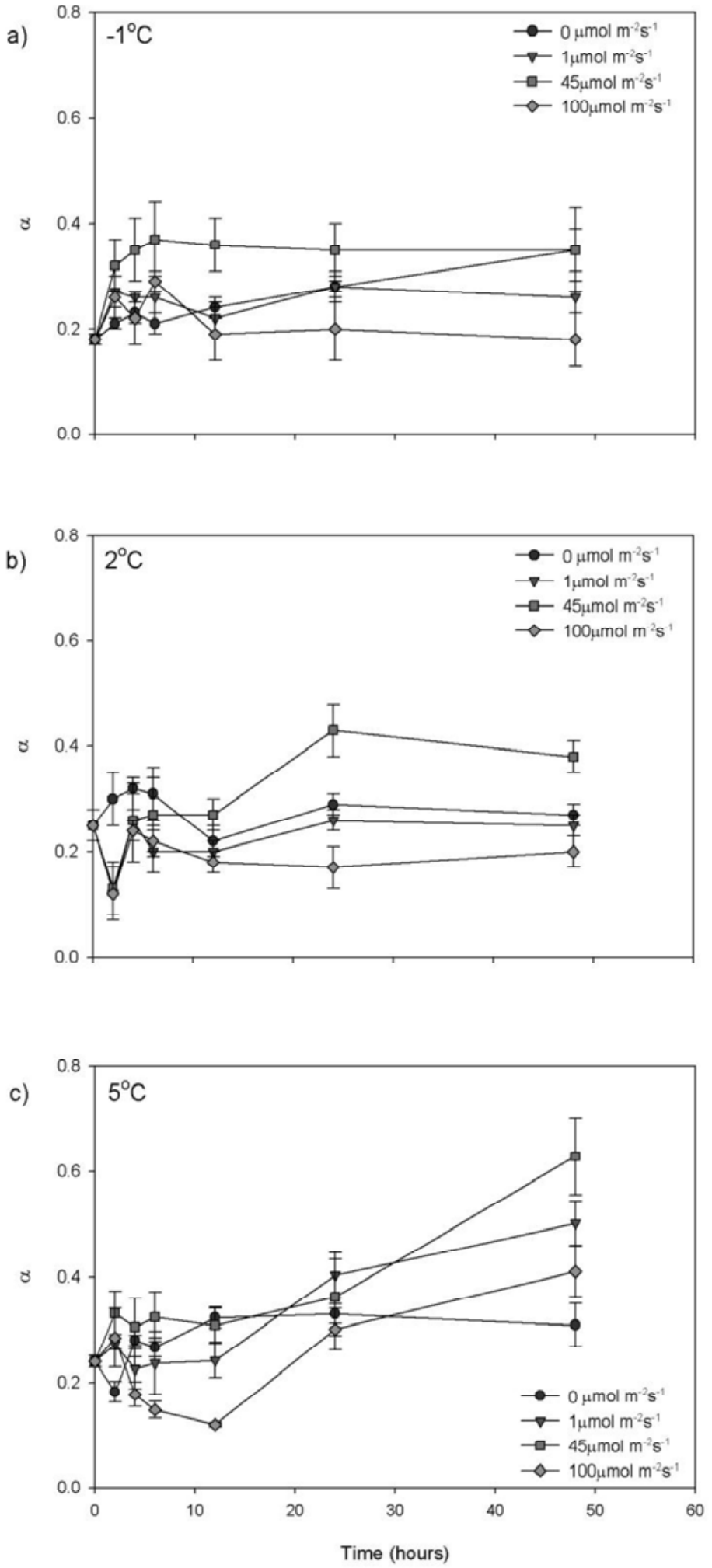

Fig A1.1 Photosynthetic efficiency $(\alpha)$ of bottom ice algae at $0,2,4,6,12,24$ and $48 \mathrm{~h}$. Cultures were maintained at four PAR levels of $0,1,45$ or $100 \mu \mathrm{mol} \mathrm{m}^{-2} \mathrm{~s}^{-1}$ and at (a) $1^{\circ} \mathrm{C}$, (b) $2^{\circ} \mathrm{C}$ and (c) $5^{\circ} \mathrm{C}$. Error bars indicate standard error. 


\section{A1.1.5 Saturation Irradiance $\left(E_{\mathrm{k}}\right)$}

Initially a repeated measures ANOVA was conducted with time as the 'within' factor and temperature and treatment as 'between' factors. This showed no significant effects of time $(\mathrm{p}=0.246)$, time by temperature $(\mathrm{p}=0.330)$ and time by treatment $(\mathrm{p}=0.402)$ and the three-way interaction between time, temperature and treatment $(p=0.343)$ (Table A1.4).

Table A1.5 Changes in saturation irradiance $\left(E_{\mathrm{k}}\right)$ over $48 \mathrm{~h}$ experimental treatments at different PAR levels $\left(0,1,45\right.$ and $\left.100 \mu \mathrm{mol} \mathrm{m}^{-2} \mathrm{~s}^{-1}\right)$ at $-1^{\circ} \mathrm{C}, 2^{\circ} \mathrm{C}$ and $5^{\circ} \mathrm{C}$, analysed using a 2 factor repeated measures ANOVA. Significant changes identified by post hoc pairwise analyses are also listed.

\begin{tabular}{|llllll|}
\hline Source of variation & $\mathrm{df}$ & $\mathrm{MS}$ & $F$ & $\mathrm{p}$ & post hoc comparisons \\
\hline Within subjects & & & & & \\
Time & 1.024 & 61367.296 & 1.390 & 0.246 & \\
Time x Temperature & 3.072 & 52052.484 & 1.179 & 0.330 & No significance \\
Time x Treatment & 2.048 & 41335.805 & 0.936 & 0.402 & \\
Time x Temperature x Treatment & 6.145 & 51488.988 & 1.166 & 0.343 & \\
Error & 40.966 & 44140.268 & & & \\
& & & & & \\
Between subjects & & & & & \\
Temperature & 3 & 6809.576 & 0.950 & 0.426 & \\
Treatments & 2 & 9911.086 & 1.383 & 0.263 & No significance \\
Temperature x Treatment & 6 & 9732.471 & 1.358 & 0.255 & \\
Error & 40 & 7167.928 & & & \\
\hline
\end{tabular}


a)

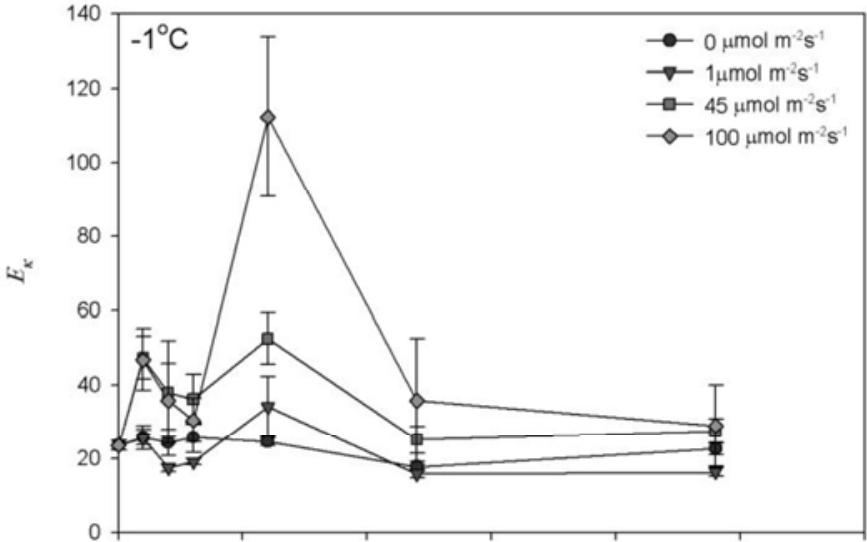

b)

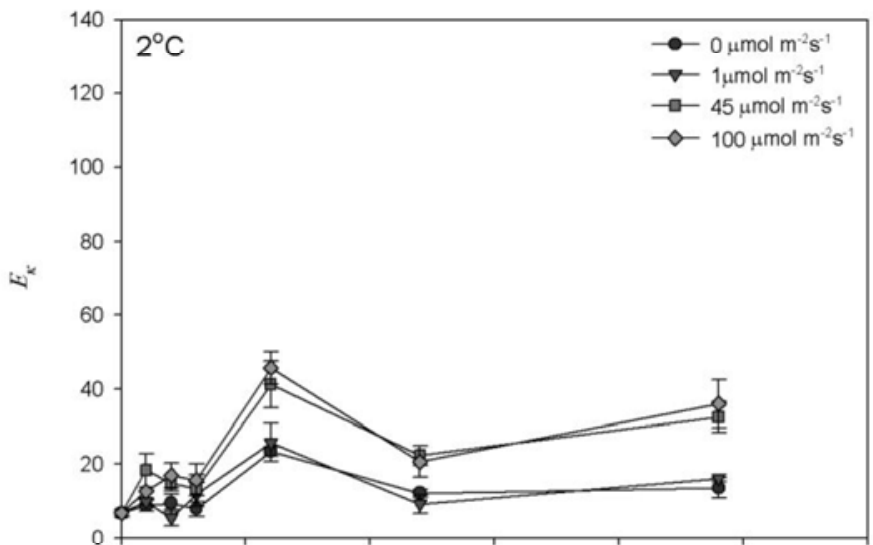

c)

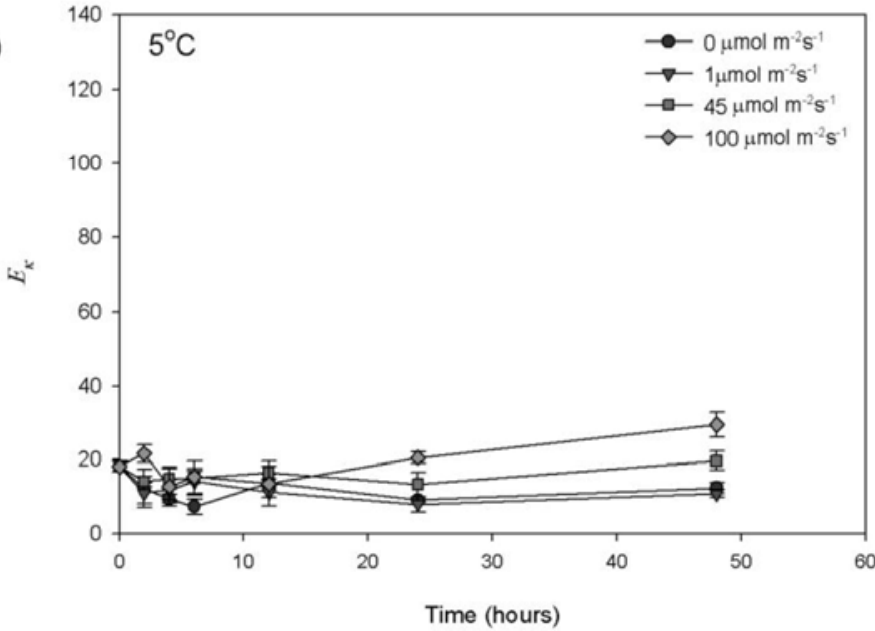

Fig A1.2 Saturation Irradiance $\left(E_{\mathrm{k}}\right)$ of bottom ice algae at $0,2,4,6,12,24$ and $48 \mathrm{~h}$. Cultures were maintained at four PAR levels of $0,1,45$ or $100 \mu \mathrm{mol} \mathrm{m}^{-2} \mathrm{~s}^{-1}$ and at (a) $1^{\circ} \mathrm{C}$, (b) $2^{\circ} \mathrm{C}$ and (c) $5^{\circ} \mathrm{C}$. Error bars indicate standard error. 


\section{A1.2 MAA production at higher temperature exposures}

Initially a repeated measures ANOVA was conducted with time as the 'within' factor and both temperature and treatment as 'between' factors. This only showed significant effects of the interaction between time and temperature $(p=0.009)$. All other terms were not significant ( $p>0.05)$ (Table A1.6).

Table A1.6. Changes in MAA production over $48 \mathrm{~h}$ experimental treatments at different PAR levels $\left(1,45\right.$ and $\left.100 \mu \mathrm{mol} \mathrm{m}^{-2} \mathrm{~s}^{-1}\right)$ at $4^{\circ} \mathrm{C}, 14^{\circ} \mathrm{C}$ and $24^{\circ} \mathrm{C}$, analysed using a 2 factor repeated measures ANOVA. Significant changes identified by post hoc pairwise analyses are also listed.

\begin{tabular}{|llllll|}
\hline Source of variation & $\mathrm{df}$ & $\mathrm{MS}$ & $F$ & $\mathrm{p}$ & post hoc comparisons \\
\hline Within subjects & & & & & \\
Time & 1 & 0.000 & 0.071 & 0.793 & \\
Time x Temperature & 2 & 0.017 & 6.212 & 0.009 & No significance \\
Time x Treatment & 2 & 0.001 & 0.182 & 0.835 & \\
Time x Tempe & & & & &
\end{tabular}

Time $\mathrm{x}$ Tempe 


\section{A1.3 Thylakoid Integrity experiment}

\section{A1.3.1 Electron Microscopy}

Sub-samples of algal cells were preserved in 2.5\% EM-grade glutaraldehyde at $4^{\circ} \mathrm{C}$. The sample was then subjected to post-fixation with osmium tetroxide through a dehydration schedule as described in Appendix 2, followed by embedding in epoxy resin using the PROCURE 812 embedding kit (Proscitech, Australia) as described in Luft (1961).

The dehydration schedule was as follows:

Buffer for $10 \mathrm{~min}$

$1 \%$ osmium tetroxide for $1 \mathrm{~h}$

Buffer for 10 min

$30 \%$ ethanol for $10 \mathrm{~min}$

$50 \%$ ethanol for $10 \mathrm{~min}$

$70 \%$ ethanol for $10 \mathrm{~min}$

$80 \%$ ethanol for $10 \mathrm{~min}$

$90 \%$ ethanol for $10 \mathrm{~min}$

$95 \%$ ethanol for $10 \mathrm{~min}$

$100 \%$ ethanol for $10 \mathrm{~min}$

$100 \%$ ethanol for $10 \mathrm{~min}$

Analar $100 \%$ ethanol for $10 \mathrm{~min}$

$100 \%$ propylene oxide for $20 \mathrm{~min}$

It was then embedded into resin through these steps:

$50 \%$ propylene oxide and 50\% epoxy resin for $20 \mathrm{~min}$. Allow to stand overnight. $100 \%$ resin left to cure in an oven at $60^{\circ} \mathrm{C}$ for $24 \mathrm{~h}$.

The resin capsules were then sectioned to 1 micron thickness with an ultramicrotome (Leica Microsystems, Wetzlar, Germany) and placed on copper mesh grids before being viewed under the Transmission Electron Microscope. 
A1.3.2 Results
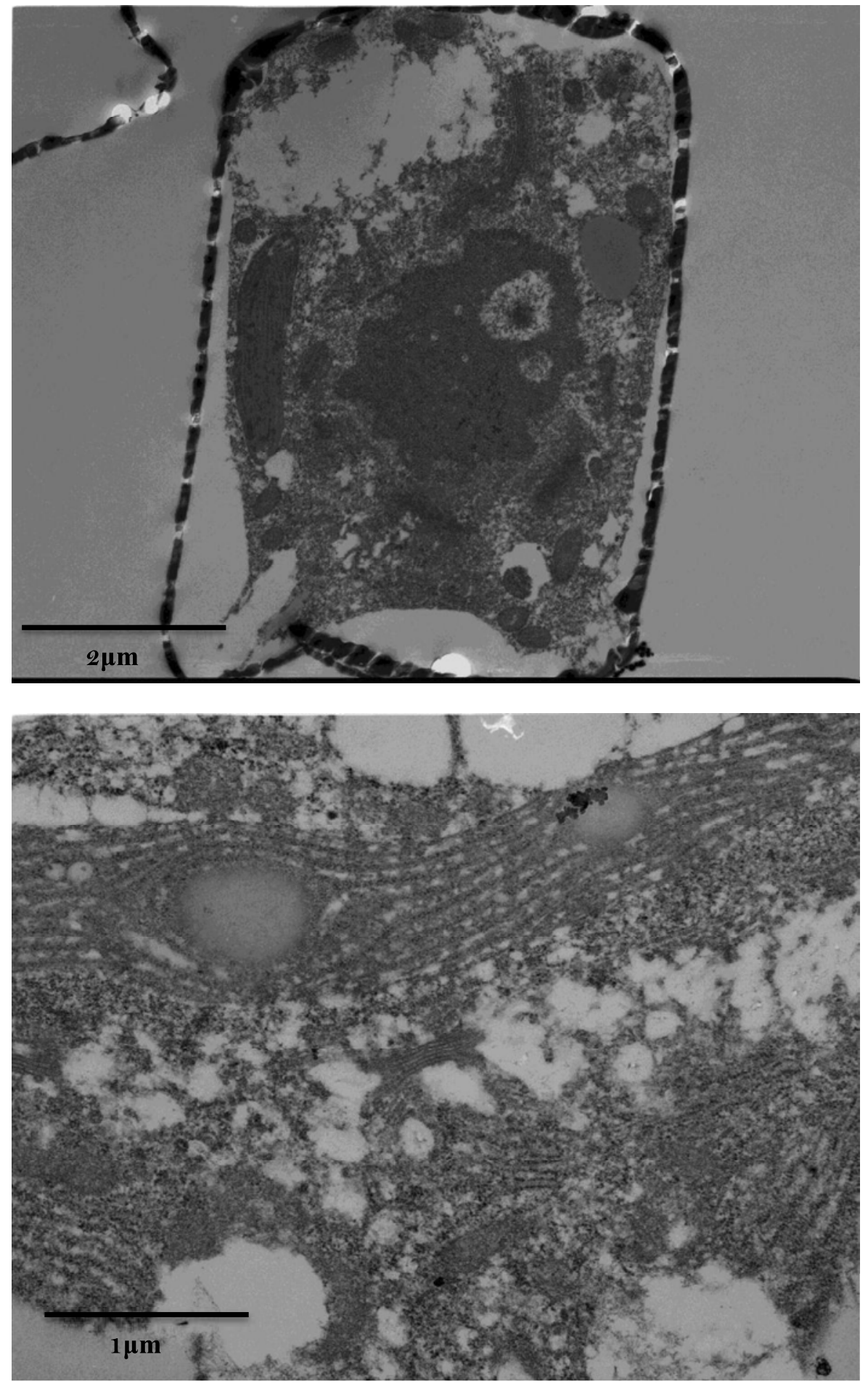

Fig. A2 Algal cell sections as viewed under the transmission electron microscope, showing (a) An entire algal cell with a chloroplast at the left margin and (b) Details of thylakoids in the chloroplast. 


\section{APPENDIX 2}

\section{Additional data from Chapter 3}

\section{A2.1 Response of algae to to UV-B level of $5 \mathrm{~mW} \mathrm{~m}^{-2}$ at three temperatures}

\section{A2.1.1 Quantum Yield}

Initially a repeated measures ANOVA was conducted with time as the 'within' factor and temperature and treatment as 'between' factors. This showed significant effects of time $(\mathrm{p}<0.001)$ and time by temperature $(\mathrm{p}<0.001)$ but the time by treatment $(\mathrm{p}=0.533)$ and the three-way interaction between time, temperature and treatment was not significant $(p=0.845)$ (Table A2.1).

Table A2.1 Changes in quantum yield of photosystem II over $48 \mathrm{~h}$ experimental treatments at one UV-B level of $5 \mathrm{mWm}^{-2}$ and $1 \mu \mathrm{mol} \mathrm{m} \mathrm{m}^{-2} \mathrm{~s}^{-1}$; and $0 \mu \mathrm{mol} \mathrm{m}^{-2} \mathrm{~s}^{-1}$ at $-1^{\circ} \mathrm{C}$, $2^{\circ} \mathrm{C}$ and $5^{\circ} \mathrm{C}$, analysed using a 2 factor repeated measures ANOVA. Significant changes identified by post hoc pairwise analyses are also listed.

\begin{tabular}{|llllll|}
\hline Source of variation & $\mathrm{df}$ & $\mathrm{MS}$ & $F$ & $\mathrm{p}$ & post hoc comparisons \\
\hline Within subjects & & & & & \\
Time & 6 & 0.030 & 10.283 & $<0.001$ & Increase over $48 \mathrm{~h}$ \\
Time x Temperature & 12 & 0.010 & 3.287 & $<0.001$ & \\
Time x Treatment & 6 & 0.002 & 0.850 & 0.533 & \\
Time x Temperature x Treatment & 12 & 0.002 & 0.593 & 0.845 & \\
Error & 144 & 0.003 & & & \\
& & & & & \\
Between subjects & & & & & \\
Temperature & 2 & 0.261 & 9.656 & 0.001 & $-1^{\circ} \mathrm{C}=2^{\circ} \mathrm{C} ;-^{\circ} \mathrm{C}=5^{\circ} \mathrm{C}$ \\
Treatments & 1 & 0.118 & 4.378 & 0.047 & $2^{\circ} \mathrm{C}>5^{\circ} \mathrm{C}$ \\
Temperature x Treatment & 2 & 0.023 & 0.859 & 0.436 & \\
Error & 24 & 0.027 & & & \\
\hline
\end{tabular}

\section{A2.1.2 rETR $_{\max }$}

Initially a repeated measures ANOVA was conducted with time as the 'within' factor and temperature and treatment as 'between' factors. This showed significant effects of time $(\mathrm{p}<0.001)$ and time by temperature $(\mathrm{p}<0.001)$ but the time by treatment $(\mathrm{p}=0.347)$ and the three-way interaction between time, temperature and treatment was not significant $(p=0.914)$ (Table A2.2). 
Table A2.2 Changes in rETRmax over $48 \mathrm{~h}$ experimental treatments at one UV-B level of $5 \mathrm{mWm}^{-2}$ and $1 \mu \mathrm{mol} \mathrm{m}^{-2} \mathrm{~s}^{-1}$; and $0 \mu \mathrm{mol} \mathrm{m}^{-2} \mathrm{~s}^{-1}$ at $-1^{\circ} \mathrm{C}, 2^{\circ} \mathrm{C}$ and $5^{\circ} \mathrm{C}$, analysed using a 2 factor repeated measures ANOVA. Significant changes identified by post hoc pairwise analyses are also listed.

\begin{tabular}{|llllll|}
\hline Source of variation & $\mathrm{df}$ & $\mathrm{MS}$ & $F$ & $\mathrm{p}$ & post hoc comparisons \\
\hline Within subjects & & & & & \\
Time & 3.146 & 45.092 & 9.170 & $<0.001$ & Increase over $48 \mathrm{~h}$ \\
Time x Temperature & 6.292 & 40.499 & 8.236 & $<0.001$ & \\
Time x Treatment & 3.146 & 5.514 & 1.121 & 0.347 & \\
Time x Temperature x Treatment & 6.292 & 1.727 & 0.351 & 0.914 & \\
Error & 75.506 & 4.918 & & & \\
& & & & & \\
Between subjects & & & & & \\
Temperature & 2 & 107.409 & 9.601 & 0.001 & $2{ }^{\circ} \mathrm{C}>\left(-1^{\circ} \mathrm{C}=5^{\circ} \mathrm{C}\right)$ \\
Treatments & 1 & 18.554 & 1.658 & 0.210 & \\
Temperature x Treatment & 2 & 29.776 & 2.662 & 0.090 & \\
Error & 24 & 11.187 & & & \\
\hline
\end{tabular}

\section{A2.1.3 Photosynthetic Efficiency ( $\alpha$ )}

A repeated measures ANOVA was conducted with time as the 'within' factor and temperature and treatment as 'between' factors. This showed significant effects only for time by temperature $(\mathrm{p}=0.002)$ but the time $(\mathrm{p}=0.465)$, time by treatment $(\mathrm{p}=0.059)$ and the three-way interaction between time, temperature and treatment was not significant ( $p=0.095$ ) (Table A2.3). There was no significant change in photosynthetic efficiency at this UV-B level at all temperatures. 
Table A2.3 Changes in photosynthetic efficiency over $48 \mathrm{~h}$ experimental treatments at one UV-B level of $5 \mathrm{mWm}^{-2}$ and $1 \mu \mathrm{mol} \mathrm{m}^{-2} \mathrm{~s}^{-1}$; and $0 \mu \mathrm{mol} \mathrm{m}^{-2} \mathrm{~s}^{-1}$ at $-1^{\circ} \mathrm{C}, 2^{\circ} \mathrm{C}$ and $5^{\circ} \mathrm{C}$, analysed using a 2 factor repeated measures ANOVA. Significant changes identified by post hoc pairwise analyses are also listed.

\begin{tabular}{|llllll|}
\hline Source of variation & $\mathrm{df}$ & $\mathrm{MS}$ & $F$ & $\mathrm{p}$ & post hoc comparisons \\
\hline Within subjects & & & & & \\
Time & 3.637 & 0.006 & 0.944 & 0.465 & No change over $48 \mathrm{~h}$ \\
Time x Temperature & 7.275 & 0.022 & 3.600 & 0.002 & \\
Time x Treatment & 3.637 & 0.015 & 2.426 & 0.059 & \\
Time x Temperature x Treatment & 7.275 & 0.011 & 1.796 & 0.095 & \\
Error & 87.300 & 0.006 & & & \\
& & & & & \\
Between subjects & & & & & \\
Temperature & 2 & 0.233 & 10.965 & $<0.001$ & $2^{\circ} \mathrm{C}>\left(-1^{\circ} \mathrm{C}=5^{\circ} \mathrm{C}\right)$ \\
Treatments & 1 & 0.004 & 0.184 & 0.672 & \\
Temperature x Treatment & 2 & 0.033 & 1.537 & 0.235 & \\
Error & 24 & 0.021 & & & \\
\hline
\end{tabular}


a)

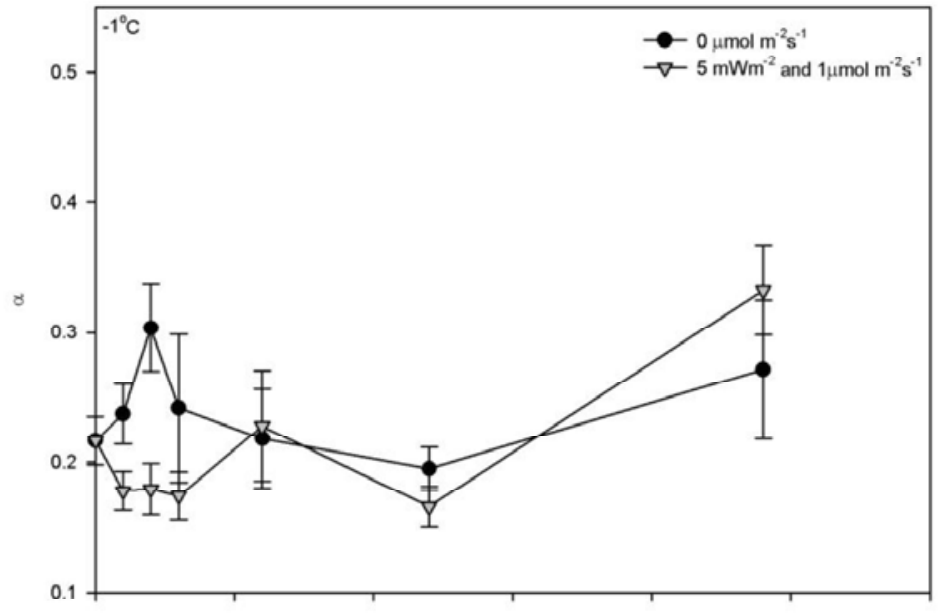

b)

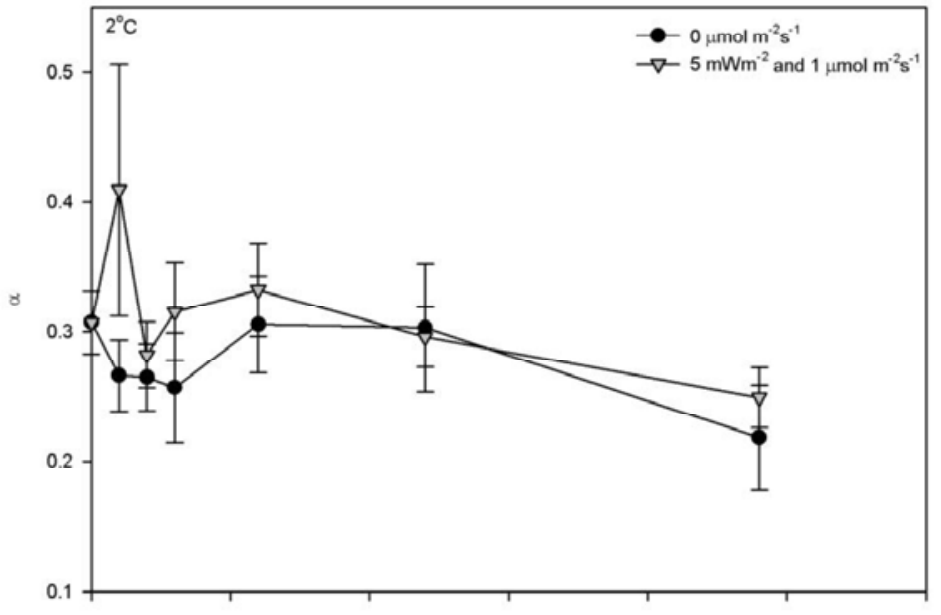

c)

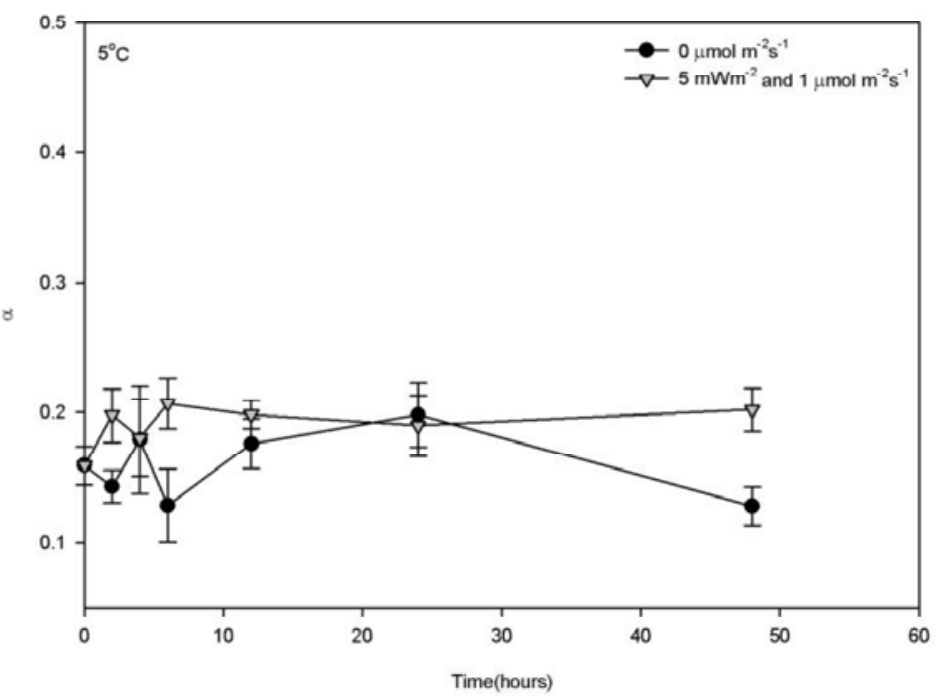

Fig A2.1. Photosynthetic efficiency $(\alpha)$ of bottom ice algae at $0,2,4,6,12,24$ and $48 \mathrm{~h}$. Cultures were maintained at $5 \mathrm{~mW} \mathrm{~m}^{-2}$ and $1 \mu \mathrm{mol} \mathrm{m}^{-2} \mathrm{~s}^{-1}$ or at $0 \mu \mathrm{mol} \mathrm{m}^{-2} \mathrm{~s}^{-1}$ (a) $-1^{\circ} \mathrm{C}$, (b) $2^{\circ} \mathrm{C}$ and (c) $5^{\circ} \mathrm{C}$. Error bars indicate standard error. 


\section{A2.1.4 Saturation irradiance $\left(E_{\mathrm{k}}\right)$}

A repeated measures ANOVA was conducted with time as the 'within' factor and temperature and treatment as 'between' factors. This showed significant effects for time $(p=0.007)$ and time by temperature $(p<0.001)$ but time by treatment $(p=0.630)$ and the three-way interaction between time, temperature and treatment was not significant $(p=0.508)$ (Table A2.4). There was no significant change in photosynthetic efficiency at this UV-B level at $-1^{\circ} \mathrm{C}$ and $5^{\circ} \mathrm{C}$. There was a significant increase (Bonferroni, $\mathrm{p}=0.011$ ) in saturation irradiance of algae incubated at $2^{\circ} \mathrm{C}$. However, there was no difference between the two exposure treatments.

Table A2.4 Changes in saturation irradiance over $48 \mathrm{~h}$ experimental treatments at one UV-B level of $5 \mathrm{mWm}^{-2}$ and $1 \mu \mathrm{mol} \mathrm{m}^{-2} \mathrm{~s}^{-1}$; and $0 \mu \mathrm{mol} \mathrm{m}^{-2} \mathrm{~s}^{-1}$ at $-1^{\circ} \mathrm{C}, 2^{\circ} \mathrm{C}$ and $5^{\circ} \mathrm{C}$, analysed using a 2 factor repeated measures ANOVA. Significant changes identified by post hoc pairwise analyses are also listed.

\begin{tabular}{|llllll|}
\hline Source of variation & $\mathrm{df}$ & $\mathrm{MS}$ & $F$ & $\mathrm{p}$ & post hoc comparisons \\
\hline & & & & & \\
Within subjects & & & & & \\
Time & 3.062 & 438.687 & 4.297 & 0.007 & No change over $48 \mathrm{~h}$ \\
Time x Temperature & 6.125 & 684.164 & 6.701 & $<0.001$ & \\
Time x Treatment & 3.062 & 59.763 & 0.585 & 0.630 & \\
Time x Temperature x Treatment & 6.125 & 90.976 & 0.891 & 0.508 & \\
Error & 73.496 & 102.103 & & & \\
& & & & & \\
Between subjects & & & & & \\
Temperature & 2 & 98.702 & 1.880 & 0.174 & No significance \\
Treatments & 1 & 43.321 & 0.825 & 0.373 & \\
Temperature x Treatment & 2 & 144.584 & 2.754 & 0.084 & \\
Error & 24 & 52.490 & & & \\
\hline
\end{tabular}


a)

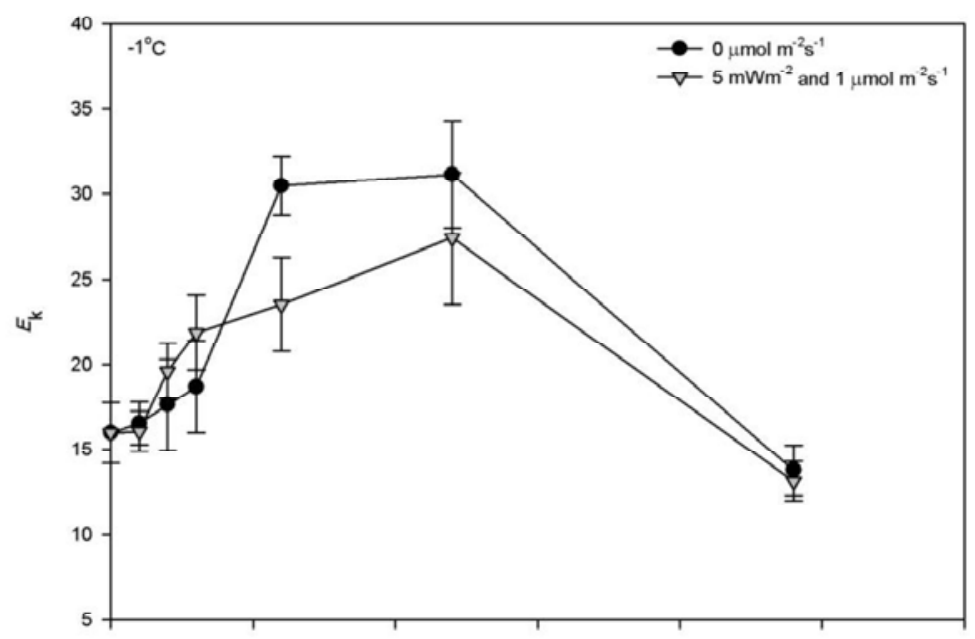

b)

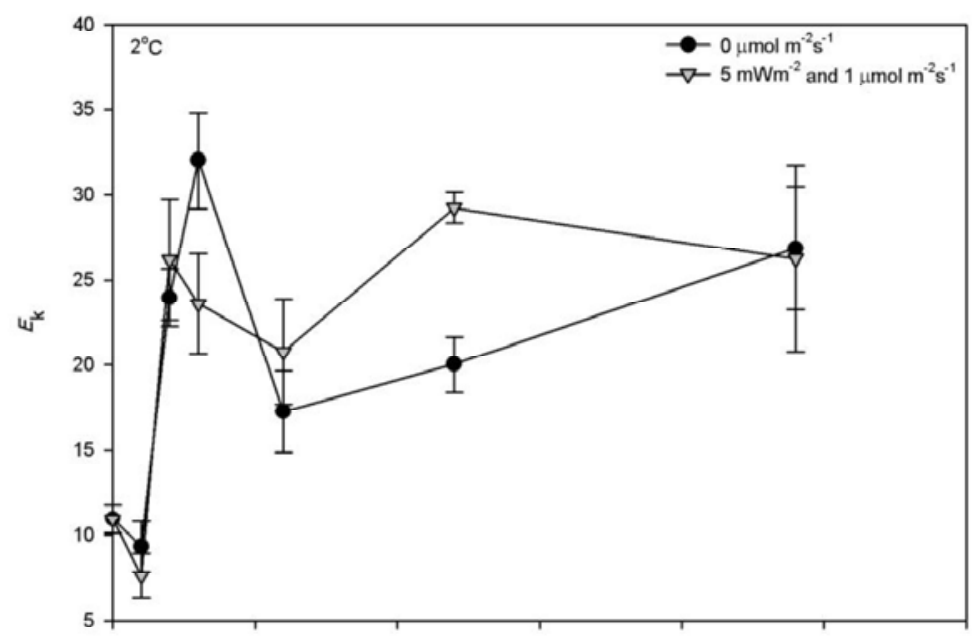

c)

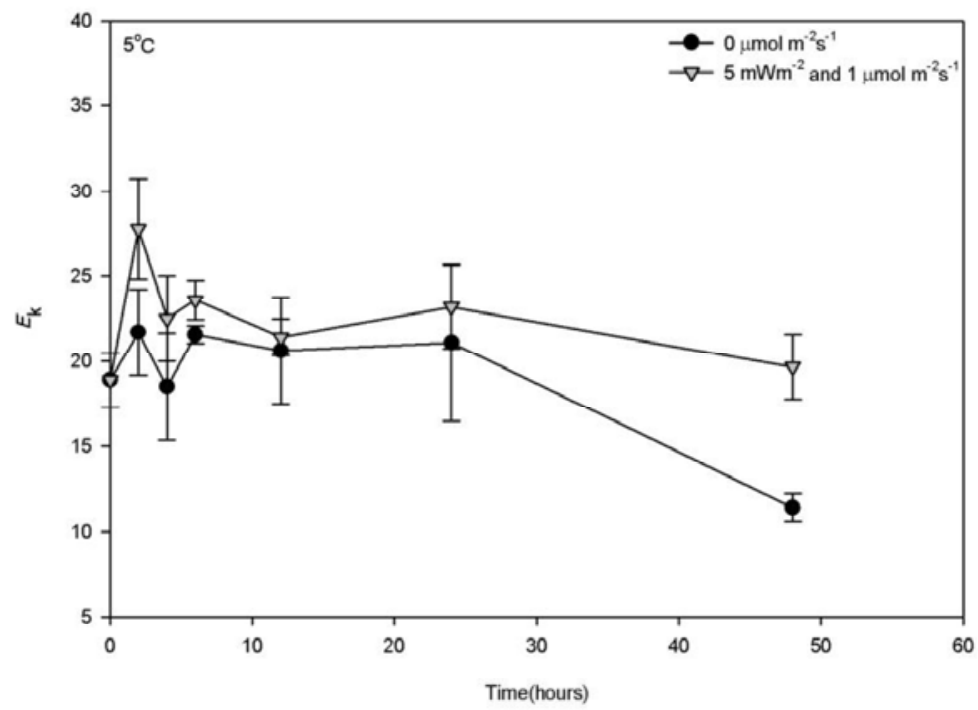

Fig A2.2. Saturation irradiance $\left(E_{\mathrm{k}}\right)$ of bottom ice algae at $0,2,4,6,12,24$ and $48 \mathrm{~h}$. Cultures were maintained at $5 \mathrm{~mW} \mathrm{~m}^{-2}$ and $1 \mu \mathrm{mol} \mathrm{m}^{-2} \mathrm{~s}^{-1}$ or at $0 \mu \mathrm{mol} \mathrm{m}^{-2} \mathrm{~s}^{-1}$ (a) $-1^{\circ} \mathrm{C}$, (b) $2^{\circ} \mathrm{C}$ and (c) $5^{\circ} \mathrm{C}$. Error bars indicate standard error 


\section{A2.1.5 MAA production}

A repeated measures ANOVA was conducted with time as the 'within' factor and temperature and treatment as 'between' factors. This showed significant effects for time $(p=0.005)$ but the effects of time by temperature $(p=0.100)$, time by treatment $(p=0.823)$ and the three-way interaction between time, temperature and treatment was not significant $(\mathrm{p}=0.773)$ (Table A2.5). There was no significant change in photosynthetic efficiency at this UV-B level at $2^{\circ} \mathrm{C}$ and $5^{\circ} \mathrm{C}$. There was a significant increase (Bonferroni, $\mathrm{p}=0.006$ ) in MAA production for algae at $-1^{\circ} \mathrm{C}$. However, there was no difference between the algae at both exposure treatments.

Table A2.5 Changes in MAA production over $48 \mathrm{~h}$ experimental treatments at one UV-B level of $5 \mathrm{mWm}^{-2}$ and $1 \mu \mathrm{mol} \mathrm{m} \mathrm{m}^{-2} \mathrm{~s}^{-1}$; and $0 \mu \mathrm{mol} \mathrm{m} \mathrm{m}^{-2} \mathrm{~s}^{-1}$ at $-1^{\circ} \mathrm{C}, 2^{\circ} \mathrm{C}$ and $5^{\circ} \mathrm{C}$, analysed using a 2 factor repeated measures ANOVA. Significant changes identified by post hoc pairwise analyses are also listed.

\begin{tabular}{|llllll|}
\hline Source of variation & $\mathrm{df}$ & $\mathrm{MS}$ & $F$ & $\mathrm{p}$ & post hoc comparisons \\
\hline Within subjects & & & & & \\
Time & 1 & 0.011 & 9.342 & 0.005 & Increase over 48 $\mathrm{h}$ \\
Time x Temperature & 2 & 0.003 & 2.533 & 0.100 & \\
Time x Treatment & 1 & $6.285 \mathrm{E}-005$ & 0.051 & 0.823 & \\
Time x Temperature x Treatment & 2 & 0.000 & 0.260 & 0.773 & \\
Error & 24 & 0.001 & & & \\
& & & & & \\
Between subjects & & & & & \\
Temperature & 2 & 0.013 & 13.454 & $<0.001$ & $\left(-1^{\circ} \mathrm{C}=5^{\circ} \mathrm{C}\right)<2^{\circ} \mathrm{C}$ \\
Treatments & 1 & 0.001 & 0.832 & 0.371 & \\
Temperature x Treatment & 2 & 0.000 & 0.307 & 0.738 & \\
Error & 24 & 0.001 & & & \\
\hline
\end{tabular}


a)

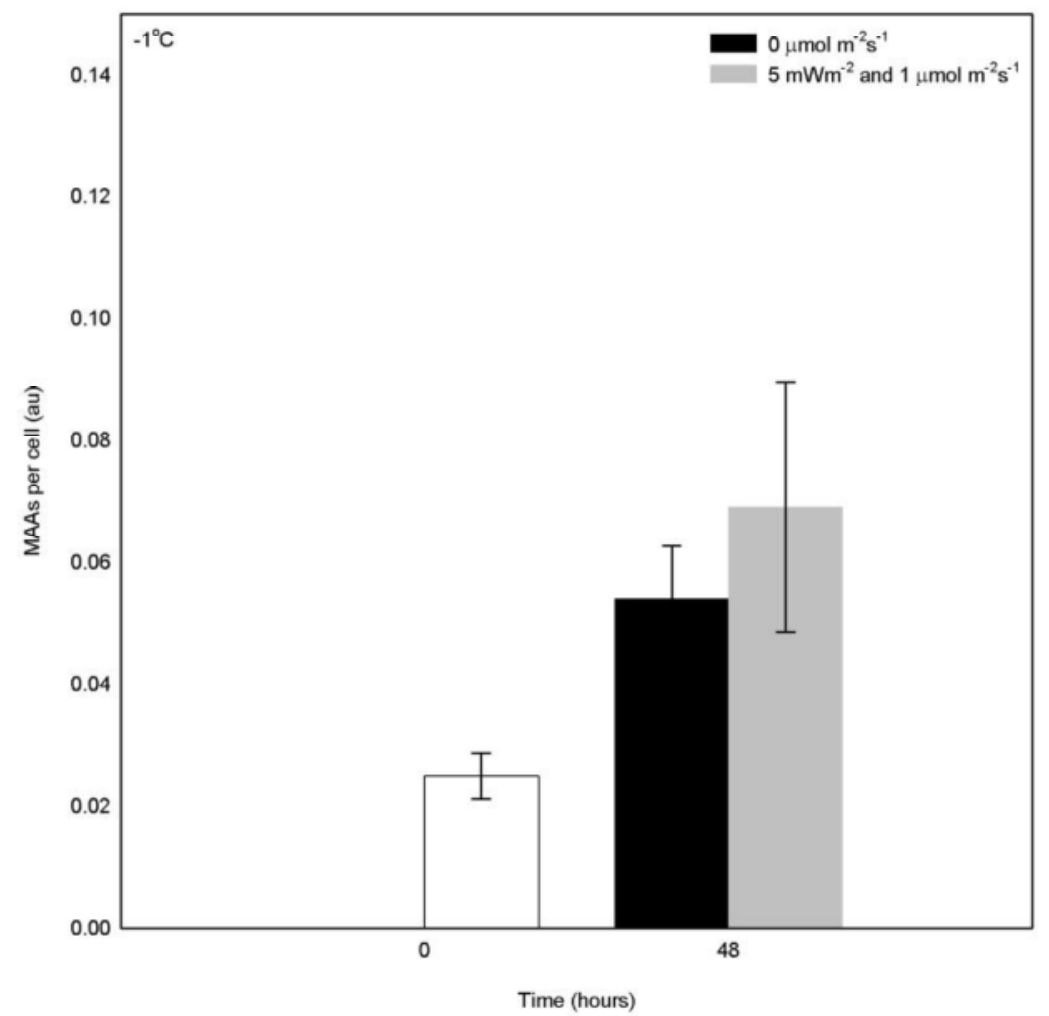

b)

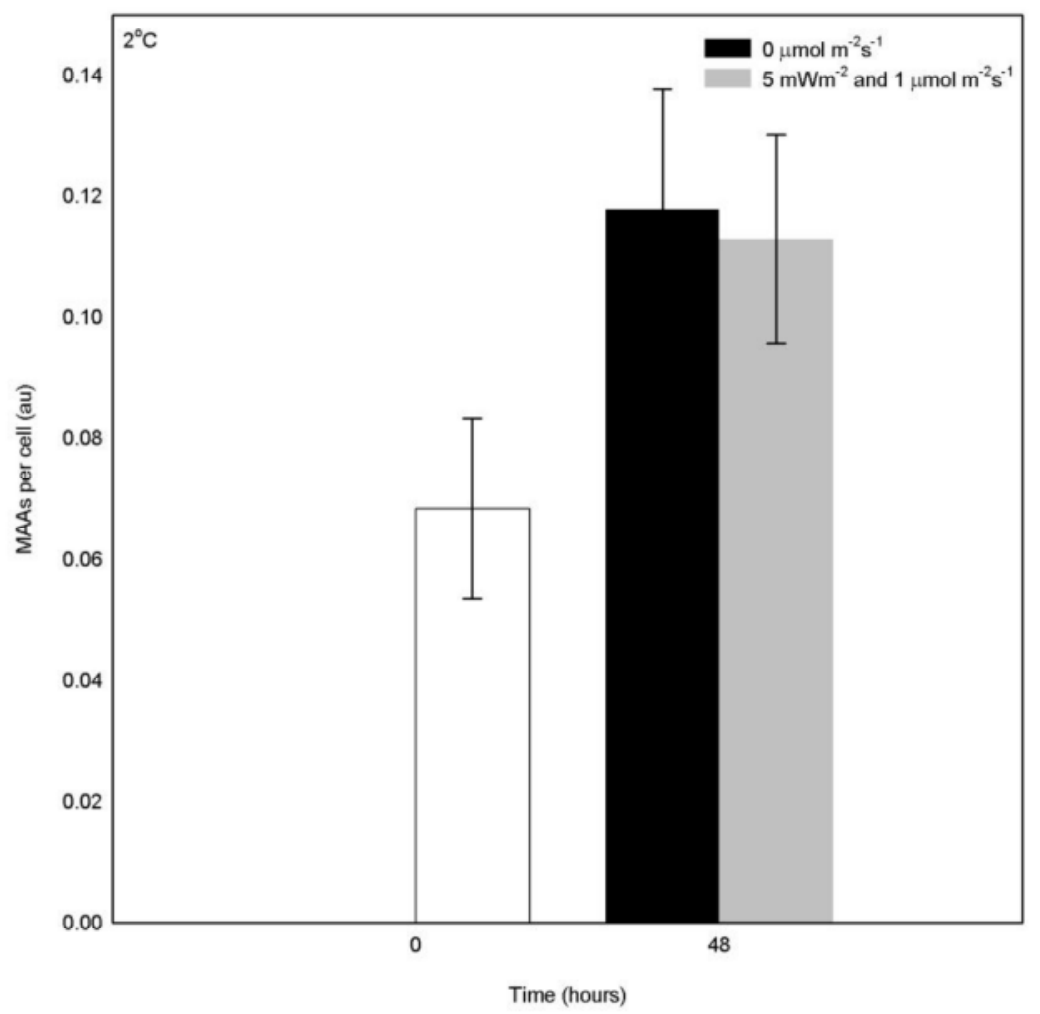




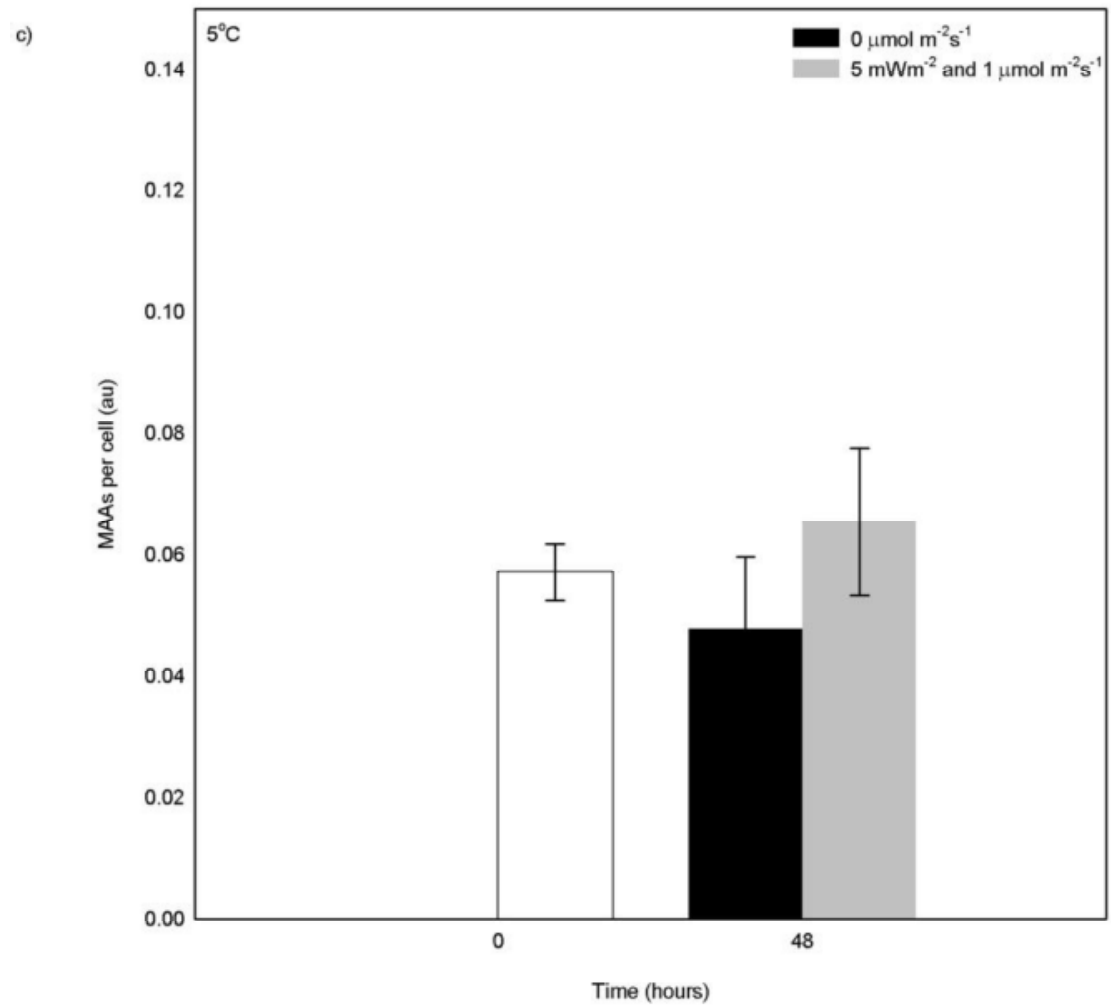

Fig A2.3. MAA production of bottom ice algae determined at 0 and $48 \mathrm{~h}$. Cultures were maintained at $5 \mathrm{~mW} \mathrm{~m} \mathrm{~m}^{-2} \mathrm{UV}-\mathrm{B}$ and a PAR level of $1 \mu \mathrm{mol} \mathrm{m} \mathrm{m}^{-2} \mathrm{~s}^{-1}$ at (a) $-1^{\circ} \mathrm{C}$, (b) $2^{\circ} \mathrm{C}$ and (c) $5^{\circ} \mathrm{C}$. Error bars indicate standard error.

\subsubsection{Exposure to UV-B level of $50 \mathrm{mWm}^{-2}$ at $2^{\circ} \mathrm{C}$}

A2.2 Exposure to $3 \mathrm{UV}$-B levels of 5,50 and $100 \mathrm{~mW} \mathrm{~m}^{-2}$ at $2^{\circ} \mathrm{C}$

\section{A2.2.1 Quantum Yield}

A repeated measures ANOVA was conducted with time as a 'within' factor and treatment as a 'between' factor. This showed significant effects of time $(p=0.030)$ and time by temperature $(\mathrm{p}=0.003)$ (Table 2.6). 
Table A2.6 Changes in quantum yield over $48 \mathrm{~h}$ experimental treatments at (a) UV-B level of $50 \mathrm{mWm}^{-2}$ and $1 \mu \mathrm{mol} \mathrm{m}^{-2} \mathrm{~s}^{-1}$; and $0 \mu \mathrm{mol} \mathrm{m}^{-2} \mathrm{~s}^{-1}$ and (b) UV-B level of $50 \mathrm{mWm}^{-}$ ${ }^{2}$ and $1 \mu \mathrm{mol} \mathrm{m}{ }^{-2} \mathrm{~s}^{-1}$; and $0 \mu \mathrm{mol} \mathrm{m}{ }^{-2} \mathrm{~s}^{-1}$ at $2^{\circ} \mathrm{C}$, analysed using a repeated measures ANOVA. Significant changes identified by post hoc pairwise analyses are also listed.

\begin{tabular}{|llllll|}
\hline Source of & $\mathrm{df}$ & $\mathrm{MS}$ & $F$ & $\mathrm{p}$ & post hoc comparisons \\
\hline Within subjects & & & & & \\
Time & 3.773 & 0.01 & 2.85 & 0.03 & No change over $48 \mathrm{~h}$ \\
Time x Treatment & 11.31 & 0.01 & 2.79 & 0.00 & \\
Error & 98.08 & 0.00 & & & \\
& & & & & \\
Between & & & & & \\
Treatments & 3 & 0.10 & 4.79 & 0.00 & $0 \mu \mathrm{mol} \mathrm{m}^{-2} \mathrm{~s}^{-1}=50 \mathrm{mWm}^{-2} ; 0 \mu \mathrm{mol} \mathrm{m}^{-2} \mathrm{~s}^{-1}=100$ \\
Error & 26 & 0.02 & & & \\
\hline
\end{tabular}

\section{A2.2.2 Relative ETR max}

A repeated measures ANOVA was conducted with time as a 'within' factor and treatment as a 'between' factor. This showed significant effects of time $(p=0.002)$ and time by temperature $(\mathrm{p}=0.005)$ (Table 2.7).

Table A2.7 Changes in $\mathrm{rETR}_{\max }$ over $48 \mathrm{~h}$ experimental treatments at (a) UV-B level of $50 \mathrm{mWm}^{-2}$ and $1 \mu \mathrm{mol} \mathrm{m}^{-2} \mathrm{~s}^{-1}$; and $0 \mu \mathrm{mol} \mathrm{m}^{-2} \mathrm{~s}^{-1}$ and (b) UV-B level of $50 \mathrm{mWm}^{-2}$ and 1 $\mu \mathrm{mol} \mathrm{m}{ }^{-2} \mathrm{~s}^{-1}$; and $0 \mu \mathrm{mol} \mathrm{m}^{-2} \mathrm{~s}^{-1}$ at $2^{\circ} \mathrm{C}$, analysed using a repeated measures ANOVA. Significant changes identified by post hoc pairwise analyses are also listed.

\begin{tabular}{|llllll|}
\hline Source of variation & $\mathrm{df}$ & $\mathrm{MS}$ & $F$ & $\mathrm{p}$ & post hoc comparisons \\
\hline Within subjects & & & & & \\
Time & 2.120 & 53.504 & 6.820 & 0.002 & No change over $48 \mathrm{~h}$ \\
Time x Treatment & 6.361 & 26.812 & 3.418 & 0.005 & \\
Error & 55.129 & 7.845 & & & \\
& & & & & \\
Between subjects & & & & & \\
Treatments & 3 & 77.656 & 4.164 & 0.016 & $0 \mu \mathrm{mol} \mathrm{m}^{-2} \mathrm{~s}^{-1}=50 \mathrm{mWm}^{-2}=100 \mathrm{mWm}^{-2}$ \\
Error & 26 & 18.649 & & & \\
\hline
\end{tabular}

\section{A2.2.3 MAA production}

A repeated measures ANOVA was conducted with time as a 'within' factor and treatment as a 'between' factor. This showed significant effects of time $(\mathrm{p}<0.001)$ but not for time by temperature $(\mathrm{p}=0.512)$ (Table 2.8$)$. 
Table A2.8 Changes in MAA production over $48 \mathrm{~h}$ experimental treatments at (a) UV-B level of $50 \mathrm{mWm}^{-2}$ and $1 \mu \mathrm{mol} \mathrm{m}^{-2} \mathrm{~s}^{-1}$; and $0 \mu \mathrm{mol} \mathrm{m}^{-2} \mathrm{~s}^{-1}$ and (b) UV-B level of $50 \mathrm{mWm}^{-}$ 2 and $1 \mu \mathrm{mol} \mathrm{m}{ }^{-2} \mathrm{~s}^{-1}$; and $0 \mu \mathrm{mol} \mathrm{m}^{-2} \mathrm{~s}^{-1}$ at $2^{\circ} \mathrm{C}$, analysed using a repeated measures ANOVA. Significant changes identified by post hoc pairwise analyses are also listed.

\begin{tabular}{|llllll|}
\hline Source of variation & $\mathrm{df}$ & $\mathrm{MS}$ & $F$ & $\mathrm{p}$ & post hoc comparisons \\
\hline Within subjects & & & & & \\
Time & 1 & 0.017 & 16.007 & $<0.001$ & Increase over $48 \mathrm{~h}$ \\
Time x Treatment & 3 & 0.001 & 0.788 & 0.512 & \\
Error & 26 & 0.001 & & & \\
& & & & & \\
Between subjects & & & & & \\
Treatments & 3 & 0.010 & 4.930 & 0.008 & $0 \mu \mathrm{mol} \mathrm{m}^{-2} \mathrm{~s}^{-1}=50 \mathrm{mWm}^{-2}=100 \mathrm{mWm}^{-2}$ \\
Error & 26 & 0.002 & & & \\
\hline
\end{tabular}

\section{A2.2.4 Photosynthetic Efficiency ( $\alpha$ )}

A repeated measures ANOVA was conducted with time as a 'within' factor and treatment as a 'between' factor. This showed no significant effects of time $(p=0.079)$ and time by temperature $(\mathrm{p}=0.059)$ (Table 2.9).

Table A2.9 Changes in photosynthetic efficiency over $48 \mathrm{~h}$ experimental treatments at (a) UV-B level of $50 \mathrm{mWm}^{-2}$ and $1 \mu \mathrm{mol} \mathrm{m}^{-2} \mathrm{~s}^{-1}$; and $0 \mu \mathrm{mol} \mathrm{m}^{-2} \mathrm{~s}^{-1}$ and (b) UV-B level of $50 \mathrm{mWm}^{-2}$ and $1 \mu \mathrm{mol} \mathrm{m}^{-2} \mathrm{~s}^{-1}$; and $0 \mu \mathrm{mol} \mathrm{m}^{-2} \mathrm{~s}^{-1}$ at $2^{\circ} \mathrm{C}$, analysed using a repeated measures ANOVA. Significant changes identified by post hoc pairwise analyses are also listed.

\begin{tabular}{|llllll|}
\hline Source of & $\mathrm{df}$ & $\mathrm{MS}$ & $F$ & $\mathrm{p}$ & post hoc comparisons \\
\hline Within subjects & & & & & \\
Time & 3.630 & 0.01 & 2.21 & 0.07 & No change over $48 \mathrm{~h}$ \\
Time x Treatment & 10.88 & 0.01 & 1.83 & 0.05 & \\
Error & 94.37 & 0.00 & & & \\
& & & & & \\
Between & & & & & \\
Treatments & 3 & 0.11 & 4.16 & 0.01 & $5 \mathrm{mWm}^{-2}>\left(0 \mu \mathrm{mol} \mathrm{m}^{-2} \mathrm{~s}^{-1}=50 \mathrm{mWm}^{-2}=100\right.$ \\
Error & 26 & 0.02 & & & \\
\hline
\end{tabular}




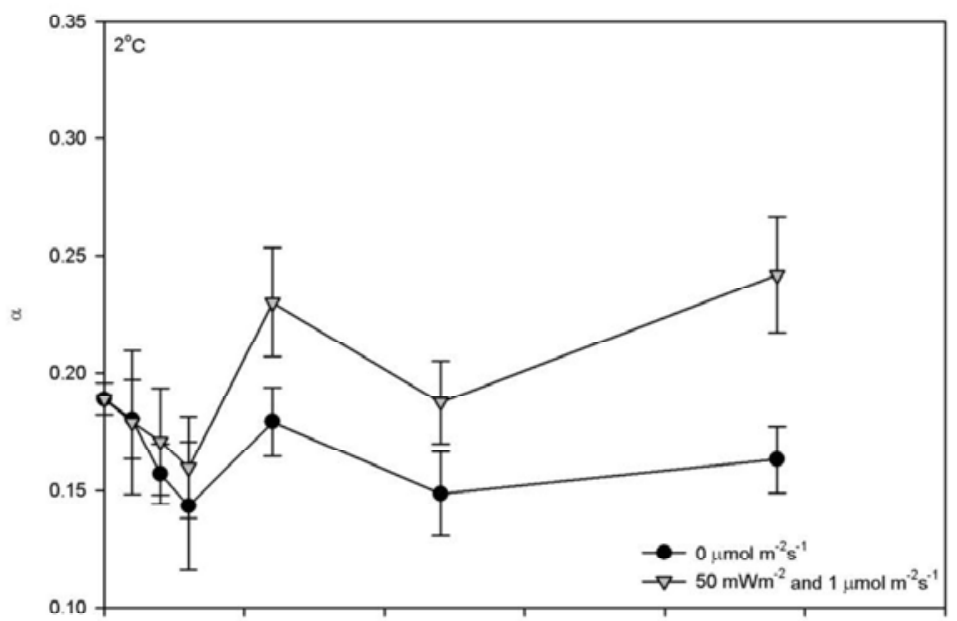

b)

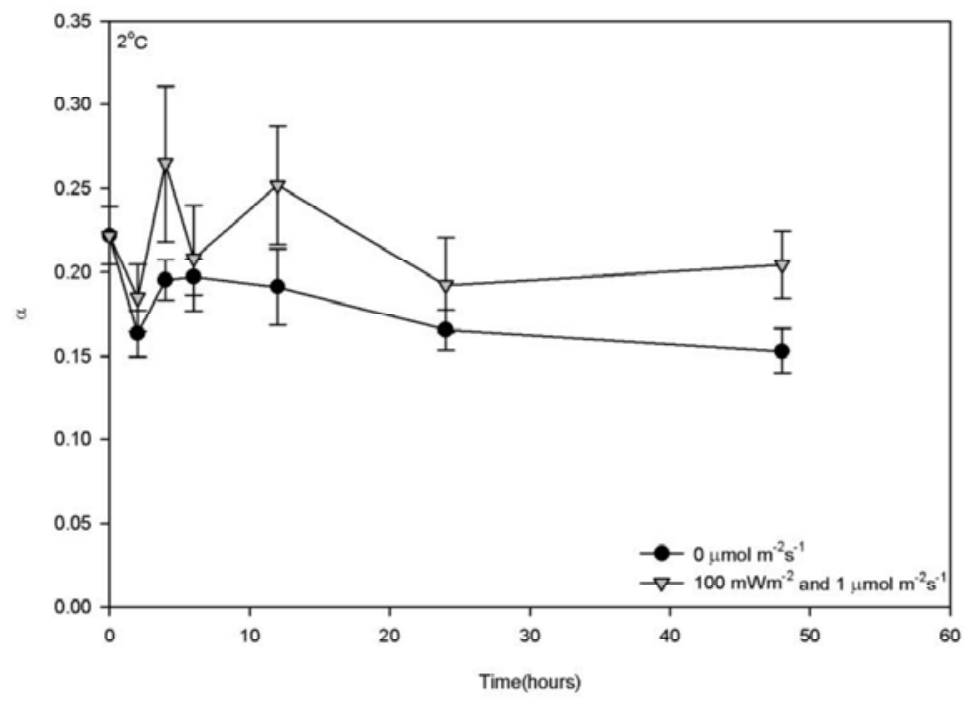

Figure A2.4. Photosynthetic efficiency ( $\alpha$ ) of bottom ice algae at $0,2,4,6,12,24$ and 48 h. Cultures were maintained at (a) $50 \mathrm{~mW} \mathrm{~m}^{-2} \mathrm{UV}-\mathrm{B}$ and a PAR level of $1 \mu \mathrm{mol} \mathrm{m}^{-2} \mathrm{~s}^{-1}$ or at $0 \mu \mathrm{mol} \mathrm{m} \mathrm{m}^{-2} \mathrm{~s}^{-1}$ and (b) $100 \mathrm{~mW} \mathrm{~m}^{-2} \mathrm{UV}-\mathrm{B}$ and a PAR level of $1 \mu \mathrm{mol} \mathrm{m} \mathrm{m}^{-2} \mathrm{~s}^{-1}$ or at $0 \mu \mathrm{mol}$ $\mathrm{m}^{-2} \mathrm{~s}^{-1}$. Error bars indicate standard error.

\section{A2.2.5 Saturation irradiance $\left(E_{\mathrm{k}}\right)$}

A repeated measures ANOVA was conducted with time as a 'within' factor and treatment as a 'between' factor. This showed significant effects of time $(p=0.015)$ and time by temperature $(\mathrm{p}=0.010)$ (Table 2.10$)$. However the post hoc tests showed no significance. 
Table A2.10 Changes in saturation irradiance over $48 \mathrm{~h}$ experimental treatments at (a) UV-B level of $50 \mathrm{mWm}^{-2}$ and $1 \mu \mathrm{mol} \mathrm{m}^{-2} \mathrm{~s}^{-1}$; and $0 \mu \mathrm{mol} \mathrm{m}^{-2} \mathrm{~s}^{-1}$ and (b) UV-B level of 50 $\mathrm{mWm}^{-2}$ and $1 \mu \mathrm{mol} \mathrm{m}^{-2} \mathrm{~s}^{-1}$; and $0 \mu \mathrm{mol} \mathrm{m}^{-2} \mathrm{~s}^{-1}$ at $2^{\circ} \mathrm{C}$, analysed using a repeated measures ANOVA. Significant changes identified by post hoc pairwise analyses are also listed.

\begin{tabular}{|llllll|}
\hline Source of variation & $\mathrm{df}$ & $\mathrm{MS}$ & $F$ & $\mathrm{p}$ & post hoc comparisons \\
\hline Within subjects & & & & & \\
Time & 3.390 & 301.052 & 3.515 & 0.015 & No change over $48 \mathrm{~h}$ \\
Time x Treatment & 10.171 & 214.764 & 2.507 & 0.010 & \\
Error & 88.146 & 85.654 & & & \\
& & & & & \\
Between subjects & & & & & \\
Treatments & 3 & 65.507 & 1.093 & 0.370 & \\
Error & 26 & 59.916 & & & \\
\hline
\end{tabular}


a)

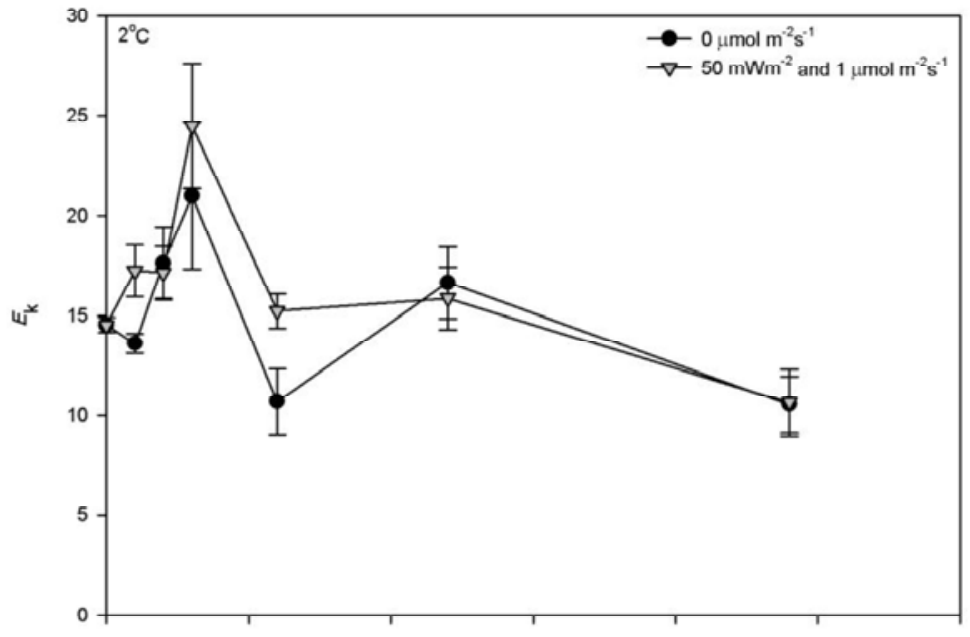

b)

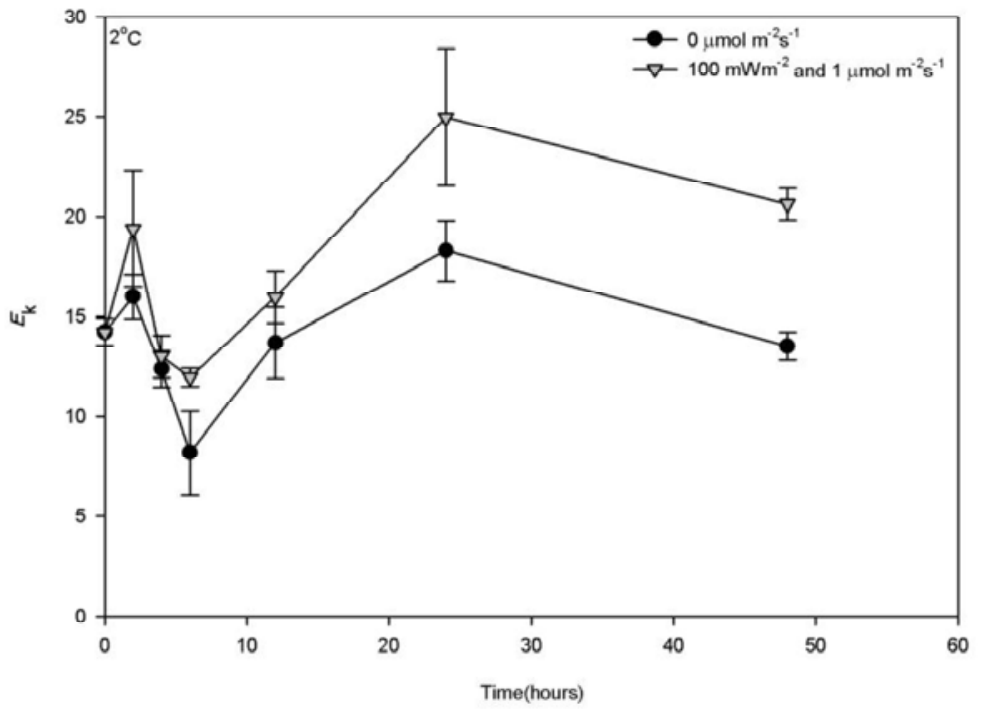

Figure A2.5. Saturation irradiance $\left(E_{\mathrm{k}}\right)$ of bottom ice algae at $0,2,4,6,12,24$ and $48 \mathrm{~h}$. Cultures were maintained at (a) $50 \mathrm{~mW} \mathrm{~m}^{-2} \mathrm{UV}-\mathrm{B}$ and a PAR level of $1 \mu \mathrm{mol} \mathrm{m}^{-2} \mathrm{~s}^{-1}$ or at 0 $\mu \mathrm{mol} \mathrm{m}{ }^{-2} \mathrm{~s}^{-1}$ and (b) $100 \mathrm{~mW} \mathrm{~m}^{-2} \mathrm{UV}-\mathrm{B}$ and a PAR level of $1 \mu \mathrm{mol} \mathrm{m} \mathrm{m}^{-2} \mathrm{~s}^{-1}$ or at $0 \mu \mathrm{mol} \mathrm{m}^{-2}$ $\mathrm{s}^{-1}$. Error bars indicate standard error. 


\section{APPENDIX 3}

\section{Additional data from Chapter 4}

\section{A3.1 Effect of different PAR levels on Thalassiosira sp. and Fragilariopsis sp.}

\section{A3.1.1 Quantum Yield}

Initially a repeated measures ANOVA was conducted with time as the 'within' factor and temperature and treatment as 'between' factors. This showed significant effects of time $(\mathrm{p}<0.001)$, time by species $(\mathrm{p}<0.001)$, time by treatment $(\mathrm{p}<0.001)$ and the three-way interaction between time, species and treatment $(\mathrm{p}=0.002)$ (Table A3.1).

Table A3.1 Changes in quantum yield of Photosystem II over $48 \mathrm{~h}$ experimental treatments at different PAR levels $\left(0,1,45\right.$ and $\left.100 \mu \mathrm{mol} \mathrm{m}^{-2} \mathrm{~s}^{-1}\right)$ at $4^{\circ} \mathrm{C}$, analysed using a 2 factor repeated measures ANOVA. Significant changes identified by post hoc pairwise analyses are also listed.

\begin{tabular}{|llllll|}
\hline Source of variation & $\mathrm{df}$ & $\mathrm{MS}$ & $F$ & $\mathrm{p}$ & post hoc comparisons \\
\hline & & & & & \\
Within subjects & & & & & \\
Time & 2.304 & 0.114 & 145.909 & $<0.001$ & Increase over $48 \mathrm{~h}$ \\
Time x Species & 2.304 & 0.009 & 12.174 & $<0.001$ & \\
Time x Treatment & 6.913 & 0.020 & 26.314 & $<0.001$ & \\
Time x Species x Treatment & 6.913 & 0.003 & 4.246 & 0.002 & \\
Error & 36.867 & 0.001 & & & \\
& & & & & \\
Between subjects & & & & & \\
Species & 1 & 0.001 & 0.397 & 0.537 & Not performed because there are \\
Treatments & 3 & 0.110 & 40.898 & $<0.001$ & fewer than 3 groups. \\
Species x Treatment & 3 & 0.033 & 12.367 & $<0.001$ & \\
Error & 48 & 0.017 & & & \\
& & & & & \\
\hline
\end{tabular}




\section{A3.1.2 rETR $_{\text {max }}$}

Initially a repeated measures ANOVA was conducted with time as the 'within' factor and temperature and treatment as 'between' factors. This showed significant effects of time $(\mathrm{p}<0.001)$, time by species $(\mathrm{p}<0.001)$, time by treatment $(\mathrm{p}<0.001)$ and the three-way interaction between time, species and treatment $(\mathrm{p}<0.001)$ (Table A3.2).

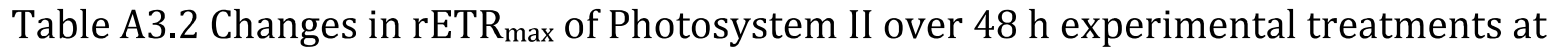
different PAR levels $\left(0,1,45\right.$ and $\left.100 \mu \mathrm{mol} \mathrm{m} \mathrm{m}^{-2} \mathrm{~s}^{-1}\right)$ at $4{ }^{\circ} \mathrm{C}$, analysed using a 2 factor repeated measures ANOVA. Significant changes identified by post hoc pairwise analyses are also listed.

\begin{tabular}{|llllll|}
\hline Source of variation & $\mathrm{df}$ & $\mathrm{MS}$ & $F$ & $\mathrm{p}$ & post hoc comparisons \\
\hline & & & & & \\
Within subjects & & & & & \\
Time & 1.866 & 85.112 & 38.872 & $<0.001$ & Increase over $48 \mathrm{~h}$ \\
Time x Species & 1.866 & 81.446 & 37.197 & $<0.001$ & \\
Time x Treatment & 5.598 & 65.487 & 29.909 & $<0.001$ & \\
Time x Species x Treatment & 5.598 & 25.198 & 11.508 & $<0.001$ & \\
Error & 29.855 & 2.190 & & & \\
& & & & & \\
Between subjects & & & & & \\
Species & 1 & 68.162 & 20.722 & $<0.001$ & Not performed because there are \\
Treatments & 3 & 30.906 & 9.396 & 0.001 & fewer than 3 groups. \\
Species x Treatment & 3 & 26.403 & 8.027 & 0.002 & \\
Error & 16 & 3.289 & & & \\
& & & & & \\
\hline
\end{tabular}




\section{A3.1.3 MAAs}

Initially a repeated measures ANOVA was conducted with time as the 'within' factor and temperature and treatment as 'between' factors. This showed significant effects of time $(\mathrm{p}<0.001)$, time by treatment $(\mathrm{p}<0.001)$ and the three-way interaction between time, species and treatment $(\mathrm{p}=0.031)$ (Table A3.4). The interaction between time and species was not significant $(\mathrm{p}=0.10)$.

Table A3.3 Changes in MAA production over $48 \mathrm{~h}$ experimental treatments at different PAR levels $\left(0,1,45\right.$ and $\left.100 \mu \mathrm{mol} \mathrm{m}^{-2} \mathrm{~s}^{-1}\right)$ at $4^{\circ} \mathrm{C}$, analysed using a 2 factor repeated measures ANOVA. Significant changes identified by post hoc pairwise analyses are also listed.

\begin{tabular}{|llllll|}
\hline Source of variation & df & MS & $F$ & $\mathrm{p}$ & post hoc comparisons \\
\hline Within subjects & & & & & \\
Time & 1 & $6.330 \mathrm{E}-009$ & 41.233 & $<0.001$ & Decrease over 48h \\
Time x Species & 1 & $5.714 \mathrm{E}-010$ & 3.722 & 0.072 & \\
Time x Treatment & 3 & $3.570 \mathrm{E}-010$ & 2.325 & 0.114 & \\
Time x Species x Treatment & 3 & $1.552 \mathrm{E}-010$ & 0.991 & 0.422 & \\
Error & 16 & $1.535 \mathrm{E}-010$ & & & \\
& & & & & \\
Between subjects & & & & & \\
Species & 1 & $8.374 \mathrm{E}-009$ & 68.168 & $<0.001$ & Not performed because there are \\
Treatments & 3 & $1.029 \mathrm{E}-010$ & 0.838 & 0.493 & fewer than 3 groups. \\
Species x Treatment & 3 & $9.854 \mathrm{E}-012$ & 0.080 & 0.970 & \\
Error & 16 & $1.228 \mathrm{E}-010$ & & & \\
& & & & & \\
\hline
\end{tabular}




\section{A3.1.4 Photosynthetic Efficiency $(\alpha)$}

Initially a repeated measures ANOVA was conducted with time as the 'within' factor and temperature and treatment as 'between' factors. This showed significant effects of time $(\mathrm{p}<0.001)$ and time by species $(\mathrm{p}=0.004)$. However the interaction between time by treatment $(p=0.423)$ and the three-way interaction between time, species and treatment ( $p=0.362$ ) were not significant (Table A3.4).

Table A3.4 Changes in $\alpha$ of Photosystem II over $48 \mathrm{~h}$ experimental treatments at different PAR levels $\left(0,1,45\right.$ and $\left.100 \mu \mathrm{mol} \mathrm{m}^{-2} \mathrm{~s}^{-1}\right)$ at $4^{\circ} \mathrm{C}$, analysed using a 2 factor repeated measures ANOVA. Significant changes identified by post hoc pairwise analyses are also listed.

\begin{tabular}{|llllll|}
\hline Source of variation & $\mathrm{df}$ & MS & $F$ & $\mathrm{p}$ & post hoc comparisons \\
\hline Within subjects & & & & & \\
Time & & & & & \\
Time x Species & 1.627 & 0.253 & 19.466 & $<0.001$ & No change over 48h \\
Time x Treatment & 1.627 & 0.099 & 7.616 & 0.004 & \\
Time x Species x Treatment & 4.881 & 0.013 & 1.024 & 0.423 & \\
Error & 4.881 & 0.015 & 1.144 & 0.362 & \\
& 26.031 & 0.013 & & & \\
Between subjects & & & & & \\
Species & & & & & \\
Treatments & 1 & 0.127 & 3.559 & 0.077 & Not performed because there are \\
Species x Treatment & 3 & 0.001 & 0.031 & 0.992 & fewer than 3 groups. \\
Error & 3 & 0.035 & 0.987 & 0.424 & \\
& 16 & 0.036 & & & \\
\hline
\end{tabular}


a)

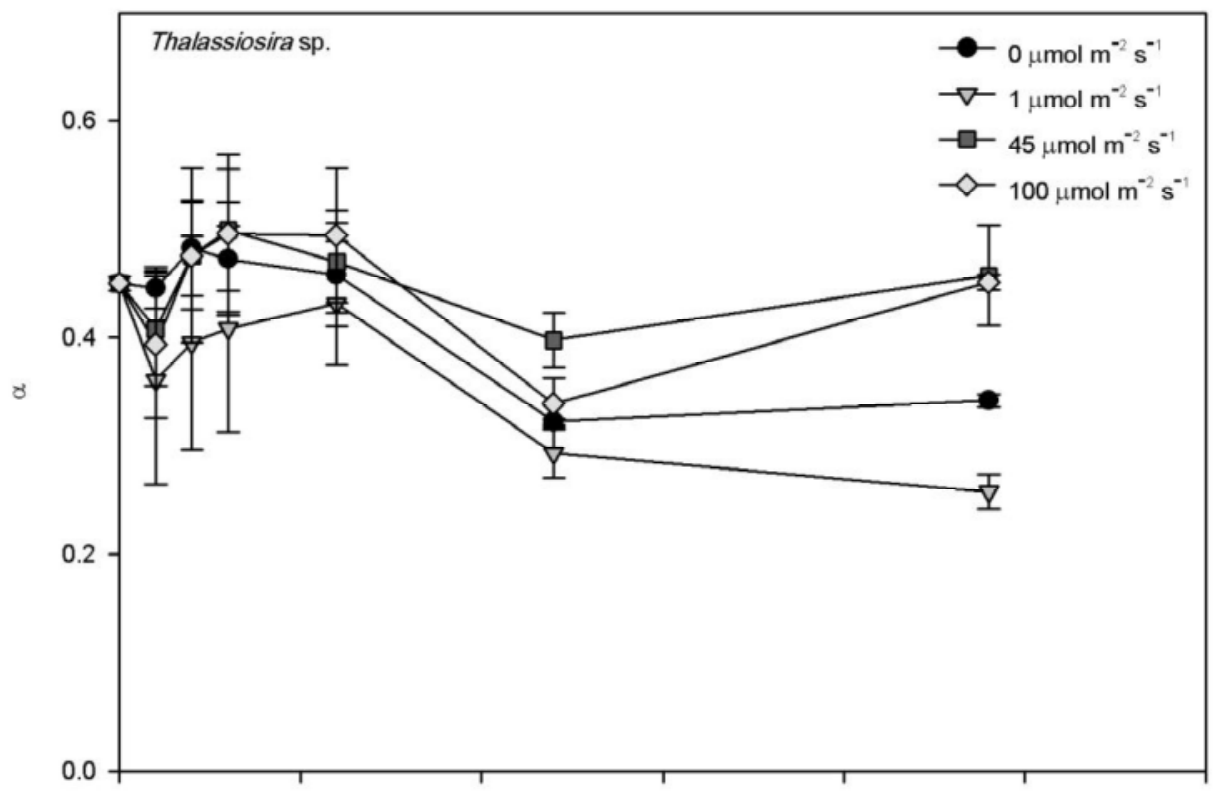

b)

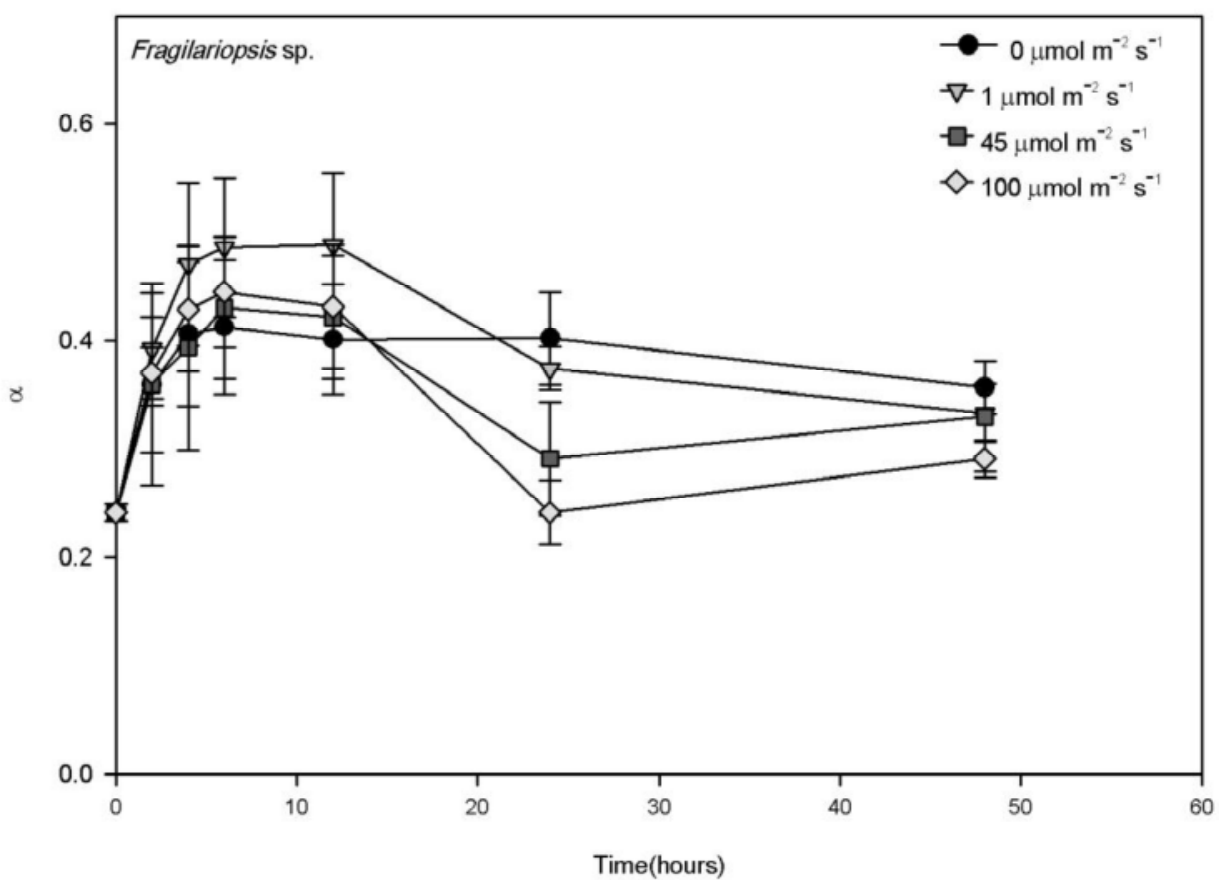

Fig A3.1. Photosynthetic efficiency ( $\alpha$ ) determined at $0,2,4,6,12,24$ and 48 h. Cultures were maintained at PAR levels of $0,1,45$ or $100 \mu \mathrm{mol} \mathrm{m}^{-2} \mathrm{~s}^{-1}$ for (a) Thalassiosira sp. and (b) Fragilariopsis sp. Error bars indicate standard error. 


\section{A3. Saturation irradiance $\left(E_{\mathrm{k}}\right)$}

Initially a repeated measures ANOVA was conducted with time as the 'within' factor and temperature and treatment as 'between' factors. This showed significant effects of time ( $\mathrm{p}<0.001)$, time by treatment $(\mathrm{p}<0.001)$ and the three-way interaction between time, species and treatment ( $\mathrm{p}=0.031$ ) (Table A3.5). The interaction between time and species was not significant $(\mathrm{p}=0.10)$.

Table A3.5 Changes in $E_{\mathrm{k}}$ of Photosystem II over $48 \mathrm{~h}$ experimental treatments at different PAR levels $\left(0,1,45\right.$ and $\left.100 \mu \mathrm{mol} \mathrm{m}^{-2} \mathrm{~s}^{-1}\right)$ at $4^{\circ} \mathrm{C}$, analysed using a 2 factor repeated measures ANOVA. Significant changes identified by post hoc pairwise analyses are also listed.

\begin{tabular}{|llllll|}
\hline Source of variation & $\mathrm{df}$ & $\mathrm{MS}$ & $F$ & $\mathrm{p}$ & post hoc comparisons \\
\hline Within subjects & & & & & \\
Time & & & & & \\
Time x Species & 2.821 & 665.347 & 95.551 & $<0.001$ & No change over 48h \\
Time x Treatment & 2.821 & 15.593 & 2.239 & 0.10 & \\
Time x Species x Treatment & 8.464 & 160.467 & 23.045 & $<0.001$ & \\
Error & 8.464 & 16.360 & 2.349 & 0.031 & \\
& 45.139 & 6.963 & & & \\
Between subjects & & & & & \\
Species & & & & & \\
Treatments & 1 & 1.686 & 0.228 & 0.639 & Not performed because there are \\
Species x Treatment & 3 & 158.689 & 21.489 & $<0.001$ & fewer than 3 groups. \\
Error & 3 & 17.577 & 2.380 & 0.108 & \\
& 16 & 7.385 & & & \\
\hline
\end{tabular}


a)

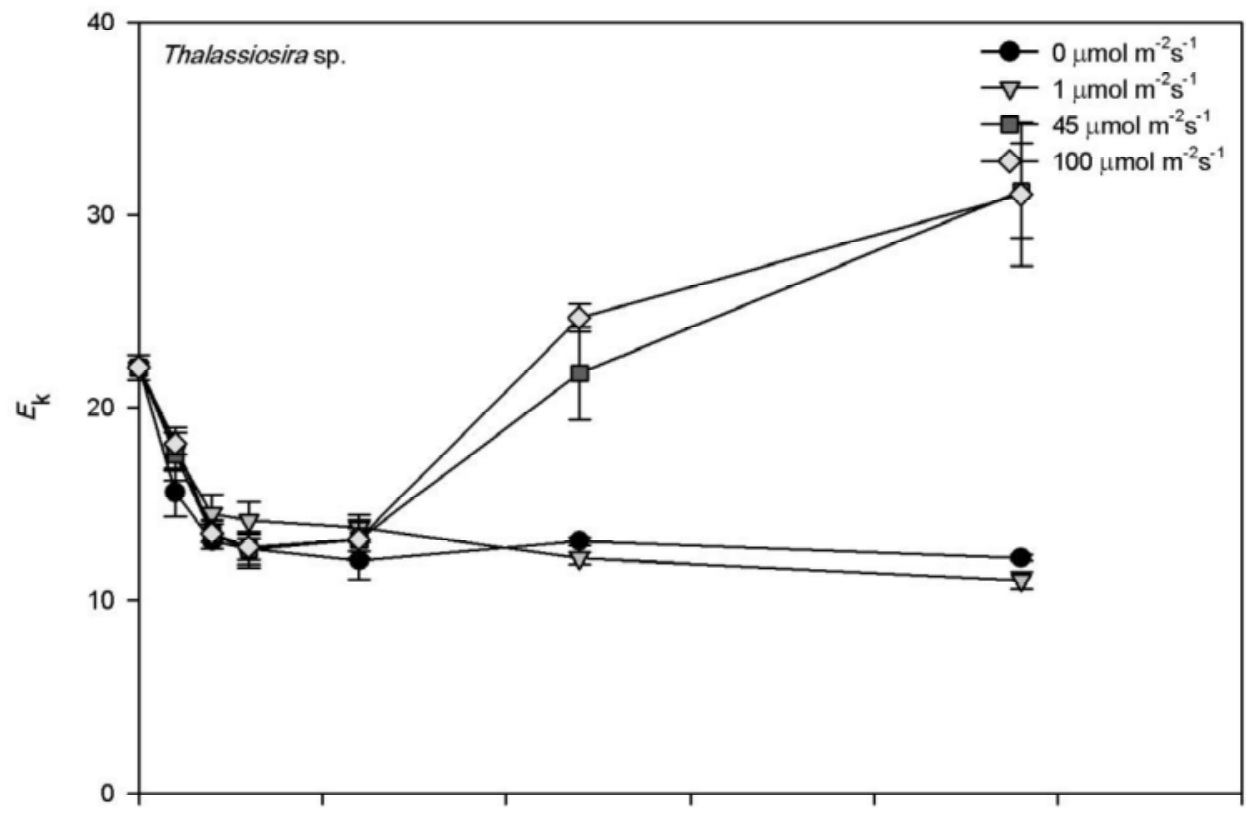

b)

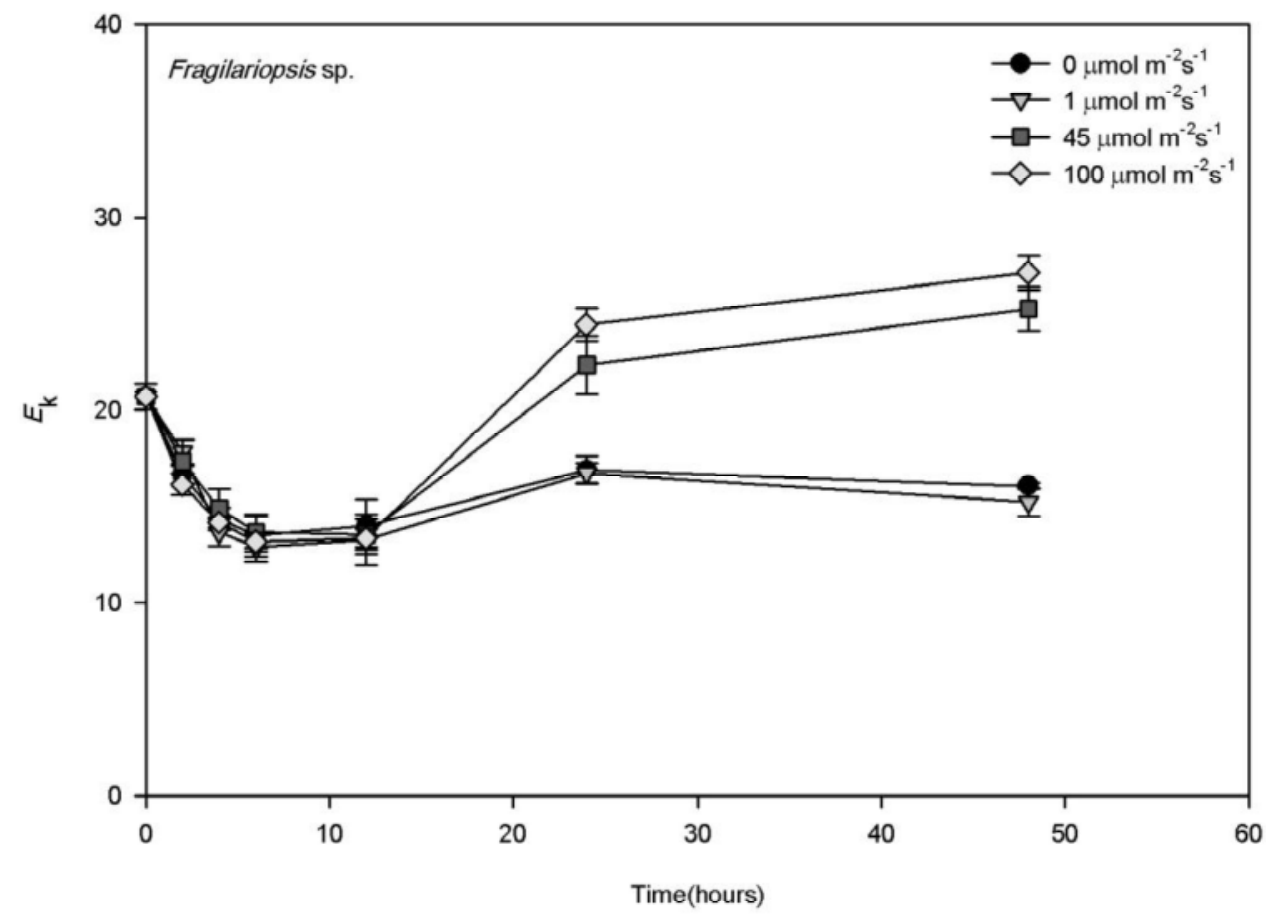

Fig A3.2. Saturation irradiance $\left(E_{\mathrm{k}}\right)$ determined at $0,2,4,6,12,24$ and $48 \mathrm{~h}$. Cultures were maintained at PAR levels of $0,1,45$ or $100 \mu \mathrm{mol} \mathrm{m}^{-2} \mathrm{~s}^{-1}$ for (a) Thalassiosira sp. and (b) Fragilariopsis sp. Error bars indicate standard error. 


\section{A3.2 Effect of UV-B exposure on Thalassiosira sp. and Fragilariopsis sp.}

\section{A3.2.1 Quantum Yield}

Initially a repeated measures ANOVA was conducted with time as the 'within' factor and temperature and treatment as 'between' factors. This showed significant effects of time $(p<0.001)$, time by species $(p<0.001)$, time by treatment $(p<0.001)$ and the three-way interaction between time, species and treatment $(p<0.001)$ (Table A3.6).

Table A3.6 Changes in Quantum Yield of Photosystem II over $48 \mathrm{~h}$ experimental treatments at different UV-B levels $\left(0,50\right.$ and $\left.150 \mathrm{mWm}^{-2}\right)$ and a PAR level of $1 \mu \mathrm{mol} \mathrm{m}$ ${ }^{2} \mathrm{~s}^{-1}$ at $4^{\circ} \mathrm{C}$, analysed using a 2 factor repeated measures ANOVA. Significant changes identified by post hoc pairwise analyses are also listed.

\begin{tabular}{|llllll|}
\hline Source of variation & $\mathrm{df}$ & $\mathrm{MS}$ & $F$ & $\mathrm{p}$ & post hoc comparisons \\
\hline Within subjects & & & & & \\
Time & & & & & \\
Time x Species & 3.175 & 0.012 & 190.87 & $<0.00$ & Increase over $48 \mathrm{~h}$ \\
Time x Treatment & 6.175 & 0.010 & 155.10 & $<0.00$ & \\
Time x Species x & 6.350 & 0.005 & 79.217 & $<0.00$ & \\
Error & 6.350 & 0.001 & 17.318 & $<0.00$ & \\
& 57.14 & $6.160 \mathrm{E}-$ & & & \\
Between subjects & & & & & \\
Species & & & & & \\
Treatments & 1 & 0.170 & 550.40 & $<0.00$ & Not performed because there \\
Species x Treatment & 2 & 0.011 & 34.129 & $<0.00$ & fewer than 3 groups. \\
Error & 2 & 0.002 & 5.303 & 0.015 & \\
& 18 & 0.000 & & & \\
\hline
\end{tabular}




\section{A3.2.2 rETR $_{\text {max }}$}

Initially a repeated measures ANOVA was conducted with time as the 'within' factor and temperature and treatment as 'between' factors. This showed significant effects of time $(\mathrm{p}<0.001)$, time by species $(\mathrm{p}<0.001)$, time by treatment $(\mathrm{p}<0.001)$ but the three-way interaction between time, species and treatment was not significant $(p=0.415)$ (Table A3.7).

Table A3.7 Changes in rETR $_{\max }$ of Photosystem II over $48 \mathrm{~h}$ experimental treatments at different UV-B levels $\left(0,50\right.$ and $\left.150 \mathrm{mWm}^{-2}\right)$ and a PAR level of $1 \mu \mathrm{mol} \mathrm{m}^{-2} \mathrm{~s}^{-1}$ at $4^{\circ} \mathrm{C}$, analysed using a 2 factor repeated measures ANOVA. Significant changes identified by post hoc pairwise analyses are also listed.

\begin{tabular}{|llllll|}
\hline Source of variation & $\mathrm{df}$ & $\mathrm{MS}$ & $F$ & $\mathrm{p}$ & post hoc comparisons \\
\hline Within subjects & & & & & \\
Time & & & & & \\
Time x Species & 1.909 & 44.065 & 76.579 & $<0.001$ & Decrease over 48h \\
Time x Treatment & 1.909 & 31.574 & 54.870 & $<0.001$ & \\
Time x Species x Treatment & 3.817 & 4.490 & 7.804 & $<0.001$ & \\
Error & 3.817 & 0.579 & 1.006 & $<0.001$ & \\
& 34.355 & 0.575 & & & \\
Between subjects & & & & & \\
Species & & & & & \\
Treatments & 1 & 188.256 & 852.388 & $<0.001$ & Not performed because there are \\
Species x Treatment & 2 & 6.558 & 29.692 & $<0.001$ & fewer than 3 groups. \\
Error & 2 & 1.213 & 5.493 & 0.014 & \\
& 18 & 0.221 & & & \\
\hline
\end{tabular}




\section{A4.3.3 MAAs}

Initially a repeated measures ANOVA was conducted with time as the 'within' factor and temperature and treatment as 'between' factors. This showed significant effects of time $(\mathrm{p}<0.001)$. However, time by species ( $\mathrm{p}=0.062)$, time by treatment ( $\mathrm{p} 0.368)$ and the three-way interaction between time, species and treatment $(0.511)$ were not significant (Table A3.8).

Table A3.8 Changes in MAA production over $48 \mathrm{~h}$ experimental treatments at different UV-B levels (0, 50 and $\left.150 \mathrm{mWm}^{-2}\right)$ and a PAR level of $1 \mu \mathrm{mol} \mathrm{m}^{-2} \mathrm{~s}^{-1}$ at $4^{\circ} \mathrm{C}$, analysed using a 2 factor repeated measures ANOVA. Significant changes identified by post hoc pairwise analyses are also listed.

\begin{tabular}{|llllll|}
\hline Source of variation & df & MS & $F$ & $\mathrm{p}$ & post hoc comparisons \\
\hline Within subjects & & & & & \\
Time & 1 & $4.797 \mathrm{E}-009$ & 72.519 & $<0.001$ & Increase over $48 \mathrm{~h}$ \\
Time x Species & 1 & $1.401 \mathrm{E}-010$ & 2.118 & 0.163 & \\
Time x Treatment & 2 & $5.235 \mathrm{E} 010$ & 7.914 & 0.003 & \\
Time x Species x Treatment & 2 & $1.530 \mathrm{E}-010$ & 2.313 & 0.128 & \\
Error & 18 & $6.614 \mathrm{E}-011$ & & & \\
& & & & & \\
Between subjects & & & & & \\
Species & 1 & $54.485 \mathrm{E}-009$ & 91.781 & $<0.001$ & Not performed because there are \\
Treatments & 2 & $1.140 \mathrm{E}-010$ & 1.907 & 0.177 & fewer than 3 groups. \\
Species x Treatment & 2 & $1.796 \mathrm{E}-011$ & 0.300 & 0.744 & \\
Error & 18 & $5.977 \mathrm{E}-011$ & & & \\
& & & & & \\
\hline
\end{tabular}




\section{A3.2.4 Photosynthetic Efficiency $(\alpha)$}

Initially a repeated measures ANOVA was conducted with time as the 'within' factor and temperature and treatment as 'between' factors. This showed significant effects of time $(\mathrm{p}<0.001)$, time by species $(\mathrm{p}<0.001)$, time by treatment $(\mathrm{p}<0.001)$ but the three-way interaction between time, species and treatment was not significant $(p=0.124)$ (Table A3.9).

Table A3.9 Changes in Photosynthetic Efficiency of Photosystem II over $48 \mathrm{~h}$ experimental treatments at different UV-B levels $\left(0,50\right.$ and $\left.150 \mathrm{mWm}^{-2}\right)$ and a PAR level of $1 \mu \mathrm{mol} \mathrm{m}{ }^{-2} \mathrm{~s}^{-1}$ at $4^{\circ} \mathrm{C}$, analysed using a 2 factor repeated measures ANOVA. Significant changes identified by post hoc pairwise analyses are also listed.

\begin{tabular}{|llllll|}
\hline Source of variation & $\mathrm{df}$ & $\mathrm{MS}$ & $F$ & $\mathrm{p}$ & post hoc comparisons \\
\hline Within subjects & & & & & \\
Time & & & & & \\
Time x Species & 3.321 & 0.051 & 34.330 & $<0.00$ & Increase over $48 \mathrm{~h}$ \\
Time x Treatment & 3.321 & 0.016 & 10.832 & $<0.00$ & \\
Time x Species x & 6.643 & 0.014 & 9.766 & $<0.00$ & \\
Error & 6.643 & 0.003 & 1.726 & 0.124 & \\
& 59.78 & 0.001 & & & \\
Between subjects & & & & & \\
Species & 1 & 1.593 & 763.25 & $<0.00$ & Not performed because there \\
Treatments & 2 & 0.009 & 4.146 & 0.033 & fewer than 3 groups. $^{-2}$ \\
Species x Treatment & 2 & $3.988 \mathrm{E}-$ & 0.019 & 0.981 & $0=150 \mathrm{~mW} \mathrm{~m}^{-2}$ \\
Error & 18 & 0.002 & & & $50>150 \mathrm{~mW} \mathrm{~m}^{-2}$ \\
& & & & & \\
\hline
\end{tabular}


a)

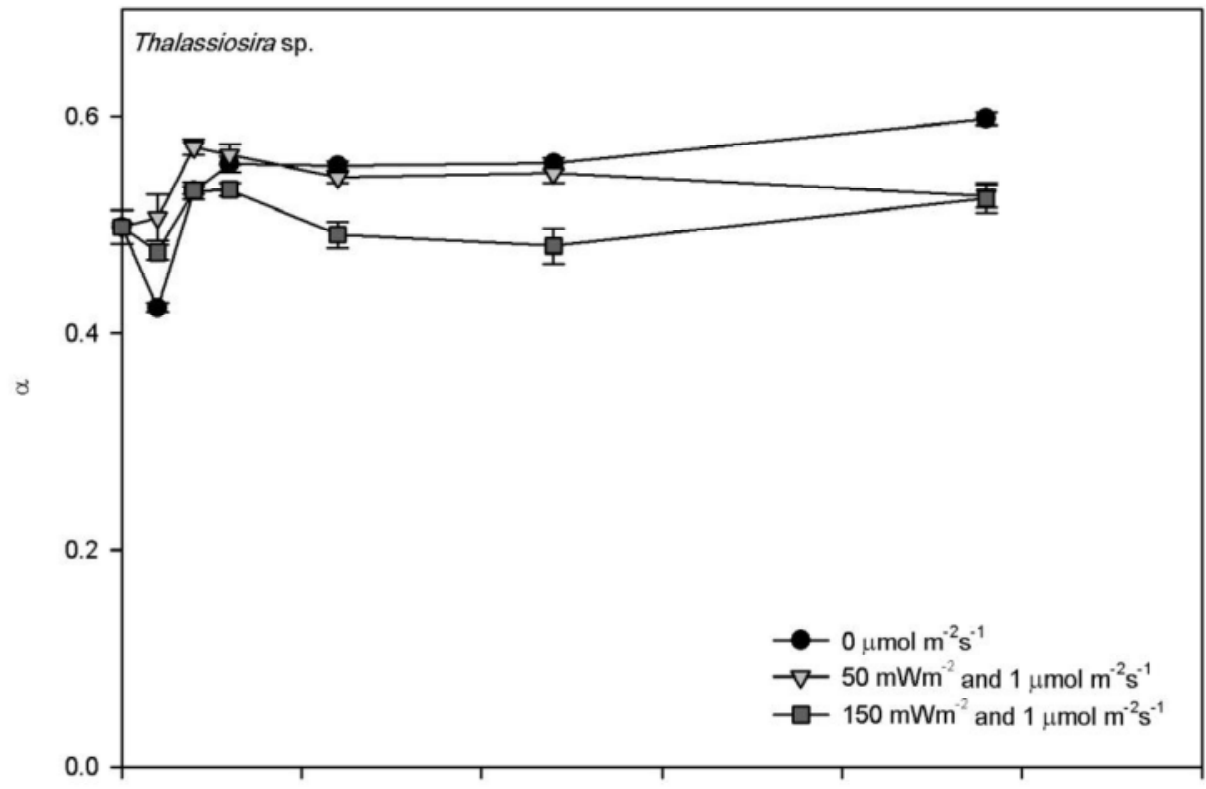

b)

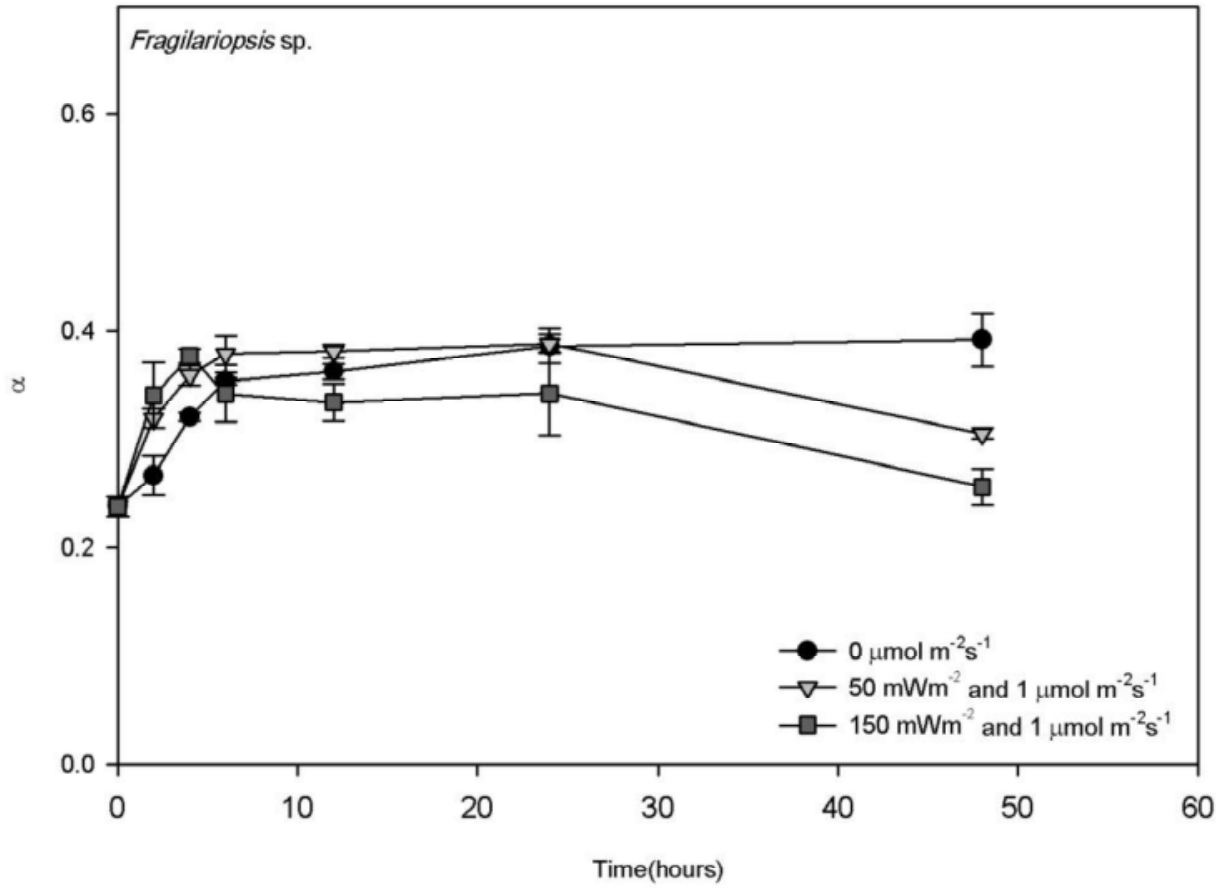

Fig A3.3. Photosynthetic efficiency at 0, 2, 4, 6, 12, 24 and $48 \mathrm{~h}$. Cultures were maintained at 0, $50 \mathrm{~mW} \mathrm{~m}^{-2}, 150 \mathrm{~mW} \mathrm{~m}^{-2} \mathrm{UV}-\mathrm{B}$ and a PAR level of $1 \mu \mathrm{mol} \mathrm{m}^{-2} \mathrm{~s}^{-1}$ for (a) Thalassiosira sp. and (b) Fragilariopsis sp. Error bars indicate standard error. 


\section{A3.2.5 Saturation irradiance $\left(E_{\mathrm{k}}\right)$}

Initially a repeated measures ANOVA was conducted with time as the 'within' factor and temperature and treatment as 'between' factors. This showed significant effects of time $(\mathrm{p}<0.001)$. However, time by species $(\mathrm{p}=0.062)$, time by treatment ( $\mathrm{p} 0.368)$ and the three-way interaction between time, species and treatment $(0.511)$ were not significant (Table A3.10).

Table A3.10 Changes in Saturation Irradiance of Photosystem II over $48 \mathrm{~h}$ experimental treatments at different UV-B levels $\left(0,50\right.$ and $\left.150 \mathrm{mWm}^{-2}\right)$ and a PAR level of $1 \mu \mathrm{mol} \mathrm{m}$ ${ }^{2} \mathrm{~s}^{-1}$ at $4^{\circ} \mathrm{C}$, analysed using a 2 factor repeated measures ANOVA. Significant changes identified by post hoc pairwise analyses are also listed.

\begin{tabular}{|llllll|}
\hline Source of variation & $\mathrm{df}$ & $\mathrm{MS}$ & $F$ & $\mathrm{p}$ & post hoc comparisons \\
\hline Within subjects & & & & & \\
Time & & & & & \\
Time x Species & 1.318 & 1005.373 & 89.822 & $<0.001$ & Decrease over $48 \mathrm{~h}$ \\
Time x Treatment & 1.318 & 39.728 & 3.549 & 0.062 & \\
Time x Species x Treatment & 2.635 & 12.152 & 1.086 & 0.368 & \\
Error & 2.635 & 8.536 & 0.763 & 0.511 & \\
& 265.483 & 11.193 & & & \\
Between subjects & & & & & \\
Species & & & & & \\
Treatments & 1 & 112.543 & 48.507 & $<0.001$ & Not performed because there are \\
Species x Treatment & 2 & 16.209 & 6.986 & 0.006 & fewer than 3 groups. $^{-2}$ \\
Error & 2 & 4.311 & 1.858 & 0.185 & $50=150 \mathrm{~mW} \mathrm{~m}^{-2}$ \\
& 18 & 2.320 & & & $0>150 \mathrm{~mW} \mathrm{~m}^{-2}$ \\
\hline
\end{tabular}


a)

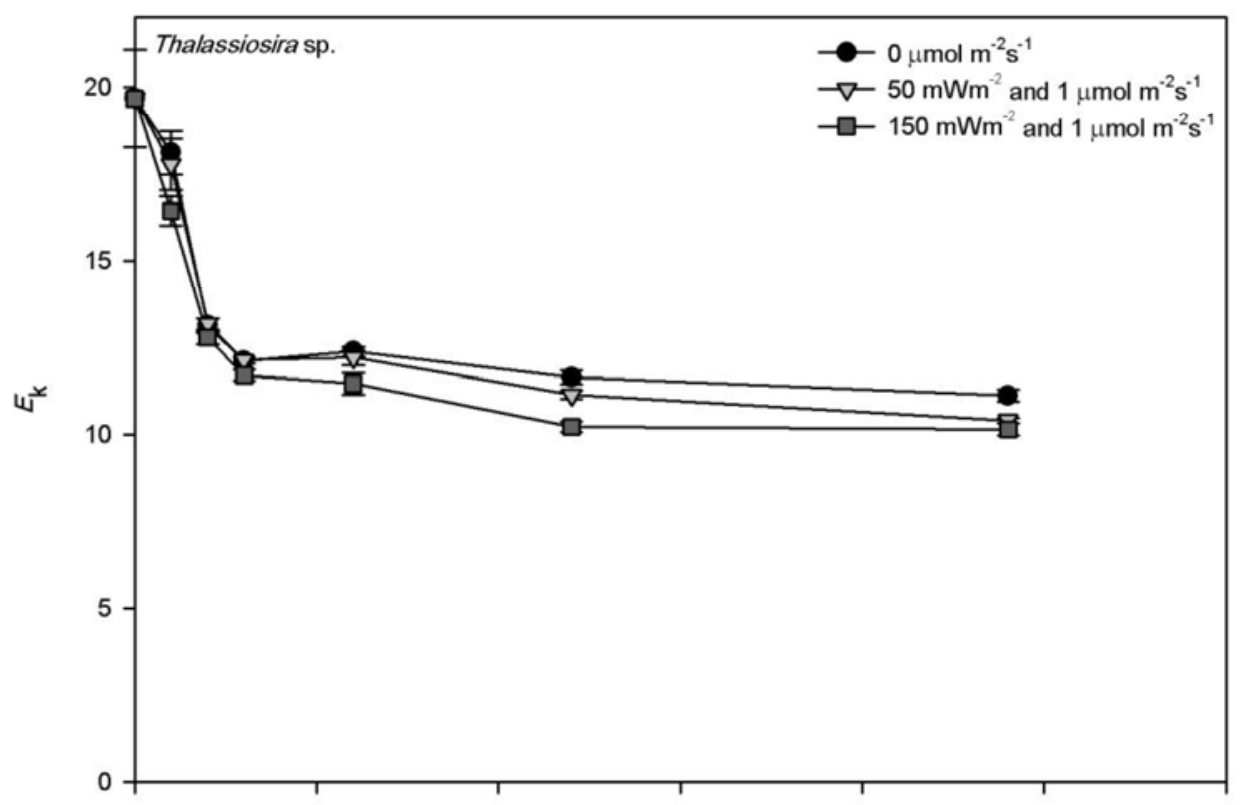

b)

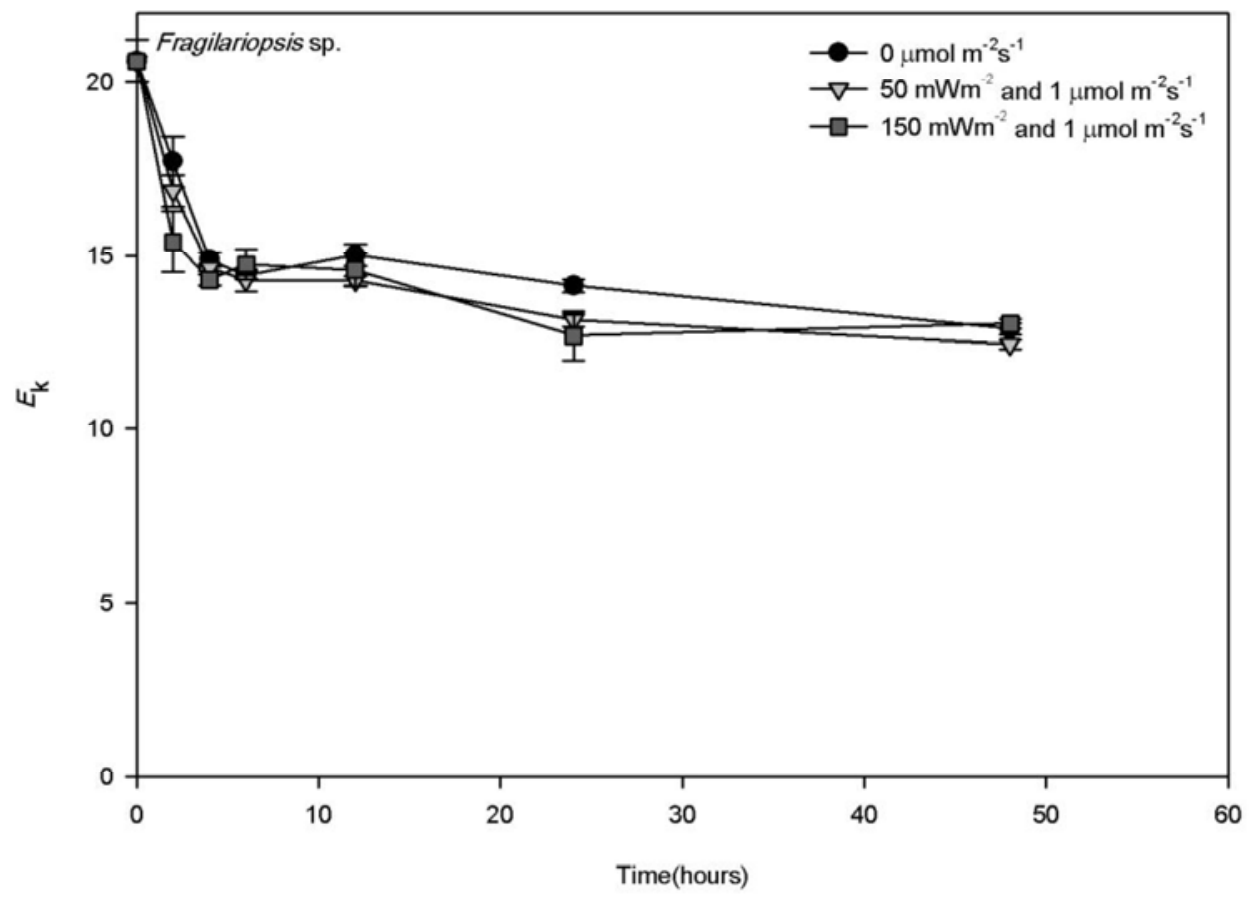

Fig A3.4. Photacclimation Index $\left(E_{\mathrm{k}}\right)$ at $0,2,4,6,12,24$ and $48 \mathrm{~h}$. Cultures were maintained at $0,50 \mathrm{~mW} \mathrm{~m}^{-2}, 150 \mathrm{~mW} \mathrm{~m}^{-2} \mathrm{UV}-\mathrm{B}$ and a PAR level of $1 \mu \mathrm{mol} \mathrm{m}^{-2} \mathrm{~s}^{-1}$ for (a) Thalassiosira sp. and (b) Fragilariopsis sp. Error bars indicate standard error. 


\section{A3.3 Effect of different PAR levels on Chaetoceros sp.}

A repeated measures ANOVA was carried to test for effects of all treatments and time (Table A3.11).

\section{A3.3.1Photosynthetic Efficiency ( $\alpha)$}

There were no significant changes in photosynthetic efficiency (Table A3.11; Figure A3.5(a)) over the time points between 0 and $48 \mathrm{~h}$ in all exposure treatments.

\section{A3.3.2 Saturation irradiance $\left(E_{\mathrm{k}}\right)$}

There were no significant changes in the saturation irradiance (Table A3.11; Figure A3.5(b)) over the time points between 0 and $48 \mathrm{~h}$ in all exposure treatments.

Table A3.11 Changes in photosynthetic parameters for Chaetoceros sp. over $48 \mathrm{~h}$ experimental treatments at PAR levels $\left(0,1,45\right.$ and $\left.100 \mu \mathrm{mol} \mathrm{m}^{-2} \mathrm{~s}^{-1}\right)$ at $4^{\circ} \mathrm{C}$, analysed using repeated measures ANOVA. Significant changes identified by post hoc pairwise analyses are also listed.

\begin{tabular}{|c|c|c|c|c|c|}
\hline Source of variation & $\mathrm{df}$ & MS & $F$ & $\mathrm{p}$ & post hoc comparisons \\
\hline \multirow{2}{*}{\multicolumn{6}{|c|}{$\begin{array}{l}\text { Photosynthetic Efficiency }(\alpha) \\
\text { Within subjects }\end{array}$}} \\
\hline & & & & & \\
\hline Time & 2.300 & 0.101 & 23.332 & $<0.001$ & \multirow{3}{*}{$\begin{array}{l}\text { Increase over } 48 \mathrm{~h} \\
\text { (see text for details) }\end{array}$} \\
\hline Time $\mathrm{x}$ Treatments & 6.900 & 0.004 & 0.991 & 0.467 & \\
\hline Error & 18.400 & 0.004 & & & \\
\hline \multicolumn{6}{|l|}{ Between subjects } \\
\hline Treatments & 3 & 0.019 & 8.439 & 0.007 & $(0=1)>100 \mu \mathrm{mol} \mathrm{m}^{-2} \mathrm{~s}^{-1}$ \\
\hline Error & 8 & 0.002 & & & $0=1=45 \mu \mathrm{mol} \mathrm{m}^{-2} \mathrm{~s}^{-1}$ \\
\hline \multirow{2}{*}{\multicolumn{6}{|c|}{$\begin{array}{l}\text { Saturation Irradiance }\left(E_{\mathrm{k}}\right) \\
\text { Within subjects }\end{array}$}} \\
\hline & & & & & \\
\hline Time & 1.772 & 930.580 & 24.839 & $<0.001$ & \multirow{3}{*}{$\begin{array}{l}\text { Increase over } 48 \mathrm{~h} \\
\text { (see text for details) }\end{array}$} \\
\hline Time $x$ Treatments & 5.315 & 104.757 & 2.796 & 0.056 & \\
\hline Error & 14.174 & 37.465 & & & \\
\hline \multicolumn{6}{|l|}{ Between subjects } \\
\hline Treatments & 3 & 583.396 & 43.692 & $<0.001$ & $(0=1)<(45=100) \mu \mathrm{mol} \mathrm{m}^{-2} \mathrm{~s}^{-1}$ \\
\hline Error & 8 & 13.269 & & & \\
\hline
\end{tabular}


a)

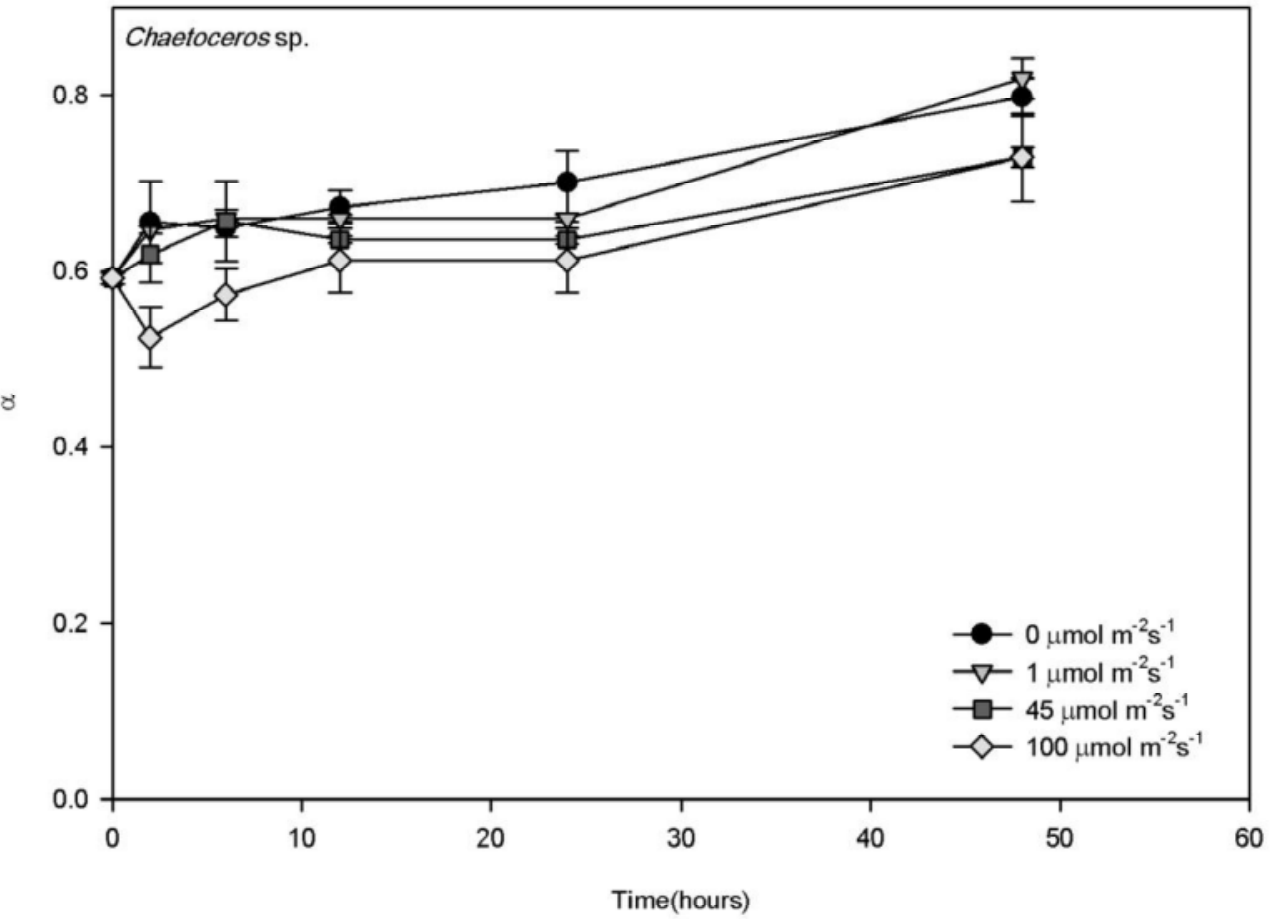

b)

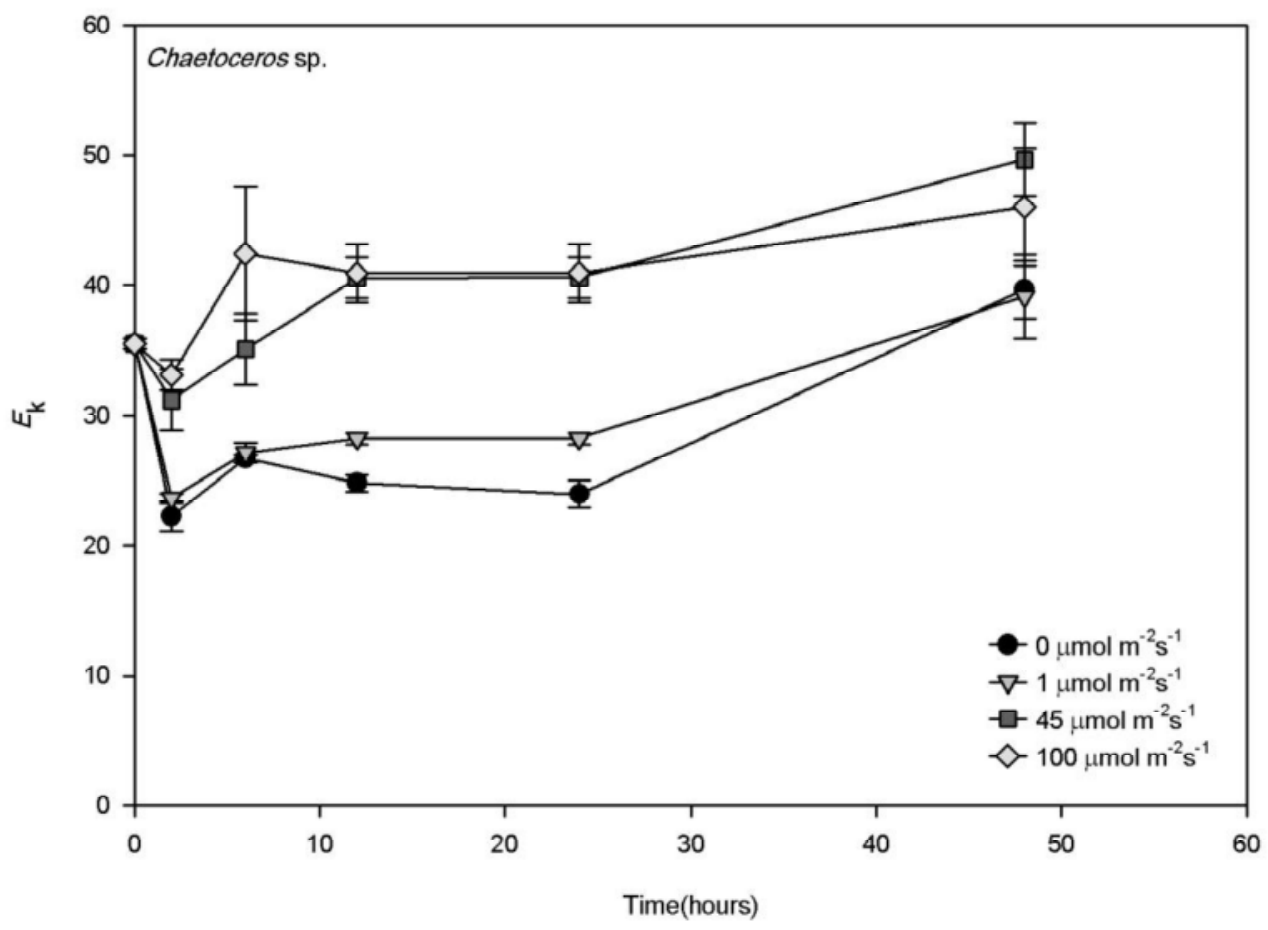

Fig A3.5 (a) Photosynthetic Efficiency ( $\alpha$ ) and (b) Saturation irradiance $\left(E_{\mathrm{k}}\right)$ determined at $0,2,4,6,12,24$ and $48 \mathrm{~h}$. Cultures were maintained at PAR levels of $0,1,45$ or 100 $\mu \mathrm{mol} \mathrm{m}{ }^{-2} \mathrm{~s}^{-1}$ for Chaetoceros sp. Error bars indicate standard error. 


\section{A3.4 Effect of different UV-B levels on Chaetoceros sp.}

A repeated measures ANOVA was carried to test for effects of all treatments and time (Table A3.12).

\section{A3.4.1 Photosynthetic Efficiency $(\alpha)$}

Repeated measures ANOVA showed that photosynthetic efficiency (Table A3.12; Figure A3.6(a)) for algae maintained in the dark decreased over $48 \mathrm{~h}$ relative to the start of the experiment (Bonferroni, $\mathrm{p}=0.01$ ). However, it remained constant over $48 \mathrm{~h}$ for those maintained at $50 \mathrm{~mW} \mathrm{~m}^{-2}$ and $150 \mathrm{~mW} \mathrm{~m}^{-2}$.

\section{A3.4.2 Saturation irradiance $\left(E_{\mathrm{k}}\right)$}

Repeated measures ANOVA showed that the saturation irradiance (Table A3.12; Figure A3.6(b)) for algae incubated in the dark decreased over $48 \mathrm{~h}$ (Bonferroni, $\mathrm{p}=0.01$ ) whereas it was constant for algae incubated at $50 \mathrm{~mW} \mathrm{~m}^{-2}$ and $150 \mathrm{~mW} \mathrm{~m}^{-2}$ over $48 \mathrm{~h}$.

Table A3.12 Changes in photosynthetic parameters for Chaetoceros sp. over $48 \mathrm{~h}$ experimental treatments at different UV-B levels (0,50 and $\left.150 \mathrm{mWm}^{-2}\right)$ and a PAR level of $1 \mu \mathrm{mol} \mathrm{m}{ }^{-2} \mathrm{~s}^{-1}$ at $4^{\circ} \mathrm{C}$, analysed using repeated measures ANOVA. Significant changes identified by post hoc pairwise analyses are also listed.

\begin{tabular}{|llllll|}
\hline Source of variation & $\mathrm{df}$ & MS & $F$ & $\mathrm{p}$ & post hoc comparisons \\
\hline Photosynthetic Efficiency $(\boldsymbol{\alpha})$ & & & & & \\
Within subjects & & & & & \\
Time & 6 & 0.040 & 16.951 & $<0.001$ & No change over $48 \mathrm{~h}$ \\
Time x Treatments & 12 & 0.016 & 7.040 & $<0.001$ & (see text for details) \\
Error & 9 & 0.002 & & & \\
& & & & & \\
Between subjects & & & & & \\
Treatments & 2 & 0.094 & 29.867 & $<0.001$ & $0<50<150$ mWm $^{-2}$ \\
Error & 9 & 0.003 & & & \\
Saturation Irradiance $\left(\boldsymbol{E}_{\mathrm{k}}\right)$ & & & & & \\
Within subjects & & & & & \\
Time & 2.164 & 292.576 & 14.778 & $<0.001$ & No change over $48 \mathrm{~h}$ \\
Time x Treatments & 4.328 & 33.618 & 1.698 & 0.188 & (see text for details) \\
Error & 19.474 & 19.798 & & & \\
& & & & & \\
Between subjects & & & & & \\
Treatments & 2 & 56.969 & 4.675 & 0.041 & No significant differences \\
Error & 9 & 12.187 & & & \\
\hline
\end{tabular}


a)

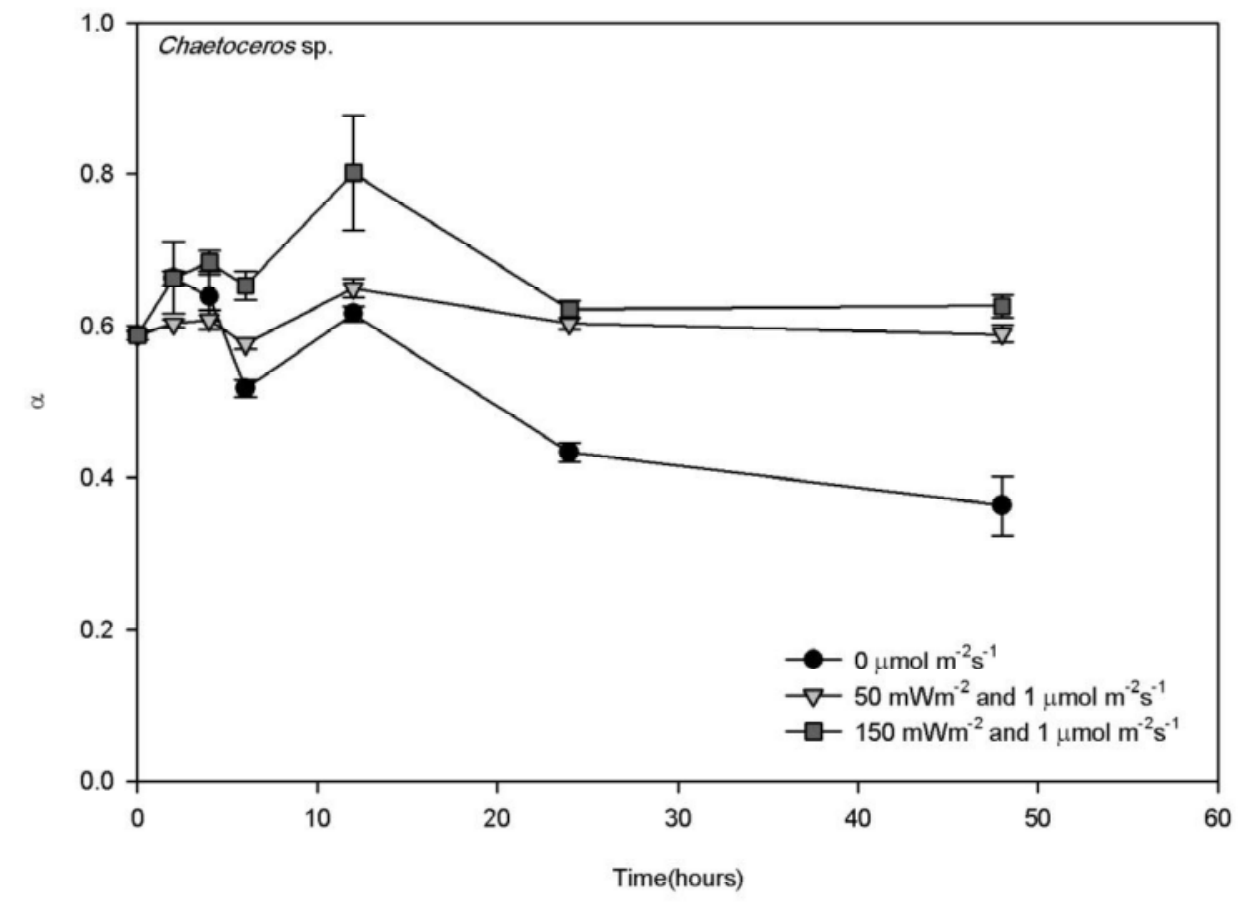

b)

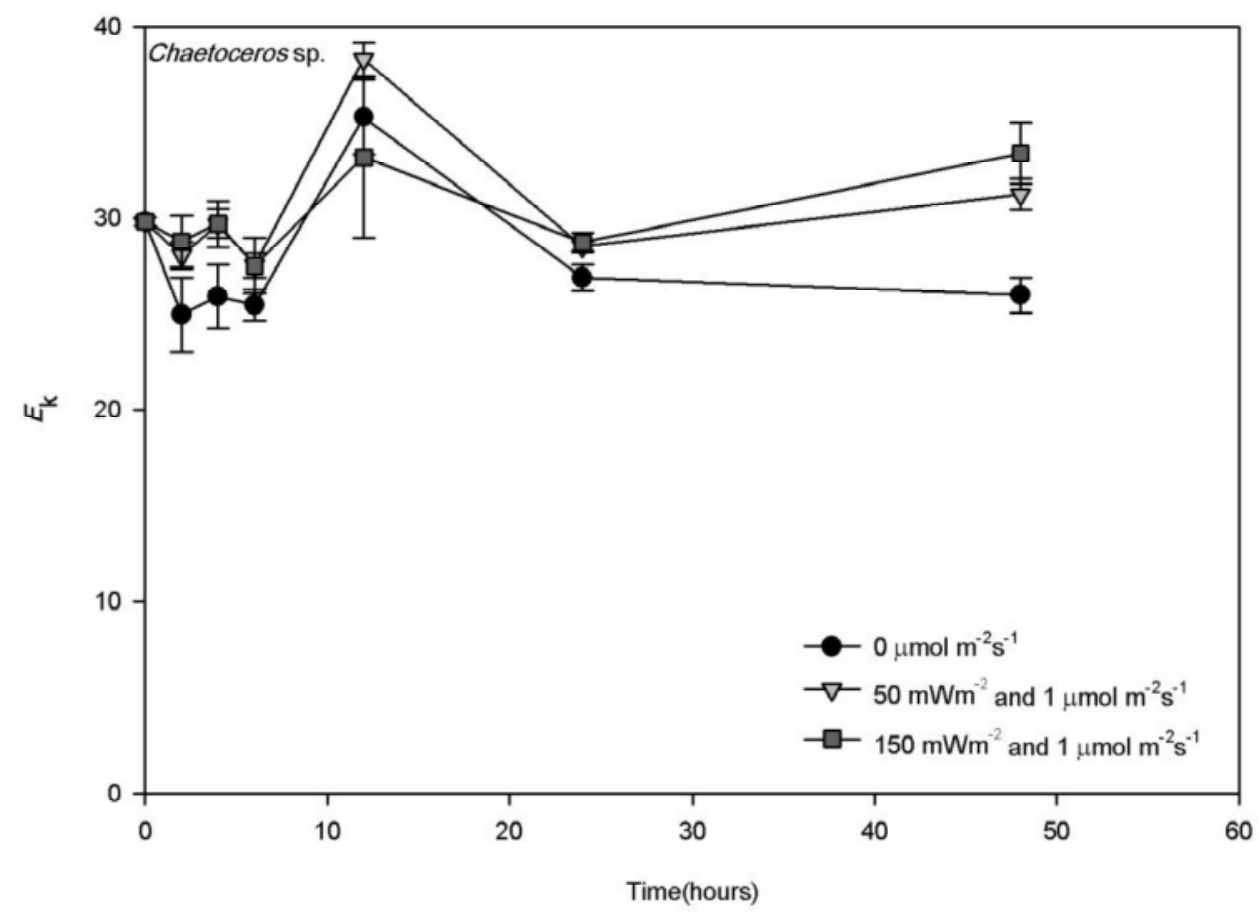

Fig. A3.6 (a) Saturation irradiance $(\alpha)$ and (b) Photacclimation Index $\left(E_{\mathrm{k}}\right)$ at $0,2,4,6,12$, 24 and $48 \mathrm{~h}$. Cultures were maintained at $0,50 \mathrm{~mW} \mathrm{~m}^{-2}, 150 \mathrm{~mW} \mathrm{~m}^{-2} \mathrm{UV}-\mathrm{B}$ and a PAR level of $1 \mu \mathrm{mol} \mathrm{m}^{-2} \mathrm{~s}^{-1}$ for Chaetoceros sp. Error bars indicate standard error. 


\section{APPENDIX 4}

\section{Additional data from Chapter 5}

\section{A4.1 Effect of different light levels on Thalassiosira antarctica (Ross Sea), Chaetoceros socialis (Antarctic Peninsula) and C. socialis (Arctic Ocean)}

\section{A4.1.1 Quantum Yield}

Initially a repeated measures ANOVA was conducted with time as the 'within' factor and temperature and treatment as 'between' factors. This showed significant effects of time $(p<0.001)$, time by species $(p<0.001)$, time by treatment $(p<0.001)$ and the three-way interaction between time, species and treatment $(\mathrm{p}<0.001)$ (Table A4.1).

\section{A4.1.2 rETR $_{\text {max }}$ \\ Initially a repeated measures ANOVA was conducted with time as the 'within' factor and temperature and treatment as 'between' factors. This showed significant effects of time $(\mathrm{p}<0.001)$, time by species $(\mathrm{p}<0.001)$, time by treatment $(\mathrm{p}<0.001)$ and the three-way interaction between time, species and treatment $(\mathrm{p}<0.001)$ (Table A4.2).}

\section{A4.1.3 SOD activity}

Initially a repeated measures ANOVA was conducted with time as the 'within' factor and temperature and treatment as 'between' factors. This showed significant effects of time $(p=0.005)$ and time by species $(p<0.001)$. The effects for time by treatment $(p=0.765)$ and the three-way interaction between time, species and treatment $(\mathrm{p}=0.167)$ were not significant (Table A4.3). 
Table A4.1 Changes in quantum yield of Photosystem II over $168 \mathrm{~h}$ experimental treatments at different li $\mathrm{L} 1=1 \mu \mathrm{mol} \mathrm{m}{ }^{-2} \mathrm{~s}^{-1} ; \mathrm{L} 2=45 \mu \mathrm{mol} \mathrm{m}{ }^{-2} \mathrm{~s}^{-1}$ and $50 \mathrm{mWm}^{-2} ; \mathrm{L} 4=100 \mu \mathrm{mol} \mathrm{m}^{-2} \mathrm{~s}^{-1}$ and $100 \mathrm{mWm}^{-2}$ ) at $4^{\circ} \mathrm{C}$, analys measures ANOVA. Significant changes identified by post hoc pairwise analyses are also listed.

\begin{tabular}{|llllll|}
\hline Source of variation & $\mathrm{df}$ & $\mathrm{MS}$ & $F$ & $\mathrm{p}$ & post hoc comparisons \\
\hline Within subjects & & & & & \\
Time & 5.462 & 0.074 & 118.635 & $<0.001$ & Decrease over 168h \\
Time x Treatment & 16.385 & 0.032 & 51.114 & $<0.001$ & \\
Time x Species & 10.923 & 0.014 & 21.943 & $<0.001$ & \\
Time x Treatement x Species & 32.770 & 0.010 & 15.444 & $<0.001$ & \\
Error & 131.082 & 0.001 & & & \\
& & & & & \\
Between subjects & & & & & \\
Treatments & 3 & 1.433 & 302.855 & $<0.001$ & L1 $>$ L0 $>$ L3 $>$ L2 \\
Species & 2 & 0.071 & 14.947 & $<0.001$ & Thalassiosira ant. $>$ (Chaetoceros soc. (Ant pen) \\
Treatments x Species & 6 & 0.031 & 6.506 & $<0.001$ & \\
Error & 24 & 0.005 & & & \\
& & & & & \\
\hline
\end{tabular}


Table A4.2 Changes in rETR $_{\max }$ of Photosystem II over $168 \mathrm{~h}$ experimental treatments at different light lev $\mu \mathrm{mol} \mathrm{m}{ }^{-2} \mathrm{~s}^{-1} ; \mathrm{L} 2=45 \mu \mathrm{mol} \mathrm{m}^{-2} \mathrm{~s}^{-1}$ and $50 \mathrm{mWm}^{-2} ; \mathrm{L} 4=100 \mu \mathrm{mol} \mathrm{m}^{-2} \mathrm{~s}^{-1}$ and $100 \mathrm{mWm}^{-2}$ ) at $4^{\circ} \mathrm{C}$, analysed us measures ANOVA. Significant changes identified by post hoc pairwise analyses are also listed.

\begin{tabular}{|llllll|}
\hline Source of variation & $\mathrm{df}$ & $\mathrm{MS}$ & $F$ & $\mathrm{p}$ & post hoc comparisons \\
\hline Within subjects & & & & & \\
Time & & & & & \\
Time x Treatment & 5.349 & 340.014 & 214.933 & $<0.001$ & Increase over $168 \mathrm{~h}$ \\
Time x Species & 16.046 & 95.755 & 60.530 & $<0.001$ & \\
Time x Treatment x Species & 10.697 & 135.015 & 85.346 & $<0.001$ & \\
Error & 32.092 & 28.902 & 18.270 & $<0.001$ & \\
& 117.669 & 1.582 & & & \\
Between subjects & & & & & \\
Treatments & & & & & \\
Species & 3 & 1493.359 & 330.458 & $<0.001$ & L0 < L3 < (L1 = L2) \\
Treatments x Species & 2 & 122.067 & 27.012 & $<0.001$ & Thalassiosira ant. $>$ (Chaetoceros soc. (Ant pe \\
Error & 6 & 122.342 & 27.073 & $<0.001$ & \\
& 24 & 4.519 & & & \\
\end{tabular}


Table A4.3 Changes in SOD activity per cell over $168 \mathrm{~h}$ experimental treatments at different light levels (L ${ }^{2} \mathrm{~s}^{-1} ; \mathrm{L} 2=45 \mu \mathrm{mol} \mathrm{m}^{-2} \mathrm{~s}^{-1}$ and $50 \mathrm{mWm}^{-2} ; \mathrm{L} 4=100 \mu \mathrm{mol} \mathrm{m}^{-2} \mathrm{~s}^{-1}$ and $100 \mathrm{mWm}^{-2}$ ) at $4^{\circ} \mathrm{C}$, analysed using a $2 \mathrm{fo}$ ANOVA. Significant changes identified by post hoc pairwise analyses are also listed.

\begin{tabular}{|llllll|}
\hline Source of variation & $\mathrm{df}$ & $\mathrm{MS}$ & $F$ & $\mathrm{p}$ & post hoc comparisons \\
\hline Within subjects & & & & & \\
Time & 2 & 91489.549 & 6.050 & 0.005 & Decrease over 168h \\
Time x Treatment & 6 & 8361.960 & 0.553 & 0.765 & \\
Time x Species & 4 & 555645.678 & 36.746 & $<0.001$ & \\
Time x Treatment x Species & 12 & 22292.118 & 1.474 & 0.167 & \\
Error & 48 & 15121.259 & & & \\
& & & & & \\
Between subjects & & & & & \\
Treatments & 3 & 50079.438 & 3.060 & 0.048 & L0 = L1 = L2 = L3 \\
Species & 2 & 31187.494 & 1.906 & 0.171 & Thalassiosira ant. $=$ Chaetoceros soc. (Ant pen) \\
Treatments x Species & 6 & 4929.031 & 0.301 & 0.930 & \\
Error & 24 & 16366.146 & & & \\
& & & & & \\
\end{tabular}




\section{Photosynthetic Efficiency ( $\alpha)$}

A repeated measures ANOVA was carried out for each species separately to test for effect of all treatments and time (Table A4.4).

\section{Thalassiosira antarctica (Ross Sea)}

The general response of this species (Figure A4.1(a)) at all light levels except 0 was an initial increase in $\alpha$ followed by a decrease to the same level as at time $0 \mathrm{~h}$. Algae at L0 remained constant until the end of the incubation. Repeated measures ANOVA showed no significant change in $\alpha$ over $168 \mathrm{~h}$ for algae at L0 (Bonferroni, $\mathrm{p}=0.110$ ) and L1 (Bonferroni, $p=0.113$ ). Algae at the higher light levels showed a significant change with alpha at L2 (Bonferroni, $\mathrm{p}=0.003$ ) and L3 (Bonferroni, $\mathrm{p}=0.016$ ). However there was no significant increase or decrease between time 0 and 168h (L2: Bonferroni, $p=1.000$; L3: Bonferroni, $\mathrm{p}=1.000$ )

\section{Chaetoceros socialis (Antarctic Peninsula)}

The general response of this species (Figure A4.1(b)) at all light levels except L0 was an initial increase in $\alpha$ followed by alpha decreasing to the same level as at time $0 \mathrm{~h}$. Algae at $\mathrm{L} 0$ remained constant until the end of the incubation. Repeated measures ANOVA showed no significant change in $\alpha$ over $168 \mathrm{~h}$ for algae at L0 (Bonferroni, $\mathrm{p}=0.129$ ), L1 (Bonferroni, $p=0.219$ ) and L2 (Bonferroni, $p=0.049$ ). Algae incubated at L3 showed a significant change in $\alpha$ (Bonferroni, $p=0.004$ ). However, there was no overall significant increase (Bonferroni, $\mathrm{p}=1.000$ ).

\section{C. socialis (Arctic Ocean)}

The general response of the species (Figure A4.1(b)) for all light treatments other than at L0 was a slight increase in $\alpha$ followed by a stable response to reach a level higher than at time $0 \mathrm{~h}$. Algae at L0 did not show any change over time. Repeated measures ANOVA showed no significant change in $\alpha$ over $168 \mathrm{~h}$ for algae at L0 (Bonferroni, $\mathrm{p}=$ 0.368) and L1 (Bonferroni, $p=0.063$ ). Algae incubated at L2 showed a significant increase in $\alpha$ (Bonferroni, $p=0.045$ ) in the first $2 \mathrm{~h}$, but showed no overall change (Bonferroni, $p=0.167$ ). Algae incubated at L3 also showed a significant change in $\alpha$ (Bonferroni, $p=0.018$ ) but there was no overall change (Bonferroni, $p=0.332$ ) over $168 \mathrm{~h}$. 
Table A4.4. Changes in alpha( $\alpha$ ) of photosystem II over $168 \mathrm{~h}$ experimental treatments at different light levels ( $\mathrm{L} 0=0 \mu \mathrm{mol} \mathrm{m}^{-2} \mathrm{~s}^{-1} ; \mathrm{L} 1=1 \mu \mathrm{mol} \mathrm{m}^{-2} \mathrm{~s}^{-1}$; $\mathrm{L} 2=45 \mu \mathrm{mol} \mathrm{m}^{-2} \mathrm{~s}^{-1}$ and 50 $\mathrm{mWm}^{-2} ; \mathrm{L} 4=100 \mu \mathrm{mol} \mathrm{m}^{-2} \mathrm{~s}^{-1}$ and $100 \mathrm{mWm}^{-2}$ ) at $4^{\circ} \mathrm{C}$, analysed using repeated measures ANOVA. Significant changes identified by post hoc pairwise analyses are also listed.

\begin{tabular}{|c|c|c|c|c|c|}
\hline Source of variation & $\mathrm{df}$ & MS & $F$ & $\mathrm{p}$ & post hoc comparisons \\
\hline \multicolumn{6}{|c|}{ Thalassiosira antarctica (Ross Sea) } \\
\hline \multicolumn{6}{|c|}{ Within subjects } \\
\hline Time & 2.381 & 0.066 & 21.489 & $<0.001$ & No change over $168 \mathrm{~h}$ \\
\hline Time $x$ Treatments & 7.144 & 0.017 & 5.510 & 0.001 & (see text for details) \\
\hline Error & 19.051 & 0.003 & & & \\
\hline \multicolumn{6}{|l|}{ Between subjects } \\
\hline Treatments & 3 & 0.110 & 14.640 & 0.001 & $(\mathrm{~L} 0, \mathrm{~L} 1, \mathrm{~L} 2)=\mathrm{L} 3$ \\
\hline Error & 8 & 0.008 & & & $\mathrm{~L} 0<(\mathrm{L} 1=\mathrm{L} 2)$ \\
\hline \multicolumn{6}{|c|}{ Chaetoceros socialis (Antarctic Peninsula) } \\
\hline \multicolumn{6}{|c|}{ Within subjects } \\
\hline Time & 2.697 & 0.053 & 16.734 & $<0.001$ & No change over $168 \mathrm{~h}$ \\
\hline Time $\mathrm{x}$ Treatments & 8.092 & 0.017 & 5.294 & 0.001 & (see text for details) \\
\hline Error & 21.578 & 0.003 & & & \\
\hline \multicolumn{6}{|l|}{ Between subjects } \\
\hline Treatments & 3 & 0.087 & 13.005 & 0.002 & L0 = L3; L1 = (L2,L3) \\
\hline Error & 8 & 0.007 & & & $\mathrm{~L} 0<(\mathrm{L} 1=\mathrm{L} 45) ;(\mathrm{L} 2>\mathrm{L} 3)$ \\
\hline \multicolumn{6}{|c|}{ C. socialis (Arctic Ocean) } \\
\hline \multicolumn{6}{|c|}{ Within subjects } \\
\hline Time & 3.309 & 0.093 & 24.759 & $<0.001$ & Increase over $168 \mathrm{~h}$ \\
\hline Time $x$ Treatments & 9.928 & 0.019 & 5.137 & $<0.001$ & (see text for details) \\
\hline Error & 26.476 & 0.004 & & & \\
\hline \multicolumn{6}{|l|}{ Between subjects } \\
\hline Treatments & 3 & 0.243 & 21.762 & $<0.001$ & $\mathrm{~L} 0<(\mathrm{L} 1=\mathrm{L} 3)<\mathrm{L} 2$ \\
\hline Error & 8 & 0.011 & & & \\
\hline
\end{tabular}



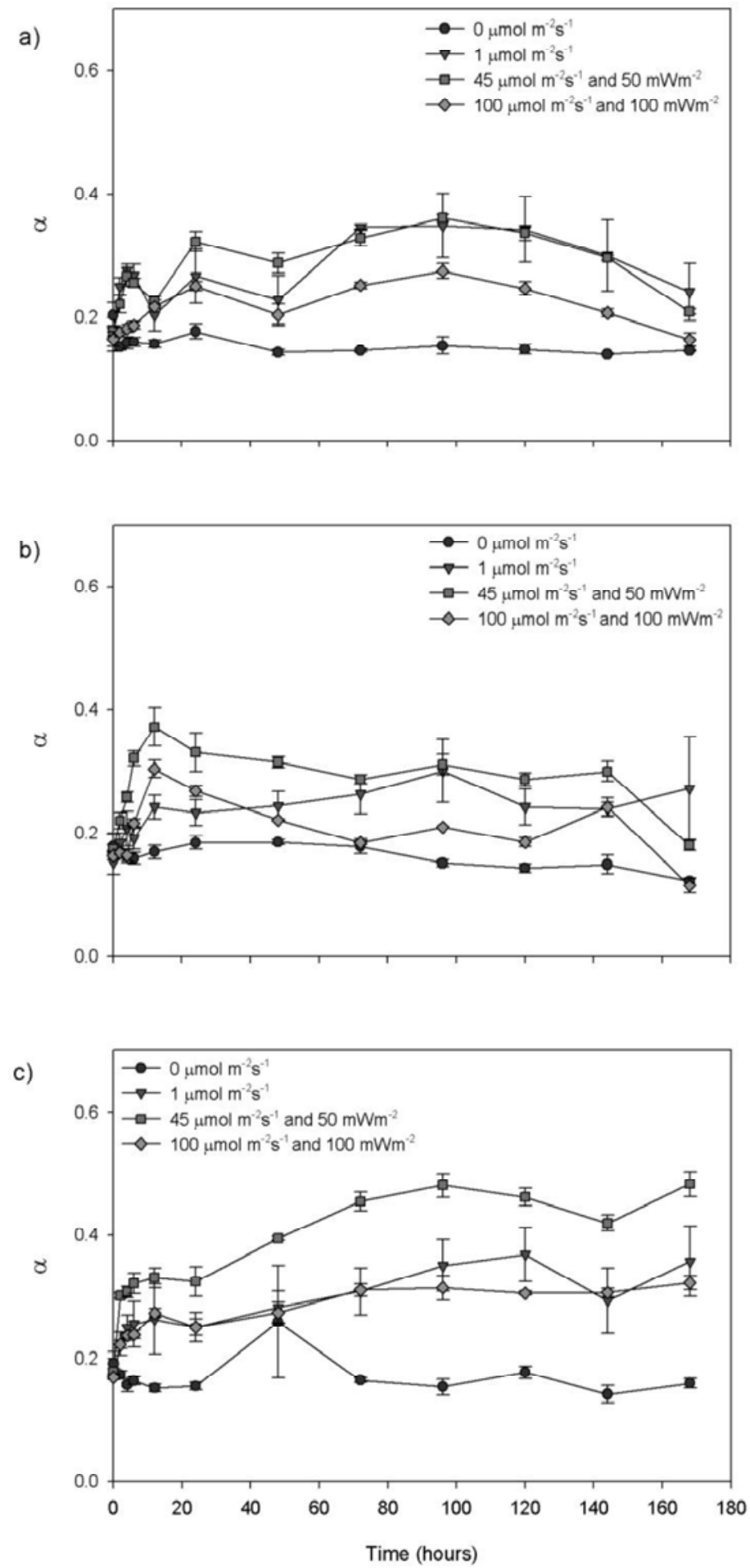

Fig A4.1. Alpha( $\alpha)$ at 0, 2, 4, 6, 12, 24, 48, 72, 96, 120, 144 and 168 h. Cultures were maintained at light levels $\left(0 \mu \mathrm{mol} \mathrm{m}{ }^{-2} \mathrm{~s}^{-1} ; 1 \mu \mathrm{mol} \mathrm{m}^{-2} \mathrm{~s}^{-1} ; 45 \mu \mathrm{mol} \mathrm{m} \mathrm{m}^{-2} \mathrm{~s}^{-1}\right.$ and $50 \mathrm{mWm}^{-2}$; $100 \mu \mathrm{mol} \mathrm{m}^{-2} \mathrm{~s}^{-1}$ and $100 \mathrm{mWm}^{-2}$ ), for (a) Thalassiosira antarctica (Ross Sea), (b) Chaetoceros socialis (Antarctic Peninsula) and (c) C. socialis (Arctic Ocean). Error bars indicate standard error. 


\section{Saturation Irradiance $\left(E_{\mathrm{k}}\right)$}

A repeated measures ANOVA was carried out for each species separately to test for effect of all treatments and time (Table A4.5).

\section{Thalassiosira antarctica (Ross Sea)}

The general response of this species (Figure A4.2(a)) at all light levels except L1 was a lack of change in $E_{\mathrm{k}}$ during the entire incubation. Algae at L1 showed an increase in $E_{\mathrm{k}}$ followed by a decrease to almost the same level as at $0 \mathrm{~h}$. Repeated measures ANOVA showed no significant change in $E_{\mathrm{k}}$ over $168 \mathrm{~h}$ for algae at all light treatments (L0:Bonferroni, $p=0.306$; L1: Bonferroni, $p=0.218$; L2: Bonferroni, $p=1.000$; L3: Bonferroni, $\mathrm{p}=0.113$ ).

\section{Chaetoceros socialis (Antarctic Peninsula)}

The general response of this species (Figure A4.2(b)) at all light levels except L1 was slight decrease in $E_{\mathrm{k}}$ over the duration of the incubation. Algae at L1 showed a slight increase in $E_{\mathrm{k}}$. Repeated measures ANOVA showed no significant change in $E_{\mathrm{k}}$ over 168 $\mathrm{h}$ for algae at all light treatments (L0:Bonferroni, $\mathrm{p}=0.055$; L1: Bonferroni, $\mathrm{p}=0.124$; L2: Bonferroni, $p=0.087$; L3: Bonferroni, $p=0.328$ ).

\section{C. socialis (Arctic Ocean)}

The general response of the species (Figure A4.2(c)) for all light treatments other than at $\mathrm{L} 0$ was an increase in $E_{\mathrm{k}}$ reaching a level higher than that at $0 \mathrm{~h}$. Algae at L1 did not show any change in $E_{\mathrm{k}}$ over time. Repeated measures ANOVA showed no significant change in $E_{\mathrm{k}}$ over $168 \mathrm{~h}$ for algae at L0 (Bonferroni, $\mathrm{p}=0.147$ ), L1 (Bonferroni, $\mathrm{p}=$ 0.0 .057 ) and L2 (Bonferroni, $p=0.164$ ). Algae incubated at L3 showed a significant increase (Bonferroni, $\mathrm{p}=0.001$ ) in $E_{\mathrm{k}}$ between 144 and $168 \mathrm{~h}$, leading an overall significant increase (Bonferroni, $p=0.024$ ) over $168 \mathrm{~h}$. 
Table A4.5. Changes in Saturation Irradiance $\left(E_{\mathrm{k}}\right)$ of photosystem II over $168 \mathrm{~h}$ experimental treatments at different light levels $\left(\mathrm{L} 0=0 \mu \mathrm{mol} \mathrm{m}^{-2} \mathrm{~s}^{-1} ; \mathrm{L} 1=1 \mu \mathrm{mol} \mathrm{m}^{-2} \mathrm{~s}^{-1}\right.$; $\mathrm{L} 2=45 \mu \mathrm{mol} \mathrm{m}^{-2} \mathrm{~s}^{-1}$ and $50 \mathrm{mWm}^{-2} ; \mathrm{L} 4=100 \mu \mathrm{mol} \mathrm{m}^{-2} \mathrm{~s}^{-1}$ and $100 \mathrm{mWm}^{-2}$ ) at $4^{\circ} \mathrm{C}$, analysed using repeated measures ANOVA. Significant changes identified by post hoc pairwise analyses are also listed.

\begin{tabular}{|c|c|c|c|c|c|}
\hline Source of variation & $\mathrm{df}$ & MS & $F$ & $\mathrm{p}$ & post hoc comparisons \\
\hline \multicolumn{6}{|c|}{ Thalassiosira antarctica (Ross Sea) } \\
\hline \multicolumn{6}{|c|}{ Within subjects } \\
\hline Time & 1.455 & 7847.305 & 3.710 & 0.067 & \multirow{3}{*}{$\begin{array}{l}\text { No change over } 168 \mathrm{~h} \\
\text { (see text for details) }\end{array}$} \\
\hline Time $x$ Treatments & 4.364 & 5235.578 & 2.475 & 0.099 & \\
\hline Error & 11.638 & 2115.351 & & & \\
\hline \multicolumn{6}{|l|}{ Between subjects } \\
\hline Treatments & 3 & 7174.421 & 11.019 & 0.003 & $\mathrm{~L} 1>(\mathrm{L} 0=\mathrm{L} 2=\mathrm{L} 3)$ \\
\hline Error & 8 & 2115.351 & & & \\
\hline \multicolumn{6}{|c|}{ Chaetoceros socialis (Antarctic Peninsula) } \\
\hline \multicolumn{6}{|c|}{ Within subjects } \\
\hline Time & 3.329 & 749.654 & 7.538 & 0.001 & \multirow{3}{*}{$\begin{array}{l}\text { No change over } 168 \mathrm{~h} \\
\text { (see text for details) }\end{array}$} \\
\hline Time $\mathrm{x}$ Treatments & 9.986 & 616.441 & 6.197 & $<0.001$ & \\
\hline Error & 26.628 & 99.471 & & & \\
\hline \multicolumn{6}{|l|}{ Between subjects } \\
\hline Treatments & 3 & 7016.087 & 12.520 & 0.002 & $\mathrm{~L} 1>(\mathrm{L} 0=\mathrm{L} 2=\mathrm{L} 3)$ \\
\hline Error & 8 & 560.39 & & & \\
\hline \multicolumn{6}{|c|}{ C. socialis (Arctic Ocean) } \\
\hline \multicolumn{6}{|c|}{ Within subjects } \\
\hline Time & 2.820 & 2991.995 & 62.007 & $<0.001$ & Increase over $168 \mathrm{~h}$ \\
\hline Time $x$ Treatments & 8.460 & 391.592 & 8.115 & $<0.001$ & (see text for details) \\
\hline Error & 22.561 & 48.253 & & & \\
\hline \multicolumn{6}{|l|}{ Between subjects } \\
\hline Treatments & 3 & 3293.020 & 20.760 & $<0.001$ & $\mathrm{~L} 0<(\mathrm{L} 1=\mathrm{L} 2=\mathrm{L} 3)$ \\
\hline Error & 8 & 158.623 & & & \\
\hline
\end{tabular}



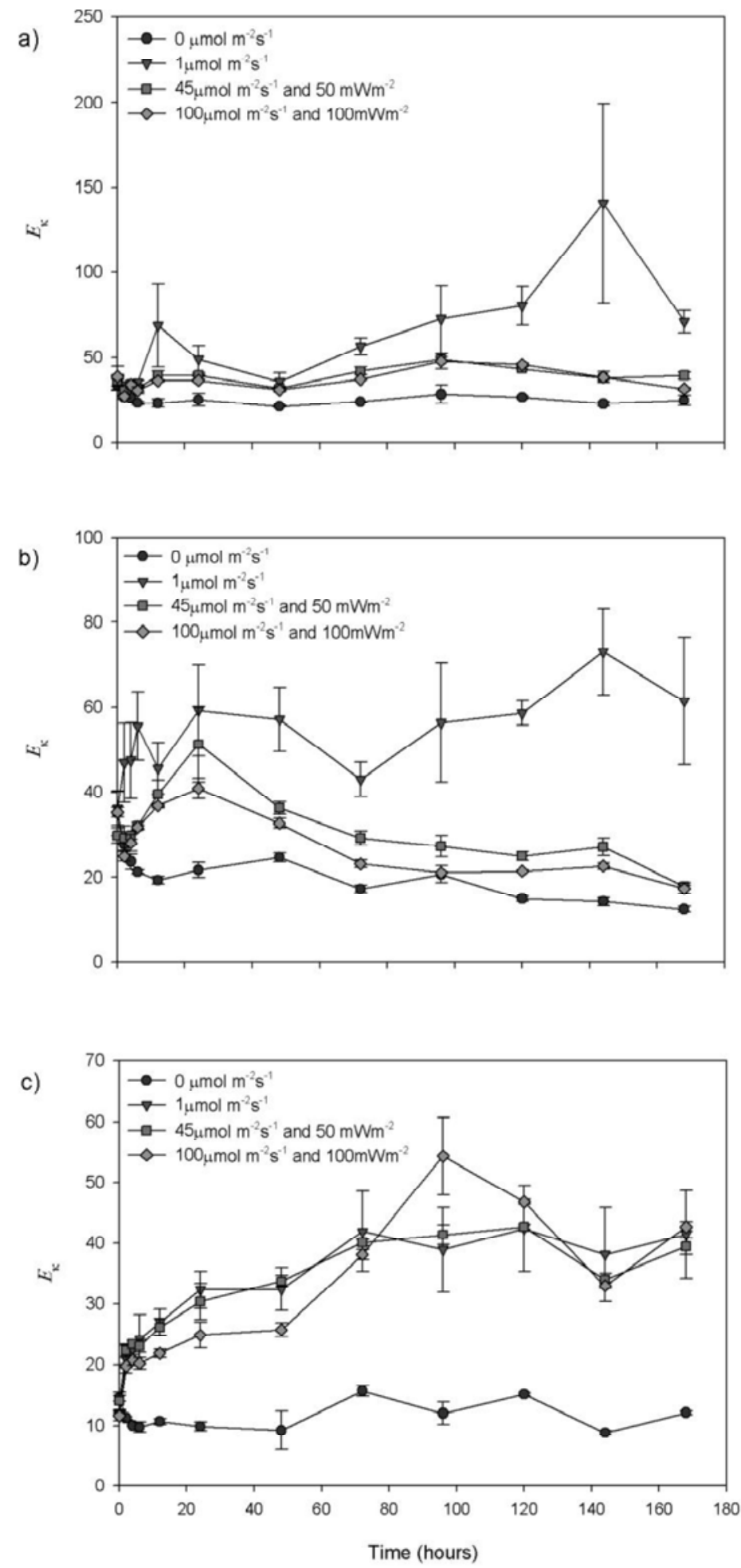

Fig A4.2. $E_{\mathrm{k}}$ at $0,2,4,6,12,24,48,72,96,120,144$ and $168 \mathrm{~h}$. Cultures were maintained at light levels $\left(0 \mu \mathrm{mol} \mathrm{m} \mathrm{m}^{-2} \mathrm{~s}^{-1} ; 1 \mu \mathrm{mol} \mathrm{m}^{-2} \mathrm{~s}^{-1} ; 45 \mu \mathrm{mol} \mathrm{m}^{-2} \mathrm{~s}^{-1}\right.$ and $50 \mathrm{mWm}^{-2} ; 100 \mu \mathrm{mol}$ $\mathrm{m}^{-2} \mathrm{~s}^{-1}$ and $100 \mathrm{mWm}^{-2}$ ), for (a) Thalassiosira antarctica (Ross Sea), (b) Chaetoceros socialis (Antarctic Peninsula) and (c) C. socialis (Arctic Ocean). Error bars indicate standard error. 